March 2001 • NREL/TP-500-29103

\title{
NedWind 25 Blade Testing at NREL for the European Standards Measurement and Testing Program
}

Scott Larwood and Walt Musial National Renewable Energy Laboratory Golden, Colorado

Gregg Freebury

G. Edward Engineering

Lafayette, Colorado

Alan G. Beattie

Physical Acoustics Corporation

Corrales, New Mexico
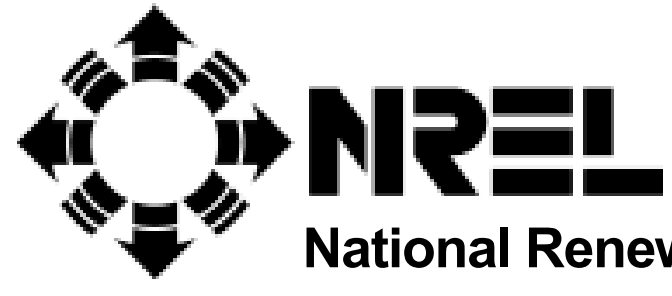

National Renewable Energy Laboratory

1617 Cole Boulevard

Golden, Colorado 80401-3393

NREL is a U.S. Department of Energy Laboratory

Operated by Midwest Research Institute • Battelle • Bechtel

Contract No. DE-AC36-99-G010337 
March 2001 • NREL/TP-500-29103

\section{NedWind 25 Blade Testing at NREL for the European Standards Measurement and Testing Program}

Scott Larwood and Walt Musial National Renewable Energy Laboratory Golden, Colorado

Gregg Freebury

G. Edward Engineering

Lafayette, Colorado

Alan G. Beattie

Physical Acoustics Corporation

Corrales, New Mexico

Prepared under Task No. WER1.2450

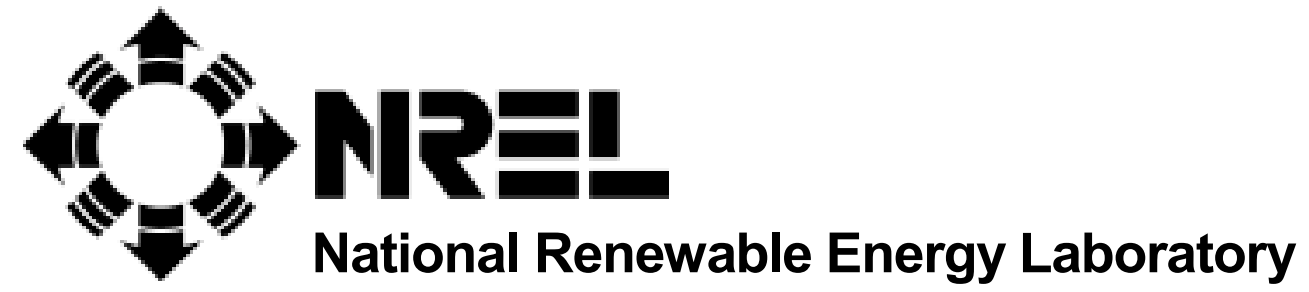

1617 Cole Boulevard

Golden, Colorado 80401-3393

NREL is a U.S. Department of Energy Laboratory

Operated by Midwest Research Institute $\bullet$ Battelle $\bullet$ Bechtel

Contract No. DE-AC36-99-G010337 


\section{NOTICE}

This report was prepared as an account of work sponsored by an agency of the United States government. Neither the United States government nor any agency thereof, nor any of their employees, makes any warranty, express or implied, or assumes any legal liability or responsibility for the accuracy, completeness, or usefulness of any information, apparatus, product, or process disclosed, or represents that its use would not infringe privately owned rights. Reference herein to any specific commercial product, process, or service by trade name, trademark, manufacturer, or otherwise does not necessarily constitute or imply its endorsement, recommendation, or favoring by the United States government or any agency thereof. The views and opinions of authors expressed herein do not necessarily state or reflect those of the United States government or any agency thereof.

Available electronically at http://www.doe.gov/bridge

Available for a processing fee to U.S. Department of Energy

and its contractors, in paper, from:

U.S. Department of Energy

Office of Scientific and Technical Information

P.O. Box 62

Oak Ridge, TN 37831-0062

phone: 865.576.8401

fax: 865.576.5728

email: reports@adonis.osti.gov

Available for sale to the public, in paper, from:

U.S. Department of Commerce

National Technical Information Service

5285 Port Royal Road

Springfield, VA 22161

phone: 800.553.6847

fax: 703.605.6900

email: orders@ntis.fedworld.gov

online ordering: http://www.ntis.gov/ordering.htm

Printed on paper containing at least $50 \%$ wastepaper, including $20 \%$ postconsumer waste 


\section{Table of Contents}

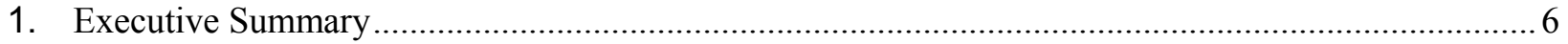

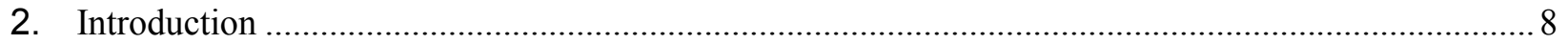

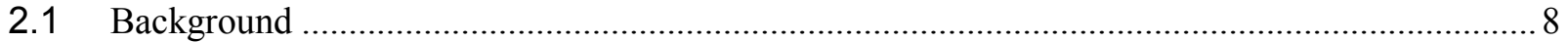

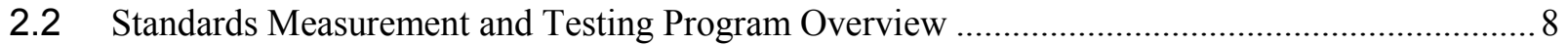

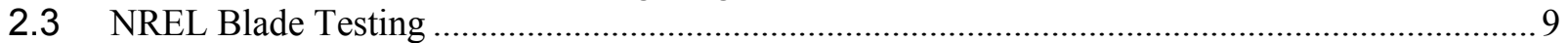

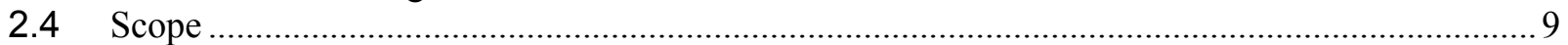

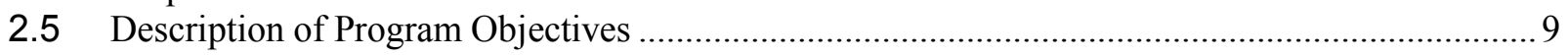

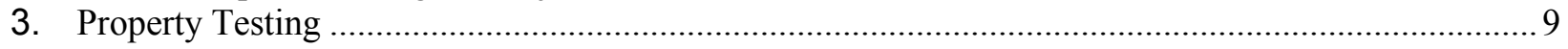

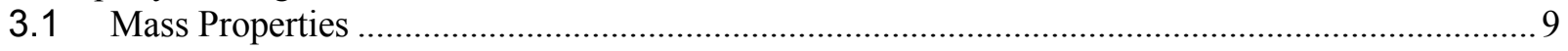

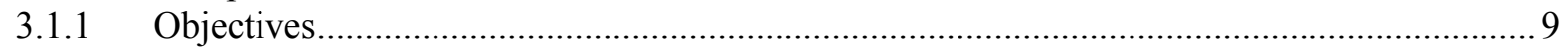

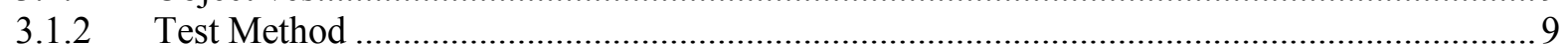

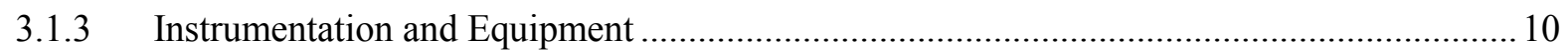

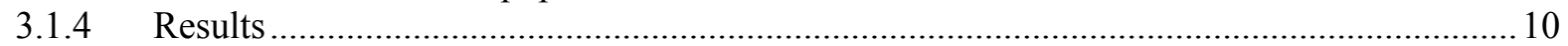

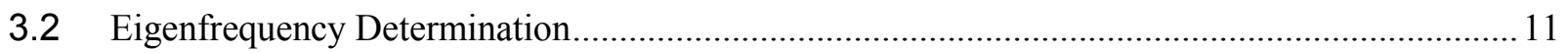

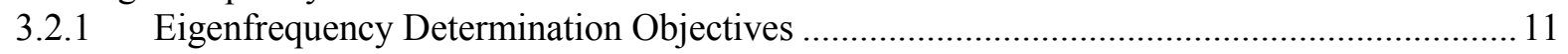

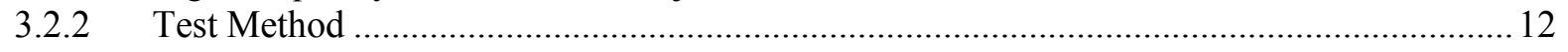

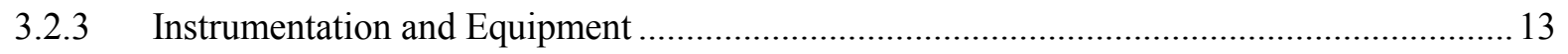

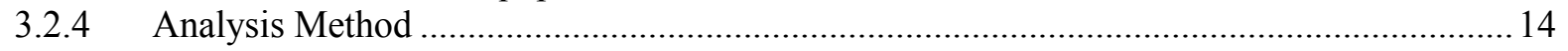

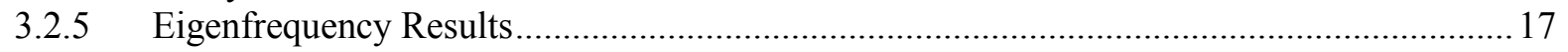

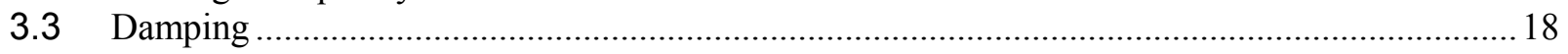

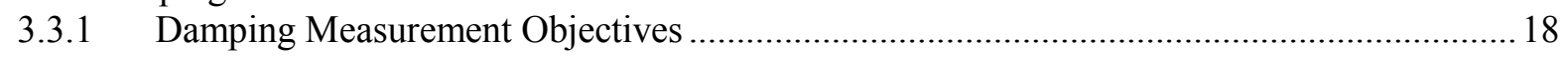

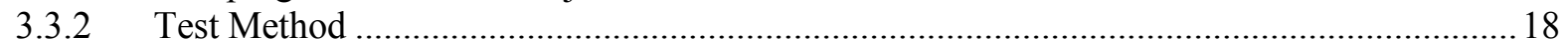

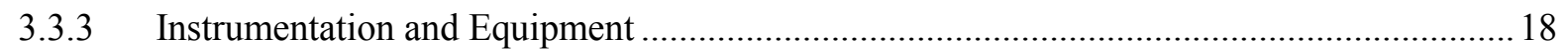

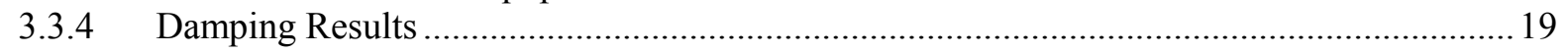

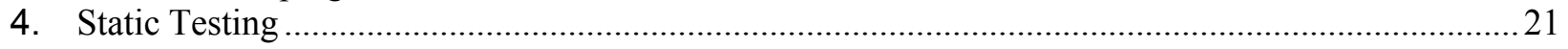

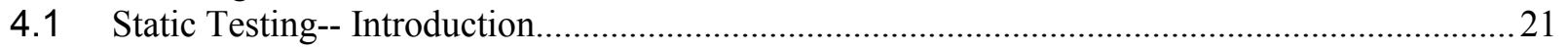

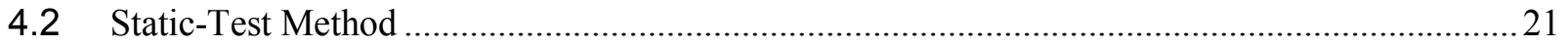

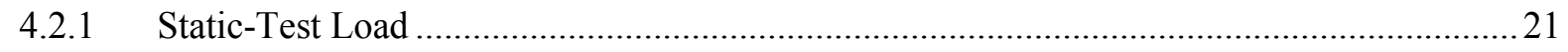

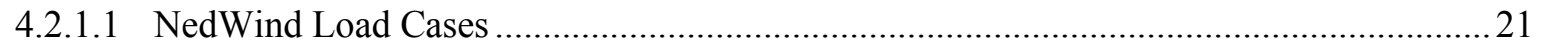

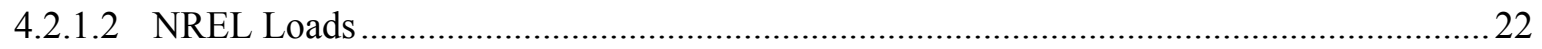

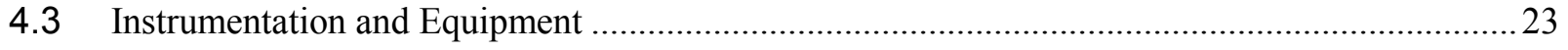

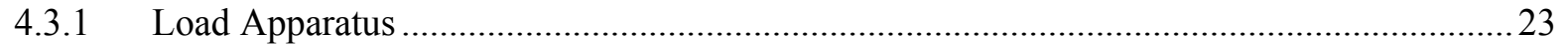

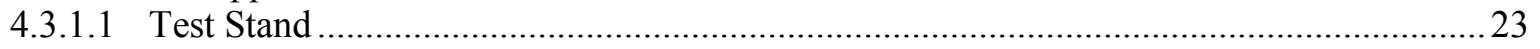

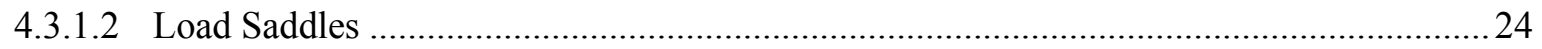

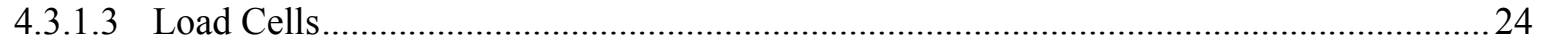

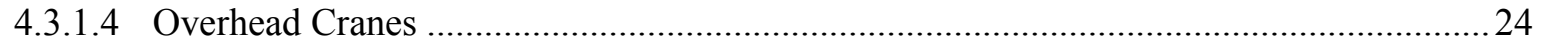

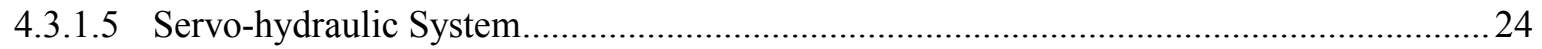

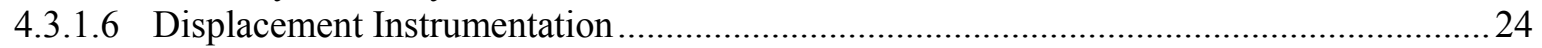

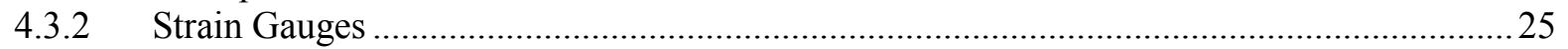

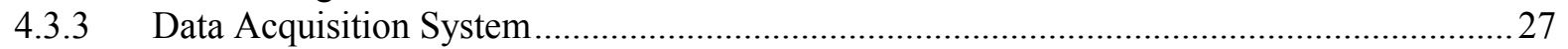

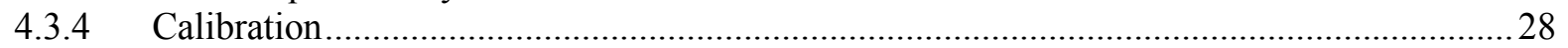

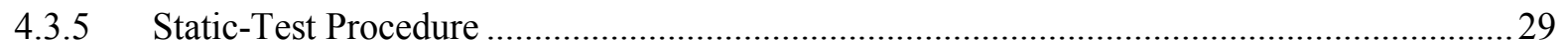

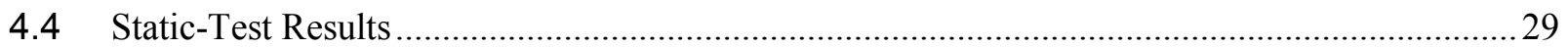

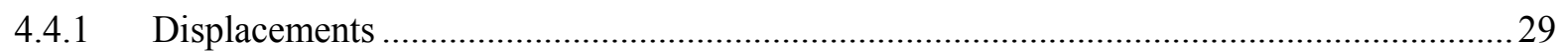

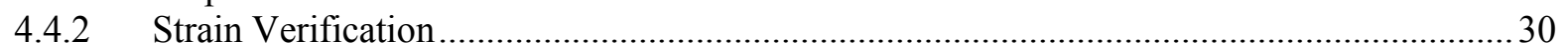

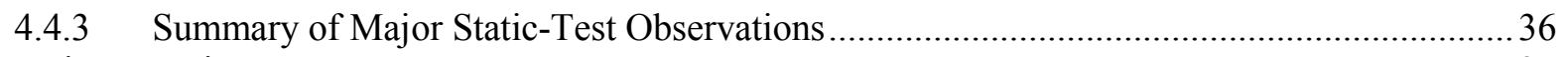

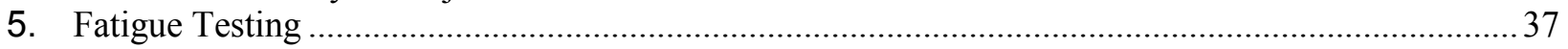

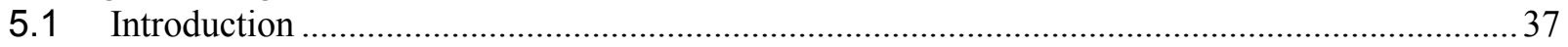




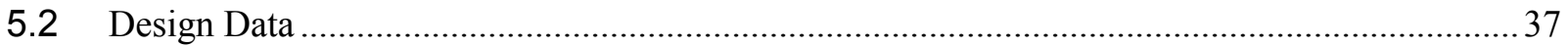

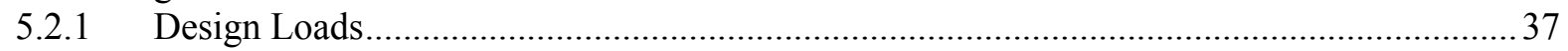

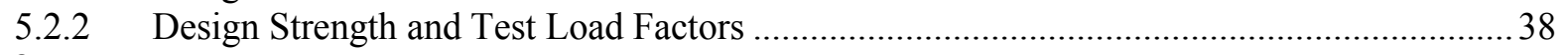

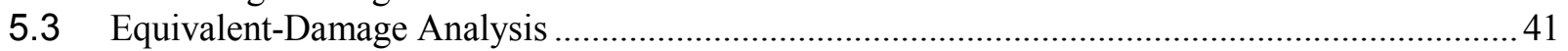

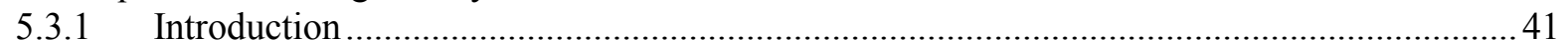

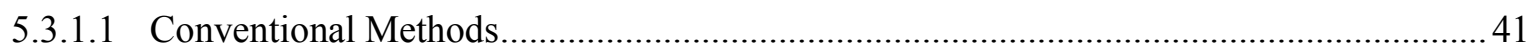

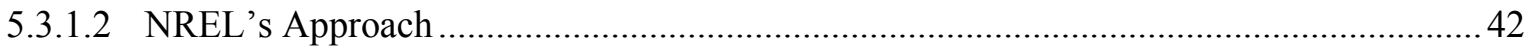

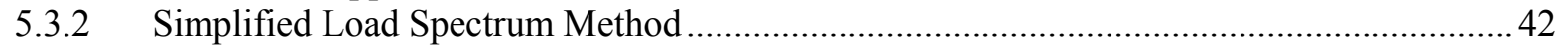

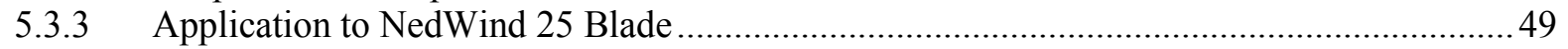

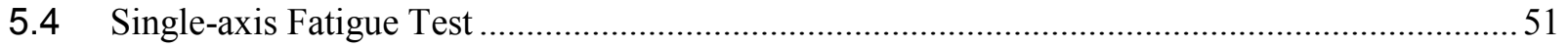

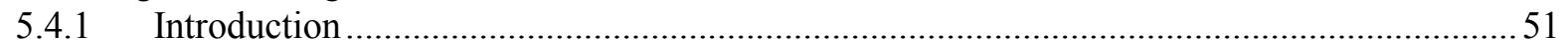

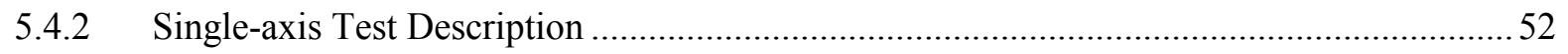

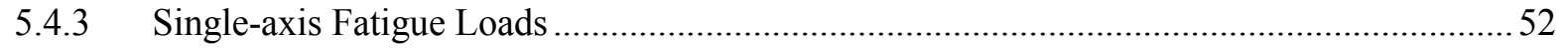

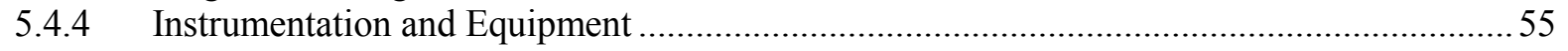

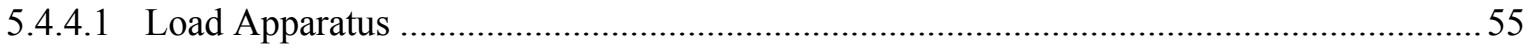

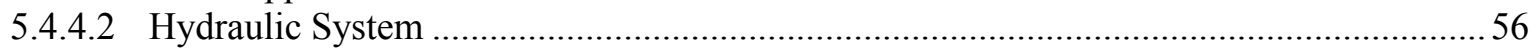

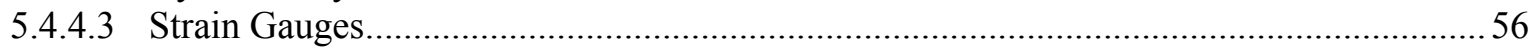

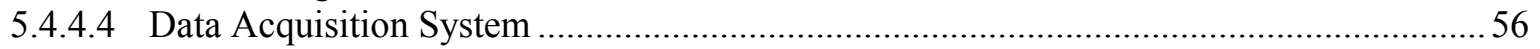

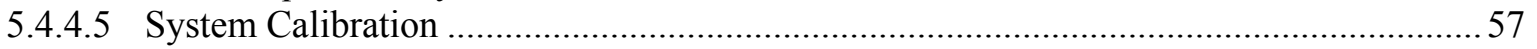

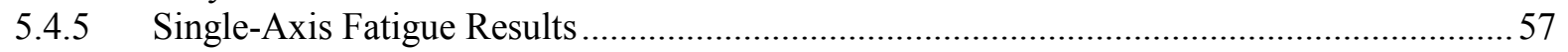

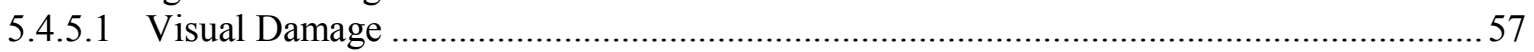

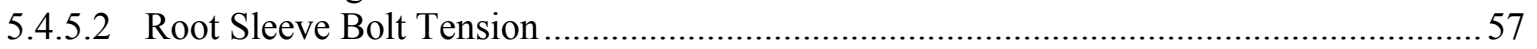

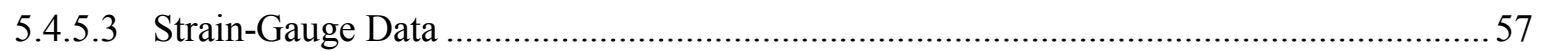

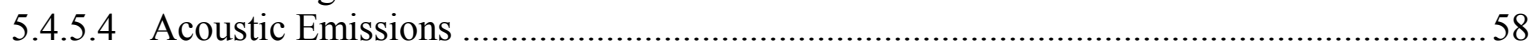

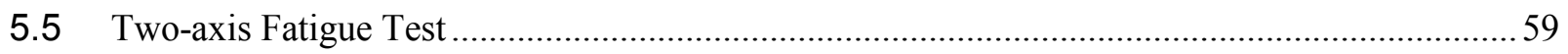

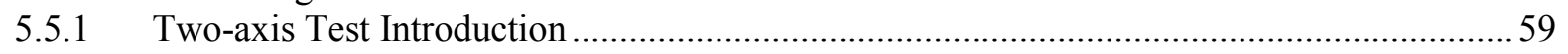

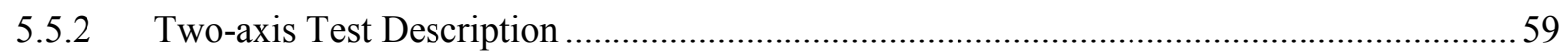

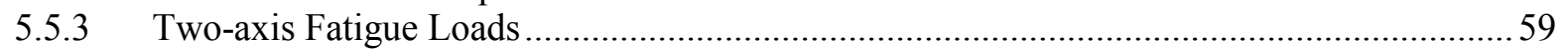

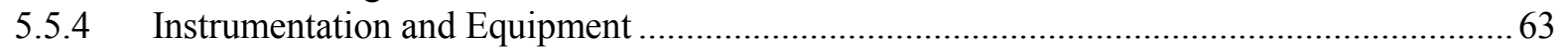

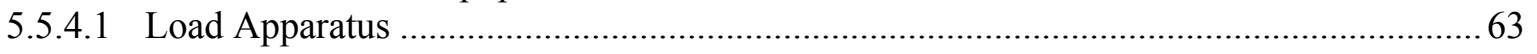

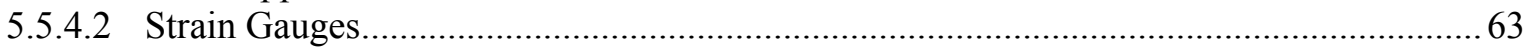

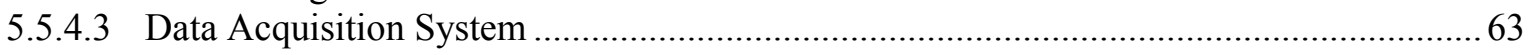

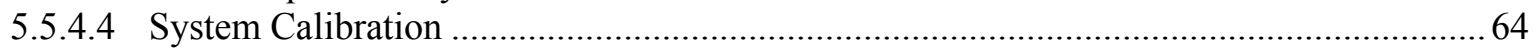

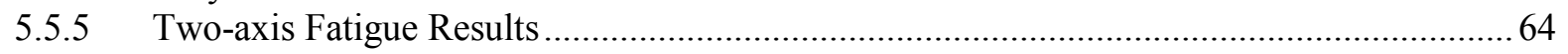

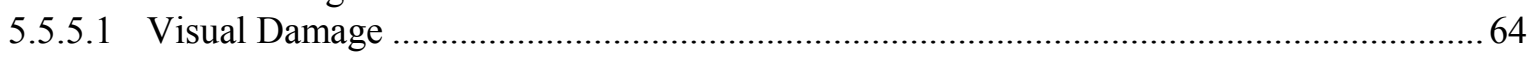

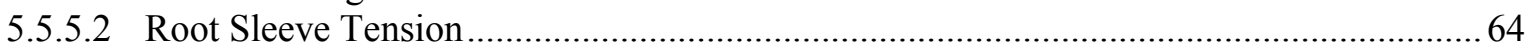

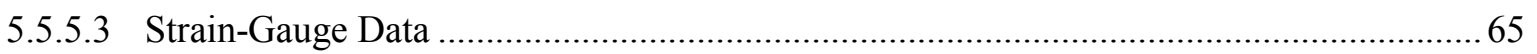

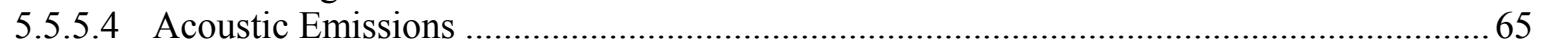

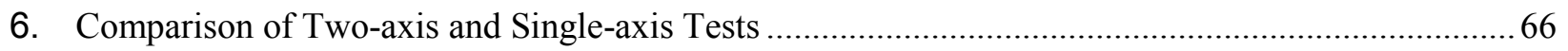

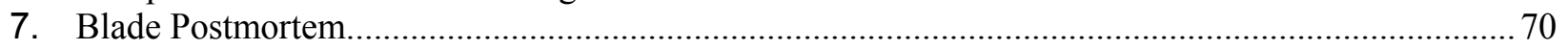

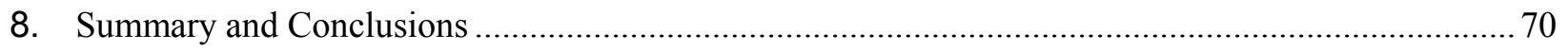

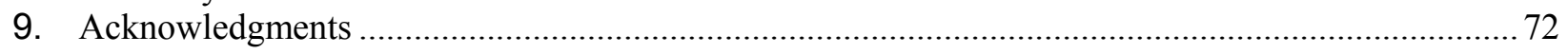

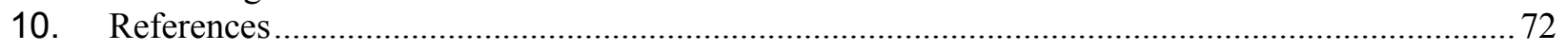

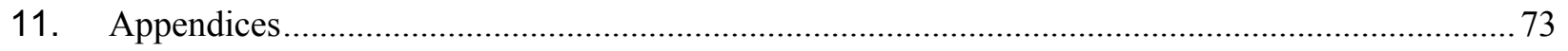




\section{List of Figures}

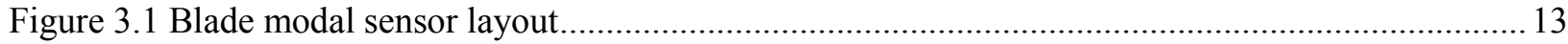

Figure 3.2 Blade \#66 flap-bending-mode residual plot ..................................................................... 15

Figure 3.3 Blade \#66 cross product of flap response at Positions \#20 and \#31 with flap excitation at

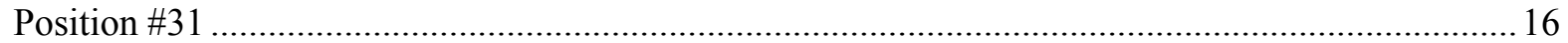

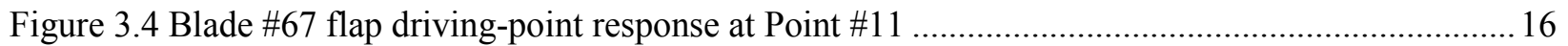

Figure 3.5 Blade \#67 Edge driving-point response at Point \#11 ........................................................... 17

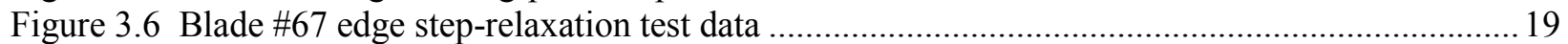

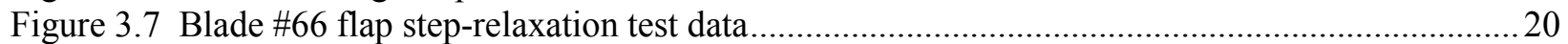

Figure 4.1 NedWind 25 Blade Setup Edge Static-Loading Building 252 (A-60), NWTC......................23

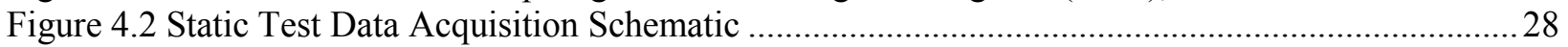

Figure 4.3 Blade \#66 flap static test pre- and post-fatigue test gauge comparison .................................... 33

Figure 4.4 Blade \#66 edge static test pre- and post-fatigue test gauge comparison ................................. 33

Figure 4.5 Blade \#67 flap static test pre- and post-fatigue test gauge comparison.................................. 34

Figure 4.6 Blade \#67 edge static test pre- and post-fatigue test gauge comparison ................................. 34

Figure 4.7 Blades \#66 and \#67 comparison for SMT-prescribed 75\% flap static tests ............................ 35

Figure 4.8 Blades \#66 and \#67 comparison for SMT-prescribed 75\% edge static tests ........................... 35

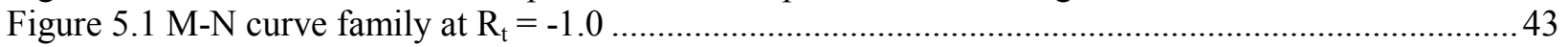

Figure 5.2 Goodman diagram and sample load case \#1 .............................................................. 44

Figure 5.3 Normalized Goodman Diagram based on MSU/DOE database [22] and NedWind 25 load

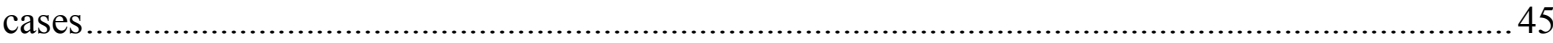

Figure 5.4 Rotorline analysis modified Goodman relation (Equation 5-1) with truncation of tensile failure

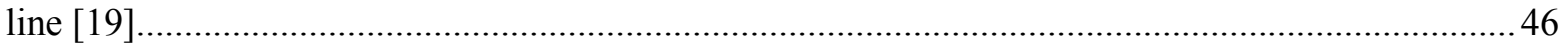

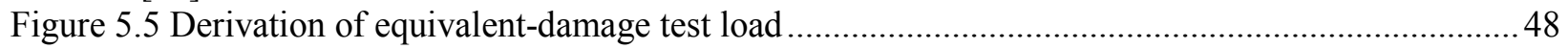

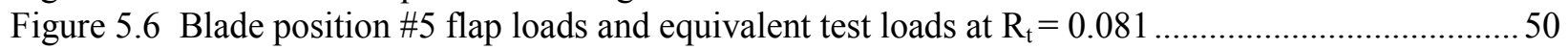

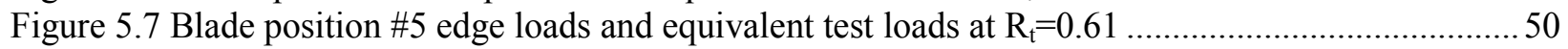

Figure 5.8 Blade \#67 Single-Axis Fatigue Test In NREL Building 252 ............................................ 52

Figure 5.9 Moment distribution of single-axis fatigue test including optimum damage-equivalent

moments, fatigue-test moments, and 100\% static-test moments ...................................................53

Figure 5.10 Resultant single-axis fatigue test load--looking at tip chord ..............................................5 54

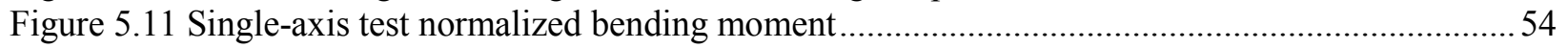

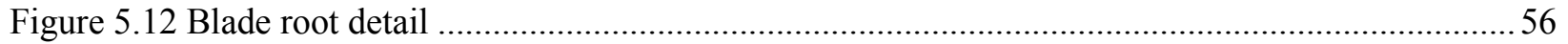

Figure 5.13 Blade \#67 global stiffness data for single-axis fatigue test ...........................................58

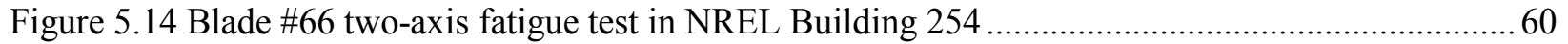

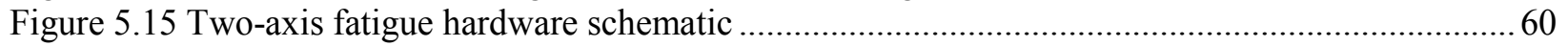

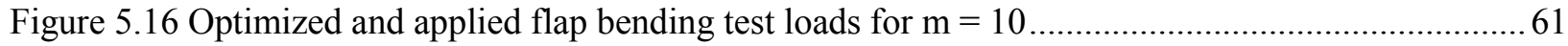

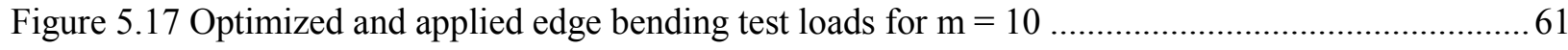

Figure 5.18 Two-axis bending moment normalized to single axis test moment.......................................62

Figure 5.19 Blade \#66 stiffness data from the two-axis fatigue test .......................................................65

Figure 6.1 Comparison of resultant fatigue load cycle for single- and two-axis tests ..............................67

Figure 6.2 Comparison of resultant fatigue load angles for single- and two axis tests............................. 67

Figure 6.3 Calculated difference in allowable cycles between Blade \#66 (two-axis test) and Blade \#67

(single-axis test) at each strain-gauge measurement location......................................................... 70 


\section{List of Tables}

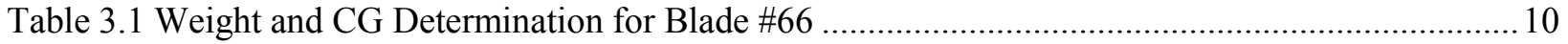

Table 3.2 Weight and CG Determination for Blade \#67-- Without Tip ................................................. 11

Table 3.3 Weight And CG Determination for Blade \#67-- Tip Only ................................................... 11

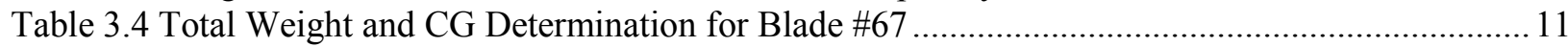

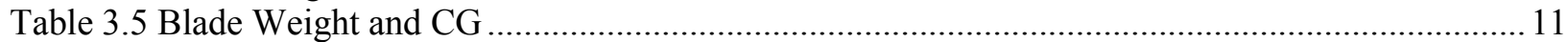

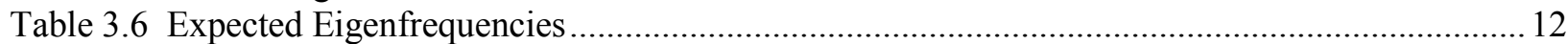

Table 3.7 Equipment Used for Blade \#66 Driving-Point Measurements .................................................. 14

Table 3.8 Equipment Used for Blade \#66 Modal Survey ...................................................................... 14

Table 3.9 Equipment Used for Blade \#66 Torsion Measurements ........................................................ 14

Table 3.10 Equipment Used for Blade \#67 Flap-Driving Measurements............................................. 14

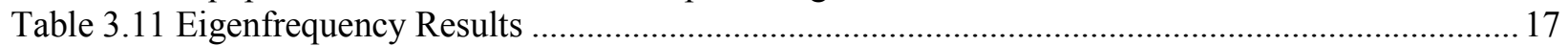

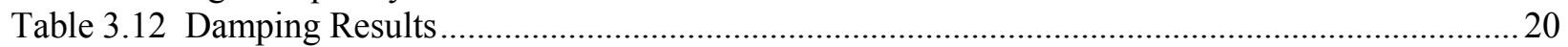

Table 4.1. Rotorline Static-Test Blade Deflections .............................................................................. 22

Table 4.2 Mass Distribution for Static-Test Blade Weight Tare [10] .................................................22

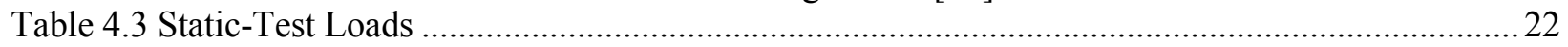

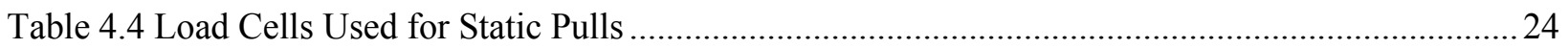

Table 4.5 Static-Pull Displacement Instrumentation--Load Application Point ........................................25

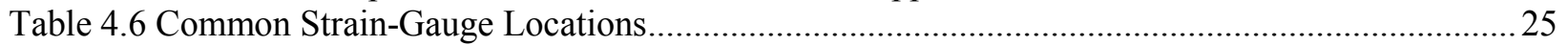

Table 4.7 Strain Gauge Setup for Edgewise Static Pulls ..................................................................... 26

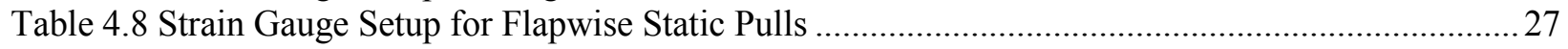

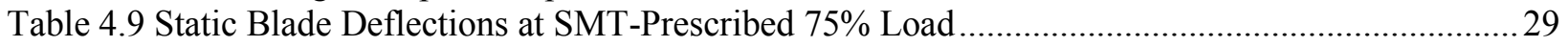

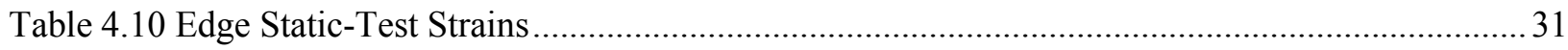

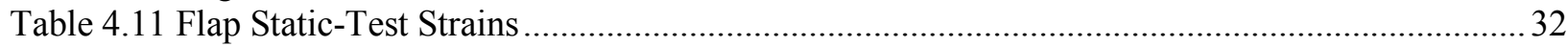

Table 5.1 Spanwise Positions for Load Cases (File name NW25.LKB) ................................................. 38

Table 5.2 Example Contents of File NW25.CSB, Range of Load Cases ................................................ 38

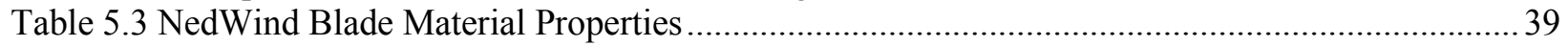

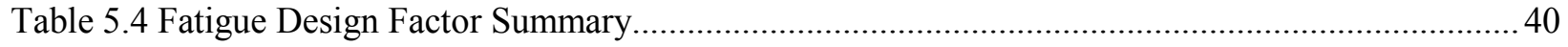

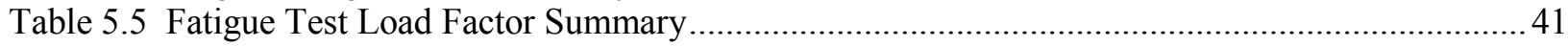

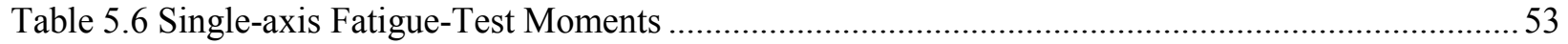

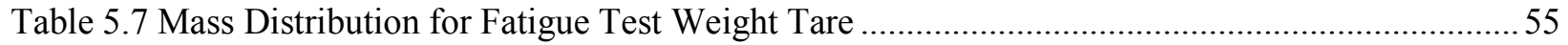

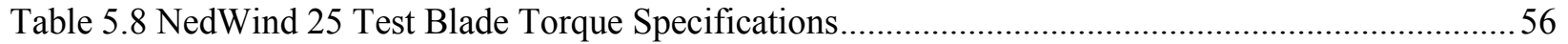

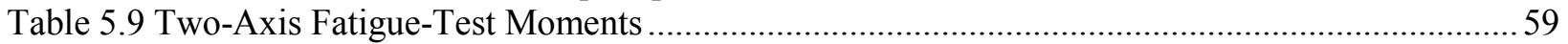

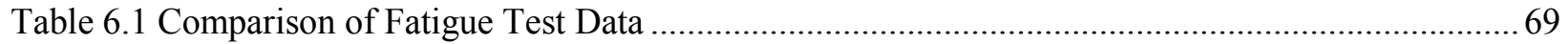




\section{Executive Summary}

In the mid-90's the European Community initiated the Standards, Measurements, and Testing (SMT) program to harmonize testing and measurement procedures in several industries. Within the program, a project was carried out called the European Wind Turbine Testing Procedure Development (EWTTPD). The second part of that project, called Blade Test Methods and Techniques, included the United States and was devised to help blade-testing laboratories harmonize their testing methods. The project supported the need for comparison of the testing procedures used at the different laboratories, and, on this basis, supported the work of the International Electrotechnical Commission (IEC). Each of the individual laboratories benefited by having its procedures evaluated and accepted internationally, while they were able to observe, first hand, the methods used by others.

Three European Union member states and the United States participated in this project. The project was called SMT for short. Five laboratories were represented including RIS $\varnothing$ (Denmark), the Center for Renewable Energy Sources (CRES--Greece), the Technical University of Delft (Netherlands), the Netherlands Energy Research Foundation (ECN), and the National Renewable Energy Laboratory (NREL--United States). CRES and NREL tested two blades while the other laboratories tested one blade. NREL, an invited member of this project voluntarily used internal funding from the U.S. Department of Energy.

The program objectives were:

- To make a reference database for different test methods, techniques, and results of static and fatigue testing of wind turbine blades used by different laboratories.

- To gain a greater collective understanding of the technical challenges of blade testing and to bring the international laboratories closer to a unified approach. As a result of this program, we anticipated that results from different laboratories will be shared and widely accepted.

SMT Program laboratories began by selecting a commercial blade model with good design records that could be released to the participating laboratories. They selected the Rotorline 12-meter and randomly chose blades from a sequential production series. The blades were weighed and identified at Rotorline at the time of manufacture. Each blade was marked at ECN to identify the position of common strain gauges. The laboratories were free to add additional measurement locations at their discretion.

The SMT project laboratories agreed on common prescribed static-tests to determine blade properties. Each laboratory was then required to perform a fatigue test on the blade. The laboratories were to independently determine fatigue test loads based on the design data, and then perform the tests using their "business as usual" practices. When possible, the laboratories agreed to follow the principles in IEC 61400-23 to reduce variability in the methods. NREL used the test load factors described in the draft IEC 61400-23 document to determine its test loads.

NREL's blades were designated by serial numbers \#66 and \#67. NREL performed all of the required measurements of the program. We performed identical mass property tests on both blades we received. We then determined eigenfrequencies by conducting modal tests for the flap and edge directions on both blades. NREL results showed very good agreement with those from the other laboratories, although modal results showed slightly lower frequencies associated with Blade \#67. Torsional frequencies were much lower than predicted by Rotorline. However, this result was consistent with results from the other 
laboratories. Damping was measured using a log decrement method, however NREL did not test at two temperatures as requested by the SMT program due to practical constraints in controlling laboratory temperature.

We also performed static-strength tests prior to and after the fatigue tests. The project laboratories agreed on common load magnitudes and a spanwise application location to perform strain verification tests on the blade. Several strain-gauge measurement locations were prescribed. Additional measurement locations were chosen by NREL. A total of 36 strain measurements and 2 bending bridges were used for each blade. For each blade test, the SMT project prescribed measurement of blade displacements at the load application point and at the tip.

Static test loads were taken from the NedWind 25 design extreme load cases. To determine the design loading, the extreme loads were multiplied by a design load factor of 1.5. The mandatory test load was taken to be $75 \%$ of this value. The load application point was at the $7.65-\mathrm{m}$ spanwise location for both flap and edge loading. NREL elected to increase the load to $110 \%$ of the extreme loads to verify that the blade strains would maintain linearity throughout the fatigue test load range. No abnormal behavior or non-linearities were detected during the static testing. The highest strain in the flap-loading case was measured at $41 \%$ span at $40 \%$ chord.

We performed fatigue tests on both blades using NREL's servo-hydraulic system. One blade was tested using single-axis loading and the other using two-axis loading. Loads for both tests were generated using a damage-equivalent load model that was developed at NREL using the linear damage principles of Miner's Rule. Single-axis loads were constrained to a single load amplitude ratio and in-phase loading. Two-axis testing used an optimized load amplitude ratio for flap and edge components and a $90^{\circ}$-phase angle between them. The resulting peak single-axis loads were more severe than the two-axis loads and produced an earlier onset of damage, although the same cracks appeared for both tests. Most of the strain gauges showed higher strain on the single-axis test.

We conducted a post-fatigue static test on both blades to $100 \%$ of the design load prescribed. Results showed that both blades appeared to have stiffened between the pre- and post-fatigue tests. This result is unusual but might be explained by a drier ambient environment in Colorado than their original climate in the Netherlands. No unusual blade-to-blade variations were detected either globally or at individual strain measurement locations. However, we observed some local differences that were not explained by the strain-data analysis. A postmortem inspection was planned to identify possible anomalies in the construction but was not conducted due to time constraints on the program. 


\section{Introduction}

\subsection{Background}

In the mid-90's the European Community initiated the Standards, Measurements, and Testing (SMT) program to harmonize testing and measurement procedures in several industries. Within the program, a project was carried out called the European Wind Turbine Testing Procedure Development (EWTTPD). The second part of that project, called Blade Test Methods and Techniques, was devised to help bladetesting laboratories harmonize their testing methods. Three European Union member states and the United States participated in this project. The project was called SMT for short. According to SMT documents, response to a survey initiated by the Strength and Fatigue of Large Wind Turbine Rotors Project (S\&FAT) in Europe on the need for blade testing, showed that a majority of the European wind turbine and blade manufacturers believe that blade testing is a necessary part of wind turbine design [1]. This sentiment seems to be shared in the United States as well.

The standardization of blade testing was initiated in 1994 within the International Electrotechnical Committee (IEC) working group 8. The document, IEC 61400-23, was submitted for vote to the IEC TC88 technical committee as an IEC technical report and was accepted in May 2000. It was not developed as a standard because, at the time of its writing, the area of structural blade testing had not matured to a level where a prescriptive standard could be internationally adopted and accepted by a majority of countries.

\subsection{Standards Measurement and Testing Program Overview}

SMT Program laboratories began by selecting a commercial blade model with good design records that could be released to the participating laboratories. They selected blades from a series production and randomly assigned a blade to each laboratory. The Center for Renewable Energy Sources (CRES) and the National Renewable Energy Laboratory (NREL) agreed to test two blades while the other laboratories performed their tests on one blade. The blades were weighed at Rotorline at the time of manufacture. Each blade was also marked at the Netherlands Energy Research Foundation (ECN) to identify the position of common strain gauges. The laboratories were free to add additional measurement locations at their discretion.

The SMT project laboratories agreed on three tests that were to be conducted on each blade received.

1. Property tests, which included eigenfrequency measurements, weight, CG verification, and damping

2. A common set of prescribed static tests for strain verification

3. A fatigue test

The laboratories were to independently determine fatigue test loads based on the design data, and then perform the tests using their "business as usual" practices. When possible, the laboratories agreed to follow the principles in IEC 61400-23 to reduce variability in the methods. NREL used the test load factors described in the draft IEC 61400-23 document to determine its fatigue test loads. 


\subsection{NREL Blade Testing}

NREL has been involved in blade testing since 1990 and has tested more than 75 wind turbine blades. Most of these tests were funded through the U.S. Department of Energy's (DOE's) turbine development projects. Because this work is proprietary in nature and is not usually available to the public, its development and dissemination of NREL testing methods have been inhibited. The SMT program gave NREL an opportunity to share its test results and methods amongst the project laboratories and with the wind industry at large. NREL currently has three blade test bays where blades as long as 34 meters can be fatigue or static tested [2].

\subsection{Scope}

This is the final report to be delivered to ECN under the Standards, Measurement, and Testing program. It covers all of the testing activities conducted by NREL under this program between 1997 and 2000.

\subsection{Description of Program Objectives}

The program objectives were:

- To make a reference database for different test methods, test techniques, and test results of static and fatigue testing of wind turbine blades being used by different laboratories.

- To gain a greater collective understanding of the technical challenges of blade testing and to bring the international laboratories closer to a unified approach. From this program, results from different laboratories may be shared and widely accepted.

\section{Property Testing}

\subsection{Mass Properties}

\subsubsection{Objectives}

All laboratories were to measure the weight and center of gravity (CG) of the blades. This data was needed to develop of blade structural and full-system dynamic models. The blade weights and CGs must also be verified so that the turbine manufacturer will have matched blade sets.

The blades received at NREL were weighed and adjusted for CG position at NedWind Heerhugowaard (later changed to Rotorline) and documented in a project document, "Jeroen 8" [3]. The blades were simultaneously weighed at the flange and at the 9.5-meter station. These weights and CGs are presented with the results in Table 3.5.

\subsubsection{Test Method}

NREL duplicated the method used by NedWind to determine weight and CG. Weight at the flange and at the 9.5-meter station were both measured during the lift. The 9.5-meter station was lifted with a strap 
configured into a choker. The flange was lifted with a strap over a steel rod inserted into one of the flange holes. It was assumed that the flange lift was over the center of the flange, which was 70.8-mm thick.

Because of an oversight, we did not perform these mass property tests until the completion of the fatigue tests. The results include the effect of the strain gauges and lead wires, which we assumed to be negligible. Also, the tip (outboard 2-meters) for Blade \#67 had been removed. We determined the weight of Blade \#67 by adding the weight of the two parts. We determined the total blade CG by first determining the $\mathrm{CG}$ of the main blade section by weighing at the flange and at the 9.5 -meter section as mentioned above. We then weighed the blade tip with a lower capacity load cell. We determined the tip CG by balancing it over a piece of angle iron. The total blade weight was the sum of the part weights (less material lost when cutting the blade, assumed to be negligible). The total CG was determined by adding the mass moment of inertia of the parts and dividing by the total weight (see Tables 3.2 to 3.4).

\subsubsection{Instrumentation and Equipment}

The blades were measured in NREL's Building 251 high bay. The blade was lifted at the flange with the 15-ton-capacity overhead crane. The weight was measured at this point with a $10,000-1 \mathrm{~b}(4536-\mathrm{kg})$ capacity load cell (Transducer Techniques, model number SW0-10K, serial number 90132). The 9.5-m station was lifted with a 1-ton-capacity engine hoist. The weight was measured at this point with a 2000lb (907-kg) capacity load cell (Transducer Techniques, model number SW0-2K, serial number 87158). The load cells were hooked up to NREL's Blade Structural Testing Real-Time Acquisition Interface Network (BSTRAIN) [4] for readout of the measurements.

The tip piece of Blade \#67 was weighed with a 200-lb (91-kg) capacity load cell with external readout (Cardinal, model number HSDC-200, serial number 9407-35).

\subsubsection{Results}

Table 3.1 below lists the weight and CG data for Blade \#66. Tables 3.2 to 3.4 list the data for Blade \#67. Table 3.5 lists the compiled results along with the Rotorline data. The uncertainties in the NREL values are $\pm 6 \mathrm{~kg}$ and \pm 0.02 meters. Note that the total weight matches within the experimental uncertainty. The CG values however, are 3\% greater for the NREL measurements. Our first concern was that the straingauge installation (weight is estimated at less than one kilogram) effected the results. However, the NREL CG measurements matched those of the other laboratories [5], with the exception of ECN.

Table 3.1 Weight and CG Determination for Blade \#66

\begin{tabular}{cccccc}
\hline $\begin{array}{c}\text { Weight at } \\
\begin{array}{c}\text { Flange* } \\
(\mathrm{kg})\end{array}\end{array}$ & $\begin{array}{c}\text { Weight at } \\
\begin{array}{c}9.5-\mathrm{m} \text { Span } \\
(\mathrm{kg})\end{array}\end{array}$ & $\begin{array}{c}\text { Total } \\
\text { Weight } \\
(\mathrm{kg})\end{array}$ & $\begin{array}{c}\text { Mass } \\
\text { Moment } \\
\text { about Flange } \\
(\mathrm{kg}-\mathrm{m})\end{array}$ & $\begin{array}{c}\text { CG } \\
\text { Distance } \\
\text { from Flange } \\
(\mathrm{m})\end{array}$ & $\begin{array}{c}\text { CG Distance } \\
\text { from Hub- } \\
\text { Mating Surface } \\
(\mathrm{m})\end{array}$ \\
\hline 513.9 & 242.7 & 756.6 & 2297 & 3.04 & 3.07 \\
\hline
\end{tabular}

*Note that the flange center is $35.4 \mathrm{~mm}$ from the hub-mating surface. 
Table 3.2 Weight and CG Determination for Blade \#67-- Without Tip

\begin{tabular}{cccccc}
\hline $\begin{array}{c}\text { Weight at } \\
\text { Flange }(\mathrm{kg})\end{array}$ & $\begin{array}{c}\text { Weight at 9.5- } \\
\mathrm{m} \text { span }(\mathrm{kg})\end{array}$ & $\begin{array}{c}\text { Total Weight } \\
\text { of Main Piece } \\
(\mathrm{kg})\end{array}$ & $\begin{array}{c}\text { Mass Moment } \\
\text { about Flange } \\
(\mathrm{kg}-\mathrm{m})\end{array}$ & $\begin{array}{c}\text { CG Distance } \\
\text { from Flange } \\
(\mathrm{m})\end{array}$ & $\begin{array}{c}\text { CG Distance } \\
\text { from Hub- } \\
\text { Mating Surface } \\
(\mathrm{m})\end{array}$ \\
\hline 519.8 & 205.9 & 725.7 & 1949 & 2.69 & 2.72 \\
\hline
\end{tabular}

Table 3.3 Weight And CG Determination for Blade \#67-- Tip Only

\begin{tabular}{ccc}
\hline $\begin{array}{c}\text { Tip Weight } \\
(\mathrm{kg})\end{array}$ & $\begin{array}{c}\text { CG Distance to Cut } \\
(\mathrm{m})\end{array}$ & $\begin{array}{c}\text { CG Distance from Hub- } \\
\text { Mating Surface* }(\mathrm{m})\end{array}$ \\
\hline 31.6 & 1.03 & 10.99 \\
\hline
\end{tabular}

*Note that the blade was cut at 9.96-meters.

Table 3.4 Total Weight and CG Determination for Blade \#67

\begin{tabular}{ccccc}
\hline $\begin{array}{c}\text { Total Weight } \\
(\mathrm{kg})\end{array}$ & $\begin{array}{c}\text { Mass Moment } \\
\text { of Main Piece } \\
(\mathrm{kg}-\mathrm{m})\end{array}$ & $\begin{array}{c}\text { Mass Moment } \\
\text { of Tip }(\mathrm{kg}-\mathrm{m})\end{array}$ & $\begin{array}{c}\text { Total Mass } \\
\text { Moment } \\
(\mathrm{kg}-\mathrm{m})\end{array}$ & $\begin{array}{c}\text { CG Distance from } \\
\text { Hub-Mating Surface } \\
(\mathrm{m})\end{array}$ \\
\hline 757.3 & 1974 & 347 & 2321 & 3.07 \\
\hline
\end{tabular}

Table 3.5 Blade Weight and CG

\begin{tabular}{ccc}
\hline $\begin{array}{c}\text { Blade } \\
\text { Number }\end{array}$ & $\begin{array}{c}\text { Rotorline } \\
\text { Weight/CG } \\
(\mathrm{kg} / \mathrm{meters})\end{array}$ & $\begin{array}{c}\text { NREL } \\
\text { Weight/CG } \\
(\mathrm{kg} / \mathrm{meters})\end{array}$ \\
\hline 66 & $759.36 / 2.99$ & $757 / 3.07$ \\
67 & $759.28 / 2.99$ & $757 / 3.07$ \\
\hline
\end{tabular}

\subsection{Eigenfrequency Determination}

\subsubsection{Eigenfrequency Determination Objectives}

All of the laboratories were required to determine the first and second flap and edge blade frequencies and the first torsional frequency of the blades prior to static testing. The purpose was to determine the measurement scatter among the laboratories. This data could also be used as a boundary for the fatigue test frequency. Although not a specific objective of this program, this data could be used in the development of blade-structural and full-system dynamic models.

From [6] ("Jeroen 4") and [3] ("Jeroen 8"- included in Appendix F), the expected frequencies (blade cantilevered) are given. They are also summarized below in Table 3.6. 
Table 3.6 Expected Eigenfrequencies

\begin{tabular}{lcl}
\hline \multicolumn{1}{c}{ Mode } & $\begin{array}{c}\text { Blade } \\
\text { Frequency } \\
(\mathrm{Hz})\end{array}$ & \\
\hline First Flap & 2.52 & Reference \\
First Edge & 4.0 & Jeroen 4 4 \\
Second Flap & 7.8 & Jeroen 4 \\
Second Edge & 26.1 & Jeroen 4 \\
First Torsion & 37.5 & Jeroen 8 \\
\hline
\end{tabular}

\subsubsection{Test Method}

The eigenfrequencies were determined by measuring the frequency response function at various locations along the blade. Figure 3.1 shows a layout of the blade for the modal testing and the measurement positions used. Driving-point measurements (collocation of input and response) were made at position \#9 (end of spar) and at position \#5 (center of gravity) in the flap and edge directions. A modal survey was then conducted by impacting the blade at the survey test points and measuring the response at position \#9. Based on a preliminary review of the data, we believe that position \#9 was a node for the second flap frequency. We then changed the measurement position to \#11.

To determine the first torsional frequency, a measurement was made taking the cross product of the flap response at positions \#20 and \#31 (leading edge and trailing edge at end of spar). The second blade (\#67) was not extensively surveyed as the first blade. Driving-point measurements were only made at position \#11 based on the first blade survey. 


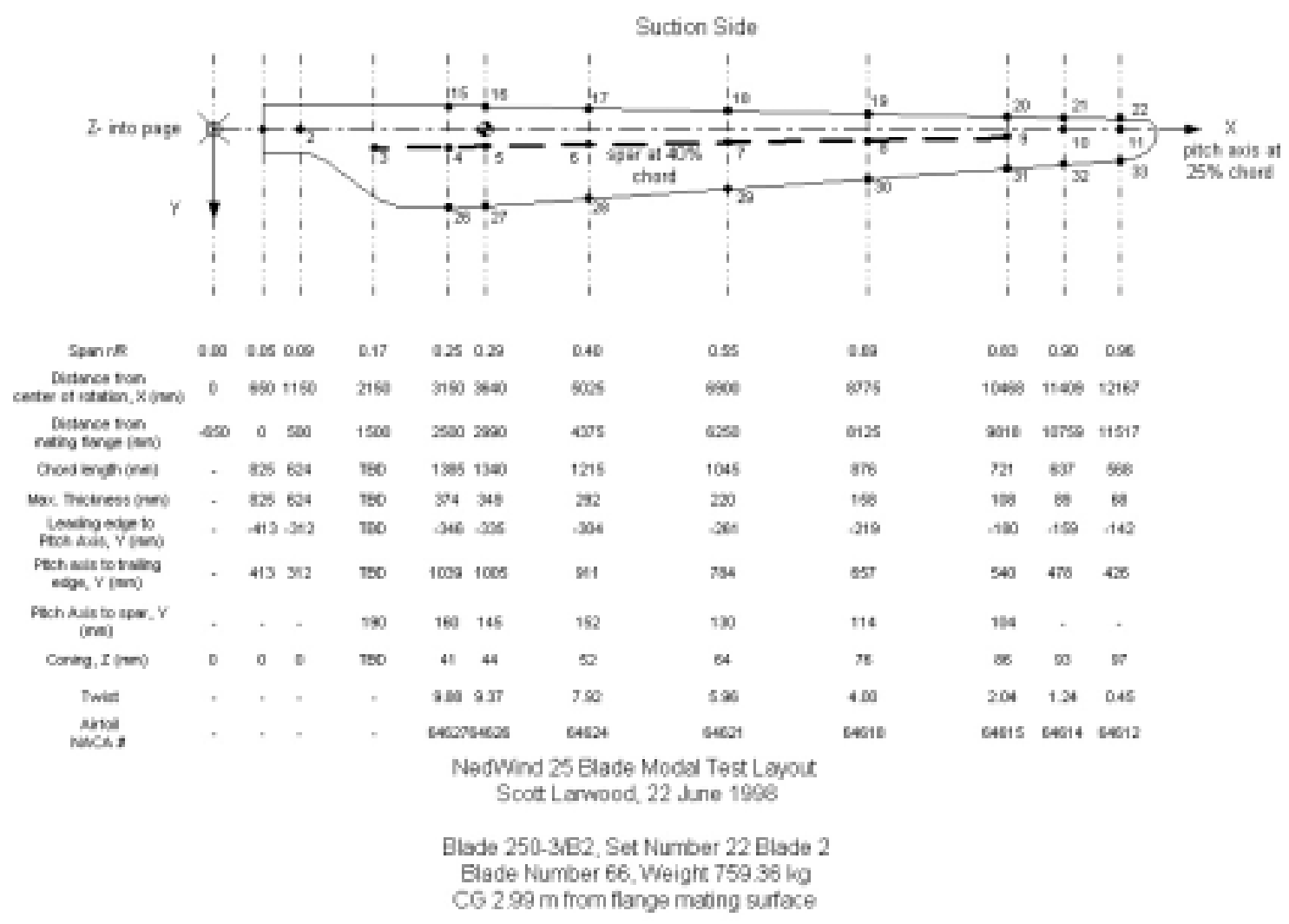

Figure 3.1 Blade modal sensor layout

\subsubsection{Instrumentation and Equipment}

The blades were connected to NREL's 1.35 million N-m (1 million ft-lb) capacity blade test stand with a custom adapter plate (see Appendix $\mathrm{H}$ for drawing). The blade was positioned with the tip chord perpendicular to horizontal, with the trailing edge down, and the pitch axis parallel to the floor. This was the same setup used in the edge static pulls. These tests were conducted in Building 252 (A-60) at the National Wind Technology Center (NWTC).

The accelerometers were mounted to the blade using the following procedure. At each measurement position, aluminum tape was applied to the curved surface of the blade. A small balsa square was sanded into a wedge and glued to the tape to provide a vertical surface for the accelerometer mount. Another layer of aluminum tape was applied over the wedge and the accelerometers were hot-glued to the wedge to orient the accelerometer's z-axis parallel to the ground. The accelerometer cable was then taped to the blade for strain relief.

Tables 3.7 to 3.10 below list the equipment used in the various aspects of the test. 
Table 3.7 Equipment Used for Blade \#66 Driving-Point Measurements

\begin{tabular}{cccc}
\hline Device & Manufacturer & Model No. & Serial No. \\
\hline Dynamic Signal & Scientific & SD380Z & 719 \\
Analyzer & Atlanta & & \\
Force Hammer & PCB & $086 \mathrm{C} 20$ & 216 \\
Three-axis & PCB & $356 \mathrm{~A} 18$ & 4152 \\
Accelerometer & & & \\
\hline
\end{tabular}

Table 3.8 Equipment Used for Blade \#66 Modal Survey

\begin{tabular}{llll}
\hline Device & Manufacturer & Model No. & Serial No. \\
\hline Dynamic Signal & Hewlett-Packard & HP3565S & various \\
Analyzer & & System & \\
Force Hammer & PCB & $086 \mathrm{C} 20$ & 216 \\
Accelerometers & PCB & $370 \mathrm{~A} 03$ & various \\
\hline
\end{tabular}

Table 3.9 Equipment Used for Blade \#66 Torsion Measurements

\begin{tabular}{llll}
\hline Device & Manufacturer & Model No. & Serial No. \\
\hline Dynamic Signal & Scientific & SD380 & TBD \\
Analyzer & Atlanta & & \\
Force Hammer & PCB & $086 C 20$ & 216 \\
Accelerometers & PCB & $370 \mathrm{~A} 03$ & 361,362 \\
\hline
\end{tabular}

Table 3.10 Equipment Used for Blade \#67 Flap-Driving Measurements

\begin{tabular}{llll}
\hline Device & Manufacturer & Model No. & Serial No. \\
\hline $\begin{array}{l}\text { Dynamic Signal } \\
\text { Analyzer }\end{array}$ & Scientific & SD380Z & 719 \\
Force Hammer & Atlanta & & \\
Accelerometers & Kistler & 086 C20 & 216 \\
& & $8638 B 50$ & C106090, \\
& & C106091 \\
\hline
\end{tabular}

\subsubsection{Analysis Method}

The blade modes were determined by plotting the residuals of the frequency response functions (FRFs) that were measured during the modal survey. The residual at each location and for each direction (flap and edge) was determined with the Hewlett-Packard (HP) analyzer and noted in a table. Each residual was then divided by the maximum value along the blade. The residual plots for each frequency were then qualitatively analyzed to determine the blade modes. Figure 3.2 shows a plot of the first and second flapbending modes. These residuals are from the spar location. The drop in the first flap mode could be due to a change in blade structure (no spar) at this location. 


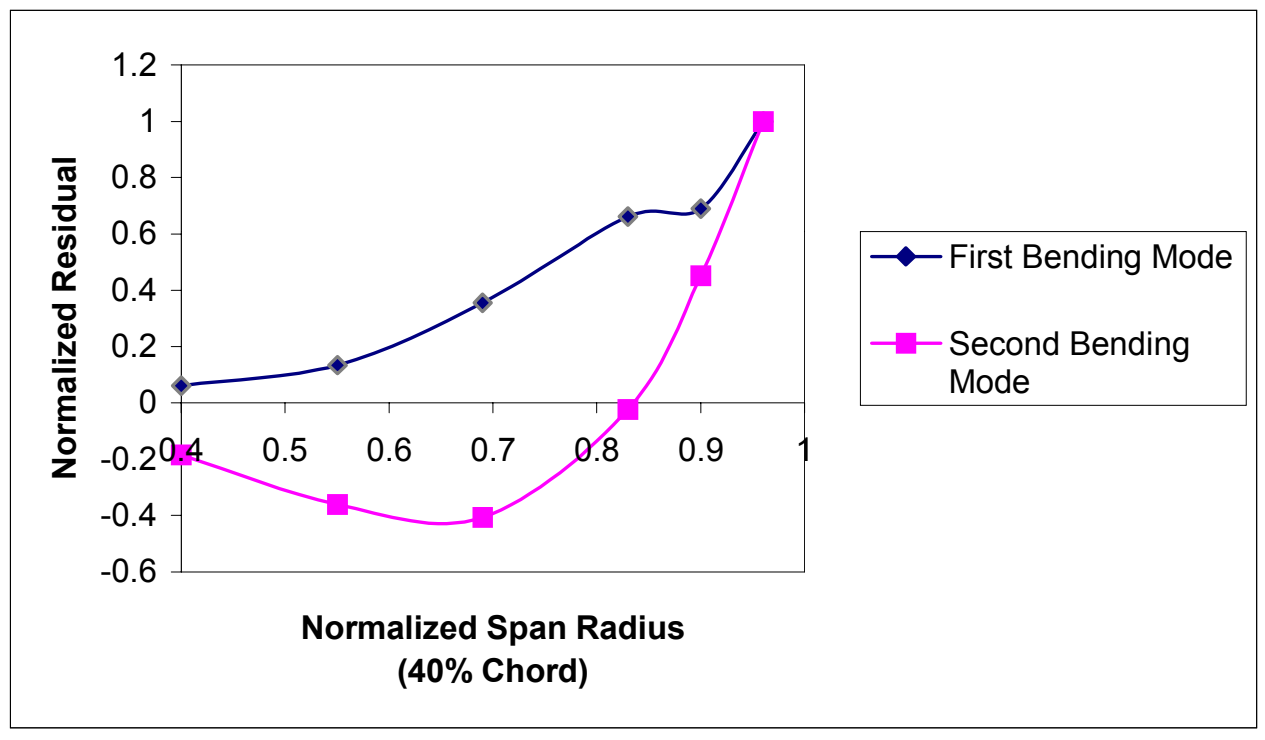

Figure 3.2 Blade \#66 flap-bending-mode residual plot

The first torsion frequency for Blade \#66 was determined by measuring the cross product of flap positions $\# 20$ and \#31. The blade was excited in the flap direction at position \#31. The torsion frequency was noted by a $180^{\circ}$ phase shift at $25.875 \mathrm{~Hz}$. This frequency was also evident in the flap driving point measurements. Figure 3.3 shows the cross product plot.

It was assumed that frequencies for Blade \#67 would be similar, therefore only driving point measurements were made at position \#11. Figure 3.4 shows the flap driving-point FRF for Blade \#67. Figure 3.5 shows the edge driving-point FRF for Blade \#67. 


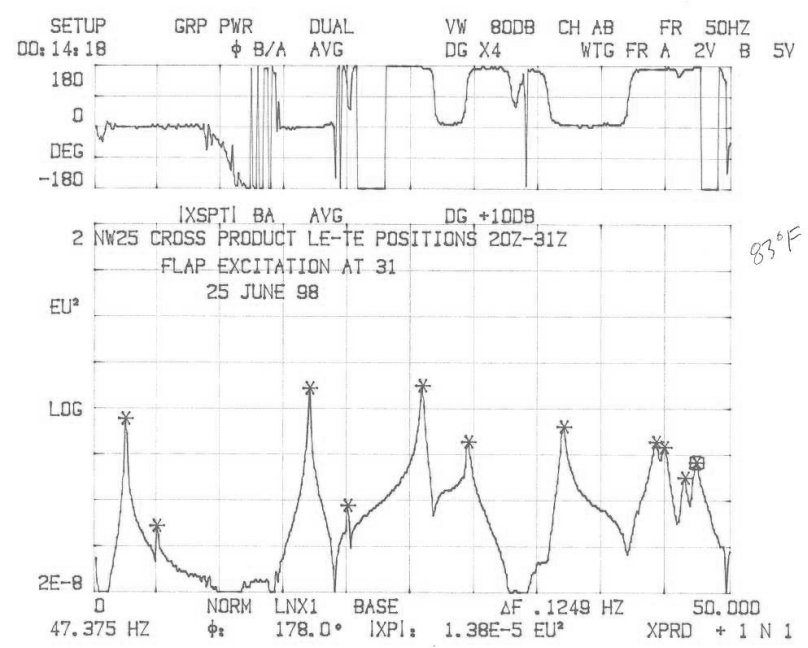

Figure 3.3 Blade \#66 cross product of flap response at Positions \#20 and \#31 with flap excitation at Position \#31

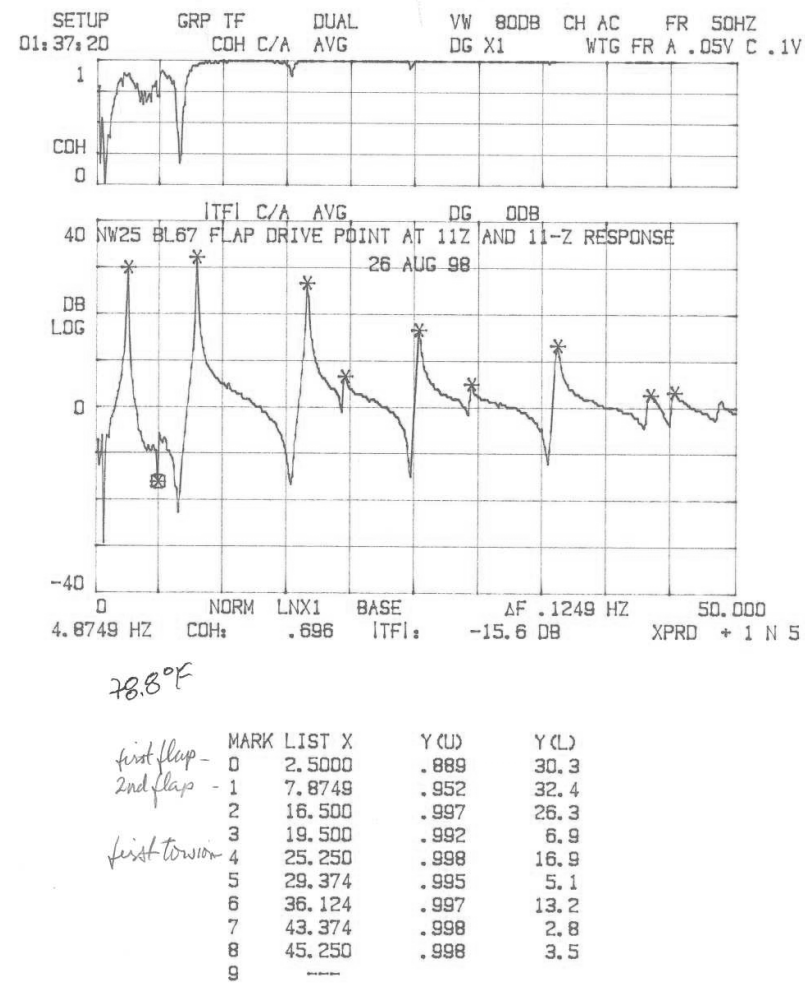

Figure 3.4 Blade \#67 flap driving-point response at Point \#11 


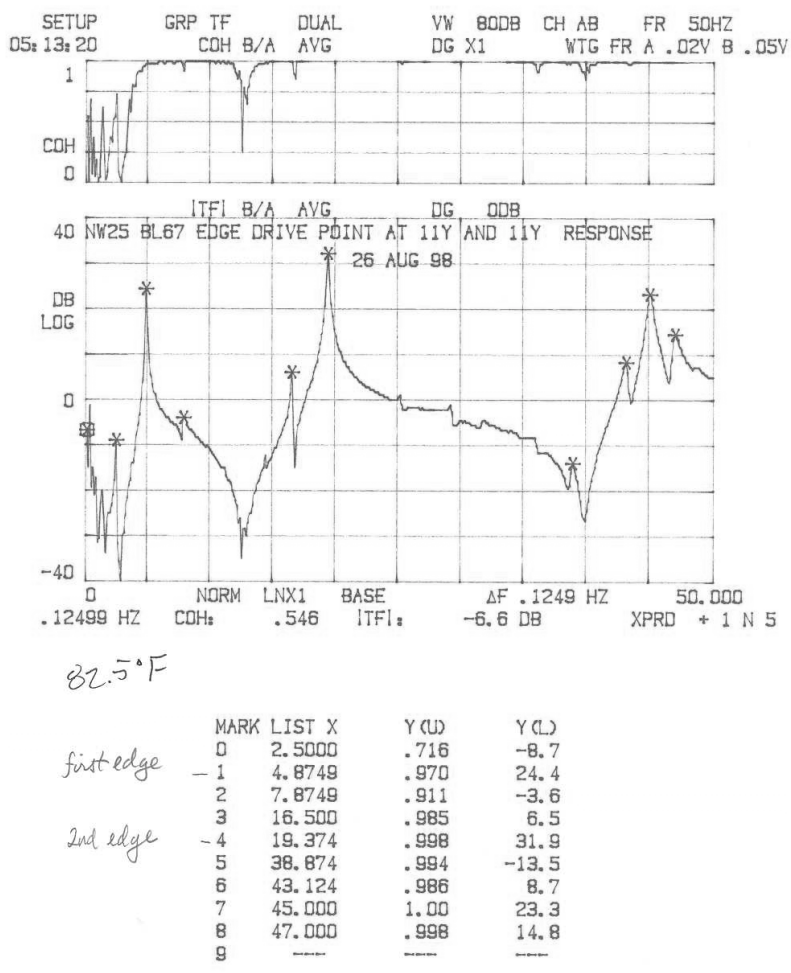

\section{Figure 3.5 Blade \#67 Edge driving-point response at Point \#11}

\subsubsection{Eigenfrequency Results}

Table 3.11 below shows the results of the eigenfrequency tests. The resolution of the frequency measurement was $0.125 \mathrm{~Hz}$. The expected frequencies are also listed, with only the first and second flap modes being predicted to within 4\%. Amongst these modes was a coupled-flap/edge mode near $17 \mathrm{~Hz}$ for both blades.

Table 3.11 Eigenfrequency Results

\begin{tabular}{lllll}
\hline Mode & $\begin{array}{l}\text { Blade \#66 } \\
\text { Frequency }(\mathrm{Hz})\end{array}$ & $\begin{array}{l}\text { Blade \#67 } \\
\text { Frequency }(\mathrm{Hz})\end{array}$ & $\begin{array}{l}\text { Expected } \\
\text { Frequency }(\mathrm{Hz})\end{array}$ & $\begin{array}{l}\text { Average } \Delta \% \\
\text { from Expected }\end{array}$ \\
\hline First Flap & 2.500 & 2.500 & 2.52 & 0.8 \\
First Edge & 5.000 & 4.875 & 4.0 & -19.0 \\
Second Flap & 8.250 & 7.875 & 7.8 & -3.3 \\
Second Edge & 20.000 & 19.374 & 26.1 & 32.6 \\
First Torsion & 25.875 & 25.250 & 37.5 & 46.7 \\
\hline
\end{tabular}




\subsection{Damping}

\subsubsection{Damping Measurement Objectives}

The laboratories were to measure the damping for the first flap and edge bending modes of the blade. This data, which is part of the modal properties of the blade, could be used with the eigenfrequency data to develop blade-structural and full-system dynamic models. The damping can be dependent on the temperature of the blade structure. Also, aerodynamic damping can contribute to the measurement depending on the deflection of the blade during excitation.

The SMT program requirements were to measure the damping with log decrement. Measurements at two different temperatures were also specified but this requirement was overlooked by NREL.

\subsubsection{Test Method}

NREL used a step-relaxation method to measure the blade damping. The blade was set up for the edge measurement as shown in Figure 4.1. For the flap measurement, the blade was rotated clockwise $90^{\circ}$ in pitch from this position so that the tip chord was horizontal (high pressure side down) with the pitch axis remaining horizontal.

For initial deflecting the blade, $90 \mathrm{lb}(41 \mathrm{~kg})$ was suspended $11.5 \mathrm{~m}$ from the flanged mating surface with rope and tie-straps. The root strain gauge bending bridge was connected to a bridge power supply and storage oscilloscope. The oscilloscope was armed to collect approximately twenty cycles of data on the bridge signal. The tie-straps were cut to release the weight and the bridge signal was stored in the oscilloscope. Five trails were made for each measurement and the damping values were averaged.

The critical damping coefficient was determined by fitting a damped sine wave to the data, using a nonlinear regression program NLREG [7]. The damping is unit-less and is determined by fitting the following equation to the data [8]:

$$
x(t)=A e^{-\zeta \omega_{n} t} \sin \left(\omega_{d} t-\phi\right),
$$

where:

and,

$$
\begin{array}{ll}
\mathrm{x}(\mathrm{t}) & =\text { signal value at time } \mathrm{t} \\
\mathrm{A} & =\text { undamped amplitude } \\
\zeta & =\text { damping factor } \\
\omega_{\mathrm{n}} & =\text { undamped natural frequency } \\
\phi & =\text { phase angle }
\end{array}
$$

$\omega_{d}=\omega_{n} \sqrt{1-\zeta^{2}}$

The difference between $\omega_{\mathrm{d}}$ and $\omega_{\mathrm{n}}$ is a small quantity of second order. The curve fit was used to solve for the damping, $\zeta$.

\subsubsection{Instrumentation and Equipment}

The bending-bridge gauges used for generating the time series are described in the static-testing Section 4.3.2. The bridge 08BFLAP was used for the flap measurements and bridge 08BLDLG was used for the edge measurement. The bridges were hooked up to a Measurements Group P-3500 digital strain indicator 
with the output connected to a Tektronix THS710A digital-storage oscilloscope. The time series data was then downloaded to a PC using WaveStar software [9]. NLREG is then used to fit a damped sine wave to the data.

\subsubsection{Damping Results}

Figure 3.6 shows data for an edge step relaxation test for Blade \#67. The damped sine curve parameters for this data are:

$$
\begin{array}{ll}
\mathrm{A} & =0.00393 \\
\zeta & =0.0037 \\
\omega_{\mathrm{d}} & =30.8 \mathrm{radians} / \mathrm{sec}(4.90 \mathrm{~Hz}-\text { compare to } 4.875 \mathrm{~Hz} \text { in Table } 3.11) \\
\phi & =0.935 \text { radians } \\
\text { offset } & =\text { negligible }
\end{array}
$$

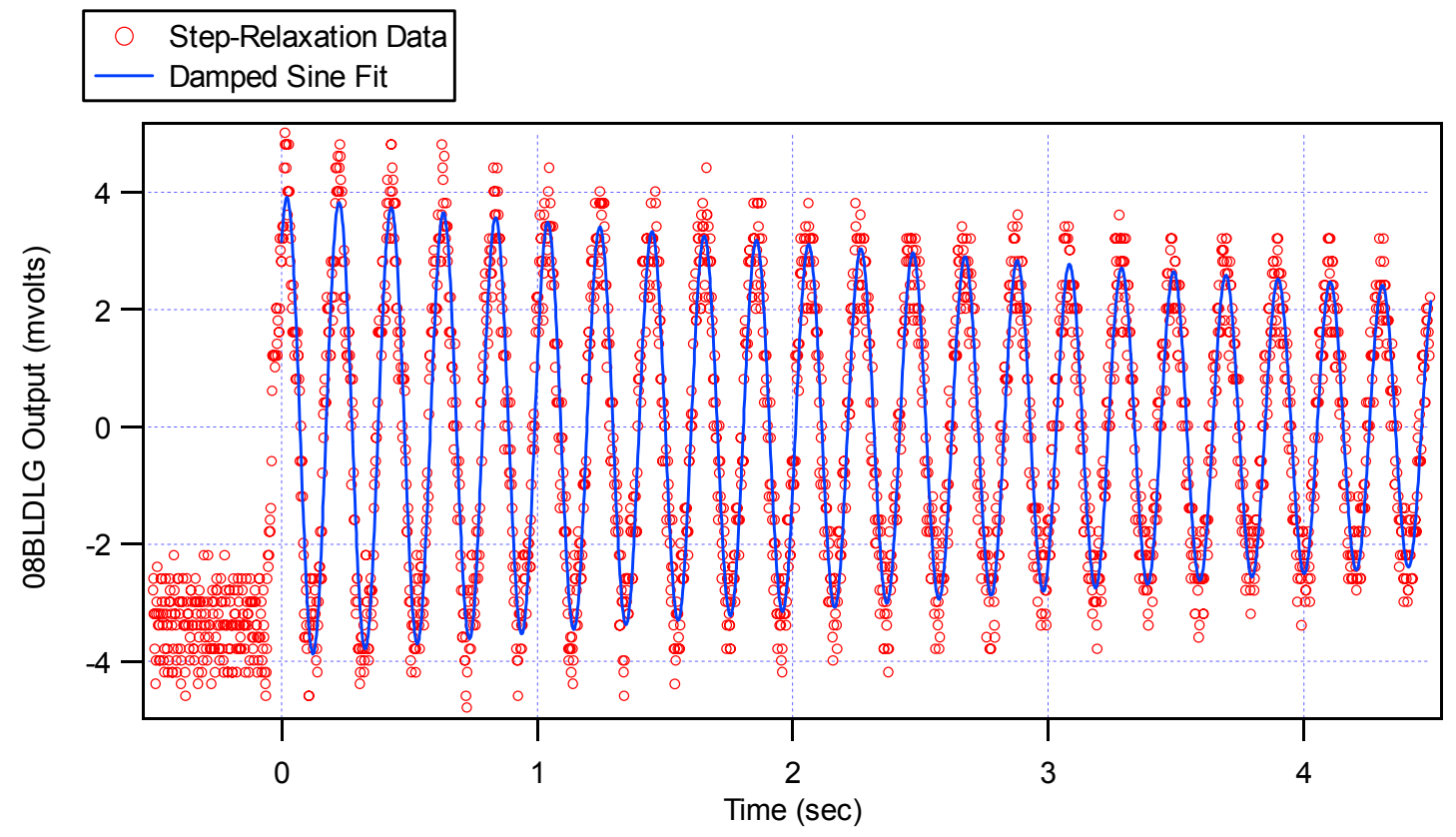

Figure 3.6 Blade \#67 edge step-relaxation test data

Figure 3.7 shows data for a flap step relaxation test for Blade \#66. The damped sine-curve parameters for this data are:

$$
\begin{array}{ll}
\mathrm{A} & =0.00645 \\
\zeta & =0.0038 \\
\omega_{\mathrm{d}} & =16.0 \mathrm{radians} / \mathrm{sec}(2.55 \mathrm{~Hz} \text { - compare to } 2.50 \mathrm{~Hz} \text { in Table } 3.11) \\
\phi & =0.012 \text { radians } \\
\text { offset } & =-0.0017 \text { volts }
\end{array}
$$




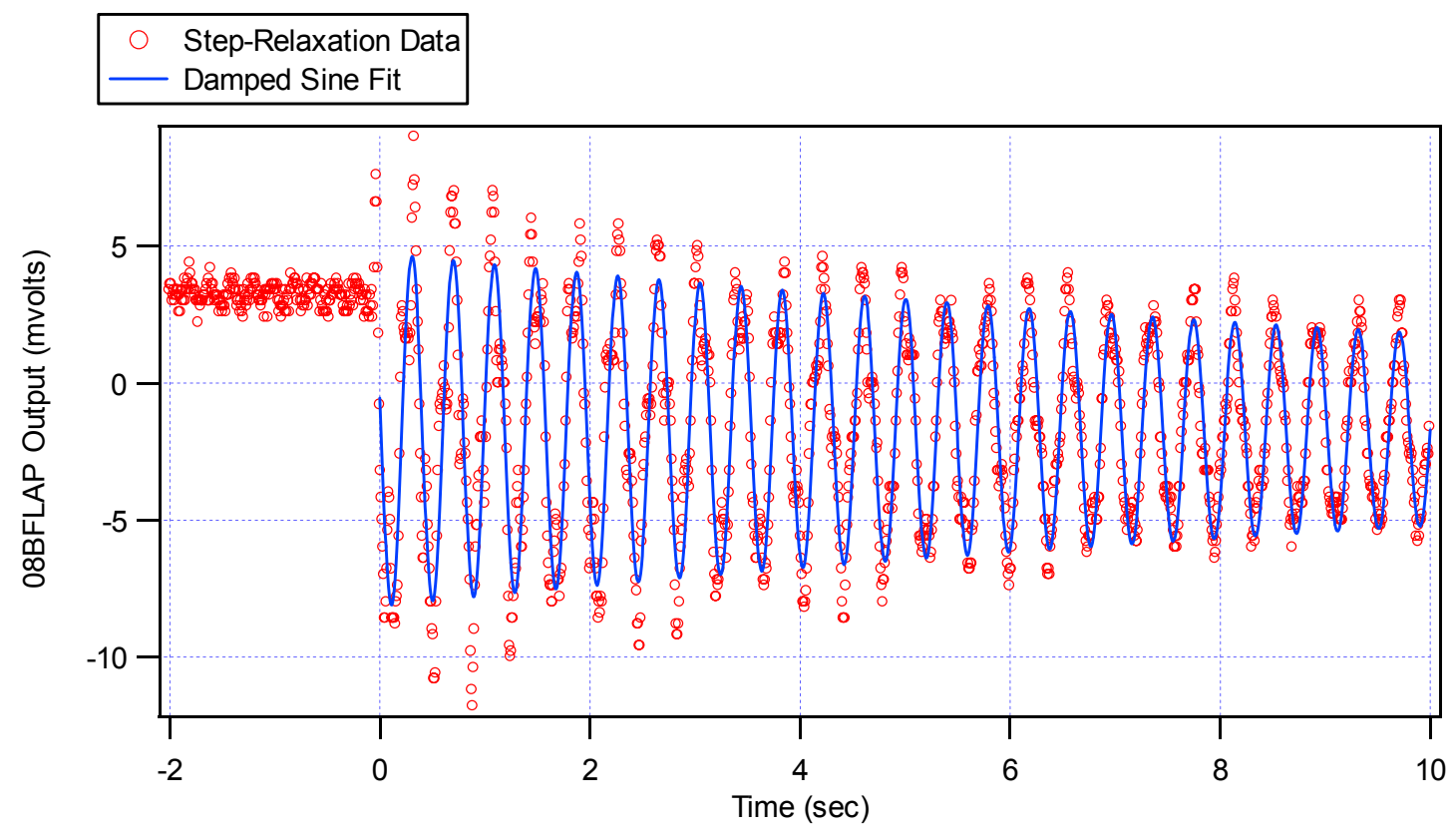

Figure 3.7 Blade \#66 flap step-relaxation test data

Table 3.12 Damping Results

\begin{tabular}{lllll}
\hline Mode & Blade \#66 & Test & Blade \#67 & Test \\
& Damping & Temperature & Damping & Temperature \\
\hline First Flap & $0.0038 \pm 0.0006$ & Not recorded & $0.0044 \pm 0.0008$ & $22^{\circ} \mathrm{C}$ \\
First Edge & $0.0042 \pm 0.0002$ & $27^{\circ} \mathrm{C}$ & $0.0037 \pm 0.0001$ & $27^{\circ} \mathrm{C}$ \\
\hline
\end{tabular}

Table 3.12 lists the damping results. The values are the average of five measurements. The uncertainty, which includes random and systematic components, is within the $95 \%$ confidence limit. The systematic uncertainty for the measurements is for the curve fit output from NLREG. The random component is due to the variation in five measurements.

Because the energy released in the step relaxation contains all frequencies, all modes are excited in the blade. This creates a noisy signal that reduces the accuracy (error of $16 \%$ for the flap) of the damping curve fit. A better approach would be to excite the blade at the first mode frequency with an electrodynamic shaker and then remove the excitation and record the decaying signal. 


\section{Static Testing}

\subsection{Static Testing-- Introduction}

The purpose of the static tests under the SMT program was to demonstrate that the individual laboratories could make the same measurements of strain, load, and deflection on different blades having the same characteristics and global properties. Blades were carefully selected and common strain-gauge locations were marked to assure uniformity. Under normal practice, this type of information is useful for validating structural models that predict stresses or strains on the blade, and to validate load-carrying capability and strength. Unfortunately, it was not possible under this program to perform a complete static-strength validation because of the requirement for most of the labs to incorporate all testing into a single blade. Therefore, the common test procedure prescribed did not include a test to failure.

At NREL we tried to meet the requirements of the program but also to try and produce a static test that was more representative of our common practice. We met the SMT requirement of loading to $75 \%$ of the extreme design load case. In addition, however, we added a step to increase the load to $110 \%$ in order to verify a minimum acceptable load for the fatigue test, which was expected to have cyclic test load peaks of nearly $100 \%$ of the design case. One of the reasons NREL agreed to purchase two blades was to demonstrate extreme-load-carrying capability. With two blades, we knew that an unexpected failure of one blade would not end the program.

Even though we were somewhat freed from a conservative static approach, the methods used in this program were not exactly consistent with the NREL recommendations or standard practices. Specifically, we believe the static-test procedure should include a test-to-failure on a blade to validate the strength and determine the design margins.

\subsection{Static-Test Method}

\subsubsection{Static-Test Load}

\subsubsection{NedWind Load Cases}

Static-test loads were derived from the load spectrum from NedWind in Appendix A. For the flapwise test, load case 93 was used. From [6], this was the case of the turbine parked at the extreme wind speed $(52.2 \mathrm{~m} / \mathrm{s})$. For the edgewise test, load case 97 was used, which corresponds to a grid short circuit at $20 \mathrm{~m} / \mathrm{s}$. These load cases correspond to the maximum flapwise and edgewise moments respectively.

Rotorline performed a static test in 1992. The blade was loaded separately in flapwise and edgewise directions. The maximum flapwise bending moment came from load case 93. To apply the maximum bending moment, Rotorline applied a test load of $23000 \mathrm{~N}(5171 \mathrm{lb})$ at 7 meters from the blade flange. The edgewise test was performed with a load of $7150 \mathrm{~N}(1607 \mathrm{lb})$ at 7 meters from the blade flange. The maximum edgewise bending moment came from load case 97; however this value was not used. Table 4.1 shows the result of the Rotorline tests. 
TP-500-29103

Table 4.1. Rotorline Static-Test Blade Deflections

\begin{tabular}{llll}
\hline Load $(\mathrm{N})$ & Load Direction & $\begin{array}{l}\text { Displacement } \\
\text { at } 7.65 \mathrm{~m}\end{array}$ & $\begin{array}{l}\text { Tip } \\
\text { Displacement }\end{array}$ \\
\hline 23000 & flapwise & $150 \mathrm{~mm}$ & $382 \mathrm{~mm}$ \\
7150 & edgewise & $20 \mathrm{~mm}$ & $45 \mathrm{~mm}$ \\
\hline
\end{tabular}

\subsubsection{NREL Loads}

The loads prescribed by the SMT project were $75 \%$ of the extreme load cases moment at the flange ( 0.65 meter) multiplied by a partial safety factor of 1.5 . The loads were to be applied at the same location as the Rotorline test at the 7.65-meter station.

In addition, NREL tested up to $110 \%$ of the extreme moments at the $0.2 \mathrm{~m}$ station (with 1.5 partial safety factor) to determine if there was adequate stability in the range of the expected fatigue-test loads.

The tare loads for the test were determined by the weight of the load saddle and the blade mass moment from the maximum chord position out to the load application point. The mass moment of this section was determined from "Alex 9" [10]. Table 4.2 shows the blade mass distribution. Adding the blade and saddle tare weight to the test loads would approximate zero bending at the maximum chord during the start of the test. The blade tare weight was $1980 \mathrm{~N}(445 \mathrm{lb})$. Table 4.3 shows the static-test loads used at NREL.

Table 4.2 Mass Distribution for Static-Test Blade Weight Tare [10]

\begin{tabular}{ll}
\hline $\begin{array}{l}\text { Position } \\
(\mathrm{mm})\end{array}$ & $\begin{array}{l}\text { Mass Moment } \\
(\mathrm{N}-\mathrm{mm})\end{array}$ \\
\hline 7651 & $2.335 \mathrm{E} 06$ \\
3151 & $11.243 \mathrm{E} 06$ \\
\hline
\end{tabular}

Table 4.3 Static-Test Loads

\begin{tabular}{|c|c|c|c|c|c|c|}
\hline $\begin{array}{l}\text { Load } \\
\text { Direction } \\
\text { (load case) }\end{array}$ & $\begin{array}{l}\text { Moment to } \\
\text { Match at } 0.65 \mathrm{~m} \\
\text { Flange (N-m) }\end{array}$ & $\begin{array}{l}\text { SMT- } \\
\text { Prescribed } \\
\text { Load at } 7.65 \mathrm{~m}\end{array}$ & $\begin{array}{l}\text { Moment to } \\
\text { Match at } 0.2 \mathrm{~m} \\
(\mathrm{~N}-\mathrm{m})\end{array}$ & $\begin{array}{l}\text { NREL } \\
110 \% \\
\text { Load at } \\
7.65 \mathrm{~m}\end{array}$ & $\begin{array}{l}\text { Saddle } \\
\text { Tare } \\
\text { Weight }\end{array}$ & $\begin{array}{l}\text { Total Tare } \\
\text { Weight }\end{array}$ \\
\hline edge (97) & 92143.9 & $\begin{array}{l}14809 \mathrm{~N} \\
(3329 \mathrm{lb})\end{array}$ & 102865 & $\begin{array}{l}22782 \mathrm{~N} \\
(5122 \mathrm{lb})\end{array}$ & $\begin{array}{l}1027 \mathrm{~N} \\
(231 \mathrm{lb})\end{array}$ & $\begin{array}{l}3007 \mathrm{~N} \\
(676 \mathrm{lb})\end{array}$ \\
\hline flap (93) & 153834 & $\begin{array}{l}24723 \mathrm{~N} \\
(5558 \mathrm{lb})\end{array}$ & 165036 & $\begin{array}{l}36552 \mathrm{~N} \\
(8218 \mathrm{lb})\end{array}$ & $\begin{array}{l}912 \mathrm{~N} \\
(205 \mathrm{lb})\end{array}$ & $\begin{array}{l}2892 \mathrm{~N} \\
(650 \mathrm{lb})\end{array}$ \\
\hline
\end{tabular}




\subsection{Instrumentation and Equipment}

\subsubsection{Load Apparatus}

\subsubsection{Test Stand}

The test stand used for the static tests can be seen in Figure 4.1. This stand is one of the two stands at the NWTC with a 1.36 million N-m capacity ( 1 million $\mathrm{ft}-\mathrm{lb}$ ). The test-stand mounting face was set to perpendicular for the edgewise testing and was tilted back approximately $8^{\circ}$ for the flapwise static tests. The tilt was necessary for the installation of the hydraulic actuator in the flapwise test.

An adapter plate was constructed of A-36, 102-mm (4-in.) steel plate. This plate was built to adapt the NedWind 753-mm (29.65-in.) bolt circle to the test stand 1219-mm (48-in.) bolt circle. A drawing of the adapter plate is in Appendix G. The adapter plate was mounted to the test stand with $1.25 \times 7.00 \mathrm{UNC}$ Grade 8 bolts torqued to $1360 \mathrm{~N}-\mathrm{m}(1000 \mathrm{ft}-\mathrm{lb})$. The blade was mounted to the adapter plate with M24×200 10.9 metric bolts torqued to $800 \mathrm{~N}-\mathrm{m}(590 \mathrm{ft}-\mathrm{lb})$. This was the blade-to-hub torque specified by NedWind [11].

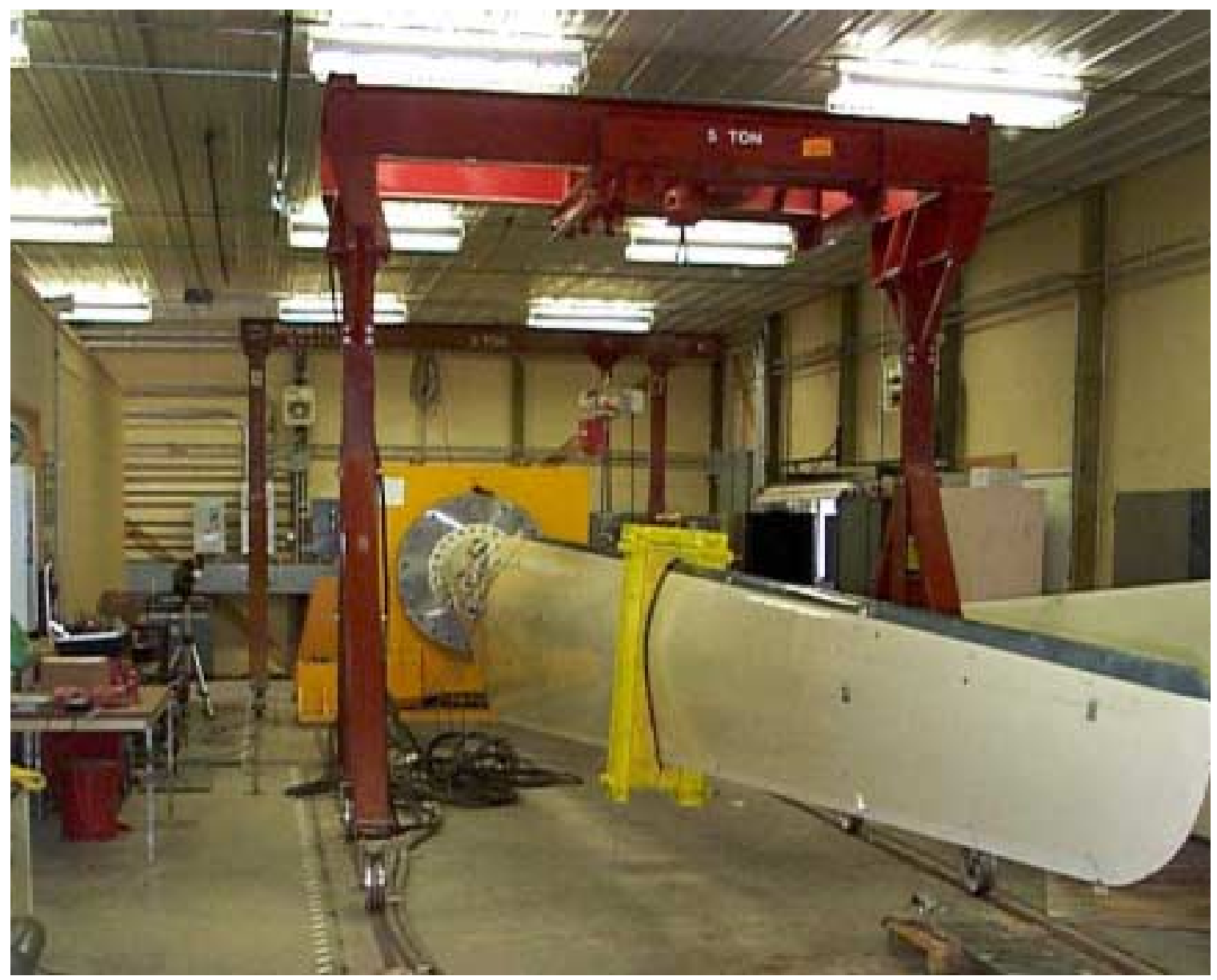

Figure 4.1 NedWind 25 Blade Setup Edge Static-Loading Building 252 (A-60), NWTC 


\subsubsection{Load Saddles}

Loads were introduced into the blade at the $7.65-\mathrm{m}$ station with a load saddle. A drawing of the load saddle is shown in Appendix $\mathrm{H}$. The saddle consists of a metal frame that can withstand the loads normal and parallel to the blade chord line. The metal frame compresses wood blocks with a cutout of the blade section. In between the wood and blade is a 76-mm (3-in.) wide strip of high durometer ( 80 shore-A) polyurethane. The polyurethane was molded directly to the blade section, which allowed the load to be spread around the blade section.

The saddle had a connection for the edge loading that pulled in the direction aligned with the blade section chord line. For the flap load, the load actuator was connected so that the load was normal to the blade section at $40 \%$ chord.

\subsubsection{Load Cells}

Table 4.4 below lists the information for the load cells used in the static tests.

Table 4.4 Load Cells Used for Static Pulls

\begin{tabular}{|c|c|c|c|c|}
\hline Pull Direction & Manufacturer & Model No. & Serial No. & Capacity \\
\hline Edge & $\begin{array}{l}\text { Tri-Coastal } \\
\text { Industries }\end{array}$ & TG 303 & 898 & $\begin{array}{l}133,440 \mathrm{~N} \\
(30,000 \mathrm{lb})\end{array}$ \\
\hline Flap & MTS $\AA$ & $661.20 \mathrm{E}-03$ & 78892 & $\begin{array}{l}97,856 \mathrm{~N} \\
(22,000 \mathrm{lb})\end{array}$ \\
\hline $\begin{array}{l}\text { Flap } \\
\text { (blade } 66 \text { post-fatigue) }\end{array}$ & $\operatorname{MTS} \circledast$ & $661.20 \mathrm{E}-03$ & 66265 & $\begin{array}{l}97,856 \mathrm{~N} \\
(22,000 \mathrm{lb})\end{array}$ \\
\hline
\end{tabular}

\subsubsection{Overhead Cranes}

The 5-ton (44,480-N) overhead crane in Building 252 was used to apply the edge load, which was displayed on a large digital display for operator feedback. The crane can be seen in Figure 4.1. The crane winch is hydraulically powered and operated with hand valves in an adjacent control room. The crane has wheels that allow for free movement in the blade longitudinal direction.

For the post-fatigue edgewise static test on Blade \#66, the 35-ton $(311,360-\mathrm{N})$ overhead crane in Building 254 was used.

\subsubsection{Servo-hydraulic System}

Flap static-loads were applied with a hydraulic actuator controlled by an MTS ${ }^{\circ} 458.14$ servo-hydraulic system controller. The controller was operated with MTS ${ }^{\circledR}$ T/RAC software. A 762-mm (30-in.) stroke, $46,260 \mathrm{~N}(10,400-\mathrm{lb})$ capacity actuator was used to apply the loads. The controller was set to apply the load in a slow ramp and hold at load for 10 seconds.

For the post-fatigue flapwise static test on Blade \#66, the same actuator was used but it was connected to an MTS ${ }^{\circledR} 497.13$ Flex Test IIm System Controller.

\subsubsection{Displacement Instrumentation}

Table 4.5 lists the instrumentation used for measuring the displacement at the load application point $(7.6 \mathrm{~m})$. A string potentiometer was used to measure the edge load application point displacement. The 
TP-500-29103

flap load application point displacement was measured using the load actuator's internal linear variable differential transformer (LVDT).

Table 4.5 Static-Pull Displacement Instrumentation--Load Application Point

\begin{tabular}{llllll}
\hline $\begin{array}{l}\text { Pull } \\
\text { Direction }\end{array}$ & Type & Manufacturer & Model No. & Serial No. & Capacity \\
\hline Edge & $\begin{array}{l}\text { String } \\
\text { Potentiometer }\end{array}$ & Patriot & P-40B(A56) & 19540 & 1016 mm (40 in.) \\
Flap & LVDT & MTS ${ }^{8}$ & 247.11 & 0234238 & $762 \mathrm{~mm} \mathrm{(30} \mathrm{in.)}$ \\
\hline
\end{tabular}

Tip displacement was measured for both flap and edge tests using linear retractable scales. The tip displacement scale readings were recorded by hand at the start of each load application and at the test load.

\subsubsection{Strain Gauges}

Common strain-gauge locations were prescribed by the SMT program and documented in "Jeroen 8" [3] and [12]. These locations were marked on the blades at ECN prior to shipment to the laboratories. The partners were to measure these common gauge locations according to procedures outlined in the SMT project plan [13].

Table 4.6 Common Strain-Gauge Locations

\begin{tabular}{|c|c|c|c|c|c|c|c|}
\hline $\begin{array}{l}\text { SMT } \\
\text { Gauge }\end{array}$ & $\begin{array}{l}\text { NREL } \\
\text { Gauge }\end{array}$ & $\begin{array}{l}\text { Blade \#66 } \\
\text { Radial* }\end{array}$ & $\begin{array}{l}\text { Blade \#67 } \\
\text { Radial* }\end{array}$ & $\Delta \%$ & $\begin{array}{l}\text { Blade \#66 } \\
\text { Circumferential* }\end{array}$ & $\begin{array}{l}\text { Blade \#67 } \\
\text { Circumferential* }\end{array}$ & $\Delta \%$ \\
\hline $400 \mathrm{E} 1$ & 08BLDLG & 0.393 & 0.408 & 3.8 & 0 & 0 & 0.0 \\
\hline $400 \mathrm{E} 2$ & 08BLDLG & 0.416 & 0.405 & -2.6 & 0.981 & 0.993 & 1.2 \\
\hline $400 \mathrm{~F} 1$ & 08BFLAP & 0.407 & 0.407 & 0.0 & 0.498 & 0.506 & 1.6 \\
\hline $400 \mathrm{~F} 2$ & 08BFLAP & 0.403 & 0.407 & 1.0 & 1.463 & 1.484 & 1.4 \\
\hline $1500 \mathrm{~S} 1$ & 17S38UA & 1.498 & 1.501 & 0.2 & 1.730 & 1.703 & -1.6 \\
\hline 1500P1 & 17S38LA & 1.505 & 1.500 & -0.3 & 0.740 & 0.696 & -5.9 \\
\hline $1500 \mathrm{~S} 0$ & 17R62UA & 1.488 & 1.486 & -0.1 & 2.000 & 1.972 & -1.4 \\
\hline 1500P0 & 17R62LA & 1.486 & 1.486 & 0.0 & 0.469 & 0.425 & -9.4 \\
\hline $1500 S 45$ & 17R62UB & 1.493 & 1.492 & -0.1 & 1.995 & 1.968 & -1.4 \\
\hline $1500 \mathrm{P} 45$ & 17R62LB & 1.492 & 1.492 & 0.0 & 0.474 & 0.430 & -9.3 \\
\hline $1500 \mathrm{~S} 90$ & 17R62UC & 1.497 & 1.497 & 0.0 & 1.991 & 1.962 & -1.5 \\
\hline $1500 \mathrm{P} 90$ & 17R62LC & 1.469 & 1.497 & 1.9 & 0.478 & 0.435 & -9.0 \\
\hline $2500 \mathrm{~S} 1$ & 25S26UA & 2.498 & 2.503 & 0.2 & 1.907 & 1.899 & -0.4 \\
\hline 2500P1 & 25S26LA & 2.506 & 2.500 & -0.2 & 1.037 & 0.998 & -3.8 \\
\hline $2500 \mathrm{~S} 0$ & 25R45UA & 2.488 & 2.487 & 0.0 & 2.179 & 2.167 & -0.6 \\
\hline 2500P0 & 25R45LA & 2.491 & 2.487 & -0.2 & 0.766 & 0.726 & -5.2 \\
\hline $2500 S 45$ & 25R45UB & 2.492 & 2.490 & -0.1 & 2.173 & 2.161 & -0.6 \\
\hline $2500 \mathrm{P} 45$ & $25 \mathrm{R} 45 \mathrm{LB}$ & 2.495 & 2.492 & -0.1 & 0.722 & 0.730 & 1.1 \\
\hline $2500 S 90$ & 25R45UC & 2.497 & 2.496 & 0.0 & 2.169 & 2.157 & -0.6 \\
\hline $2500 \mathrm{P} 90$ & 25R45LC & 2.499 & 2.497 & -0.1 & 0.776 & 0.736 & -5.2 \\
\hline
\end{tabular}

*Radial dimension is measured from flange mating surface, circumferential dimension is measured from trailing edge starting on pressure side. All dimensions are in meters [13].

The project partners were free to add additional measurement locations. In total, NREL applied 36 strain and 2 bending bridges to each blade. Tables 4.7 and 4.8 list the NREL gauge locations. 
Gauges were placed at five blade span locations including the root. Gauges were placed at mid-panel fore and aft of the blade spar and along the spar. Three-axis rectangular rosette gauges were used on the compressive side mid-panels.

Tables 4.7 and 4.8 show the strain-gauge measurement locations for the edge and flap static tests respectively. Single element gauges were Measurements Group WK-09-250BF-10C. Measurements Group WK-09-250RD-10C were used for rectangular rosettes. Data sheets for these strain gauges are included in Appendix H.

Note that 08BLDLG and 08BFLAP were configured into active four-arm bending bridges. This was due to preliminary program information stating that these gauge locations would be used to measure bending. Later we found that the other laboratories were measuring the strain at these locations.

Table 4.7 Strain Gauge Setup for Edgewise Static Pulls

\begin{tabular}{|c|c|c|c|c|c|c|c|c|c|c|c|c|}
\hline GAUGE NAME & SMT NAME & $\begin{array}{l}\text { BIB BOX } \\
\text { HOOK-UP }\end{array}$ & $\begin{array}{l}\text { GAUGE } \\
\text { CHANNEL }\end{array}$ & TYPE & \begin{tabular}{|c} 
DISTANCE \\
FROM CENTER \\
OF ROTATION
\end{tabular} & \begin{tabular}{|c|} 
DISTANCE \\
FROM ROOT \\
PLANE
\end{tabular} & $\begin{array}{l}\text { CHORD } \\
\text { LENGTH }\end{array}$ & $\begin{array}{l}\text { PERCENT } \\
\text { SPAN }\end{array}$ & $\begin{array}{l}\text { PERCENT } \\
\text { CHORD }\end{array}$ & SURFACE & ORIENTATION & \\
\hline & & & & & $\mathrm{mm}$ & $\mathrm{mm}$ & $\mathrm{mm}$ & & & & & \\
\hline 08BLDLG & $400 \mathrm{E} 1 / \mathrm{E} 2$ & $1-1$ & 4 & BENDING & 1050 & 400 & TBD & 8 & N/A & LEAD-LAG & $0^{\circ}$ & \\
\hline 08BFLAP & $400 \mathrm{~F} 1 / \mathrm{F} 2$ & $1-2$ & 5 & \begin{tabular}{|l|} 
BENDING \\
\end{tabular} & 1050 & 400 & TBD & 8 & $\mathrm{~N} / \mathrm{A}$ & FLAP & $0^{\circ}$ & \\
\hline \begin{tabular}{|l|}
$17 \mathrm{~S} 38 \mathrm{UA}$ \\
\end{tabular} & $1500 \mathrm{~S} 1$ & $1-3$ & 6 & SINGLE & 2150 & 1500 & 1060 & 17 & 38 & UPPER & $0^{\circ}$ & \\
\hline 17S38LA & $1500 \mathrm{P} 1$ & $1-4$ & 7 & $\begin{array}{l}\text { SINGLE } \\
\end{array}$ & 2150 & 1500 & 1060 & 17 & 38 & LOWER & $0^{\circ}$ & \\
\hline \begin{tabular}{|l|}
$17 R 62 U A$ \\
\end{tabular} & $1500 \mathrm{~S} 0$ & $1-5$ & 8 & ROSETTE & 2150 & 1500 & 1060 & 17 & 62 & UPPER & $0^{\circ}$ & \\
\hline 17R62UC & $1500 S 90$ & $1-6$ & 9 & ROSETTE & 2150 & 1500 & 1060 & 17 & 62 & UPPER & $90^{\circ}$ & \\
\hline \begin{tabular}{|l|} 
17R62LA \\
\end{tabular} & $1500 \mathrm{P} 0$ & $1-7$ & 10 & ROSETTE & 2150 & 1500 & 1060 & 17 & 62 & LOWER & $0^{\circ}$ & \\
\hline 17R62LC & 1500P90 & $1-8$ & 11 & ROSETTE & 2150 & 1500 & 1060 & 17 & 62 & LOWER & $90^{\circ}$ & \\
\hline \begin{tabular}{|l|}
$25 \mathrm{R} 20 \mathrm{UA}$ \\
\end{tabular} & & $2-1$ & 12 & ROSETTE & 3150 & 2500 & 1385 & 25 & 20 & UPPER & $0^{\circ}$ & \\
\hline 17R62UB & $1500 \mathrm{~S} 45$ & $2-2$ & 13 & ROSETTE & 2150 & 1500 & 1060 & 17 & 62 & UPPER & $45^{\circ}$ & \\
\hline $25 S 20 L A$ & & $2-3$ & 14 & SINGLE & 3150 & 2500 & 1385 & 25 & 20 & LOWER & $0^{\circ}$ & \\
\hline 25S26UA & $2500 \mathrm{~S} 1$ & $2-4$ & 15 & SINGLE & 3150 & 2500 & 1385 & 25 & 26 & UPPER & $0^{\circ}$ & \\
\hline $25 \mathrm{~S} 26 \mathrm{LA}$ & $2500 \mathrm{P} 1$ & $2-5$ & 16 & SINGLE & 3150 & 2500 & 1385 & 25 & 26 & LOWER & $0^{\circ}$ & \\
\hline 25S40UA & & $2-6$ & 17 & SINGLE & 3150 & 2500 & 1385 & 25 & 40 & UPPER & $0^{\circ}$ & REPLACES 31R20UC \\
\hline $25 \mathrm{~S} 40 \mathrm{LA}$ & & $2-7$ & 18 & SINGLE & 3150 & 2500 & 1385 & 25 & 40 & LOWER & $0^{\circ}$ & REPLACES 31R70UC \\
\hline 25 S70LA & & $2-8$ & 19 & SINGLE & 3150 & 2500 & 1385 & 25 & 70 & LOWER & $0^{\circ}$ & \\
\hline 25R45UA & $2500 \mathrm{~S} 0$ & $3-1$ & 20 & ROSETTE & 3150 & 2500 & 1385 & 25 & 45 & UPPER & $0^{\circ}$ & \\
\hline 25R45UC & 2500 S90 & $3-2$ & 21 & ROSETTE & 3150 & 2500 & 1385 & 25 & 45 & UPPER & $90^{\circ}$ & \\
\hline $25 \mathrm{R} 45 \mathrm{LA}$ & $2500 \mathrm{P} 0$ & $3-3$ & 22 & ROSETTE & 3150 & 2500 & 1385 & 25 & 45 & LOWER & $0^{\circ}$ & \\
\hline 25R45LC & $2500 \mathrm{P} 90$ & $3-4$ & 23 & ROSETTE & 3150 & 2500 & 1385 & 25 & 45 & LOWER & $90^{\circ}$ & \\
\hline 25R70UA & & $3-5$ & 24 & ROSETTE & 3150 & 2500 & 1385 & 25 & 70 & UPPER & $0^{\circ}$ & \\
\hline 17R62LB & $1500 \mathrm{P} 45$ & $3-6$ & 25 & ROSETTE & 2150 & 1500 & 1060 & 17 & 62 & LOWER & $45^{\circ}$ & \\
\hline 31R20UA & & $3-7$ & 26 & ROSETTE & 3900 & 3250 & 1317 & 31 & 20 & UPPER & $0^{\circ}$ & \\
\hline 25R45LB & 2500P45 & $3-8$ & 27 & ROSETTE & 3150 & 2500 & 1385 & 25 & 45 & LOWER & $45^{\circ}$ & \\
\hline 31S20LA & & $4-1$ & 28 & SINGLE & 3900 & 3250 & 1317 & 31 & 20 & LOWER & $0^{\circ}$ & REPLACES 25R70UC \\
\hline $31 \mathrm{~S} 40 \mathrm{UA}$ & & $4-2$ & 29 & SINGLE & 3900 & 3250 & 1317 & 31 & 40 & UPPER & $0^{\circ}$ & \\
\hline 31S40LA & & $4-3$ & 30 & SINGLE & 3900 & 3250 & 1317 & 31 & 40 & LOWER & $0^{\circ}$ & \\
\hline 31R70UA & & $4-4$ & 31 & ROSETTE & 3900 & 3250 & 1317 & 31 & 70 & UPPER & $0^{\circ}$ & \\
\hline $25 \mathrm{R} 45 \mathrm{UB}$ & $2500 S 45$ & $4-5$ & 32 & ROSETTE & 3150 & 2500 & 1385 & 25 & 45 & UPPER & $45^{\circ}$ & \\
\hline 31S70LA & & $4-6$ & 33 & SINGLE & 3900 & 3250 & 1317 & 31 & 70 & LOWER & $0^{\circ}$ & REPLACES 25R20UC \\
\hline $41 \mathrm{~S} 40 \mathrm{LA}$ & & $4-7$ & 34 & SINGLE & 5150 & 4500 & 1204 & 41 & 40 & LOWER & $0^{\circ}$ & \\
\hline 41S40UA & & $4-8$ & 35 & SINGLE & 5150 & 4500 & 1204 & 41 & 40 & UPPER & $0^{\circ}$ & \\
\hline \multicolumn{13}{|c|}{ GAUGES NOT USED FOR EDGEWISE TESTING } \\
\hline 31R20UC & $\mathrm{N} / \mathrm{A}$ & $\mathrm{N} / \mathrm{A}$ & ROSETTE & 3900 & 3250 & 1317 & 31 & 20 & UPPER & $90^{\circ}$ & & \\
\hline 31R70UC & $\mathrm{N} / \mathrm{A}$ & N/A & ROSETTE & 3900 & 3250 & 1317 & 31 & 70 & UPPER & $90^{\circ}$ & & \\
\hline 25R70UC & N/A & $\mathrm{N} / \mathrm{A}$ & ROSETTE & 3150 & 2500 & 1385 & 25 & 70 & UPPER & $90^{\circ}$ & & \\
\hline 25R20UC & N/A & N/A & ROSETTE & 3150 & 2500 & 1385 & 25 & 20 & UPPER & $90^{\circ}$ & & \\
\hline
\end{tabular}

Using the following formula [14] we made an estimate of the strain at these locations:

$$
e_{0}=\frac{E K}{4}\left(\varepsilon_{1}-\varepsilon_{2}+\varepsilon_{3}-\varepsilon_{4}\right)
$$

which reduces to:

$$
e_{0}=\frac{E K}{4} \varepsilon
$$

this assumes that strain, $\varepsilon$, is equal in all four bridge arms. 
$\mathrm{e}_{0}=$ measured voltage

$\mathrm{E}=3.333 \mathrm{VDC}$ excitation voltage

$\mathrm{K}=2.04$, gauge factor for $\mathrm{WK}-09-250 \mathrm{BF}-10 \mathrm{C}$.

Table 4.8 Strain Gauge Setup for Flapwise Static Pulls

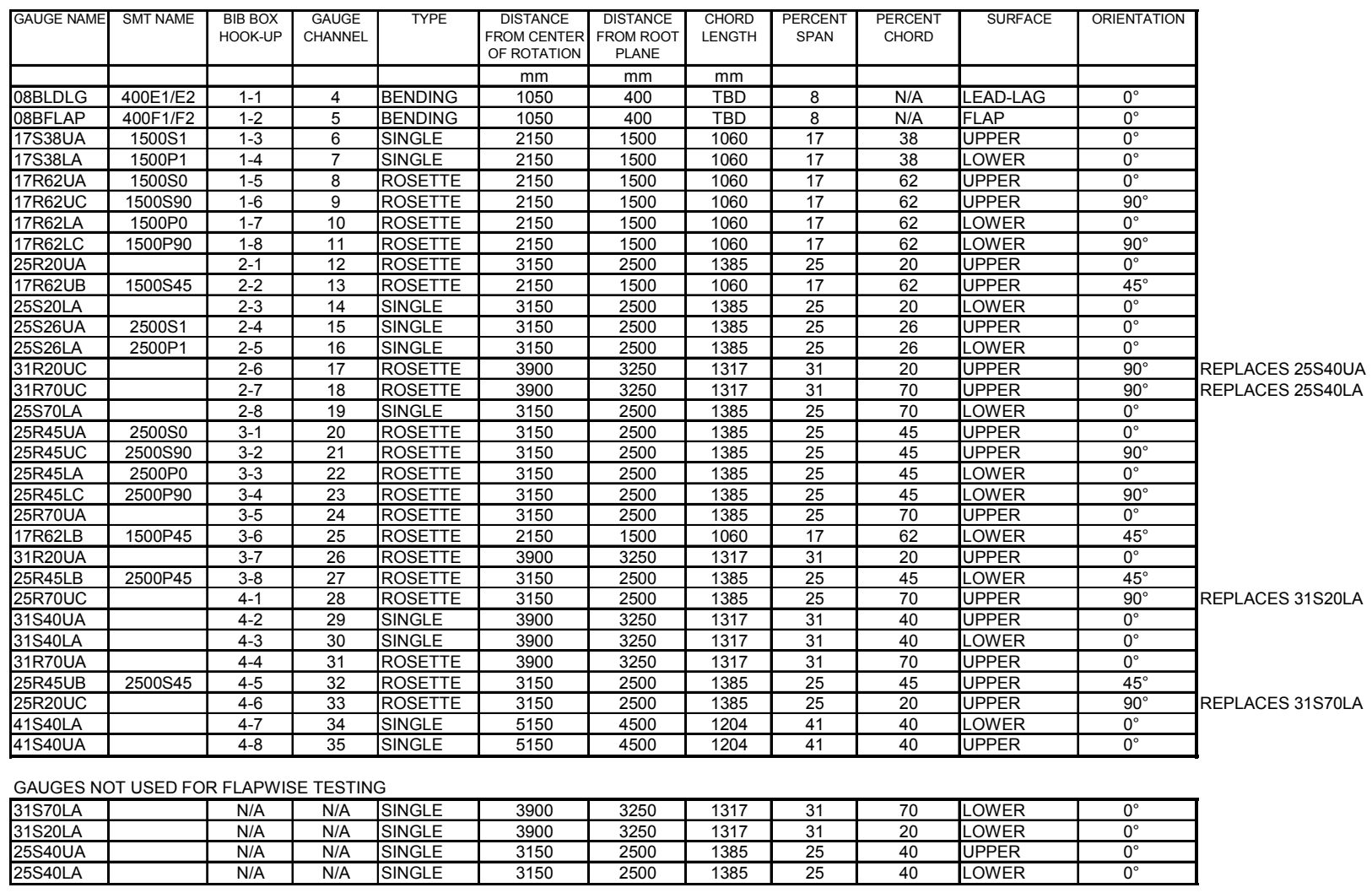

\subsubsection{Data Acquisition System}

NREL's BSTRAIN was used for acquiring the static-test data. BSTRAIN is described in [15] and [4]. Figure 4.2 shows a schematic of the BSTRAIN system.

At the time of test planning the allowable number of channels measured during the static tests was limited to 36; therefore, different strain gauges were measured during the edge and flap tests, as shown in Tables 4.7 and 4.8 above.

The SCXI 1121 modules were configured with the low-pass frequency set at $4 \mathrm{~Hz}$. The gain was 200 and the excitation was $3.333 \mathrm{VDC}$ for the strain-gauge channels. The channel sampling-rate was set at $2 \mathrm{~Hz}$. 


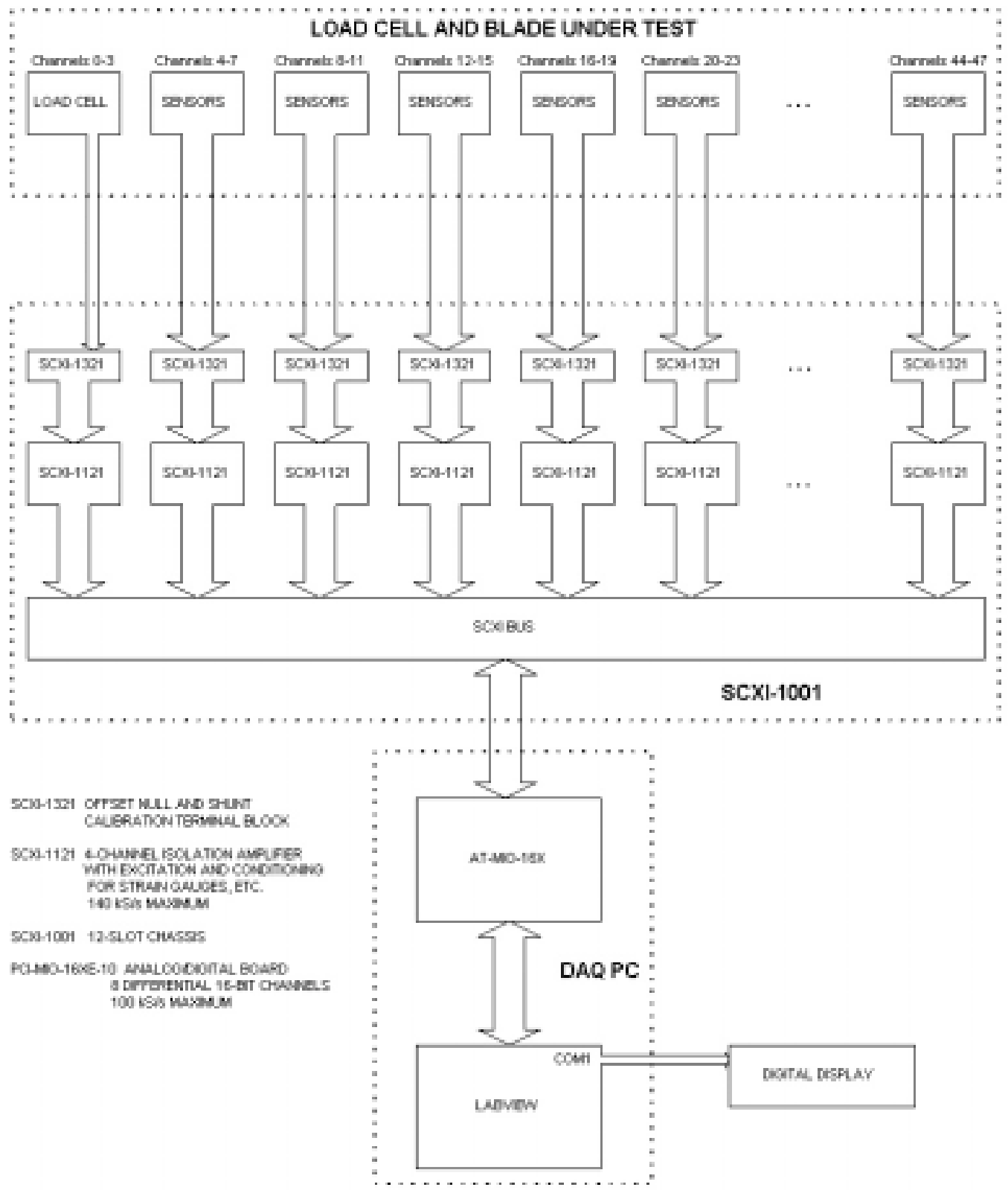

Figure 4.2 Static Test Data Acquisition Schematic

\subsubsection{Calibration}

For the edgewise-static pulls, the load cell was calibrated by an off-site calibration facility. Prior to testing, the load cell was checked through the data acquisition system up to $2000 \mathrm{lb}(8896 \mathrm{~N})$ using a calibrated deadweight. The string potentiometer at the load application point was calibrated through the data acquisition system with a ruler over the full range. Factory-supplied strain-gauge factors were used for the strain data.

For the flapwise-static pulls, the load cell and actuator LVDT were calibrated through the control system by the MTS $₫$ representative prior to testing. 


\subsubsection{Static-Test Procedure}

The static tests were conducted according to the following general procedures:

1. Mount blade to test stand in the proper orientation for the load.

2. Connect loading apparatus to blade.

3. Start data acquisition system.

4. Zero strain gauges at tare load.

5. Apply $75 \%$ design load to blade.

6. Hold for 10 seconds.

7. Return to tare load.

8. Apply $100 \%$ design load.

9. Hold for 10 seconds.

10. Return to tare load.

11. Apply $110 \%$ design load. (pre-fatigue only)

12. Hold for 10 seconds.

13. Return to tare loads.

14. Stop data acquisition.

\section{$4.4 \quad$ Static-Test Results}

\subsubsection{Displacements}

Displacements were measured at the load application point $(7.65 \mathrm{~m})$ and at the blade tip. Figures C.1 and C.2 in Appendix C show the data for edge test. Figures D.1 and D.2 in Appendix D show the data for flap test. The figures show the $75 \%$ and $110 \%$ load data for the static tests conducted prior to the fatigue tests. The $75 \%$ and $100 \%$ post-fatigue test data are also presented. Table 4.9 lists the results for the deflection at the $75 \%$ load point for pre- and post-fatigue tests. There data were interpolated from the $110 \%$ pre-fatigue test and the $100 \%$ post-fatigue test and were given to allow comparison with other laboratories. Note that the tip was removed for the fatigue test of Blade \#67, so post-fatigue test tip deflection data were not available.

Table 4.9 Static Blade Deflections at SMT-Prescribed 75\% Load

\begin{tabular}{lllllll}
\hline Pull Direction & Load & Position & $\begin{array}{l}\# 66 \\
\text { Pre-Fatigue } \\
(\mathrm{mm})\end{array}$ & $\begin{array}{l}\# 66 \\
\text { Post-Fatigue } \\
(\mathrm{mm})\end{array}$ & $\begin{array}{l}\# 67 \\
\text { Pre-Fatigue } \\
(\mathrm{mm})\end{array}$ & $\begin{array}{l}\# 67 \\
\text { Post-Fatigue } \\
(\mathrm{mm})\end{array}$ \\
\hline Edgewise & $\begin{array}{l}14,809 \mathrm{~N} \\
(3329 \mathrm{lb})\end{array}$ & $\begin{array}{l}\text { Load point } \\
(7.65 \mathrm{~m})\end{array}$ & 46 & 48 & 48 & 51 \\
Edgewise & $\begin{array}{l}14,809 \mathrm{~N} \\
(3329 \mathrm{lb})\end{array}$ & $\begin{array}{l}\text { Tip } \\
(12.65 \mathrm{~m})\end{array}$ & 94 & 98 & 102 & N/A \\
Flapwise & $\begin{array}{l}24,723 \mathrm{~N} \\
(5558 \mathrm{lb})\end{array}$ & $\begin{array}{l}\text { Load point } \\
(7.65 \mathrm{~m})\end{array}$ & 192 & 188 & 191 & 187 \\
Flapwise & $\begin{array}{l}24,723 \mathrm{~N} \\
(5558 \mathrm{lb})\end{array}$ & $\begin{array}{l}\text { Tip } \\
(12.65 \mathrm{~m})\end{array}$ & 504 & 497 & 502 & N/A \\
\hline
\end{tabular}

These data show very slight differences in the deflection between the pre-fatigue and the post-fatigue static tests. Both of the edge tests show a very slight increase in displacement under the same load, indicating a drop in global stiffness. However, these differences are very small (less than $4 \mathrm{~mm}$ ) and are within the uncertainty of the measurement system. The flap direction displacements showed a slight decrease in displacement under the prescribed $75 \%$ load. This is an unusual result because most blades 
show a slight decrease in global stiffness after being subjected to fatigue loading. This increase in stiffness is also seen in the strain measurements, thus giving credence to its validity. This result is discussed later.

\subsubsection{Strain Verification}

Strain versus load data for the edgewise static-tests are presented in Appendix C. Data for the flapwisestatic test are presented in Appendix D. Each page in the Appendix represents one gauge position. Prefatigue data is presented for each blade for the $75 \%$ and $110 \%$ load cases. Post-fatigue data are presented for each blade for the $75 \%$ and $100 \%$ load cases. Table 4.10 lists pre- and post-fatigue strain for the edgewise $75 \%$ and $100 \%$ loads. Table 4.11 lists the same for the flap test. These strain values were interpolated from the $110 \%$ load case data for the pre-fatigue test and from the $100 \%$ load case data from the post-fatigue test. The deflection data are also included in these tables.

One of the primary reasons NREL deviated from the SMT-prescribed load of $75 \%$ design and loaded up to $110 \%$, was to determine the stable test load range that could be used for fatigue testing on the basis of linearity. The figures in the appendices show the linearity of each measurement location (except for offaxis "B" and " $\mathrm{C}$ " gauges) and show that even under the $110 \%$ load, there was no apparent danger of local buckling at these loads. This reassured us that fatigue loading at these levels could be achieved without inducing a buckling failure mode. This could not be determined from the $75 \%$ load tests. Moreover, under NREL's common practices, we would strongly have recommended a test to failure for at least one of the blades, preferably before the fatigue test, but certainly during the post-fatigue static test. This was not done to allow a uniform comparison among laboratories in the postmortem inspections.

Unfortunately, these inspections were never done.

Figures 4.3 through 4.8 show various comparisons between the pre- and post-fatigue test strain-gauge data and comparisons between the two blades tested.

Generally, the differences between Blades \#66 and \#67 appeared to be random and could not be attributed to a significant difference in fabrication or testing technique without more extensive postmortem dissections. These results are shown best in Figures 4.7 and 4.8, which compare the flap and edge strains, respectively, at each strain measurement location for Blades \#66 and \#67 at the prescribed $75 \%$ static load for the SMT program. In a few locations, there appears to be very poor agreement between blades, particularly in the non-axial gauges. Gauge placement or low strain in the principal gauge direction can explain almost all of these differences. Most of the differences seemed to be characteristic of the blade itself and the differences did not appear to be altered by the fatigue test, with few exceptions. In other words, if the difference between blades existed before the fatigue test it was usually there after the fatigue test also, in about the same proportions. No distinguishable pattern was drawn from this data that would indicate a clear difference in manufacturing strength or blade properties. Any differences seem to average themselves out and did not affect the global property measurements.

Both of the blades' stiffness appeared to increase during fatigue testing. This phenomenon can be observed in Figures 4.3 through 4.6, which compare the static strains before and after the fatigue tests. These charts show reduced strain sensitivity in the post-fatigue static test as compared to the pre-fatigue static test, especially in the flap direction. For Blade \#66 this effect was not noticeable in the edge direction but it was observed in Blade \#67 in both flap and edge. This phenomenon is the opposite of the expected result, which would usually be a slight decline in blade stiffness over the course of a load-based fatigue test. This effect cannot be explained by load sensor error as we had originally thought. Both blades exhibited the same behavior but were tested at different times. Post static tests were conducted in different laboratories (Blade \#66 in Building 254 and Blade \#67 in Building 252). All of the pre-fatigue tests were conducted in Building 252. Load cell calibrations were double-checked to rule out sensor 
errors. For Blade \#66, the load cell used for the post-fatigue test was different than the one used for Blade \#67, although the same result was observed. Additional evidence that suggests the effect was real is that the displacement sensors for both tests corroborate the strain data, with higher displacements following higher strain measurements in all cases (see Table 4.9).

One explanation for these results is that the blades may have stiffened slightly due to lower environmental humidity in Colorado. The blades originated in the Netherlands, where they may have absorbed ambient moisture for several years before being shipped to NREL. The strength gained due to the drying of the laminates in the Colorado climate may have been enough to offset and overshadow any stiffness losses encountered during the test.

Table 4.10 Edge Static-Test Strains

\begin{tabular}{|c|c|c|c|c|c|c|c|c|c|}
\hline Measurement & $\begin{array}{c}\text { SMT } \\
\text { Nomenclature }\end{array}$ & $\begin{array}{c}\text { Blade } 66 \text { pre- } \\
\text { fatigue } 75 \% \\
\text { loading }\end{array}$ & $\begin{array}{l}\text { Blade } 66 \text { pre- } \\
\text { fatigue } 100 \% \\
\text { loading }\end{array}$ & $\begin{array}{l}\text { Blade } 66 \text { post- } \\
\text { fatigue } 75 \% \\
\text { loading }\end{array}$ & $\begin{array}{c}\text { Blade } 66 \text { post- } \\
\text { fatigue } 100 \% \\
\text { loading }\end{array}$ & $\begin{array}{c}\text { Blade } 67 \text { pre- } \\
\text { fatigue } 75 \% \\
\text { loading }\end{array}$ & $\begin{array}{l}\text { Blade } 67 \text { pre- } \\
\text { fatigue } 100 \% \\
\text { loading }\end{array}$ & \begin{tabular}{|c|} 
Blade 67 post- \\
fatigue $75 \%$ \\
loading
\end{tabular} & $\begin{array}{l}\text { Blade } 67 \text { post- } \\
\text { fatigue } 100 \% \\
\text { loading }\end{array}$ \\
\hline Disp Load (mm) & & 46 & 66 & 48 & 66 & 48 & 68 & 51 & 71 \\
\hline Disp Tip (mm) & & 94 & 131 & 98 & 136 & 102 & 142 & - & - \\
\hline 08BLDLG ( $\mu$ strain) & 400E1/2 & 439 & 619 & 452 & 633 & 433 & 610 & 431 & 607 \\
\hline 08BFLAP ( $\mu$ strain) & $400 \mathrm{~F} 1 / 2$ & 146 & 203 & 127 & 174 & 86 & 118 & 82 & 113 \\
\hline 17S38UA ( $\mu$ strain) & 1500S1 & -92 & -125 & -99 & -136 & -104 & -142 & -93 & -128 \\
\hline 17S38LA ( $\mu$ strain) & $1500 \mathrm{P} 1$ & 176 & 243 & 186 & 254 & 290 & 401 & 267 & 367 \\
\hline 17R62UA ( $\mu$ strain) & $1500 \mathrm{~S} 0$ & 402 & 568 & 391 & 544 & 394 & 558 & 392 & 551 \\
\hline 17R62LA ( $\mu$ strain) & 1500P0 & 629 & 879 & 633 & 873 & 741 & 1042 & 737 & 1030 \\
\hline 17R62UB ( $\mu$ strain) & $1500 S 45$ & 29 & 45 & 29 & 43 & 38 & 59 & 36 & 54 \\
\hline 17R62LB ( $\mu$ strain) & $1500 \mathrm{P} 45$ & 140 & 197 & 151 & 207 & 219 & 309 & 228 & 319 \\
\hline 17R62UC ( $\mu$ strain) & $1500 S 90$ & -139 & -191 & -137 & -187 & -90 & -120 & -77 & -103 \\
\hline 17R62LC ( $\mu$ strain) & $1500 \mathrm{P} 90$ & 19 & 7 & 53 & 48 & -16 & -44 & -50 & -90 \\
\hline 25R20UA ( $\mu$ strain) & & -507 & -713 & -518 & -720 & -559 & -788 & -545 & -764 \\
\hline 25S20LA ( $\mu$ strain) & & -104 & -149 & -91 & -129 & -166 & -238 & failed & failed \\
\hline 25S26UA ( $\mu$ strain) & $2500 S 1$ & -489 & -689 & -498 & -691 & -408 & -500 & -396 & -554 \\
\hline 25S26LA ( $\mu$ strain) & $2500 \mathrm{P} 1$ & 4 & 4 & 14 & 19 & 82 & 114 & 77 & 105 \\
\hline 25S40UA ( $\mu$ strain) & & -21 & -26 & -30 & -41 & -42 & -55 & -38 & -51 \\
\hline 25S40LA ( $\mu$ strain) & & 289 & 405 & 296 & 408 & 358 & 502 & 353 & 493 \\
\hline 25R45UA ( $\mu$ strain) & $2500 S 0$ & 119 & 172 & 110 & 153 & 99 & 145 & 102 & 145 \\
\hline 25R45LA ( $\mu$ strain) & $2500 \mathrm{P} 0$ & 421 & 590 & 421 & 580 & 446 & 622 & 440 & 614 \\
\hline 25R45UB ( $\mu$ strain) & $2500 S 45$ & -55 & -76 & -54 & -76 & -58 & -84 & -57 & -81 \\
\hline 25R45LB ( $\mu$ strain) & $2500 \mathrm{P} 45$ & -1 & 9 & 4 & 13 & -22 & -19 & -21 & -18 \\
\hline 25R45UC ( $\mu$ strain) & $2500 S 90$ & -112 & -166 & -111 & -159 & -105 & -152 & -98 & -142 \\
\hline 25R45LC ( $\mu$ strain) & 2500P90 & -336 & -461 & -320 & -430 & -354 & -475 & -349 & -472 \\
\hline 25R70UA ( $\mu$ strain) & & 371 & 539 & 382 & 541 & 408 & 578 & 404 & 573 \\
\hline 25S70LA ( $\mu$ strain) & & 674 & 949 & 672 & 931 & 637 & 900 & 633 & 890 \\
\hline 31R20UA ( $\mu$ strain) & & -378 & -532 & -391 & -542 & -454 & -631 & -444 & -621 \\
\hline 31S20LA ( $\mu$ strain) & & -117 & -169 & -109 & -152 & -4 & -11 & -11 & -17 \\
\hline 31S40UA ( $\mu$ strain) & & -113 & -156 & -124 & -172 & -130 & -175 & failed & failed \\
\hline 31S40LA ( $\mu$ strain) & & 202 & 284 & 209 & 290 & 312 & 434 & 297 & 417 \\
\hline 31R70UA ( $\mu$ strain) & & 512 & 722 & 500 & 691 & 445 & 624 & 445 & 624 \\
\hline 31S70LA ( $\mu$ strain) & & 532 & 777 & 545 & 777 & 663 & 947 & 669 & 959 \\
\hline 41S40UA ( $\mu$ strain) & & -99 & -135 & -112 & -154 & -134 & -184 & -129 & -177 \\
\hline 41S40LA ( $\mu$ strain) & & 154 & 219 & 164 & 227 & 189 & 261 & 179 & 249 \\
\hline hendin & 18 & , & & & & & & & \\
\hline
\end{tabular}


Table 4.11 Flap Static-Test Strains

\begin{tabular}{|c|c|c|c|c|c|c|c|c|c|}
\hline Measurement & $\begin{array}{c}\text { SMT } \\
\text { Nomenclature }\end{array}$ & $\begin{array}{c}\text { Blade } 66 \text { pre- } \\
\text { fatigue } 75 \% \\
\text { loading }\end{array}$ & $\begin{array}{c}\text { Blade } 66 \text { pre- } \\
\text { fatigue } 100 \% \\
\text { loading }\end{array}$ & $\begin{array}{c}\text { Blade } 66 \text { post- } \\
\text { fatigue } 75 \% \\
\text { loading }\end{array}$ & $\begin{array}{c}\text { Blade } 66 \text { post- } \\
\text { fatigue } 100 \% \\
\text { loading }\end{array}$ & $\begin{array}{c}\text { Blade } 67 \text { pre- } \\
\text { fatigue } 75 \% \\
\text { loading }\end{array}$ & $\begin{array}{c}\text { Blade } 67 \text { pre- } \\
\text { fatigue } 100 \% \\
\text { loading }\end{array}$ & $\begin{array}{c}\text { Blade } 67 \text { post- } \\
\text { fatigue } 75 \% \\
\text { loading }\end{array}$ & $\begin{array}{c}\text { Blade } 67 \text { post } \\
\text { fatigue } 100 \% \\
\text { loading }\end{array}$ \\
\hline Disp Load (mm) & & 192 & 260 & 188 & 252 & 191 & 259 & 187 & 253 \\
\hline Disp Tip (mm) & & 504 & 678 & 497 & 669 & 502 & 675 & - & - \\
\hline 08BLDLG ( $\mu$ strain) & 400E1/E2 & 91 & 131 & 101 & 140 & 32 & 51 & 25 & 38 \\
\hline 08BFLAP ( $\mu$ strain) & 400F1/F2 & 946 & 1275 & 935 & 1256 & 963 & 1297 & 955 & 1278 \\
\hline 17S38UA ( $\mu$ strain) & $1500 S 1$ & -1242 & -1685 & -1225 & -1656 & -1283 & -1741 & -1251 & -1668 \\
\hline 17S38LA ( $\mu$ strain) & 1500P1 & 1153 & 1554 & 1140 & 1531 & 1369 & 1841 & 1273 & 1703 \\
\hline 17R62UA ( $\mu$ strain) & $1500 S 0$ & -1163 & -1584 & -1101 & -1492 & -1282 & -1754 & -1256 & -1707 \\
\hline 17R62LA ( $\mu$ strain) & 1500P0 & 975 & 1313 & 962 & 1320 & 970 & 1306 & 921 & 1237 \\
\hline 17R62UB ( $\mu$ strain) & $1500 S 45$ & -386 & -497 & -354 & -453 & -515 & -675 & -493 & -622 \\
\hline 17R62LB ( $\mu$ strain) & 1500P45 & 453 & 619 & 430 & 617 & 461 & 634 & 453 & 622 \\
\hline 17R62UC ( $\mu$ strain) & $1500 S 90$ & -117 & -166 & -114 & -139 & -264 & -363 & -241 & -314 \\
\hline 17R62LC ( $\mu$ strain) & 1500P90 & 94 & 143 & 80 & 154 & 123 & 177 & 104 & 132 \\
\hline 25R20UA ( $\mu$ strain) & & -1724 & -2369 & -1692 & -2314 & -1400 & -1941 & -1350 & -1859 \\
\hline 25S20LA ( $\mu$ strain) & & 1267 & 1710 & 1261 & 1722 & 1261 & 1701 & failed & failed \\
\hline 25R20UC ( $\mu$ strain) & & -55 & -181 & -41 & -155 & 70 & 9 & 61 & 4 \\
\hline 25S26UA ( $\mu$ strain) & $2500 S 1$ & -588 & -810 & -2404 & -3288 & -302 & -417 & -1946 & -2668 \\
\hline 25S26LA ( $\mu$ strain) & 2500P1 & 1296 & 1747 & 1269 & 1704 & 1394 & 1881 & 1355 & 1818 \\
\hline 25R45UA ( $\mu$ strain) & 2500 S0 & -1354 & -1822 & -1330 & -1784 & -1486 & -1999 & -1451 & -1942 \\
\hline 25R45LA ( $\mu$ strain) & $2500 \mathrm{P0}$ & 1301 & 1751 & 1274 & 1712 & 1135 & 1528 & 1089 & 1439 \\
\hline 25R45UB ( $\mu$ strain) & $2500 S 45$ & -700 & -932 & -677 & -925 & -724 & -963 & -694 & -941 \\
\hline 25R45LB ( $\mu$ strain) & 2500P45 & 519 & 715 & 501 & 692 & 400 & 566 & 392 & 548 \\
\hline 25R45UC ( $\mu$ strain) & $2500 S 90$ & 309 & 437 & 324 & 456 & 269 & 383 & 280 & 375 \\
\hline 25R45LC ( $\mu$ strain) & 2500P90 & -426 & -546 & -435 & -558 & -413 & -525 & -386 & -510 \\
\hline 25R70UA ( $\mu$ strain) & & -321 & -418 & -330 & -399 & -389 & -512 & -392 & -512 \\
\hline 25S70LA ( $\mu$ strain) & & 506 & 686 & 476 & 671 & 365 & 501 & 330 & 430 \\
\hline 25R70UC ( $\mu$ strain) & & 472 & 633 & 422 & 585 & 418 & 562 & 394 & 544 \\
\hline 31R20UA ( $\mu$ strain) & & -1307 & -1772 & -1299 & -1781 & -1468 & -1984 & -1421 & -1911 \\
\hline 31R20UC ( $\mu$ strain) & & 307 & 341 & 300 & 336 & 311 & 349 & failed & failed \\
\hline 31S40UA ( $\mu$ strain) & & -1849 & -2510 & -1833 & -2478 & -1771 & -2400 & failed & failed \\
\hline 31S40LA ( $\mu$ strain) & & 1441 & 1945 & 1420 & 1910 & 1528 & 2073 & 1448 & 1930 \\
\hline 31R70UA ( $\mu$ strain) & & -829 & -1077 & -804 & -1046 & -654 & -849 & -663 & -853 \\
\hline 31R70UC ( $\mu$ strain) & & 268 & 287 & 283 & 327 & 290 & 374 & 284 & 384 \\
\hline 41S40UA ( $\mu$ strain) & & -1939 & -2641 & -1925 & -2641 & -1840 & -2503 & -1824 & -2499 \\
\hline 41S40LA ( $\mu$ strain) & & 1560 & 2163 & 1568 & 2140 & 1607 & 2170 & 1550 & 2089 \\
\hline \multicolumn{8}{|c|}{ Strain from bending bridges in BOLD are estimates based on 3.333 VDC excitation and 2.04 gauge factor. } & & \\
\hline
\end{tabular}




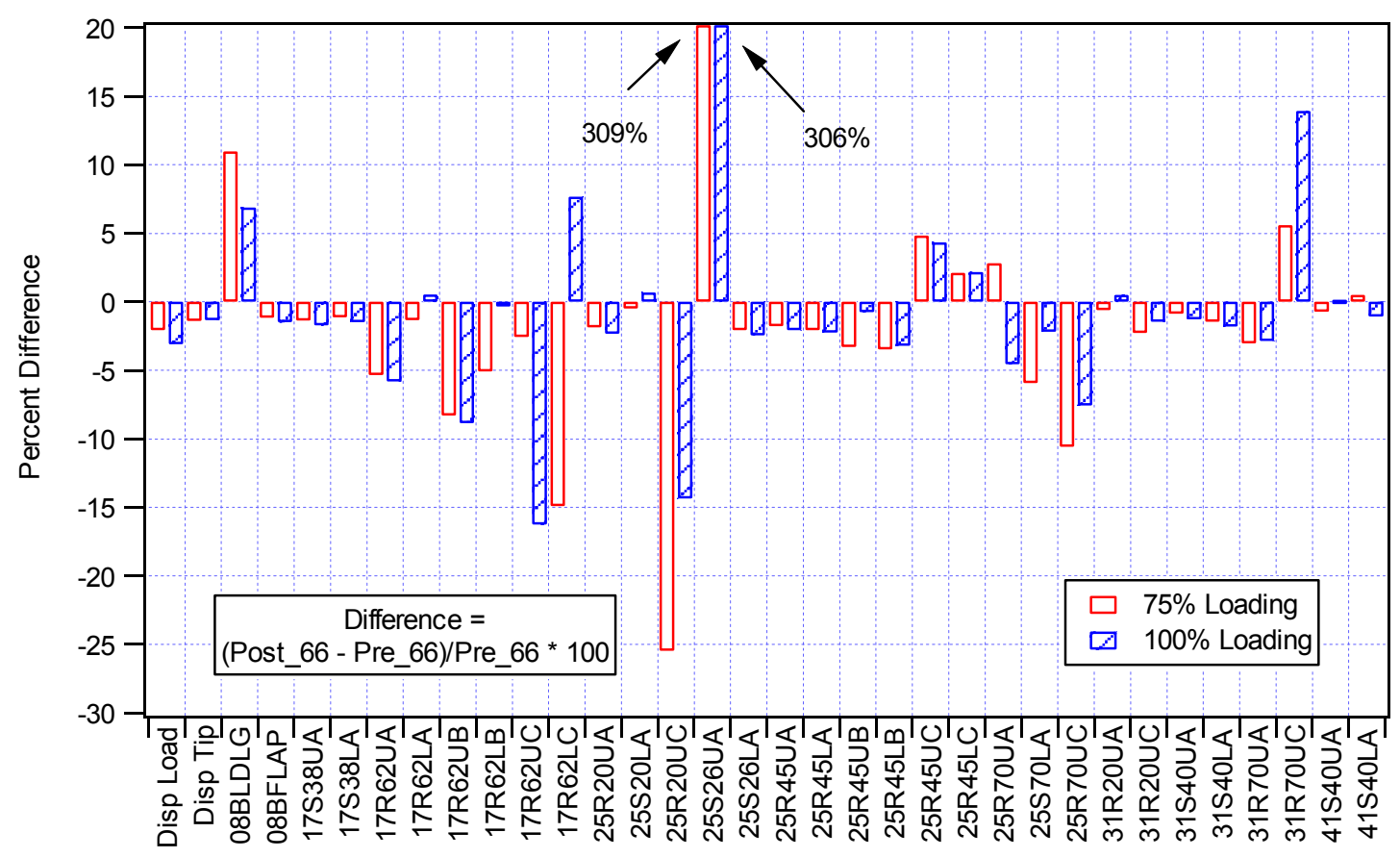

Flap Test Gauge

Figure 4.3 Blade \#66 flap static test pre- and post-fatigue test gauge comparison

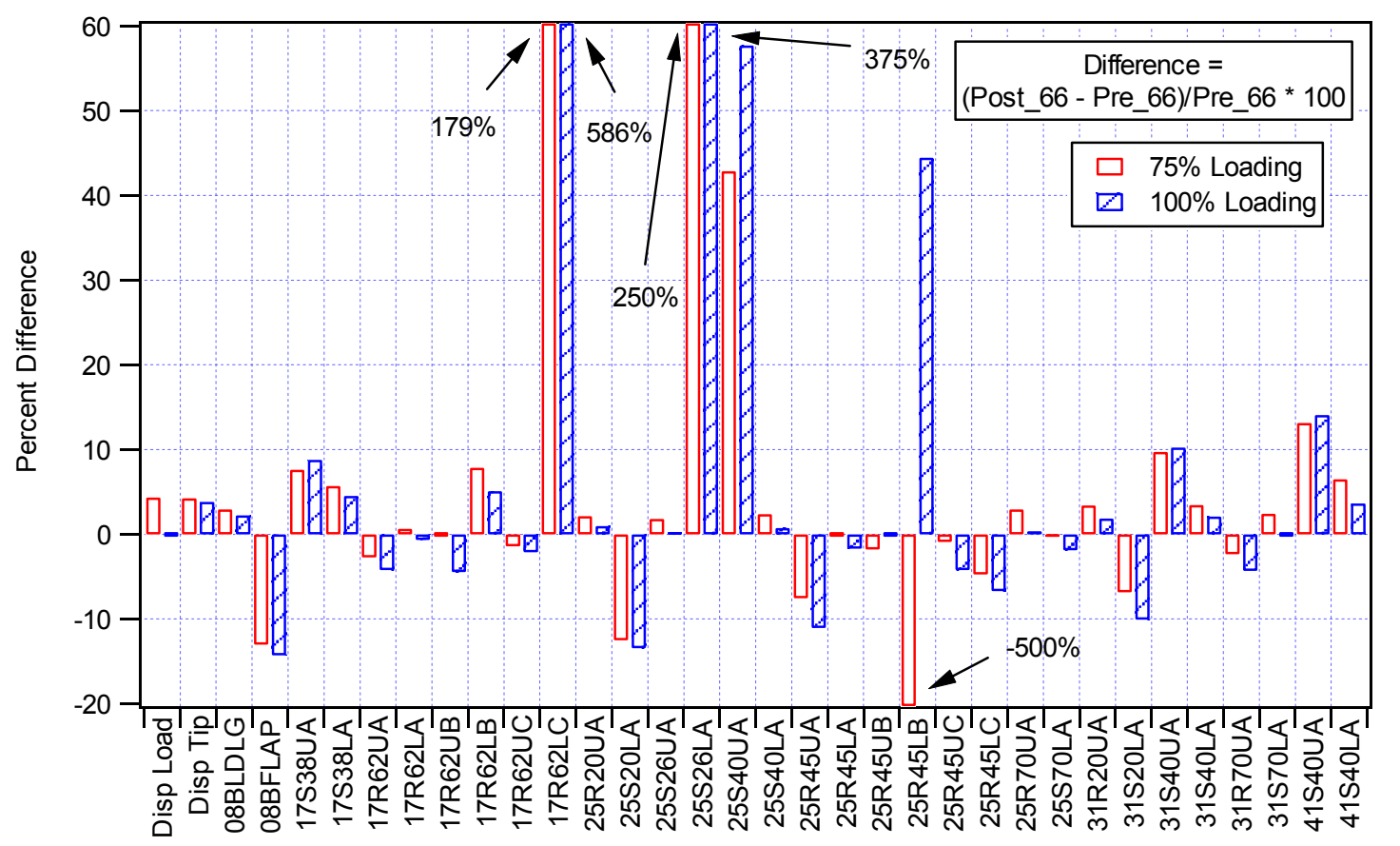

Edge Test Gauge

Figure 4.4 Blade \#66 edge static test pre- and post-fatigue test gauge comparison 


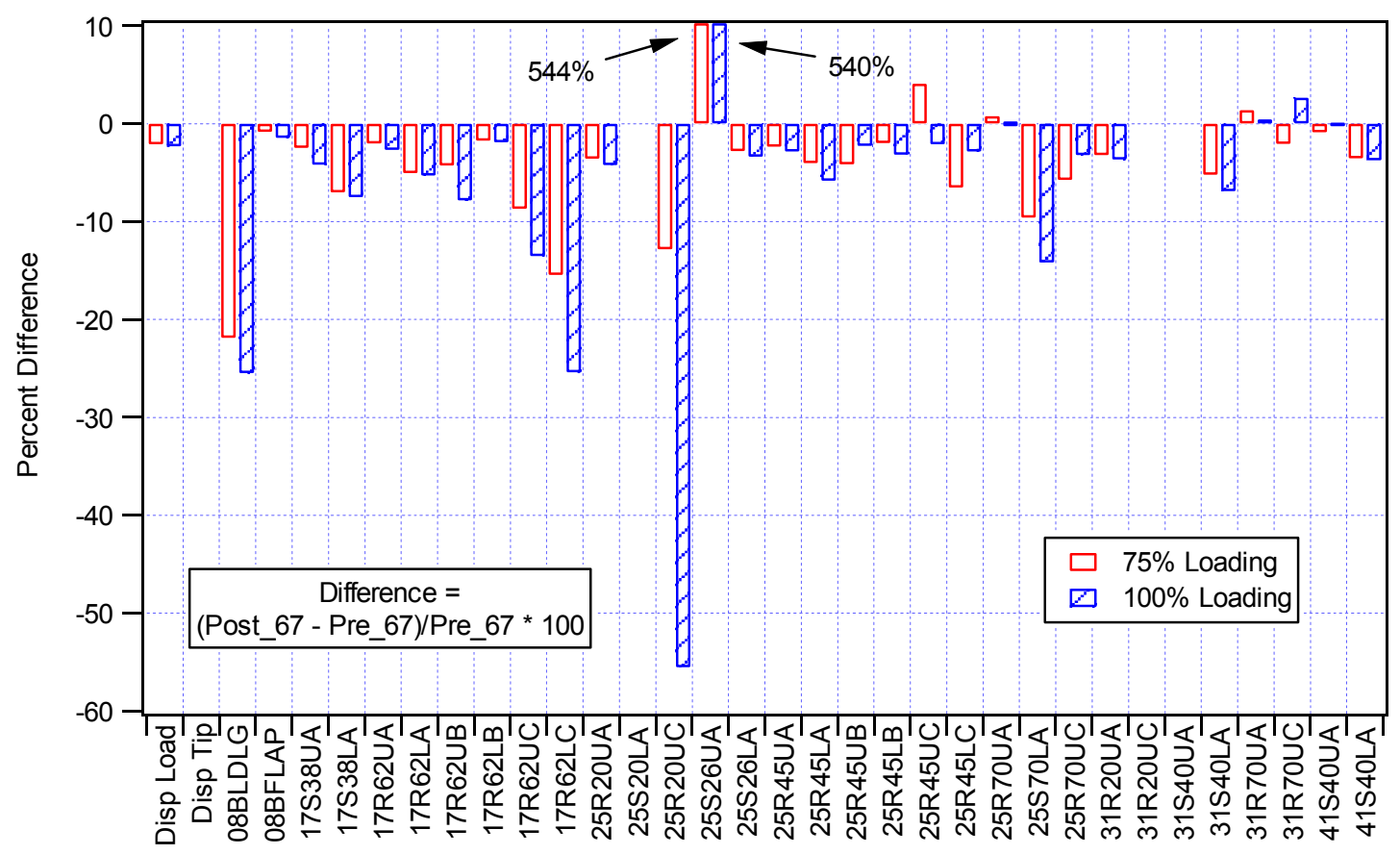

Flap Test Gauge

Figure 4.5 Blade \#67 flap static test pre- and post-fatigue test gauge comparison

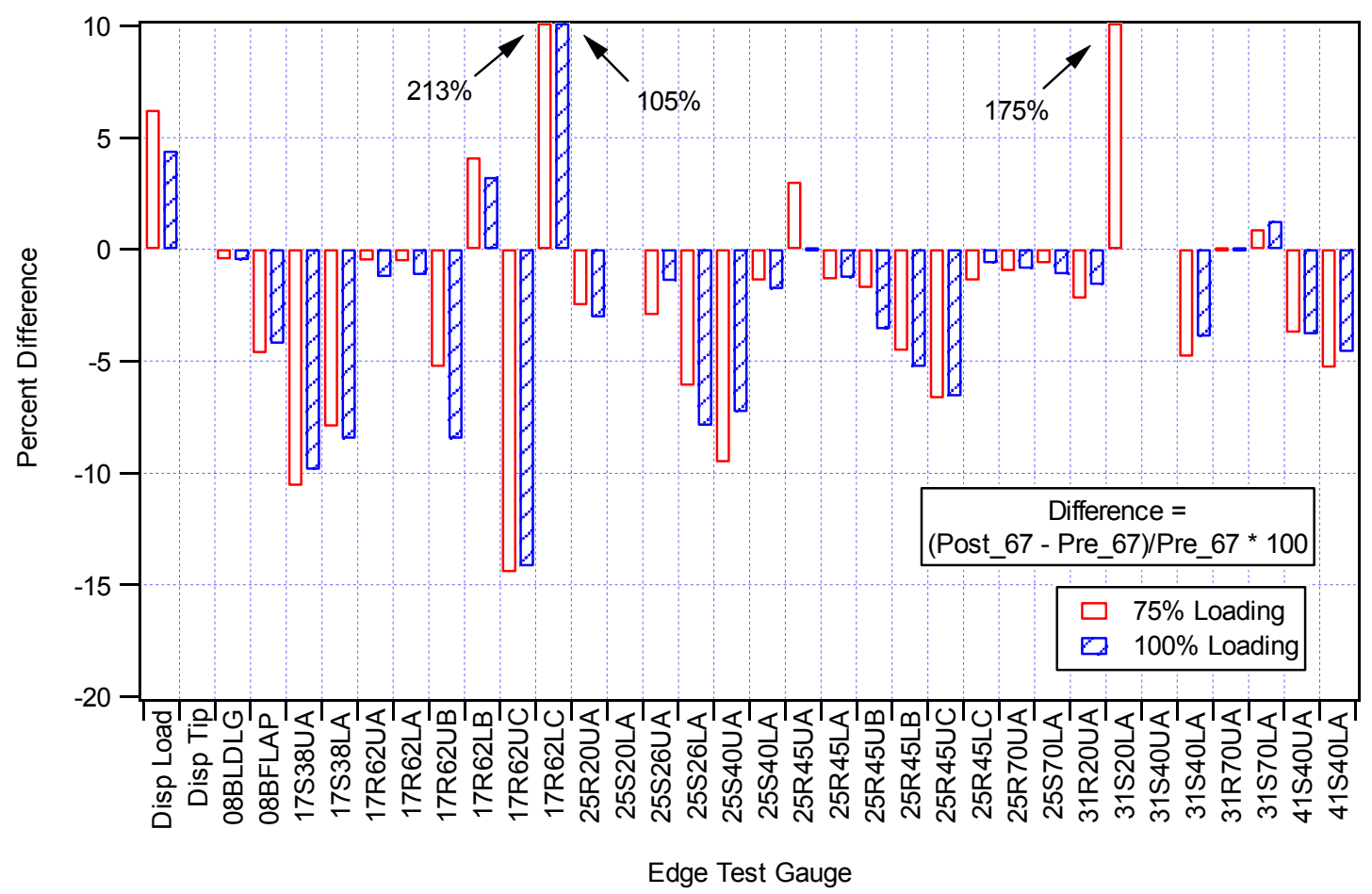

Figure 4.6 Blade \#67 edge static test pre- and post-fatigue test gauge comparison 


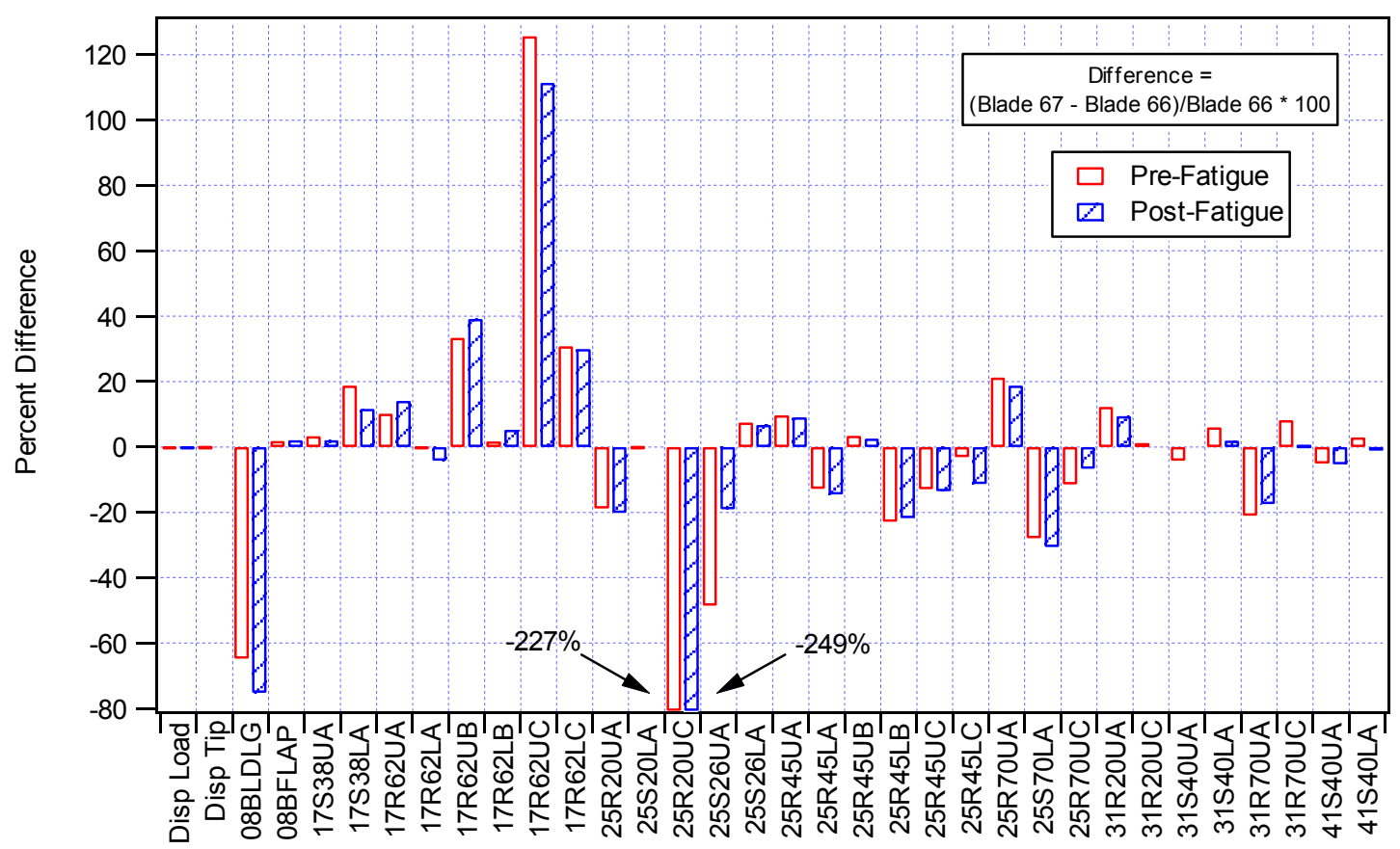

Flap Test Gauge

Figure 4.7 Blades \#66 and \#67 comparison for SMT-prescribed $75 \%$ flap static tests

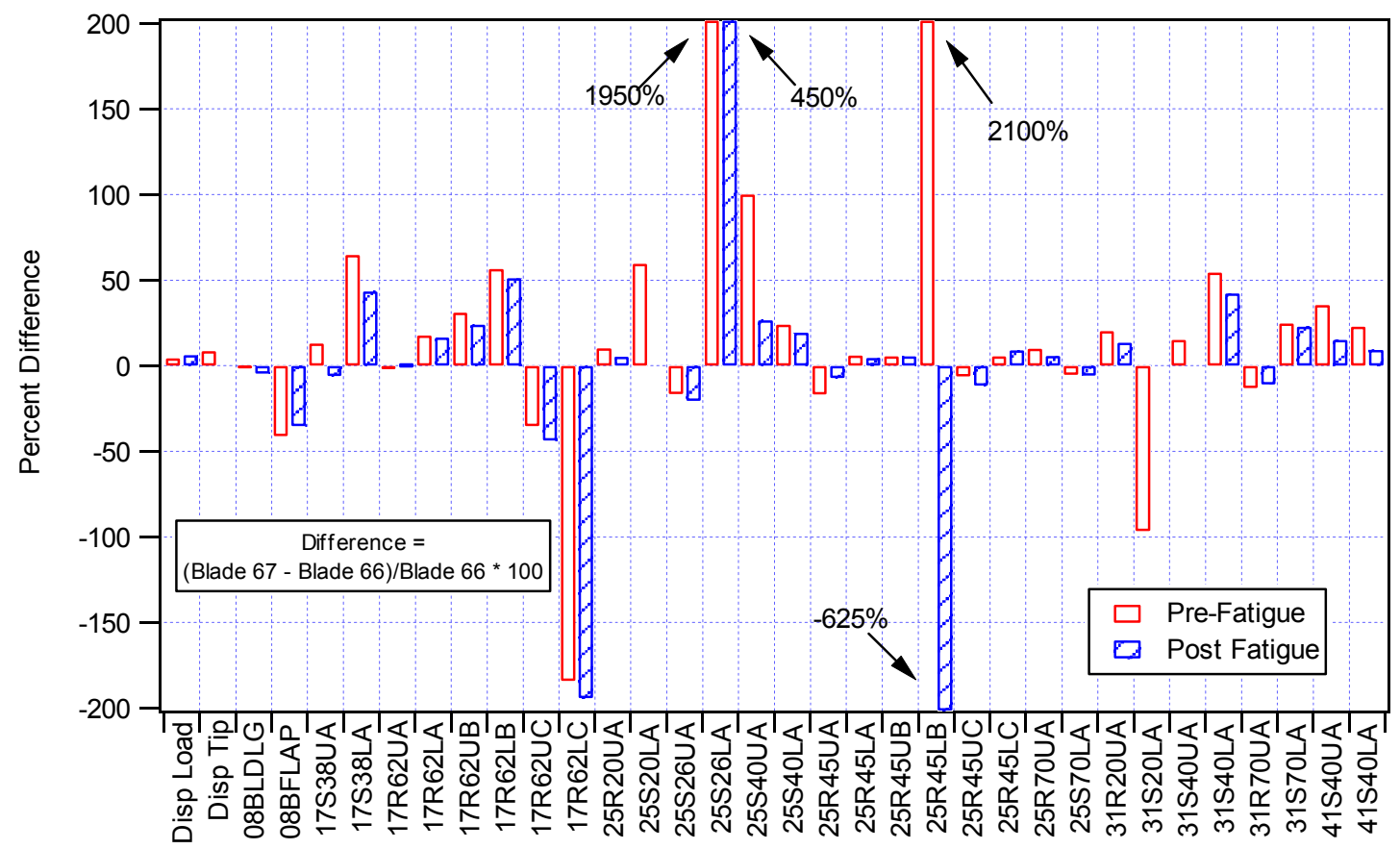

Edge Test Gauge

Figure 4.8 Blades \#66 and \#67 comparison for SMT-prescribed $75 \%$ edge static tests 


\subsubsection{Summary of Major Static-Test Observations}

1. Blade \#66 and Blade \#67 appear to have some random differences but their global properties are very similar.

2. Pre- and post-fatigue data show a probable increase in blade stiffness due to possible laminate drying effects. This effect is most obvious in the flap direction.

3. The effect described in \#2 above overshadowed any possible decline in global blade properties due to fatigue testing. Some local strain changes may have occurred but could not be fully evaluated for this test.

4. The SMT-prescribed static-test load (75\% of ultimate) was insufficient to evaluate possible nonlinearities for fatigue loading.

5. The SMT-prescribed static-test loading procedure was inadequate to evaluate extreme load behavior and did not allow the actual blade strength to be determined. 


\section{Fatigue Testing}

\subsection{Introduction}

The methodology for conducting fatigue tests of wind turbine blades is inherently more complex than for static testing. The extreme static design loads can usually be applied to the test blade at near face value with a high level of confidence and without any complex manipulations. The fatigue load spectrum, however, must first be compressed and simplified, then applied to the blade within the constraints of the laboratory's hardware. As a result, fatigue-testing methodology has more variations among the laboratories and is less easily restricted to a single procedure. The SMT partners agreed that the "business as usual" practices for each laboratory should be followed to allow a wider range of methods to be examined.

For a particular fatigue test procedure, the methodology is determined by both the analytical technique used to synthesize the design loads, and the hardware constraints on the test lab. In practice, it is difficult to separate the two. A highly accurate damage model will not result in a representative test if the hardware cannot reproduce the loads. Similarly, an exceedingly versatile set of hydraulic equipment will not improve the test if the design loads are not properly reduced.

Previous fatigue tests performed at NREL have used the following test hardware arrangements:

1. Independent (sequential) fatigue tests of the flap and edge loads

2. Combined flap and edge fatigue test with blade pitched to a prescribed angle for the proper resultant load using a single hydraulic actuator

3. Two-axis test with separate flap and edge load inputs from separate hydraulic actuators

To compare methods 2 and 3 above, NREL elected to conduct both a single-axis test and a two-axis test on separate blades. The single-axis test is simple and easy to implement for strength verification and design strength checks. Method 1 is a subset of this type of testing. The two-axis test is more equipmentintensive but produces a better representation of the true operating conditions.

\subsection{Design Data}

\subsubsection{Design Loads}

To reduce some of the variability, the SMT program partners agreed to constrain the fatigue testing design load analysis to the original design assumptions used by Rotorline. Therefore, it was incumbent on the participants to resist temptations to apply further design enhancements while carrying out the test load development. Fatigue properties of the blade materials were given and were used to derive the equivalent damage of the load spectrum. The major constraint was that an $\mathrm{S}-\mathrm{N}$ fatigue slope of $\mathrm{m}=10$ was used for all computations.

Load cases used by NedWind to design the blades were provided to the project partners to formulate fatigue test loads. The load cases are presented in Appendix A [16] and described in [6]. One hundred load cases were presented with the number of cycles for each case. For each load case the loads at ten spanwise sections were presented. Table 5.1 from file NW25.LBK below shows the spanwise positions. Table 5.2 shows an example listing of the range file (NW25.CSB). Radial force $\left(\mathrm{F}_{\mathrm{z}}\right)$, edgewise moment $\left(\mathrm{M}_{\mathrm{x}}\right)$, and flapwise moment $\left(\mathrm{M}_{\mathrm{y}}\right)$ were given. These loads were aligned to the rotor plane with the tip 
angle at zero [17]. Separate files of the maximum load (filename NW25.CMB) and load range (filename NW25.CSB) were presented for the load cases.

Table 5.1 Spanwise Positions for Load Cases (File name NW25.LKB)

\begin{tabular}{lll}
\hline $\begin{array}{l}\text { Position } \\
\text { Number }\end{array}$ & $\begin{array}{l}\text { Radial Position } \\
\text { from Rotor } \\
\text { Center }(\mathrm{m})\end{array}$ & Description of Position \\
\hline 1 & 0.2 & Weld in hub \\
2 & 0.6 & Weld in hub \\
3 & 0.65 & Blade flange \\
4 & 0.8 & $\begin{array}{l}\text { Pin-hole connection between flange and laminate } \\
5\end{array}$ \\
6 & 2.65 & $1^{\text {st }}$ aerodynamic cross section \\
7 & 3.9 & $2^{\text {nd }}$ aerodynamic cross section \\
8 & 5.15 & $3^{\text {rd }}$ \\
9 & 6.4 & $4^{\text {th }}$ \\
10 & 7.65 & $5^{\text {th }}$ \\
\hline
\end{tabular}

Table 5.2 Example Contents of File NW25.CSB, Range of Load Cases

\begin{tabular}{|c|c|c|c|c|c|c|c|c|c|}
\hline & & \multicolumn{3}{|c|}{ Position 1} & \multicolumn{3}{|c|}{ Position 2} & \multirow[b]{2}{*}{$\cdots$} & \multirow[b]{2}{*}{ My10 } \\
\hline $\begin{array}{r}\text { No. of Load } \\
\text { Cases }\end{array}$ & 100 & Fz1 & $\overline{M x 1}$ & $\overline{M y 1}$ & Fz2 & $M \times 2$ & My2 & & \\
\hline No. of & 3747660 & 25506.9 & 67645.61 & 37281.91 & 15847.83 & 57301.43 & 35460.76 & $\ldots$ & 3728.908 \\
\hline cycles & 4145710 & 25506.9 & 72533.04 & 59440.37 & 15847.83 & 61977.53 & 56659.7 & $\cdots$ & 6738.19 \\
\hline & 3699900 & 25506.9 & 74759.94 & 46726.85 & 15847.83 & 64126.9 & 44507.67 & $\cdots$ & 5060.531 \\
\hline & 2759400 & 25506.9 & 73800.66 & 37519.26 & 15847.83 & 63223.22 & 35732.78 & $\ldots$ & 4019.418 \\
\hline & 1746710 & 25506.9 & 72519.75 & 39519.11 & 15847.83 & 62025.46 & 37717.42 & $\cdots$ & 4766.019 \\
\hline & 20 & 2550691 & $\begin{array}{c}: \\
7521484\end{array}$ & $\begin{array}{c}: \\
107461\end{array}$ & $\begin{array}{c}: \\
1584783\end{array}$ & 658466 & 1017301 & & רים 00198 \\
\hline & 20 & & & & 15841.83 & 05840.6 & $101 / 30.1$ & & 9409.942 \\
\hline
\end{tabular}

\subsubsection{Design Strength and Test Load Factors}

In the 1991 Rotorline analysis the primary equation used to determine the allowable number of cycles, N, was taken from [18] and properly stated in [19]. The equation, stated below, is a modified Goodman relation: 


$$
N=\left\{\frac{\frac{U T S+|U C S|}{2 \times C 1 \times C 2 \times C 3}-\left|S_{\text {mean }}-\frac{U T S-|U C S|}{2 \times C 1 \times C 2 \times C 3}\right|}{S_{\text {amp }}}\right\}^{10}
$$

where,

$$
\begin{aligned}
& \text { C1, C2, C3 = material factors described below } \\
& \mathrm{S}_{\text {mean }}=\text { mean stress } \\
& \mathrm{S}_{\text {amp }}=\text { stress amplitude (one-half range) } \\
& \text { UTS = ultimate tensile strength } \\
& \text { UCS = ultimate compression strength. }
\end{aligned}
$$

The values for UTS, UCS, and E (modulus) were specified in [20] and taken from [10] and are listed in Table 5.3.

Table 5.3 NedWind Blade Material Properties

\begin{tabular}{llll}
\hline Laminate & UTS (MPa) & UCS (MPa) & $\begin{array}{l}\text { Modulus E } \\
\left(\mathrm{N} / \mathrm{mm}^{2}\right)\end{array}$ \\
\hline Strength & 372 & 260 & 24,500 \\
Tail/Nose & 87 & 76 & 7000 \\
\hline
\end{tabular}

As part of the fatigue test load development, the test loading was modified to account for the various effects and uncertainties introduced by the test load analysis, by the test load methods, and by the lab conditions. The following test load factors were used to develop the test loading. The test load contains any relevant design load factors that were used in the original design. Each one is described below.

Design Load Partial Safety Factors--The design was apparently conducted under applicable Dutch codes in the 1992 time frame. As part of the design, a general fatigue load factor of 1.35 was applied to the design loads. For some sections, a larger factor of 1.5 was used, apparently for additional conservatism. NREL used the fatigue factors as applied by [18].

Stress Concentration Factors--Stress concentration factors (SCFs) were used in the design and applied to the design loads. It was assumed that the designer's intent was to account for various geometric transitions and complexities in the blade, which result in local stress amplifications. It was assumed that these stress risers were applied directly to the design loads, which in turn resulted in thicker blade sections in those areas. However, the geometric blade features that the SCFs were intended to account for are present in the actual blades, so the stress should already be higher in these regions. Therefore, it was not necessary to include the SCFs in the test load and they were ignored for this analysis.

Wind Farm Load Factor--A load factor was calculated to represent an allowable damage of only 0.66 (Miner's-rule fraction) on a 20-year life for turbines operating in a wind farm. This was a design requirement for the original blade and was included in the test. For an $\mathrm{R}$ ratio of -1.0 and assuming a slope of 10 on the S-N data, this load factor was 1.04 on the test load. It was appropriate to apply this to 
the test load because the lower damage requirement was a direct result of higher loads resulting from wind farm operation.

Material Design Strength Factor--The general material factors are used in the design to adjust the material properties of the coupon samples (e.g., UTS [calcval] on pg. 6 of Bernard 1 [18]) to the anticipated fullscale blade properties. These factors were used in the test equivalent damage analysis in the Goodman relation above as they were applied in the design. For fatigue, this factor was $\mathrm{V}_{\mathrm{mf}}=1.5$, which is the product of $\mathrm{C} 1, \mathrm{C} 2$, and $\mathrm{C} 3$. For the test load calculation, these factors are to be applied again in the modified Goodman relation given in Equation 5-1, with the exception of $\mathrm{C} 1$ (the moisture absorption factor).

Environmental Effects--Because the test laboratory was at a lower temperature and humidity than the design conditions, the blade was stronger in the laboratory than it was operating under the most severe environmental conditions. The factor, $\mathrm{C} 1$, from the manufacturer's design data was given as 1.25 . This factor was meant to account for these differences in moisture absorption between the test environment and the blade-operating environment. This effect was addressed in the test loads by not applying this factor to the Goodman relation in Equation 5-1 for the test load calculation, and determining the test equivalent damage based on a higher material strength. This resulted in a higher test load.

Errors in the Fatigue Formulation--A test load factor of 1.05 was used to account for errors in the fatigue formulation. This value was applied to remain consistent with IEC 61400-23 [21].

Blade-to-Blade Variations--A factor of 1.1 to cover blade-to-blade variations was applied in this test to account for possible variations in the as-built population if only one blade is tested. The application of this factor is not a standard practice at NREL; however, we have applied it to remain consistent with IEC 61400-23 [21] and the other laboratories.

NREL recognizes that uncertainty exists in the final manufactured population of blades; however, we do not believe that this issue is best addressed with an uncertainty factor on the blade test load that may drive up the turbine cost. We believe that this issue should be addressed in the design, by testing multiple blades if necessary, testing the blades to failure, and by postmortem evaluations to determine the relative quality of the test blade.

Tables 5.4 and 5.5 summarize the design and test load factors used.

Table 5.4 Fatigue Design Factor Summary

\begin{tabular}{lll}
\hline Parameter & Value & Description \\
\hline Vbf & 1.35 & design load factor for sections 1-4 $(0.2-0.8 \mathrm{~m})$ \\
Vbf & 1.5 & design load factor for sections 5-10 $(2.65$ to $8.9 \mathrm{~m})$ \\
C1 & 1.25 & water consumption \\
C2 & 1.00 & unidirectional/continuous \\
C3 & 1.20 & general safety factor \\
\hline
\end{tabular}


TP-500-29103

Table 5.5 Fatigue Test Load Factor Summary

\begin{tabular}{lll}
\hline Parameter & Value & Description \\
\hline C1a & 1.00 & water consumption-dry laboratory \\
C2a & 1.00 & unidirectional/continuous \\
C3a & 1.20 & general safety factor \\
$\gamma_{\text {eff }}$ & 1.05 & error in fatigue formulation \\
$\gamma_{\mathrm{sf}}$ & 1.1 & blade-to-blade variation \\
$\gamma_{\mathrm{wp}}$ & 1.04 & wind park life reduction \\
\hline
\end{tabular}

\subsection{Equivalent-Damage Analysis}

\subsubsection{Introduction}

\subsubsection{Conventional Methods}

Conventional fatigue analyses used to determine equivalent test load are typically based on the blade structural design. These methods usually require a complex and time-consuming strength analysis, as well as a thorough understanding of the fatigue performance of the blade. Many errors can be propagated through this process. Most methods convert loads to stresses at several spanwise blade sections. Then, for measured or assumed S-N curves (applied stress versus allowable cycles to failure) of the laminate, Miner's Rule is applied to determine the design damage. Equivalent-damage test loads are then computed for given test load ratios and number of load cycles. These methods determine test loads by assuming that the behavior of the test article matches the design condition exactly. If the test blade is different than the design, then significant uncertainty is introduced. For example:

- The test blade cross-section geometry will not exactly match the drawing.

- Blade laminate material properties will deviate from coupon properties (e.g., resin versus fiber rich, ply drops, material handling, and workmanship).

- The critical area may be in a bolted or bonded joint or in a stress concentration region that will have a unique S-N curve.

As a result of these variations, the calculated damage to the test blade could be higher or lower than its actual value, and may disguise a problem where high damage is sustained. Moreover, considerable time is spent calculating and applying the various blade properties at each step of the analysis. This adds complexity to the problem and exposes the analysis to possible accounting errors. This effort may be necessary if the goal is to study the exact structural design of the wind turbine blade at every location and make quantitative comparisons with the design. Usually, however, the design details are not known well enough to perform these calculation without considerable guesswork, because the blade will usually fail in an area where material fatigue data is not precisely known or where stress concentrations alter the stress field in an unpredictable manner.

Blade test standards such as IEC 61400-23 attempt to compensate for these potential errors by applying significant test load factors to the equivalent damage test loads, such as errors in the fatigue formulation or blade-to-blade variations. However, the true uncertainty is largely unknown. 


\subsubsection{NREL's Approach}

One of the goals of the SMT program at NREL was to simplify the fatigue test-load derivation process and minimize the potential errors in the analysis. It appeared that the most efficient and logical method would be to derive the fatigue test loads in a way analogous to the determination of ultimate-strength loads. The ultimate-strength loads are simply the maximum load case extracted from the load spectrum. The peak load in the spectrum is applied to the blade to verify adequate static strength. It is not necessary to know the blade geometry, material properties, or perform a complete stress analysis. The load is applied and the test is considered valid if it can survive the intended loads. The tested area is decided, by definition, based on which spanwise sections reached or exceeded the test bending moments.

For fatigue testing, the objectives should be the same. Each section of the blade that is tested to its equivalent design bending moment condition and survives has adequately demonstrated sufficient fatigue resistance. It is not necessary to evaluate the stresses at each point, especially if the calculations are limited to the parent composite material and uniform sections where blades rarely experience fatigue problems.

\subsubsection{Simplified Load Spectrum Method}

The goal of the simplified load spectrum method is to derive an equivalent damage fatigue test that is only dependent on the design-load spectrum. Using this method, the test loads are derived assuming the blade geometry and material fatigue properties are not accurately known. Then the test article is allowed to (and probably does) deviate from the intended design without affecting the test conditions.

This method remains strictly in the load domain; therefore, there is no conversion to stresses. So instead of an S-N curve there will be an M-N curve (applied moment vs. allowable cycles to failure) for the blade. The curve will be defined by the relationship,

$$
\mathrm{Ma}=\mathrm{Mu} \times \mathrm{N}^{(-1 / \mathrm{m})}
$$

where,
Ma amplitude moment in one load cycle
$\mathrm{Mu}$ ultimate moment of the blade
$\mathrm{N} \quad$ allowable cycles to failure
$\mathrm{m} \quad$ slope of the curve.

A blade's fatigue failure can occur in many locations by various modes (e.g., skin laminate failure in tension or local buckling, adhesive failure in shear or peel, or bolted-joint failure). Each failure mode could be characterized by a different M-N curve. A family of curves was defined to bound the potential $\mathrm{M}-\mathrm{N}$ combinations for the test blade. A range of ultimate moments from $1.5 \times \mathrm{M}_{\max }$ to $4.5 \times \mathrm{M}_{\max }$ and a range of slopes from $m=6$ to $m=12$ were used. $M_{\max }$ is the maximum characteristic moment in the NedWind 25 load spectrum. The $1.5 \mathrm{x} \mathrm{M}_{\max }$ was selected for the lower bound curve, which matched the $100 \%$ extreme static-test level and the extreme design-limit load. The 4.5 factor was arbitrarily selected for the higher bound to account for the possibility of conservative designs. Implicit in these boundaries is the assumption that the ultimate moment to cause blade failure is somewhere between 1.5 and 4.5 times the maximum load case experienced by the blade on the NedWind 25 turbine. 


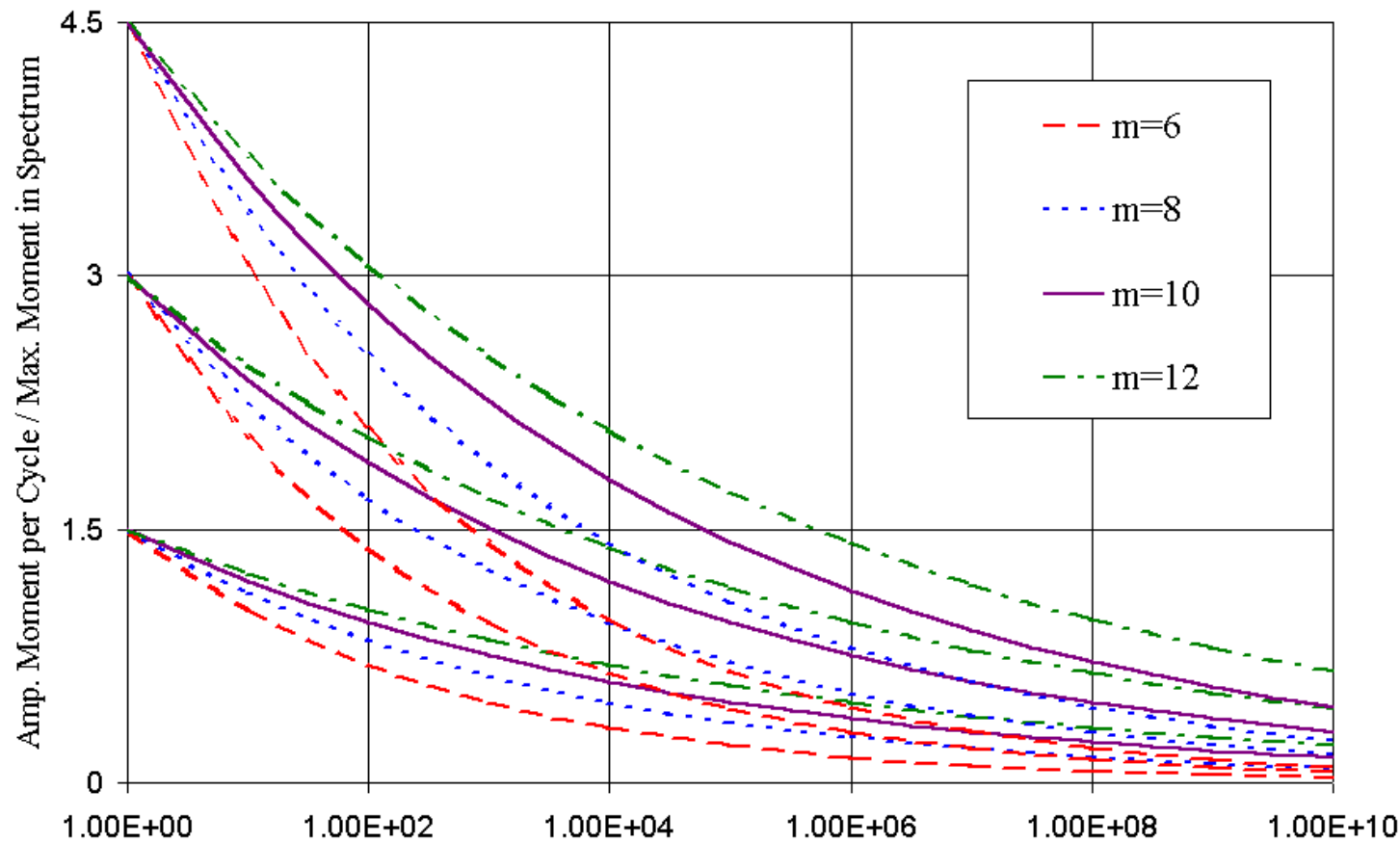

Number of Cycles to Failure

Figure 5.1 M-N curve family at $R_{t}=-\mathbf{1 . 0}$

The range of slopes from 6 to 12 was supported by an extensive database of fiberglass laminates. Slopes approaching 6 were seen in poor performing fabrics and laminates, as well as in better-performing laminates with fabrication flaws such as resin- and fiber-rich areas, ply drops, and complex geometry. The family of M-N curves is shown in Figure 5.1.

Note that three levels of moments $\left(1.5 \times \mathrm{M}_{\max }, 3.0 \times \mathrm{M}_{\max }\right.$, and $\left.4.5 \times \mathrm{M}_{\max }\right)$ were selected for this analysis, along with four $\mathrm{M}-\mathrm{N}$ slopes $(\mathrm{m}=6, \mathrm{~m}=8, \mathrm{~m}=10$, and $\mathrm{m}=12)$, giving a total of 12 curves. Using more curves to gain better resolution in the analysis was examined; however, it had very little effect on the results.

The damage associated with each curve can be calculated by applying Palmgren-Miner's Rule as follows:

$$
\text { Damage }=\sum_{i=1}^{j} \frac{n_{i}}{N_{i}}
$$

where,

i load case number

j total number of load cases

$\mathrm{n}_{\mathrm{i}} \quad$ number of load cycles for case $\mathrm{i}$

$\mathrm{N}_{\mathrm{i}} \quad$ number of load cycles to failure for case $\mathrm{i}$.

The family of M-N curves defined above are set at a load ratio of $\mathrm{R}=-1.0$. The Goodman relationship was also assumed to be linear as far as the $\mathrm{R}=-1.0$ line (vertical line showing zero mean moment in Figure 5.2). Because all but 1 of the 100 NedWind 25 load cases are on or to the right (positive mean load) of the $\mathrm{R}=-1.0$ line, it was only necessary for us to model the right half of the Goodman diagram 
(see Figure 5.2). The one case on the left side of the $\mathrm{R}=-1.0$ line is a relatively low-damage case; modifying the method to account for this case had a negligible effect.

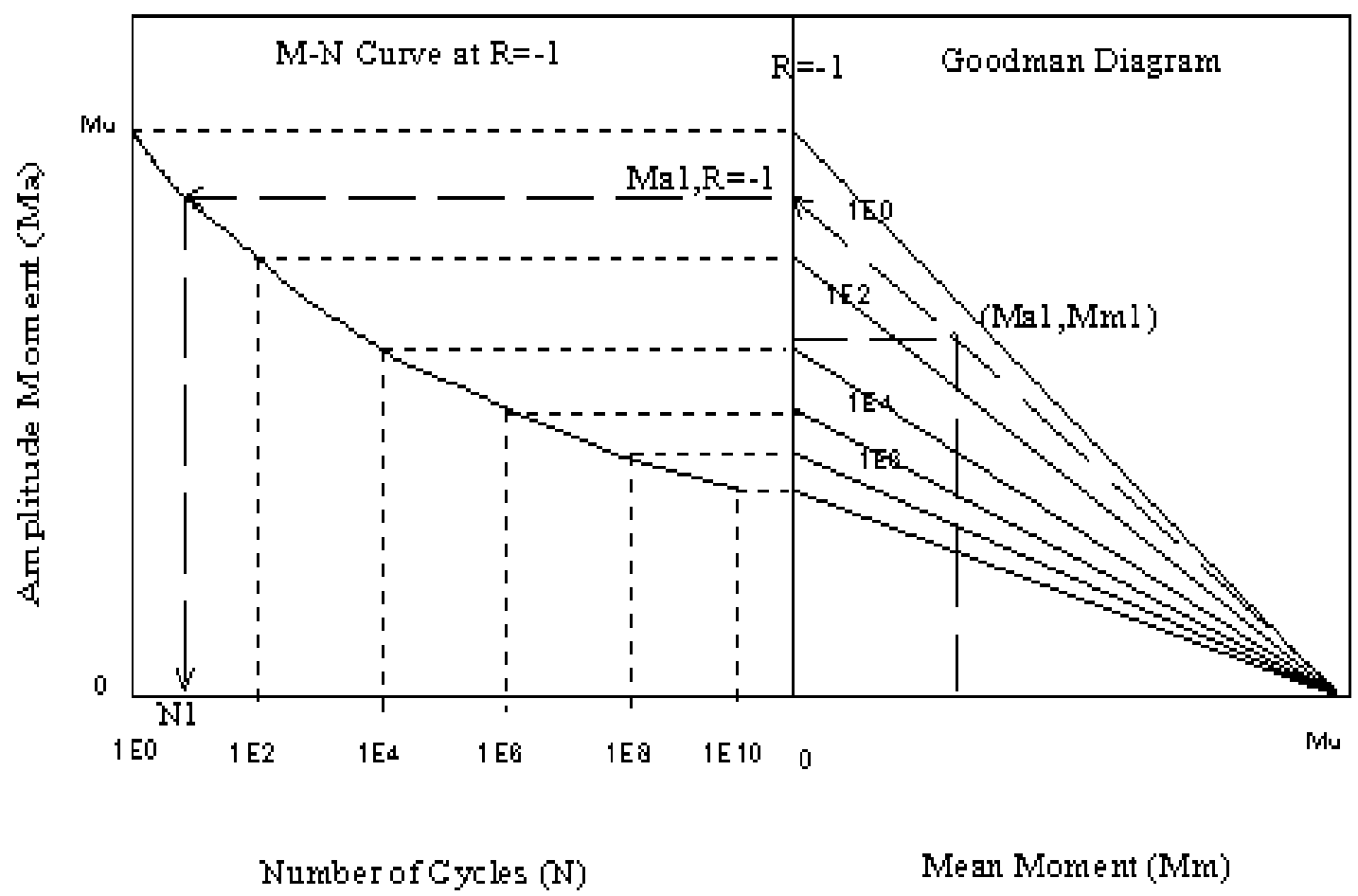

Figure 5.2 Goodman diagram and sample load case \#1

For simplicity, we proceeded with the right half of the Goodman diagram model. When looking at different fatigue failure mechanisms, this linearized Goodman model combined with the M-N family of curves appears to be a good representation of the NedWind 25 design and load spectrum described in Equation 5-1. If the blade's fatigue failure were to occur in a fiberglass laminate, one would expect that the M-N curve and Goodman diagram of the blade would be best characterized by the laminate's S-N curve and Goodman diagram. A blade in bending will have skin laminates in both tension and compression. S-N curves for compressive failure in laminates tend to have a lower ultimate stress and a higher slope than their tensile counterpart [22]. The ratio of a tensile to a compressive ultimate stress can approach 2.0. This creates a wide range of laminate material properties, but they should be well bounded by the assumed M-N curves. The laminate compression curves may be most closely characterized by the $1.5 \times \mathrm{M}_{\max }, \mathrm{m}=10-12$ curves, whereas the tension curves may better match the $4.5 \times \mathrm{M}_{\max }, \mathrm{m}=6-10$ curves.

To support our linear Goodman model, another point should be made concerning the transition from a tensile to a compressive fatigue failure in a fiberglass laminate. At low cycles (typically below 1,000), the transition is somewhere between $\mathrm{R}=0.1$ and $\mathrm{R}=-1.0$. At higher cycles, the transition is closer to $\mathrm{R}=$ -1.0 and may even trend towards $\mathrm{R}=-2.0$ as the cycles increase [22]. This produces a nonlinear Goodman diagram. The impact of this was evaluated for the NedWind 25 spectrum. When this spectrum was plotted (see Figure 5.3) onto a normalized Goodman diagram for a similar laminate from the Montana State University (MSU)/DOE fatigue database, the linear representation appeared to be the best fit [22]. 


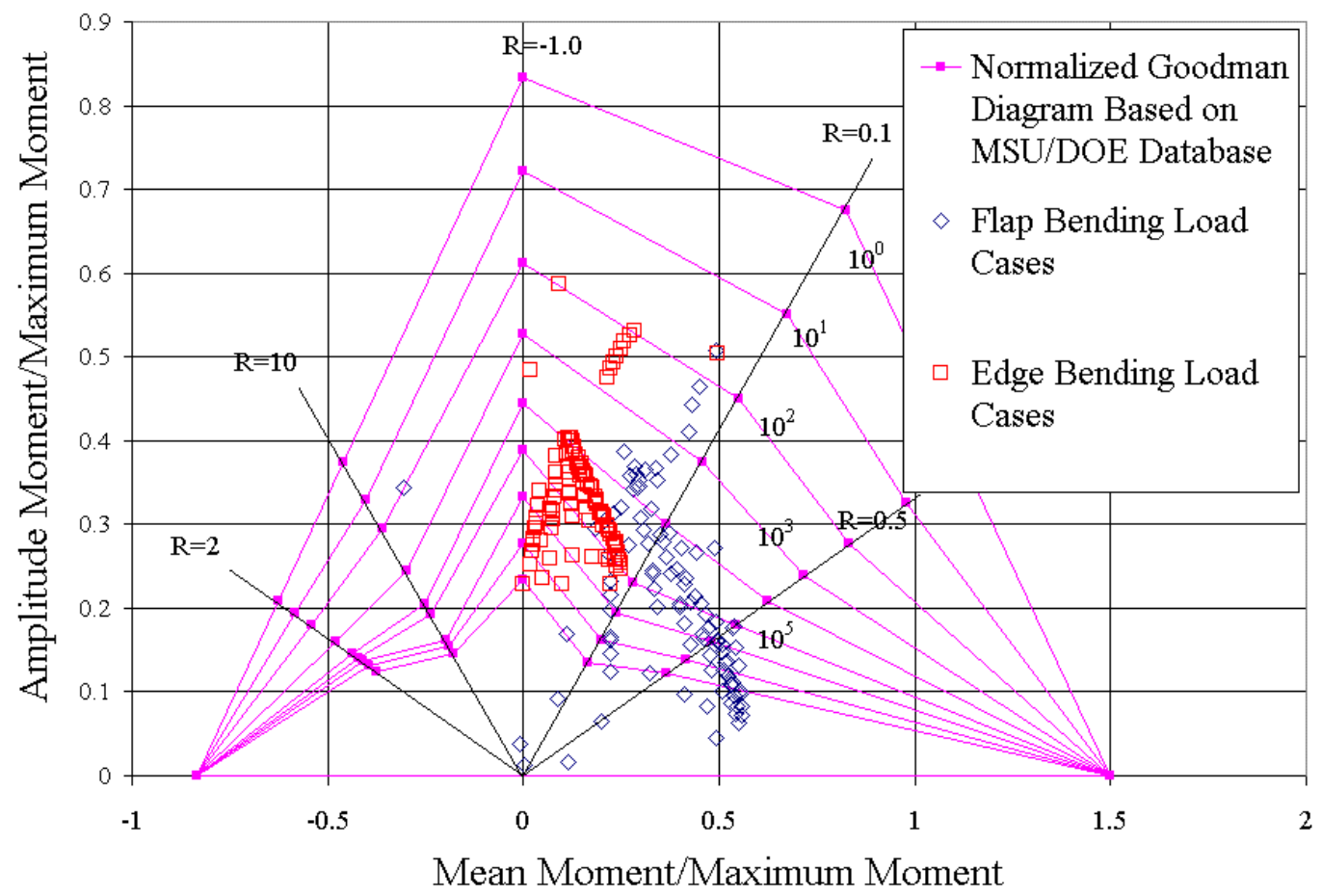

Figure 5.3 Normalized Goodman Diagram based on MSU/DOE database [22] and NedWind 25 load cases

The original NedWind 25 design analysis, using the Goodman relationship in Equation 5-1 (Figure 5.4), assumes linear-symmetric behavior about an offset to the right of the $\mathrm{R}=-1.0$ line. This offset truncated the tensile failure line, creating lower peak amplitude at the tensile-to-compressive-fatigue-failure transition point. This relationship was compared with the simplified load spectrum-based method presented in this report. The difference in resulting damage between the SMT program's offset linear model and the $\mathrm{R}=-1.0$ linear model was negligible $(0.2 \%)$. 


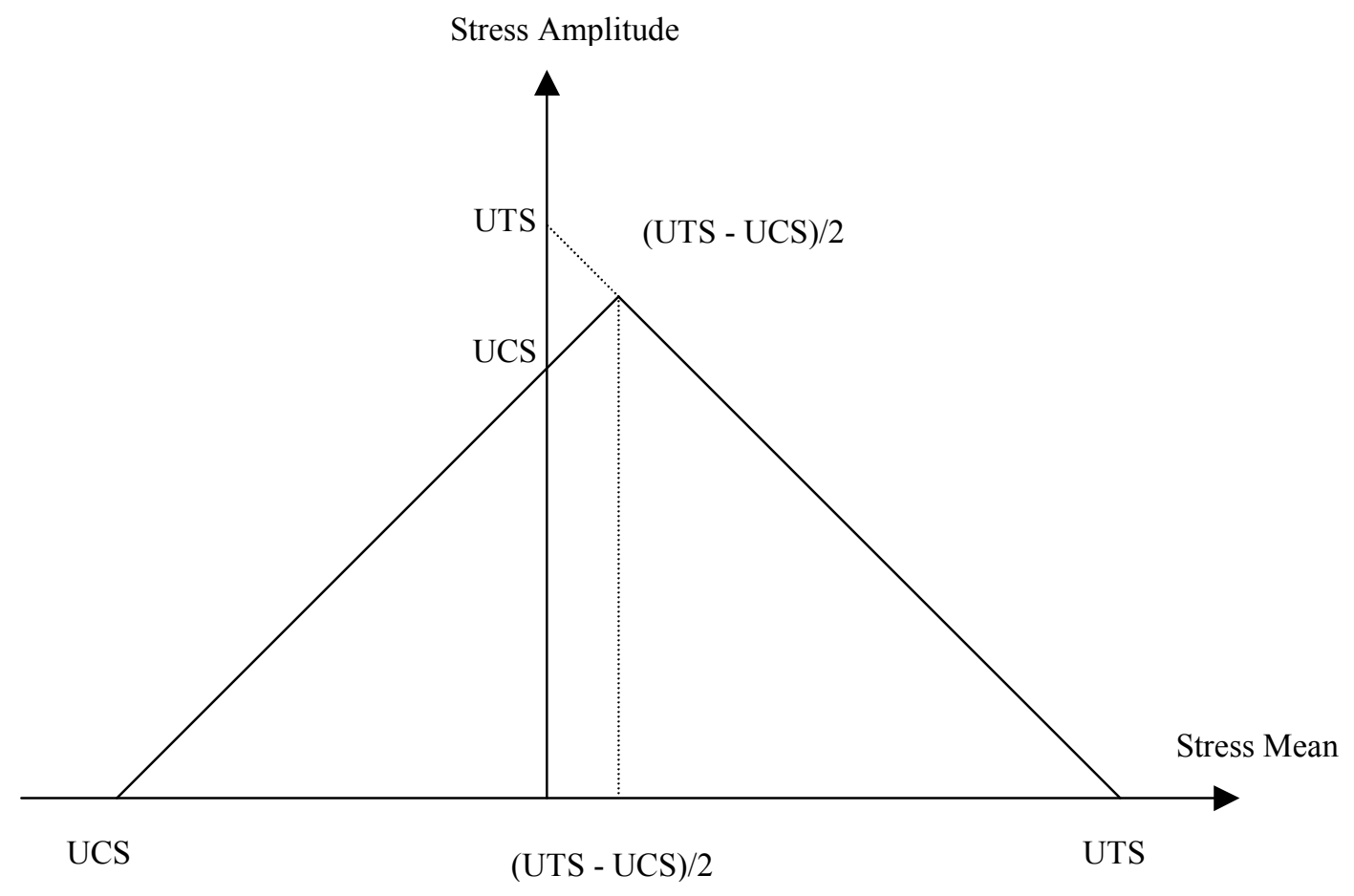

\section{Figure 5.4 Rotorline analysis modified Goodman relation (Equation 5-1) with truncation of tensile failure line [19]}

Most of the above discussion assumes that the failure occurs in the laminates where good coupon data can be collected. If the blade fatigue failure occurs in a structural detail such as a bonded or bolted joint, a Goodman relationship for the blade would be characterized by the Goodman relationship for that joint. Unfortunately, Goodman diagrams for joints are difficult to define because there is almost no joint fatigue data available and the number of test variables is greatly increased when compared to coupon testing. For lack of a better model, we considered our $\mathrm{R}=-1.0$ linear Goodman relationship reasonable for characterizing joint failures.

The $\mathrm{R}=-1.0$ linear Goodman relationship also simplifies the calculations and is easier to understand in this initial application of the method. However, this method can be applied to any nonlinear Goodman relationship by modifying the extrapolation routines that will now be discussed.

Because the load cases in the fatigue spectrum are at various load ratios, the equivalent damage will have to be extrapolated using a Goodman diagram. Each case in the load spectrum is defined with a moment amplitude, moment mean, and number of cycles. A sample load case is shown in Figure 5.2 and called load case 1 .

The value for the amplitude mean when $\mathrm{R}=-1.0\left(\mathrm{M}_{\mathrm{a} 1, \mathrm{R}=1}\right)$, is extrapolated by setting the slopes on the Goodman diagram equal (see Figure 5.2).

$$
\frac{\mathrm{Ma}_{1, \mathrm{R}=-1}}{\mathrm{Mu}}=\frac{\mathrm{Ma}_{1}}{\mathrm{Mu}-\mathrm{Mm}_{1}}
$$

Solving for $\mathrm{Ma}_{1, \mathrm{R}=-1}$, 


$$
\mathrm{Ma}_{1, \mathrm{R}=-1}=\frac{\mathrm{MuMa}_{1}}{\mathrm{Mu}-\mathrm{Mm}_{1}}
$$

Plugging Equation 5-5 into Equation 5-2 and solving for the allowable number of cycles to failure for load case 1 gives,

$$
\mathrm{N}_{1}=\left(\frac{\left(\mathrm{Mu}-\mathrm{Mm}_{1}\right)}{\mathrm{Ma}_{1}}\right)^{\mathrm{m}}
$$

The damage from load case 1 is simply $D_{1}=\frac{n_{1}}{N_{1}}$. Summing the damage from all the load cases will give the total damage, $D_{\text {total }}=\sum_{i} \frac{n_{i}}{N_{i}}$.

To get the equivalent damage test load, the test conditions must be specified. Typically, this means the test load ratio, $R_{t}$ (constant), and number of cycles, $n_{t}$. Because the total damage, $D_{t}, R_{t}$, and $n_{t}$ are known, the test amplitude load and mean load can be calculated. This can be shown again with an example in Figure 5.5 below. For this case, it is assumed that the test load ratio is 0.1 and the test cycles are $3 \times 10^{6}$.

The first step is to calculate the total number of allowable cycles to give the same total damage when the $3 \times 10^{6}$ test cycles are applied.

$$
\begin{aligned}
& \mathrm{D}_{\text {total }}=\frac{\mathrm{n}_{\mathrm{t}}}{\mathrm{N}_{\mathrm{t}}} \\
& \mathrm{N}_{\mathrm{t}}=\frac{\mathrm{n}_{\mathrm{t}}}{\mathrm{D}_{\text {total }}}
\end{aligned}
$$

where,

$\mathrm{n}_{\mathrm{t}} \quad$ number of test cycles

$\mathrm{N}_{\mathrm{t}} \quad$ number of allowable cycles to failure at test loads. 


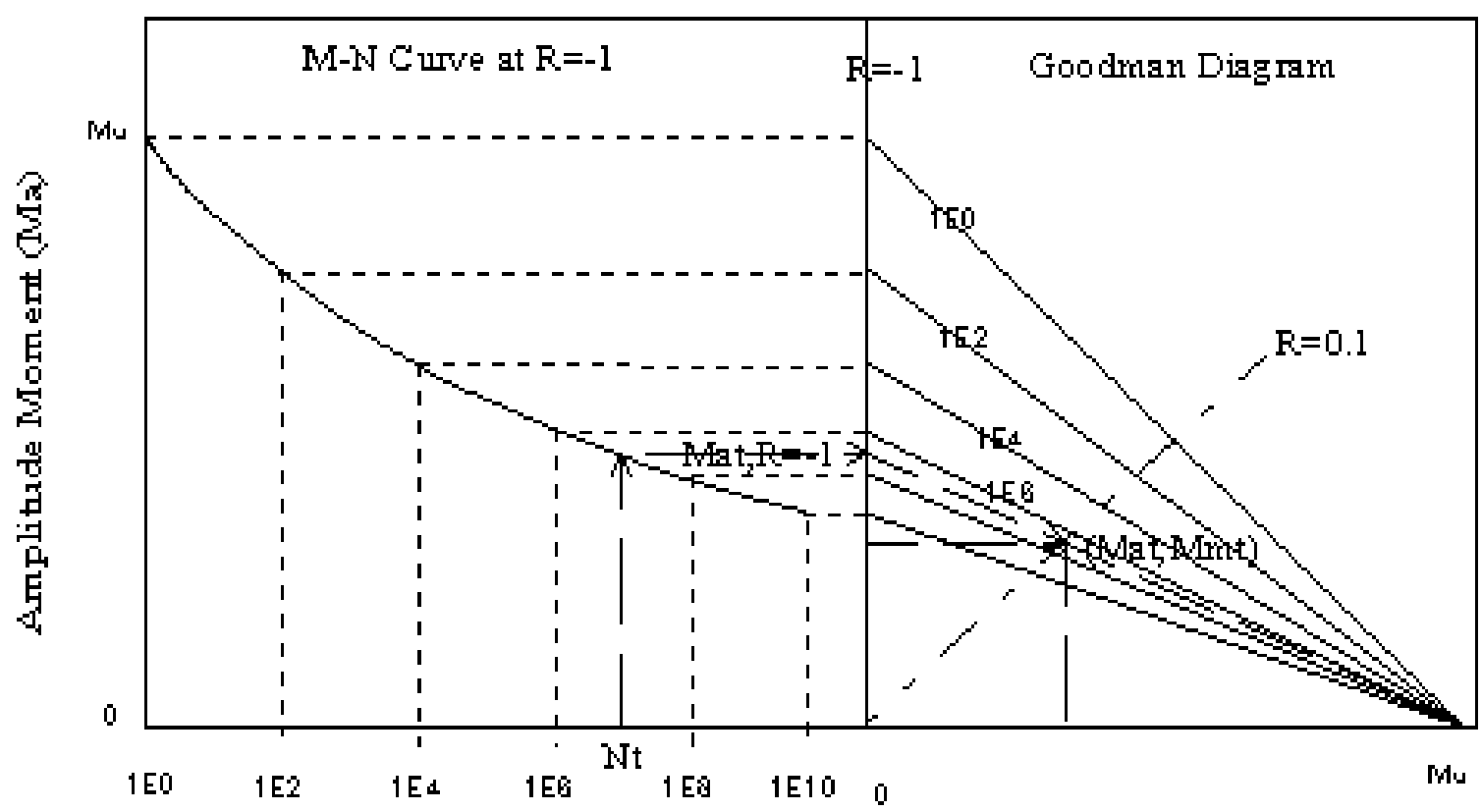

Number of Cycles (N)

Mean Moment (Mrn)

Figure 5.5 Derivation of equivalent-damage test load

From Equation 5-2,

$$
\mathrm{Ma}_{\mathrm{t}, \mathrm{R}=-1}=\mathrm{Mu} \times \mathrm{N}_{\mathrm{t}}{ }^{(-1 / \mathrm{m})} \text {. }
$$

Again setting the slopes equal,

$$
\frac{\mathrm{Ma}_{\mathrm{t}, \mathrm{R}=-1}}{\mathrm{Mu}}=\frac{\mathrm{Ma}_{\mathrm{t}}}{\mathrm{Mu}-\mathrm{Mm}_{\mathrm{t}}} .
$$

Defining the load ratio in terms of mean and amplitude moments,

$$
\mathrm{R}=\frac{\mathrm{M} \text { min,1cycle }}{\mathrm{M} \max , 1 \text { cycle }}=\frac{\mathrm{Mm}-\mathrm{Ma}}{\mathrm{Mm}+\mathrm{Ma}}
$$

Mmin,1 cycle Minimum moment in one load cycle Mmax,1cycle Maximum moment in one load cycle

From Equation 5-11, the mean test moment is,

$$
\mathrm{Mm}_{\mathrm{t}}=\mathrm{Ma}_{\mathrm{t}}\left(\frac{1+\mathrm{R}_{\mathrm{t}}}{1-\mathrm{R}_{\mathrm{t}}}\right)
$$

Combining Equations 5-10 and 5-12 and solving for $\mathrm{Ma}_{\mathrm{t}}$. 


$$
\mathrm{Ma}_{\mathrm{t}}=\frac{\mathrm{Mu}}{\frac{\mathrm{Mu}}{M \mathrm{a}_{\mathrm{t}, \mathrm{R}=-1}}+\left(\frac{1+\mathrm{R}_{\mathrm{t}}}{1-\mathrm{R}_{\mathrm{t}}}\right)}
$$

Plugging Equation 5-9 into 5-13 gives $\mathrm{Ma}_{\mathrm{t}}$ in terms of $\mathrm{N}_{\mathrm{t}}, \mathrm{Mu}$, and $\mathrm{R}_{\mathrm{t}}$.

$$
\mathrm{Ma}_{\mathrm{t}}=\frac{\mathrm{Mu}}{\mathrm{N}_{\mathrm{t}}{ }^{1 / \mathrm{m}}+\frac{1+\mathrm{R}_{\mathrm{t}}}{1-\mathrm{R}_{\mathrm{t}}}}
$$

Adding Equation 5-8 into 5-14 gives $\mathrm{Ma}_{\mathrm{t}}$ in terms of $\mathrm{D}_{\text {total }}, \mathrm{n}_{\mathrm{t}}, \mathrm{Mu}$, and $\mathrm{R}_{\mathrm{t}}$.

$$
\mathrm{Ma}_{\mathrm{t}}=\frac{\mathrm{Mu}}{\left(\frac{\mathrm{n}_{\mathrm{t}}}{\mathrm{D}_{\text {total }}}\right)^{(1 / \mathrm{m})}+\frac{1+\mathrm{R}_{\mathrm{t}}}{1-\mathrm{R}_{\mathrm{t}}}}
$$

The mean and the amplitude of the test load can now be calculated for any test load ratio, number of test cycles, and defined M-N curve using Equations 5-12 and 5-15.

The next step was to apply an interpolation routine to find the optimum test load ratio that minimized the sensitivity of the test loads to the family of M-N curves. A macro was written using Microsoft Excel's solver, which varied $R_{t}$ to find the minimum range in maximum test loads $\left(\mathrm{Ma}_{t}+\mathrm{Mm}_{t}\right)$. In other words, for any given $\mathrm{R}_{t}$, there are 12 calculated test loads that correspond to the $12 \mathrm{M}-\mathrm{N}$ curves shown in Figure 5.1. The solver finds the $R_{t}$ where the spread in the 12 test loads is at a minimum.

\subsubsection{Application to NedWind 25 Blade}

The above steps were done at blade stations 4--10 given in Table 5.1 for both flap and edge bending. Note that stations 1--3 are spanwise locations from the center of rotation to the root flange and are not relevant to this analysis.

To illustrate the method, the NedWind 25 load spectrum data are shown in Figures 5.6 and 5.7 at blade station 5 for both flap and edge moments. Blade station 5 is at 2.65 meters from the center of rotation. The 100 design load cases are presented as open, square symbols. Figures 5.6 and 5.7 also show the calculated equivalent-damage Goodman diagram curves for blade station 5 in flap and edge directions. There are 12 equivalent damage curves that correspond to the family of M-N curves for $3 \times 10^{6}$ test cycles. The Figure 5.5 example shows how each curve was generated. Because the NedWind 25 load spectrum was applied to 12 unique M-N curves, there were 12 different fatigue damage totals. So, each Goodman curve in Figures 5.6 and 5.7 shows the mean and amplitude test moments that will give the equivalent damage for the corresponding M-N curve at $3 \times 10^{6}$ test cycles. In other words, any point along each Goodman curve gives the same damage total for $3 \times 10^{6}$ test cycles as any other point on the same curve, but a different damage total from any point on any other curve. 


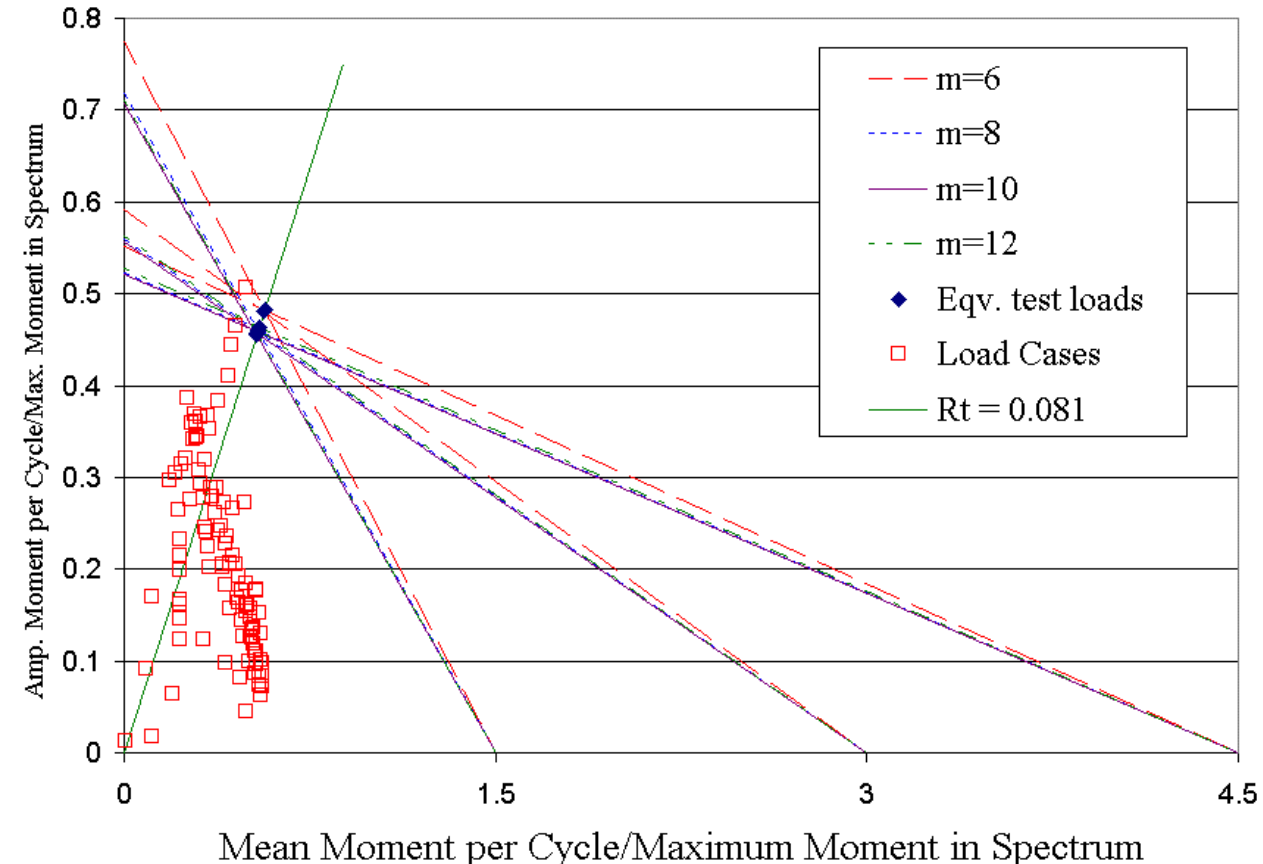

Figure 5.6 Blade position \#5 flap loads and equivalent test loads at $\mathbf{R}_{t}=\mathbf{0 . 0 8 1}$

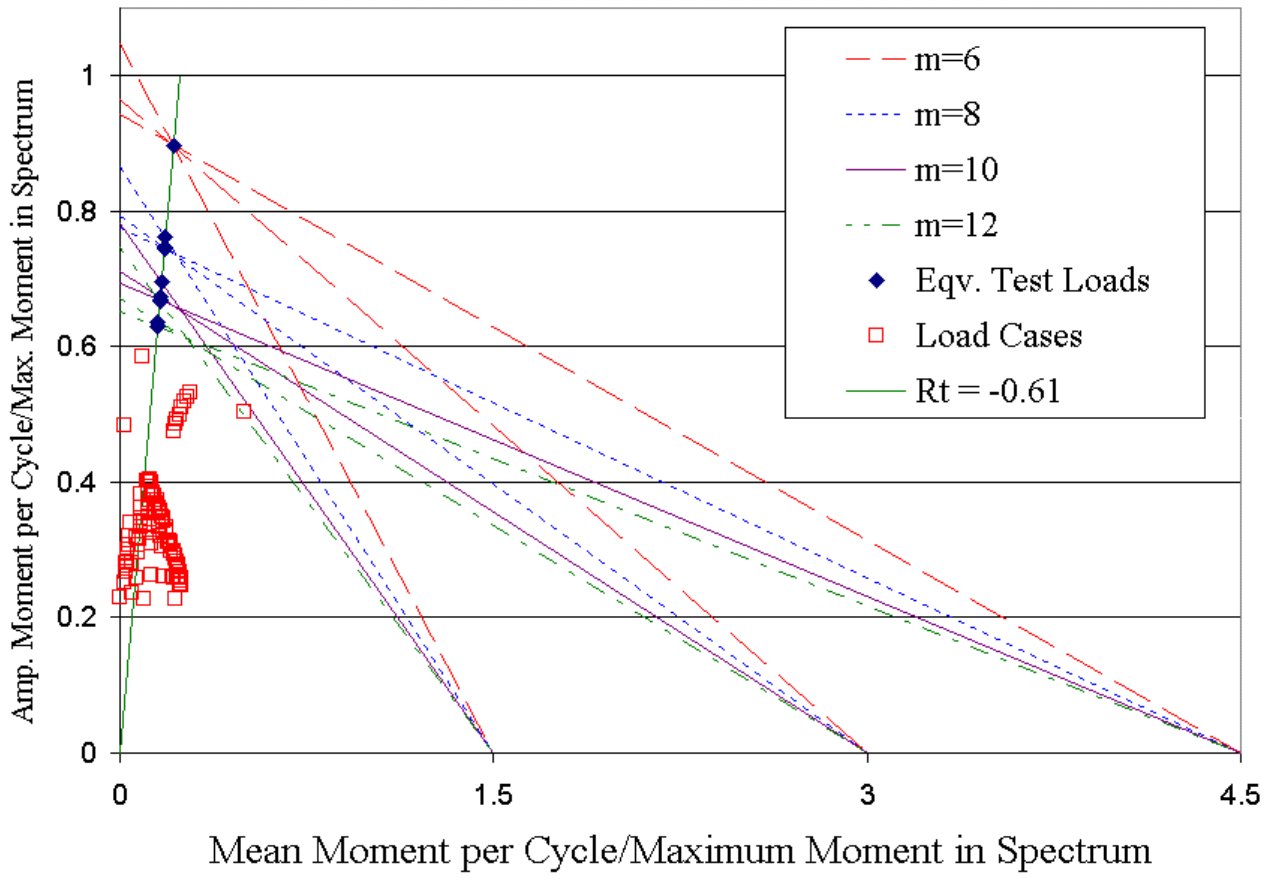

Figure 5.7 Blade position \#5 edge loads and equivalent test loads at $R_{t}=0.61$

Note the mean and amplitude moments in Figures 5.6 and 5.7 have again been normalized to the maximum moment in the load spectrum.

Figures 5.6 and 5.7 also show the optimized test load ratio $\left(R_{t}\right)$ line. Graphically, this radial line intersects the 12 equivalent-damage test load curves at the point of minimum scatter. These intersections 
are shown as closed-diamond symbols. These figures also show that there is clearly an optimum $\mathrm{R}_{\mathrm{t}}$ where possible errors in $\mathrm{S}-\mathrm{N}$ slopes are minimized. Conversely, it also shows how great the potential errors can be if $R_{t}$ is arbitrarily selected. For example, if a non-optimum $R_{t}$ was selected in Figure 5.6, at say $R=0.5$, and the $\mathrm{S}-\mathrm{N}$ curve was not accurately known, a very wide range of possible test loads will be given.

For the NedWind 25 spectrum, the scatter across the equivalent damage test loads at the $R_{t}$ is especially tight in the flap direction. This indicates that at the optimum $R_{t}$ of 0.081 , the errors associated with choosing the wrong M-N slope are minimized. For the edge loads in Figure 5.7, the scatter is lowest at $R_{t}$ $=-0.61$, but a wider scatter band is indicated. The figures also show that the optimized $\mathrm{R}_{\mathrm{t}}$ approximately passes through the centroid of data points representing the load ratios of the individual load cases in the spectrum. Intuitively, it makes sense that the optimum $\mathrm{R}_{\mathrm{t}}$ would correspond with the load spectrum data.

The final SMT program test loads at each station were taken from the maximum of the three remaining M-N curves corresponding to S-N slopes of $m=10$ at the optimized $R_{t}$. To remain consistent with the original design, all the partners applied this constraint. Therefore, all the optimized $R_{t}$ values were determined at an M-N slope of 10. In the flap direction, the difference in possible test loads was insignificant for the NedWind 25 load spectrum because the scatter was so close. For the edge loads, it can be seen from Figure 5.7 that if just the $m=10$ curves are considered, the edge scatter significantly improves because the optimum $\mathrm{R}_{\mathrm{t}}$ value shifts slightly to the right and any deviations with ultimate moment can also be ignored.

For the unconstrained case, when the full range of slopes are included, the greater scatter at the optimum $\mathrm{R}_{\mathrm{t}}$ would suggest slightly higher edge moments, leaving the final loads open to some interpretation. The final load would depend on how conservative the test needed to be and how much confidence the designer had in the fatigue formulation. Because many wind turbine blades have structural details with unknown or poorly understood material properties, or structural details with poorly performing properties, the higher loads corresponding to $\mathrm{m}=6$ would be recommended.

Station 5 loads were chosen to illustrate the method in Figures 5.6 and 5.7 because it represents one of the most critical sections of the blade. However, the same analysis was performed for all relevant blade sections (Blade positions 4 through 10 from Table 5.1) to obtain the spanwise fatigue load distribution. These results are given in Section 5.5.3.

During the development of the single-axis test plan, this method had not been matured and tested sufficiently to apply to this test. It was used only for the two-axis loads. However, subsequent checks against the method that was used show nearly perfect agreement.

\subsection{Single-axis Fatigue Test}

\subsubsection{Introduction}

The single-axis test is the simplest and fastest of the fatigue test methods used at NREL. It requires a single actuator for testing both flap and edge directions at the same time. The disadvantages are the greater inaccuracy in matching the blade damage or operating load characteristics of the test to the design loads or theoretical design damage. Single-axis loading requires the flap and edge load components to be applied in-phase at a fixed load angle over the load cycle. These constraints result in a resultant load vector that can exceed the design stresses at certain locations around the blade section, while at other locations on the section the blade may be under-stressed. Single-axis testing also requires that the flap 
and edge components be applied at the same load amplitude ratio $\left(\mathrm{R}_{\mathrm{t}}\right)$, which prevents the flap and edge loads from being optimized for the design spectrum as described in Section 5.3.

\subsubsection{Single-axis Test Description}

Figure 5.8 shows a photo of the single-axis fatigue test in operation. The test blade for the single-axis test was Blade \#67. NREL chose to reduce the design spectrum to 3 million constant-amplitude cycles with a load amplitude ratio $\left(\mathrm{R}_{\mathrm{t}}\right)$ of -0.1 . The test loads were developed by matching the damage caused by the 20 -year design-load spectrum to the damage resulting for the test load for the design S-N slope of $\mathrm{m}=10$ for the composite material. Because the single-axis test constraints require that both load components be applied at the same $R_{t}$, an $R_{t}=-0.1$ was used.

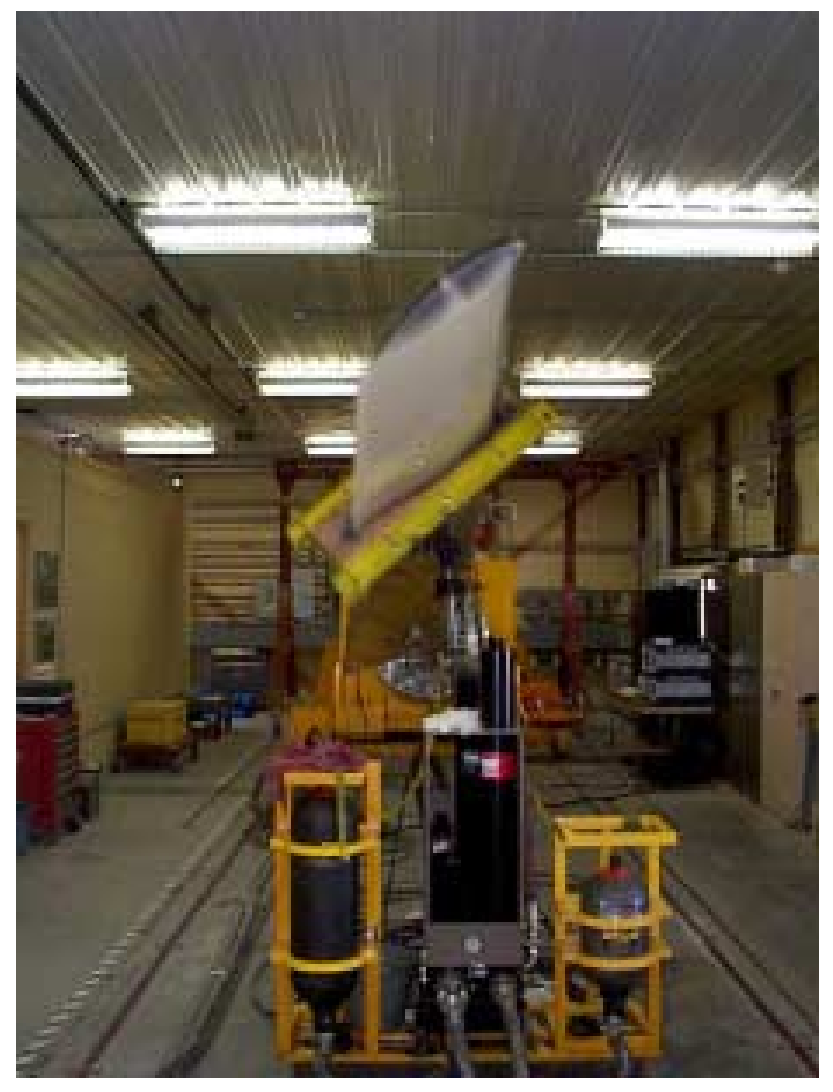

Figure 5.8 Blade \#67 Single-Axis Fatigue Test In NREL Building 252

\subsubsection{Single-axis Fatigue Loads}

The spreadsheet summarizing the single-axis fatigue test load is shown in Appendix B and is labeled "FatigueScott.xls." A $\mathrm{R}_{\mathrm{t}}$ of -0.1 was chosen for both axes. This $\mathrm{R}_{\mathrm{t}}$ was chosen using a sensitivity analysis to the optimum value for the combined edge and flap axis. The sensitivity analysis varied the strain/load ratios and damage values to determine the $\mathrm{R}_{\mathrm{t}}$ that resulted in the least variation in test loads. Figure 5.9 shows the maximum-damage equivalent edge (Mxmax) and flap (Mymax) spanwise moment distribution from the FatigueScott.xls spreadsheet. We chose the load-application point at $8.65 \mathrm{~m}$ to best match the distribution of equivalent moments. The test load linear-moment distribution (load application at $8.65 \mathrm{~m}$ ) 
and the $100 \%$ static-test load (load application at $7.65 \mathrm{~m}$ ) are shown for comparison. The edge load was chosen to match the moment (Mxmax) at point 4, the pinhole connection. This over-tested the majority of the blade span for edgewise loading. The flap load was chosen to match the moment (Mymax) at point 5 , the first true airfoil section. This position allowed the distribution to match region outboard of the root section and over-test the furthest inboard section where the most complex geometric changes are present.
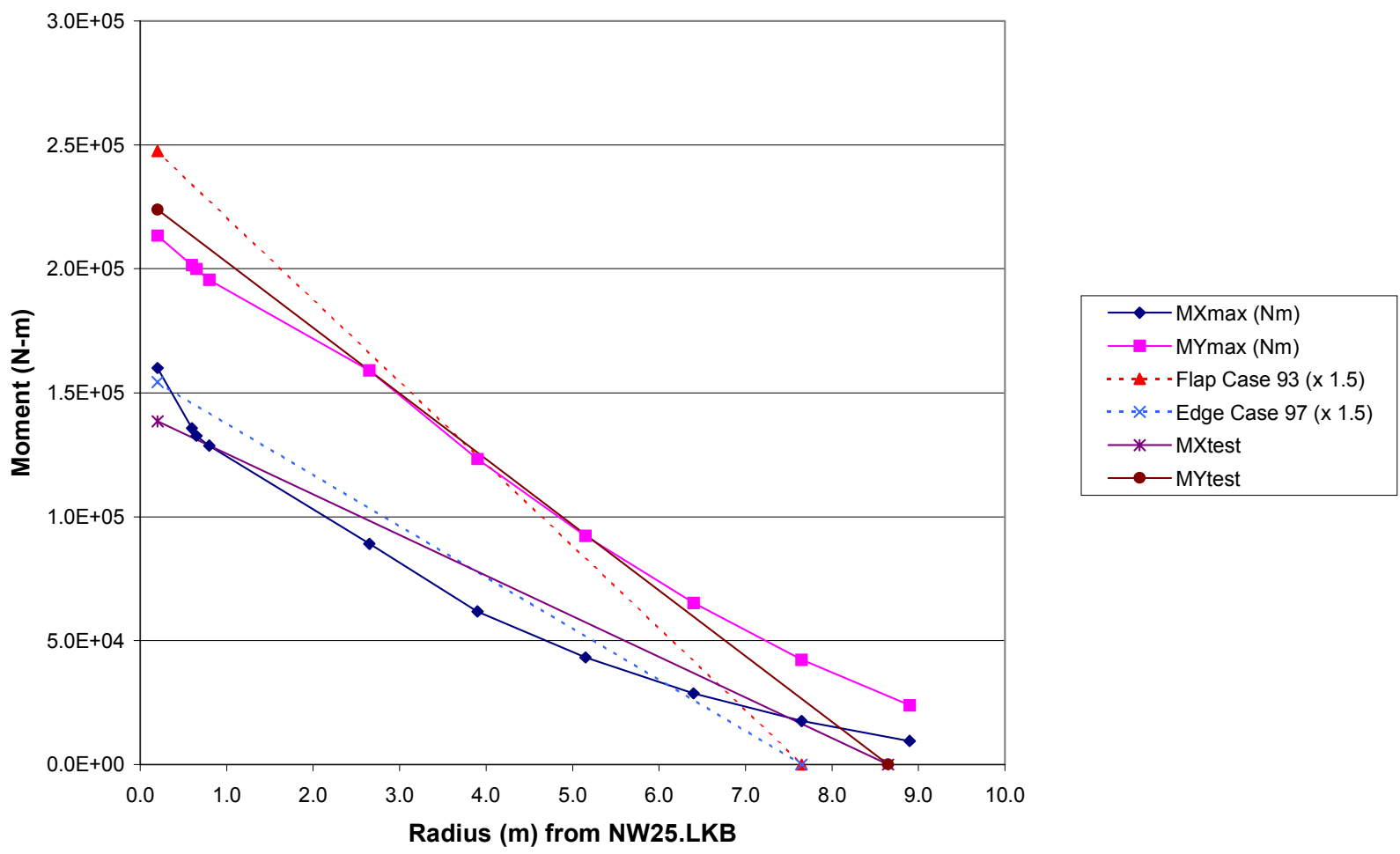

Figure 5.9 Moment distribution of single-axis fatigue test including optimum damage-equivalent moments, fatigue-test moments, and $100 \%$ static-test moments

Table 5.6 lists the single-axis fatigue-test moments used for the flap and edge directions.

Table 5.6 Single-axis Fatigue-Test Moments

\begin{tabular}{lllll}
\hline $\begin{array}{l}\text { Load } \\
\text { Direction }\end{array}$ & $\begin{array}{l}\text { NW25.LKB Position to } \\
\text { Match }\end{array}$ & $\begin{array}{l}\text { DEL Moment } \\
(\max .)\end{array}$ & Test Load at 8.65 m & $\mathrm{R}_{\mathrm{t}}$ \\
\hline Edge & $4(0.8 \mathrm{~m})$ & $151615 \mathrm{Nm}$ & $19314 \mathrm{~N}$ & -0.10 \\
Flap & $5(2.65 \mathrm{~m})$ & $140088 \mathrm{Nm}$ & $23348 \mathrm{~N}$ & same \\
\hline
\end{tabular}

The nomenclature to describe the resultant test load is presented in Figure 5.10. Typical for single-axis tests, there was initial concern that the high resultant forces from the combined in-phase loading might cause buckling in the suction side leading-edge panel. However, NREL became comfortable within the first few thousand cycles because non-linear behavior was not observed. The angle $\theta$ represents the tip chord angle for a vertical load application. The angle $\psi$ represents the angle the resultant load makes with 
respect to the tip chord. Figure 5.11 shows the test load, normalized to maximum resultant moment, over the fatigue cycle.

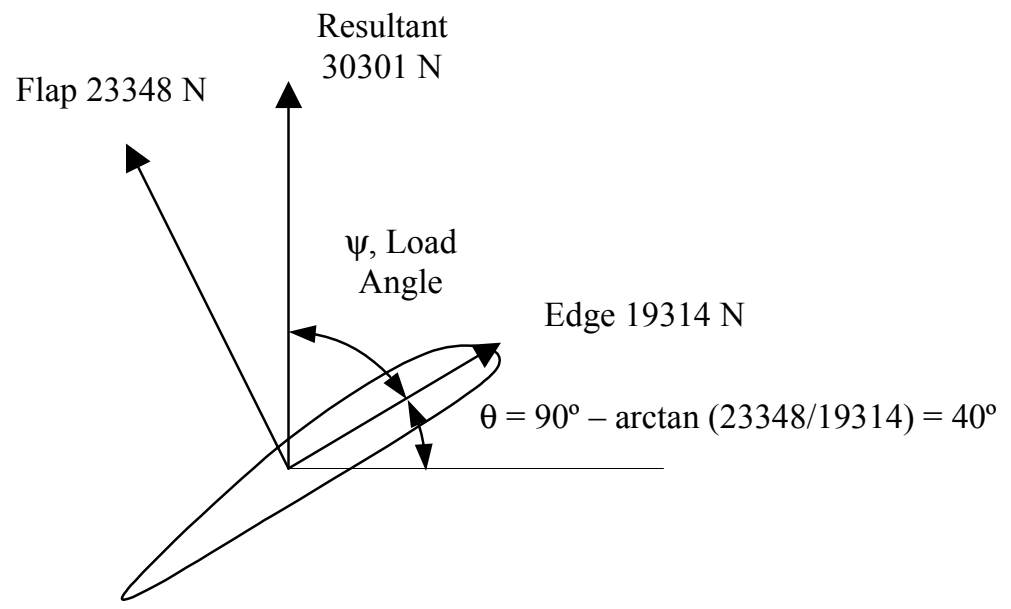

Figure 5.10 Resultant single-axis fatigue test load--looking at tip chord

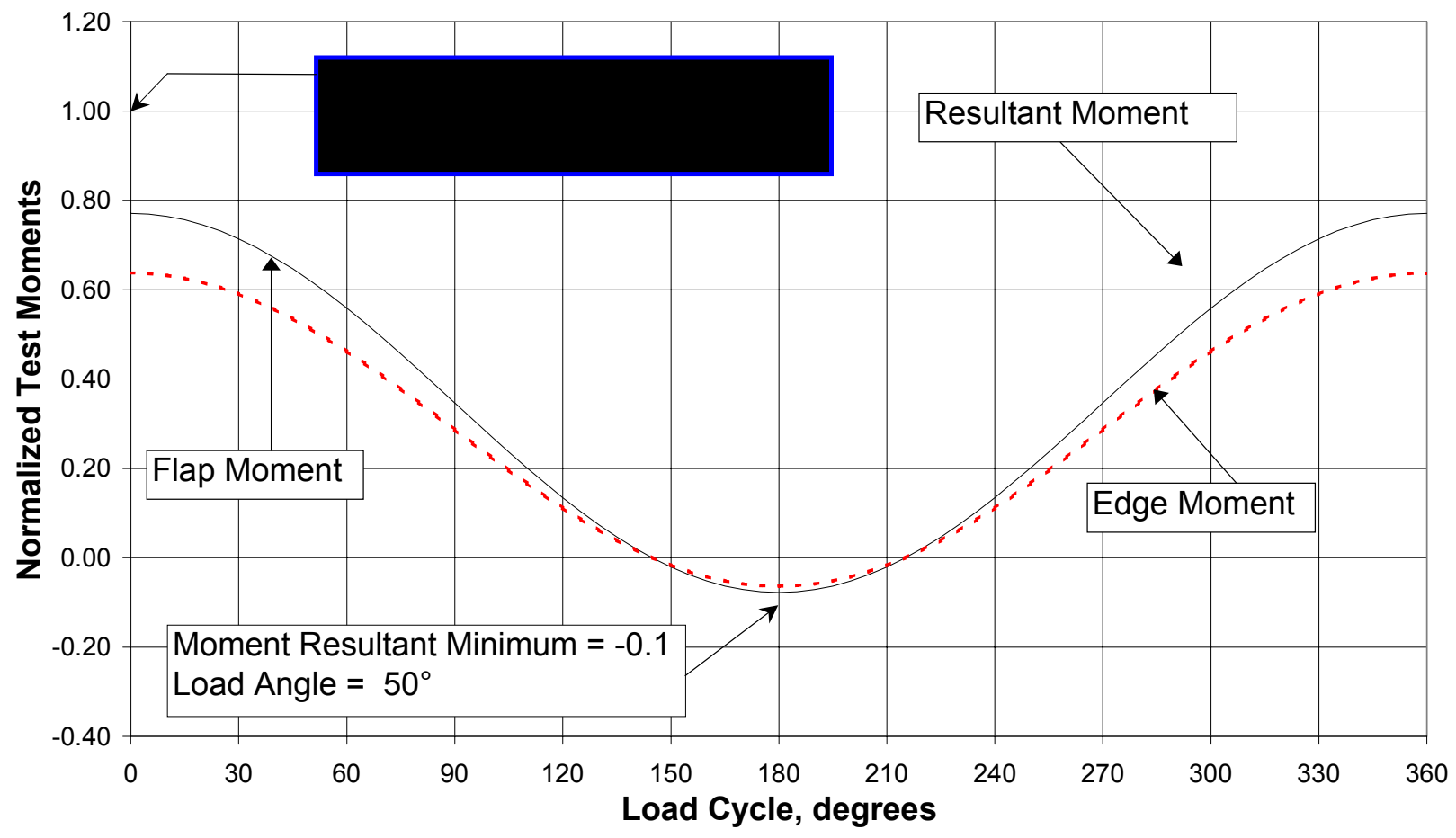

Figure 5.11 Single-axis test normalized bending moment

Blade tare and fixture tare weights were also added. The tare weight of the blade mass from load application point $(8.65 \mathrm{~m})$ to the maximum chord position $(3.15 \mathrm{~m})$ was added to the fatigue-test load. This was done to force the bending moment at the maximum chord to zero for zero applied test load as in the static tests. Table 5.7 below shows the mass moment distribution. The mass moment at $8.65 \mathrm{~m}$ was 
interpolated between the $8900-\mathrm{mm}$ and $7651-\mathrm{mm}$ positions. The blade tare weight was determined to be $1783 \mathrm{~N}(401 \mathrm{lb})$. Added to this was the fixture weight above the hydraulic actuator, including the blade saddle at $930 \mathrm{~N}(209 \mathrm{lb})$.

Table 5.7 Mass Distribution for Fatigue Test Weight Tare

\begin{tabular}{ll}
\hline Position (mm) & $\begin{array}{l}\text { Mass Moment } \\
(\mathrm{N}-\mathrm{mm})\end{array}$ \\
\hline 8900 & $2.335 \mathrm{E} 06$ \\
$8650^{*}$ & $1.440 \mathrm{E} 06^{*}$ \\
7651 & $2.335 \mathrm{E} 06$ \\
3151 & $11.243 \mathrm{E} 06$ \\
\hline & *Interpolated \\
& Source: $[10]$
\end{tabular}

The actuator was aligned such that the resultant load went through the elastic center of the chord, assumed at $40 \%$ in order to minimize the introduction of torsional moments.

The test load cycle frequency was fixed at $1.5 \mathrm{~Hz}$; however, the controller was having trouble keeping up with the command signal because the blade tip was exhibiting its own independent vibration mode at this speed. We were also concerned about the possibility of the blade tip hitting the relatively low ceiling if an unstable control anomaly were encountered. We decided to cut off the outer two meters of the blade to remedy these concerns. With the tip removed, we were able to maintain $1.5 \mathrm{~Hz}$ with stable control.

\subsubsection{Instrumentation and Equipment}

\subsubsection{Load Apparatus}

\subsection{Load Attachment}

The load attachment for the single-axis fatigue test was made at the 8.65-meter station, and the tip chord angle was rotated to nominally achieve a tip chord angle of $40^{\circ}$. This angle was constrained by the 24hole ( $15^{\circ}$ increments) bolt pattern of the test stand adapter and the root flange pattern of the NedWind 25 blade, so that the angle at the load attachment was at $41.7^{\circ}$. With the difference in twist, this resulted in a tip chord angle of $45.8^{\circ}$. Therefore, the load actuator was tilted $5.8^{\circ}$ from the vertical.

\subsection{Load Saddle}

The steel load saddle frame used for the static tests was also used for the fatigue tests. A separate wood insert sized for the airfoil at the 8.65-meter station was constructed for the fatigue tests. The load attachment was positioned such that the load actuator would act through the elastic axis (assumed at $40 \%$ chord) of the blade, thus minimizing torsional deflection. With the saddle thickness, and angle of the load saddle and hydraulic actuator taken into account, this placed the actuator attachment at $67 \%$ of chord on the lower edge of the saddle.

\subsection{Test Stand and Root Fixing}

The test stand was the same as the one used in the pre-fatigue static tests in Building 252. The tilt was set to the maximum value of $8.7^{\circ}$. Table 5.8 gives the torque specifications used for fastening the NedWind 25 blade to the test stand and for tightening the radial blade root sleeve bolts. The root sleeve attachment is shown in Figure 5.12. 
TP-500-29103

Table 5.8 NedWind 25 Test Blade Torque Specifications

\begin{tabular}{lllll}
\hline Bolted Connection & $\begin{array}{l}\text { Fastener } \\
\text { Designation }\end{array}$ & Property Class & $\begin{array}{l}\text { Lubrication } \\
\text { Specification }\end{array}$ & $\begin{array}{l}\text { Torque } \\
\text { Specification }\end{array}$ \\
\hline Test Stand to Adapter Plate & M24 & 10.9 & Anti-Seize & $800 \mathrm{~N}-\mathrm{m}$ \\
Adapter Plate to Blade Root & M24 & 10.9 & Anti-Seize & $800 \mathrm{~N}-\mathrm{m}$ \\
Root Sleeve (radial bolts) & M24 & As received & As received & $300 \mathrm{~N}-\mathrm{m}$ \\
\hline
\end{tabular}

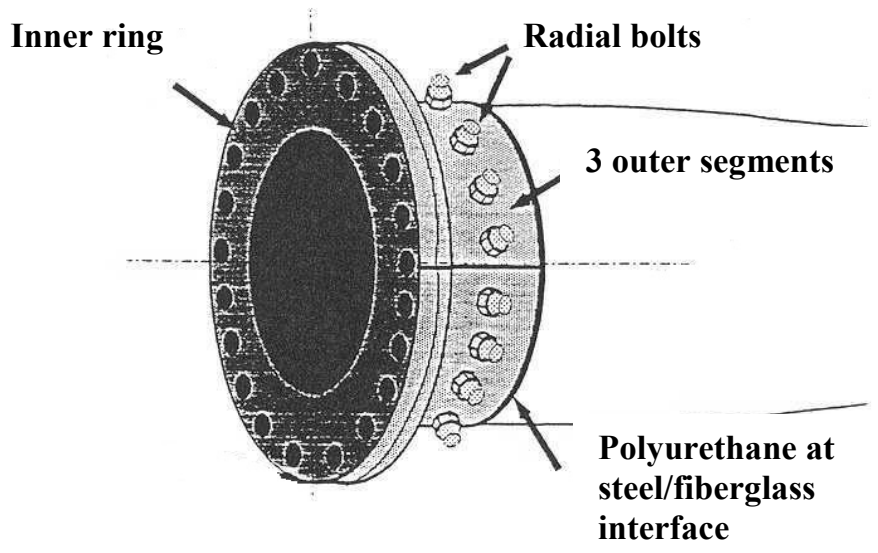

Figure 5.12 Blade root detail

\subsubsection{Hydraulic System}

Test loads were controlled with an MTS ${ }^{\circledR} 458$ analog servo-hydraulic controller and an MTS® T/RAC digital program controller. A 762-mm (30-in.) stroke, 46,260-N (10,400-lb) capacity actuator was used to apply the loads. This was the same actuator used in the static testing.

\subsubsection{Strain Gauges}

At the time of the single-axis test the data acquisition system was limited to 36 channels. The edge statictest gauge setup was used (see Table 4.7) because of a higher number of gauges near the leading and trailing edges. We felt that this gauge distribution was best for monitoring possible non-linear behavior near the leading edge.

\subsubsection{Data Acquisition System}

BSTRAIN was used for data acquisition. The data acquisition hardware setup for the single-axis fatigue setup was the same as the static tests, except that the input filter frequency was changed from 4 to $10 \mathrm{kHz}$. Data sampling frequency was set at $150 \mathrm{~Hz}$. For fatigue testing, the data collection algorithm uses a custom peak-valley routine that preserves the sequence of the extrema, provides auto-zero strain-gauge function, and monitors blade stiffness at frequent intervals. This software is described fully in Reference [15]. 


\subsubsection{System Calibration}

Prior to testing, the MTS ${ }^{\circledR}$ representative calibrated the hydraulic-actuator load cell and LVDT to the MTS® system controller. Strain-gauge data acquisition calibrations were made through shunt calibrations; end-to-end reference voltage checks were also performed.

\subsubsection{Single-Axis Fatigue Results}

\subsubsection{Visual Damage}

NREL observed two areas of visual blade damage during the test. The first was a crack that developed at the polyurethane joint interface at the root flange assembly. The crack eventually propagated around the root circular section. Although this crack did not appear to have immediate structural significance, it would allow moisture intrusion in the field, resulting in a probable functional failure.

The second damaged area was a crack inboard of the maximum chord on the trailing edge. The crack began at approximately $205 \mathrm{~cm}$ from the root flange and extended outboard to $215 \mathrm{~cm}$. This is the portion of the span where the blade transitions from an airfoil to a circular root section. The crack began forming at approximately 20,000 cycles and was very audible as it grew to about $100 \mathrm{~mm}$ in length over a short period of time. After that, the crack did not noticeably grow during the remainder of the test. This crack seemed to develop due to local stresses caused by the complex curvature of the high-pressure airfoil surface trying to straighten under positive load.

\subsubsection{Root Sleeve Bolt Tension}

Using a torque wrench, bolt pretension on the radial root bolts (see Figure 5.12) was checked under a schedule prescribed by the SMT project. The blade root bolts between the steel sleeve and GRP were torqued to $300 \mathrm{~N}-\mathrm{m}$ and were checked after $0.2 \%, 2.0 \%, 20 \%, 40 \%, 60 \%$, and $80 \%$ of the maximum number of cycles during the fatigue tests. In terms of the NREL test parameters of 3,000,000 cycles, these intervals equated to $6,000,60,000,600,000,1,200,000,1,800,000$, and 2,400,000 cycles. Slight loosening was noted on one bolt (out of 21 ) at $2 \%$ and $20 \%$ test period checks. This bolt was located on the suction side by the trailing edge.

\subsubsection{Strain-Gauge Data}

\subsection{Analysis Methods}

Data files of 15,000 rows or 7500 cycles were acquired during the fatigue test. These individual channels were concatenated into a single file of approximately 6 million points (peak and valley) for the entire test. These data files included spurious points that surrounded test starts and stops along with points around the stiffness checks. These points were removed and the remaining data were reduced to approximately 10,000 points by averaging sequential blocks of 300 peaks and valleys. These data are presented in Appendix E for each channel. Two-axis data are also included in this appendix for comparison.

\subsection{Strain-Gauge Results}

Some strain-gauge channels failed during the test. See Figure E.16.2 in Appendix E for an example. In all cases, the replacement gauge failed again. NREL concluded this was due to locally high strains in the laminate and gauge grid-area and not a fatigue failure of the gauge caused by high blade strains. No visible signs of damage could be seen on the blade at these gauge locations. 
Figure 5.13 shows the global stiffness of the blade over the test period. The global blade stiffness can be an indication of blade failure. As much as a $10 \%$ loss in stiffness has been observed in previous tests prior to failure [4]. No significant change in test stiffness was noted during the test. In fact, based on the static-test data for the pre- and post-fatigue tests, the blade's stiffness appeared to increase during the fatigue testing. This is not easy to observe from the data shown in Figure 5.13, but is more obvious in Figures 4.3 through 4.6, which show reduced strain sensitivity for most gauge locations in the postfatigue static test as compared to the pre-fatigue static test, especially in the flap direction. For Blade \#66, this effect was not noticeable in the edge direction but it was observed in Blade \#67 in both flap and edge. This phenomenon could not be explained by load sensor error. Both blades exhibited the same behavior but were tested at different times and in different laboratories. Load cell calibrations were double-checked to rule out obvious sensor errors. For Blade \#66, the load cell used for the post-fatigue test was different than the one used for Blade \#67, yet the same result was observed. Additional evidence gleaned from the displacement plots also suggests that the stiffening effect was real. The displacement sensors for both tests show that for the same displacement, the strains were lowered in the post-fatigue test in all cases.

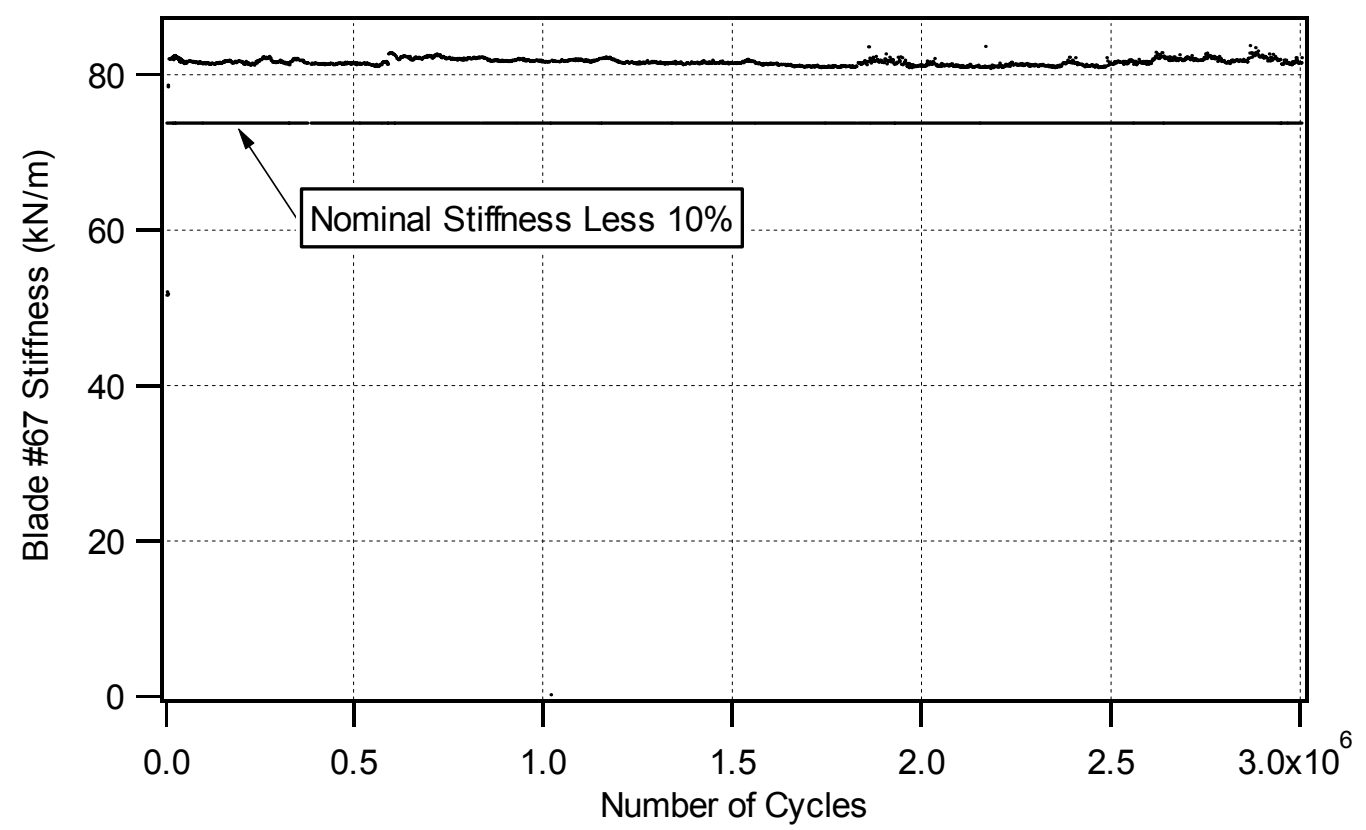

Figure 5.13 Blade \#67 global stiffness data for single-axis fatigue test

One possible explanation is that the blades may have stiffened slightly due to lower environmental humidity in Colorado. The blades originated in the Netherlands, where they had the opportunity to absorb ambient moisture for several years before being shipped to NREL. The pre-fatigue static tests were done early in the program; however, the post-fatigue tests were not done for several months after. The strength gained due to the drying of the laminates in the Colorado climate may have been enough to offset and overshadow any stiffness losses encountered during the test.

\subsubsection{Acoustic Emissions}

Although this is not a standard practice for all blades tested, Sandia National Laboratories is often invited by NREL to perform nondestructive tests on certain blades if it is of mutual benefit to the laboratories and the blade client. An acoustic emissions test was conducted in parallel with the SMT fatigue and static testing of Blade \#67 by researchers at Sandia [23]. Sensors placed along the blade measured highfrequency emissions that may be related to incipient blade damage during the test. Preliminary results 
indicated high emissions around the observed root cracking and along the spar between stations 2500 and 4200 on the compressive surface. The trailing-edge crack was not detected because the sensors were not properly positioned to detect this damage. The spar damage will be verified if postmortem sectioning is conducted. A copy of the Sandia report for this work is attached in Appendix G.

\subsection{Two-axis Fatigue Test}

\subsubsection{Two-axis Test Introduction}

Two-axis testing is more complicated than single-axis testing because it requires considerably more equipment and a more complicated control strategy [2]. However, the test loading and the resulting damage are more realistic for at least two reasons. First, the load ratio $\mathrm{R}_{\mathrm{t}}$, described in Section 5.3, can be uniquely prescribed for each load axis. Second, the phase angle between flap and edge loads can be prescribed to match field conditions. Thus, the load angle given in Figure 5.16 varies over a load cycle as it would under normal operation. Two-axis testing is faster than testing edge and flap separately, and it is similar in required time to a single-axis, combined-load test.

\subsubsection{Two-axis Test Description}

NREL developed a two-axis testing capability in 1997. Figure 5.14 and 5.15 show the two-axis load configuration used to test Blade \#66. Figure 5.15 is a line drawing of the test hardware. NREL reduced the design spectrum to three million constant-amplitude cycles for the two-axis test, thus enabling a better direct comparison to the single-axis test loads and results. The test loads were developed by matching the 20 -year design load spectrum (100 load cases) to the damage resulting from the test load for the design $\mathrm{S}-\mathrm{N}$ slope of $\mathrm{m}=10$ for the composite material. The load amplitude ratios, $\mathrm{R}_{\mathrm{t}}$, were chosen to be at their optimum values of 0.081 and -0.61 for flap and edge, respectively. The phase angle between flap and edge load components was chosen to be $90^{\circ}$, with the positive edge (leading edge in compression) lagging the positive flap load (high-pressure surface in tension).

\subsubsection{Two-axis Fatigue Loads}

The simplified load spectrum method described in Section 5.3.2 was applied to the NedWind 25 blade at blade positions 4 through 10 from Table 5.1. These distributions are shown in Figures 5.16 and 5.17, with the solid-diamond symbols representing each blade position. For reference, position 4 is the furthest to the left. They also show the single-point linear distributions of fatigue loading applied to the blade during the test at NREL. For all cases the loads were applied to the blade at the $8.65-\mathrm{m}$ station using hydraulic actuators. The linear distributions were chosen to best match the optimized distributions under the following constraints. The test loads are listed in Table 5.9.

Table 5.9 Two-Axis Fatigue-Test Moments

\begin{tabular}{lllll}
\hline Load Direction & $\begin{array}{l}\text { NW25.LKB } \\
\text { Position to } \\
\text { Match }\end{array}$ & $\begin{array}{l}\text { DEL Moment } \\
\text { to Match } \\
\text { (max.) }\end{array}$ & $\begin{array}{l}\text { Test Load at } \\
8.65 \mathrm{~m}\end{array}$ & R-Ratio $\left(\mathrm{R}_{\mathrm{t})}\right.$ \\
\hline Edge & $4(0.8 \mathrm{~m})$ & $115,000 \mathrm{Nm}$ & $14,648 \mathrm{~N}$ & -0.55 \\
Flap & $5(2.65 \mathrm{~m})$ & $159,740 \mathrm{Nm}$ & $26,623 \mathrm{~N}$ & 0.062 \\
\hline
\end{tabular}




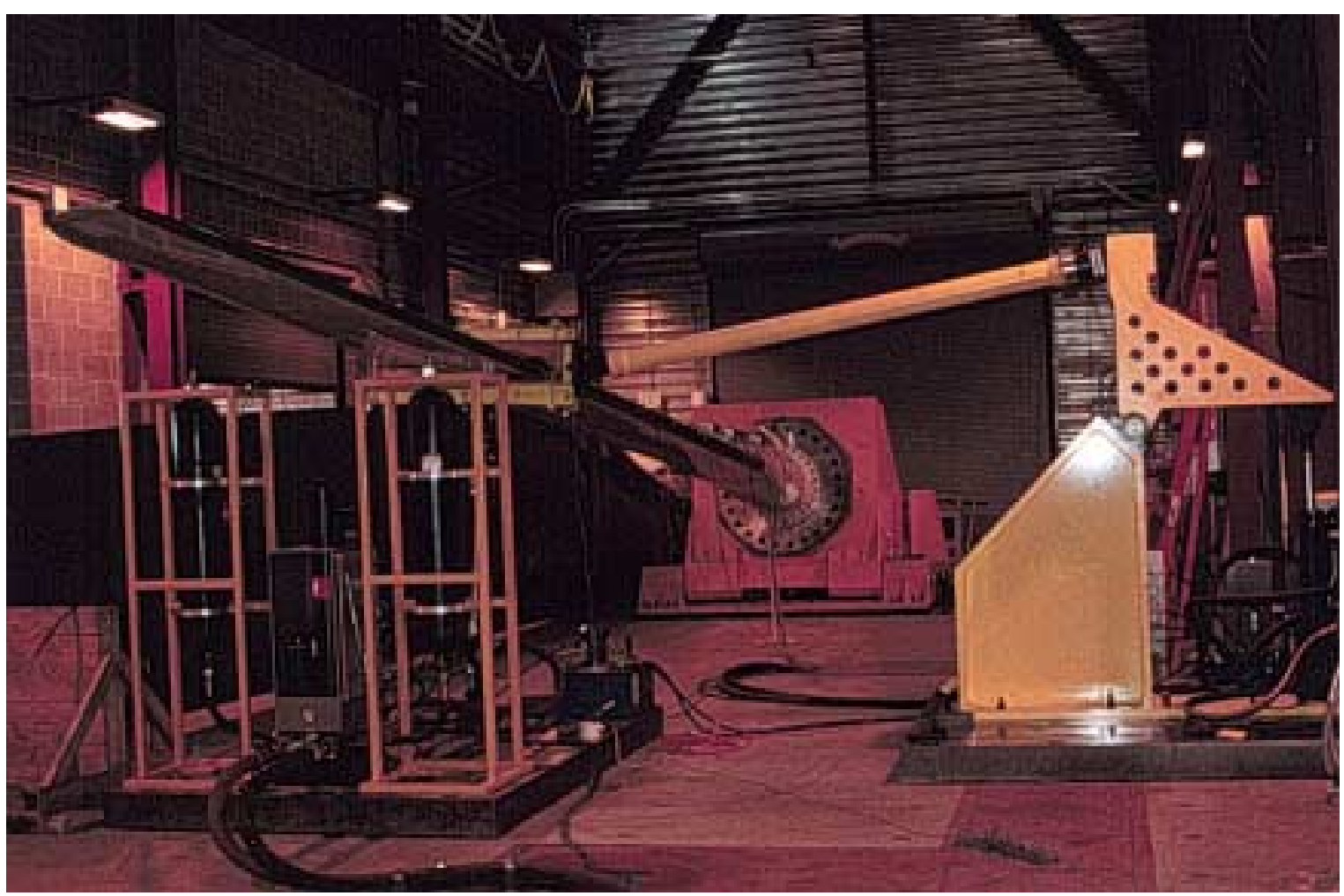

Figure 5.14 Blade \#66 two-axis fatigue test in NREL Building 254

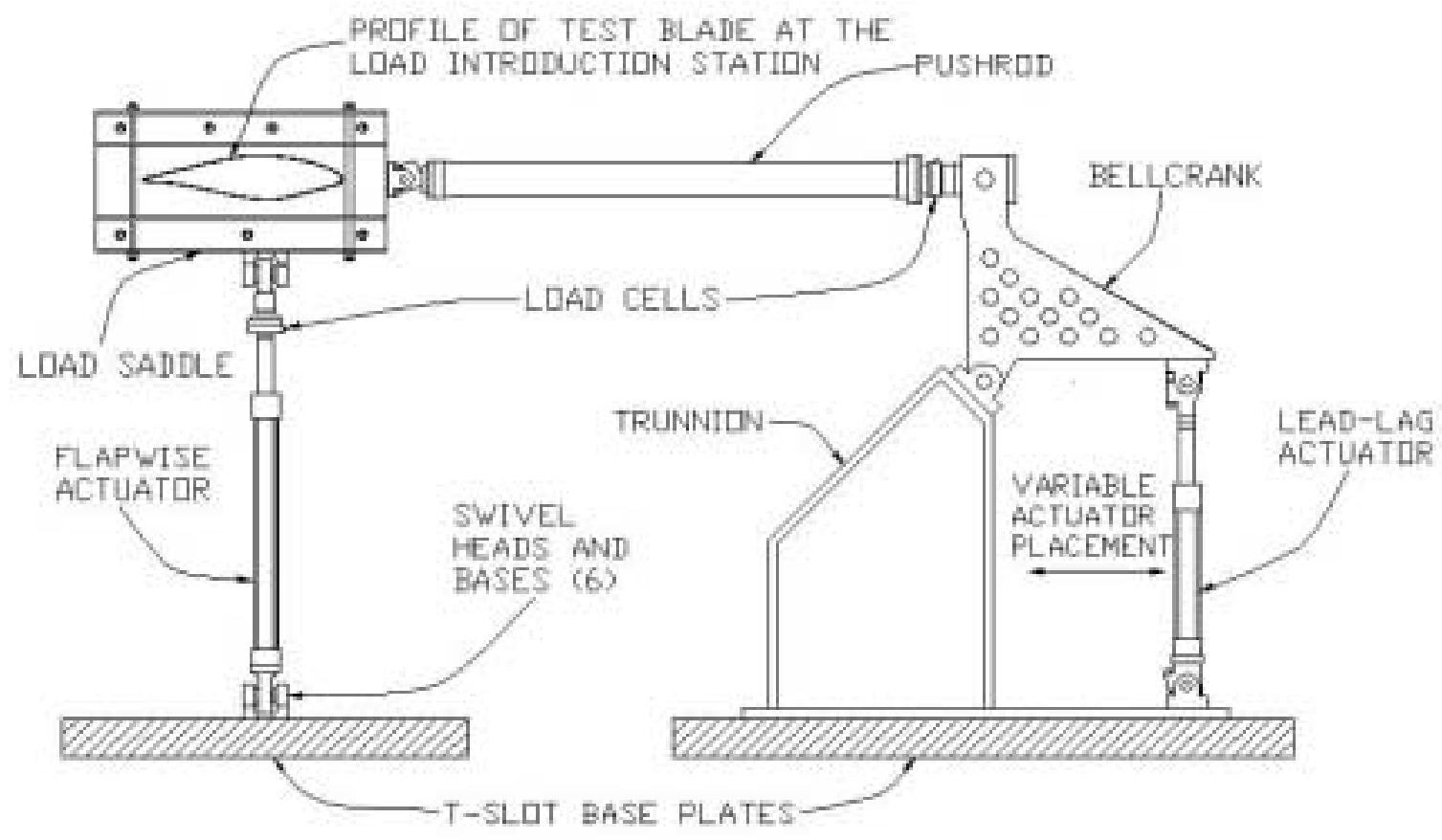

Figure 5.15 Two-axis fatigue hardware schematic 


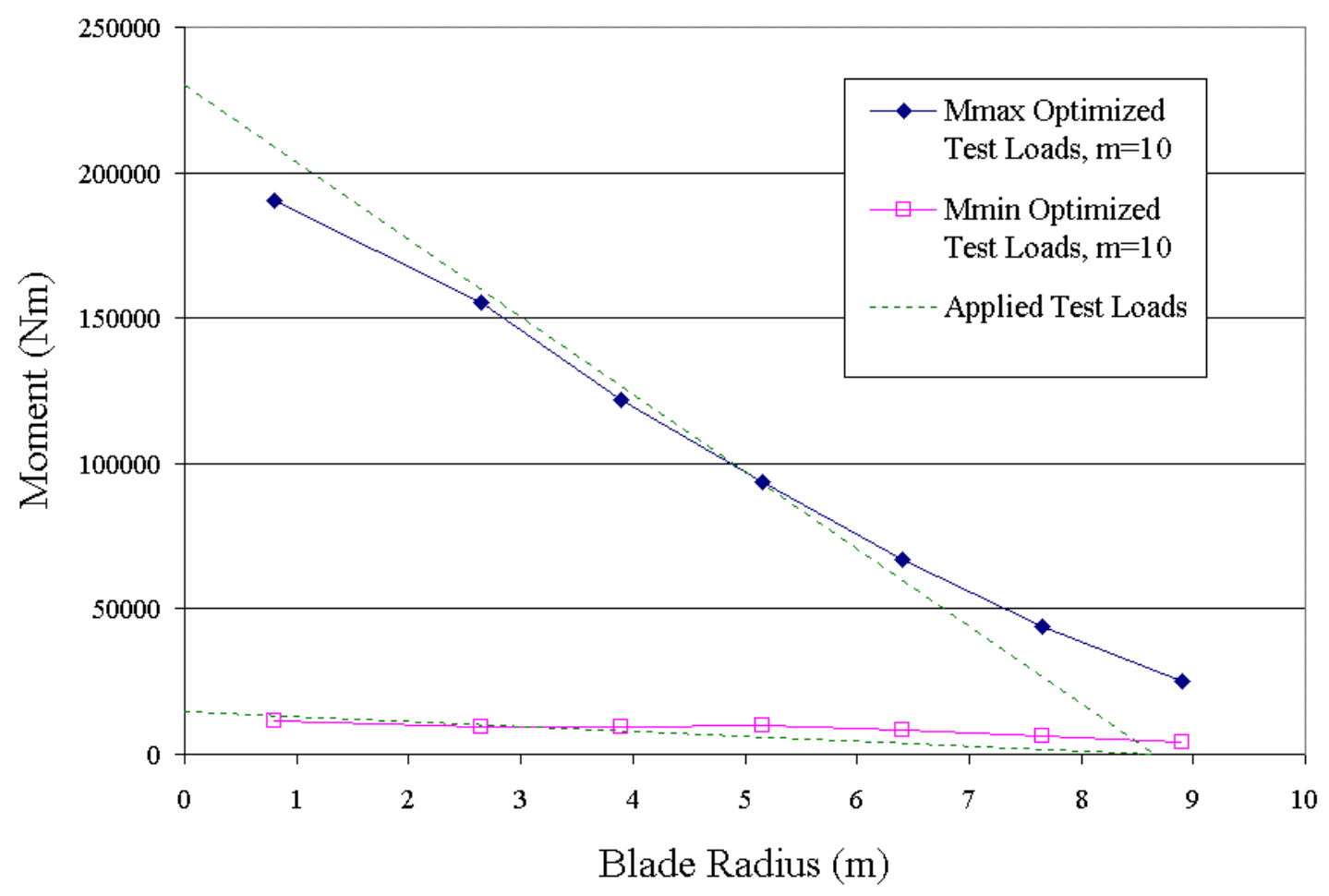

Figure 5.16 Optimized and applied flap bending test loads for $\mathbf{m}=10$

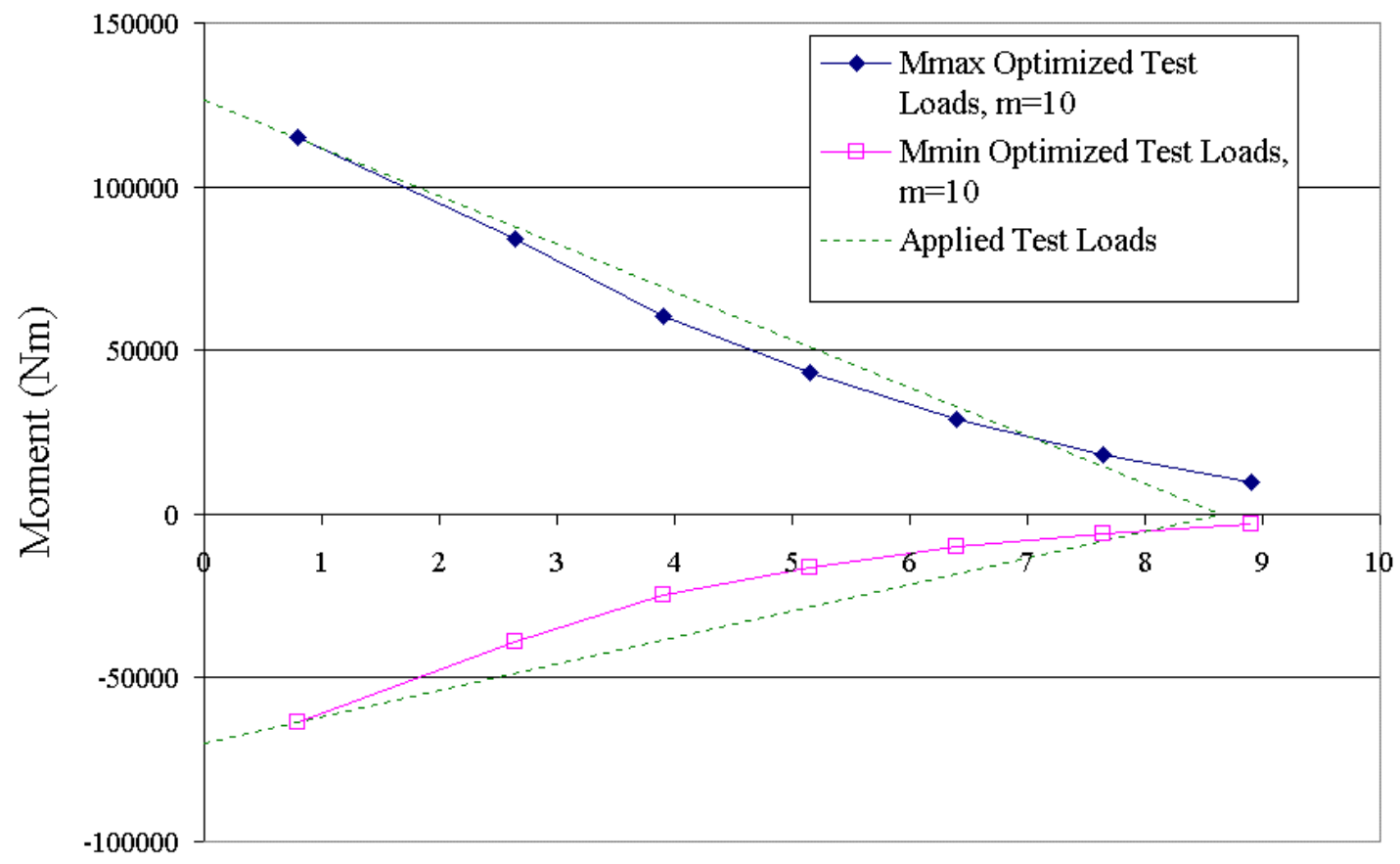

Blade Radius (m)

Figure 5.17 Optimized and applied edge bending test loads for $\mathbf{m}=\mathbf{1 0}$ 
To minimize flap displacements during the test, the load introduction point was moved inboard from the best load station, which would have been at least 1 meter further outboard from the 8.65 station. The 8.65 station still allowed the equivalent-damage flap loads to be matched or exceeded over a majority of the inboard blade stations, where most of the fatigue damage was expected.

Because both flap and edge loads had to be applied at the same station, the spanwise position of the loading could not be optimized for both flap and edge directions. Therefore, we decided to allow the edge loads to drift further from the optimized target values, while prioritizing fit of the flap loads to the optimized distribution. As shown in Figure 5.17, this problem was addressed using a conservative approach, forcing the single-point edge test loads to pass through position 4 at the root flange. This ensured that all positions from position $4(0.8 \mathrm{~m}$ from center of rotation [COR]) out to almost position 9 ( $7.65 \mathrm{~m}$ from $\mathrm{COR}$ ) were tested at or above the design condition in edge.

Another concern was that the test load apparatus could only apply the loads at one test load ratio for the entire span, although each position had a unique $R_{t}$ value. We found that the variations in $R_{t}$ values were small enough that if these differences could be introduced into the $\mathrm{M}_{\min }$ values they would not significantly alter the damage and could therefore be ignored. Based on this, the applied loads were used for the optimized $\mathrm{R}_{t}$ values for position 5 ( $2.65 \mathrm{~m}$ from COR).

Figure 5.18 shows the two-axis fatigue loading for a single load cycle. The flap and edge components are shown individually. The resultant load is also shown as the heavy solid line. The vertical axis is normalized against the peak-resultant single-axis test moment shown in Figure 5.9. Because of the $90^{\circ}$ phase angle in the two-axis loads, the peak-resultant load and the peak-flap load component do not differ very much. Also note that the two-axis peak resultant loads are approximately $10 \%$ lower than the peak single-axis loads.

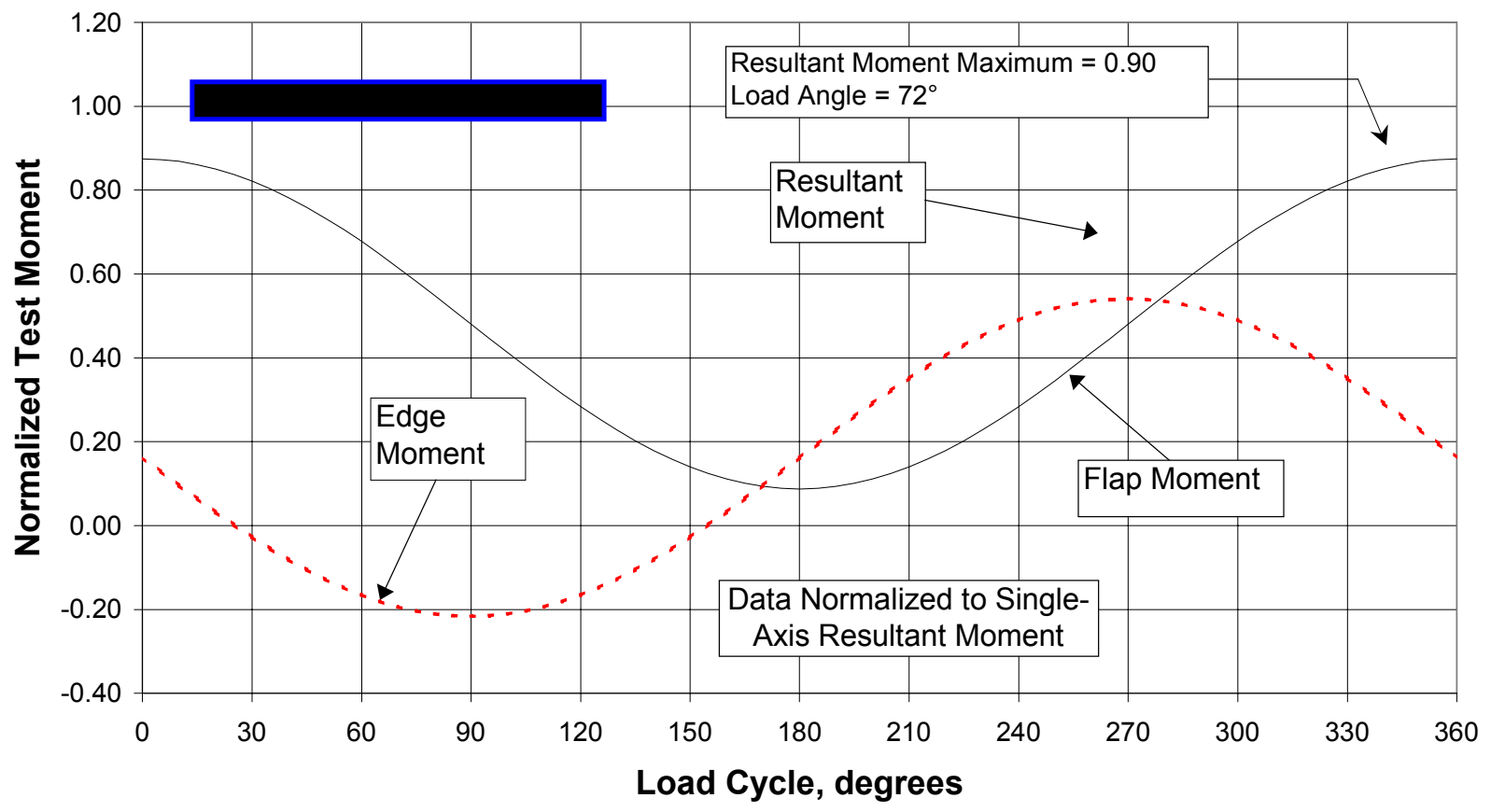

Figure 5.18 Two-axis bending moment normalized to single axis test moment 
Another major difference between the two-axis test is the direction of the load during the load cycle. For the two-axis test, the load angle is continually varying while single-axis load angle is fixed. This difference is described in more detail in Section 6.

\subsubsection{Instrumentation and Equipment}

\subsubsection{Load Apparatus}

\subsection{Load Attachment}

The load attachment for the two-axis fatigue test was made at the 8.65-meter station, and the tip chord angle was rotated for a horizontal orientation.

\subsection{Load Saddle}

The load saddle used for the two-axis test was the same used in the single-axis test, except that hardware was added for attaching the edge push-rod and restraining backlash between the blade and the saddle hardware. The flap attachment was made at the $40 \%$ chord position.

\subsection{Test stand}

The test stand used for the two-axis fatigue test was similar to the one used in the single-axis test. This stand usually resides in the NREL Building 251 High Bay but was moved to Building 254 where it was used for this test. The test stand moment capacity is 1.36 million $\mathrm{N}-\mathrm{m}$ ( 1 million $\mathrm{ft}-\mathrm{lb})$. The test stand tilt was set at $7.4^{\circ}$ with the blade angled upward.

\subsection{Hydraulic Actuators}

The actuator used for the flap direction was the same as the one used for the single-axis test. The edge actuator used was MTS ${ }^{\circledR}$ model number 247.21 (serial number 151977) with a 20-in. (508-mm) and $28,000-1 b(124,544-\mathrm{N})$ load capacity. The load cell used in the edge direction was a 22,000-lb $(97,856 \mathrm{~N})$ capacity, model number 661.20E-03 (serial number 78893). The load cell used in the flap direction also had a 22,000-lb (97,856-N) capacity, model number 661.20E-03 (serial number 66265).

\subsubsection{Strain Gauges}

Prior to the two-axis fatigue test, the BSTRAIN channel capacity was increased to 48. Therefore, all strain-gauge signals on the blade were acquired for the two-axis fatigue test.

\subsubsection{Data Acquisition System}

In order to run two-axis tests, an additional LabVIEW-based program 2ACD (2-Axis Control Determination) was written to create corrected displacement profiles for the digital closed loop servohydraulic controller. The primary function of this program is to compensate for the cross-coupling effect. Blade tests are conducted using displacement control for dynamic stability [2]. 2ACD receives user inputs of loads and a phase angle to create a displacement control profile for the servo-hydraulic controller. User inputs include the maximum and minimum flap and edge loads, and the phase relation between the flap and edge peaks. Test geometry is also an input to the program. The program, which has control of the test via the servo-hydraulic controller, cycles the blade at a reduced rate (typically $0.1 \mathrm{~Hz}$ ) in order to minimize dynamic effects. Starting with initial guesses for load maxima and phase angle, the 
program cycles the blade for three cycles, then averages both the recorded load maxima and phase angle. Next, the control program compares the maxima with the desired loads and phases, and uses proportional gains to obtain new-time load and phase control parameters. This process is iterated until the load and phase angle converges within a specified tolerance. The program then creates displacement profiles for both the flap and edge actuators. During actual testing, the servo-hydraulic controller controls the blade, using the displacement profiles created by $2 \mathrm{ACD}$. The test operator runs this program periodically throughout the test, creating new displacement parameters to account for changing stiffness of the blade.

As part of BSTRAIN, global stiffness values for both flap and edge are recorded. Stiffness monitoring is a method to determine the health of a blade under test where large changes in global stiffness can indicate a failure in progress. At regular increments during the test (typically once per hour), the blade is cycled at a reduced frequency to obtain stiffness values and to zero strain gauge scaling factors to compensate for gauge drift. A reduced frequency is used to remove dynamic effects. For single-axis testing, determining blade stiffness was straightforward, recording and calculating the stiffness as the load range divided by the displacement range. Two-axis testing requires BSTRAIN to account for the cross-coupling effect when calculating the blade stiffness. BSTRAIN had to be modified to calculate flap and edge stiffness independently.

An auto-zero function is included in BSTRAIN. After the blade has been cycled at a reduced frequency, the actuators are positioned at zero-load while BSTRAIN updates the gauge scaling constants to indicate zero strain. Unfortunately, following the testing, it was discovered that the auto-zero function was not performing properly during the two-axis test and that, therefore, the test data has a greater amount of scatter than the single-axis results.

\subsubsection{System Calibration}

An MTS ${ }^{\circledR}$ representative calibrated the load cells and LVDTs for both the flap and edge actuators on site prior to testing.

\subsubsection{Two-axis Fatigue Results}

\subsubsection{Visual Damage}

NREL ran the two-axis test at $1.25 \mathrm{~Hz}$. Above this frequency it was more difficult to maintain continuous smooth loading. The trailing edge crack at $205 \mathrm{~cm}$, developed during the single-axis test, was first observed in the two-axis test between 420,000 and 440,000 cycles. This is more than one order of magnitude beyond the cycle count when it was first observed on the single-axis test. Note that for an S-N curve slope of 10 , a $10 \%$ reduction in stress results in an order of magnitude increase in allowable cycles [24]. Therefore, we believe that the delayed onset of damage in this region is most likely due to the higher loading experienced by the single-axis test.

The same polyurethane root bond crack described for the single-axis test was also fully developed during the two-axis test, but it was more difficult to quantify the stages of growth in relation to the number of cycles.

\subsubsection{Root Sleeve Tension}

No loss of radial bolt torque was observed at scheduled checks during the two-axis test. This was a slightly better result than the single-axis test, which found one bolt had lost its pre-load and needed to be retightened. 


\subsubsection{Strain-Gauge Data}

\subsection{Analysis Methods}

As with the single-axis test, data files of 15,000 cycles were acquired during the two-axis fatigue test. These individual channels were concatenated into a single file of approximately six million points (peak and valley) for the entire test. Spurious points that surrounded test starts and stops along with points around the stiffness checks were removed. The temperature of the hydraulic-oil reservoir was also acquired during the two-axis test. The temperature cycle of the hydraulic oil had a period of approximately 800 cycles with a range of $\pm 4^{\circ} \mathrm{C}$. Due to the cooling system cycle, the fatigue-test data were averaged over each temperature cycle to reduce the number of points. The fatigue test data are presented in Appendix E.

\subsection{Strain Gauge Results}

At 824,307 cycles, NREL discovered that the load phasing was incorrect, with edge leading (instead of lagging) flap by $90^{\circ}$. This was corrected immediately. It is difficult to assess the impact this error may have had on NREL's results; however, the strain-gauge (peak/valley) responses showed little change when the phase angle was corrected. Therefore, NREL did not feel that the final results were significantly affected by this error.

No strain-gauge failures occurred during the two-axis fatigue test. Also, no measurable loss of blade stiffness was observed in the two-axis test, which is the same result as that received from the single-axis test. Figure 5.19 shows the horizontal and vertical blade stiffness for the two-axis test. No significant change in stiffness can be determined from this plot; Figures 4.3 through 4.6 reveal, however, that an apparent blade stiffening occurred in the post-fatigue static test when compared to the pre-fatigue static test, especially in the flap direction.

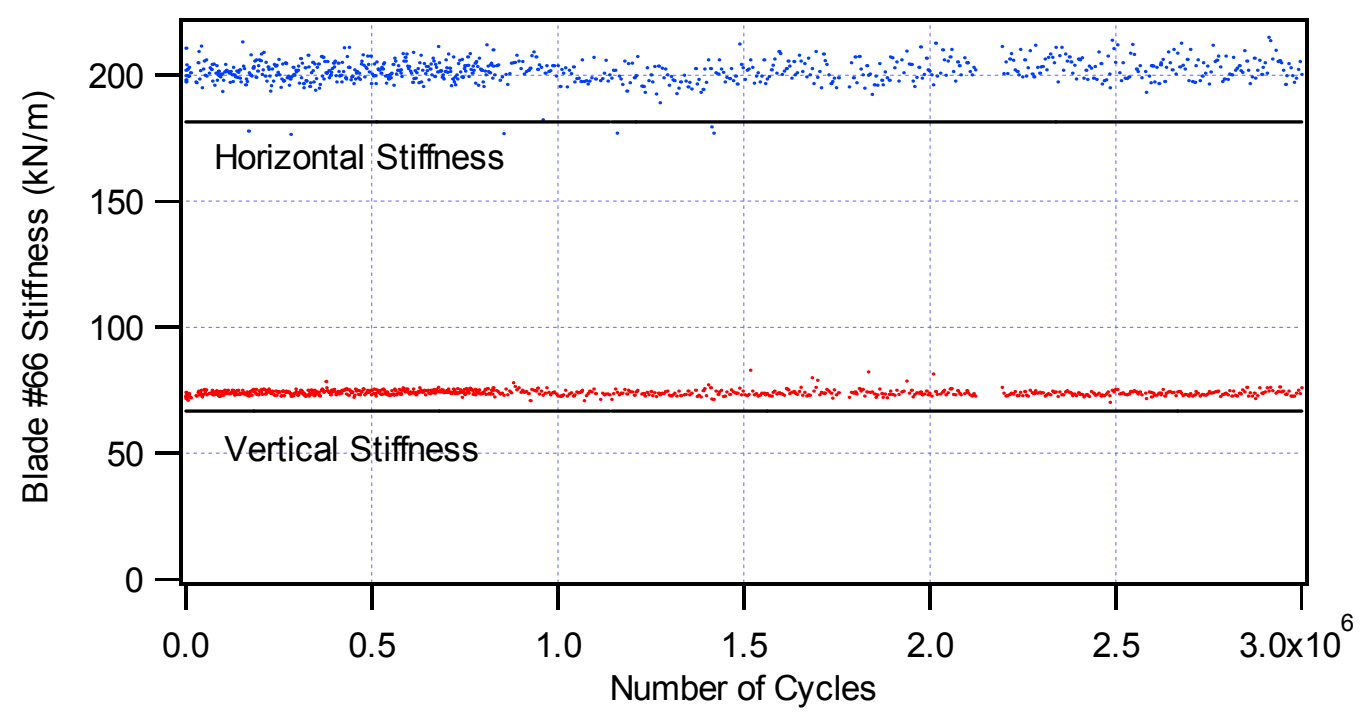

Figure 5.19 Blade \#66 stiffness data from the two-axis fatigue test

\subsubsection{Acoustic Emissions}

Acoustic emission testing was not performed on Blade \#66. 


\section{Comparison of Two-axis and Single-axis Tests}

NREL has used both single-axis and two-axis fatigue testing in its laboratories. Each type has demonstrated certain merits; however, there has never been a significant effort directed at quantifying the technical differences. Most single-axis tests were performed at NREL before the capability was available to do two-axis testing. Although the effort involved in two-axis testing was significantly greater, analytically, the two-axis results showed a better representation of true loading conditions. However, there are times when single-axis testing might still be the more appropriate method to use.

We conducted two blade fatigue tests consecutively on two different NedWind 25 blades. The first test used a single-axis (Blade \#67) test load, combining the flap and edge equivalent-damage test loads into a single resultant load. The optimum load ratios, $\mathrm{R}_{\mathrm{t}}$, were computed to be 0.081 for the flap direction and 0.61 for the edge direction. However, because a single actuator applied the loads, the value $\mathrm{R}_{t}$ for both components had to be the same. Therefore, a compromise of -0.1 was chosen. This slightly favored the flap direction, which was the dominant direction for fatigue damage. In addition, the phase angle between the two load components is fixed at zero degrees, requiring the loads to reach their maximum and minimum values at the same time. As a result of the single-axis test load constraints, the peak loads tend to be higher (see Figure 6-1). Also, because the actuator is fixed on both ends, the load angle between the blade and the actuator is fixed throughout the load cycle (see Figure 6-2). This tends to concentrate the loading on the fibers furthest from the neutral axis. At these outer fibers the blade section is usually over-tested.

The second test used a two-axis (Blade \#66) load method, which allowed the individual load components for flap and edge to be applied independently at the optimum $\mathrm{R}_{\mathrm{t}}$ of 0.081 for flap and -0.61 for edge, at a predetermined phase angle of $90^{\circ}$. The introduction of the phase angle causes the flap and edge peaks to occur at different times, which lowers the magnitude of the resultant peaks as compared to the single-axis loads. The load angle, however, is continuously varying through the load cycle that tends to stress a greater portion of the blade cross section at any given spanwise position.

The single-axis test showed visible blade damage in several areas but no catastrophic failures. The twoaxis test results showed the same visible damage as the single-axis test; however, the onset of the damage was delayed by more than an order of magnitude in cycles. This was probably due to the higher in-phase loading for the single-axis test. Correspondence with the laboratory at CRES indicated that the same visual damage seen at NREL was also seen at CRES. 


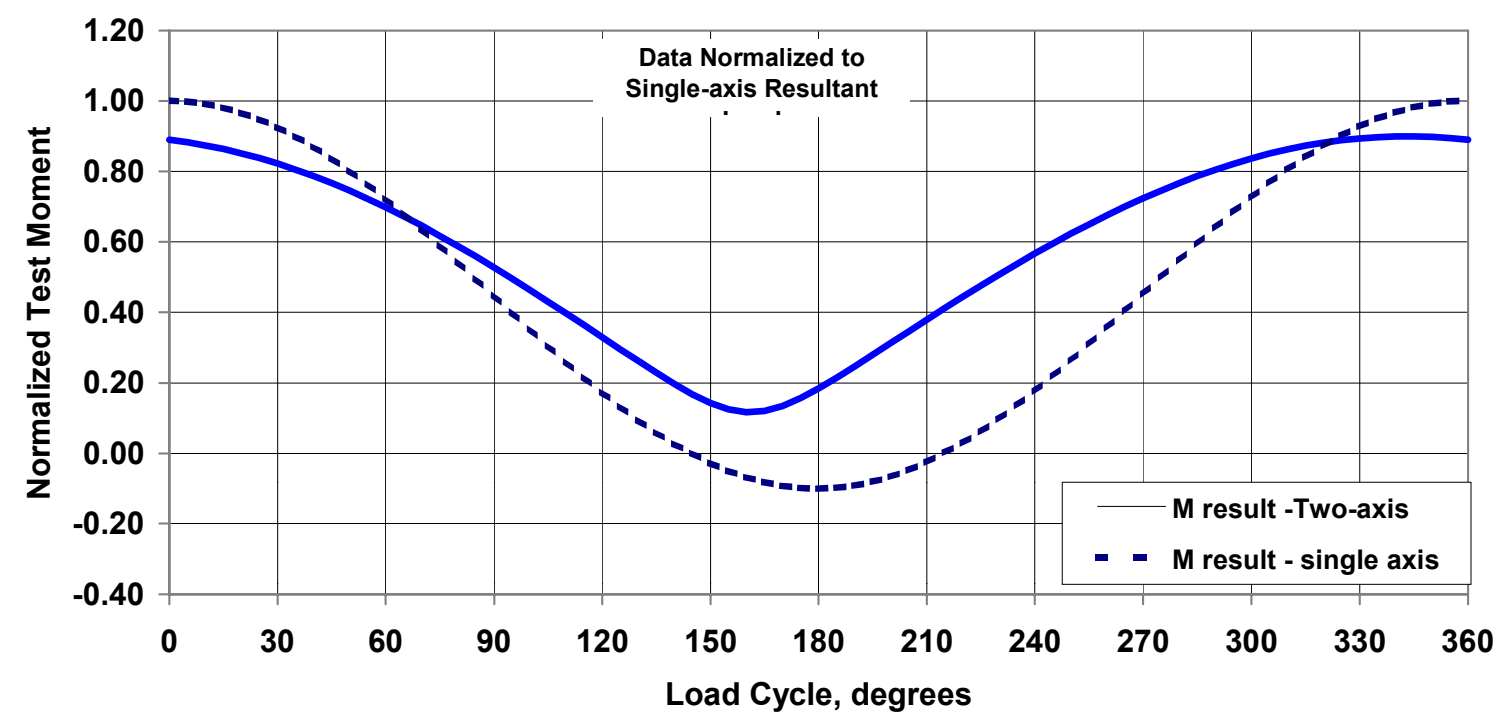

Figure 6.1 Comparison of resultant fatigue load cycle for single- and two-axis tests

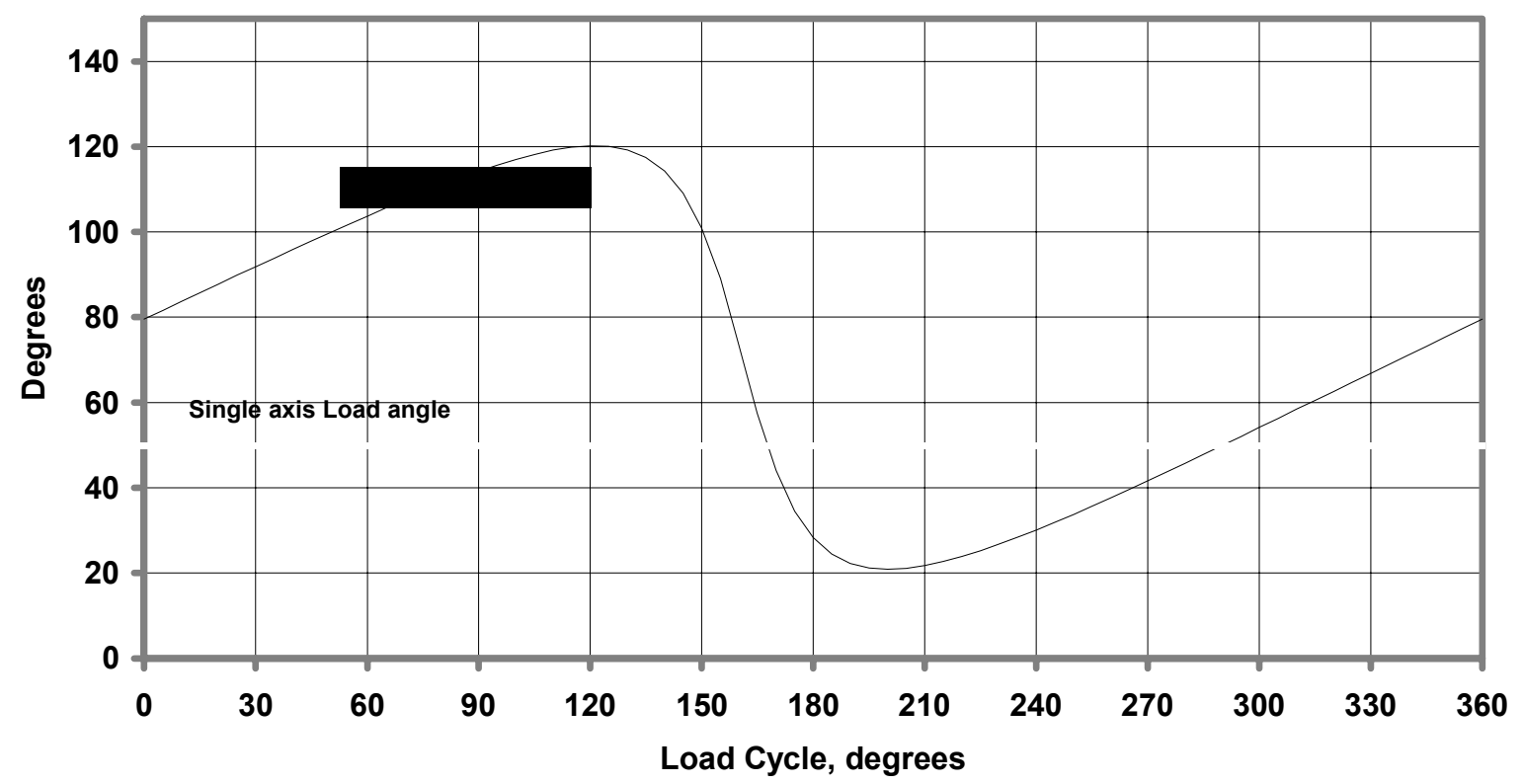

Figure 6.2 Comparison of resultant fatigue load angles for single- and two axis tests 
Table 6-1 gives direct comparisons of the numerical strain values from Blades \#66 and \#67 under each blade's respective loading. Comparison of the columns of numbers allows each strain-gauge location to be compared on the basis of severity of strain amplitude. These comparisons are difficult, however, because the damage at a particular location is dependent on the mean and the range of the load cycle. To make the evaluation of strain severity easier, an additional calculation was performed at each location to compute cycles-to-failure, N, at each location. Using Equation 5-1, the cycles-to-failure calculation was made with the following parameters:

$$
N=\left\{\frac{\frac{U T S+|U C S|}{2 \times C 1 \times C 2 \times C 3}-\left|S_{\text {mean }}-\frac{U T S-|U C S|}{2 \times C 1 \times C 2 \times C 3}\right|}{S_{\text {amp }}}\right\}^{10}
$$

where,

$$
\begin{aligned}
& \mathrm{C} 1, \mathrm{C} 2, \mathrm{C} 3=\text { material factors equal to one } \\
& \mathrm{S}_{\text {mean }}=\mathrm{E} \varepsilon_{\text {mean }} \\
& \mathrm{S}_{\mathrm{amp}}=\mathrm{E} \varepsilon_{\text {amp }} \\
& \mathrm{E} \quad=\text { modulus } 24500 \mathrm{~N} / \mathrm{mm}^{2} \text { from Table } 5.2-3 \\
& \varepsilon_{\text {mean }}=\text { mean strain from Table } 6-1 \\
& \varepsilon_{\text {amp }}=\text { strain amplitude from Table } 6-1 \\
& \mathrm{UTS}=372 \mathrm{MPa} \text { from Table } 5.2-3 \\
& \mathrm{UCS}=260 \mathrm{MPa} \text { from Table } 5.2-3
\end{aligned}
$$

This equation is the same relation used by Rotorline during the design of the blade.

These data are shown in the three columns on the far right of Table 6.1; the percent difference, using the Blade \#66 data as a reference, is plotted in Figure 6.3. From this comparison, we conclude that the single-axis test loading produced the highest damage rate for this test at almost all strain-gauge locations. 
Table 6.1 Comparison of Fatigue Test Data

\begin{tabular}{|c|c|c|c|c|c|c|c|c|c|c|c|c|c|c|c|c|}
\hline & $\begin{array}{l}\text { SMT } \\
\text { Name }\end{array}$ & \begin{tabular}{|c|} 
Gauge \\
No. for 66
\end{tabular} & \begin{tabular}{|c|c} 
Gauge \\
No. for 67
\end{tabular} & $\begin{array}{l}\text { Peak for } \\
66\end{array}$ & $\begin{array}{c}\text { Peak for } \\
67\end{array}$ & $\begin{array}{l}\text { Valley for } \\
66\end{array}$ & $\begin{array}{c}\text { Valley for } \\
67\end{array}$ & $\begin{array}{l}\text { Alternating } \\
\text { for } 66\end{array}$ & $\begin{array}{c}\text { Alternating } \\
\text { for } 67\end{array}$ & Mean for 66 & Mean for 67 & $\begin{array}{c}\text { R-ratio } \\
\text { ( } \min / \max \text { ) } \\
\text { for } 66\end{array}$ & $\begin{array}{c}\text { R-ratio } \\
\text { (min/max) } \\
\text { for } 67\end{array}$ & Blade \#66-N & Blade \#67-N & $\begin{array}{c}\text { Percent } \\
\text { Difference } \\
\text { based on } \\
66 \\
\end{array}$ \\
\hline Flap Load & & 1 & - & 26327 & - & 9302 & - & 8512.5 & - & 17814.5 & - & 0.35 & - & - & - & \\
\hline Flap LVDT & & 2 & - & 365 & - & 14 & - & 175.5 & - & 189.5 & - & 0.04 & - & - & - & \\
\hline Edge Load & & 3 & - & -11338 & - & 10305 & - & 10821.5 & - & -516.5 & - & -1.10 & - & - & - & \\
\hline Edge LVDT & & 4 & - & 136 & - & 5 & - & 65.5 & - & 70.5 & - & 0.04 & - & - & - & \\
\hline Load & & - & 5 & - & 28454 & - & 4252 & - & 12101 & - & 16353 & - & 0.15 & - & - & \\
\hline LVDT & & - & 6 & - & 435 & - & 15 & - & 210 & - & 225 & - & 0.03 & - & - & \\
\hline 08BLDLG & $400 \mathrm{E} 1 / 2$ & 7 & 7 & 487 & 625 & -320 & -75 & 403.5 & 350 & 83.5 & 275 & -0.66 & -0.12 & $1.71 \mathrm{E}+14$ & $8.48 \mathrm{E}+14$ & 395.3 \\
\hline 08BFLAP & $400 \mathrm{~F} 1 / 2$ & 8 & 8 & 1151 & 1026 & 54 & -154 & 548.5 & 590 & 602.5 & 436 & 0.05 & -0.15 & $1.28 \mathrm{E}+13$ & $5.30 \mathrm{E}+12$ & -58.5 \\
\hline \begin{tabular}{|l|}
$17 \mathrm{~S} 38 \mathrm{UA}$ \\
\end{tabular} & $1500 \mathrm{~S} 1$ & 9 & 9 & -1636 & -1654 & -112 & 227 & 762 & 940.5 & -874 & -713.5 & 14.61 & -7.29 & $1.16 \mathrm{E}+11$ & $1.67 \mathrm{E}+10$ & -85.6 \\
\hline 17S38LA & $1500 \mathrm{P} 1$ & 10 & 10 & 1513 & 1917 & 98 & -264 & 707.5 & 1090.5 & 805.5 & 826.5 & 0.06 & -0.14 & $1.20 \mathrm{E}+12$ & $1.61 \mathrm{E}+10$ & -98.7 \\
\hline \begin{tabular}{|l} 
17R62UA \\
\end{tabular} & $1500 \mathrm{~S} 0$ & 11 & 11 & -1560 & -1017 & 8 & 208 & 784 & 612.5 & -776 & -404.5 & -195.00 & -4.89 & $9.66 \mathrm{E}+10$ & $1.65 \mathrm{E}+12$ & 1610.4 \\
\hline 17R62LA & $1500 \mathrm{P} 0$ & 12 & 12 & 1492 & 2100 & -99 & -300 & 795.5 & 1200 & 696.5 & 900 & -0.07 & -0.14 & $3.37 \mathrm{E}+11$ & $6.60 \mathrm{E}+09$ & -98.0 \\
\hline \begin{tabular}{|l|} 
17R62UB \\
\end{tabular} & $1500 S 45$ & 13 & 13 & -472 & -617 & -25 & 102 & 223.5 & 359.5 & -248.5 & -257.5 & 18.88 & -6.05 & $4.60 \mathrm{E}+16$ & $3.93 E+14$ & -99.1 \\
\hline 17R62LB & 1500P45 & 14 & 14 & 655 & 935 & 12 & -109 & 321.5 & 522 & 333.5 & 413 & 0.02 & -0.12 & $2.09 \mathrm{E}+15$ & $1.77 \mathrm{E}+13$ & -99.2 \\
\hline 17R62UC & $1500 S 90$ & 15 & 15 & -406 & -409 & 23 & 62 & 214.5 & 235.5 & -191.5 & -173.5 & -17.65 & -6.60 & $7.32 \mathrm{E}+16$ & $2.93 \mathrm{E}+16$ & -60.0 \\
\hline 17R62LC & 1500P90 & 16 & 16 & 362 & 125 & -59 & -39 & 210.5 & 82 & 151.5 & 43 & -0.16 & -0.31 & $1.22 \mathrm{E}+17$ & $1.37 \mathrm{E}+21$ & 1122908.1 \\
\hline 25R20UA & & 17 & 17 & -2415 & -2580 & -112 & 285 & 1151.5 & 1432.5 & -1263.5 & -1147.5 & 21.56 & -9.05 & $1.24 \mathrm{E}+09$ & $1.59 \mathrm{E}+08$ & -87.3 \\
\hline 25S20LA & & 18 & 18 & 1678 & 1340 & 96 & -260 & 791 & 800 & 887 & 540 & 0.06 & -0.19 & $4.22 \mathrm{E}+11$ & $2.77 \mathrm{E}+11$ & -34.3 \\
\hline 25R20UC & & 19 & - & -161 & - & 88 & - & 124.5 & - & -36.5 & - & -1.83 & - & $1.96 \mathrm{E}+19$ & - & - \\
\hline $25 \mathrm{~S} 26 \mathrm{UA}$ & $2500 \mathrm{~S} 1$ & 20 & 20 & -3327 & -3160 & -217 & 350 & 1555 & 1755 & -1772 & -1405 & 15.33 & -9.03 & $3.53 \mathrm{E}+07$ & $1.58 \mathrm{E}+07$ & -55.2 \\
\hline $25 \mathrm{~S} 26 \mathrm{LA}$ & $2500 \mathrm{P} 1$ & 21 & 21 & 1695 & 1828 & 108 & -245 & 793.5 & 1036.5 & 901.5 & 791.5 & 0.06 & -0.13 & $4.14 \mathrm{E}+11$ & $2.60 \mathrm{E}+10$ & -93.7 \\
\hline 25S40UA & & 22 & 22 & -2037 & -2119 & -142 & 286 & 947.5 & 1202.5 & -1089.5 & -916.5 & 14.35 & -7.41 & $1.05 \mathrm{E}+10$ & $1.16 \mathrm{E}+09$ & -89.0 \\
\hline 25S40LA & & 23 & 23 & 1865 & 2067 & 123 & -267 & 871 & 1167 & 994 & 900 & 0.07 & -0.13 & $1.76 \mathrm{E}+11$ & $8.73 \mathrm{E}+09$ & -95.1 \\
\hline 25R45UA & $2500 S 0$ & 24 & 24 & -1746 & -1698 & -108 & 246 & 819 & 972 & -927 & -726 & 16.17 & -6.90 & $5.35 \mathrm{E}+10$ & $1.18 \mathrm{E}+10$ & -77.8 \\
\hline 25R45LA & $2500 \mathrm{PO}$ & 25 & 25 & 1777 & 1995 & 76 & -254 & 850.5 & 1124.5 & 926.5 & 870.5 & 0.04 & -0.13 & $2.11 \mathrm{E}+11$ & $1.23 \mathrm{E}+10$ & -94.2 \\
\hline 25R45UB & $2500 S 45$ & 26 & 26 & -912 & -1022 & -66 & 139 & 423 & 580.5 & -489 & -441.5 & 13.82 & -7.35 & $6.16 \mathrm{E}+13$ & $2.73 \mathrm{E}+12$ & -95.6 \\
\hline 25R45LB & $2500 \mathrm{P} 45$ & 27 & 27 & 705 & 632 & 45 & -57 & 330 & 344.5 & 375 & 287.5 & 0.06 & -0.09 & $1.67 \mathrm{E}+15$ & $1.01 \mathrm{E}+15$ & -39.9 \\
\hline 25R45UC & $2500 S 90$ & 28 & 28 & 459 & 193 & -11 & -48 & 235 & 120.5 & 224 & 72.5 & -0.02 & -0.25 & $4.35 \mathrm{E}+16$ & $3.00 \mathrm{E}+19$ & 69029.2 \\
\hline 25R45LC & $2500 \mathrm{P} 90$ & 29 & 29 & -630 & -807 & 105 & 145 & 367.5 & 476 & -262.5 & -331 & -6.00 & -5.57 & $3.14 \mathrm{E}+14$ & $2.21 \mathrm{E}+13$ & -93.0 \\
\hline 25R70UA & & 30 & 30 & -509 & 160 & 161 & -67 & 335 & 113.5 & -174 & 46.5 & -3.16 & -0.42 & $8.63 E+14$ & $5.33 \mathrm{E}+19$ & 6183983.1 \\
\hline 25S70LA & & 31 & 31 & 1042 & 1360 & -363 & -157 & 702.5 & 758.5 & 339.5 & 601.5 & -0.35 & -0.12 & $8.48 \mathrm{E}+11$ & $4.99 \mathrm{E}+11$ & -41.2 \\
\hline 25R70UC & & 32 & - & 644 & 0 & -79 & - & 361.5 & - & 282.5 & - & -0.12 & - & $6.18 \mathrm{E}+14$ & - & - \\
\hline 31R20UA & & 33 & 33 & -1907 & -2540 & -87 & 310 & 910 & 1425 & -997 & -1115 & 21.92 & -8.19 & $1.73 \mathrm{E}+10$ & $1.73 \mathrm{E}+08$ & -99.0 \\
\hline 31S20LA & & 34 & 34 & 1885 & 1902 & 105 & -254 & 890 & 1078 & 995 & 824 & 0.06 & -0.13 & $1.42 \mathrm{E}+11$ & $1.81 \mathrm{E}+10$ & -87.3 \\
\hline 31R20UC & & 35 & - & 339 & - & 20 & - & 159.5 & - & 179.5 & - & 0.06 & - & $2.01 \mathrm{E}+18$ & - & - \\
\hline 31S40UA & & 36 & 36 & -2546 & -2430 & -174 & 310 & 1186 & 1370 & -1360 & -1060 & 14.63 & -7.84 & $8.35 \mathrm{E}+08$ & $2.72 \mathrm{E}+08$ & -67.5 \\
\hline $31 \mathrm{~S} 40 \mathrm{LA}$ & & 37 & 37 & 1978 & 2377 & 132 & -293 & 923 & 1335 & 1055 & 1042 & 0.07 & -0.12 & $1.04 \mathrm{E}+11$ & $2.57 \mathrm{E}+09$ & -97.5 \\
\hline 31R70UA & & 38 & 38 & -1297 & -331 & 119 & 186 & 708 & 258.5 & -589 & -72.5 & -10.90 & -1.78 & $3.23 E+11$ & $1.27 \mathrm{E}+16$ & 3925849.2 \\
\hline 31S70LA & & 39 & 39 & 1270 & 2006 & -101 & -203 & 685.5 & 1104.5 & 584.5 & 901.5 & -0.08 & -0.10 & $1.35 \mathrm{E}+12$ & $1.52 \mathrm{E}+10$ & -98.9 \\
\hline 31R70UC & & 40 & - & 390 & - & -2 & - & 196 & - & 194 & - & -0.01 & - & $2.60 \mathrm{E}+17$ & - & - \\
\hline 41S40UA & & 41 & 41 & -2990 & -2880 & -194 & 403 & 1398 & 1641.5 & -1592 & -1238.5 & 15.41 & -7.15 & $1.25 \mathrm{E}+08$ & $3.69 \mathrm{E}+07$ & -70.5 \\
\hline 41S40LA & & 42 & 42 & 2414 & 2590 & 160 & -380 & 1127 & 1485 & 1287 & 1105 & 0.07 & -0.15 & $1.72 \mathrm{E}+10$ & $9.35 \mathrm{E}+08$ & -94.6 \\
\hline
\end{tabular}


On Blade \#66, a few locations on the upper surface at approximately $60 \%$ to $70 \%$ chord did produce higher damage for the two-axis test, because the neutral axis is fixed during the singleaxis loading and passed through this location. For the two-axis loading, the load angle is continuously varying, as is the neutral axis, so no location experiences zero strain. Also, a couple of locations showed higher damage in the transverse strain direction for the two-axis test. The majority of locations showed significantly shorter life for the single-axis test, with many locations over an order of magnitude lower life. Some locations exhibited as much as $99 \%$ change in life as a direct result of using the single-axis loading.

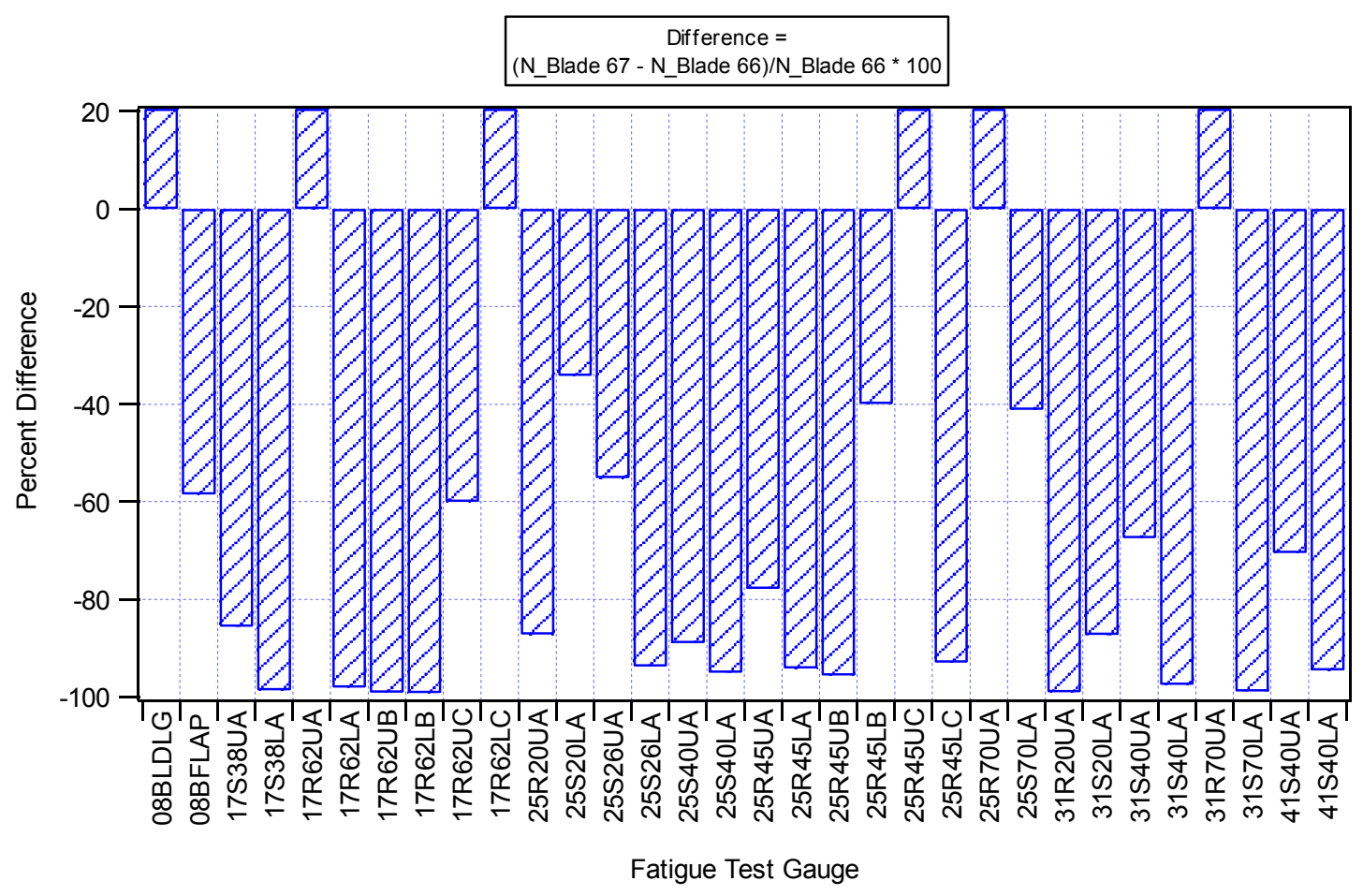

Figure 6.3 Calculated difference in allowable cycles between Blade \#66 (two-axis test) and Blade \#67 (single-axis test) at each strain-gauge measurement location

\section{Blade Postmortem}

The blades were preserved for further inspection, validation, and possible postmortem sectioning. Unfortunately, the program ended because of lack of EU funding and this portion of the project was never done.

\section{Summary and Conclusions}

Under the SMT Program, five international blade-testing laboratories participated in testing 12meter NedWind 25 wind turbine blades taken from a sequential production series at Rotorline. The purpose was to observe techniques used by different laboratories to help develop a common set of procedures for testing wind turbine blades. NREL participated as an invited partner and 
tested two blades, identified as Blades \#66 and \#67. Static tests and fatigue tests were conducted on both blades. Identical static tests were conducted on both blades. Tests included property measurements and static-strength tests based on the NedWind 25 extreme-load cases. Static tests were repeated after the fatigue testing to determine the effect of fatigue loading on the static properties. The key observations from static testing are:

1. Blade \#66 and Blade \#67 had some random differences but their global properties were very similar.

2. Pre- and post-fatigue static-test data show a probable increase in blade stiffness, possibly caused by laminate drying effects. This effect is most obvious in the flap direction.

3. The effect described in \#2 above overshadowed any possible decline in global blade properties resulting from fatigue testing. Some local strain changes may have occurred but could not be fully evaluated for this test.

4. The SMT-prescribed static-test load of $75 \%$ of the extreme design load was too low to evaluate possible non-linearities for fatigue loading.

5. The SMT-prescribed static-test loading procedure was inadequate to evaluate extreme-load behavior and did not allow the actual blade strength to be determined because the blade was not broken.

Two different methods were used for the fatigue tests. One blade was fatigue tested using singleaxis loading and the other was conducted using two-axis loading. All labs used a common set of design loads containing 100 load cases to develop the fatigue-test loads. A new method of analysis was developed at NREL to convert design loads to a damage-equivalent spectrum while staying in the load domain. The new method simplifies the conventional damage evaluation techniques but will require further validation. Some of the key fatigue test observations are:

1. The load-domain damage analysis method described illustrates how minimizing scatter optimizes the load amplitude ratio, $\mathrm{R}_{\mathrm{t}}$, of the test loading.

2. The differences in the damage equivalent test load calculated for the two-axis and singleaxis tests highlight the need to accurately determine the phase relationships between the edge and flap loads in the design.

3. Using identical design load conditions, the test loads for the two fatigue tests were significantly different and resulted in significant differences in the test outcome.

4. Phase angle uncertainty in the design data and in the test methodology led to large errors in the test blade damage.

5. Single-axis test loading was more severe than in the two-axis test using the NedWind 25 blade design loads.

6. Single-axis and two-axis tests produced virtually the same visual damage on the exterior of the blade. The onset of the trailing-edge crack was over an order of magnitude sooner for the single-axis test.

7. Single-axis test loading was less representative of true operational loading because: (a) the load amplitude ratio was not optimized for either flap or edge conditions, (b) the phase angle was forced to be $0^{\circ}$, causing the peak loading to be $10 \%$ higher, and (c) the load angle was fixed at $50^{\circ}$ and did not vary during the load cycle.

8. The NedWind 25 blade sustained the test loading without loss of global properties; however, two non-structural cracks formed that could have adverse consequences due to environmental degradation if neglected.

9. Communications with other laboratories suggest that NREL's results are similar to the results produced in the other laboratories [25]. 


\section{Acknowledgments}

The authors wish to thank the large number of active contributors who made this project a success. Special thanks go to the NREL Structural Test Team members including Toby Stensland, Todd Longacre, Doug Cook, and Rich Osgood. We also wish to thank Mike Zuteck and Jim Richmond for their special skills and insights in helping to develop the test loads, and Mark Rumsey at Sandia National Laboratories for enhancing the testing with their acoustic emission monitoring. We also like to thank our colleagues and friends in Europe at RIS $\varnothing$, CRES, Delft, and ECN for inviting us to join the project and accepting our input throughout its duration. And finally, thanks to DOE for their continued funding support and recognition of structural testing as a valued asset of the wind energy industry.

\section{References}

1. Van Grol, H.J., Strength and Fatigue Testing of Large Size Wind Turbine Rotors: Results of Questionnaire on Rotor Blade Mechanical Testing. ECN-I--95-004. Petten, The Netherlands: Netherlands Energy Research Foundation ECN, 1995; 19 p.

2. Hughes, S., W. Musial, and T. Stensland, "Implementation of a Two-Axis ServoHydraulic System for Full-Scale Fatigue Testing of Wind Turbine Blades." NREL/CP500-26896. Presented at AWEA Windpower 99, Burlington, VT, 20-23 June 1999.

3. Van Dam, J., e-mail communication. "Working Document of the EWTTPD Project. Subtask 2: Blade Test Methods and Techniques (Jeroen8)." Petten, The Netherlands: Netherlands Energy Research Foundation ECN, 15 May 1998.

4. Musial, W.D., M.E. Clark, and T. Stensland, "Application of BSTRAIN software for Wind Turbine Blade Testing." NREL/TP-440-21507. Presented at AWEA Windpower '96, Denver, CO, 23-27 June 1996.

5. Bulder, B.H., et al., "European Wind Turbine Testing Procedure Development Blade Test Methods and Techniques," 1999 European Wind Energy Conference Proceedings; 1-5 March 1999; Nice, France. London, UK: James \& James (Science Publishers) Ltd.; pp. 597-600.

6. Drost, L.F., "Load Spectrum of the NedWind 25 Windturbine" (NedWind, The Netherlands, 9 November 1992, distributed to SMT participants), 134 p.

7. NLREG Nonlinear Regression Analysis Program (1997), Sherrod Software, Brentwood, TN.

8. Thomson, W.T., "Vibration." Chapter 5 in Mark's Standard Handbook for Mechanical Engineers. New York: McGraw Hill, 1978; p. 5-67.

9. WaveStar Software for Oscilloscopes, Tektronix, Inc., Wilsonville, OR.

10. Verheul, A. and D.R.V. Van Delft, "Blade Data NedWind 25 (version II) Alex-9," (Technische Universiteit Delft, The Netherlands, 1998, distributed to SMT participants), $48 \mathrm{p}$.

11. Van Dam, J., e-mail communication. "SMT-21 Pre-load in Bolts." Petten, The Netherlands: Netherlands Energy Research Foundation ECN, 26 May 1998.

12. Van Dam, J., e-mail communication. "SMT-100 Nomenclature for Common Gauges." Petten, The Netherlands: Netherlands Energy Research Foundation ECN, 18 February 1999.

13. Bulder, B., e-mail communication. "SMT-98 Fwd: Strain Gauge Location \& Project Plan." Petten, The Netherlands: Netherlands Energy Research Foundation ECN, 9 December 1998.

14. "Strain Gage Technology Workshop." (Measurements-Group, Raleigh, NC, 1998, distributed to class participants). 
15. Stensland, T. "BSTRAIN Manual" (National Renewable Energy Laboratory, Golden, CO, 1999, unpublished)

16. Van Dam, J. Facsimile communication. "Load Spectrum NW25 Rotorblade" Petten, The Netherlands: Netherlands Energy Research Foundation ECN, 10 February 1998.

17. Van Dam, J., e-mail communication. "SMT-25 Radial Position, Pull Direction, Etc." Petten, The Netherlands: Netherlands Energy Research Foundation ECN, 9 December 1998.

18. Dobbe, T., "Strength Calculations of the NW25 Rotorblade Design" (NedWind, The Netherlands, 28 October 1992, distributed to SMT participants), $75 \mathrm{p}$.

19. Rademakers, L.W.M.M., P.P. Soullié, and P.A. Van Der Werff, Voorstel Tot Wijziging Technische Criteria Met Betrekking Tot De Vermoeiingseigenschappen Van Vezelversterkte Kunststoffen. De-Memo-91-58. Petten, Netherlands: ECN, 1991; 25 p.

20. Van Dam, J., e-mail communication. "SMT-47 Data Sets." Petten, The Netherlands: Netherlands Energy Research Foundation ECN, 15 July 1998.

21. IEC-88/84/CD, Draft IEC 61400-23: Testing of Rotor Blades. 1998, International Electrotechnical Commission.

22. Mandell, J.F. and D.D. Samborsky, DOE/MSU Composite Material Fatigue Database: Test Methods, Materials, and Analysis. SAND97-3002. Albuquerque, NM: Sandia National Laboratories, 1997; 202 p.

23. Beattie, A.G., "Acoustic Emission Monitoring of a Wind Turbine Blade During a Fatigue Test," A Collection of the 1997 ASME Wind Energy Symposium Technical Papers; 6-9 January 1997; Reno, $N V$. Reston, VA: American Institute of Aeronautics and Astronautics; pp. 239-248.

24. Mandell, J.F., "Fatigue Behavior of Short Fiber Composite Materials," in Fatigue of Composite Materials. New York: Elsevier Science, 1991; p. 232.

25. Van Dam, J., Full Scale testing of a NedWind NW25 Rotor Blade. ECN-C--00-057. Petten, The Netherlands: Netherlands Energy Research Foundation ECN; 53 p.

\section{Appendices}

Appendix A -- Fatigue Design Load Matrix Appendix B -- Equivalent-Damage Spreadsheets Appendix C -- Edgewise Static Data Appendix D -- Flapwise Static Data Appendix E -- Fatigue Data Appendix F -- Correspondence

SMT [21] Pre-load in bolts

Jeroen 8

SMT [98] CRES strain-gauge locations

SMT [100] Nomenclature for common gauges

SMT [25] Radial position, pull direction, etc.

SMT [47] Data sets

Appendix G -- Acoustic Emissions Report

Appendix H -- Drawings and Calibration Records

Adapter plate

Load saddle

Strain-gauge data sheets 


\section{Appendix A}

Fatigue Design Load Matrix 


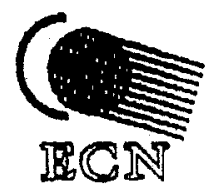

ECM DUURZAME ENERGIE A4->A4 18/02/98 $17: 02$ Pg: $1 / 2$

TO

\section{Energleonderzoek Centrum Nederland} Netherlands Energy Research Foundation ECN

ECN SOLAR \& WIND ENERGY

\section{FACSIMILE MESSAGE}

$:$

Martln Winther Jensen, Pantells Vlonls, Don van Delft, Scott Larwood

FAX

+4542372965, +\$016039905, 0152782308, +13033847055

REF

FROM

: load spectrum NW25 rotorblade/7.4262.01.02.20

PHONE

: Jeroen van Dam

$+31224564277$

FAX

: +31224563214

CC .

PAOES

DATE

: Bernard Bulder

$: 2$

: 10 February 1998

ME88AGE:

Dear colleagues,

We have recelved information on the loadspectrum of the NW25 rotorblade.

The load spectrum Is described by three flles. These flles can be downloaded from the directory lpubldelbuider on the ECN ftp-server: FTP.ECN.NL.

NW25.LKB gives ten positlons for whlch the loads have been calculated.

The ten positlons are:

Postbus 1, 17.55 ZG Petten

Westerdulnweg 3, 1755 LE Petten:

Telefoon: (0224) 564949 Fax: (0224) 564480

WWW: http://WwW.ech.nl/ weld lik hub

weld in hub

Flange of the blade

Pin-hole connectlon between flange and laminate

1st aerodynamic cross section

2nd aerodynamic cross section

5.15

6.4

7.65

8.9

The flle NW25.CSB and NW25.CMB descrlbe the ranges and means of three load components for the ten positlons for all hundred load cases. The loads are glven without

If you dld not recelve all pages or find that they are llleglble, please contact the above mentloned phone number

PO Box 1, 1755 ZG Petten, The Netherlands Westerduinweg 3, 1755 LE Petten, The Netherlands Phone: +3】 224564949 Fax: +31 224564480

WWW: http://www.ecn.nl/ 
any load factor. In the first column of these fles the number of cycles for each loadcase is glven. A small part of NW25.CSB is given below.

\begin{tabular}{|c|c|c|c|c|c|c|c|c|c|}
\hline \multicolumn{2}{|c|}{ Explanation of do } & \multicolumn{3}{|c|}{ ontents of flle NW25.CSB } & \multicolumn{3}{|c|}{ 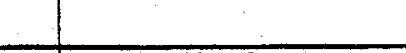 } & \multirow[b]{3}{*}{$\ldots$} & \multirow[b]{3}{*}{ Myto } \\
\hline & & \multicolumn{3}{|c|}{ position 1} & \multicolumn{3}{|c|}{ positton 2} & & \\
\hline $\begin{array}{l}\text { No. of load } \\
\text { cases }\end{array}$ & $\overline{0}$ & $F=1$ & $\overline{M \times 1}$ & My1 & F² & $\overline{M \times 2}$ & My2 & & \\
\hline No. of & 374766 & 25506.9 & 67645.61 & 37281.01 & 15847.83 & 67301.43 & 35460.76 & $\ldots$ & 3728.908 \\
\hline cyclog & $4145\} 1$ & \begin{tabular}{l|l}
05506.8 \\
0
\end{tabular} & 72633.04 & 59440.37 & 16847.83 & 61977.53 & 58659.7 & $\ldots$ & 8738.19 \\
\hline & 369980 & \begin{tabular}{l|l}
0 & 26508.9
\end{tabular} & 74769.84 & 46726.85 & 15847.83 & 64126.8 & 44507.87 & $\ldots$ & 5060.531 \\
\hline & 276840 & D. 25506.8 & 73800.68 & $|37518.26|$ & 16847.83 & 63223.22 & 36732.78 & $\ldots$ & 4018.418 \\
\hline & 174671 & $\begin{array}{ll}0 & 26508.9\end{array}$ & 72518.75 & 38518.11 & 16847.83 & 62025.46 & 37717.42 & $\ldots$ & 4766.019 \\
\hline & $\begin{array}{c}1 \\
20\end{array}$ & $\begin{array}{c}\vdots \\
26508.91\end{array}$ & $\begin{array}{c}: \\
t+5214.84\end{array}$ & $\begin{array}{c}i \\
107461\end{array}$ & 16847.83 & $\begin{array}{c}: \\
85846.6\end{array}$ & $\begin{array}{c}: \\
101730.1\end{array}$ & .... & $\begin{array}{c}\vdots \\
9400.842\end{array}$ \\
\hline
\end{tabular}

The three flles should glve enough Information for a test spectrum.

Yours sincerely

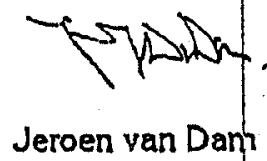


Author: Jeroen van Dam [SMTP:vandam@ecn.nl] at SMTP

Date: 2/24/98 4:03 AM

Priority: Normal

TO: Scott Larwood at NREL

'C: bulder@ecn.nI [SMTP:bulder@ecn.n1] at SMTP

subject: answers w.r.t. NW25

scott,

Here are the answers to your questions, sorry for my late reply.

1. Is NW25.CSB the range of the loads? RAN6E

2. Is NW25. CMB the mean loads? MAYimum

No, in my fax I incorrectly mentioned that the means and ranges are in these two files. Comparing the numbers in the files and Table I1 and I2 of "Jeroen 4" gives that NW25.CMB contains the maximum loads and NW25.CSB contains the load ranges.

3. What are the units for the forces and moments?

Again comparing the files with Table Il gives that the forces are in [N] and the moments are in $[\mathrm{Nm}]$.

4. What is the reference axis for $\mathrm{Fz}, \mathrm{Mx}$, and $\mathrm{MY}$ and how do these compare to the forces and moments in appendix $\mathrm{H}$ of "Jeroen 4 "?

Fz is comparable with "FR kracht radiaal" which means that it is the radial force component.

My is comparable with "MT moment tangentiaal", being the flatwise moment $x$ is comparable with "MA moment axiaal", being the edgewise moment. Although these last two of these load components do not match one on one, this probabily has to do with different dates of the simulations.

5. Why do these load spectrum exclude the other 2 forces ar:d 1 moment in appendix $\mathrm{H}$ of "Jeroen 4 "?

Only these three load components were taken into account for the strength and fatigue calculations. This was done to save some calculation time.

6. Why are the radial positions in NW25. LKB differ from those analyzed in appendix $\mathrm{H}$ of "Jeroen 4 "?

The simulations were run before it was known which crosssections were critical. Afterwards the cross sections which were of interest where interpolated, these data are in the files on the FTP-site.The cross sections given in the files are more or less the same as the cross sections which were calculated on fatigue in "Bernard 1 ".

7. What do the filenames for the aerodynamic profiles mean?

The filename can be read as follows : "r10.65" gives the contour at 10.65 meter from the rotor centre. This is 10 meter from the blade flange.

8. What is the format for the aerodynamic profile files?

is far as I can see in the first column is the coordinate along the chord in [mm], in the second column the distance of the blade surface perpendicular to the chord is given also in [mm].

Regards, 
Author: Scott Larwood at NREL

Date: $2 / 19 / 98 \quad 9: 29$ AM

Priority: Normal

TO: vandam@ecn.nl at SMTP

ubject: NW25 Information

Greetings Jeroen,

I would like some clarification on the NW25 files from the FTP site:

1. Is NW25.CSB the range of the loads?

2. Is NW25.CMB the mean loads?

3. What are the units for the forces and moments?

4. What is the reference axis for $\mathrm{Fz}, \mathrm{Mx}$, and $\mathrm{MY}$ and how do these

compare to the forces and moments in appendix $H$ of "Jeroen 4"?

5. Why do these load spectrum exclude the other 2 forces and 1 moment

in appendix $\mathrm{H}$ of "Jeroen 4 "?

6. Why are the radial positions in NW25.LKB differ from those analyzed in appendix $\mathrm{H}$ of "Jeroen 4 "?

7. What do the filenames for the aerodynamic profiles $\pi$ ?an?

8. What is the format for the aerodynamic profile files?

Scott Larwood 
MAXIMUM

NW25.CMB

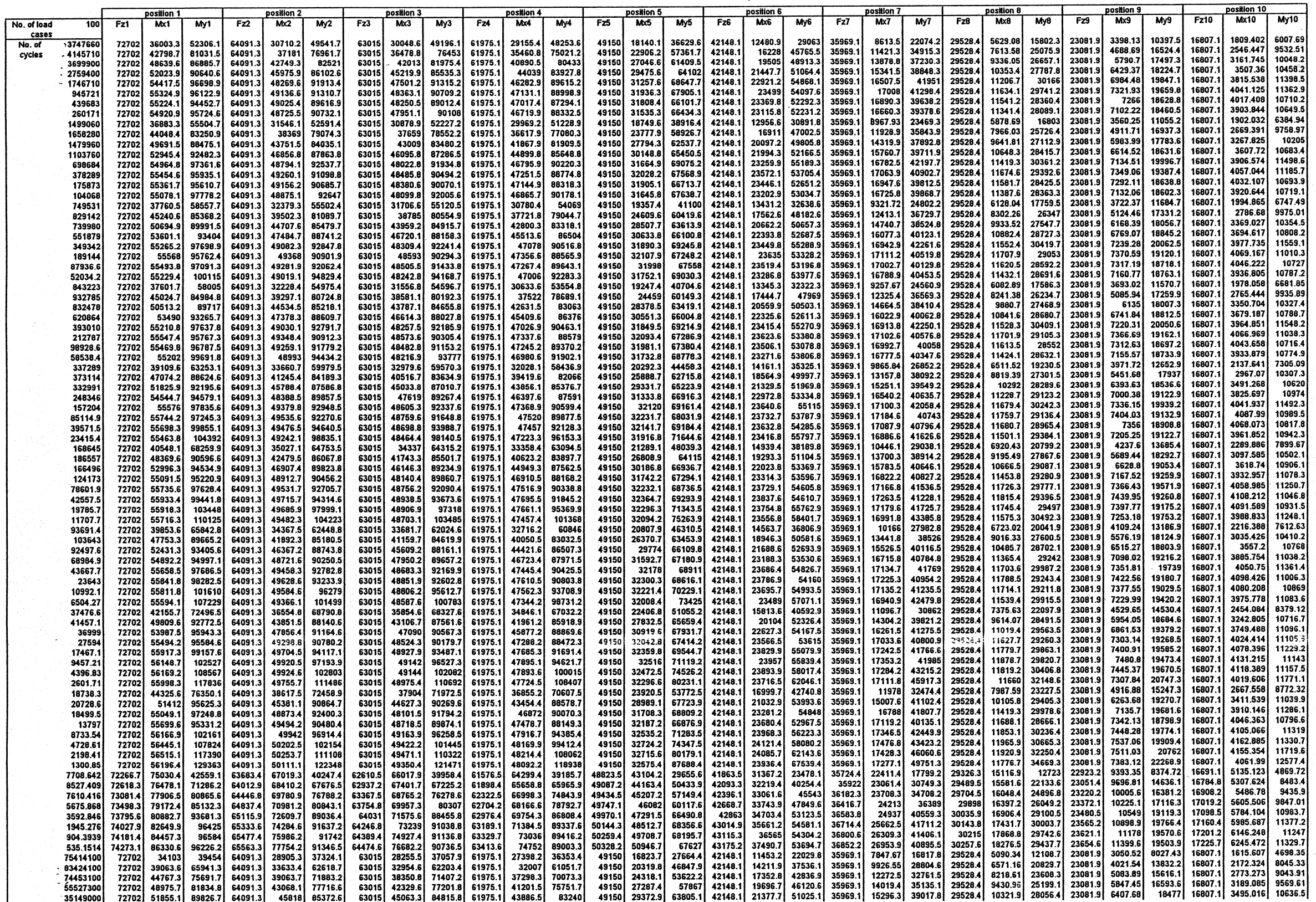




\section{NW25.CMB}

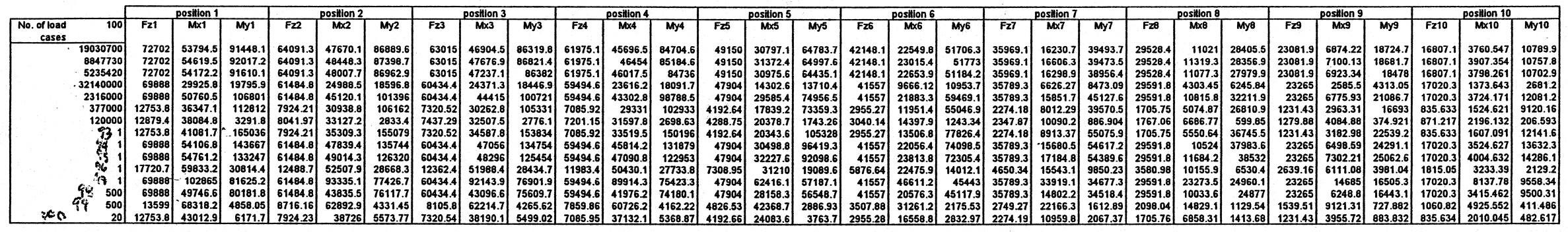


RANGE NWL5.CSB

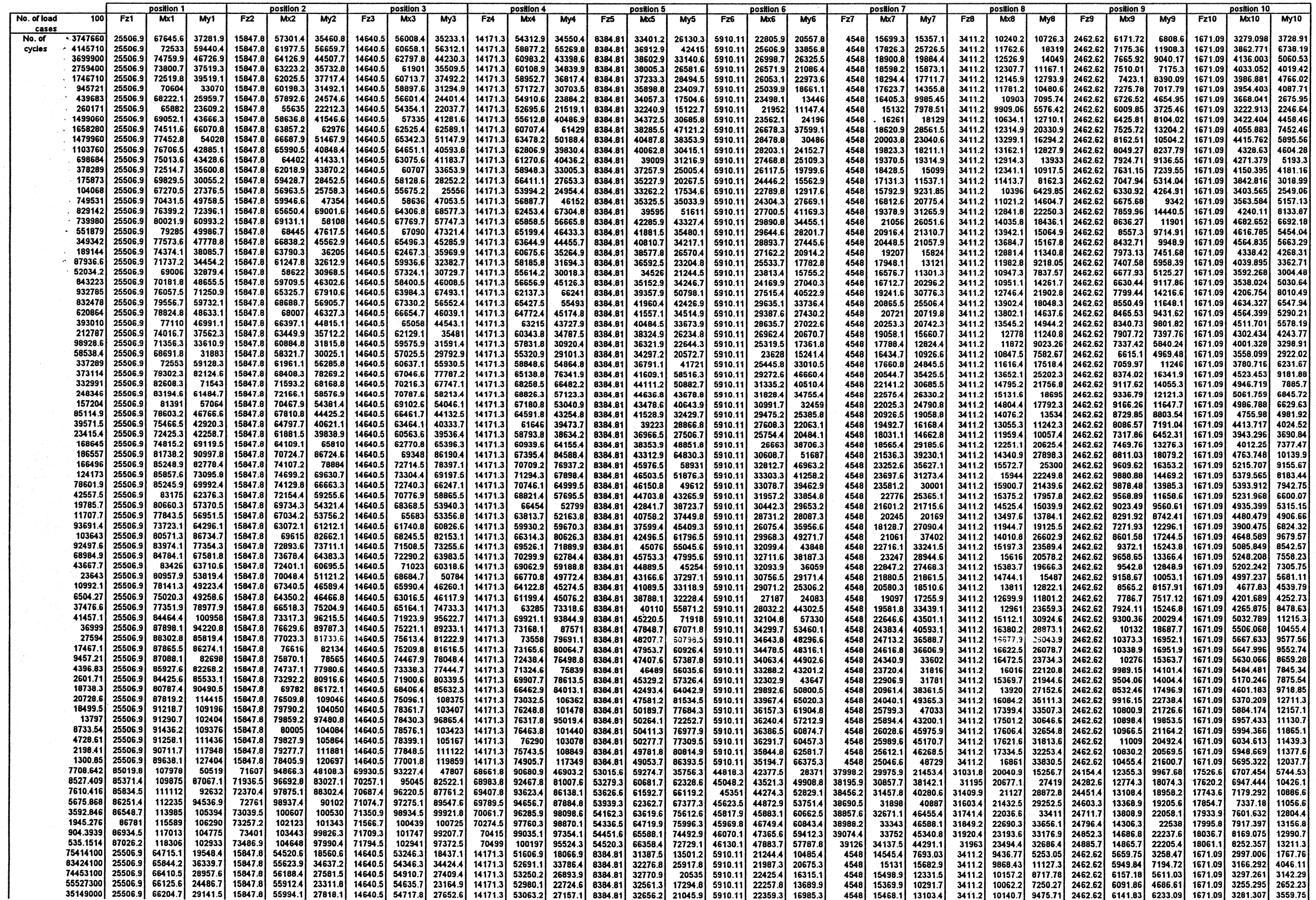




\section{Nw25.CSB}

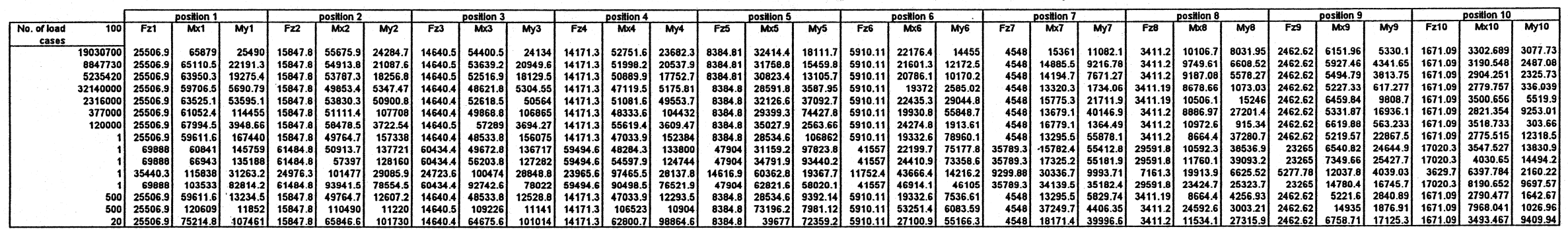


TP-500-29103

\section{Appendix B}

Equivalent-Damage Spreadsheets

B-1 
Vbf_t_4 1.35 design load factor sections 1 to 4 $\mathrm{Vmf}=$ 1.50

UTS_str $=372.0$. strength laminate uitimate tensile strength laminate ultimate compressive
Vbf_5_10 =

UTS_t $n=87.0$

UCS_t_n $=76: 0$
1.5 design load factor sections 5 to 10

tail/nose ultimate tensile

tail/nose ultimate compressive
Design Material Factors

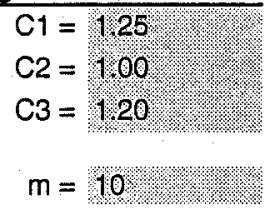

Test Material Factors

$\mathrm{C} 1 \mathrm{a}=1.00$

$\mathrm{C} 2 \mathrm{a}=1.00$

$\mathrm{C} 3 \mathrm{a}=120$

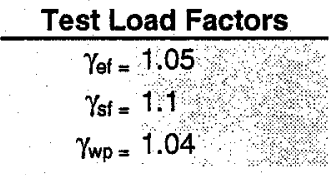

\begin{tabular}{lr|l} 
& & Sum n \\
\hline NW25csb & Range & $4.28 \mathrm{E}+08$ \\
NW25cmb & Maximum & $4.28 \mathrm{E}+08$
\end{tabular}

DEL (Damage Equivalent Loads)

\begin{tabular}{|c|c|c|c|c|c|c|c|c|}
\hline \multicolumn{9}{|c|}{ DEL (Damage Equivalent Loads) } \\
\hline \multirow{2}{*}{\multicolumn{2}{|c|}{$\mathrm{kFx}$}} & \multirow[b]{2}{*}{ Sum n/N } & \multicolumn{3}{|c|}{$\mathrm{kM}=$ strain $/ \mathrm{N}-\mathrm{m}$} & & \multicolumn{2}{|c|}{$\mathrm{kMy}=$ strain $/ \mathrm{N}-\mathrm{m}$} \\
\hline & & & & kMx & Sum $n / N$ & & $\mathrm{kMy}$ & Sum $n / N$ \\
\hline Fxi & $1.1448 \mathrm{E}-03$ & 9.99E-01 & $\overline{M \times 1}$ & $1.5964 \mathrm{E}-04$ & $1.00 \mathrm{E}+00$ & My1 & $6.8404 E-04$ & $1.00 \mathrm{E}+00$ \\
\hline $\mathrm{F} \times 2$ & $1.3881 \mathrm{E}-03$ & $1.00 E+00$ & $M \times 2$ & 1.8829E-04 & $1.00 E+00$ & My2 & 7.2479E-04 & $1.00 \mathrm{E}+00$ \\
\hline Fx3 & 1.4192E-03 & $1.00 E+00$ & $\mathrm{M} \times 3$ & 1.9255E-04 & $1.00 E+00$ & My3 & 7.3016E-04 & $9.99 E-01$ \\
\hline $\mathrm{Fx} 4$ & $1.4448 \mathrm{E}-03$ & $1.00 E+00$ & Mx4 & 1.9849E-04 & $1.00 E+00$ & My4 & 7.4634E-04 & 9.99E-01 \\
\hline $\mathrm{F} \times 5$ & 1.6653E-03 & $1.00 E+00$ & Mx5 & 2.8695E-04 & $1.00 \mathrm{E}+00$ & My5 & 9.1855E-04 & $1.00 E+00$ \\
\hline Fx6 & $1.9558 \mathrm{E}-03$ & $1.00 E+00$ & Mx6 & 4.1330E-04 & $1.00 E+00$ & My6 & 1.1839E-03 & $1.00 \mathrm{E}+00$ \\
\hline $\mathrm{Fx} 7$ & $2.2991 \mathrm{E}-03$ & $1.00 E+00$ & $M \times 7$ & 5.9108E-04 & $1.00 E+00$ & My7 & 1.5830 E-03 & $1.00 E+00$ \\
\hline$F \times 8$ & 2.8076E-03 & $1.00 E+00$ & Mx8 & 8.9084E-04 & $1.00 E+00$ & My8 & 2.2394E-03 & $1.00 \mathrm{E}+00$ \\
\hline Fx 9 & $3.5990 \mathrm{E}-03$ & $1.00 E+00$ & $\mathrm{Mxg}$ & $1.4521 \mathrm{E}-03$ & $1.00 E+00$ & My9 & 3.4529E-03 & $1.00 \mathrm{E}+00$ \\
\hline$F \times 10$ & $4.9510 \mathrm{E}-03$ & $1.00 E+00$ & $\mathrm{Mx} 10$ & $2.6844 \mathrm{E}-03$ & $1.00 \mathrm{E}+00$ & My10 & 6.1043E-03 & $1.00 E+00$ \\
\hline
\end{tabular}

\section{Define Test Fatigue Load}

$\mathrm{N}=$ 3.00E E06 test cycles

radial and flap loads (Fx, My strength laminate)

damage $=$ 1.00

Sm_str $=1 \%$. 88.2 Assume mean stress

Sa_str $=\quad 58.9$ test alternating stress from S/N curve

$R=\quad-0.10$ test ratio of $\mathrm{min} / \mathrm{max}$

Smax_str $=\quad 128.7$ test $\max$ stress

Smin_str $=\quad-12.9$ test $\min$ stress edge loads ( $M x$ tail/nose laminate)

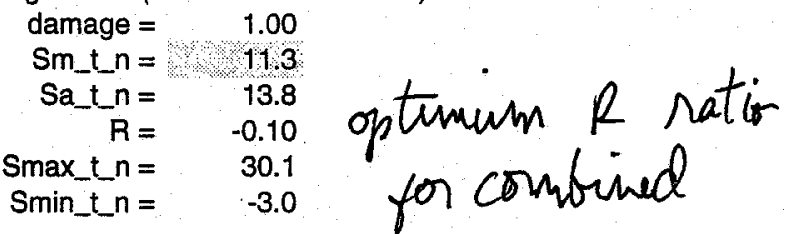

TEST LOADS

\begin{tabular}{|c|c|c|c|c|c|c|c|c|c|}
\hline \multicolumn{3}{|c|}{$F X \max (\mathrm{Nm}) F X \min (\mathrm{Nm})$} & \multicolumn{3}{|c|}{$\mathrm{MX} \max (\mathrm{Nm}) \mathrm{MX} \min (\mathrm{Nm})$} & \multicolumn{2}{|c|}{ MYmax (Nm) } & MYmin (Nm) & \multirow[t]{2}{*}{ Radius(m) } \\
\hline$\overline{F \times 1}$ & 112400.9 & -11238.4 & Mx1 & 188513.3 & -18855.2 & My1 & 188114.6 & -18808.6 & \\
\hline$F \times 2$ & 92703.4 & -9268.9 & $M \times 2$ & 159827.9 & -15986.1 & My2 & 177538.3 & -17751.1 & 0. \\
\hline$F \times 3$ & 90668.4 & -9065.5 & $M \times 3$ & 156288.1 & -15632.1 & My3 & 176232.6 & -17620.6 & 0.65 \\
\hline Fx4 & 89061.0 & -8904.7 & Mx4 & 151615.4 & -15164.7 & My4 & 172411.7 & -17238.5 & 0.8 \\
\hline Fx5 & 77270.1 & -7725.8 & $M \times 5$ & 104873.6 & -10489.5 & My5 & 140087.8 & -14006.6 & 2.65 \\
\hline Fx6 & 65792.8 & -6578.3 & Mx6 & 72813.3 & -7282.8 & My6 & 108686.2 & -10867.0 & 3 \\
\hline$F \times 7$ & 55969.3 & -5596.1 & $M \times 7$ & 50912.4 & -5092.3 & My7 & 81288.2 & -8127.6 & 5.1 \\
\hline Fx8 & 45832.0 & -4582.5 & Mx8 & 33781.0 & -3378.8 & My8 & 57462.2 & -5745.3 & 6.4 \\
\hline Fx9 & 35753.4 & -3574.8 & $M \times 9$ & 20723.7 & -2072.8 & My9 & 37266.3 & -3726.1 & 7.65 \\
\hline Fxto & 25990.3 & -2598.6 & Mx10 & 11210.4 & -1121.3 & My10 & 21079.8 & -2107.7 & 8 \\
\hline
\end{tabular}

Extreme Load - Load Case $93 \times 1.5$

\begin{tabular}{rr|rr} 
& $R$ & Flap-Extr. & Load $(\mathrm{N})$ \\
\hline My1 & 0.2 & 247554.0 & 33,229 \\
& 7.65 & 0 &
\end{tabular}

Extreme Load - Load Case $97 \times 1.5$

$\mathrm{Mx} 1$
Test Load match Mx4max and My5max

My1

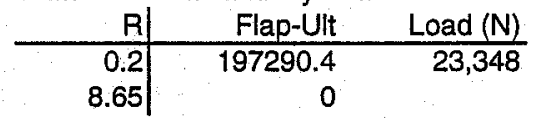

$M \times 1$

\begin{tabular}{|c|c|c|}
\hline $\mathrm{R}$ & Edge-Ult & Load $(\mathrm{N})$ \\
\hline 0.2 & 163203.9 & 19,314 \\
\hline 8.65 & 0 & \\
\hline
\end{tabular}




\title{
Appendix C
}

\author{
Edgewise Static Data
}

C-1 

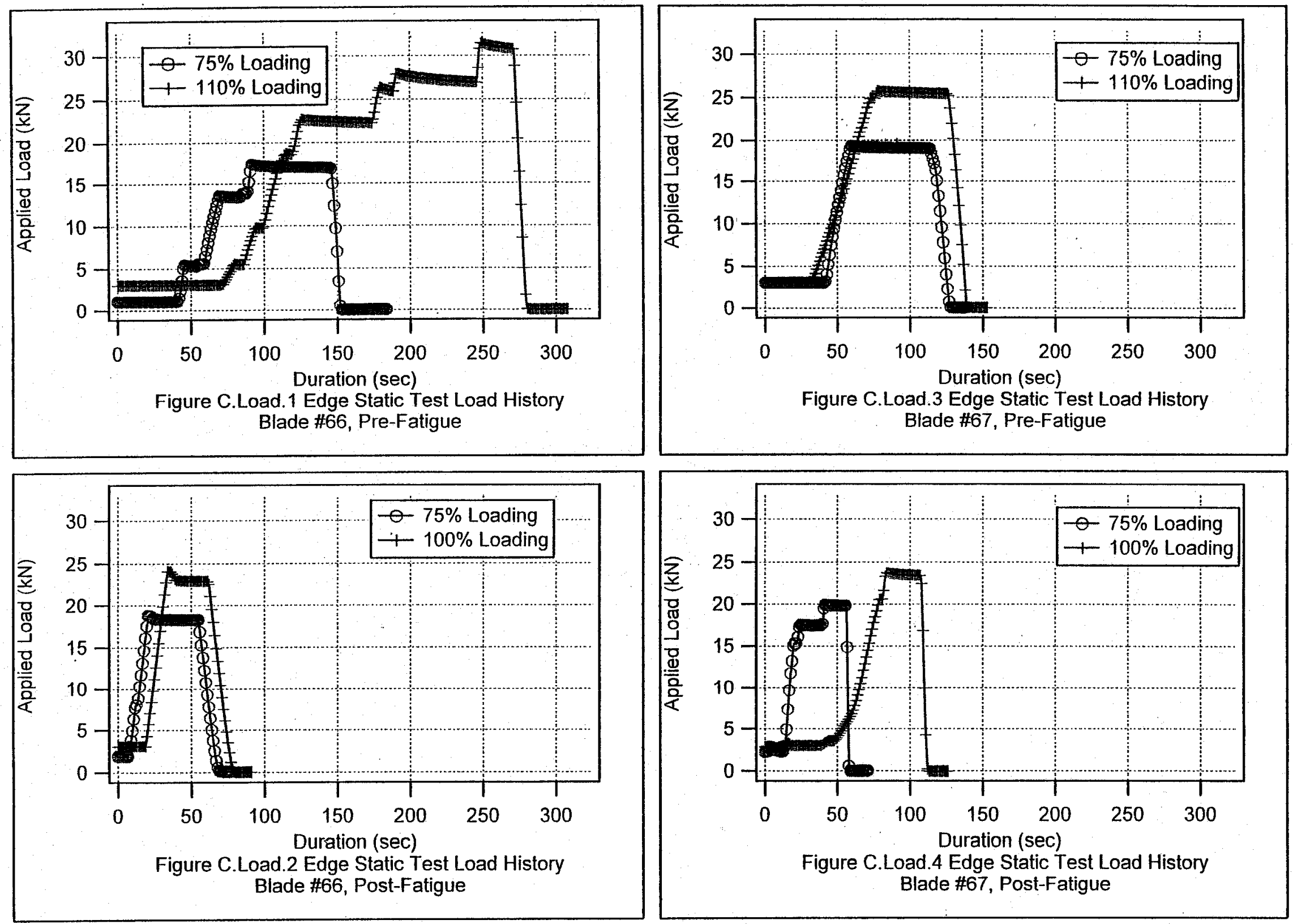

Figure C.Load.4 Edge Static Test Load History Blade \#67, Post-Fatigue 

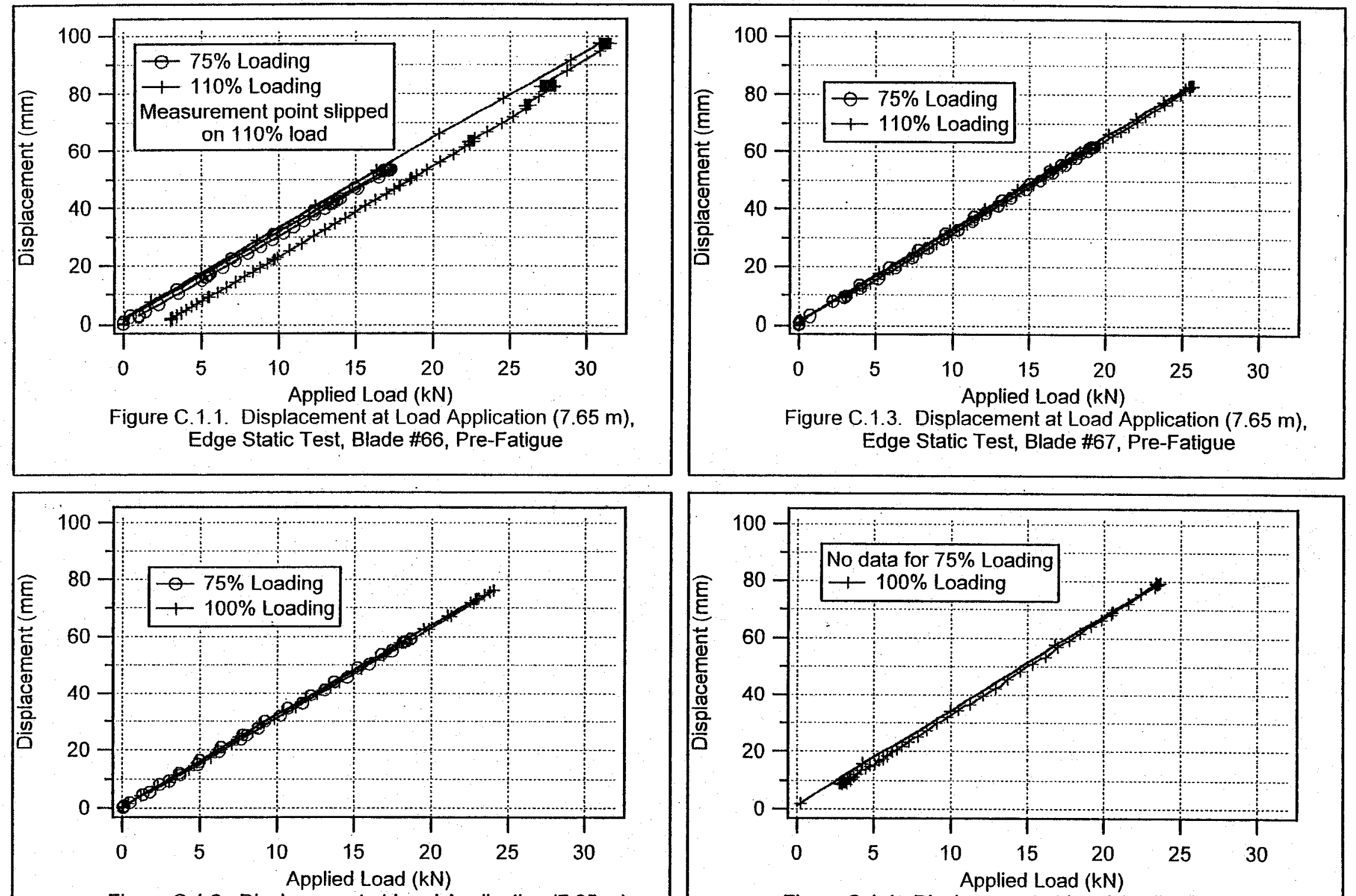

Figure C.1.2. Displacement at Load Application $(7.65 \mathrm{~m})$, Edge Static Test, Blade \#66, Post-Fatigue

Figure C.1.4. Displacement at Load Application (7.65 m), Edge Static Test, Blade \#67, Post-Fatigue 

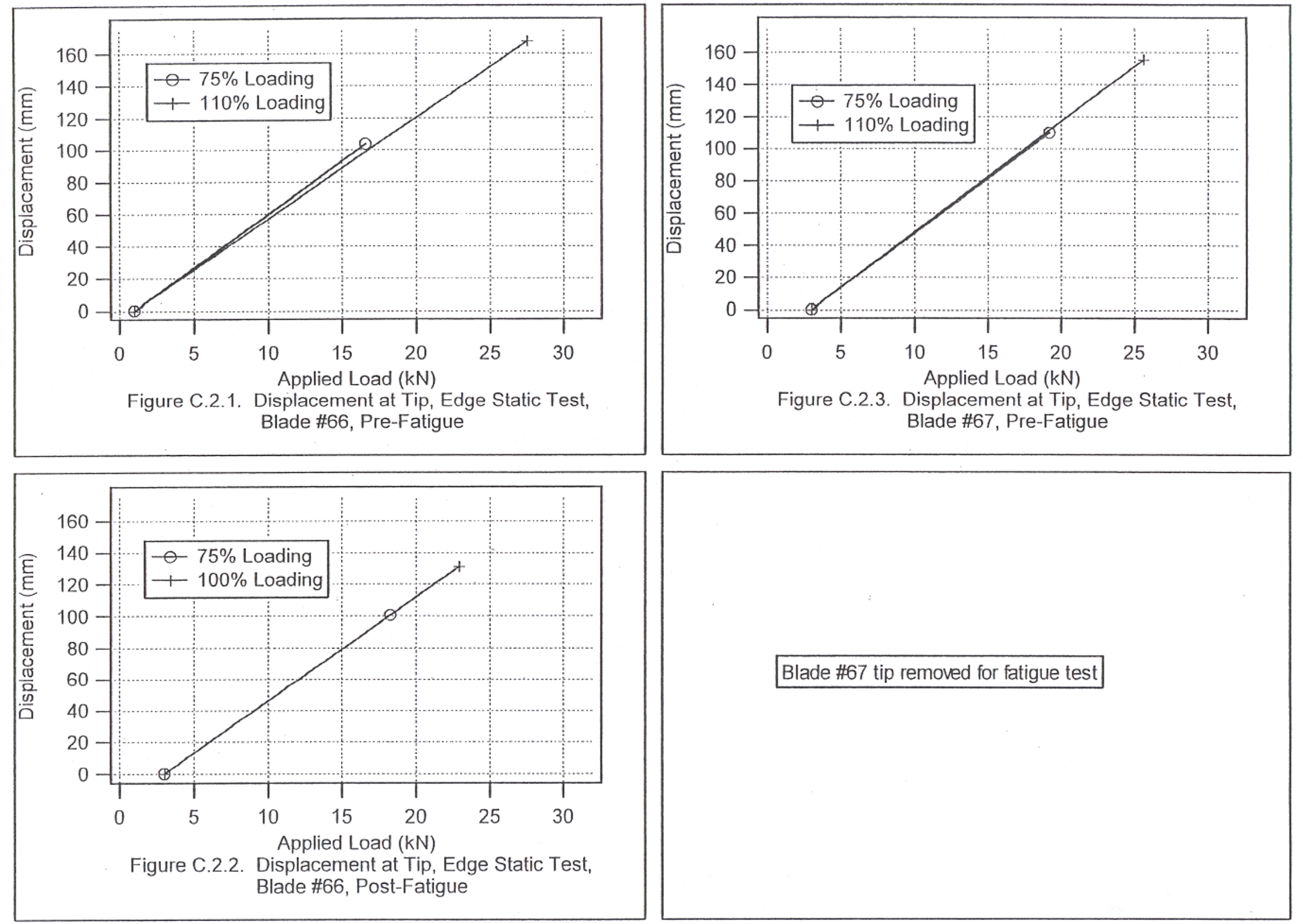

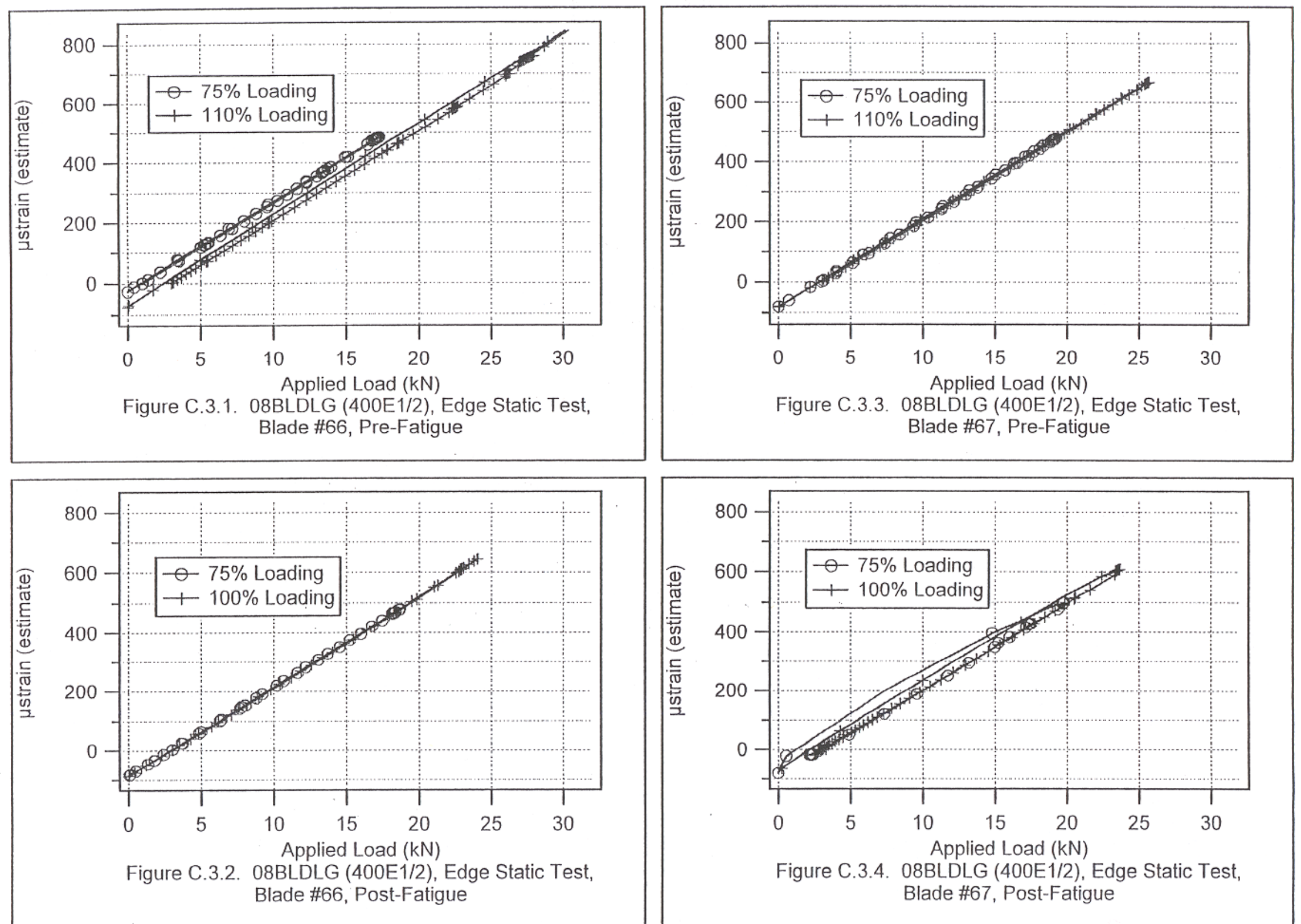

Figure C.3.4. 08BLDLG (400E1/2), Edge Static Test, Blade \#67, Post-Fatigue 

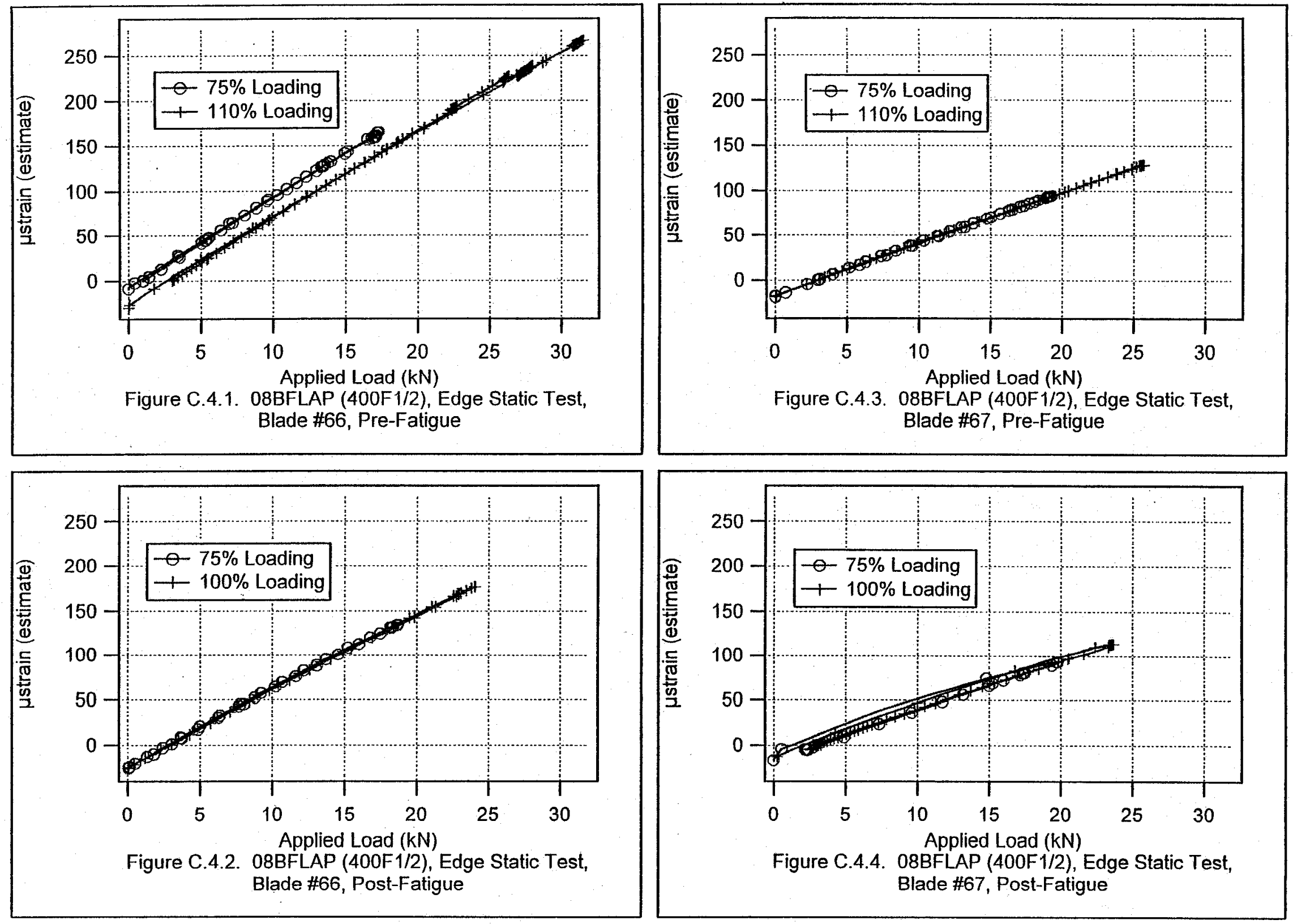

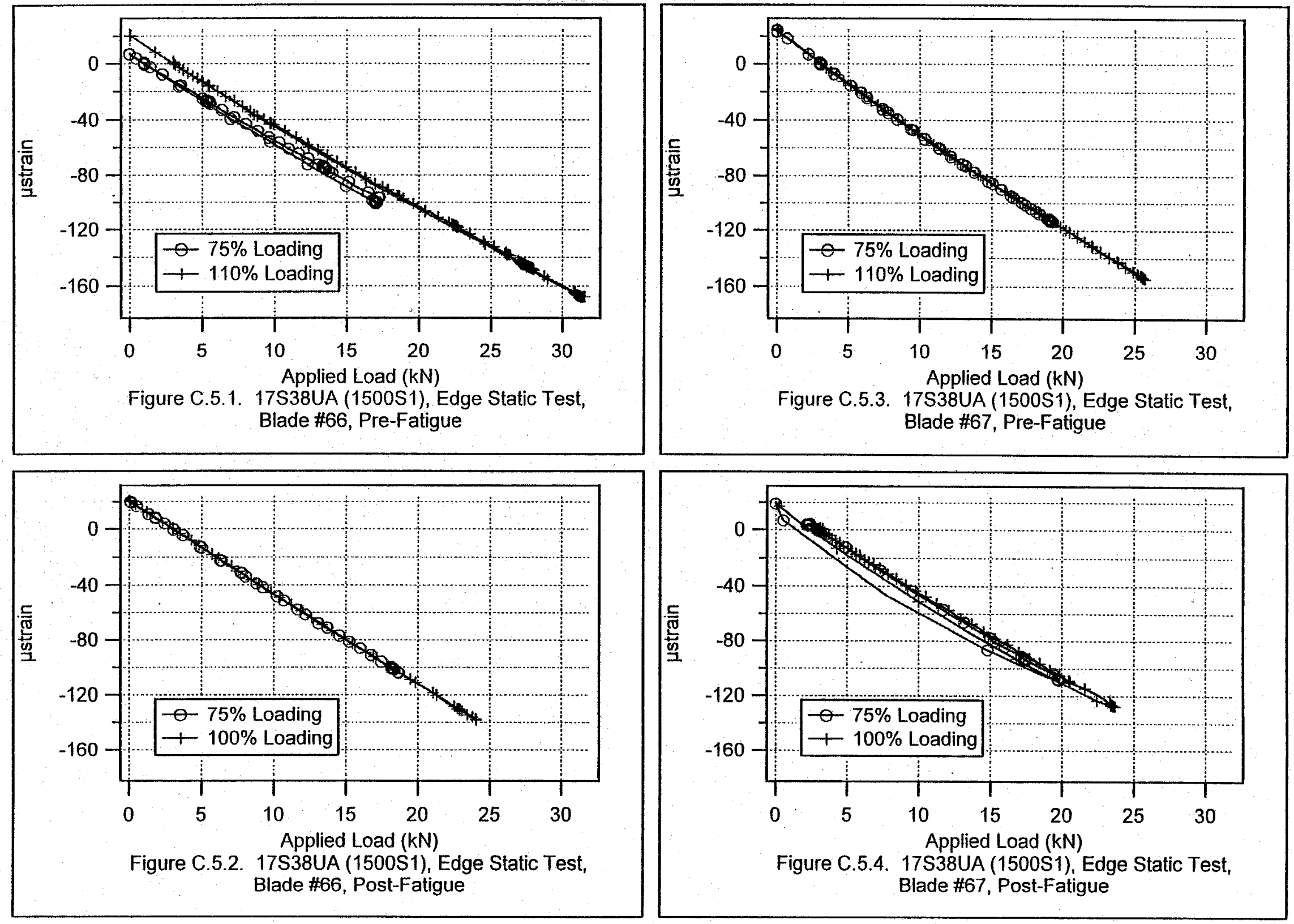

Figure C.5.4. 17S38UA (1500S1), Edge Static Test, Blade \#67, Post-Fatigue 

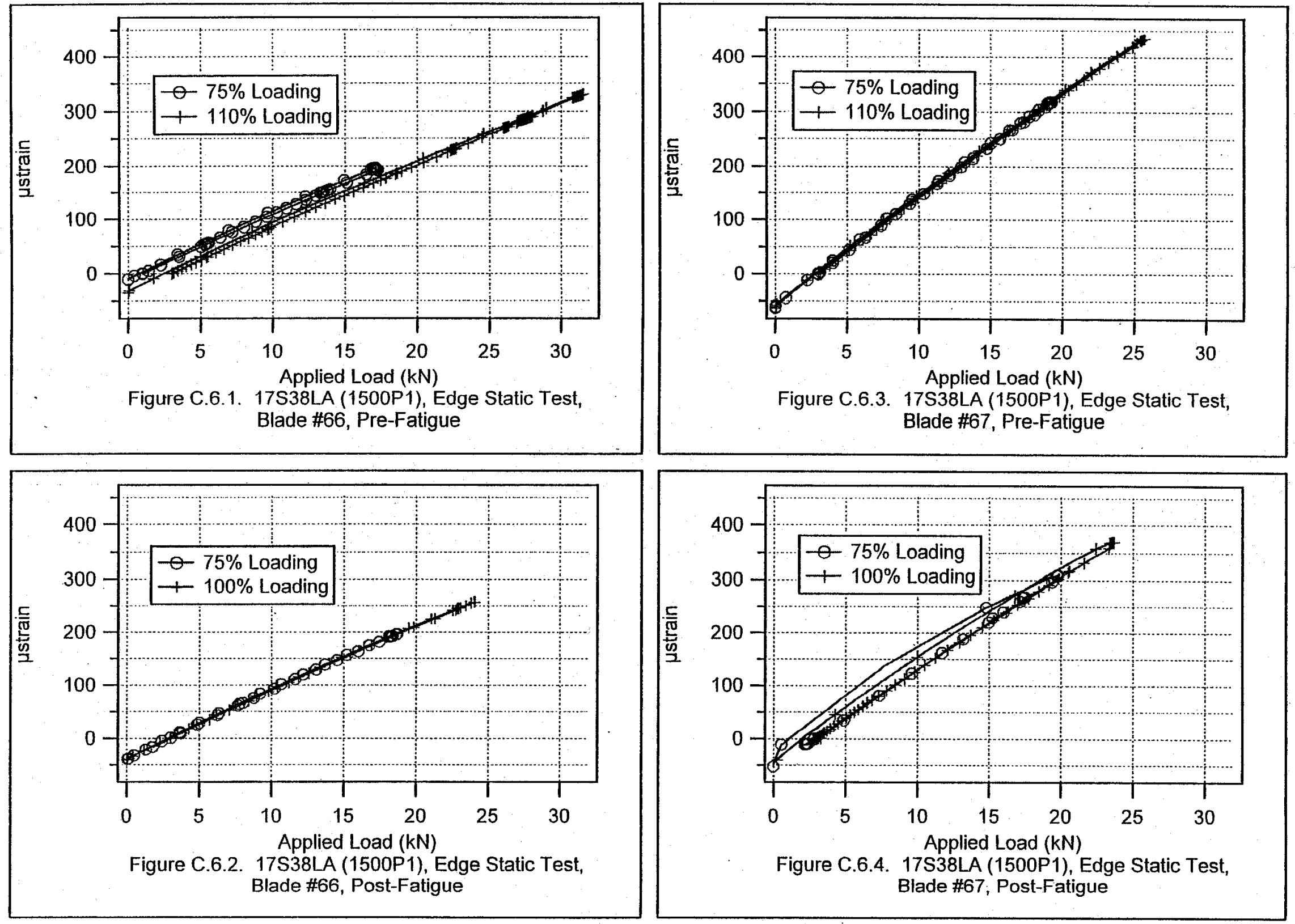

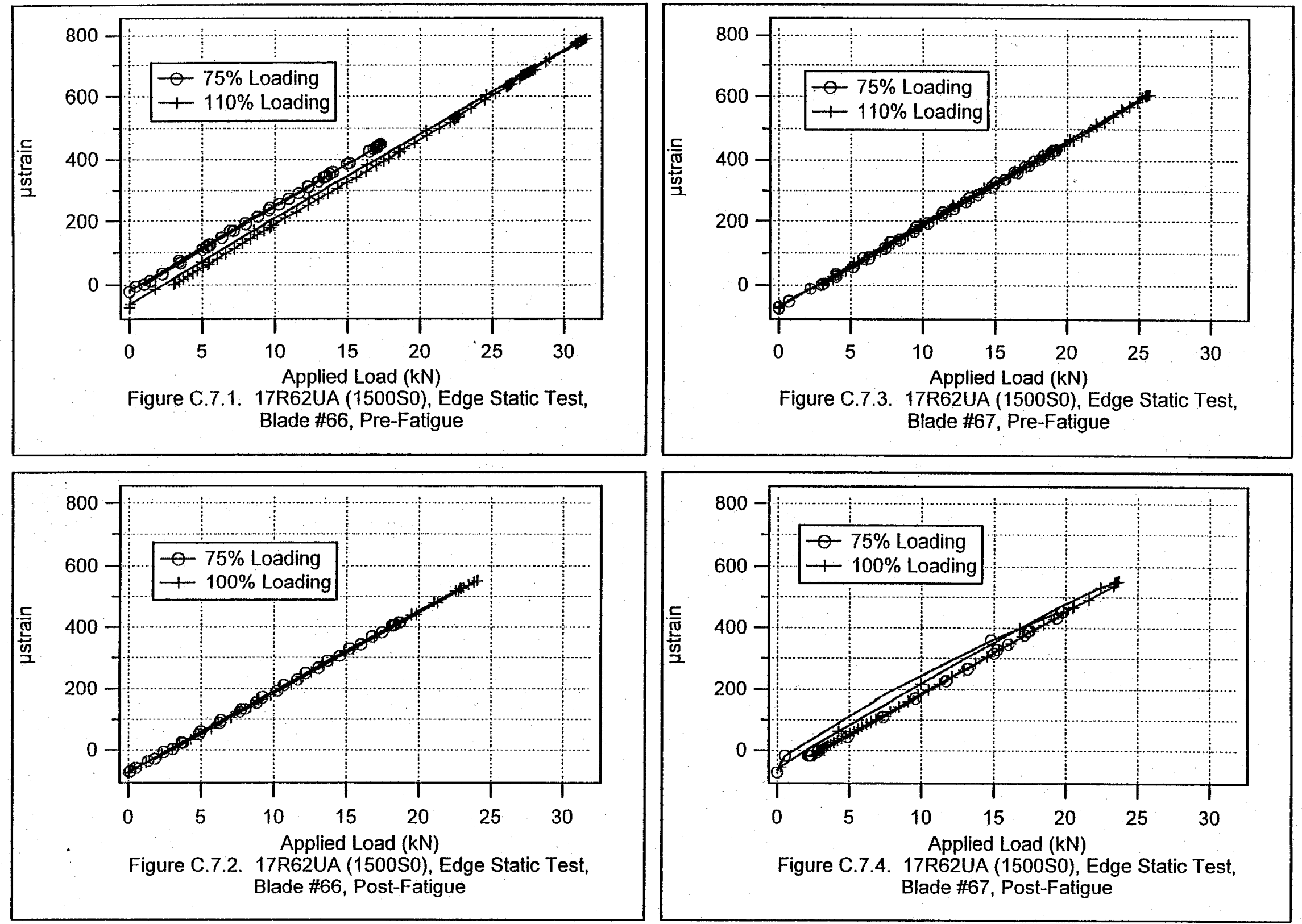

Figure C.7.4. 17R62UA (1500S0), Edge Static Test, Blade \#67, Post-Fatigue 

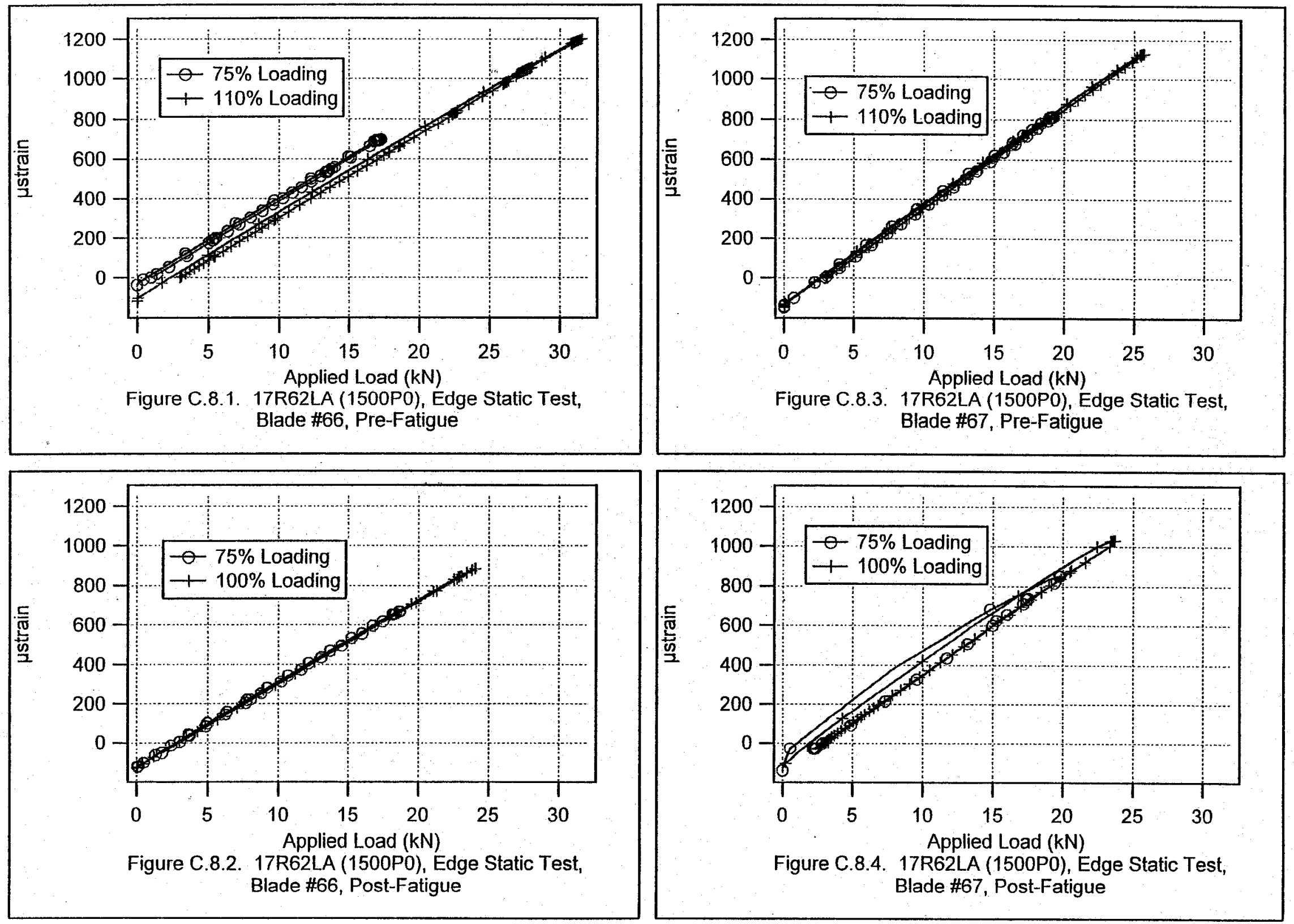

Figure C.8.4. 17R62LA (1500P0), Edge Static Test, Blade \#67, Post-Fatigue 

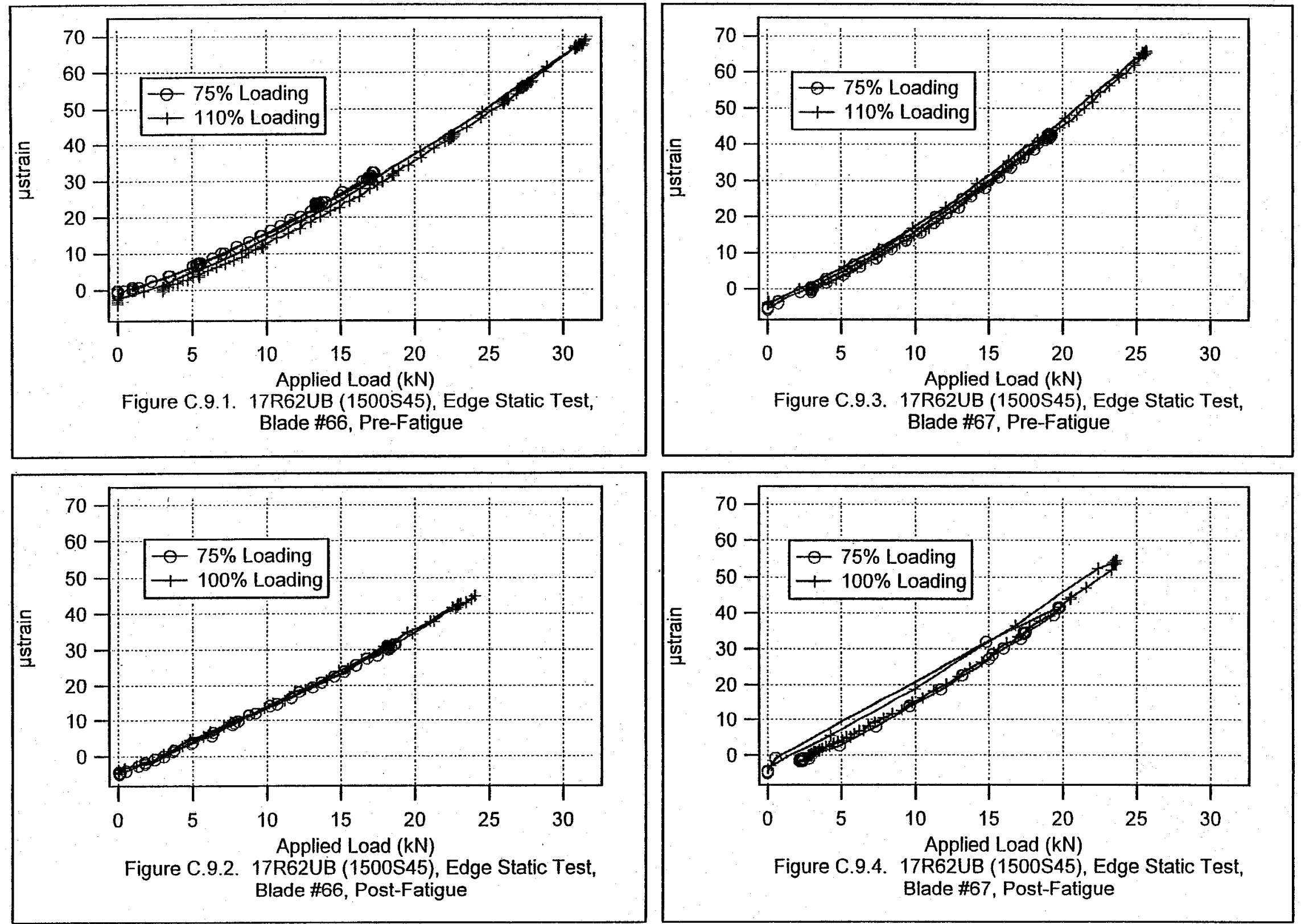

Figure C.9.4. 17R62UB (1500S45), Edge Static Test, Blade \#67, Post-Fatigue 

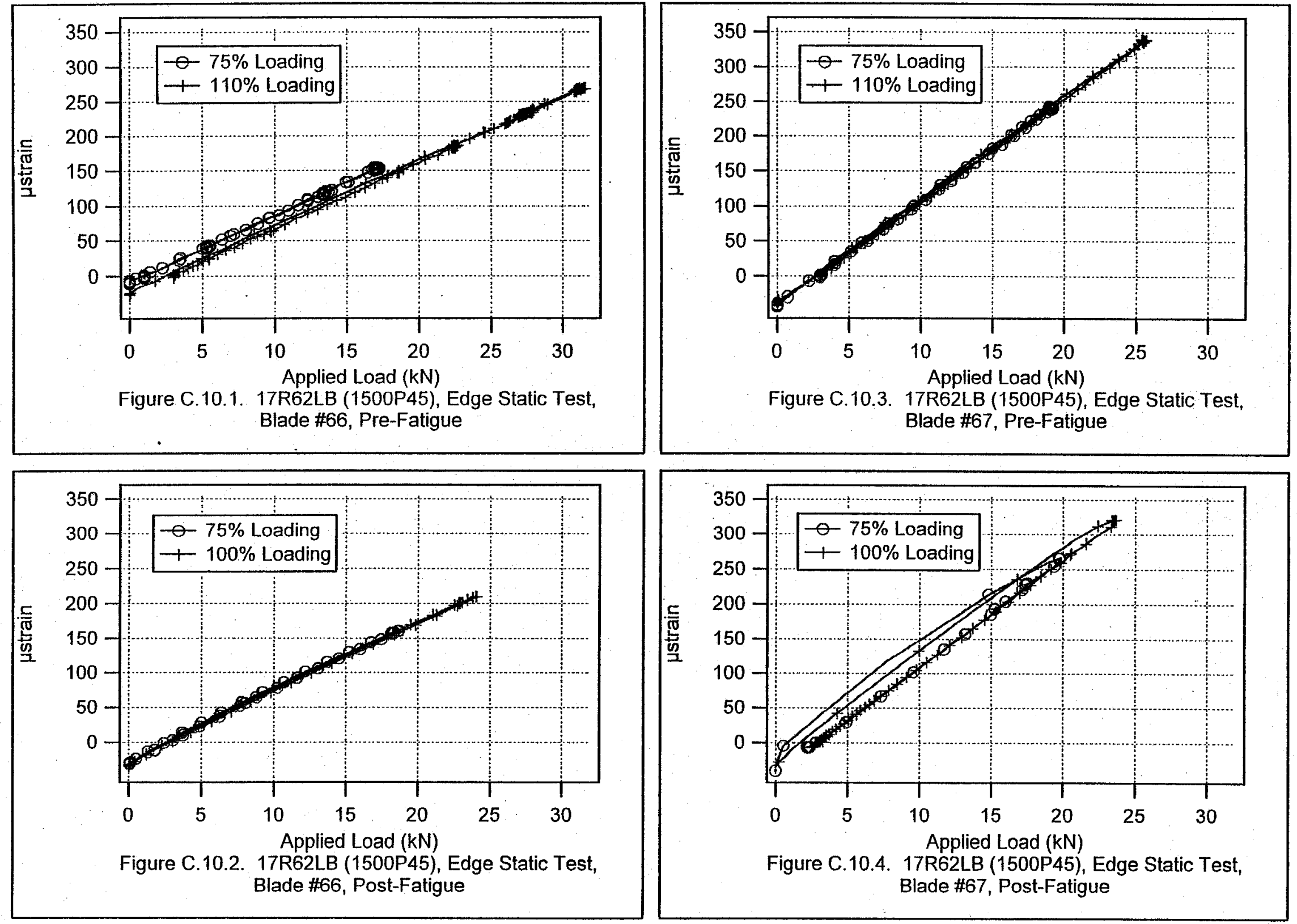

Figure C.10.4. 17R62LB (1500P45), Edge Static Test, Blade \#67, Post-Fatigue 

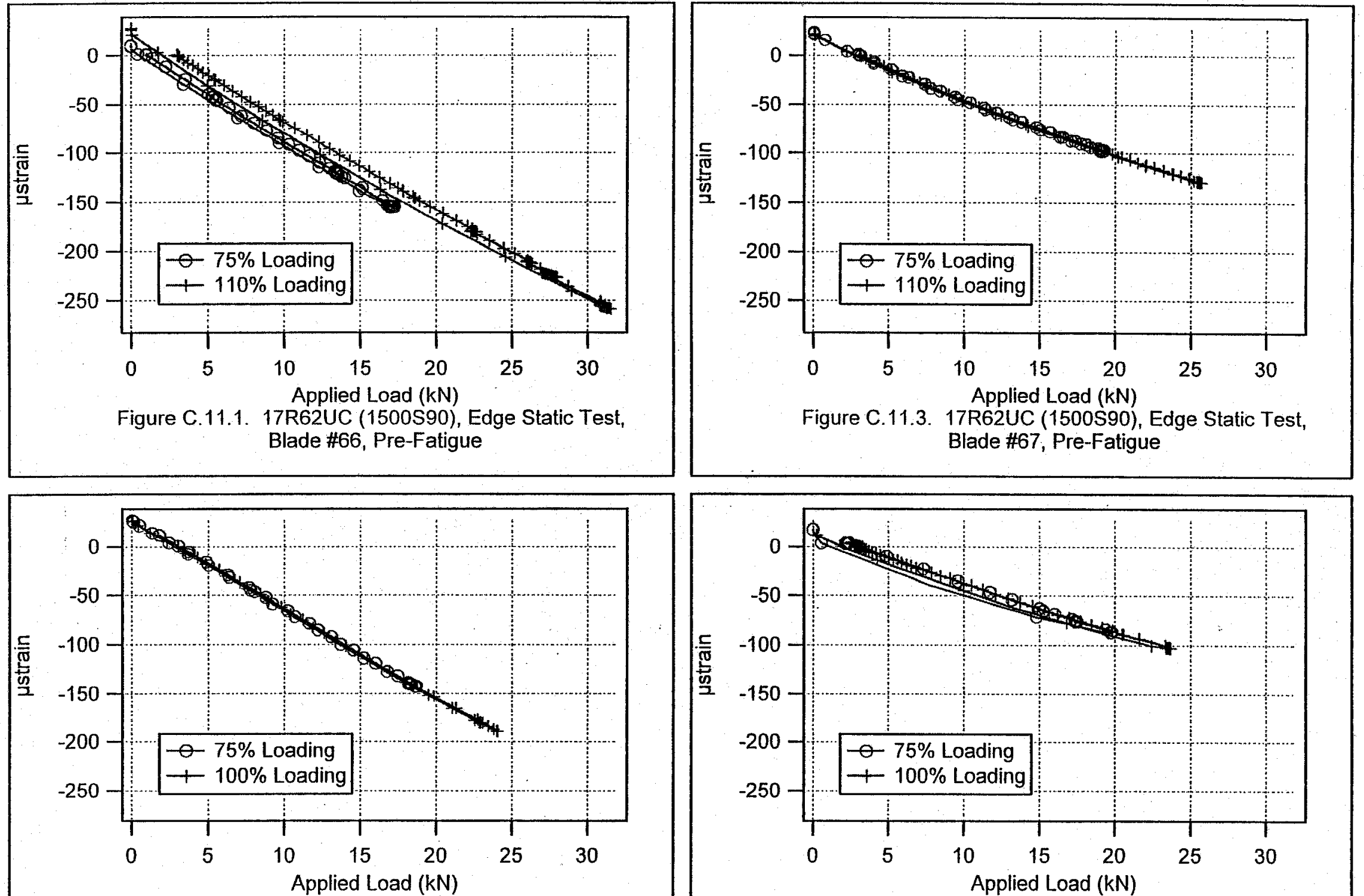

Figure C.11.2. 17R62UC (1500S90), Edge Static Test, Blade \#66, Post-Fatigue

Figure C.11.4. 17R62UC (1500S90), Edge Static Test, Blade \#67, Post-Fatigue 


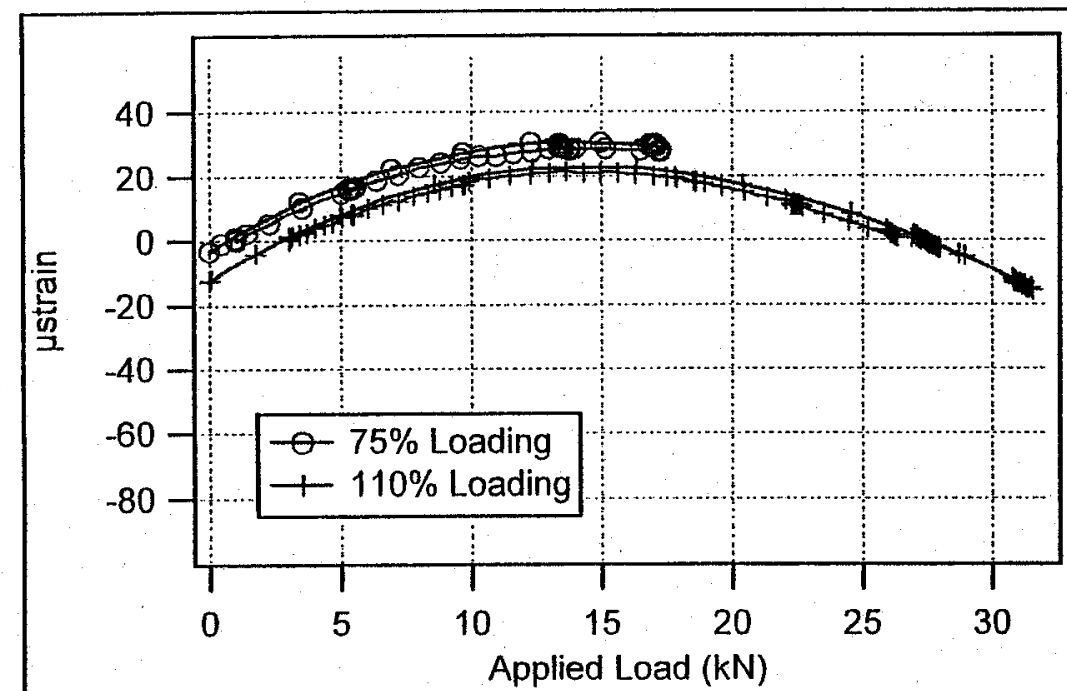

Figure C.12.1. 17R62LC (1500P90), Edge Static Test, Blade \#66, Pre-Fatigue

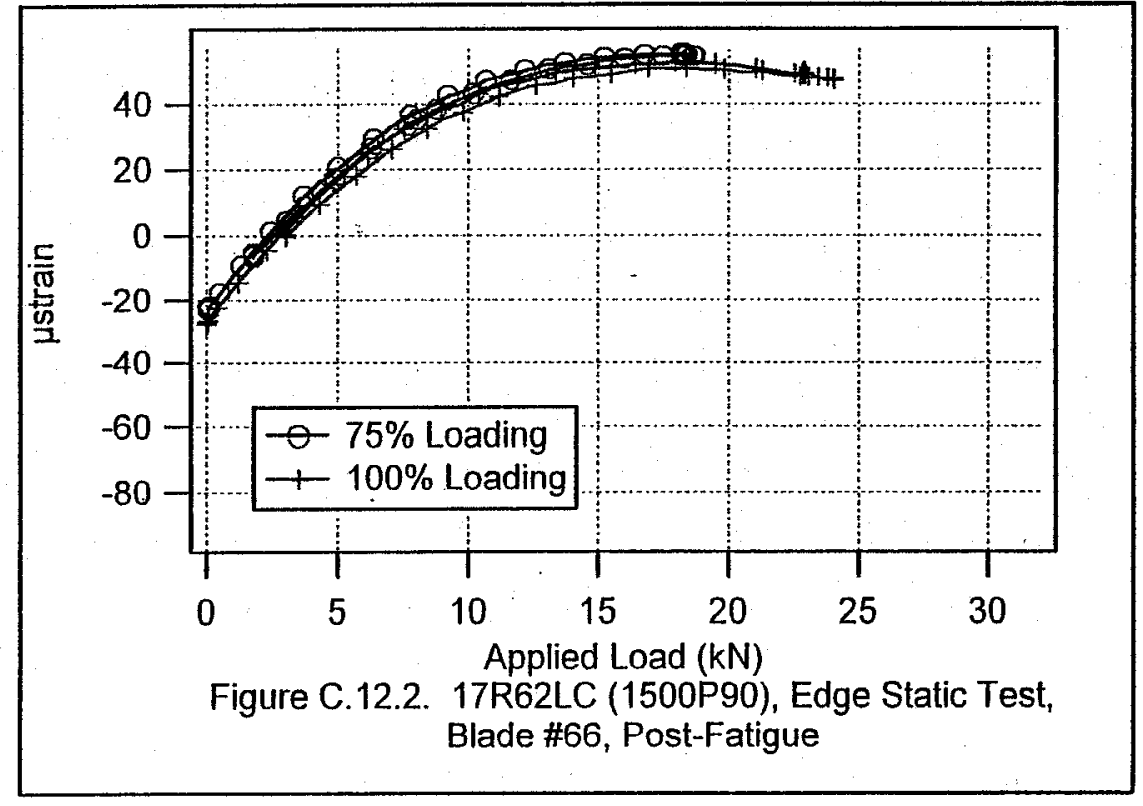

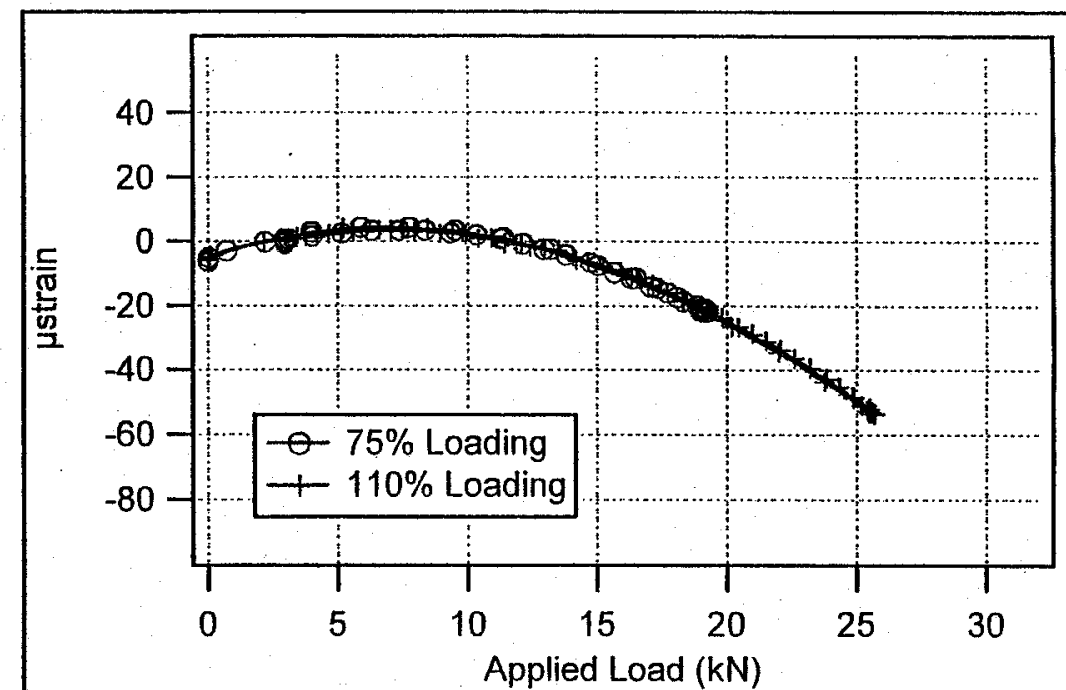

Figure C.12.3. 17R62LC (1500P90), Edge Static Test, Blade \#67, Pre-Fatigue

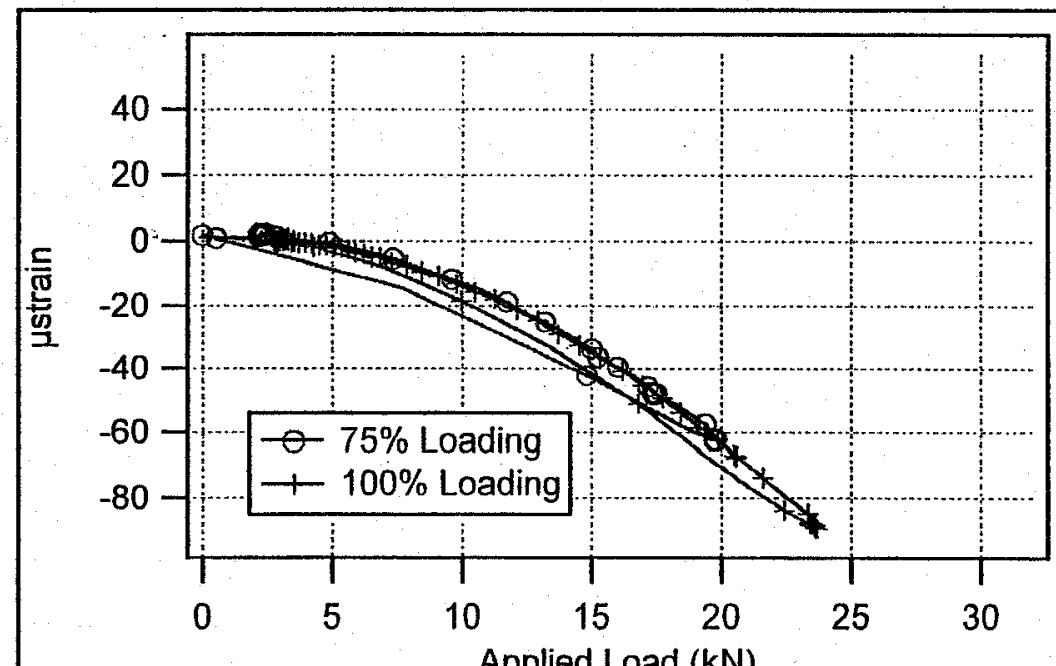

Figure C.12.4. 17R62LC (1500P90), Edge Static Test, Blade \#67, Post-Fatigue 

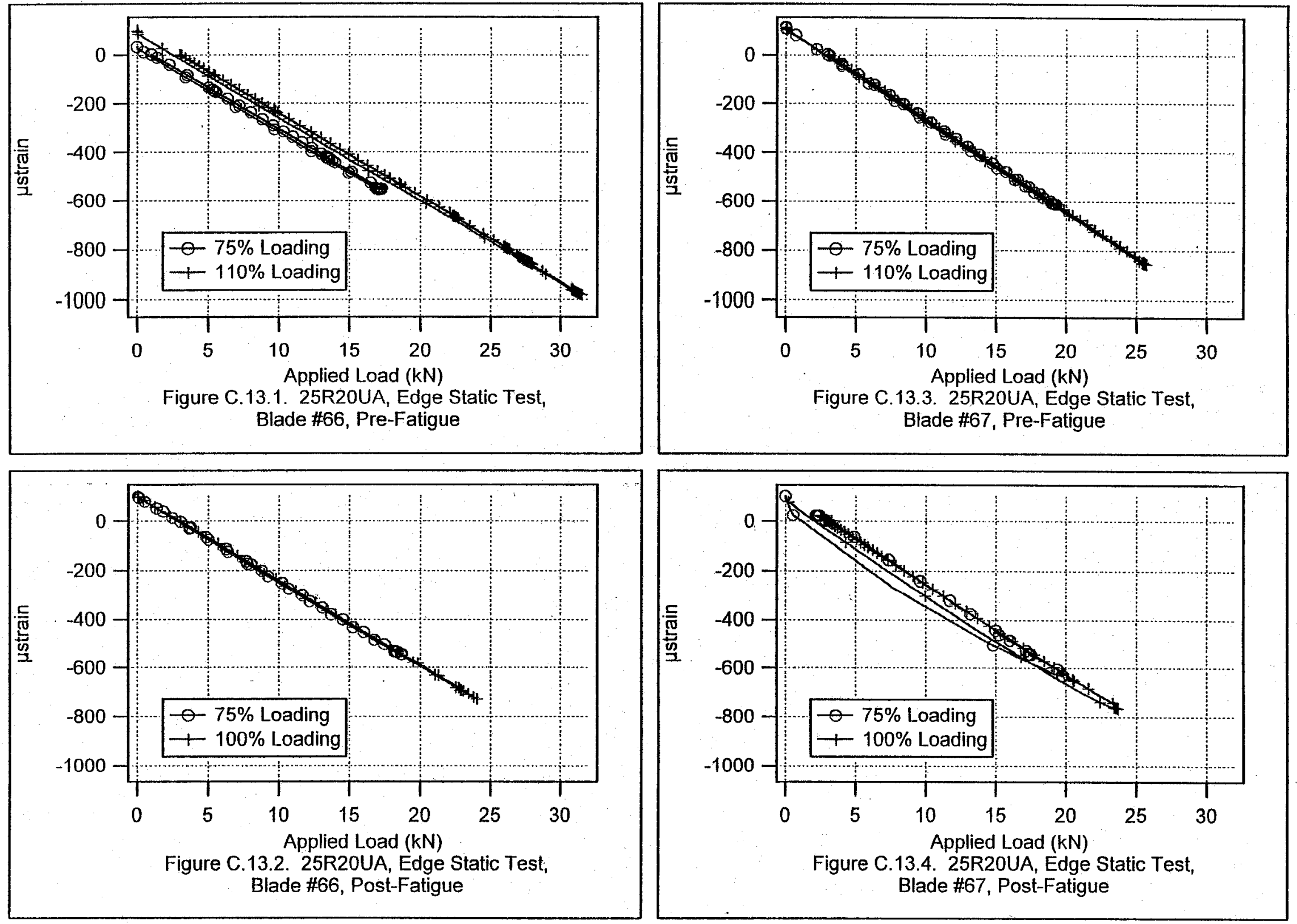

Figure C.13.4. 25R20UA, Edge Static Test, Blade \#67, Post-Fatigue 

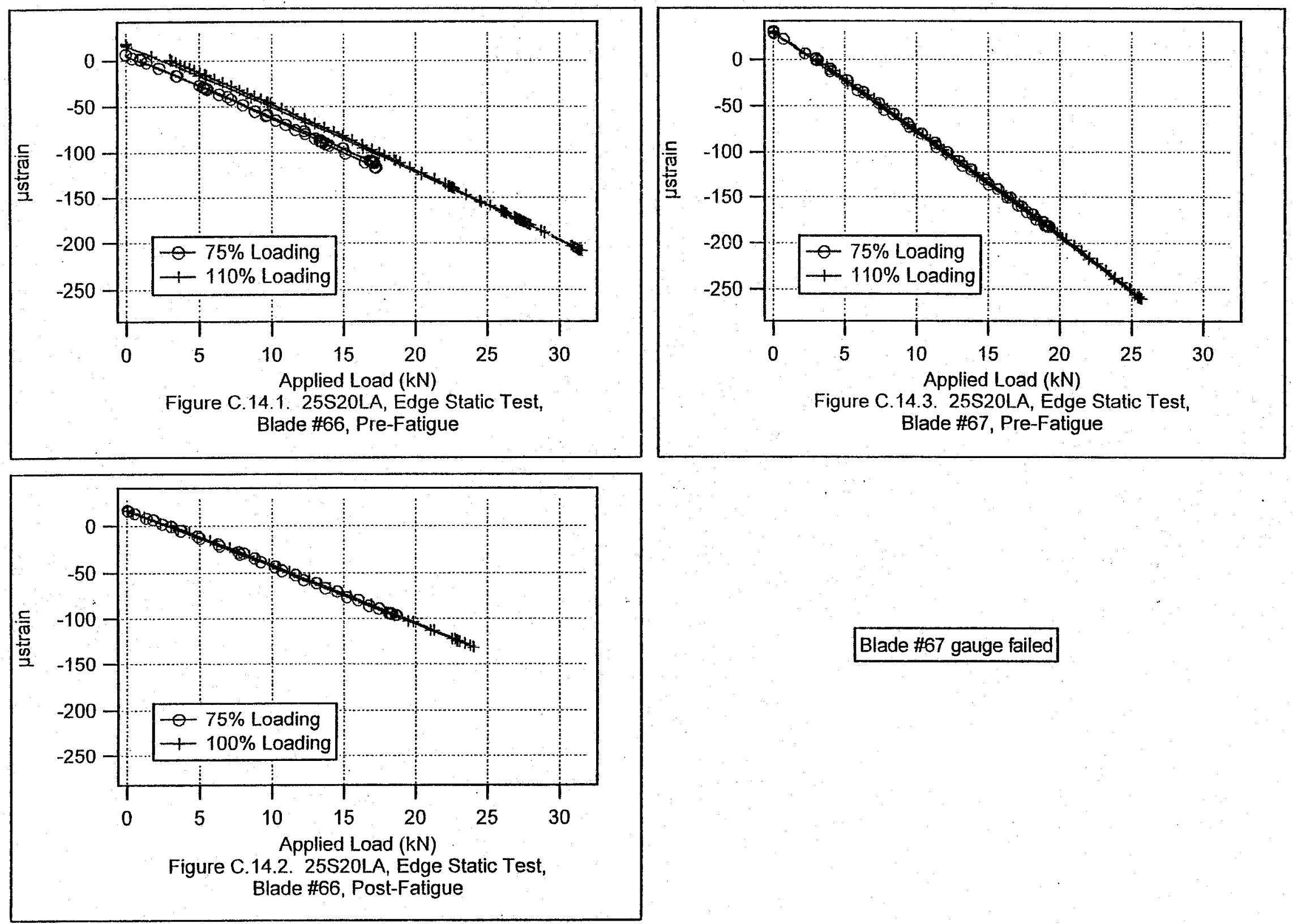

Blade \#67 gauge failed 

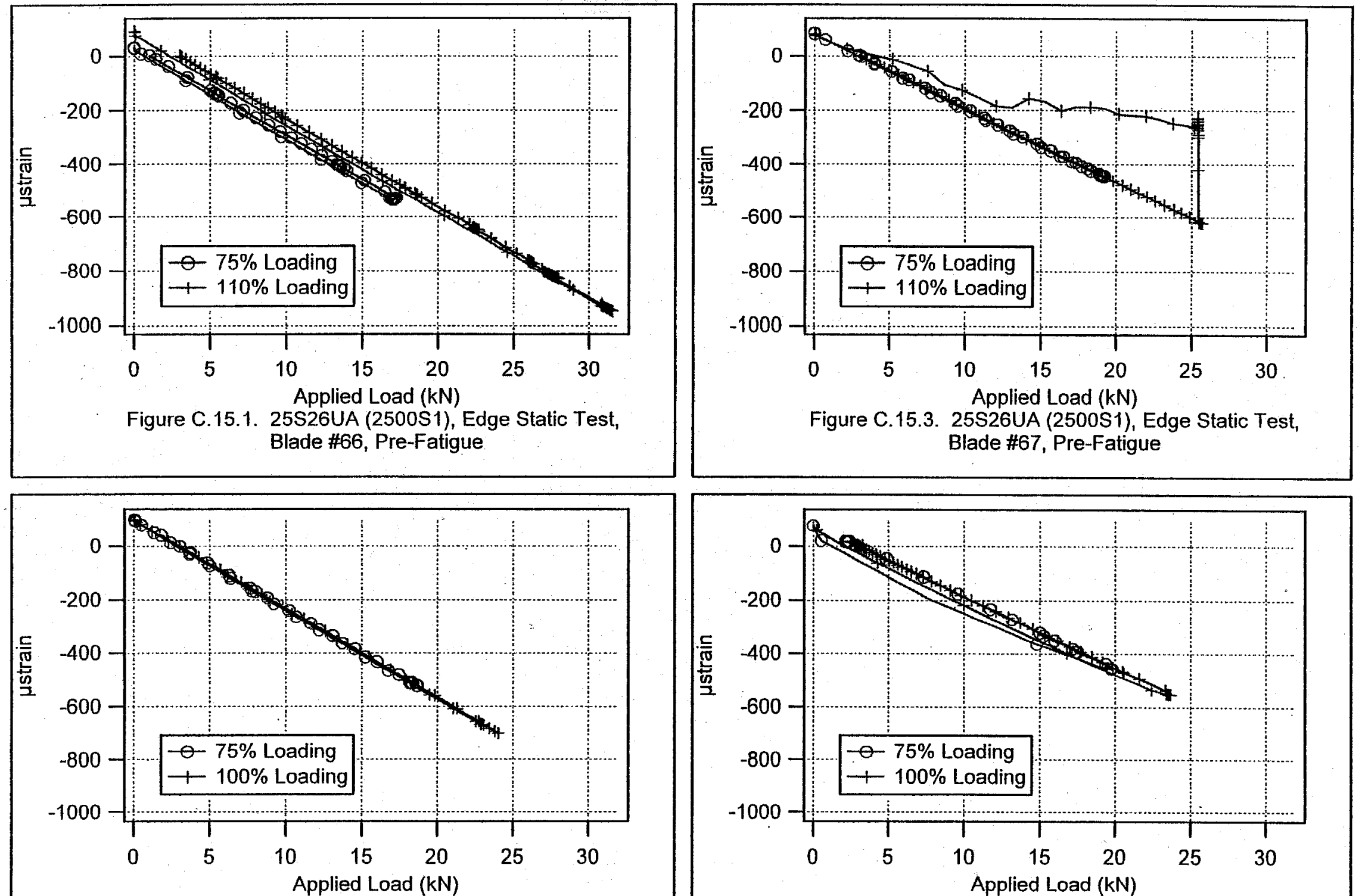

Figure C.15.2. 25S26UA (2500S1), Edge Static Test, Blade \#66, Post-Fatigue

Figure C.15.4. 25S26UA (2500S1), Edge Static Test Blade \#67, Post-Fatigue 

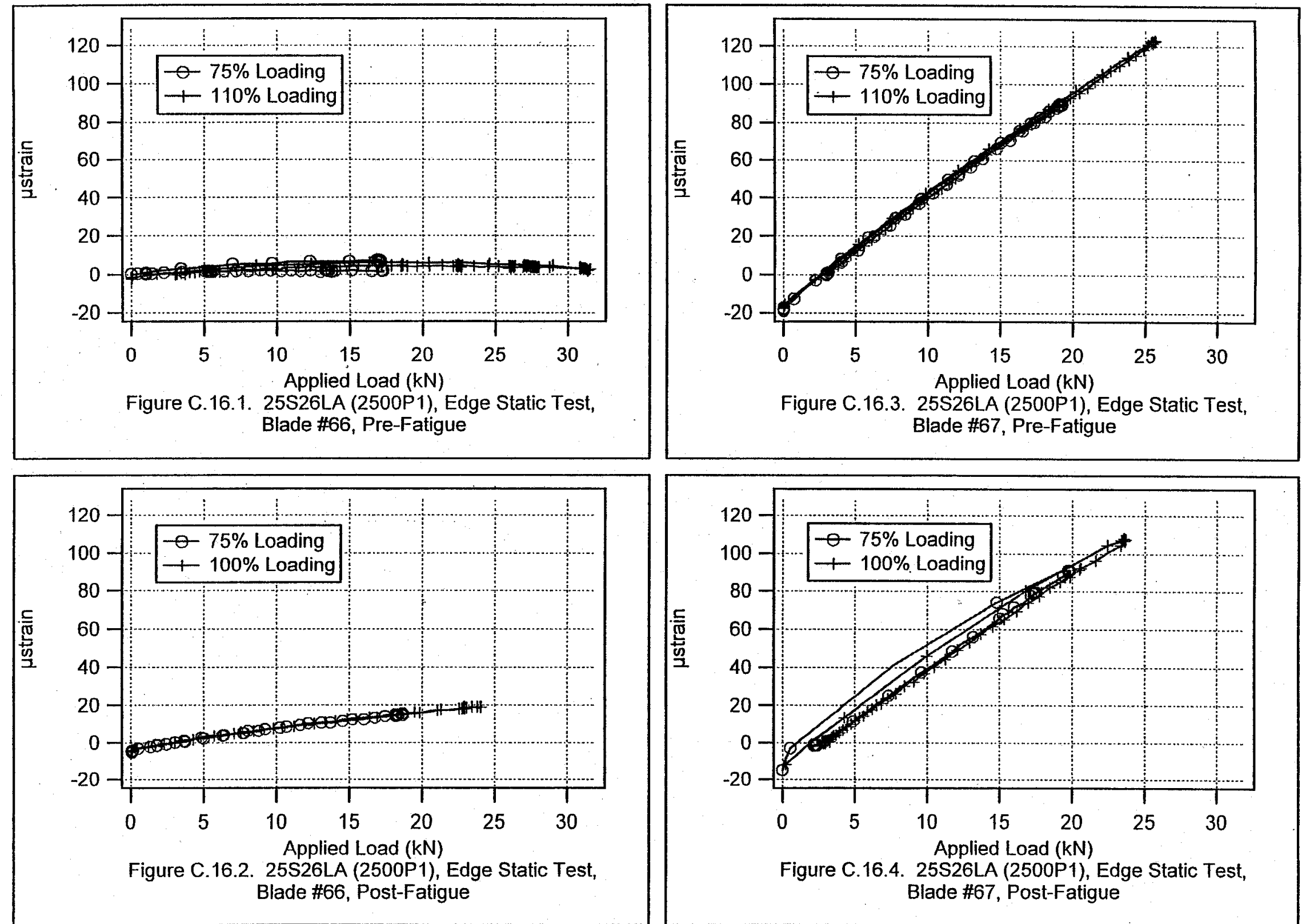

Figure C.16.4. 25S26LA (2500P1), Edge Static Test, Blade \#67, Post-Fatigue 

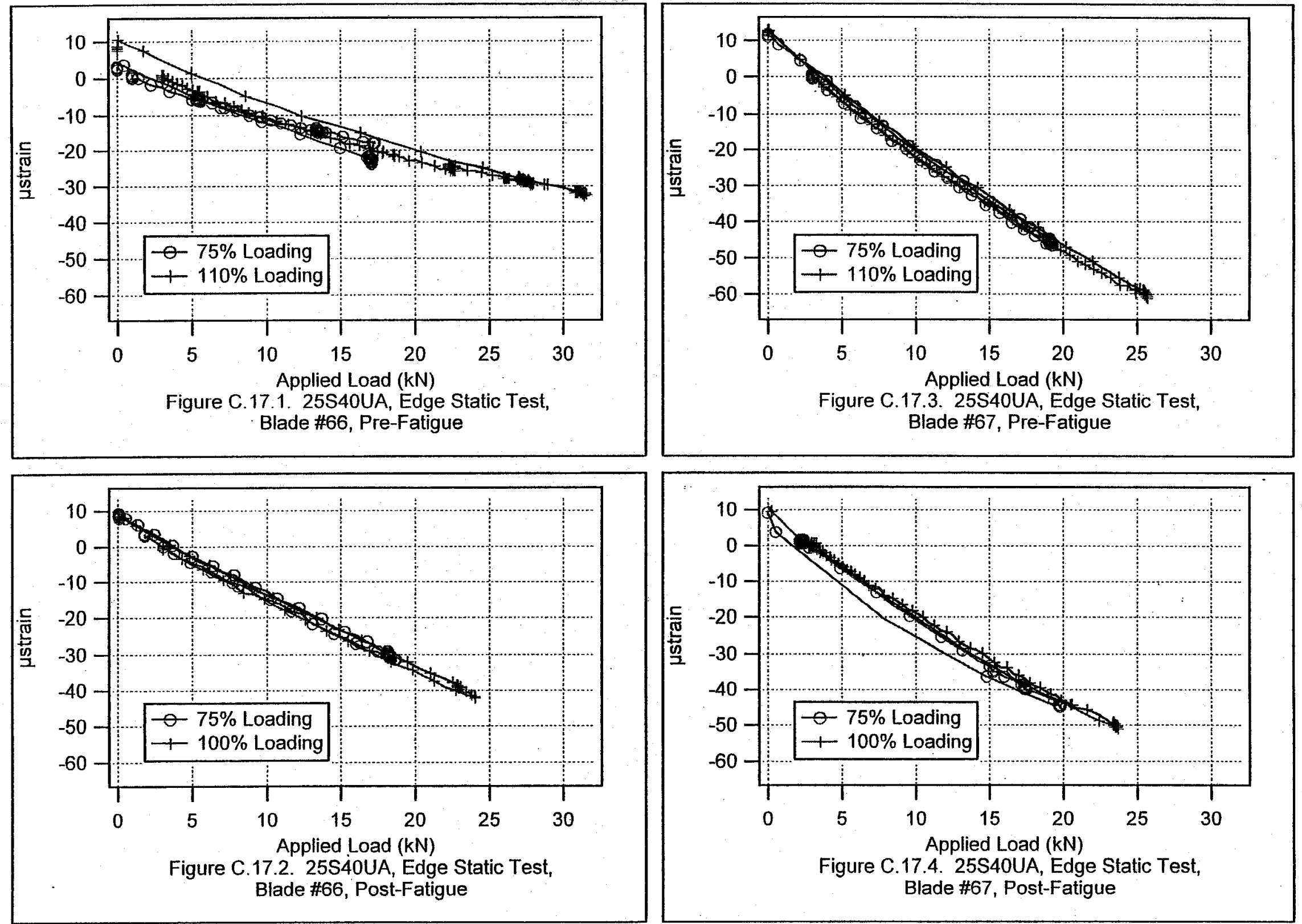

Figure C.17.4. 25S40UA, Edge Static Test, Blade \#67, Post-Fatigue 

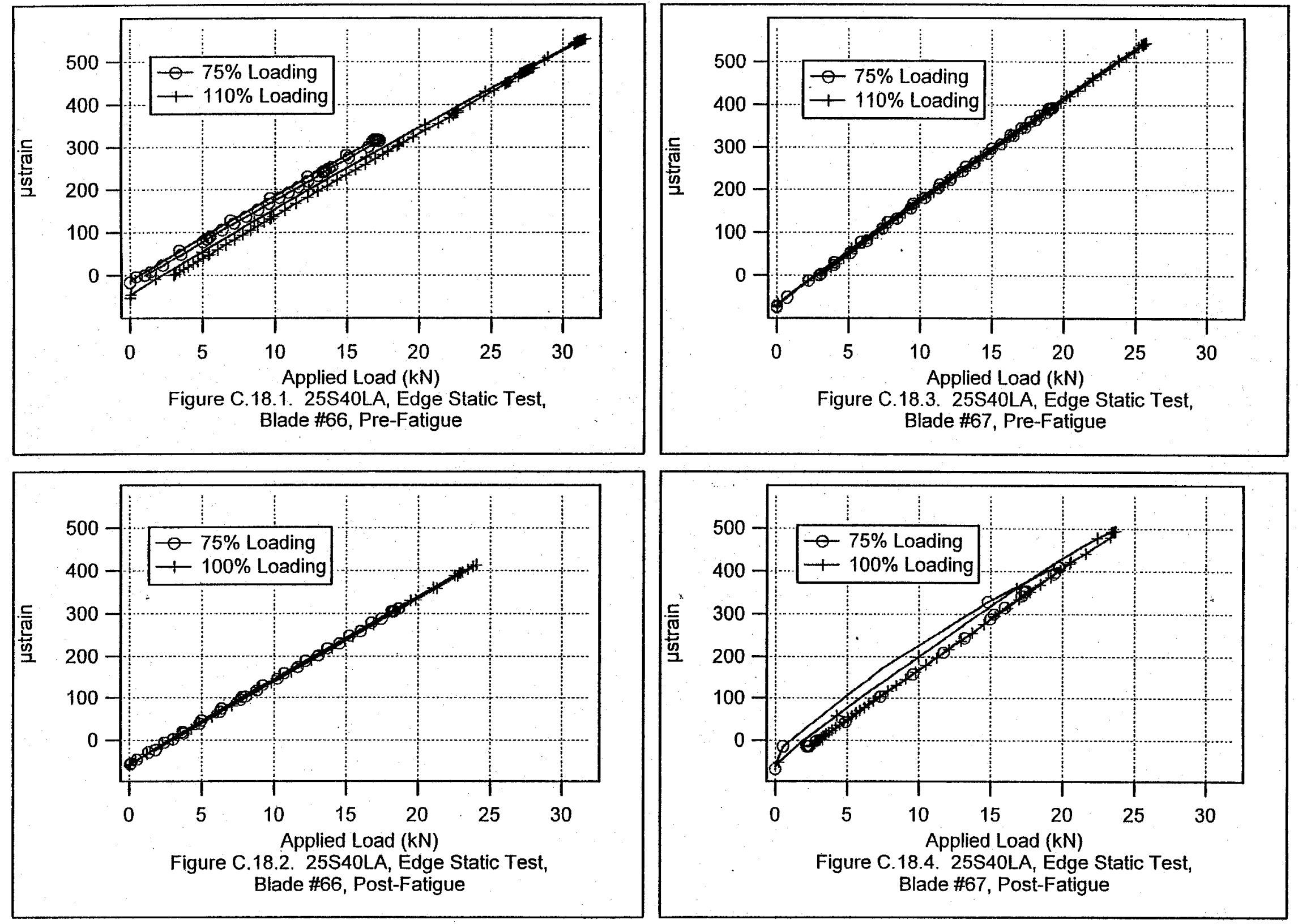

Figure C.18.4. 25S40LA, Edge Static Test, Blade \#67, Post-Fatigue 

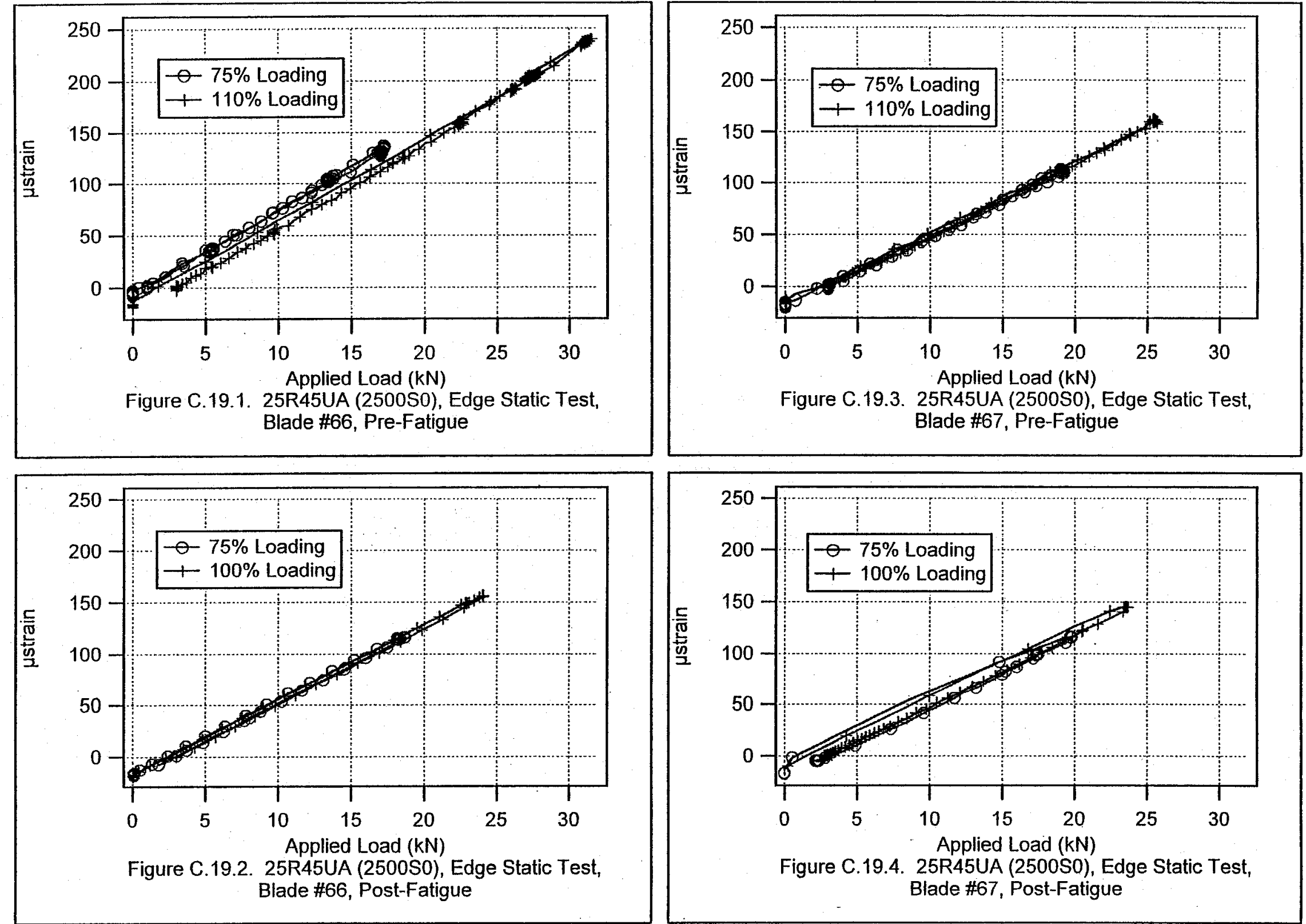

Figure C.19.4. 25R45UA (2500SO), Edge Static Test, Blade \#67, Post-Fatigue 

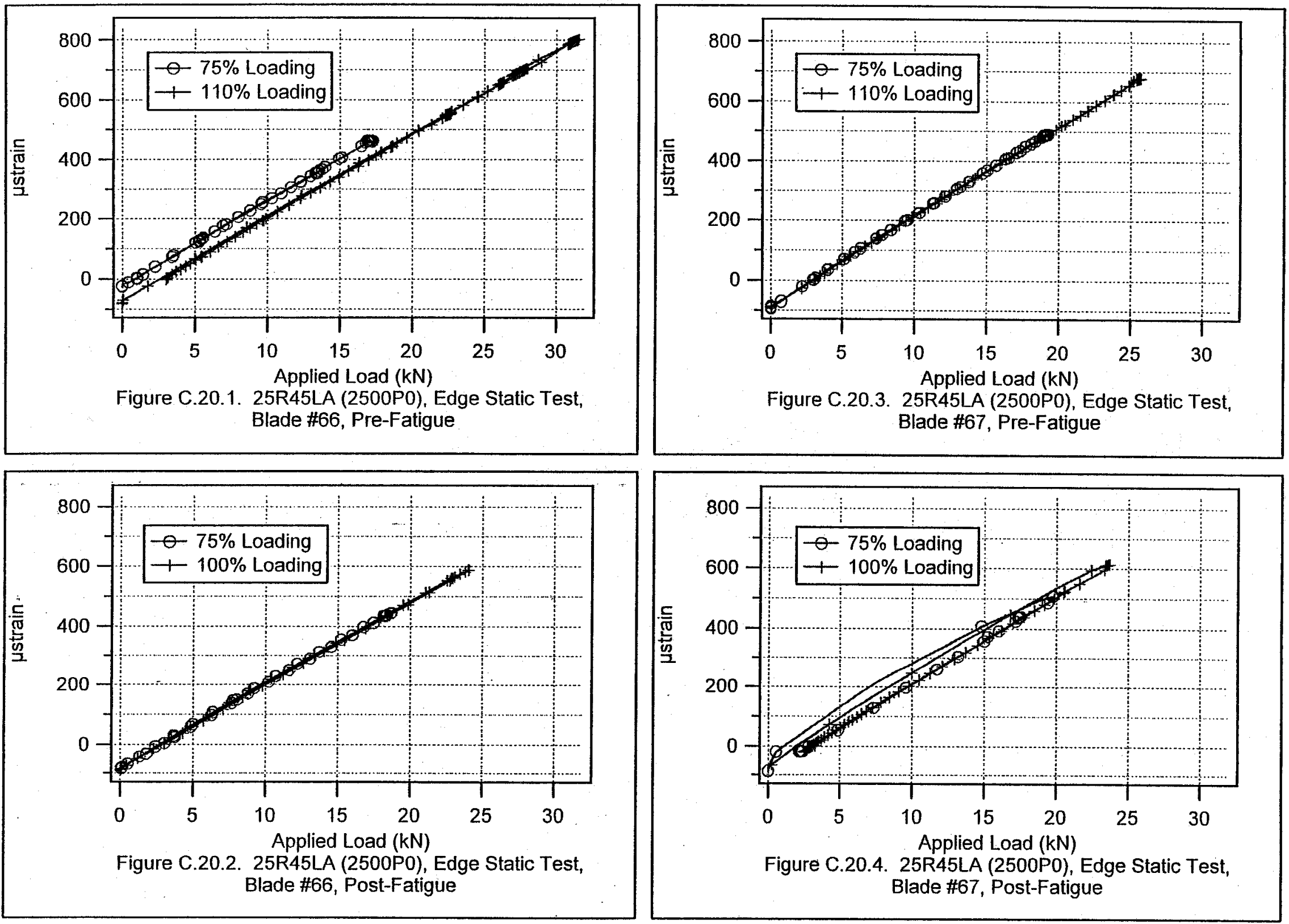

Figure C.20.4. 25R45LA (2500P0), Edge Static Test, Blade \#67, Post-Fatigue 

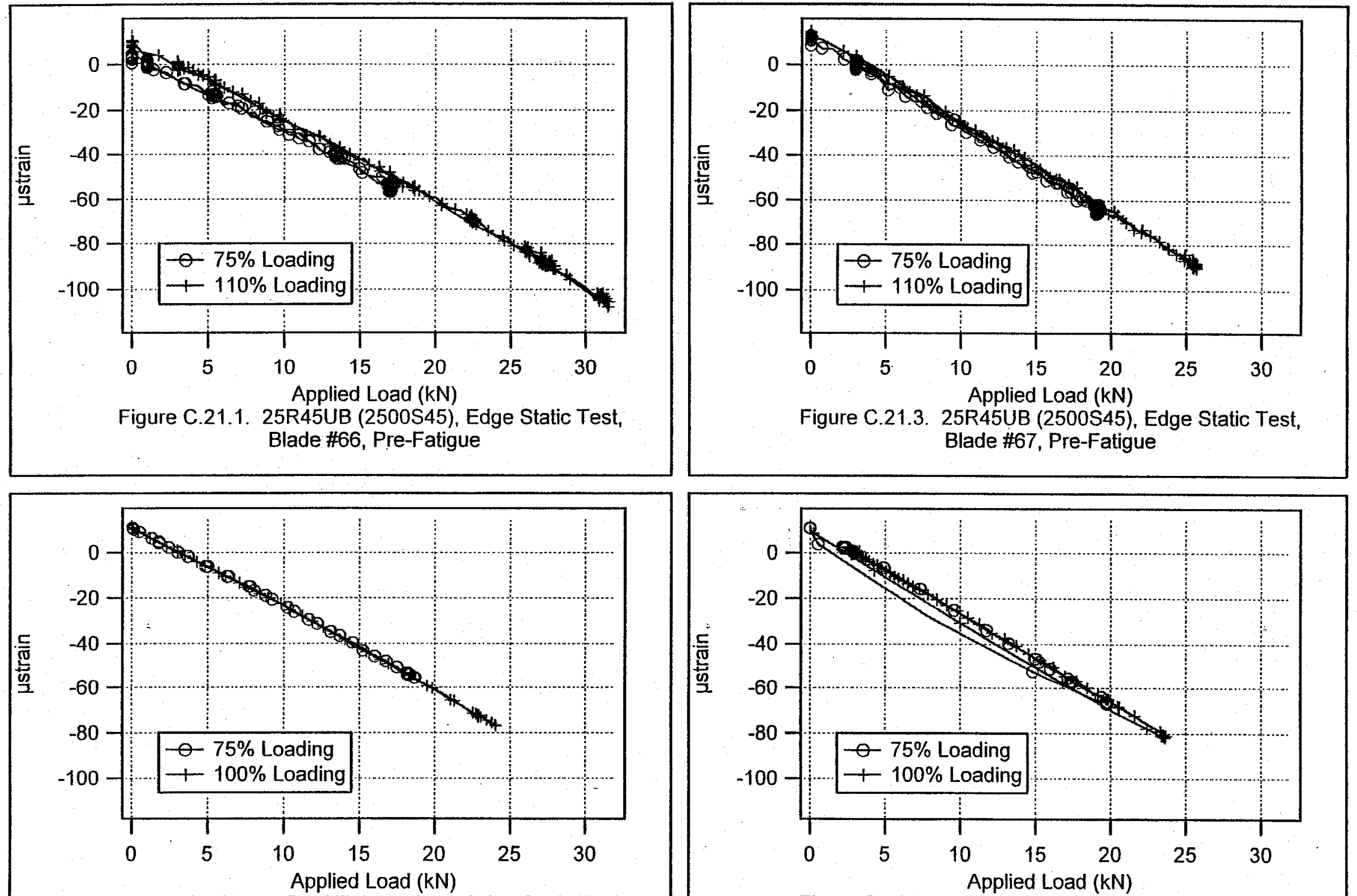

Figure C.21.2. 25R45UB (2500S45), Edge Static Test, Blade \#66, Post-Fatigue

Figure C.21.4. 25R45UB (2500S45), Edge Static Test, Blade \#67, Post-Fatigue 

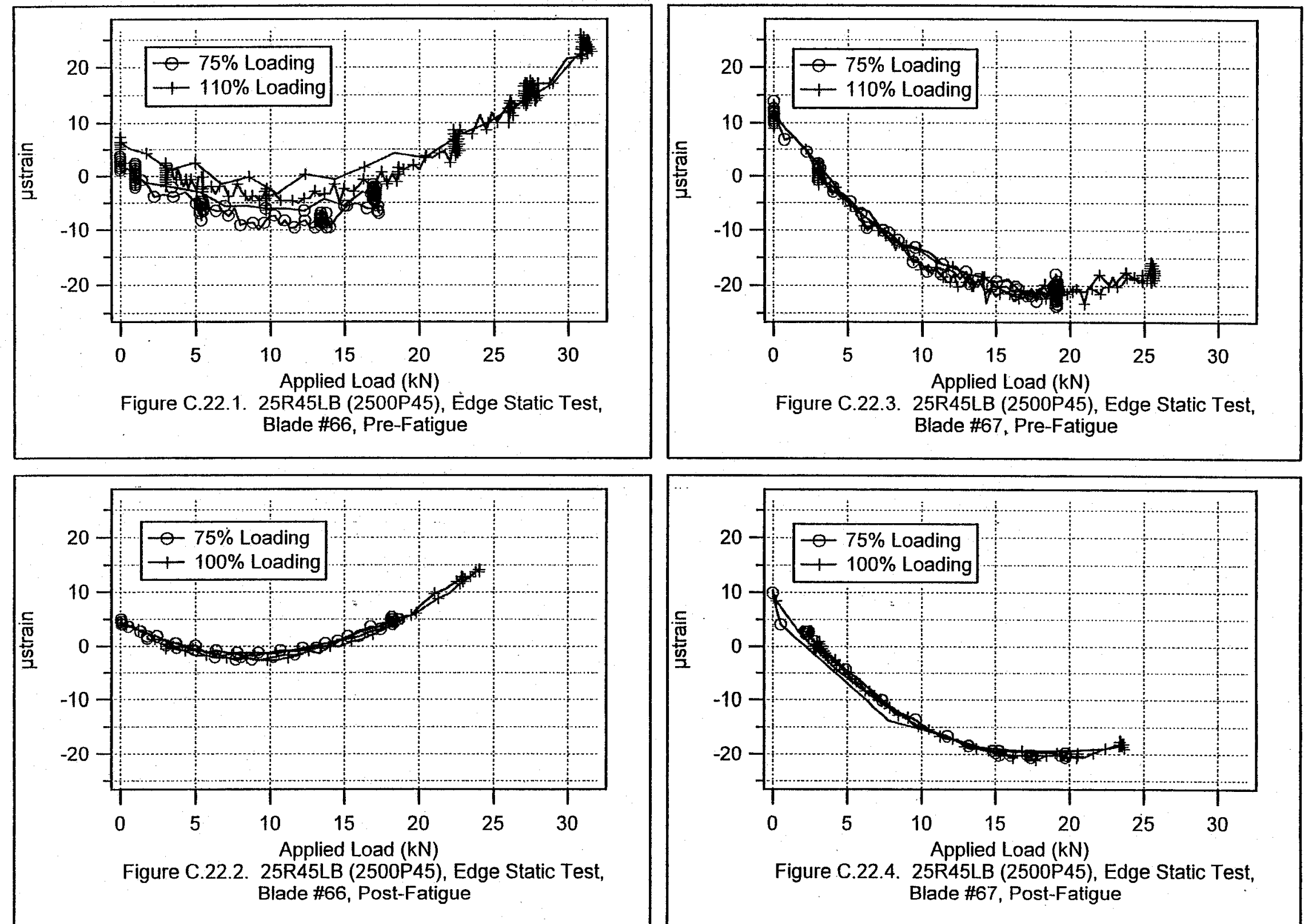

Figure C.22.4. 25R45LB (2500P45), Edge Static Test, Blade \#67, Post-Fatigue 


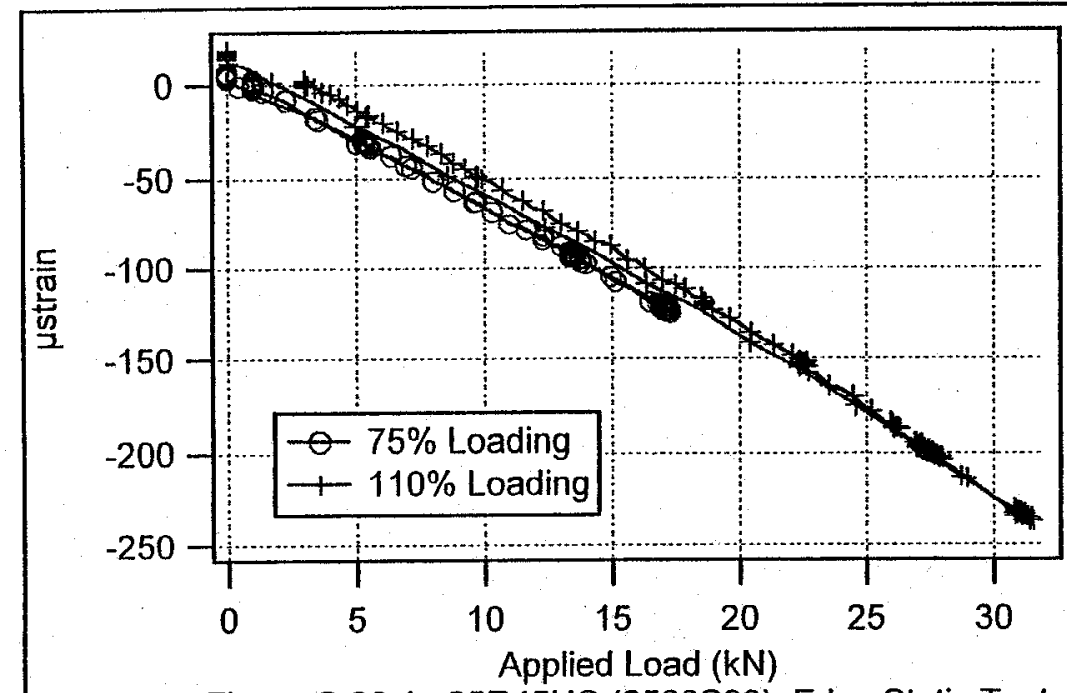

Figure C.23.1. 25R45UC (2500S90), Edge Static Test, Blade \#66, Pre-Fatigue

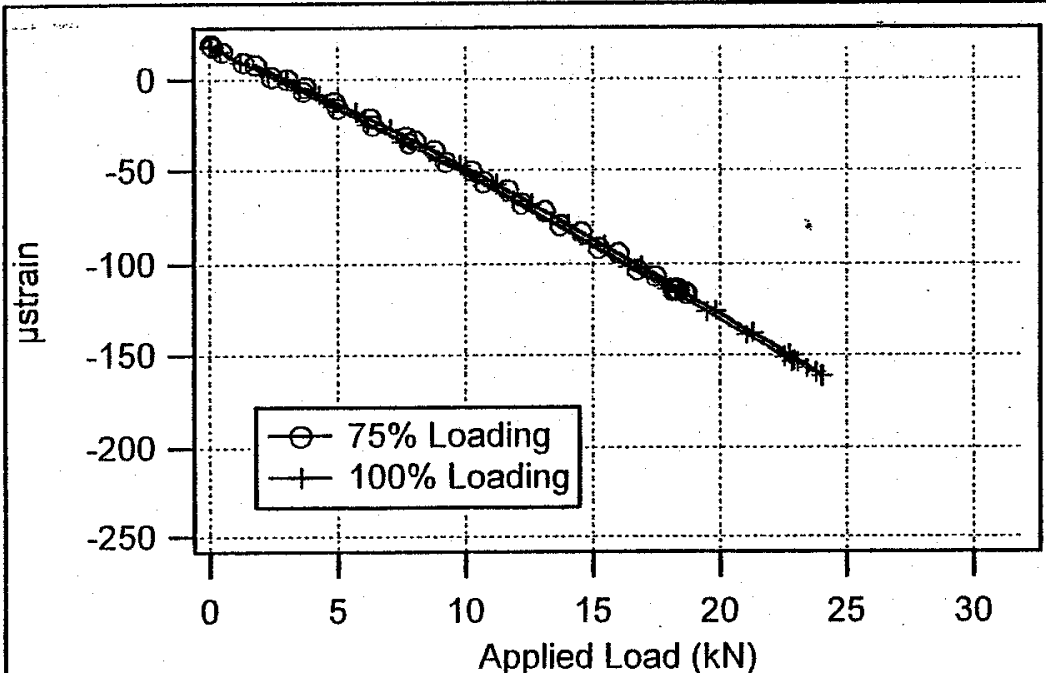

Figure C.23.2. 25R45UC (2500S90), Edge Static Test, Blade \#66, Post-Fatigue

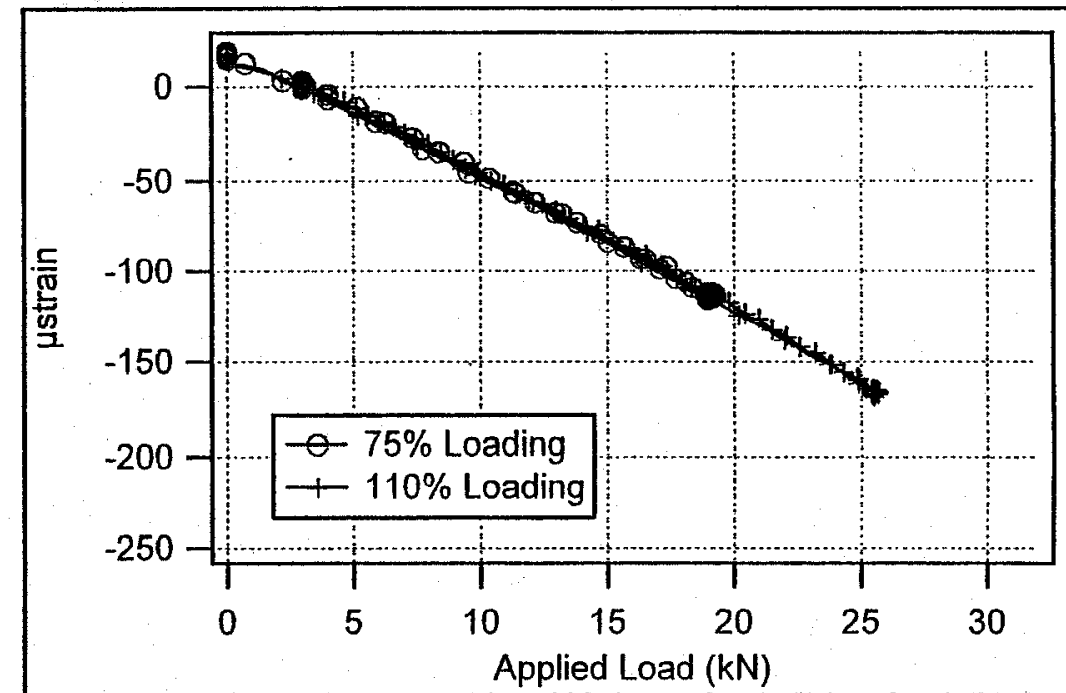

Figure C.23.3. 25R45UC (2500S90), Edge Static Test, Blade \#67, Pre-Fatigue

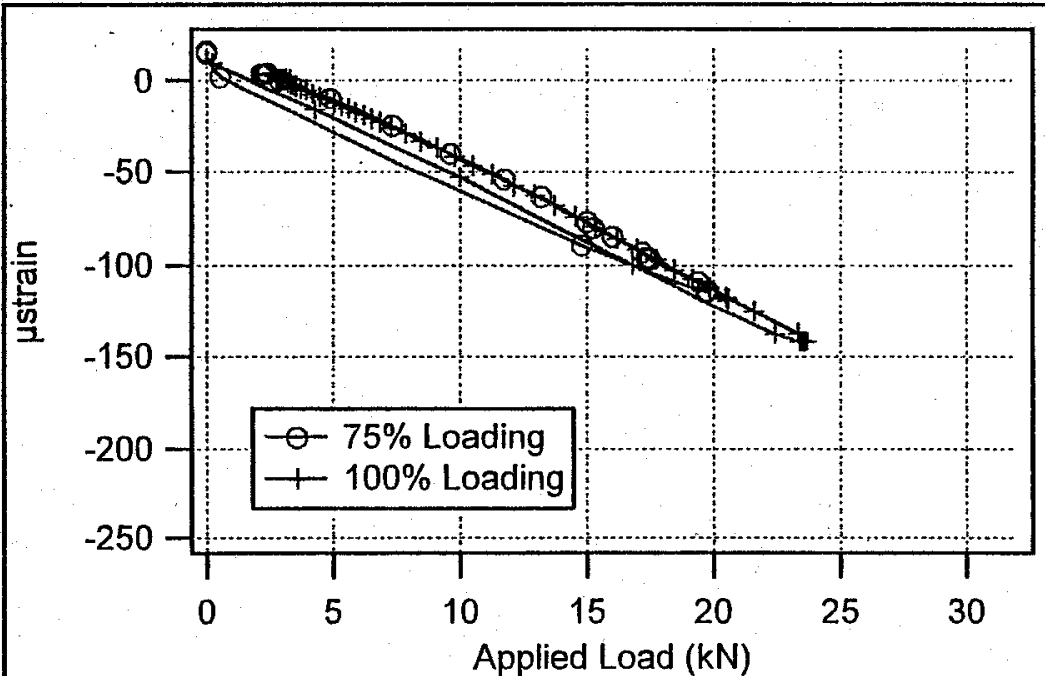

Figure C.23.4. 25R45UC (2500S90), Edge Static Test, Blade \#67, Post-Fatigue 

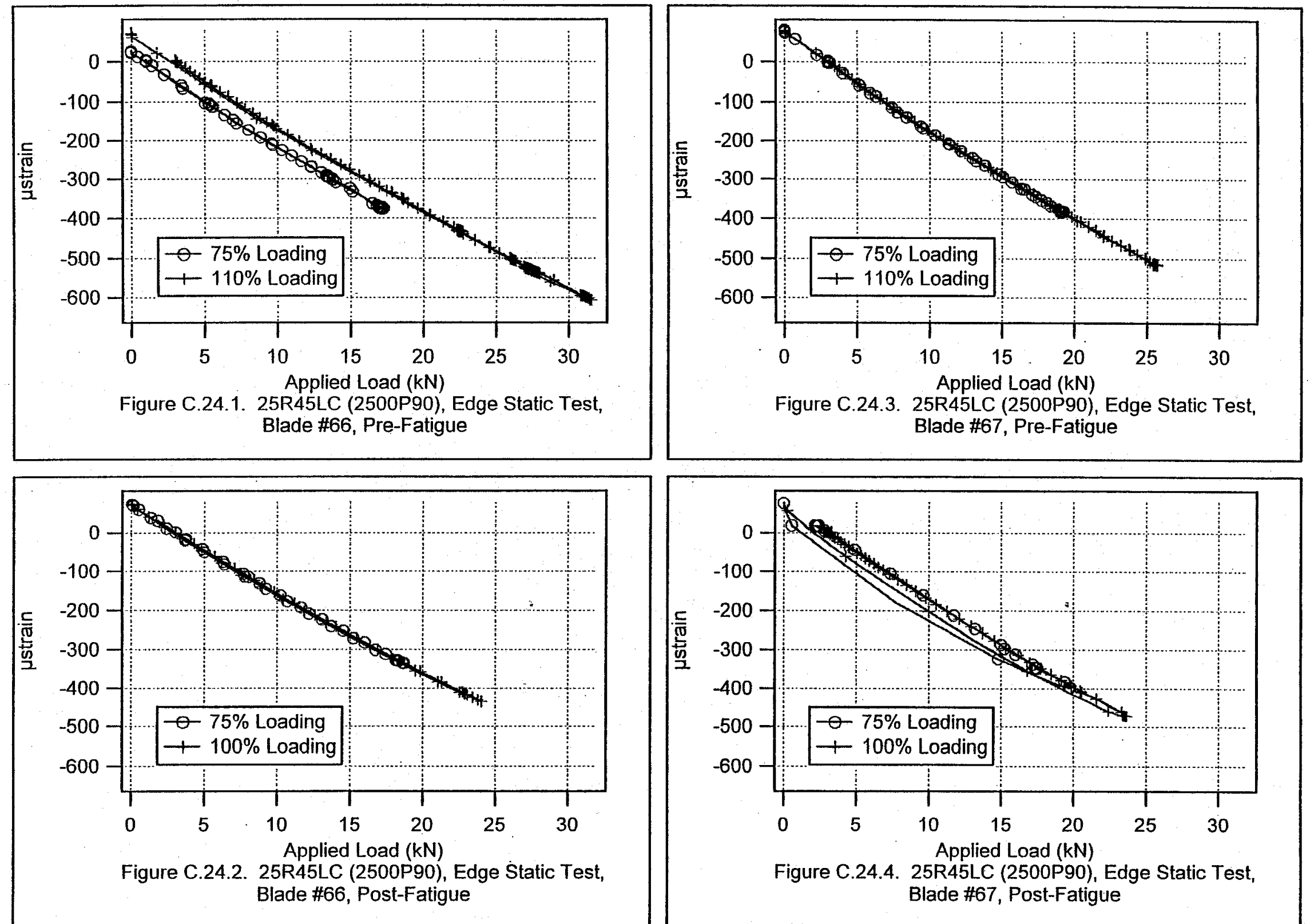

Figure C.24.4. 25R45LC (2500P90), Edge Static Test, Blade \#67, Post-Fatigue 

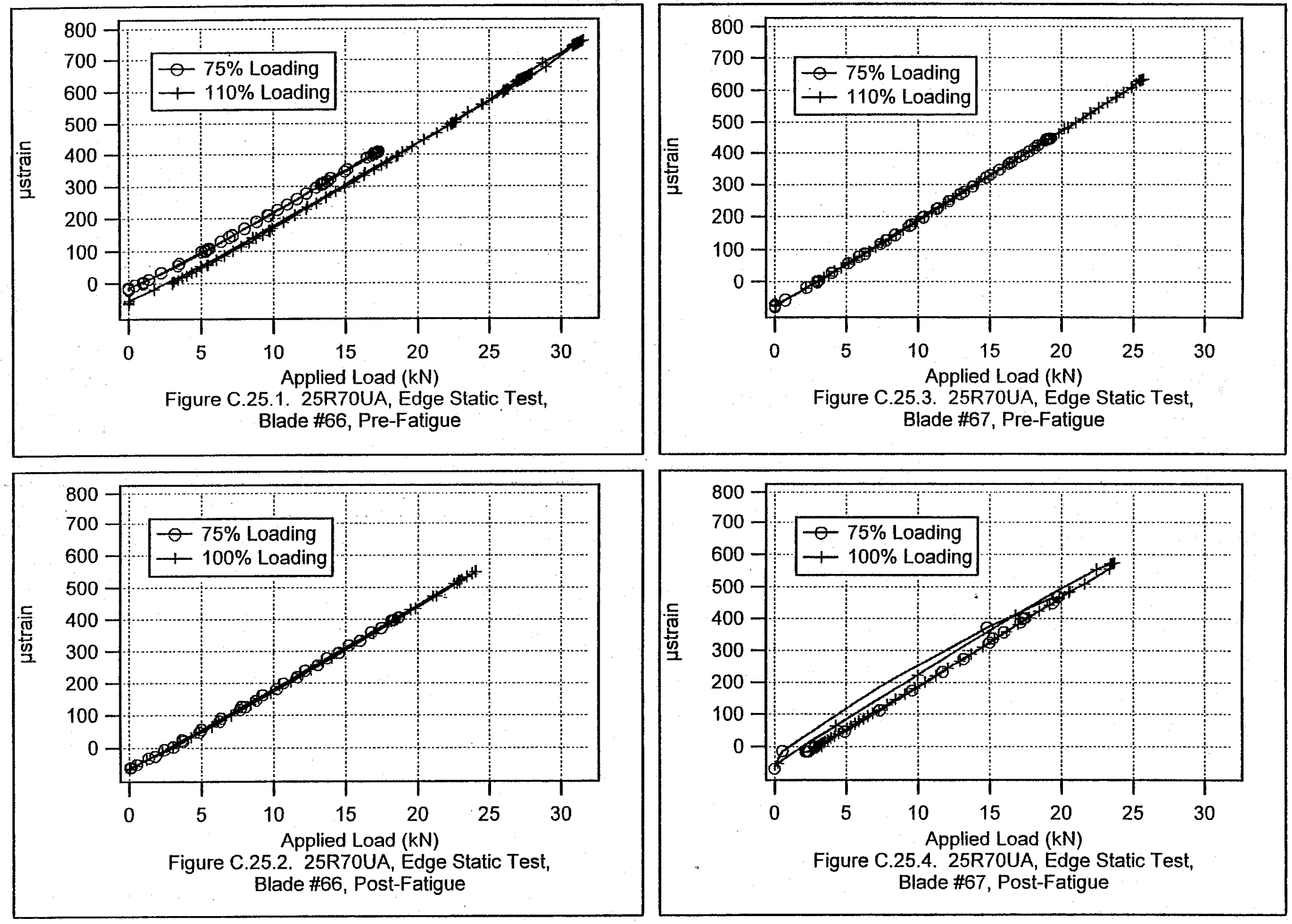

Figure C.25.4. 25R70UA, Edge Static Test, Blade \#67, Post-Fatigue 

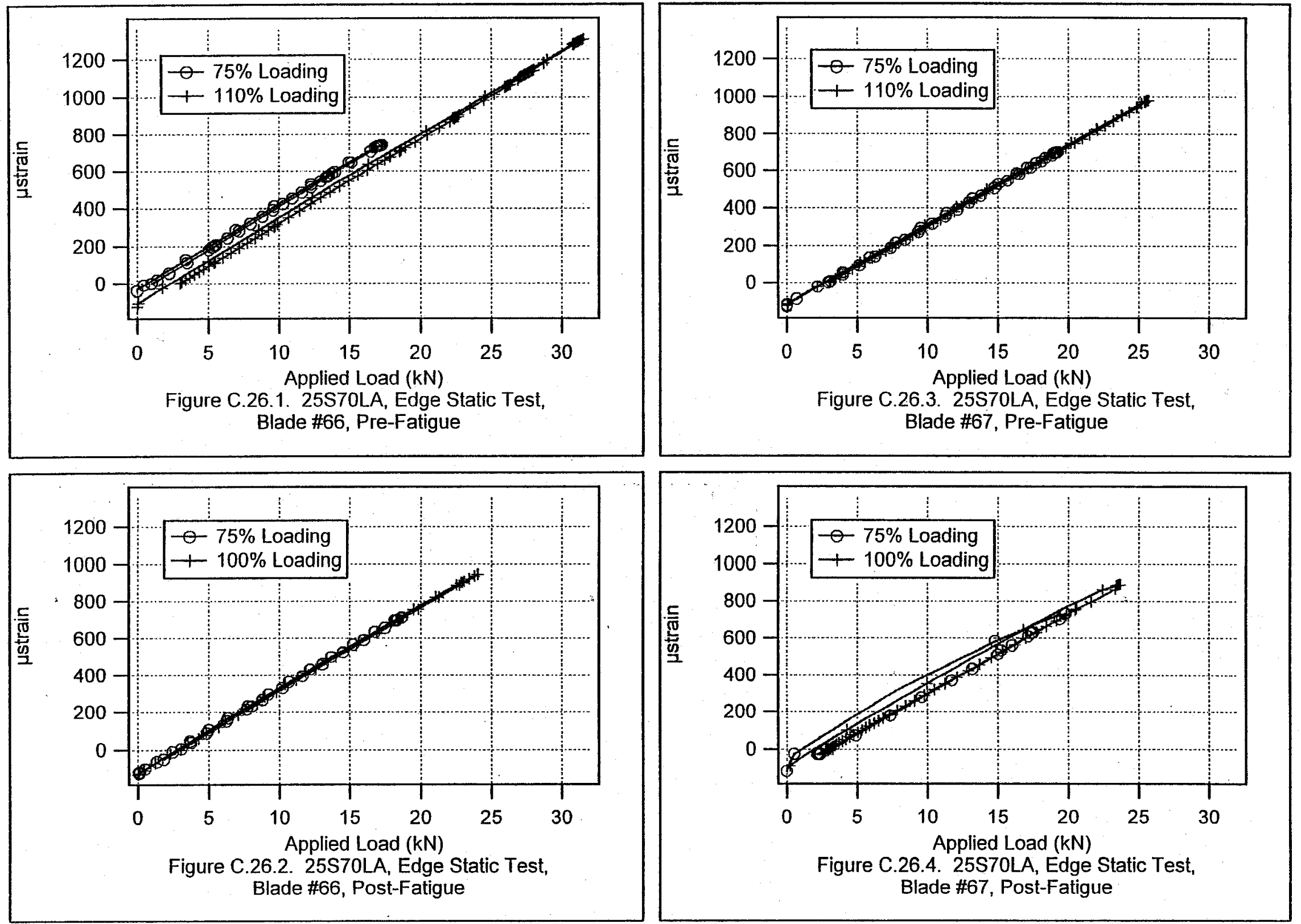

Figure C.26.4. 25S70LA, Edge Static Test, Blade \#67, Post-Fatigue 

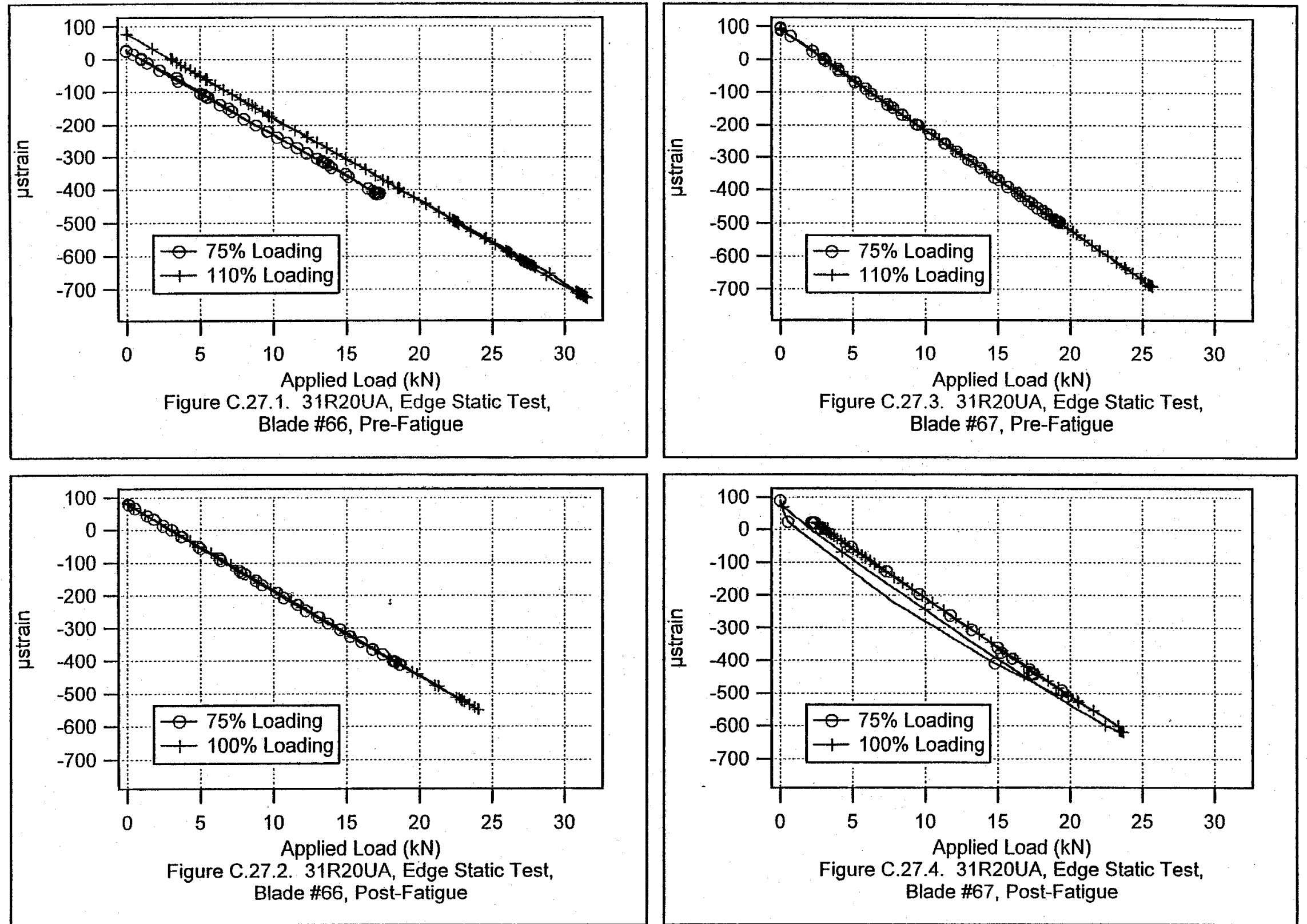

Figure C.27.4. 31R20UA, Edge Static Test, Blade \#67, Post-Fatigue 

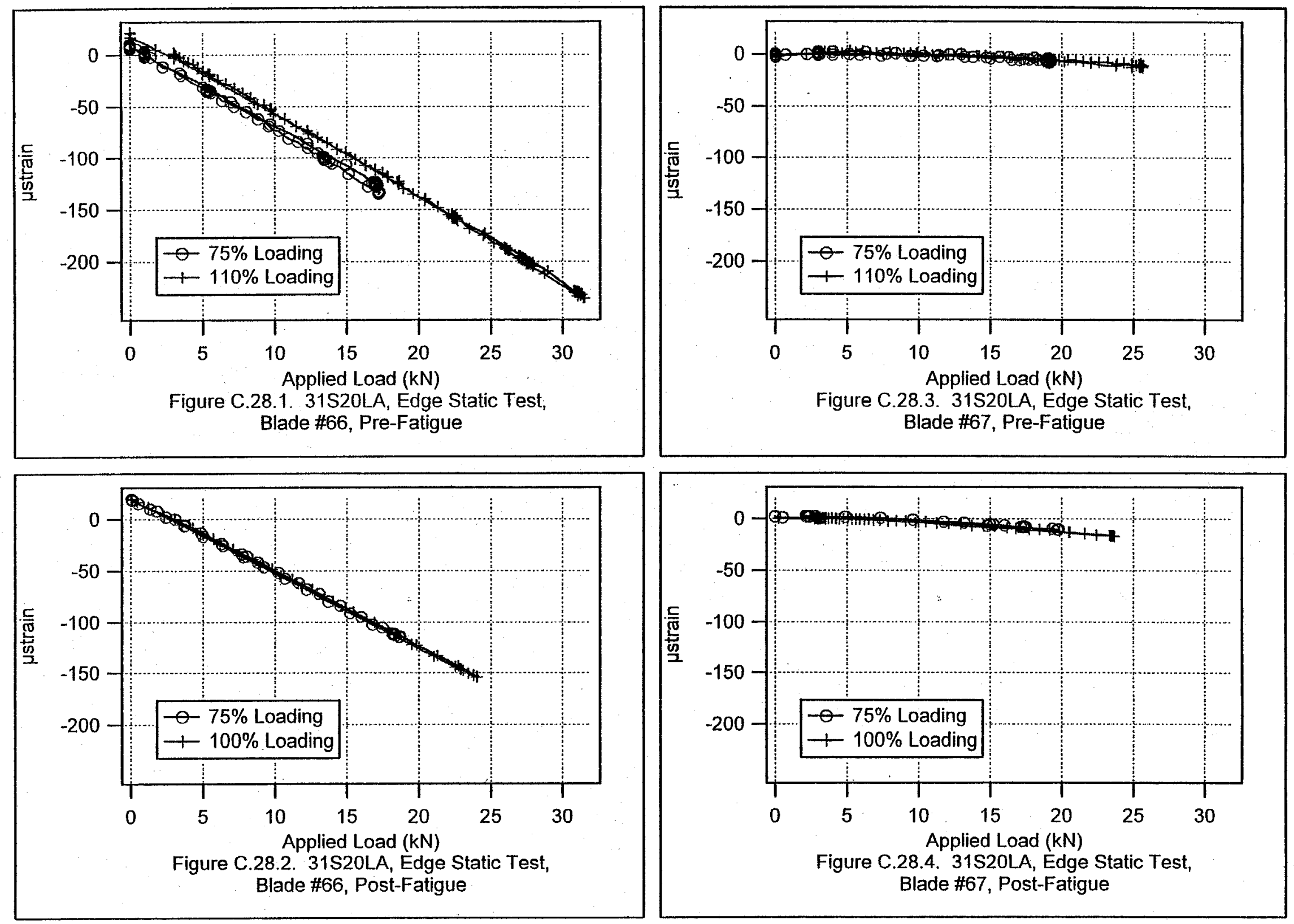

Figure C.28.4. 31S20LA, Edge Static Test, Blade \#67, Post-Fatigue 

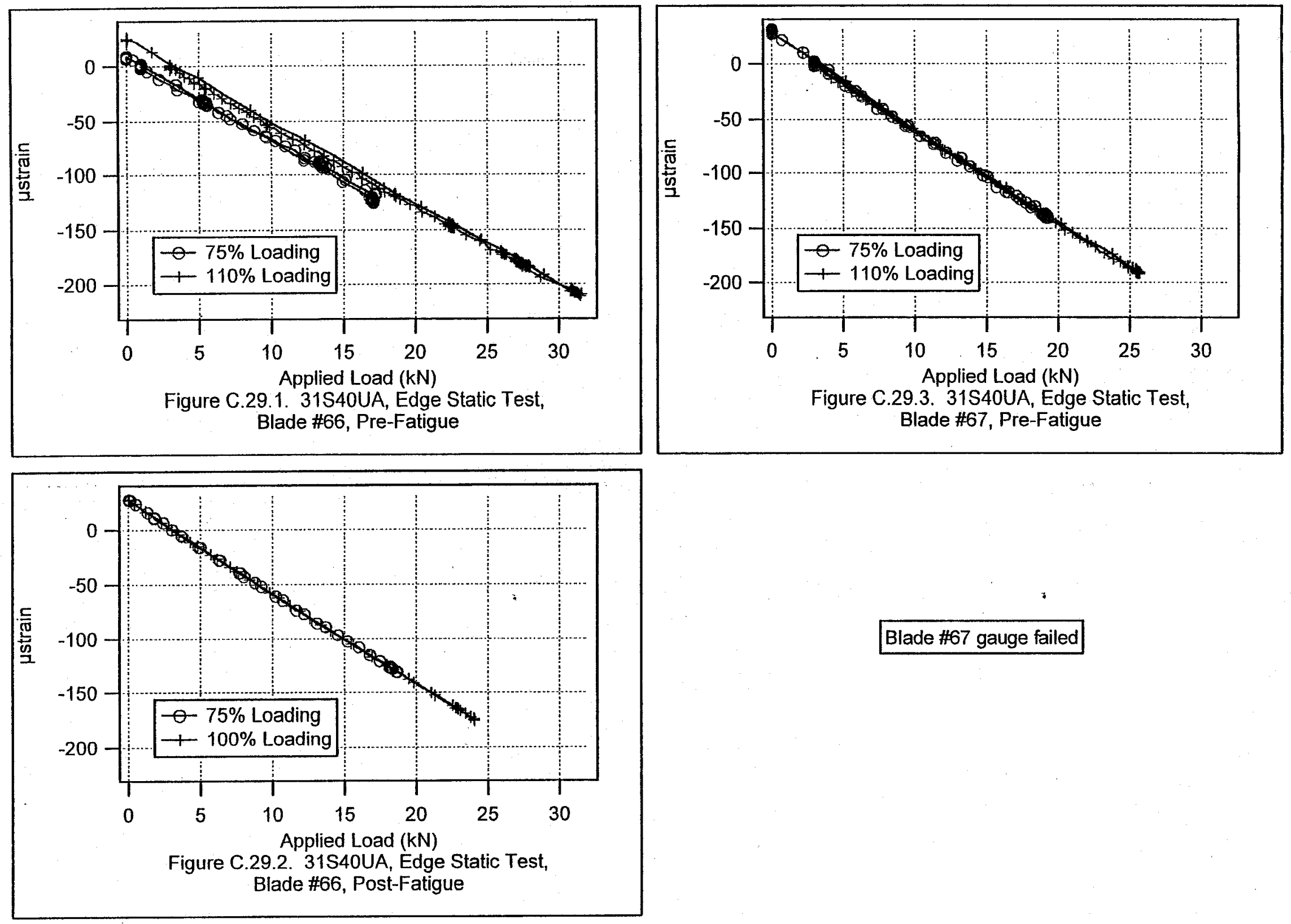

Blade \#67 gauge failed 

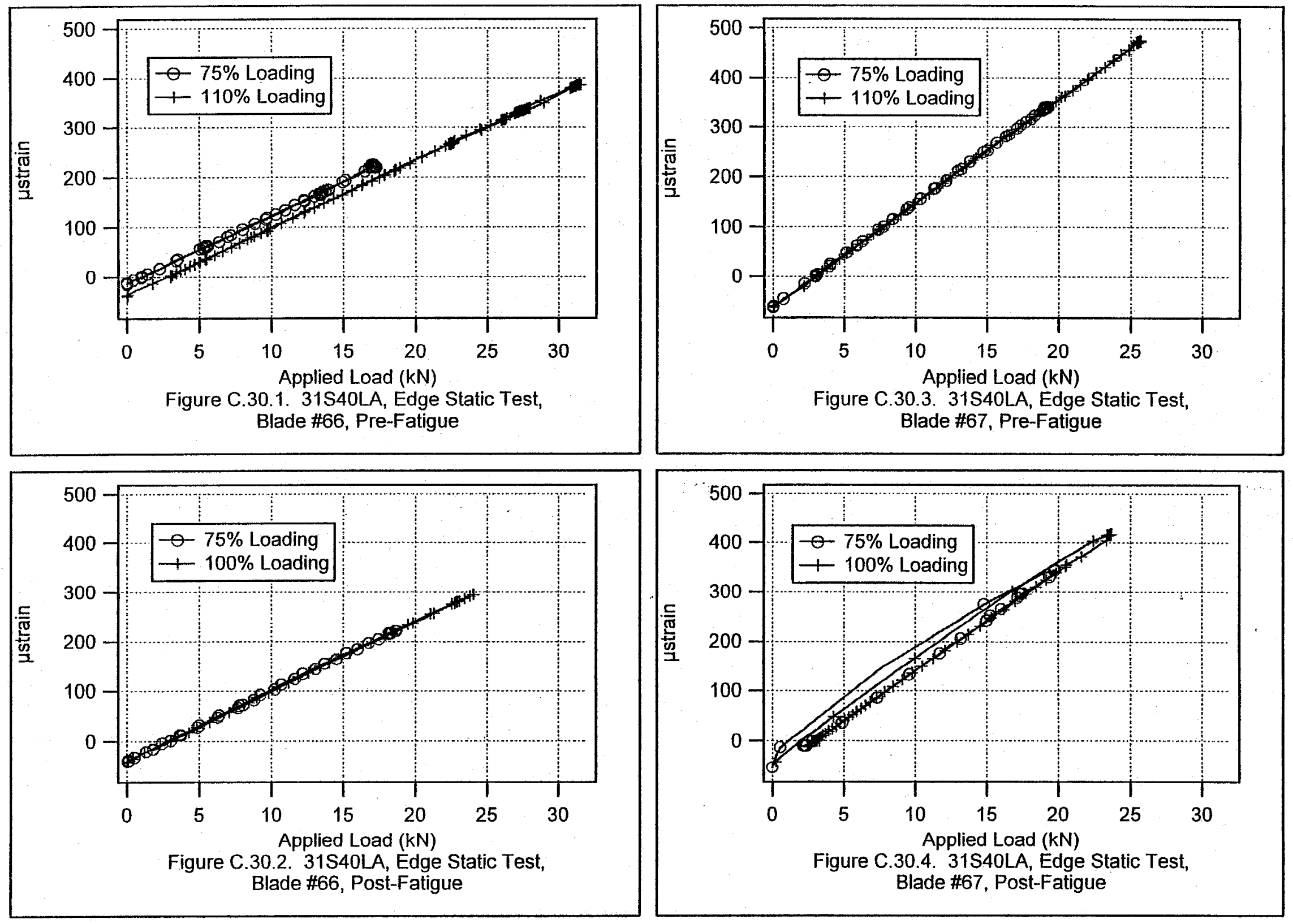

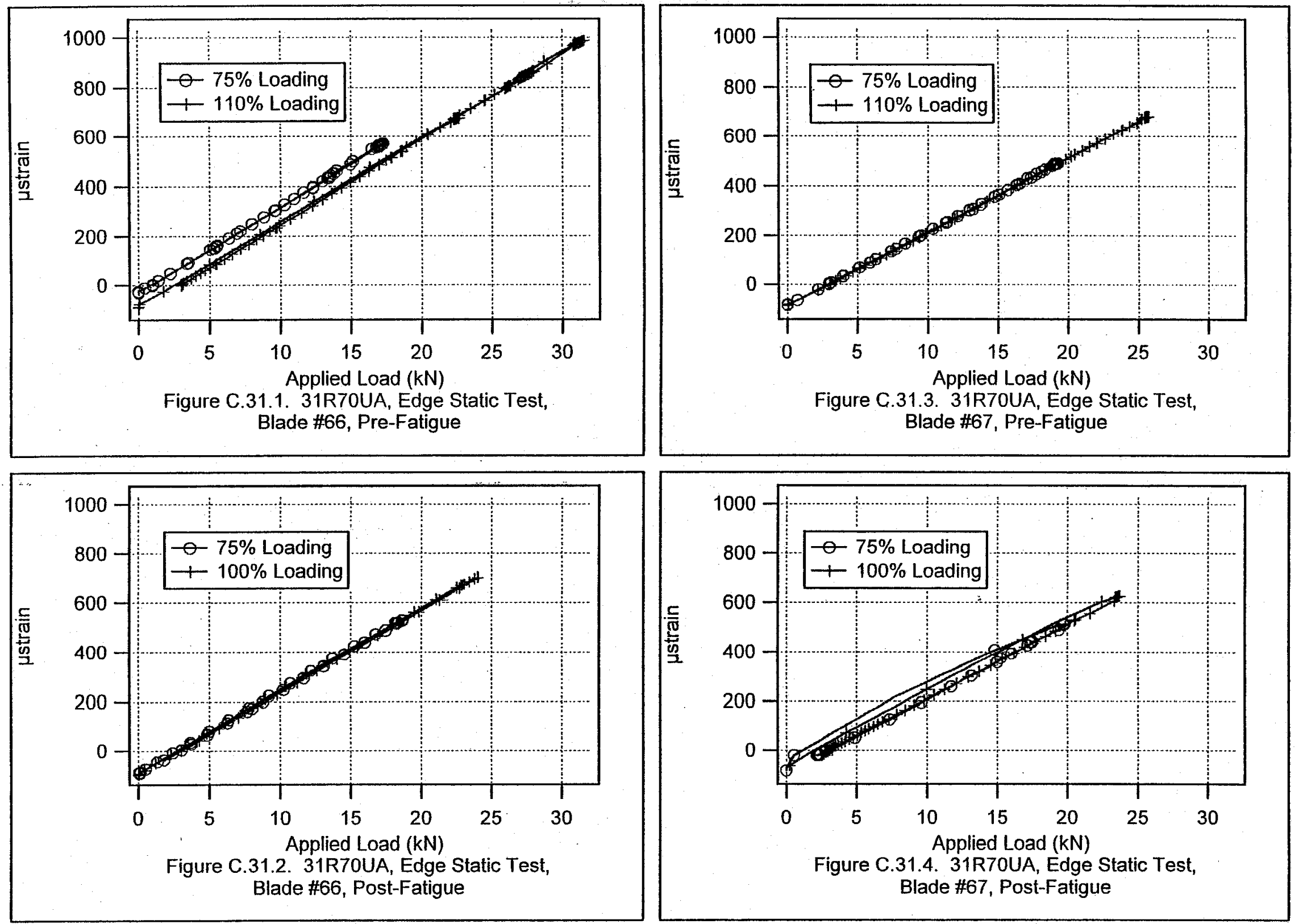

Figure C.31.4. 31R70UA, Edge Static Test, Blade \#67, Post-Fatigue 

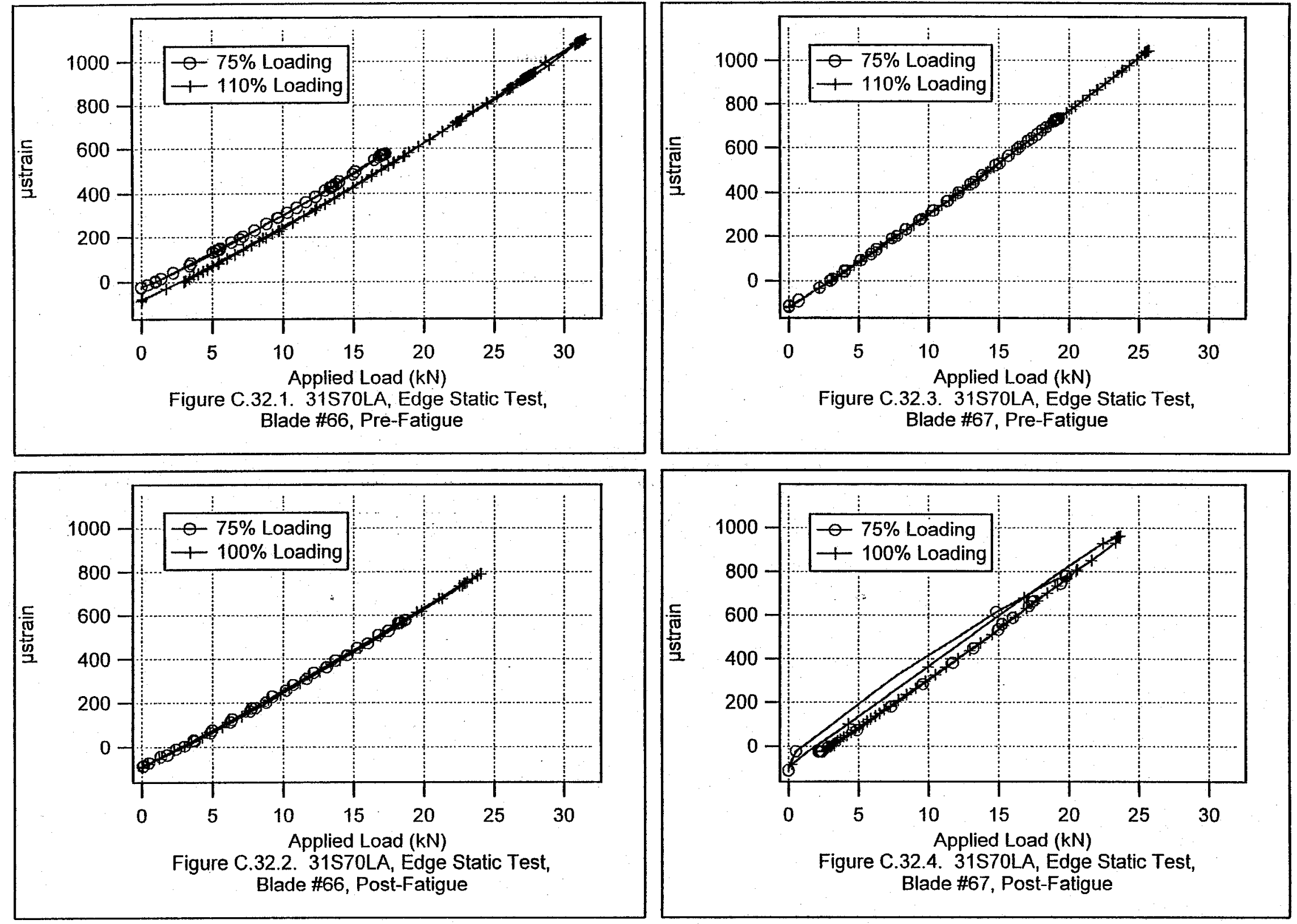

Figure C.32.4. 31S70LA, Edge Static Test, Blade \#67, Post-Fatigue 

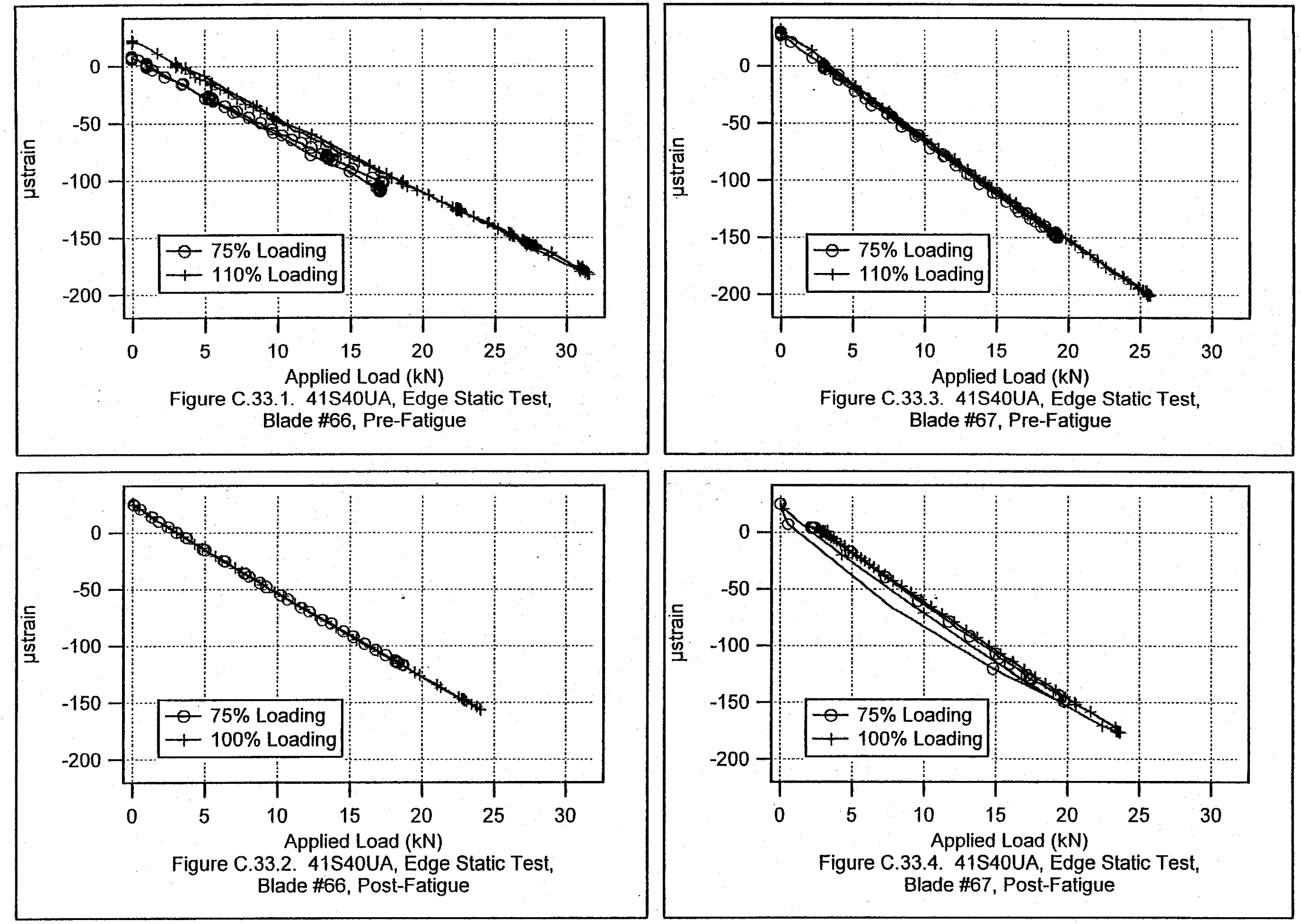

Figure C.33.4. 41S40UA, Edge Static Test, Blade \#67, Post-Fatigue 

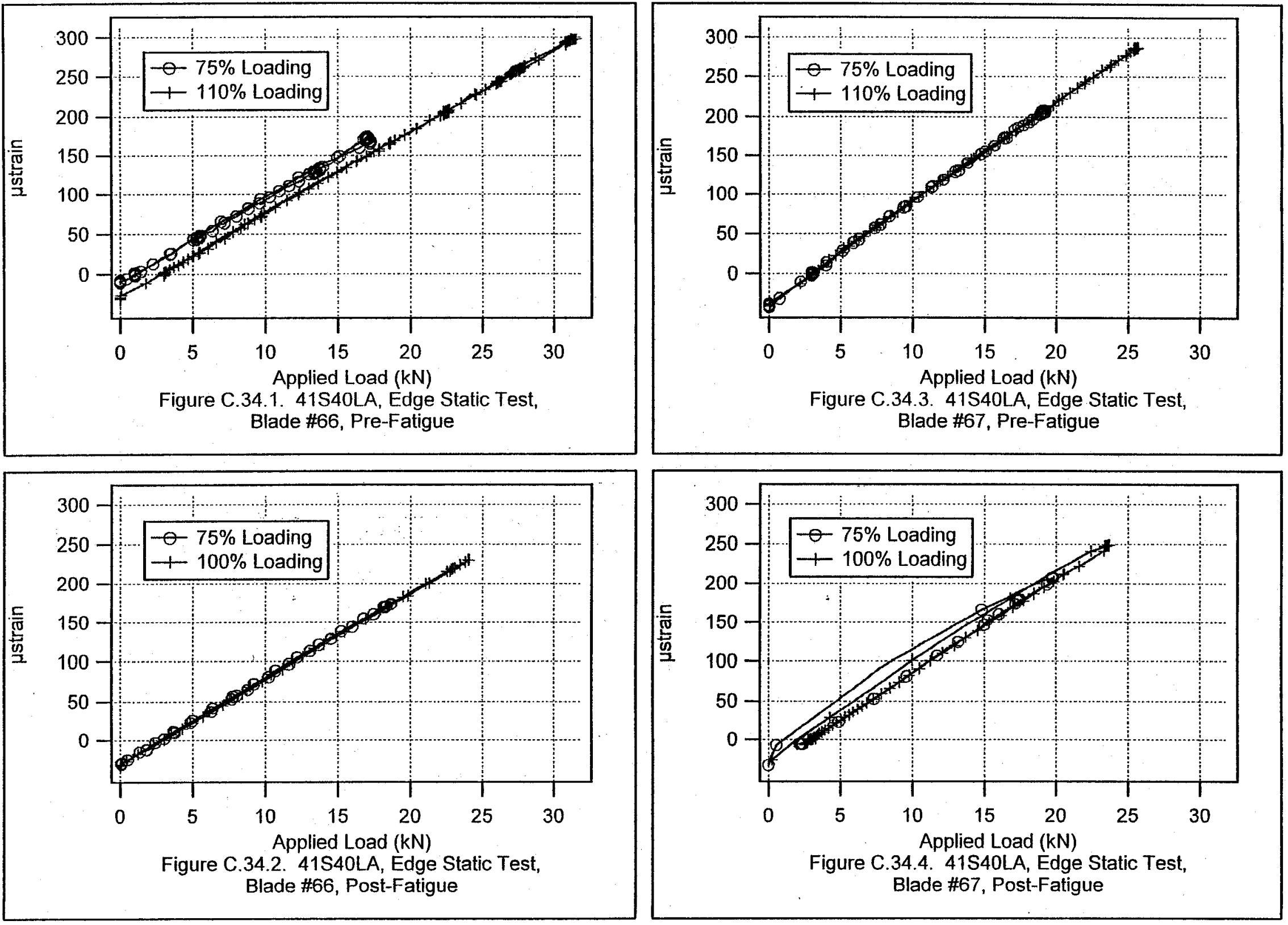

Figure C.34.4. 41S40LA, Edge Static Test, Blade \#67, Post-Fatigue 
TP-500-29103

\section{Appendix D}

Flapwise Static Data

D-1 

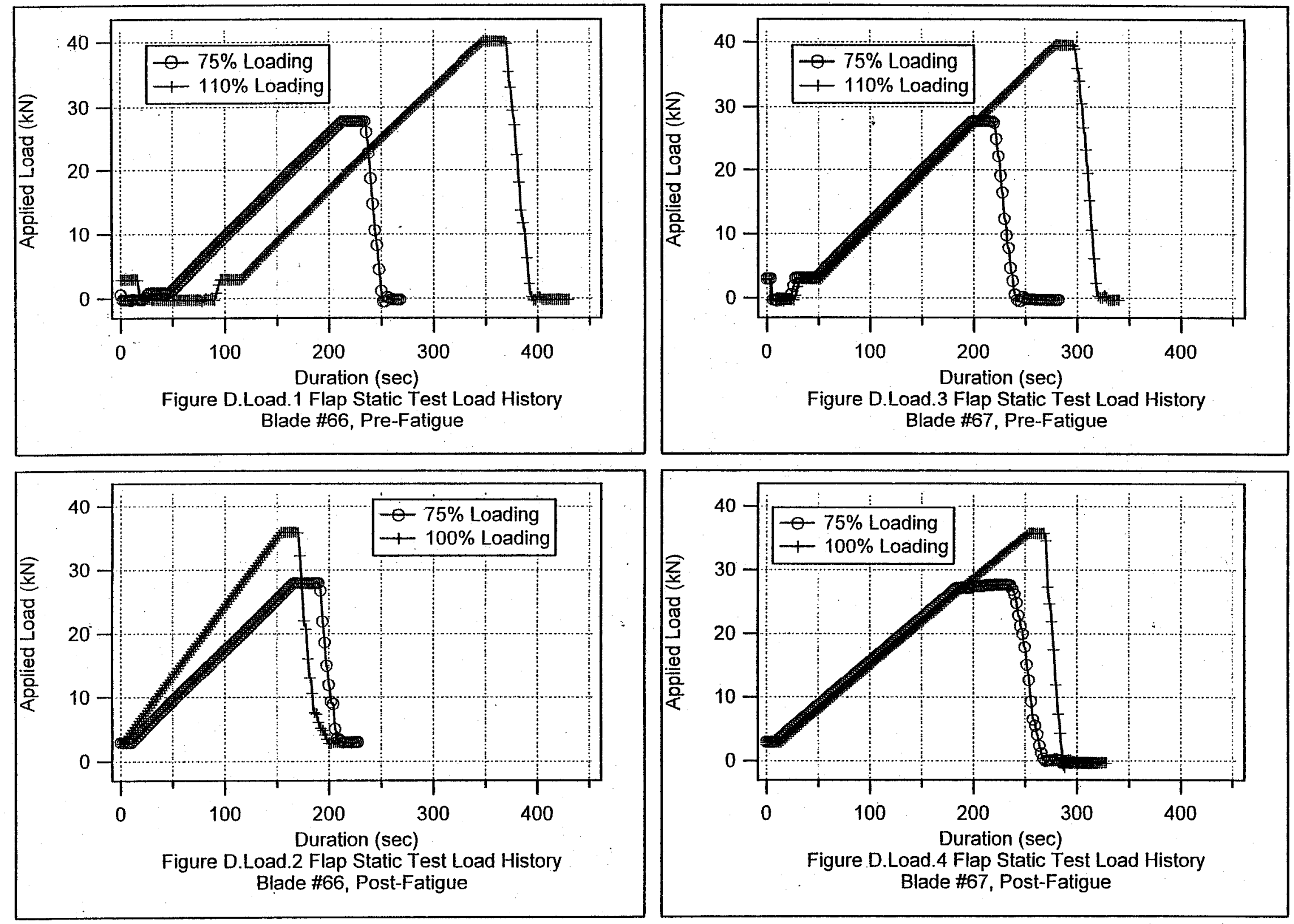

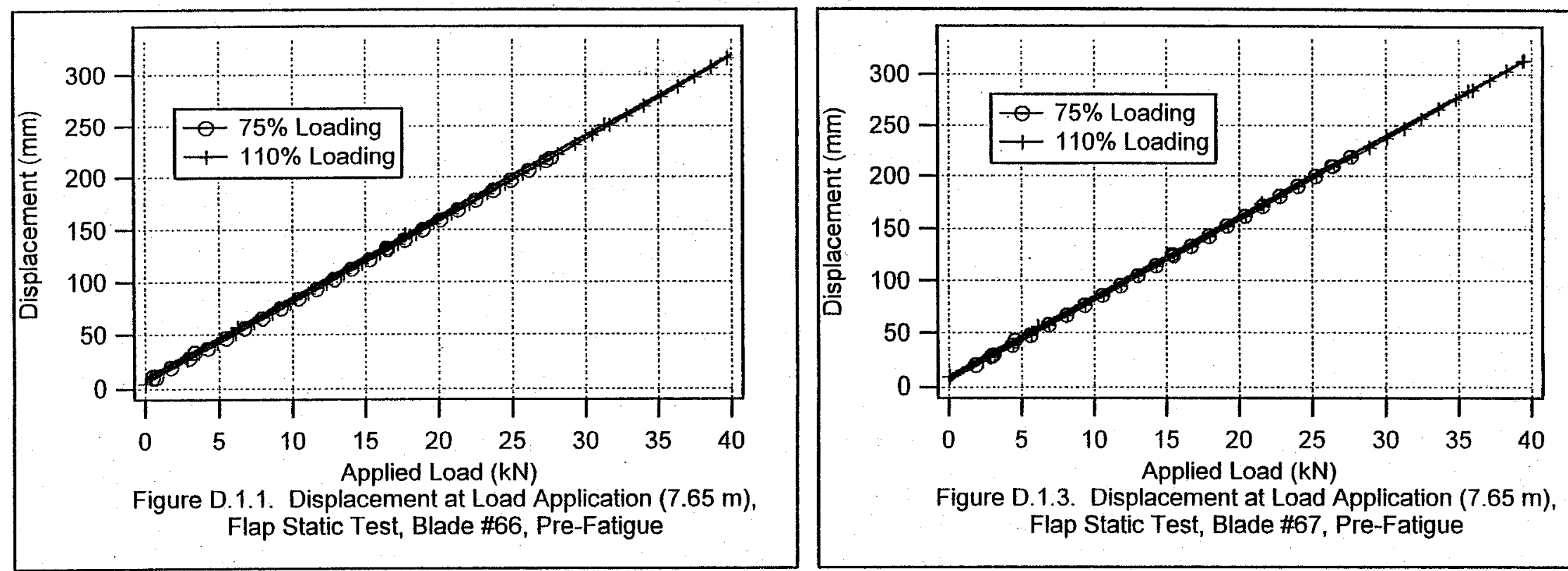

Figure D.1.3. Displacement at Load Application $(7.65 \mathrm{~m})$, Flap Static Test, Blade \#67, Pre-Fatigue

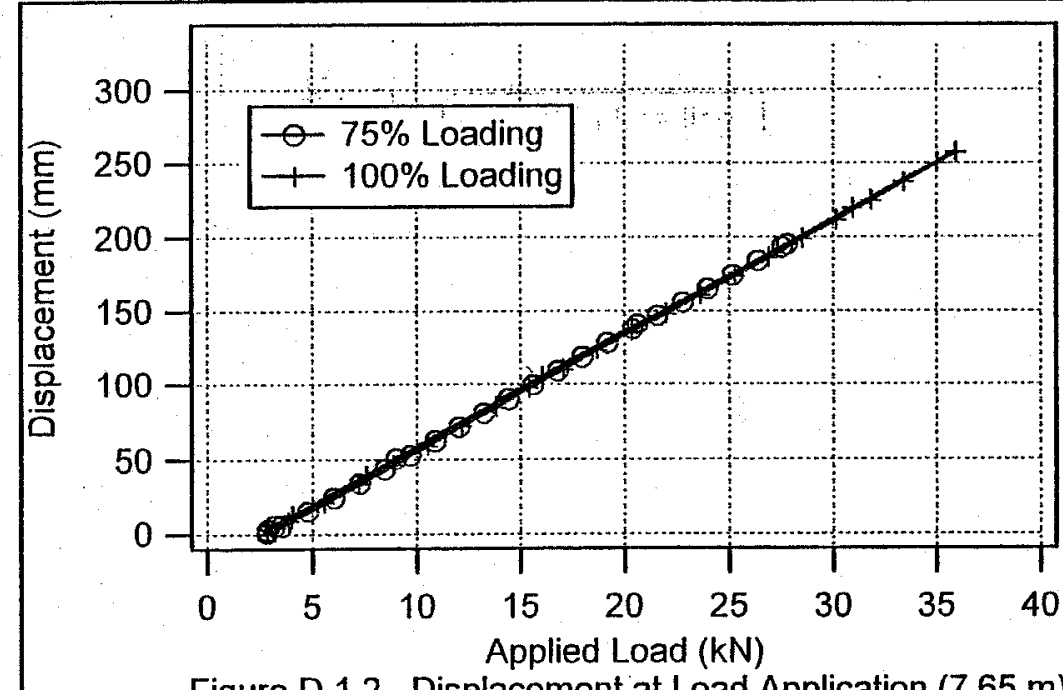

Figure D.1.2. Displacement at Load Application (7.65 m), Flap Static Test, Blade \#66, Post-Fatigue

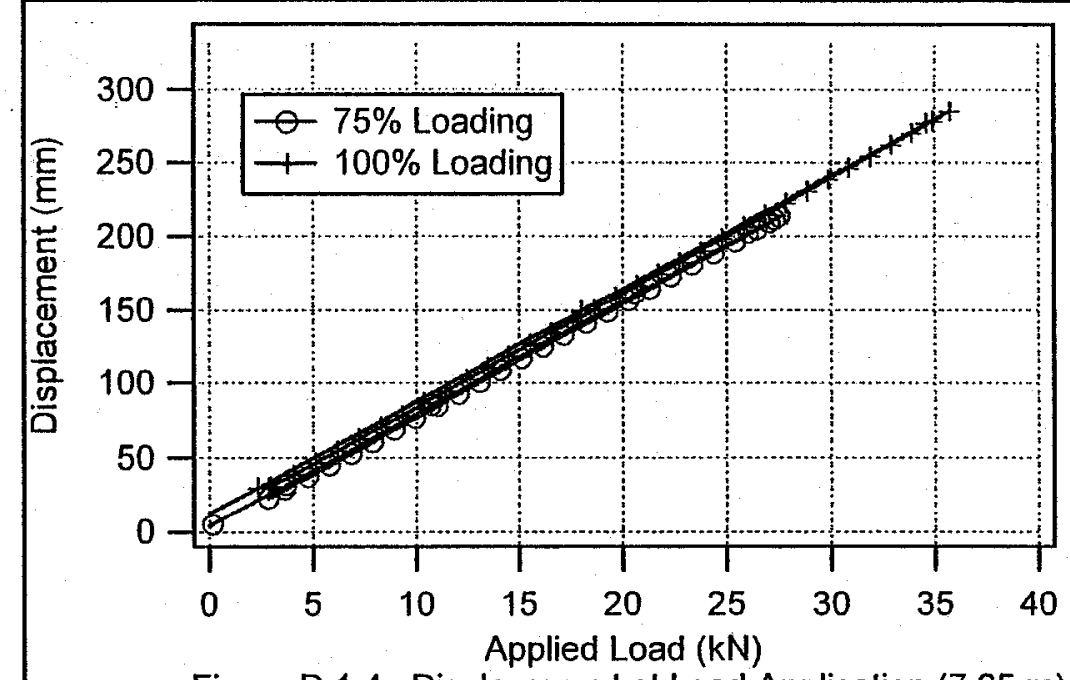

Figure D.1.4. Displacement at Load Application (7.65 m), Flap Static Test, Blade \#67, Post-Fatigue 

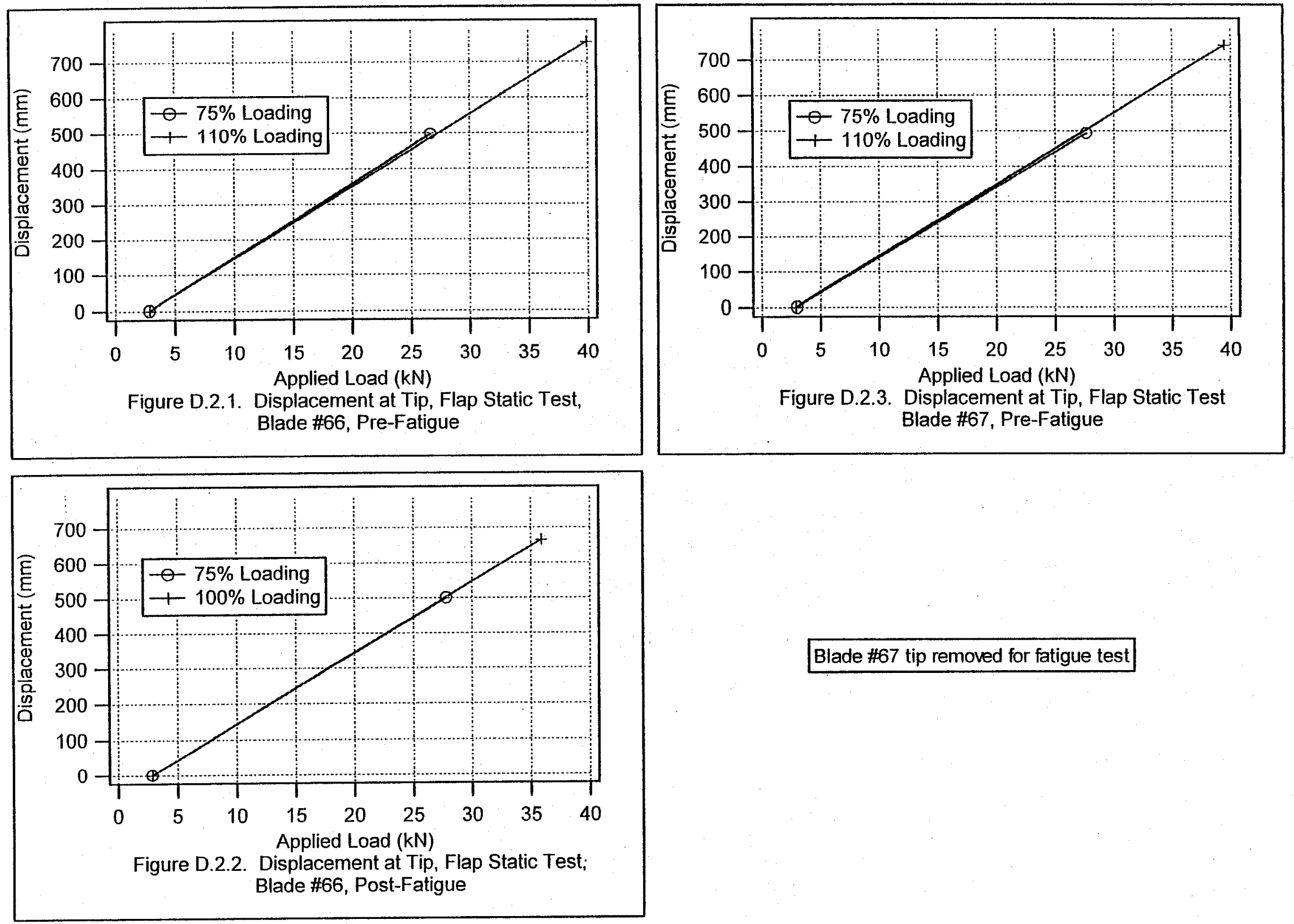

Blade \#67 tip removed for fatigue test 

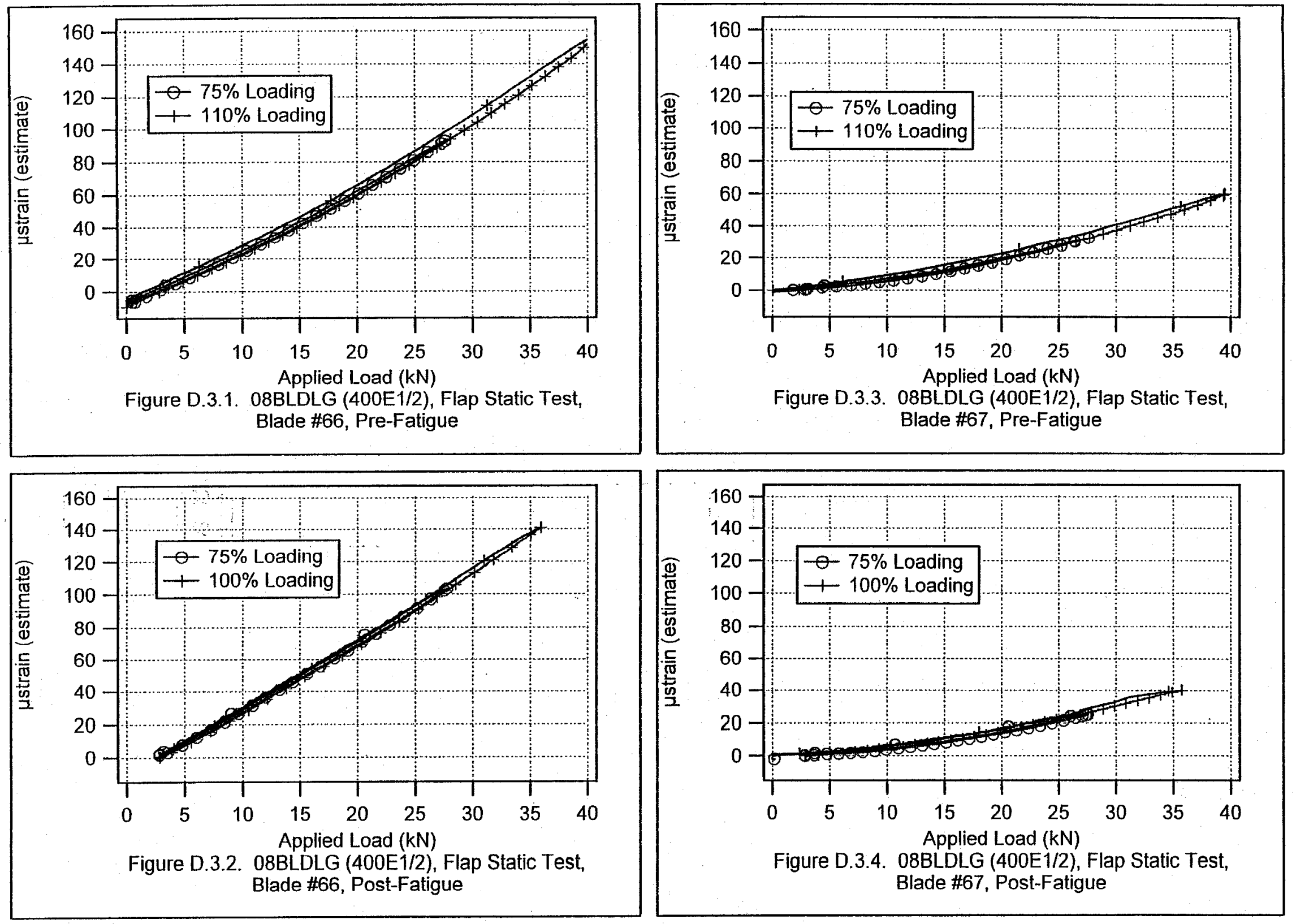

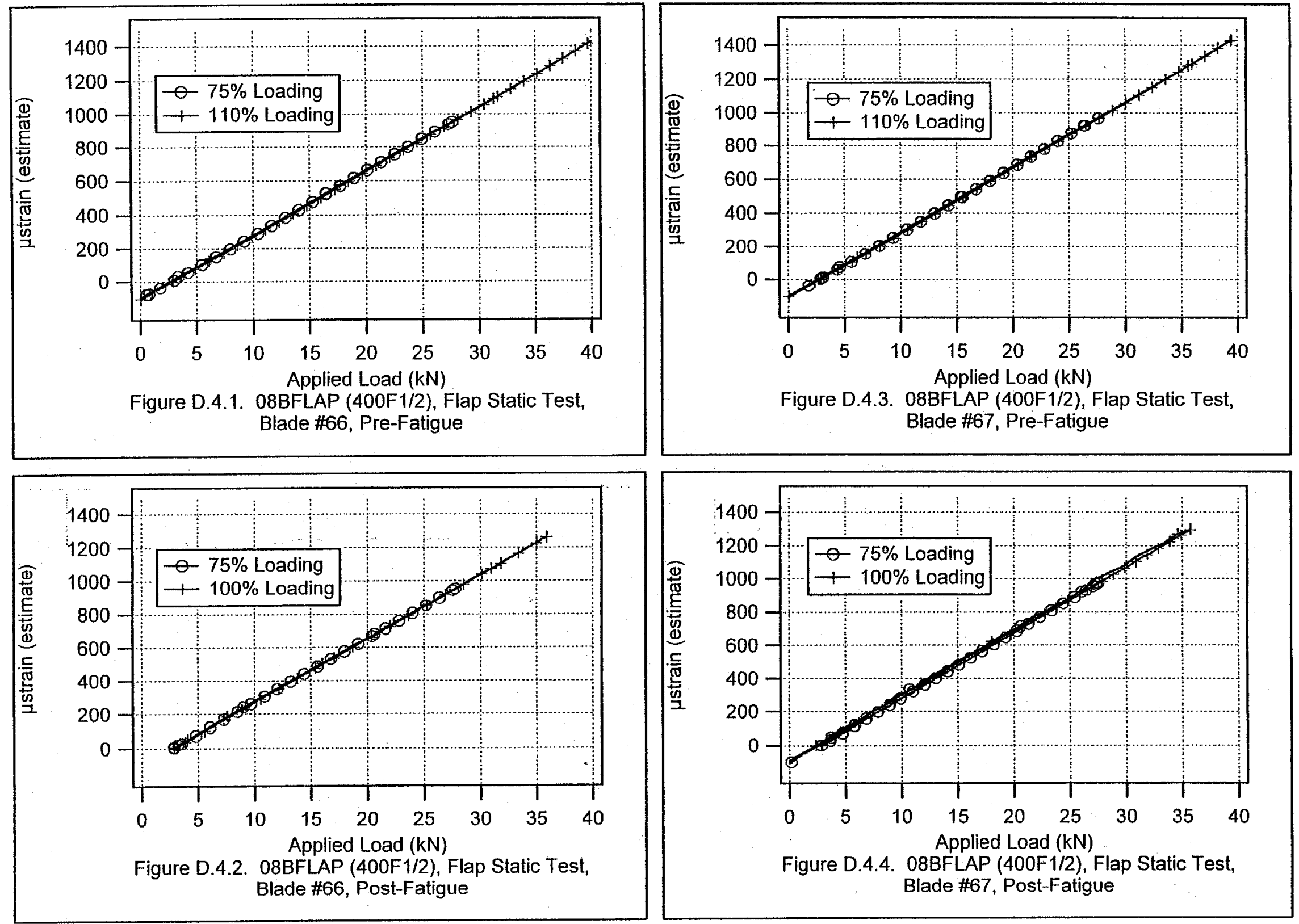

Figure D.4.4. 08BFLAP (400F1/2), Flap Static Test, Blade \#67, Post-Fatigue 

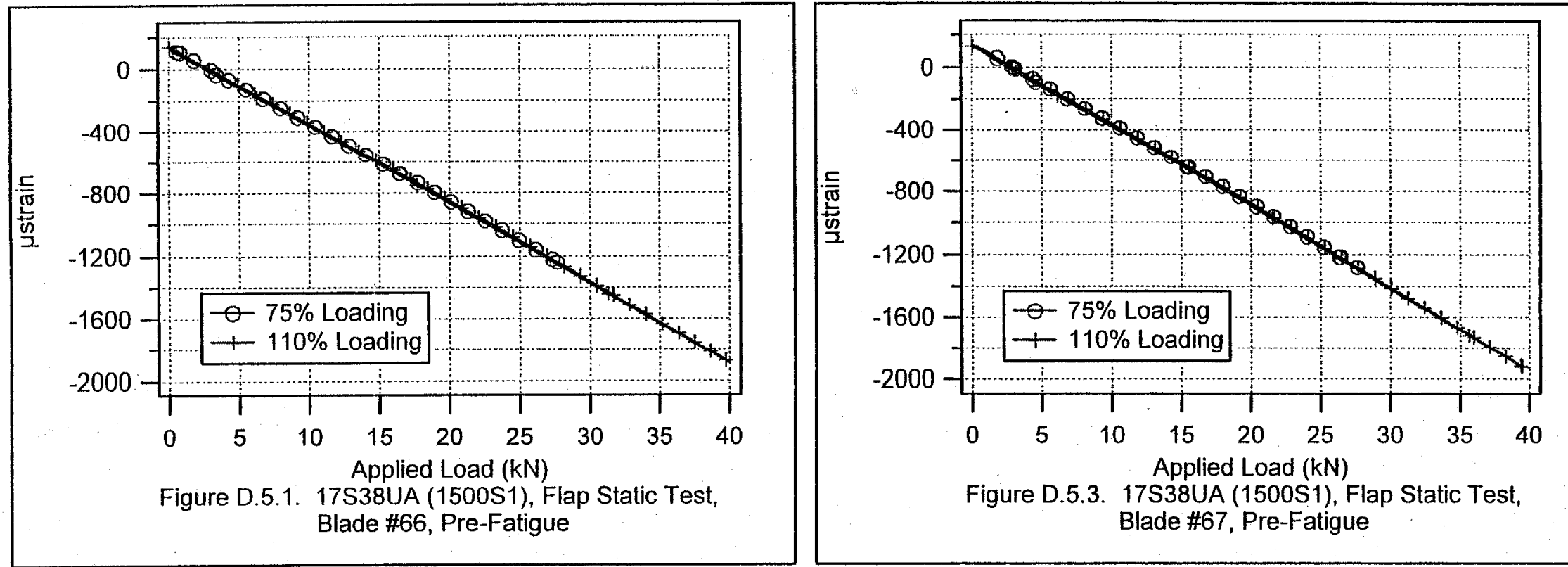

Figure D.5.3. 17S38UA (1500S1), Flap Static Test, Blade \#67, Pre-Fatigue
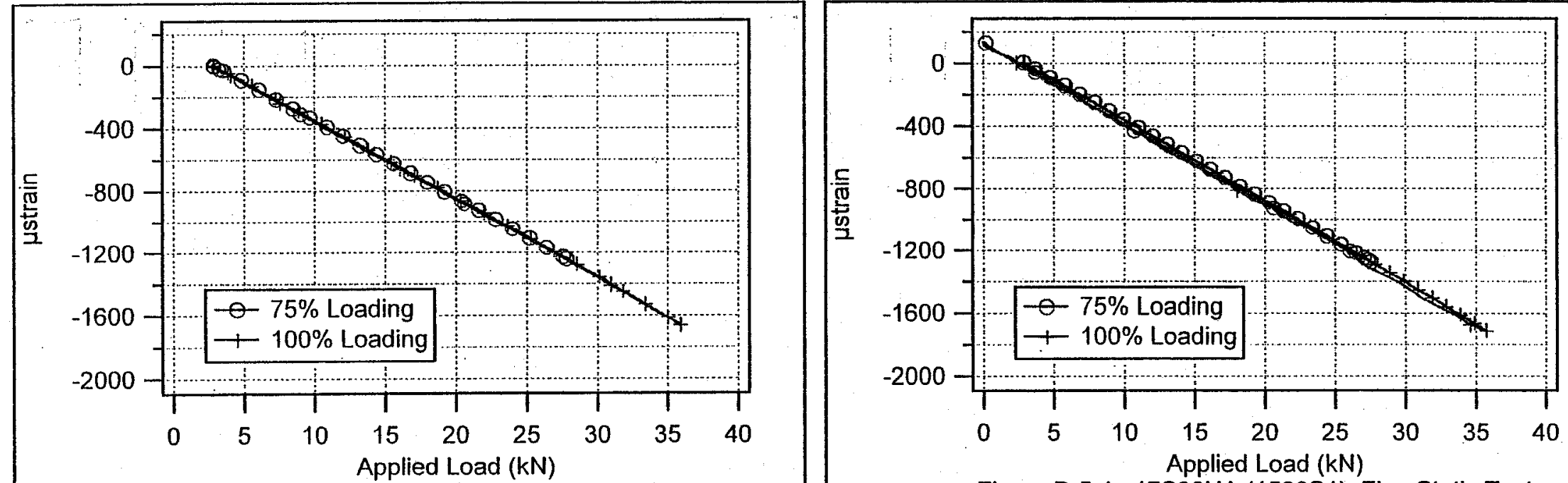

Figure D.5.2. 17S38UA (1500S1), Flap Static Test, Blade \#66, Post-Fatigue

Figure D.5.4. 17S38UA (1500S1), Flap Static Test, Blade \#67, Post-Fatigue 

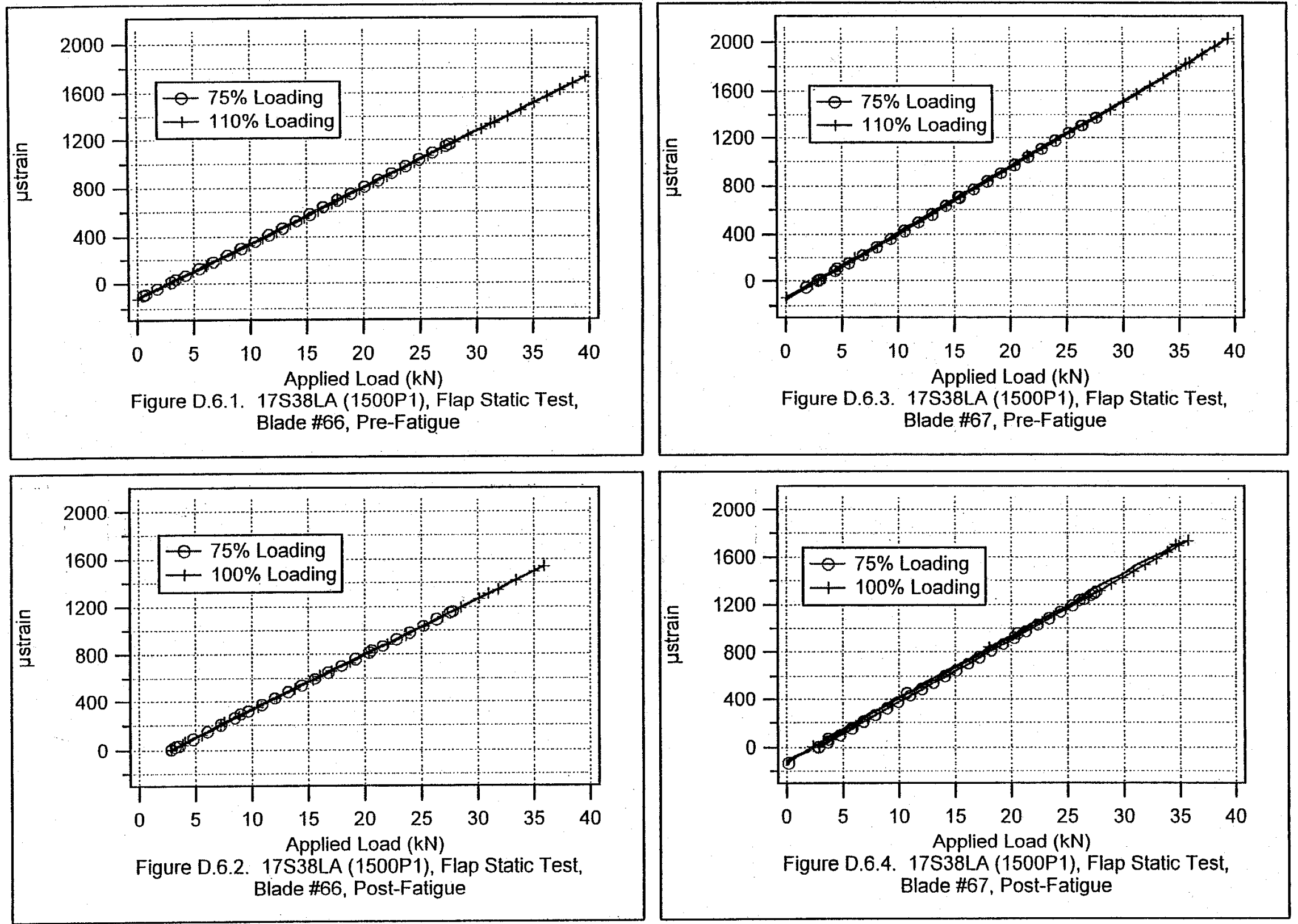

Figure D.6.4. 17S38LA (1500P1), Flap Static Test, Blade \#67, Post-Fatigue 

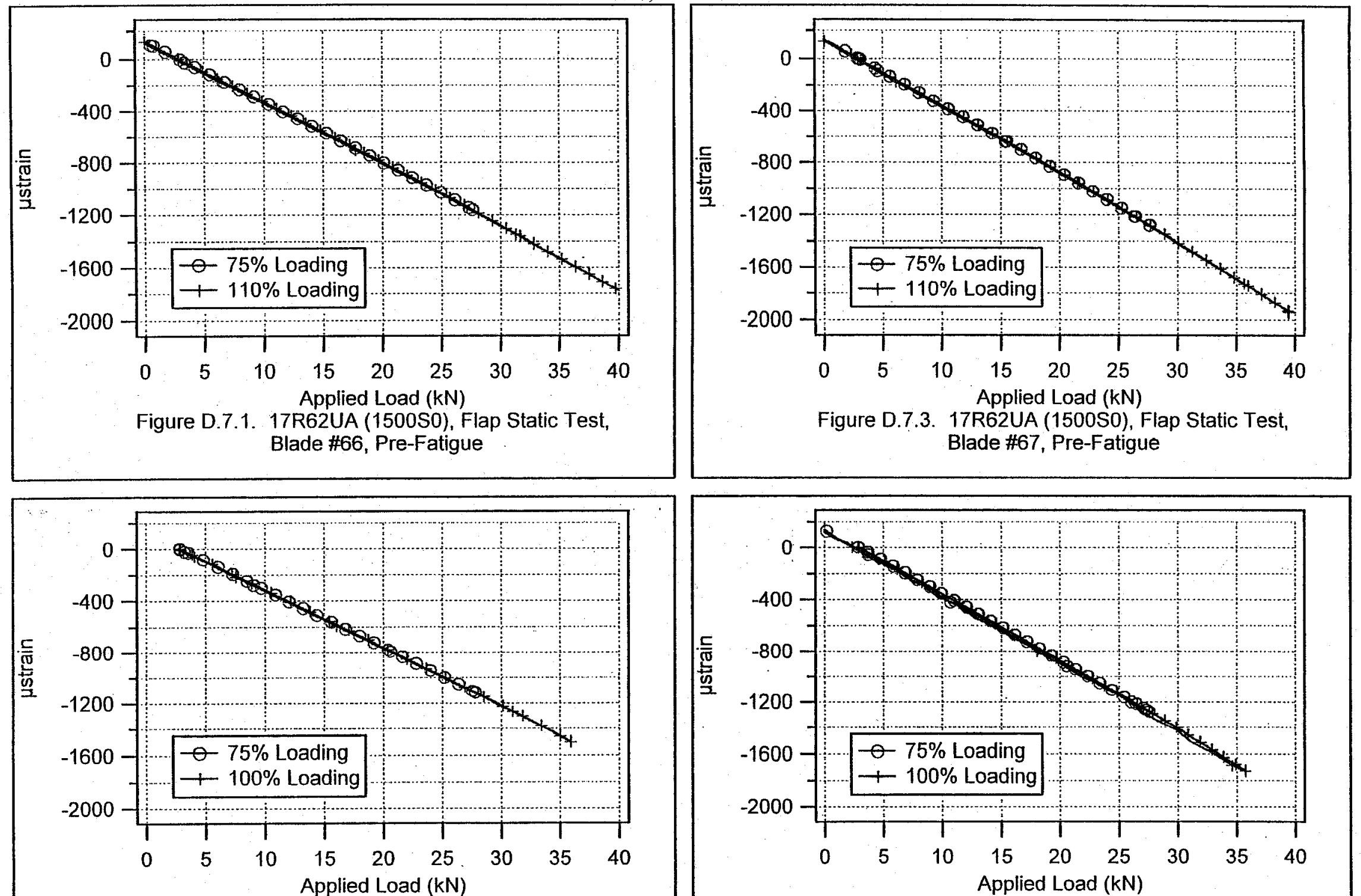

Figure D.7.2. 17R62UA (1500S0), Flap Static Test, Blade \#66, Post-Fatigue

Figure D.7.4. 17R62UA (1500S0), Flap Static Test, Blade \#67, Post-Fatigue 

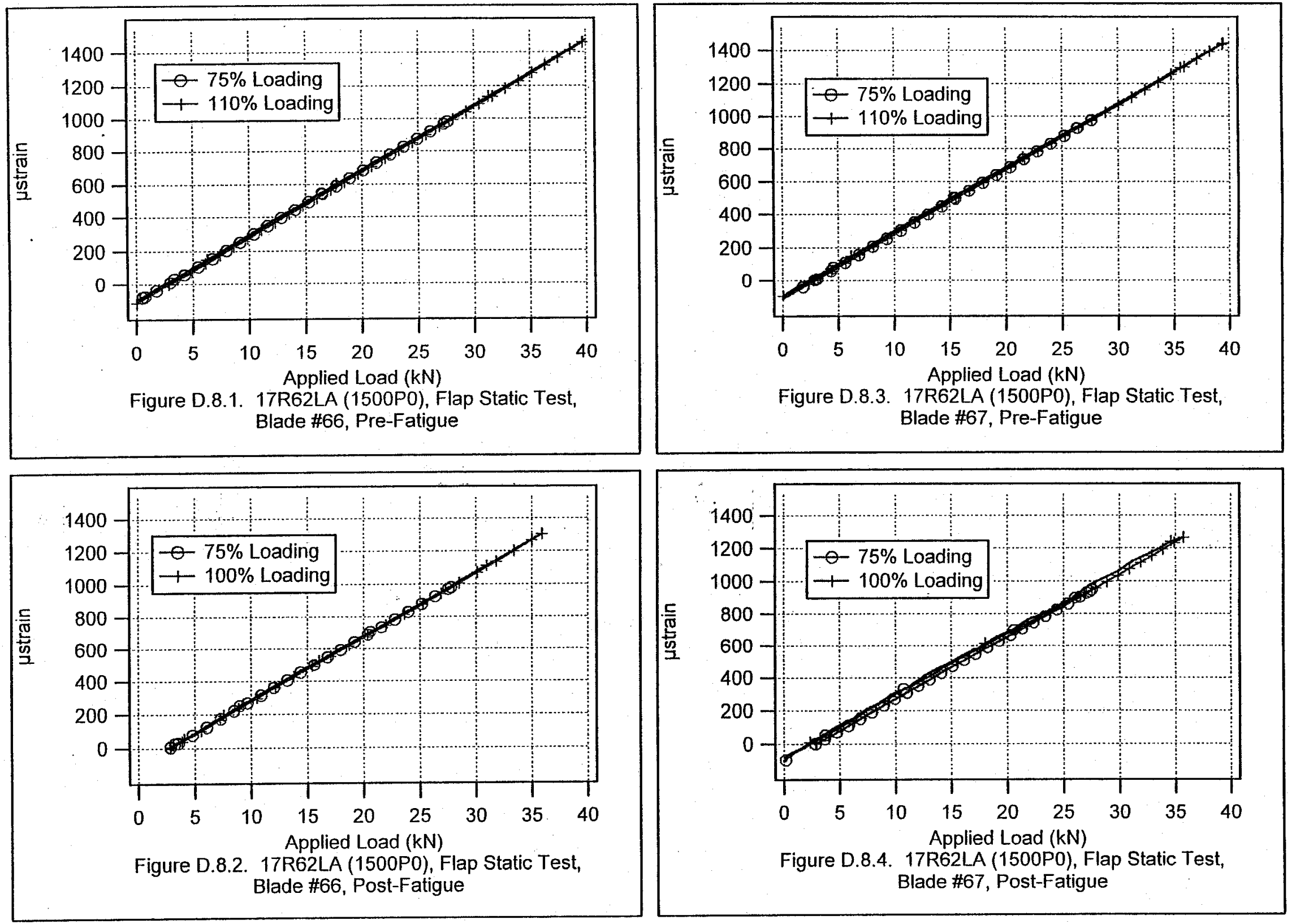

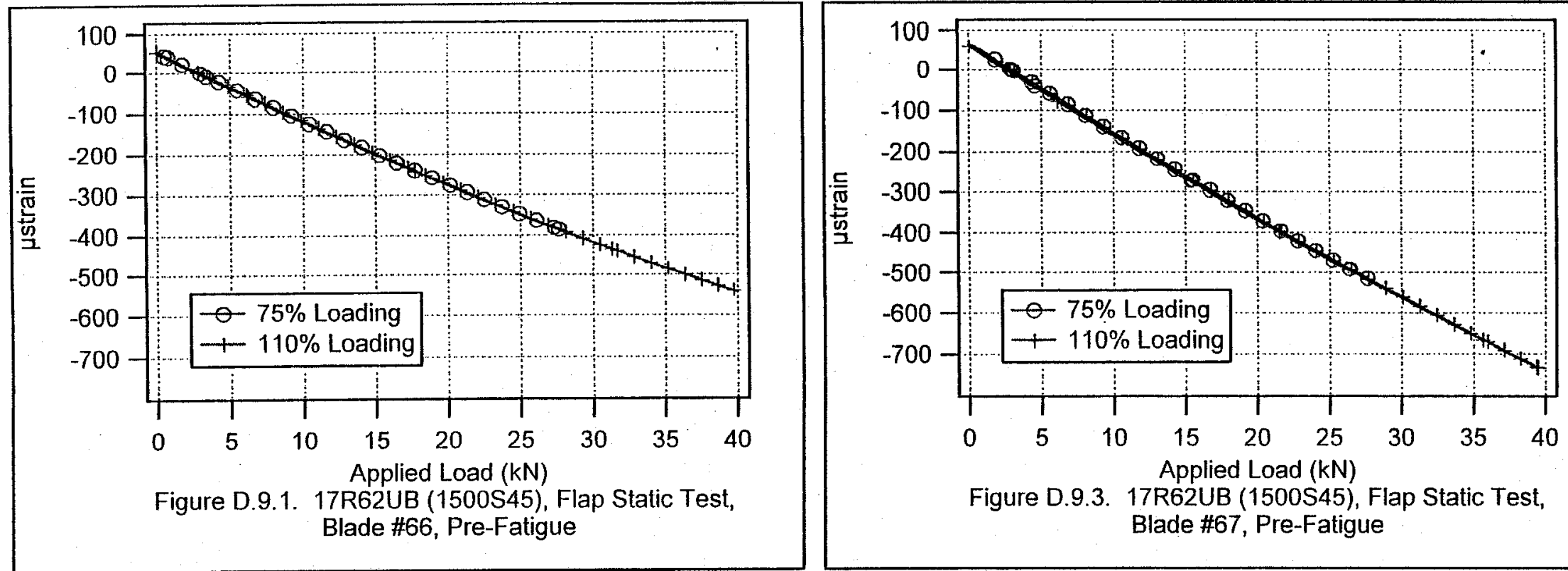

Figure D.9.3. 17R62UB (1500S45), Flap Static Test, Blade \#67, Pre-Fatigue

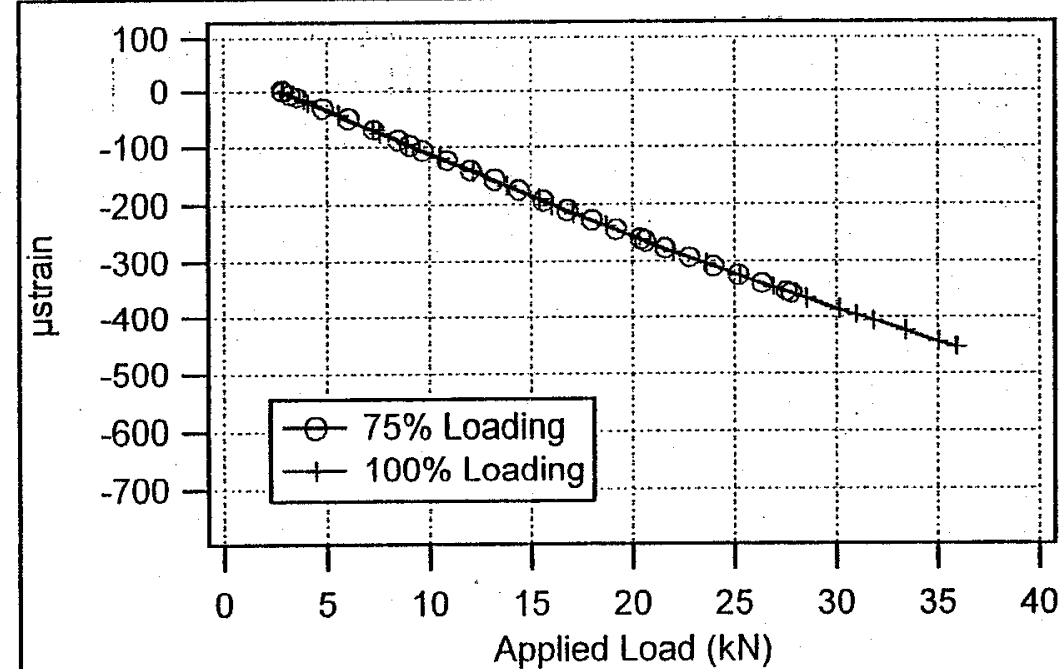

Figure D.9.2. 17R62UB (1500S45), Flap Static Test Blade \#66, Post-Fatigue

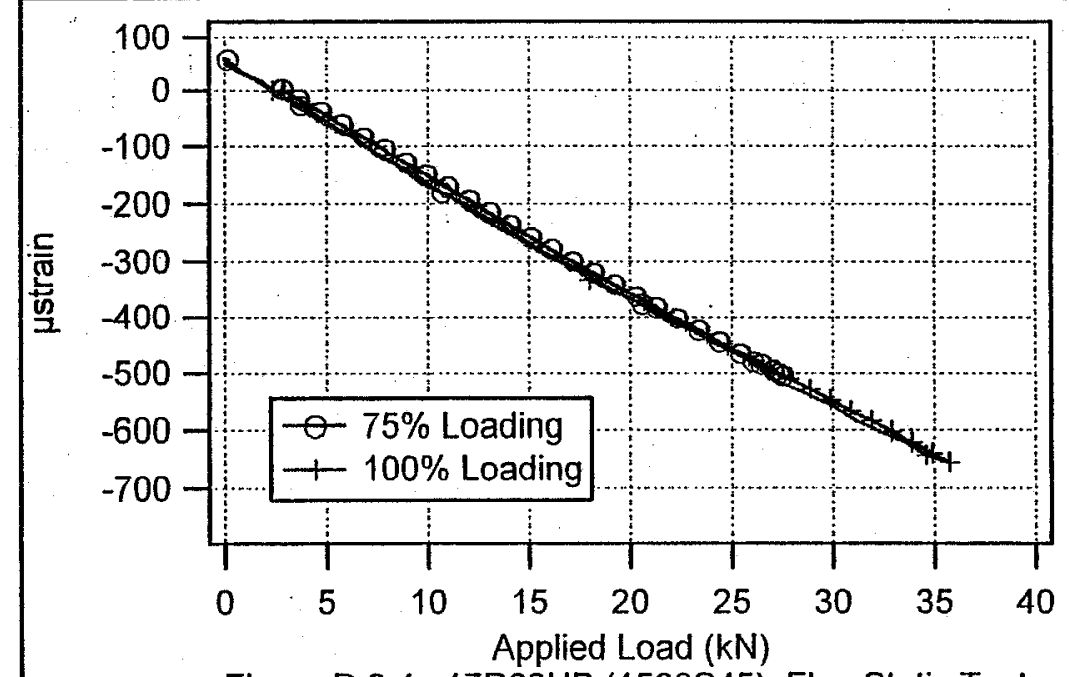

Figure D.9.4. 17R62UB (1500S45), Flap Static Test. Blade \#67, Post-Fatigue 

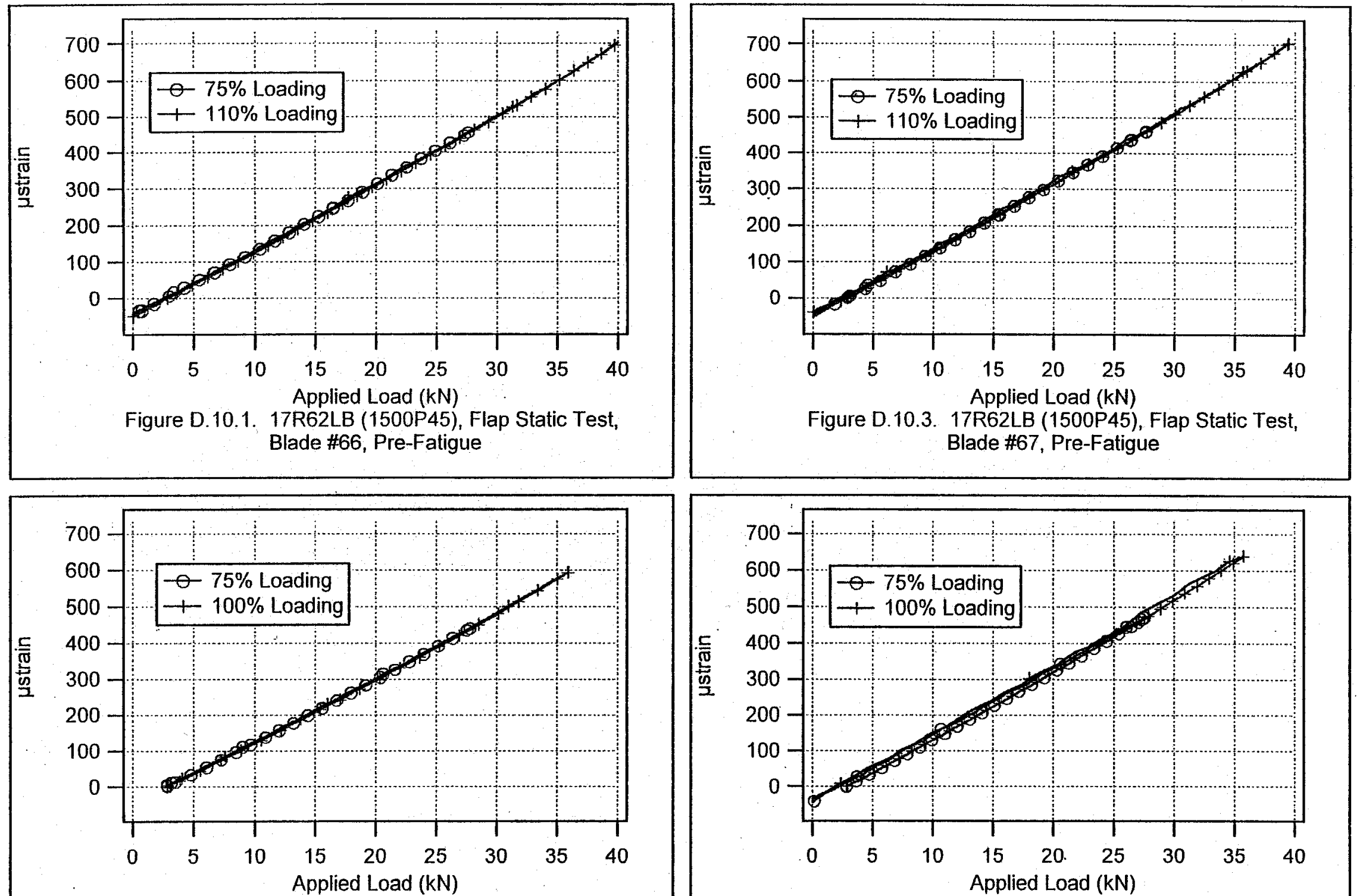

Figure D.10.2. 17R62LB (1500P45), Flap Static Test, Blade \#66, Post-Fatigue

Figure D.10.4. 17R62LB (1500P45), Flap Static Test, Blade \#67, Post-Fatigue 

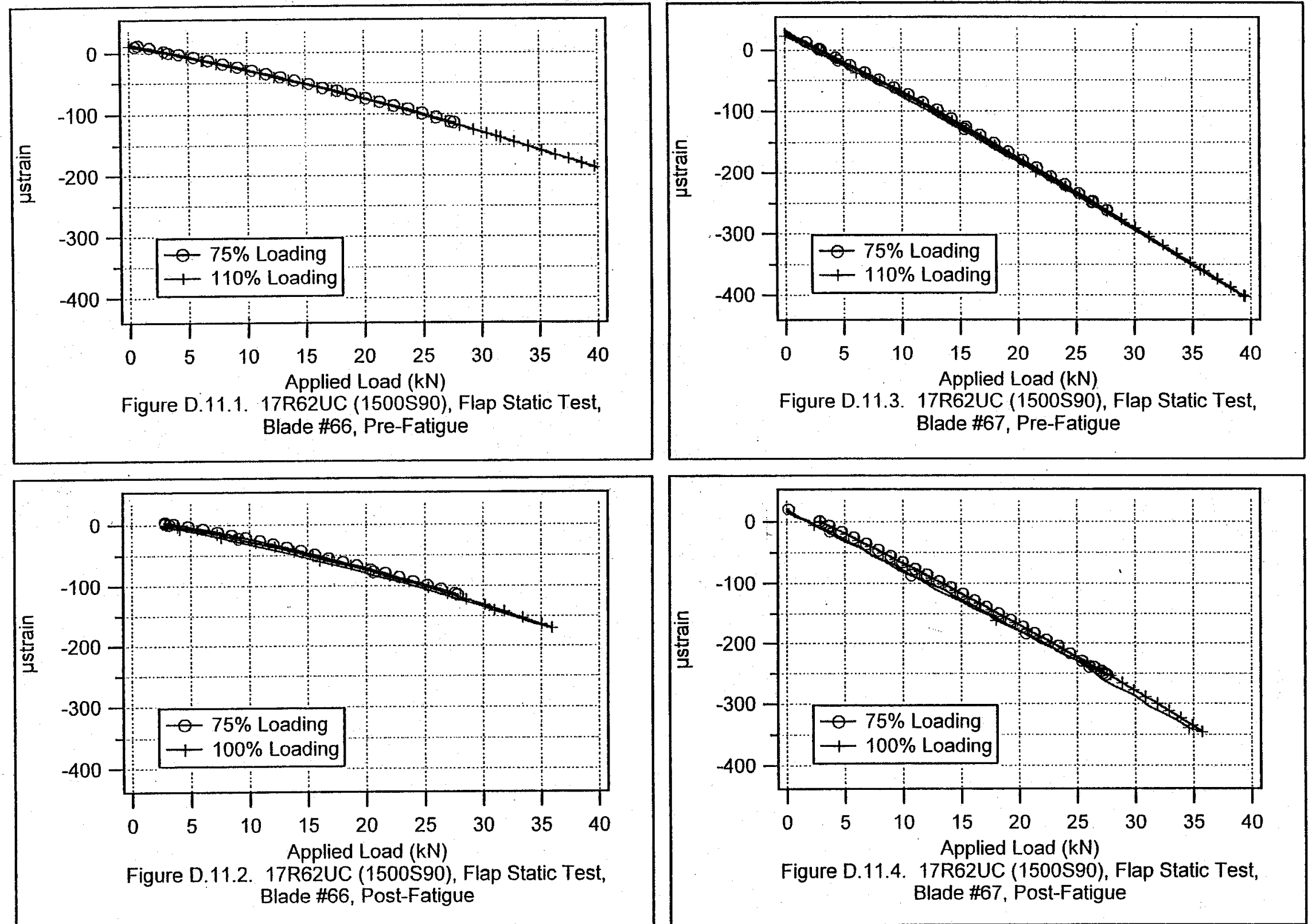

Figure D.11.4. 17R62UC (1500S90), Flap Static Test, Blade \#67, Post-Fatigue 

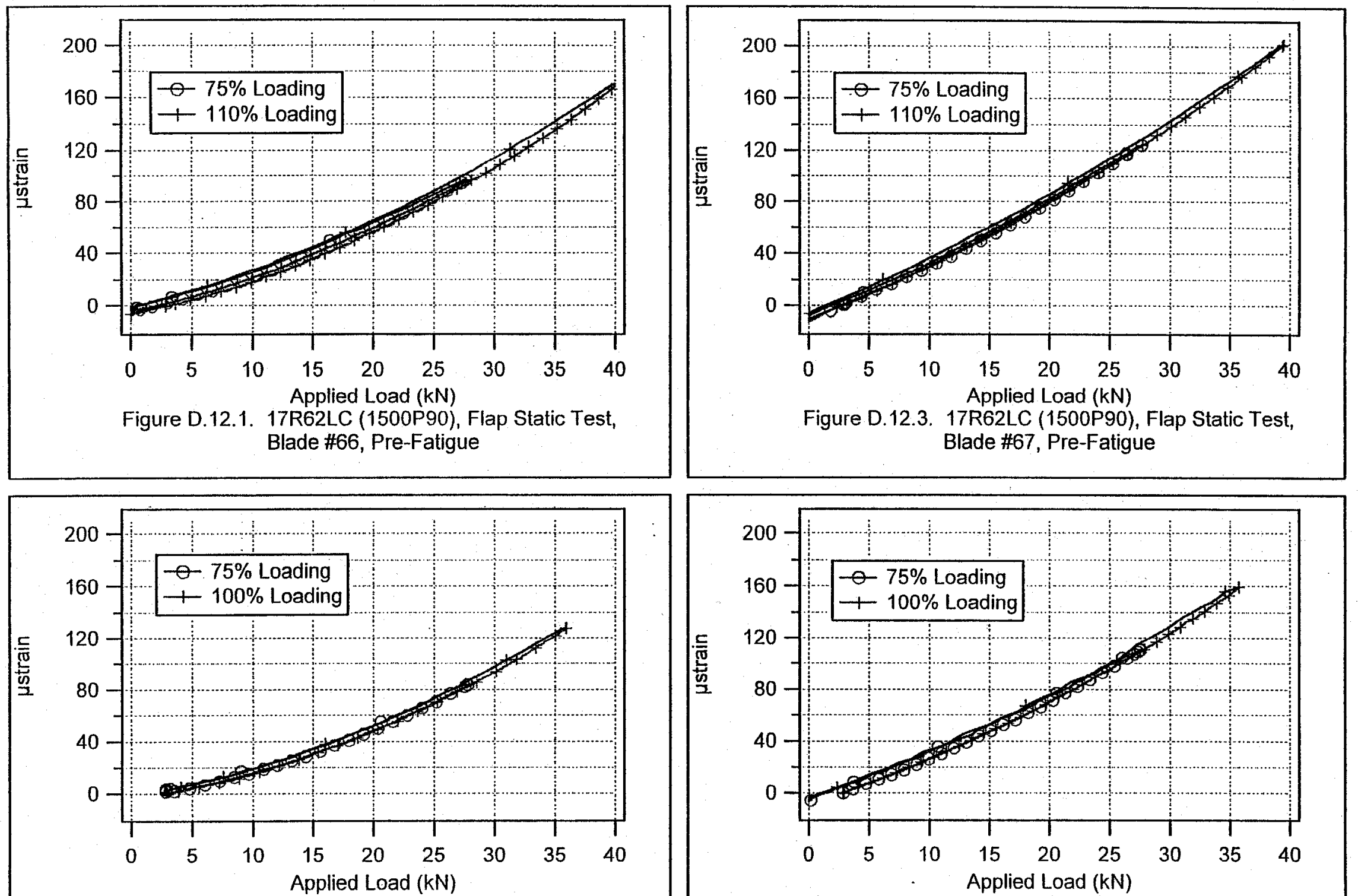

Figure D.12.2. 17R62LC (1500P90), Flap Static Test, Blade \#66, Post-Fatigue

Figure D.12.4. 17R62LC (1500P90), Flap Static Test Blade \#67, Post-Fatigue 

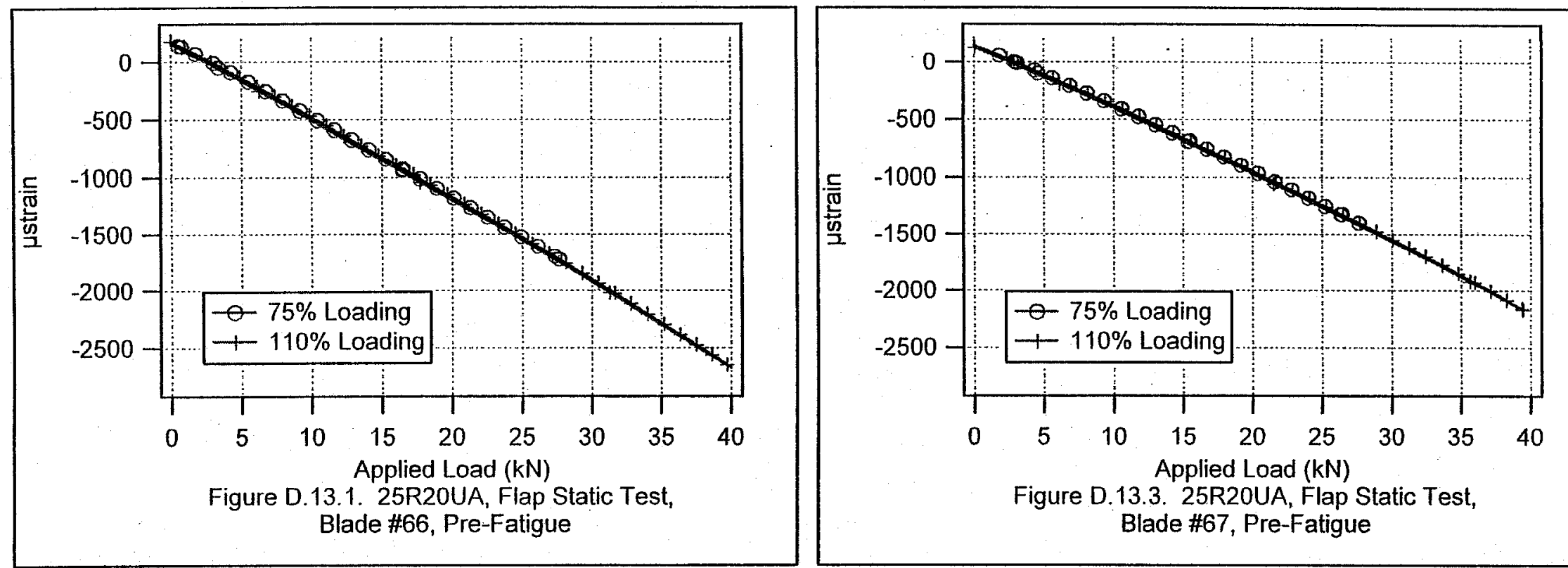

Figure D.13.3. 25R20UA, Flap Static Test, Blade \#67, Pre-Fatigue
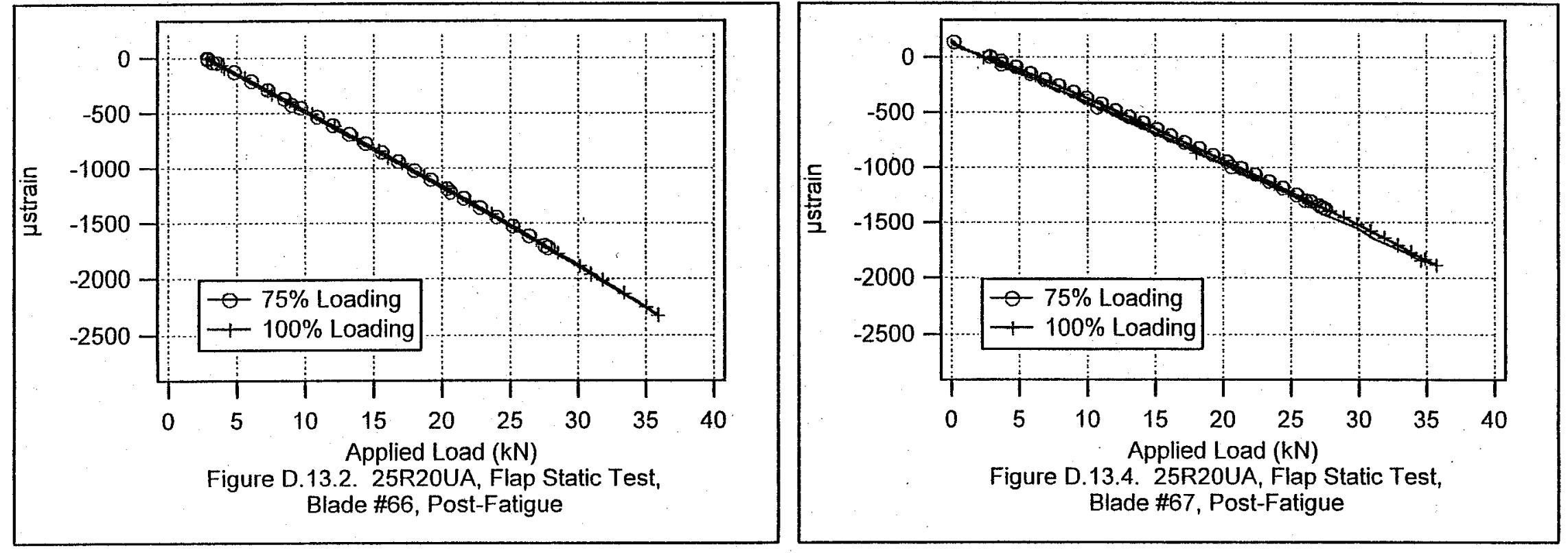

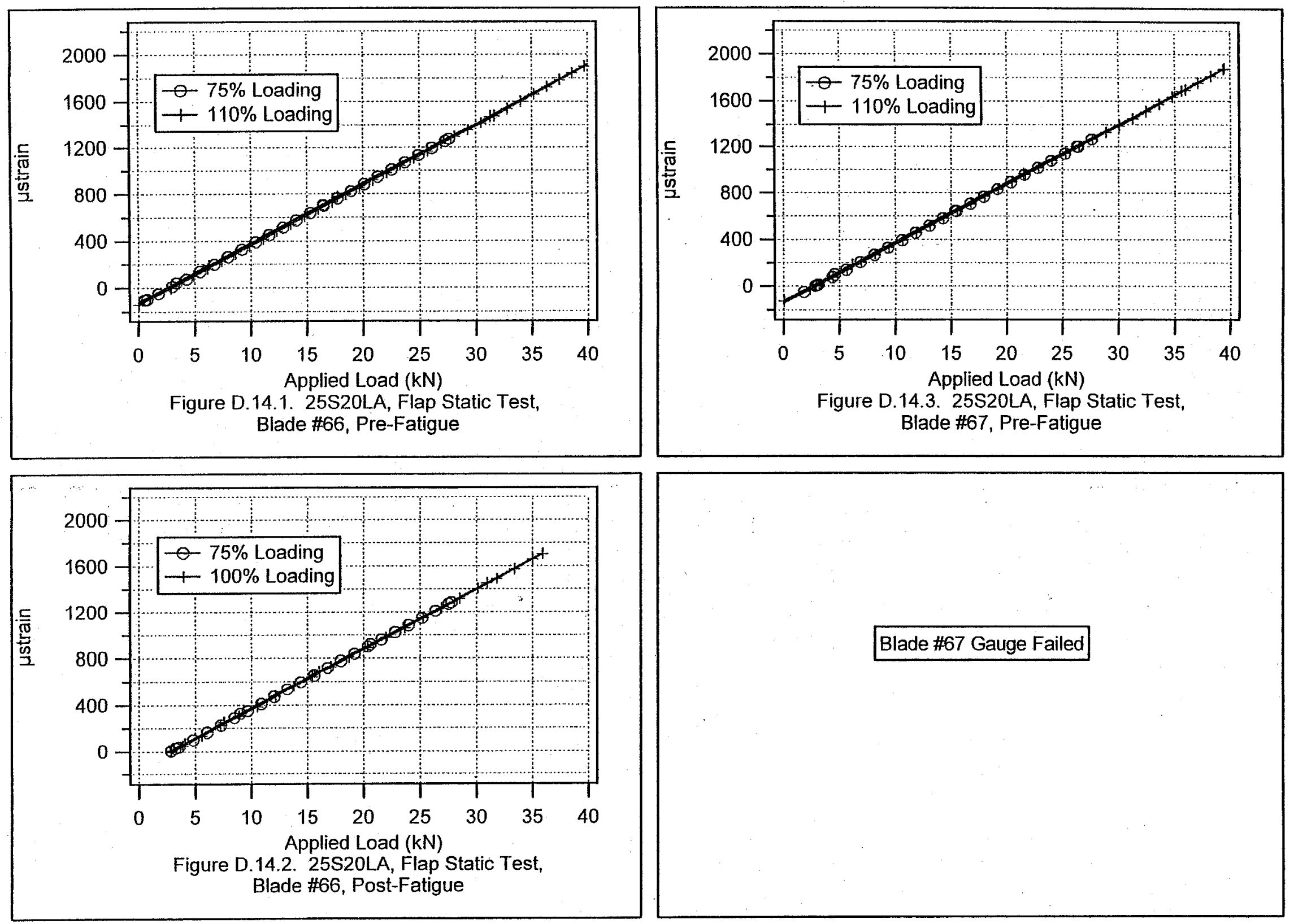

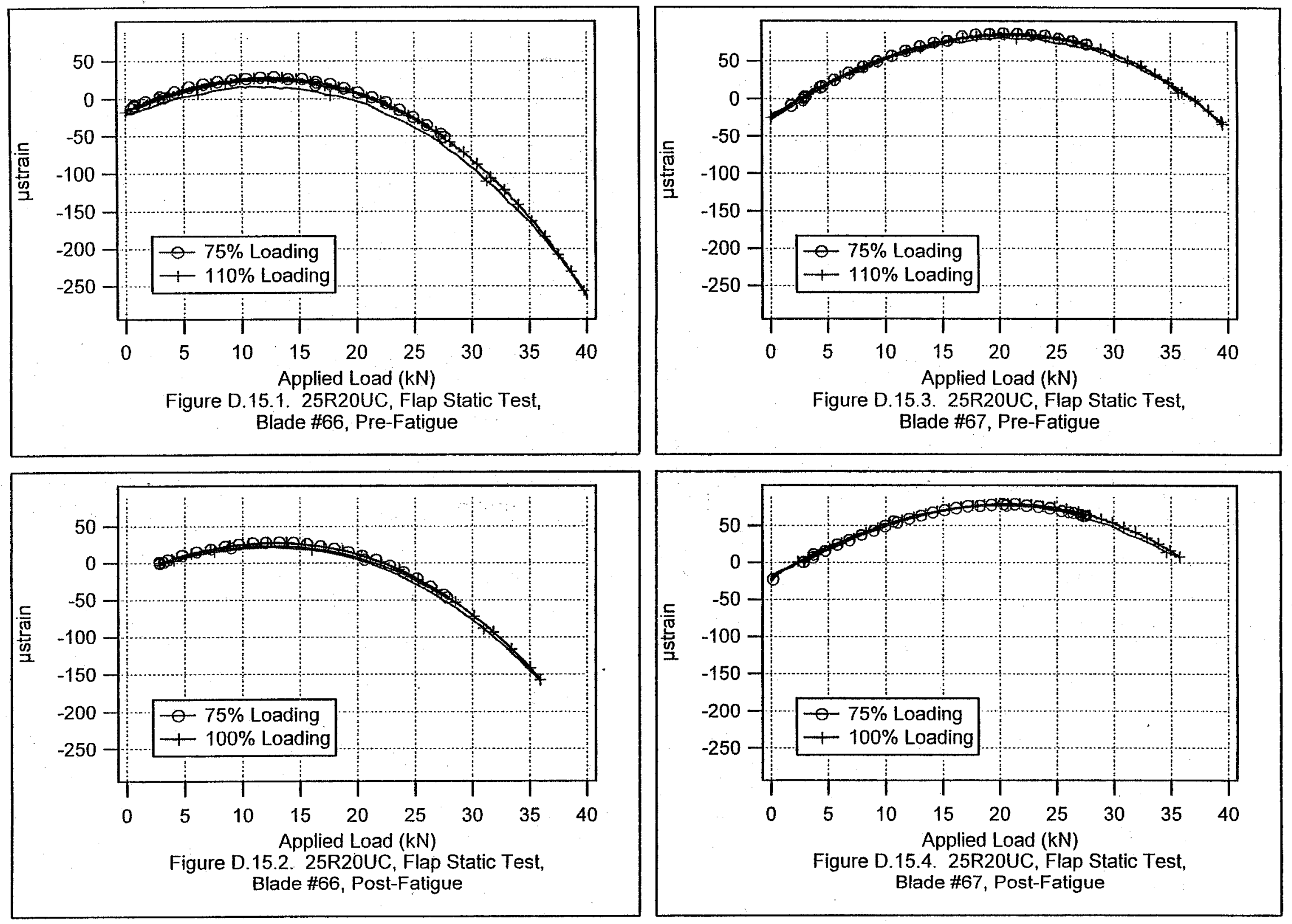


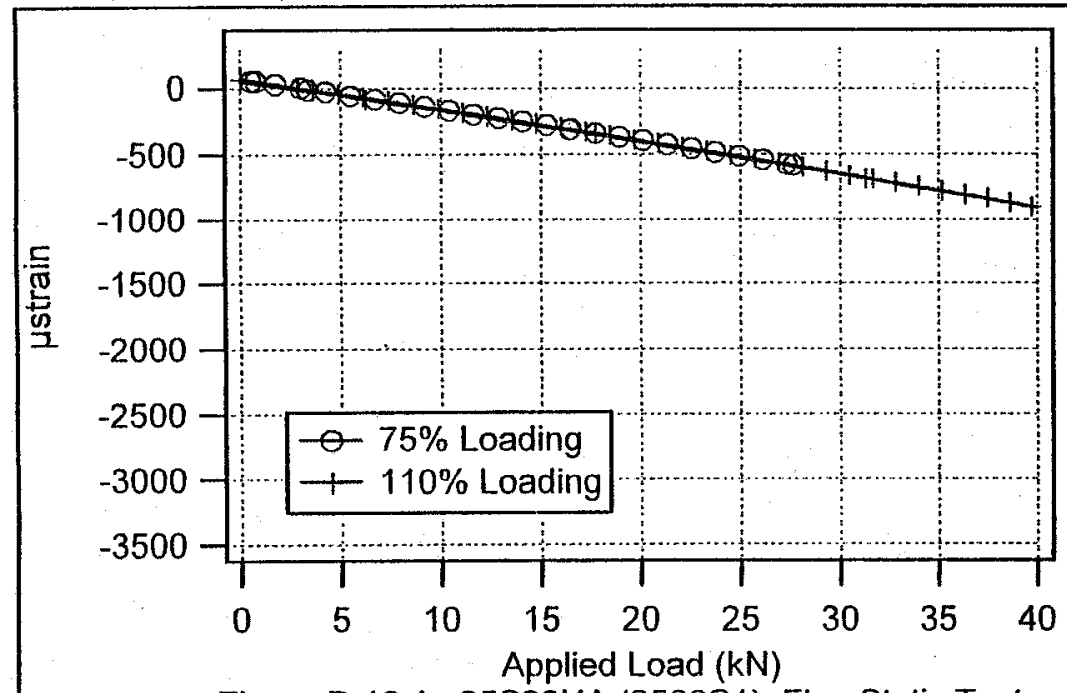

Figure D.16.1. 25S26UA (2500S1), Flap Static Test, Blade \#66, Pre-Fatigue

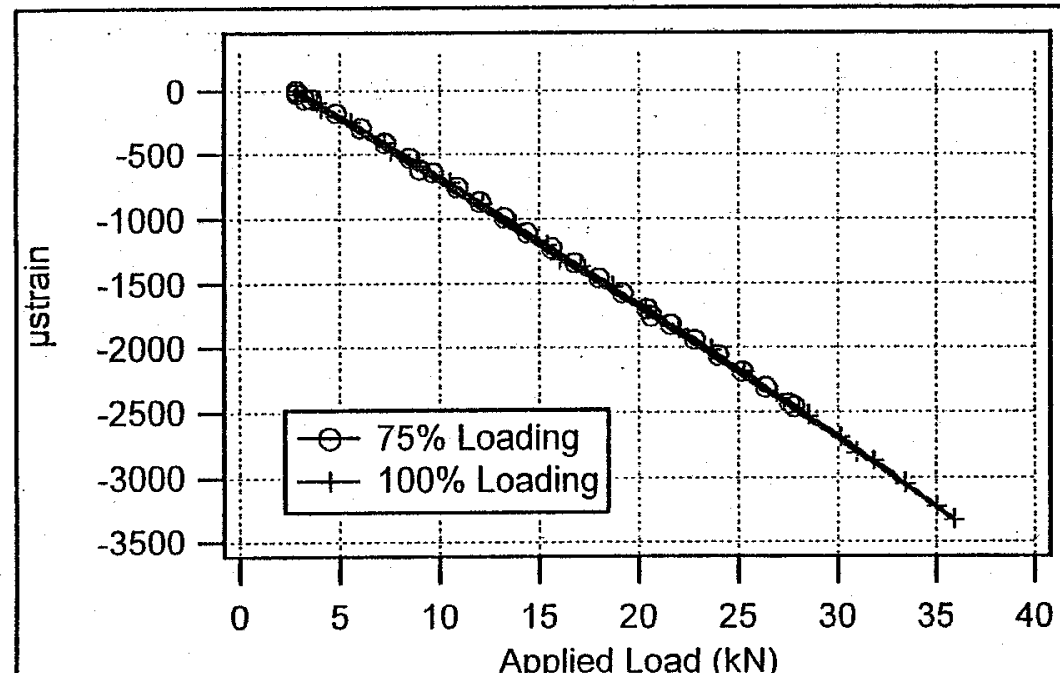

Figure D.16.2. 25S26UA (2500S1), Flap Static Test, Blade \#66, Post-Fatigue

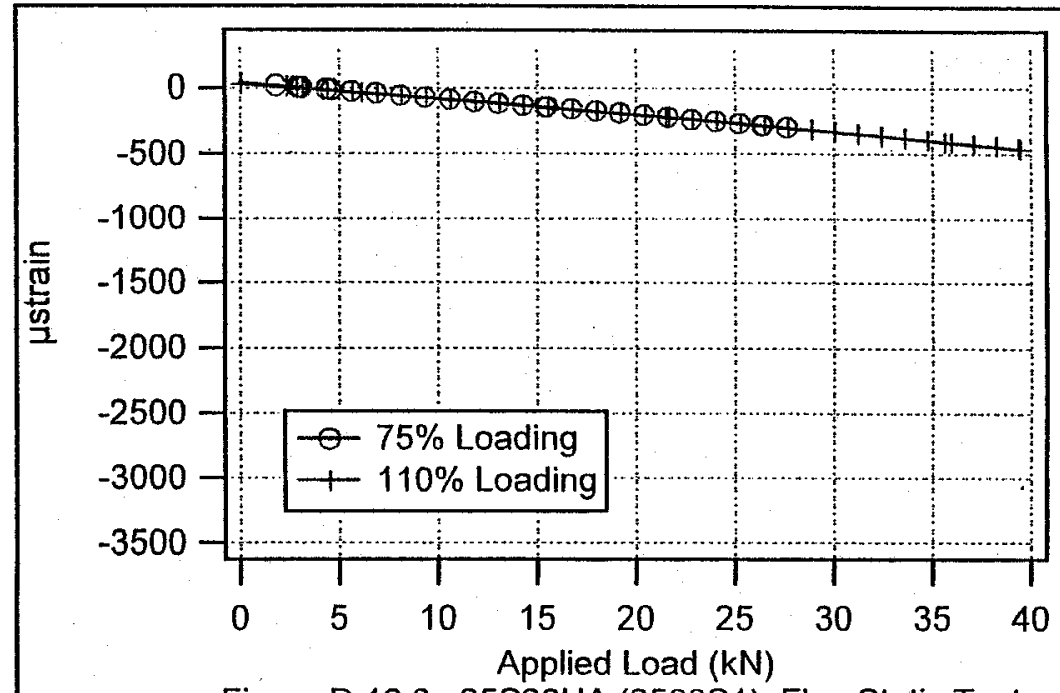

Figure D. 16.3. 25S26UA (2500S1), Flap Static Test, Blade \#67, Pre-Fatigue

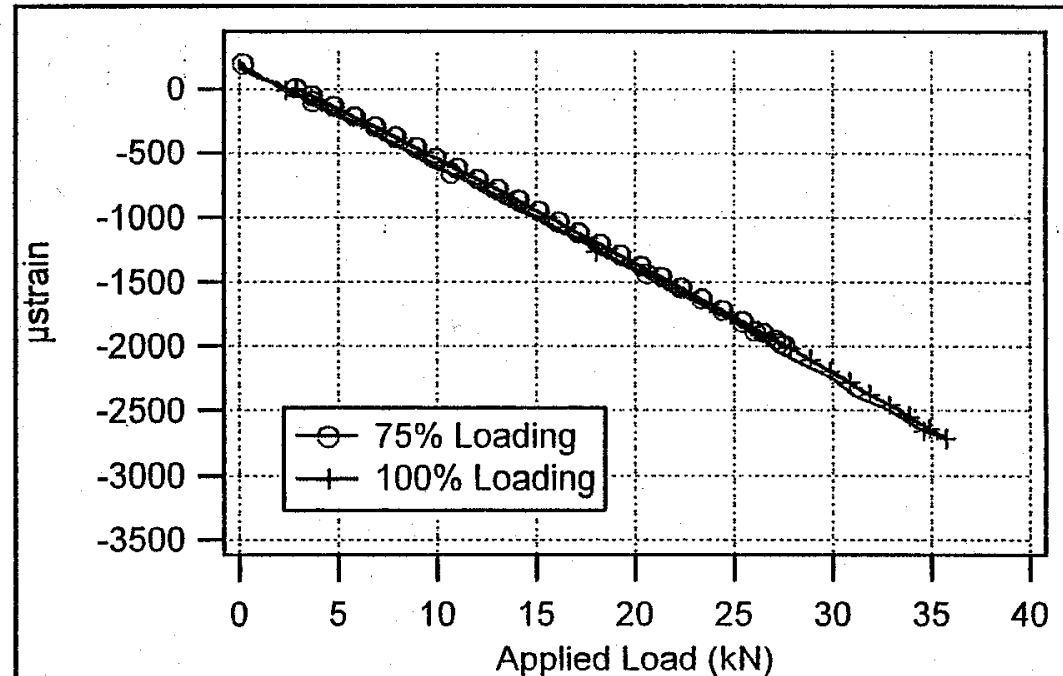

Figure D.16.4. 25S26UA (2500S1), Flap Static Test, Blade \#67, Post-Fatigue 

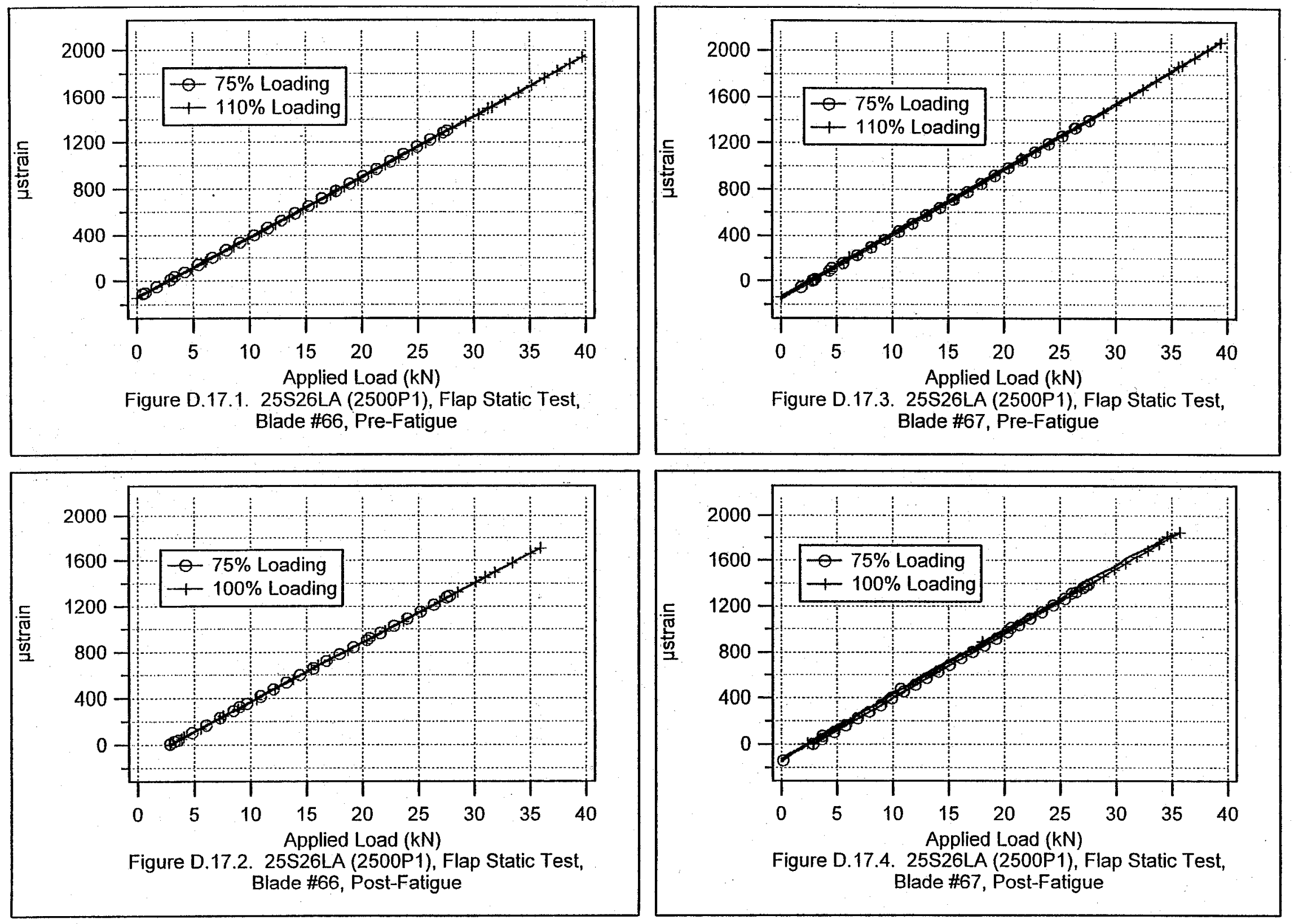

Figure D.17.4. 25S26LA (2500P1), Flap Static Test, Blade \#67, Post-Fatigue 

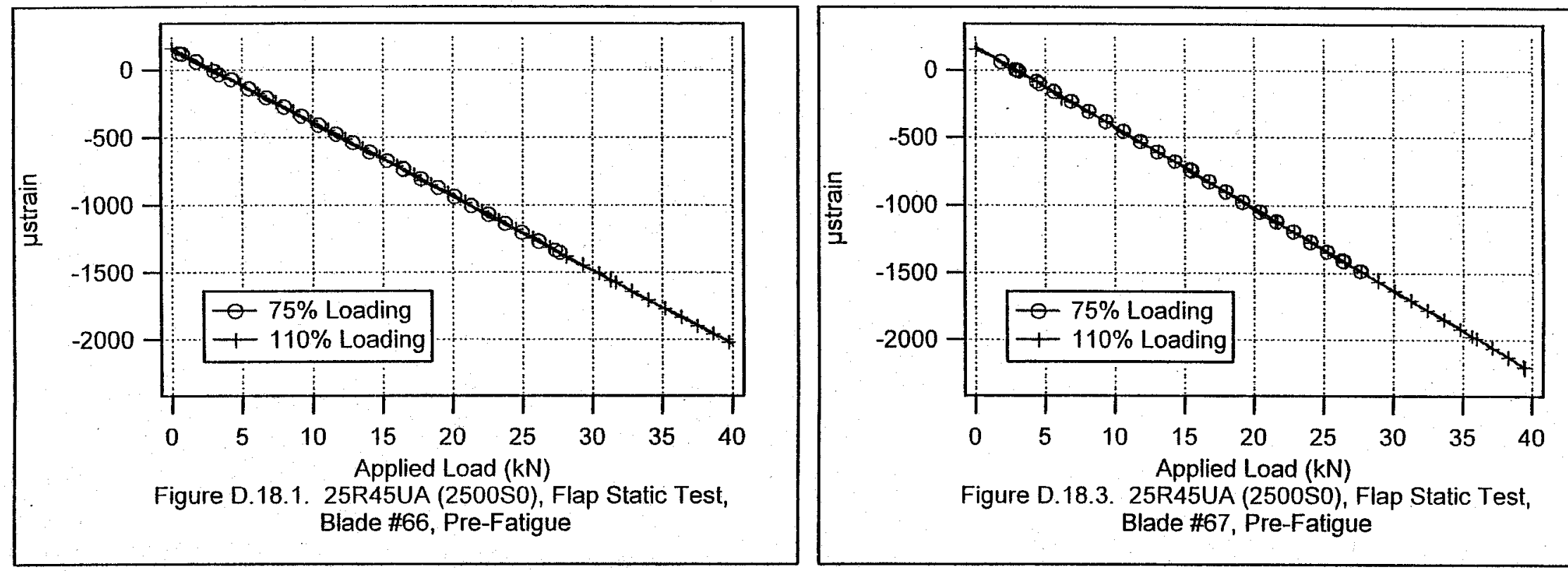

Figure D.18.3. 25R45UA (2500S0), Flap Static Test, Blade \#67, Pre-Fatigue

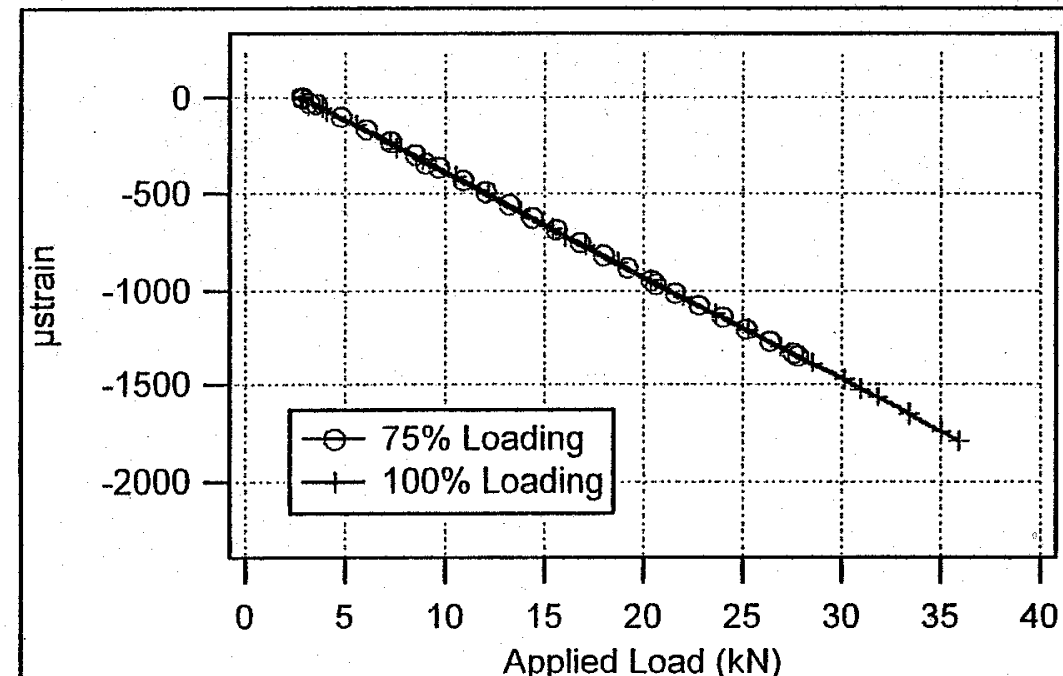

Figure D.18.2. 25R45UA (2500S0), Flap Static Test, Blade \#66, Post-Fatigue

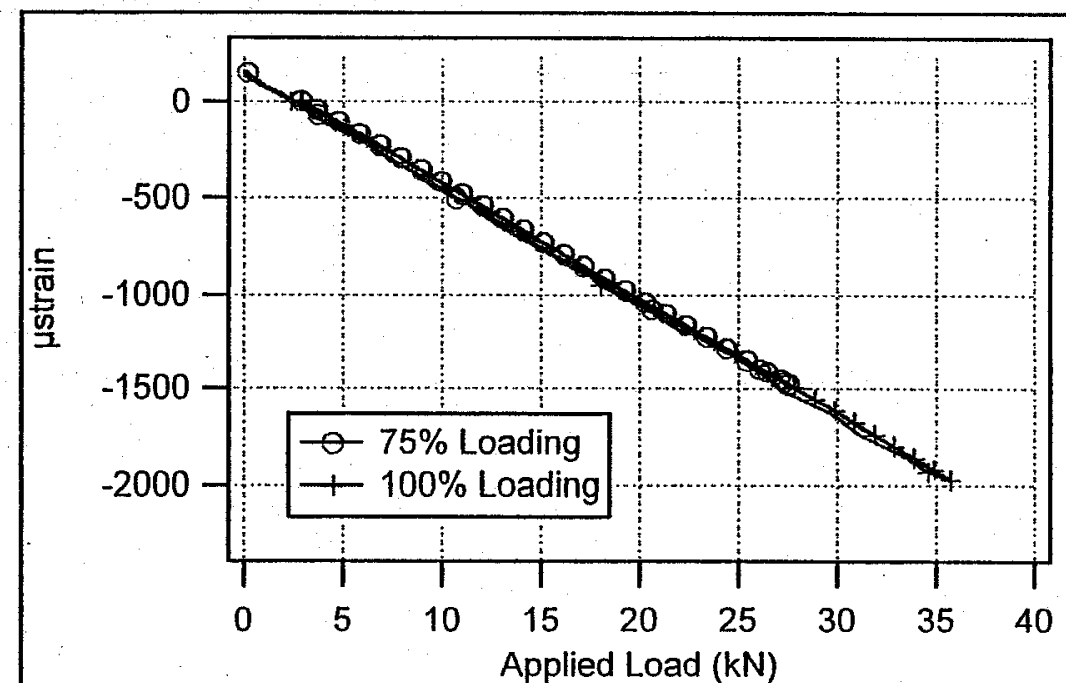

Figure D.18.4. 25R45UA (2500S0), Flap Static Test, Blade \#67, Post-Fatigue 

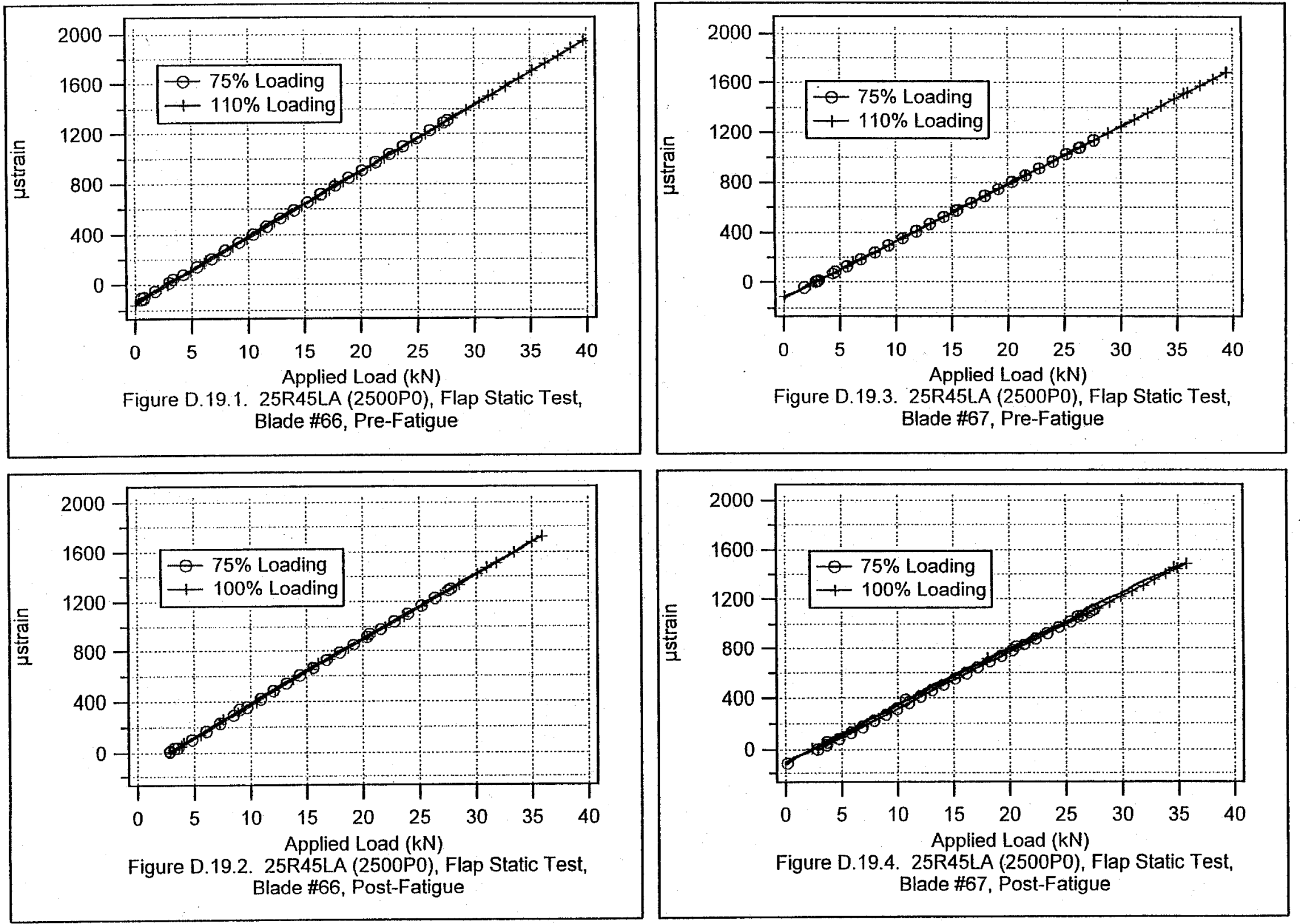

Figure D.19.4. 25R45LA (2500P0), Flap Static Test, Blade \#67, Post-Fatigue 

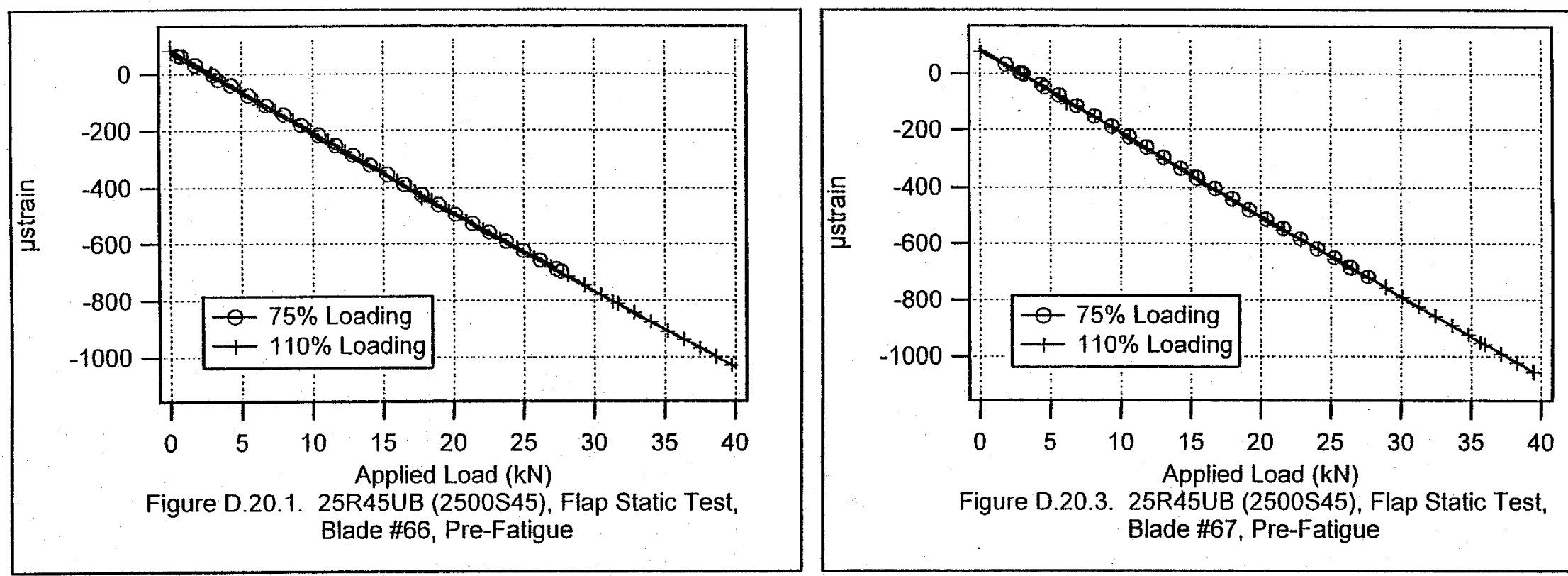

Figure D.20.3. 25R45UB (2500S45); Flap Static Test, Blade \#67, Pre-Fatigue
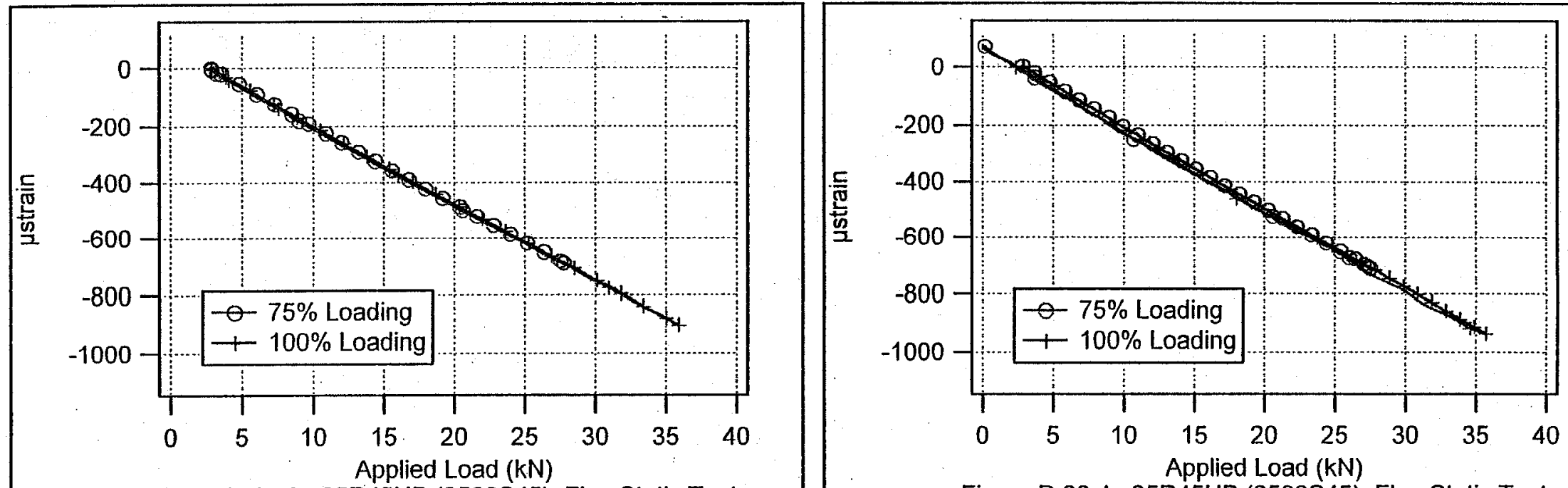

Figure D.20.2. 25R45UB (2500\$45), Flap Static Test, Blade \#66, Post-Fatigue

Figure D.20.4. 25R45UB (2500S45), Flap Static Test, Blade \#67, Post-Fatigue 

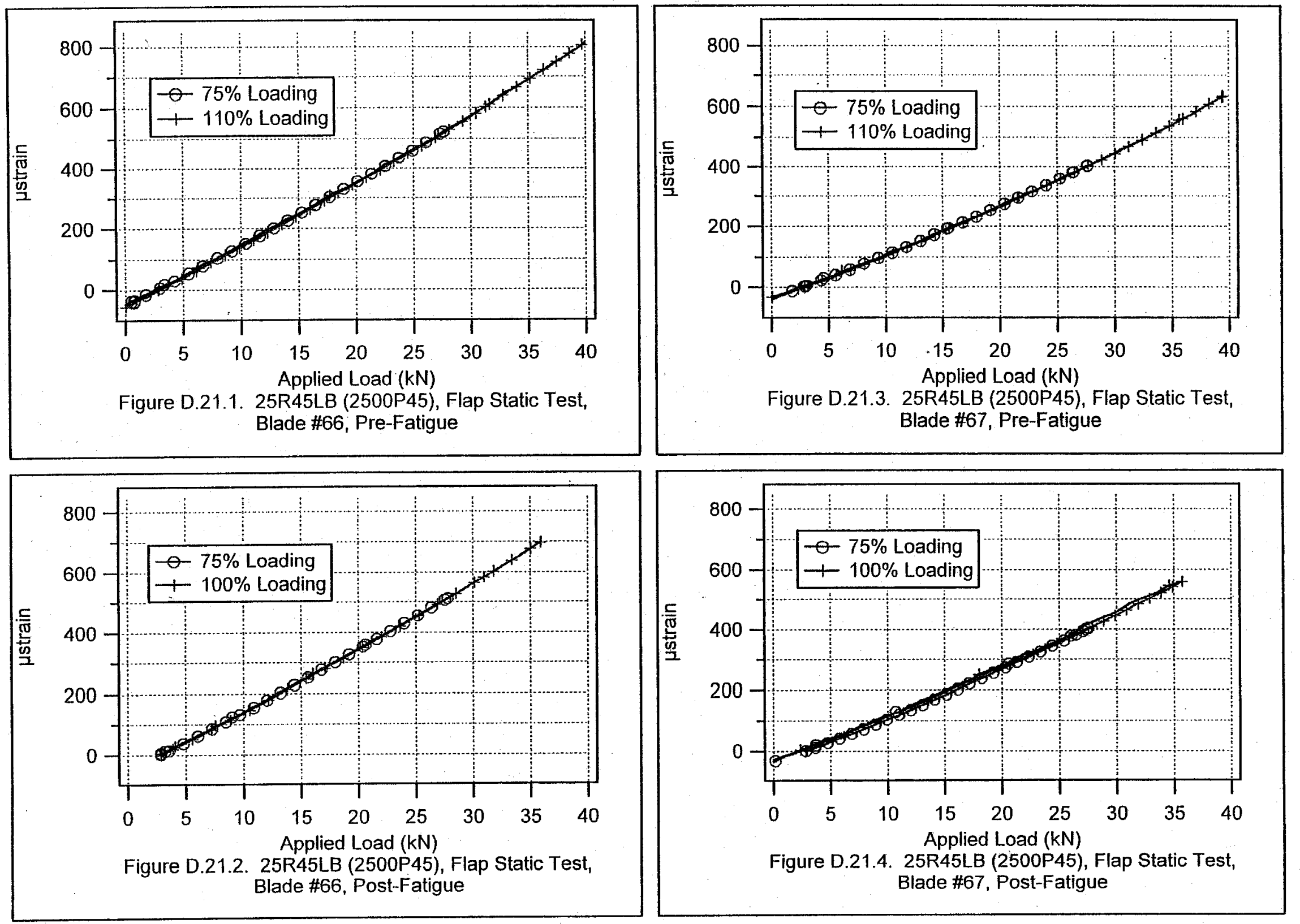

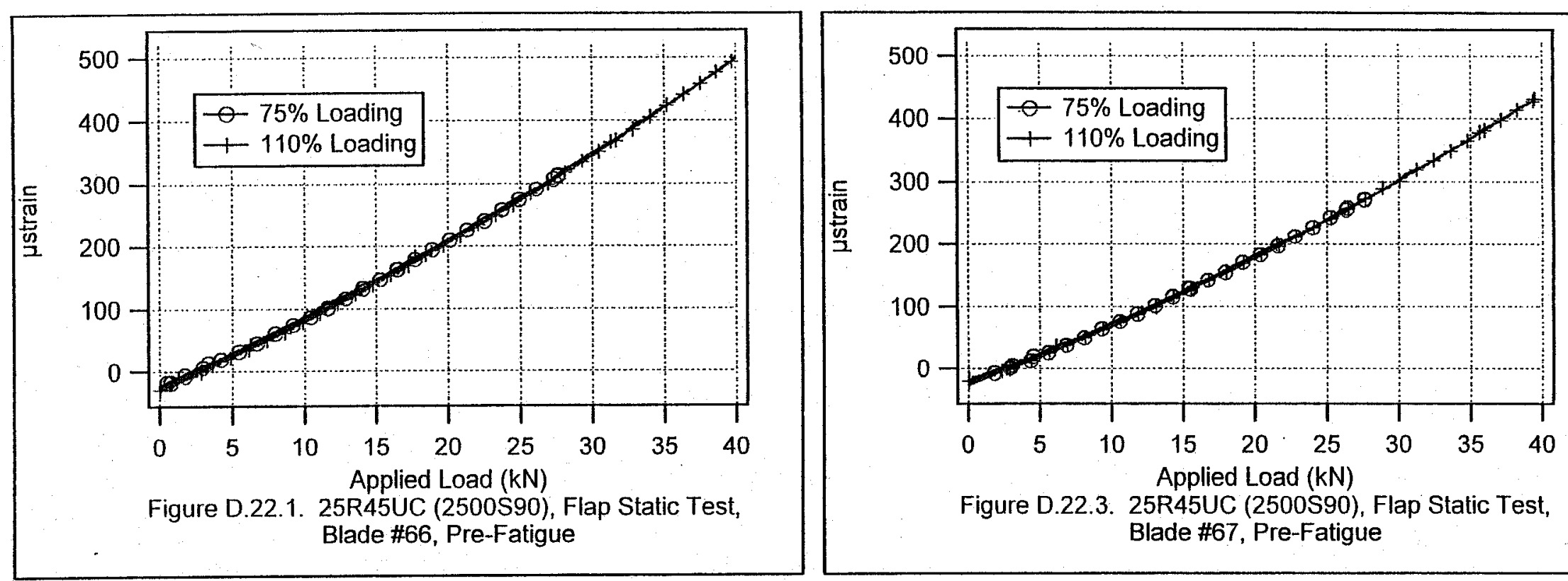

Figure D.22.3. 25R45UC (2500S90), Flap Static Test, Blade \#67, Pre-Fatigue
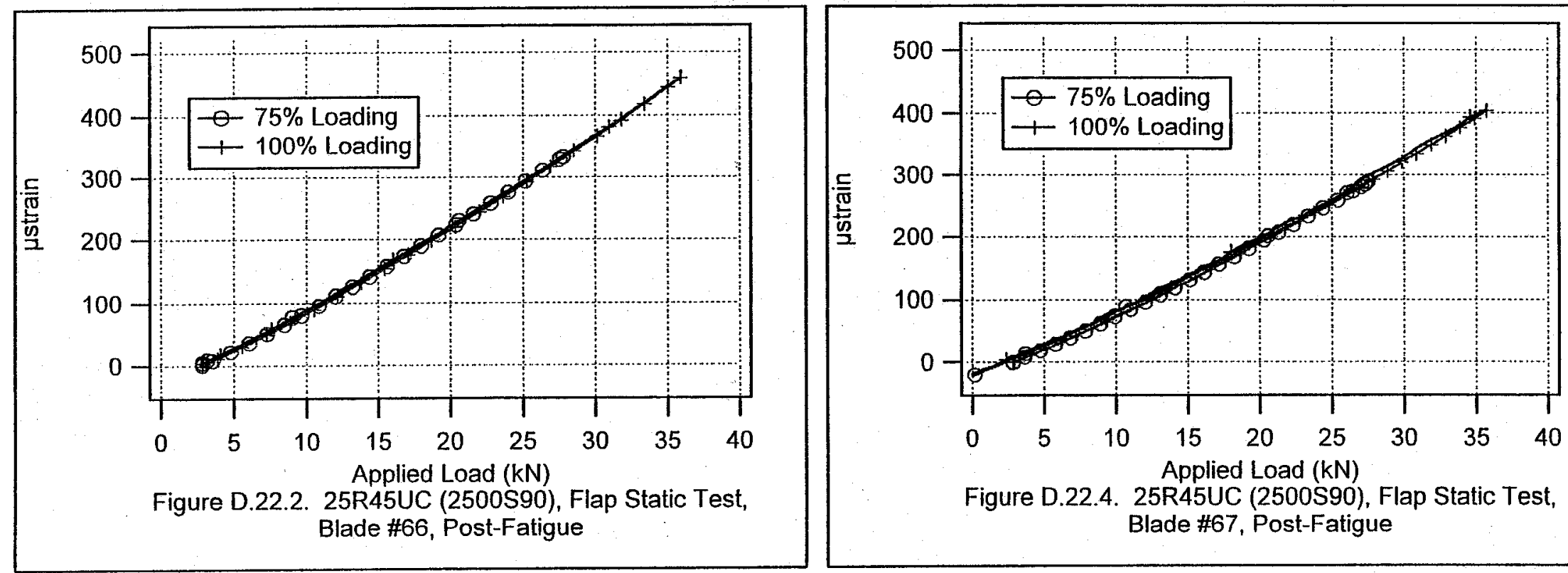

Figure D.22.4. 25R45UC (2500S90), Flap Static Test, Blade \#67, Post-Fatigue 

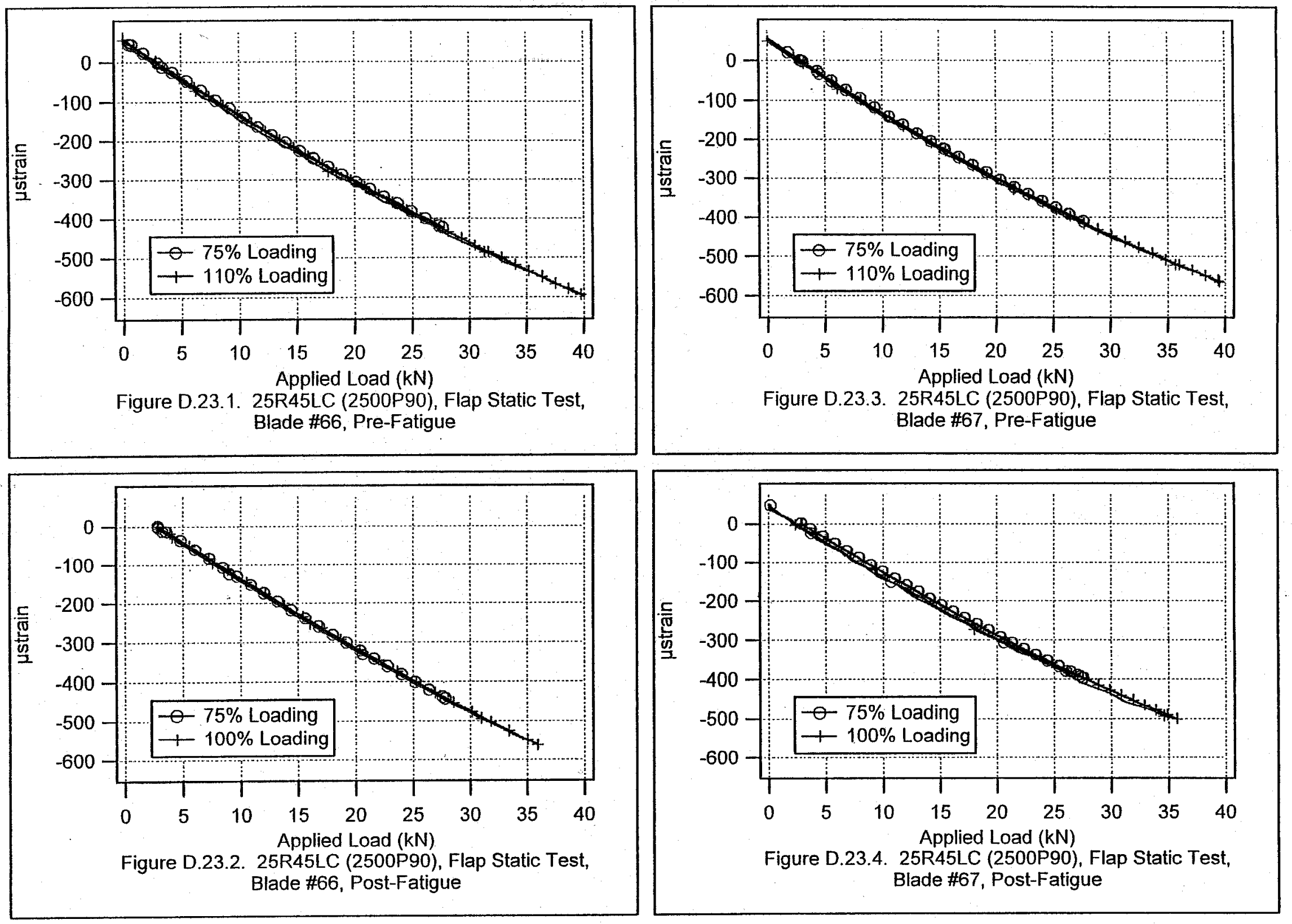

Figure D.23.4. 25R45LC (2500P90), Flap Static Test, Blade \#67, Post-Fatigue 


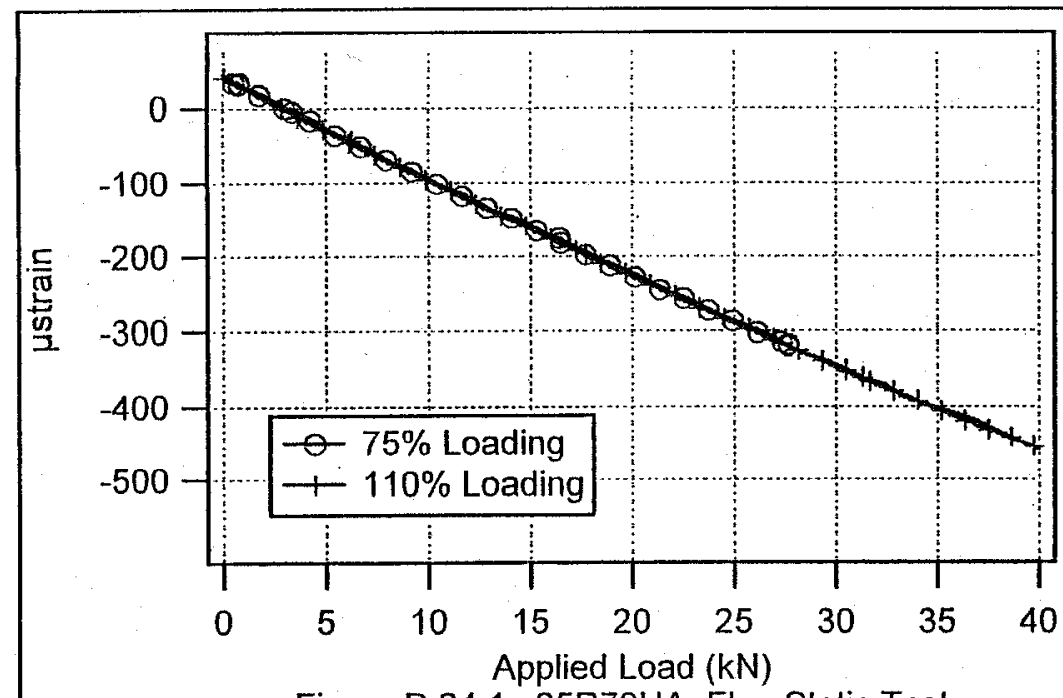

Figure D.24.1. 25R70UA, Flap Static Test, Blade \#66, Pre-Fatigue

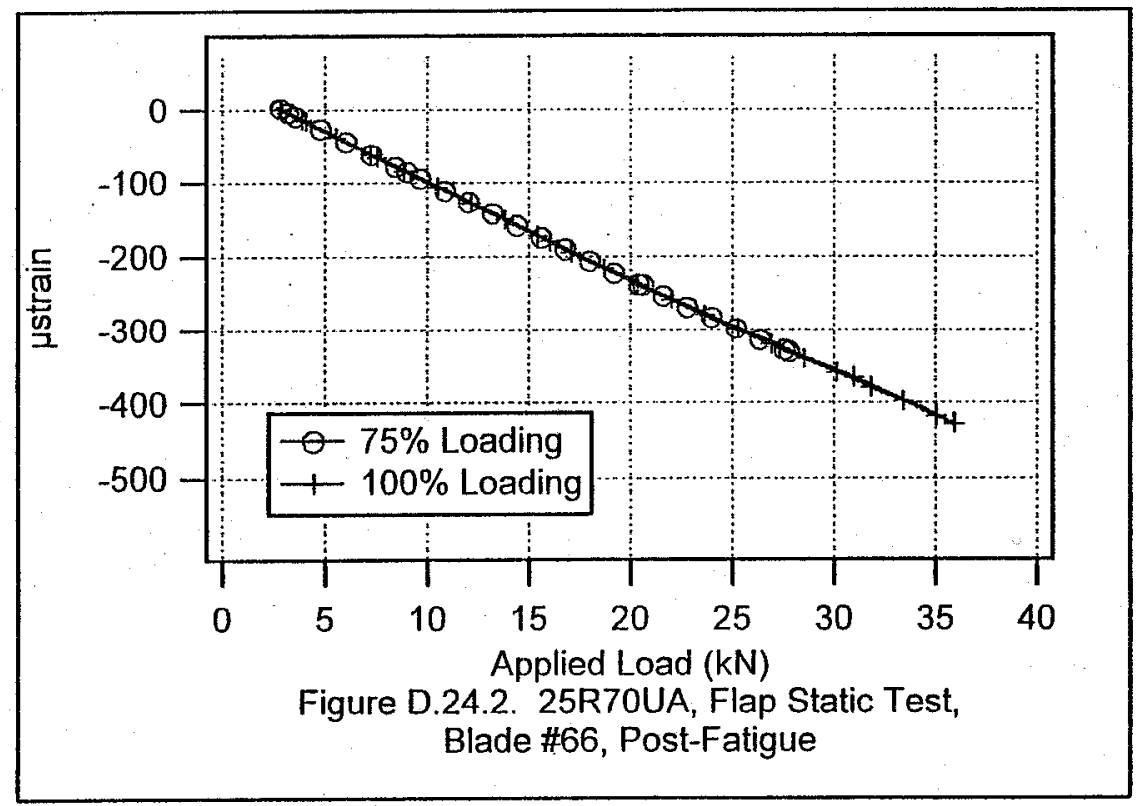

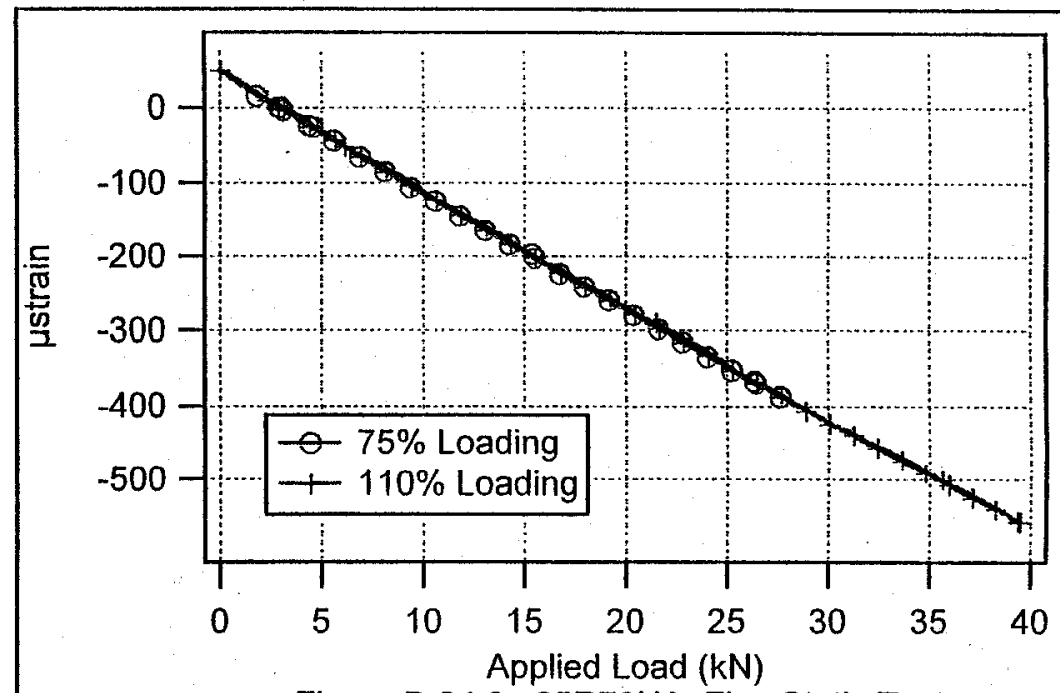

Figure D.24.3. 25R70UA, Flap Static Test, Blade \#67, Pre-Fatigue

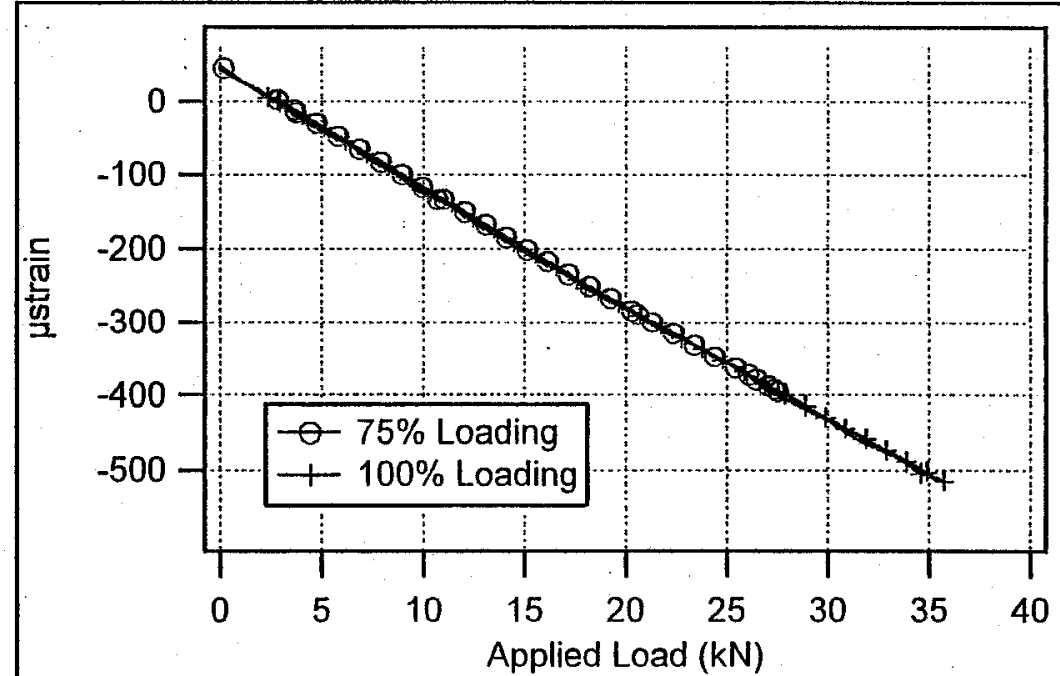

Figure D.24.4. 25R70UA, Flap Static Test, Blade \#67, Post-Fatigue 

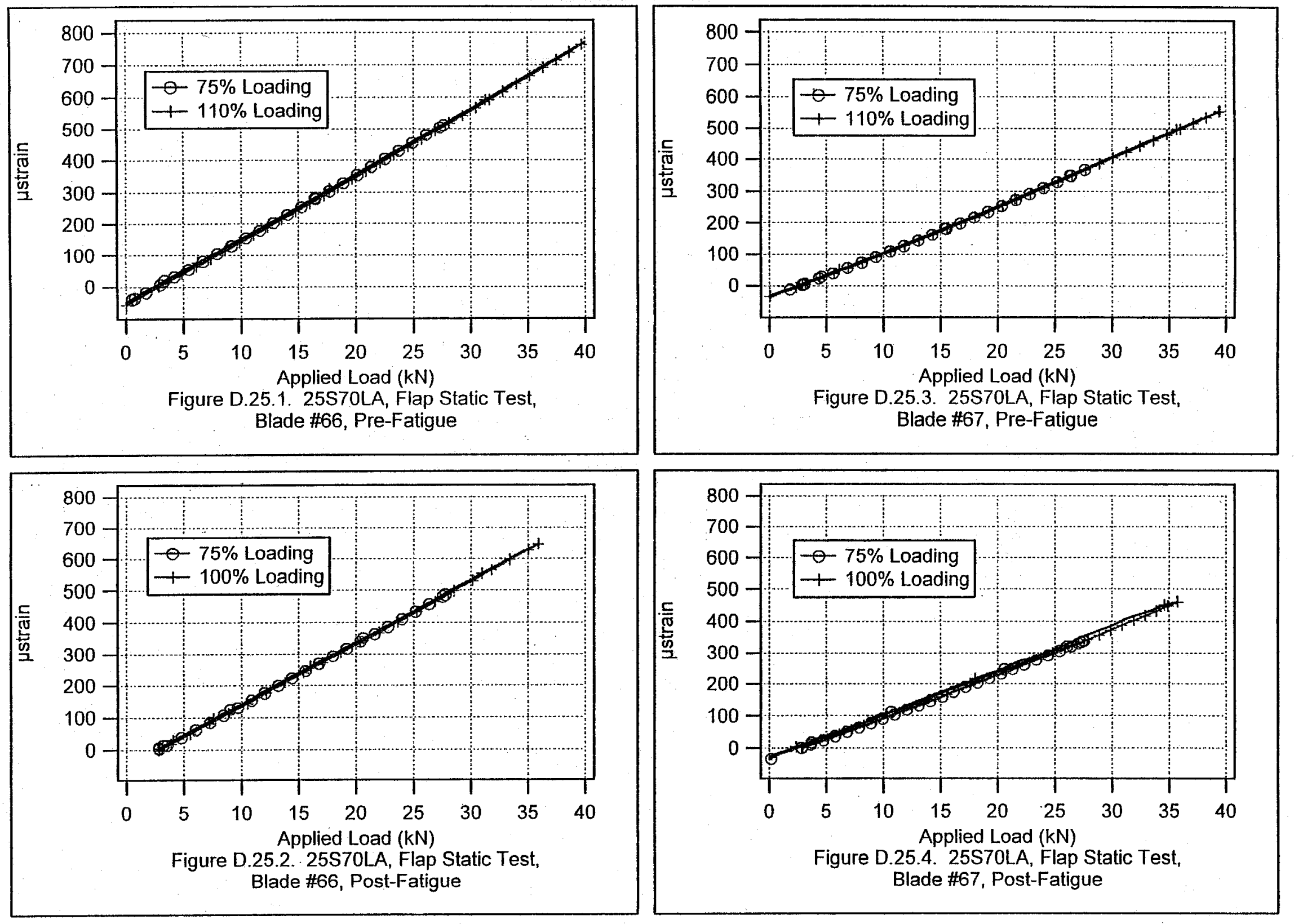

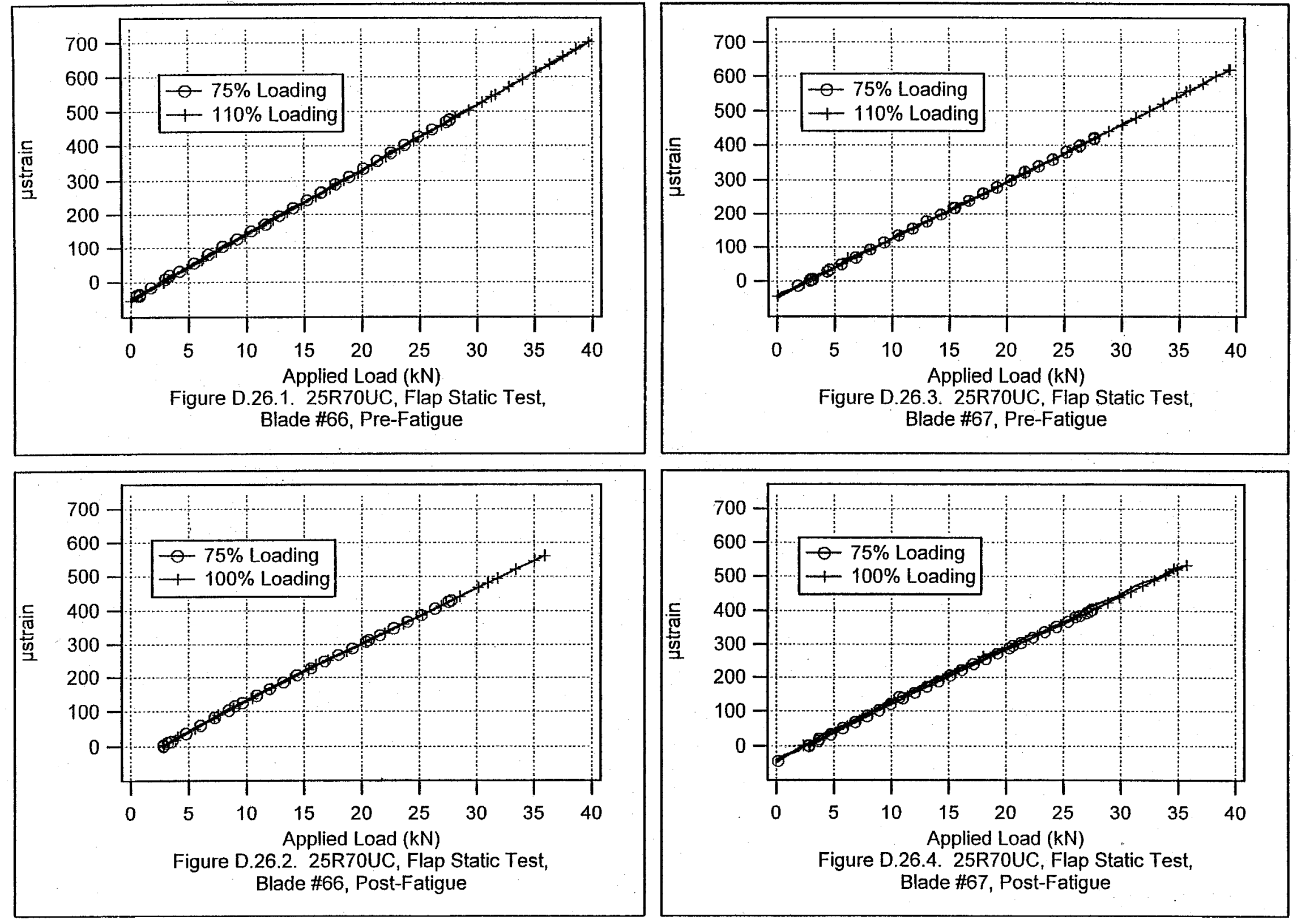

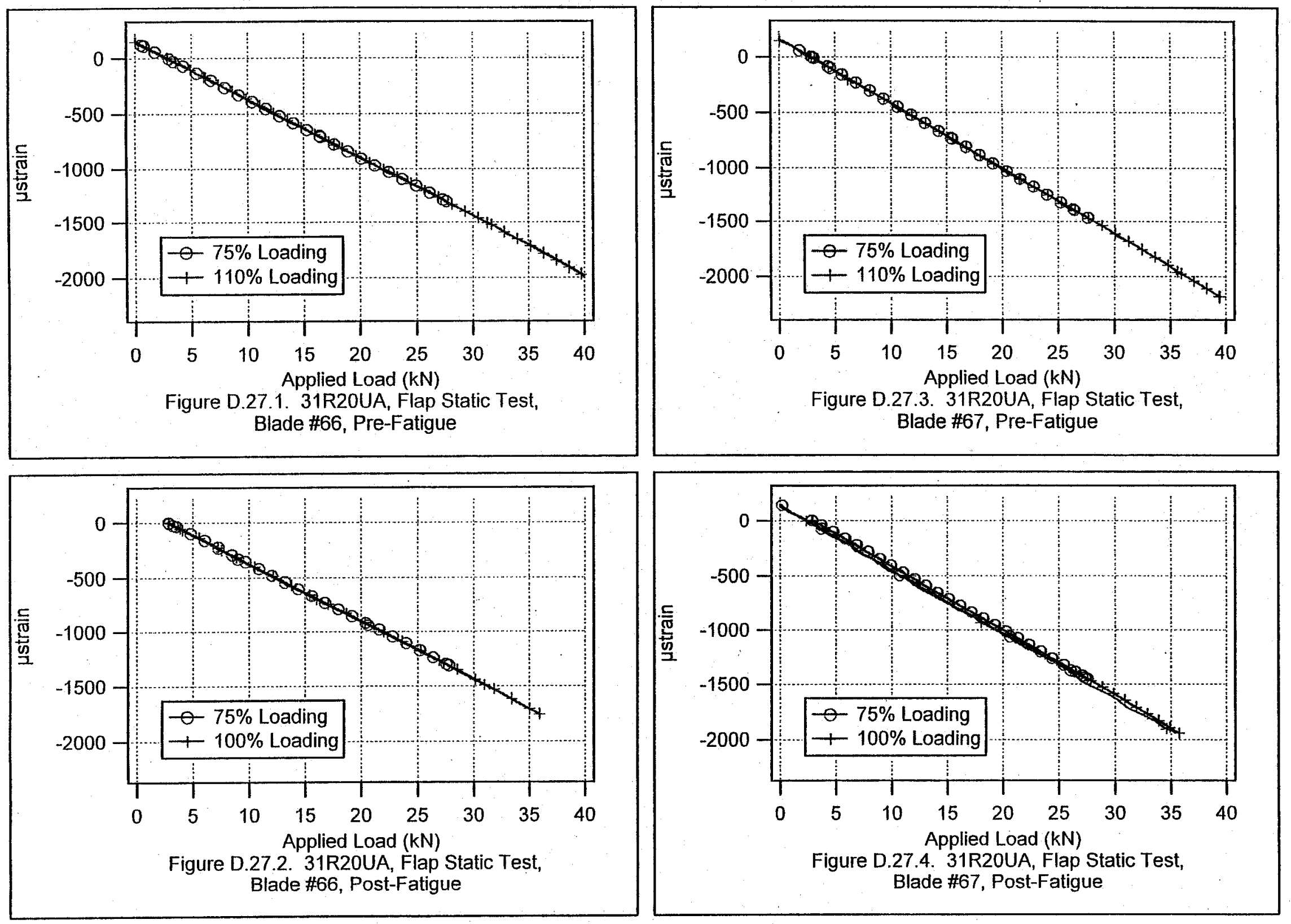

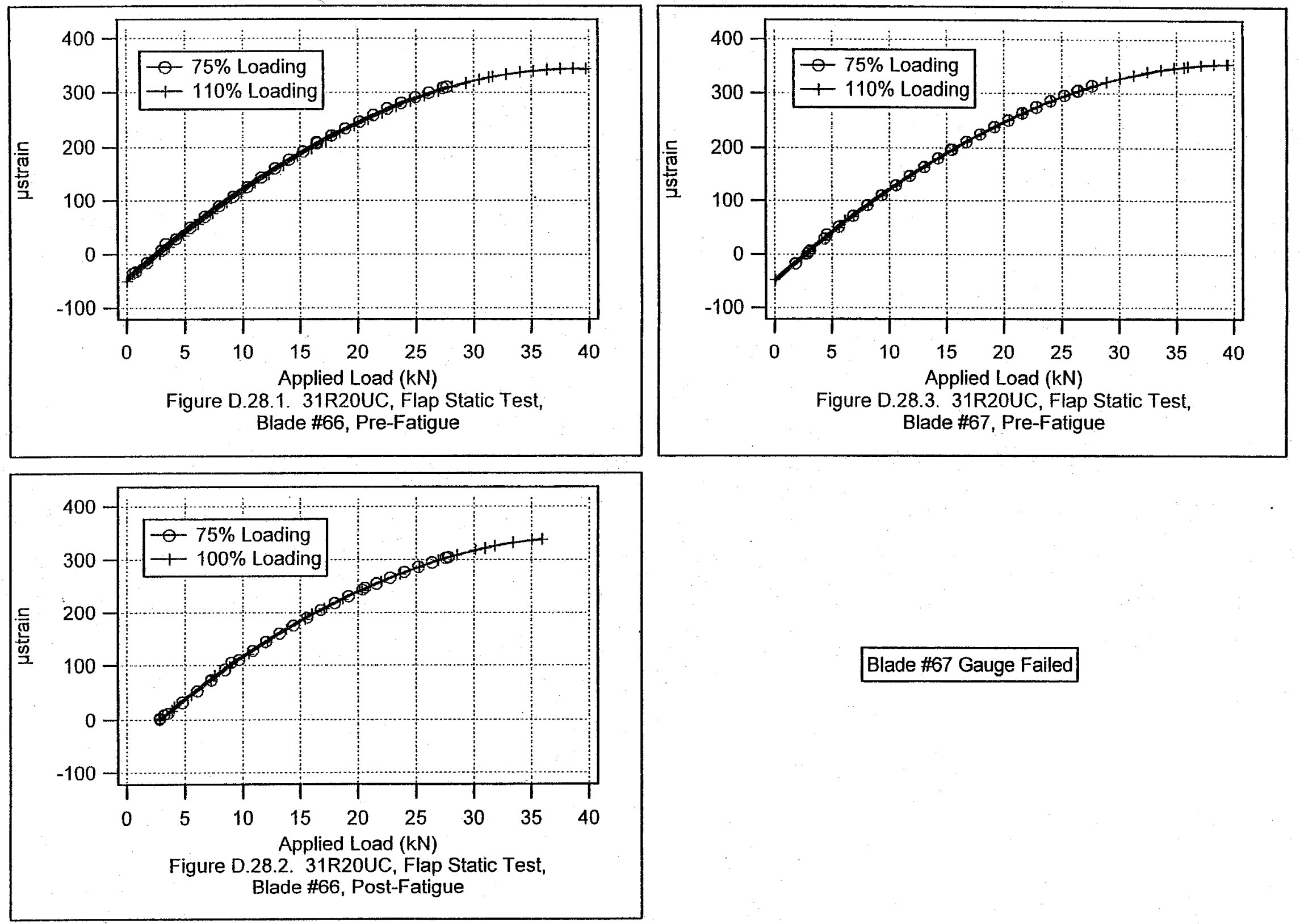

Blade \#67 Gauge Failed 

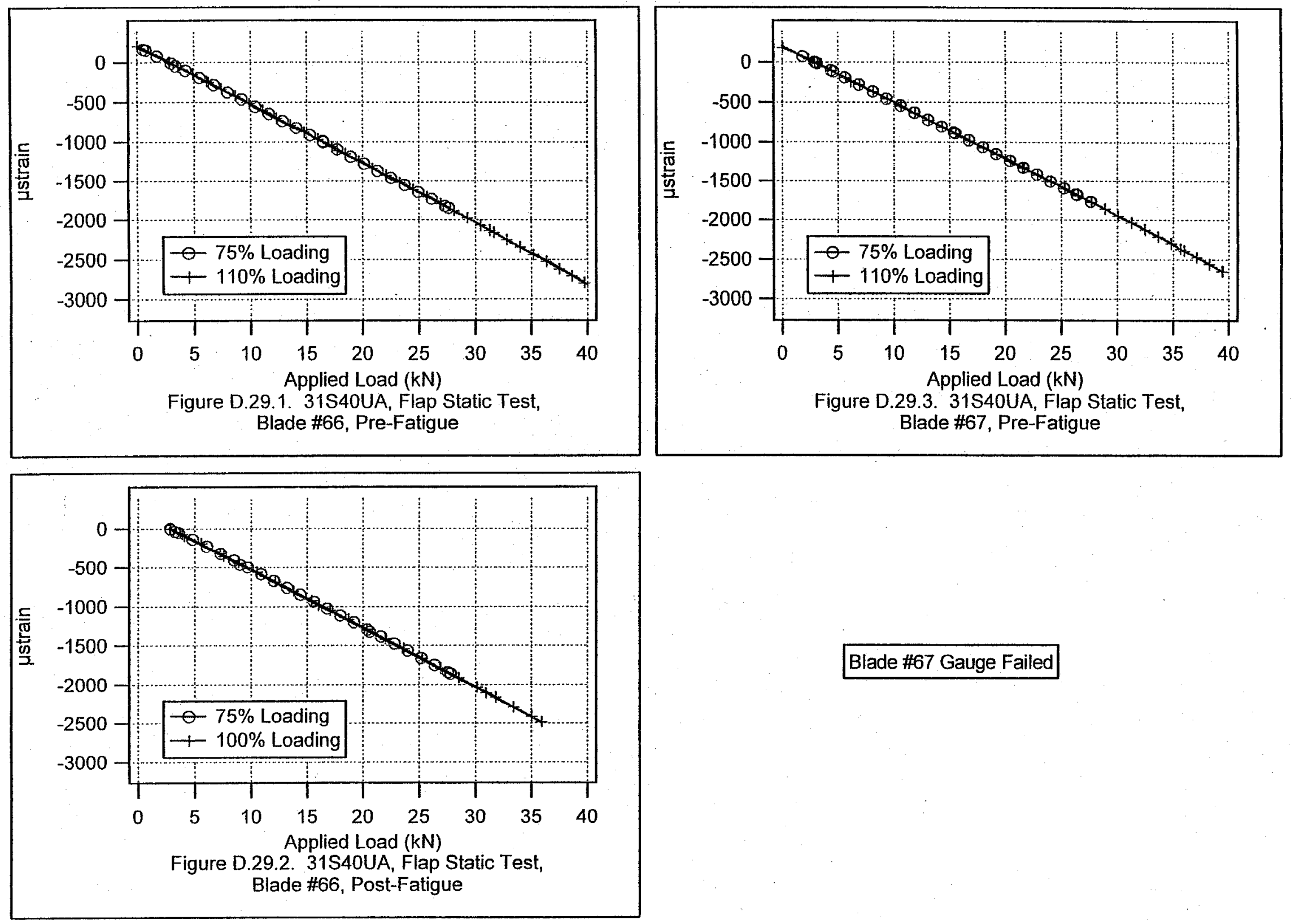

Blade \#67 Gauge Failed 

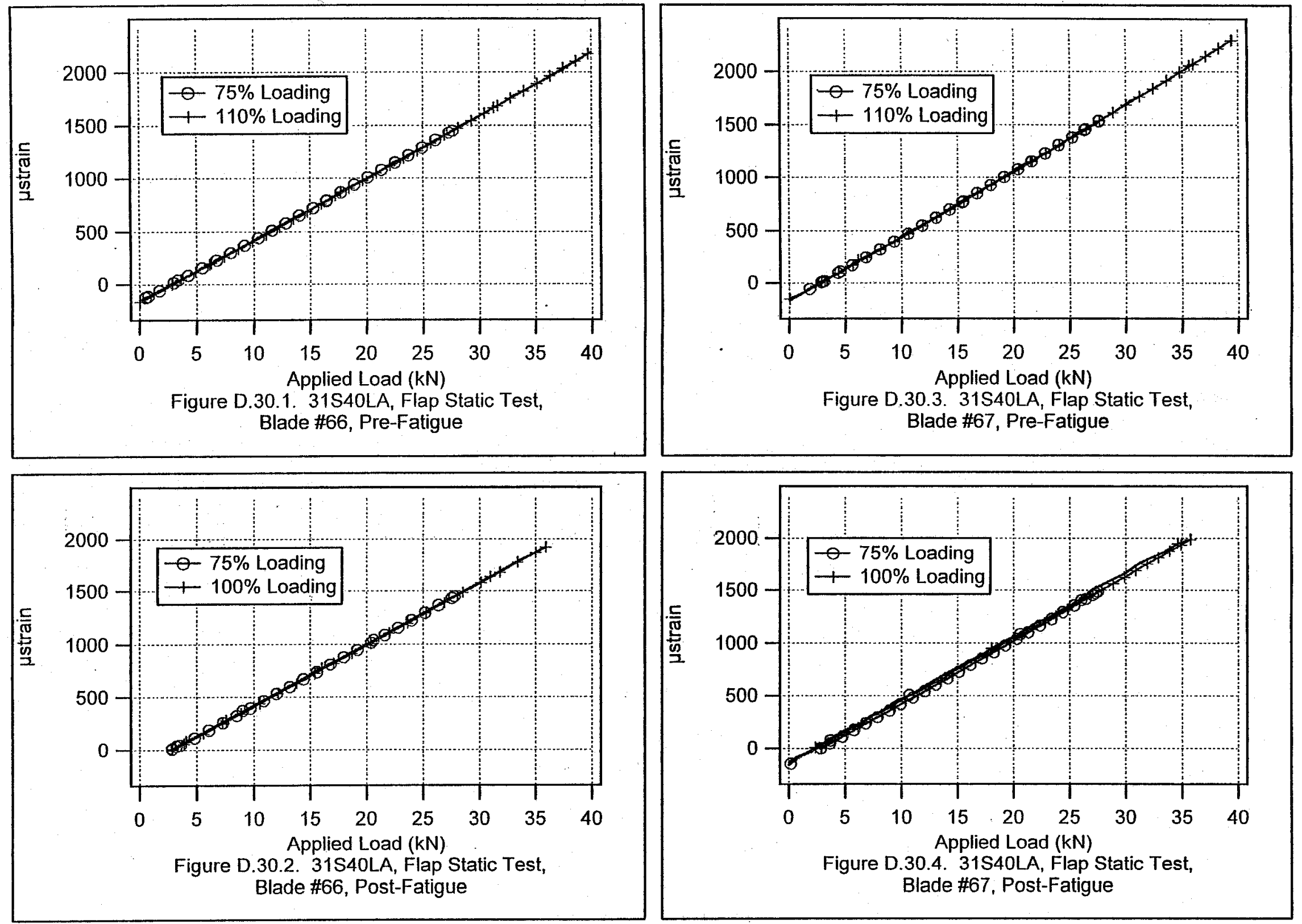

Figure D.30.4. 31S40LA, Flap Static Test, Blade \#67, Post-Fatigue 

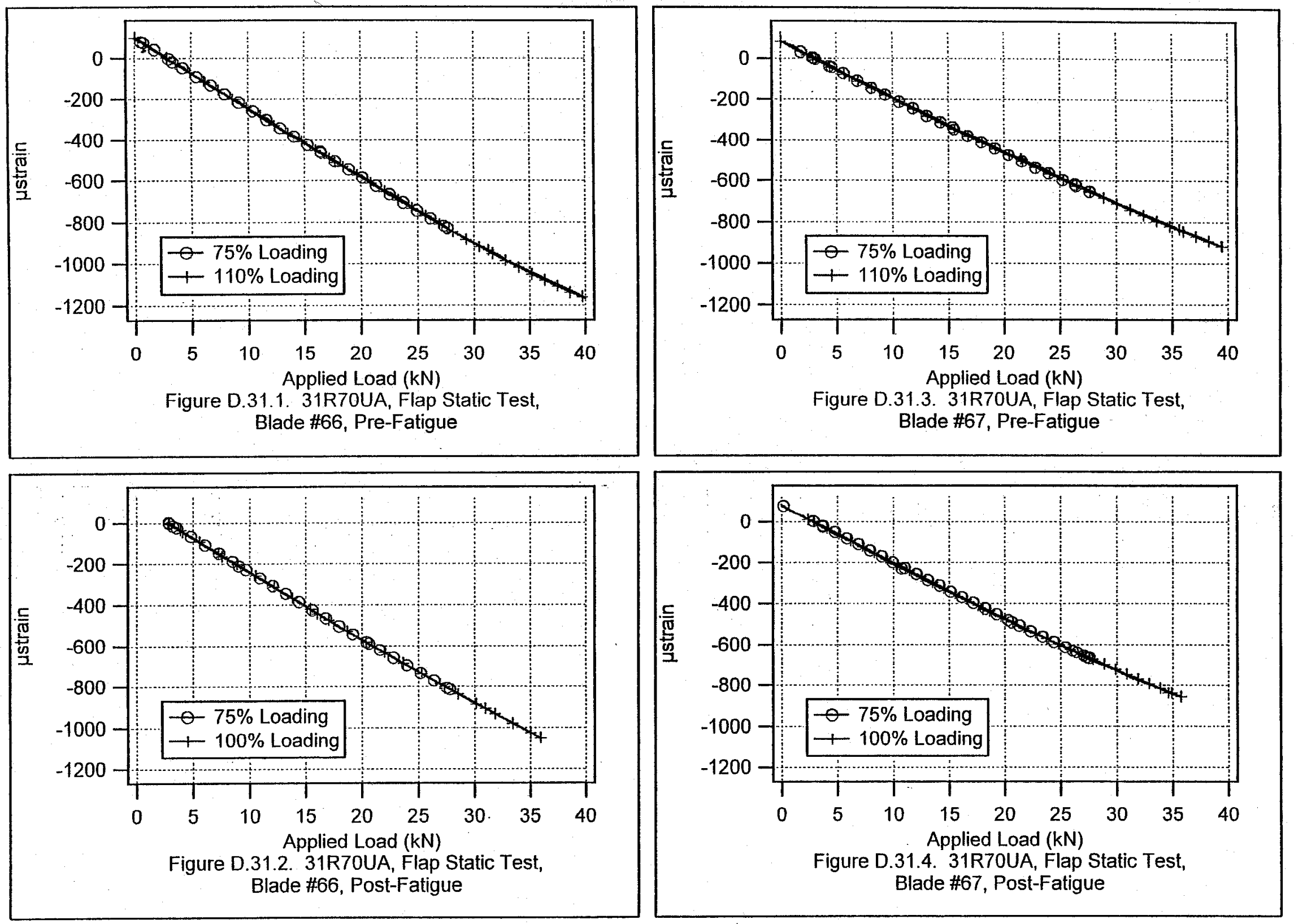

Figure D.31.4. 31R70UA, Flap Static Test, Blade \#67, Post-Fatigue 

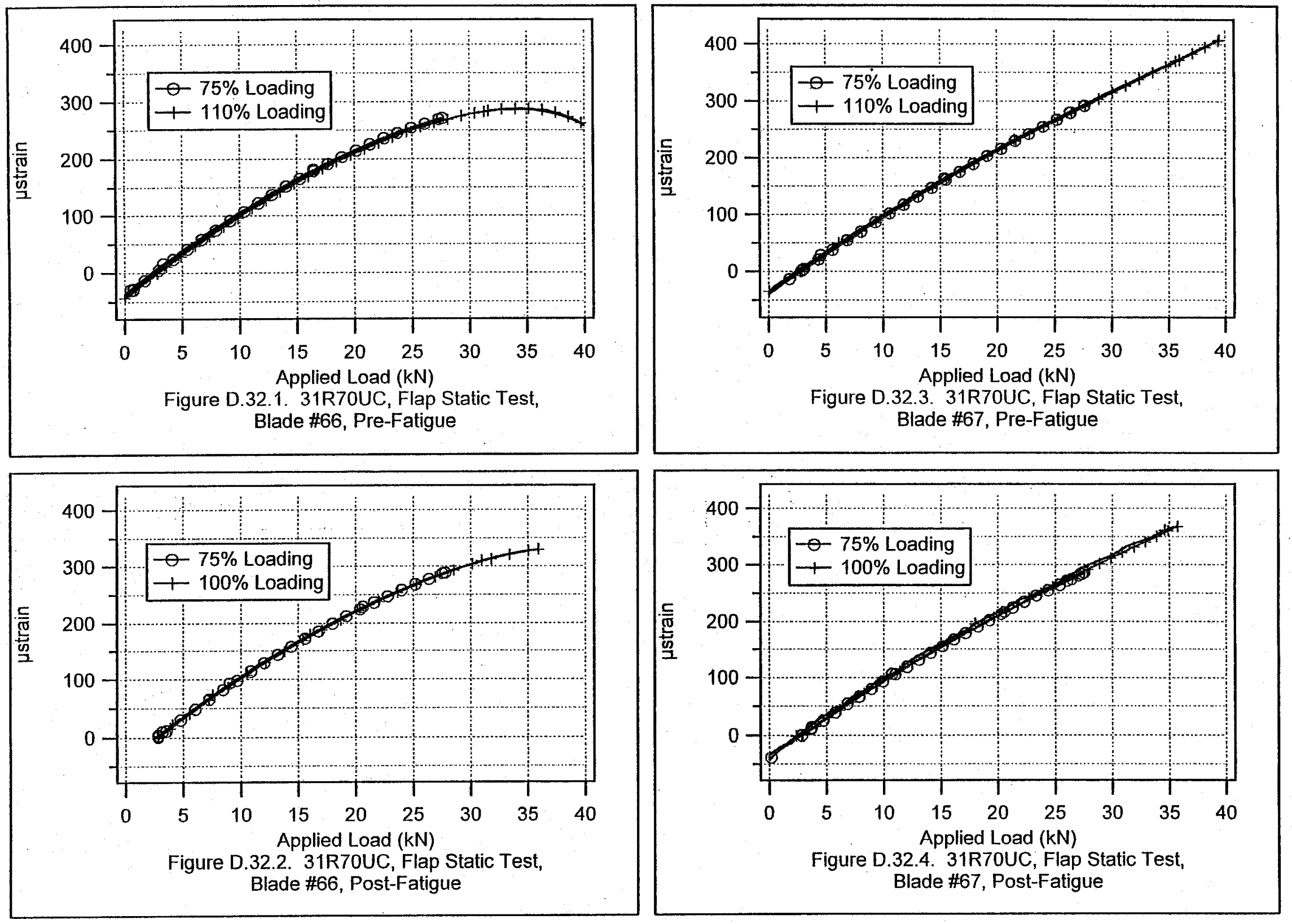

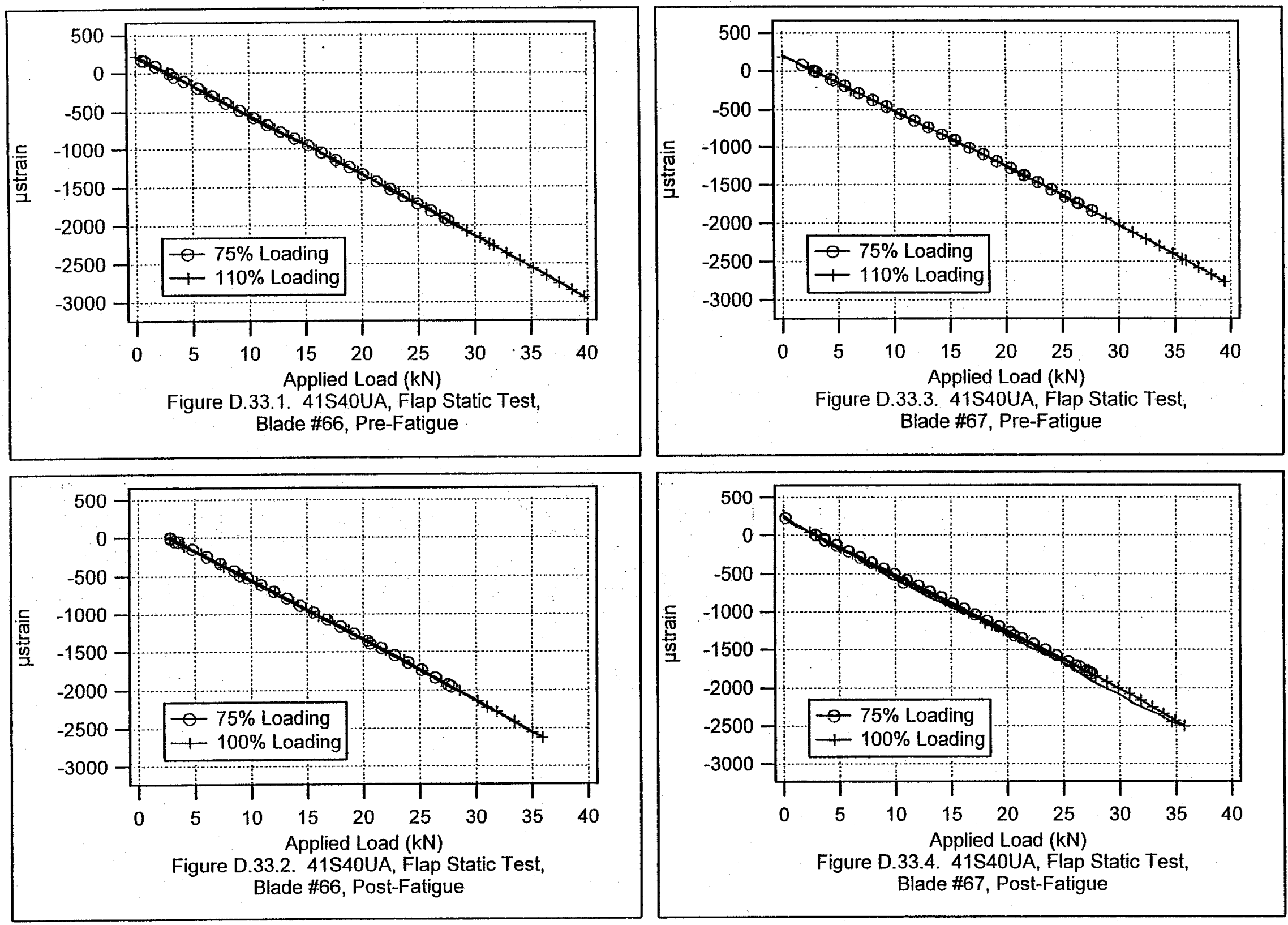

Figure D.33.4. 41S40UA, Flap Static Test, Blade \#67, Post-Fatigue 

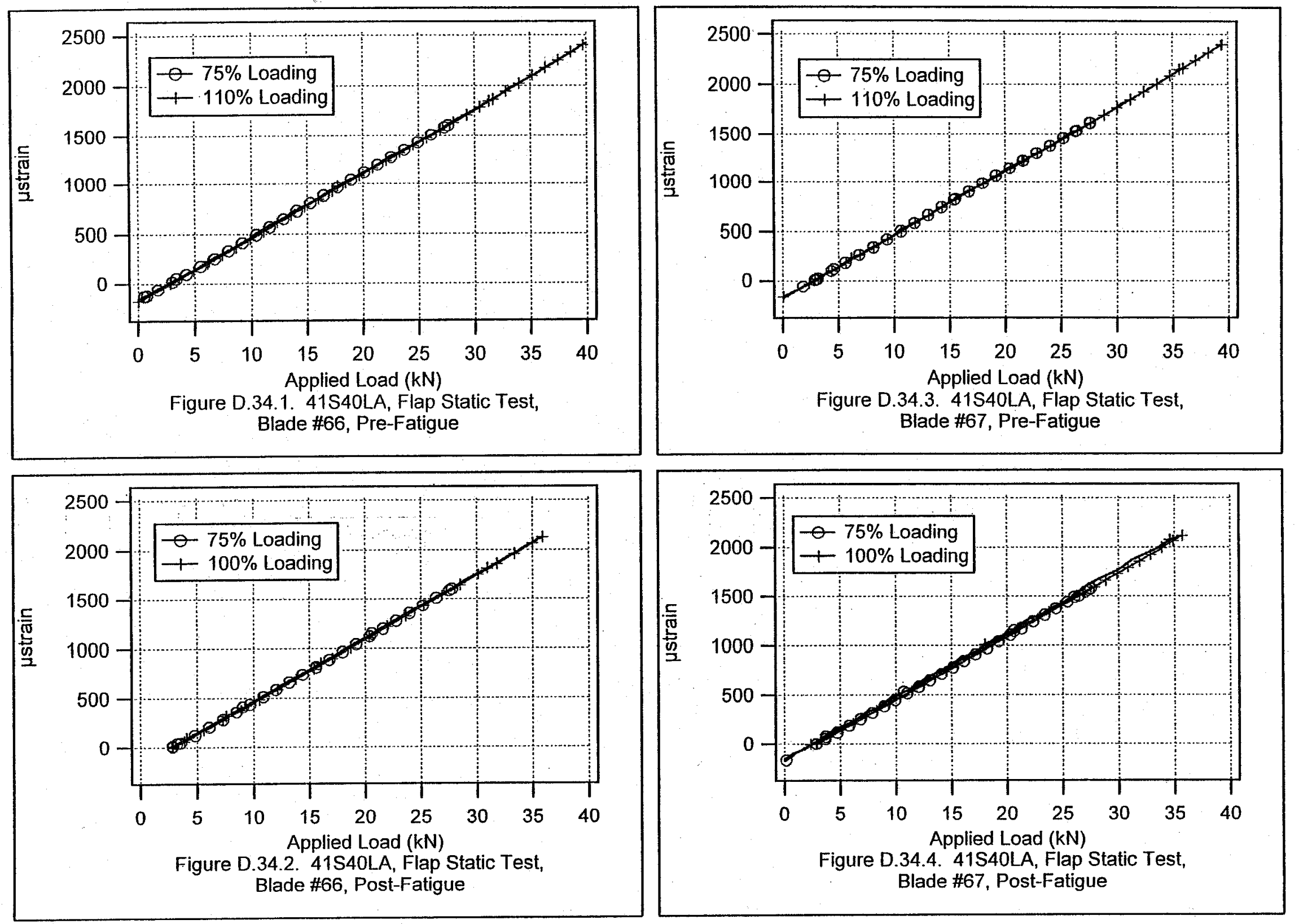
TP-500-29103

\section{Appendix E}

Fatigue Data

E-1 

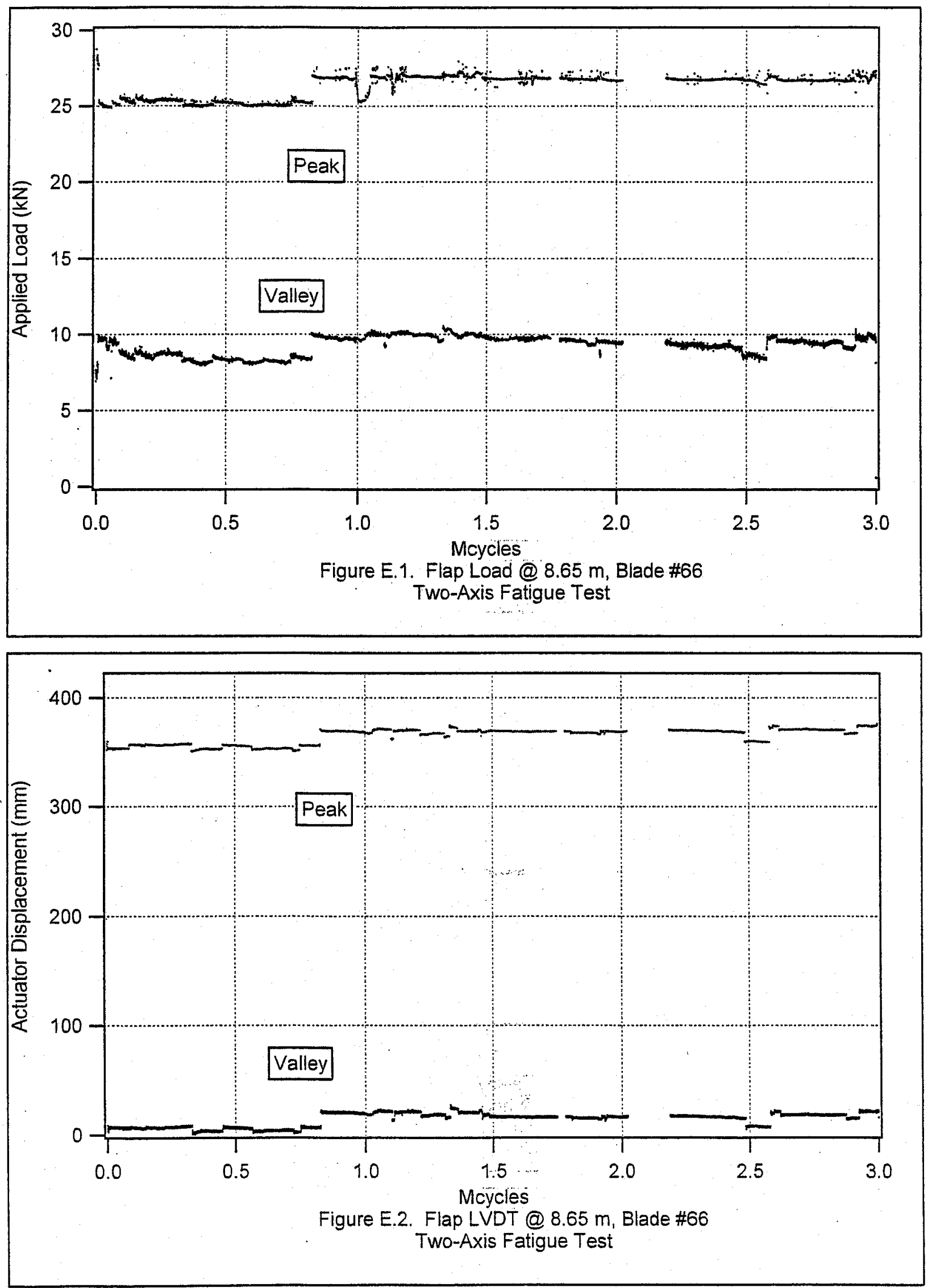

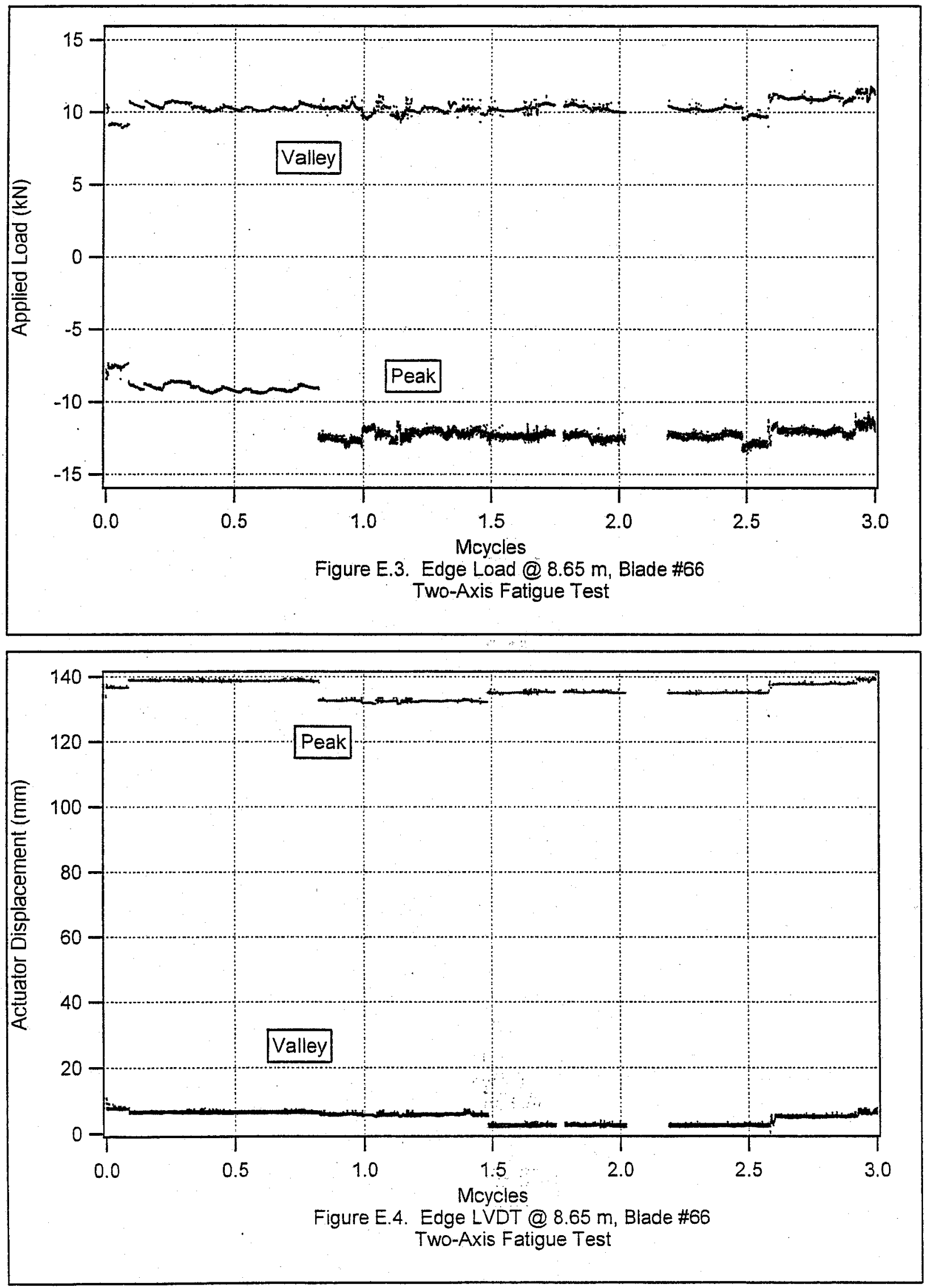

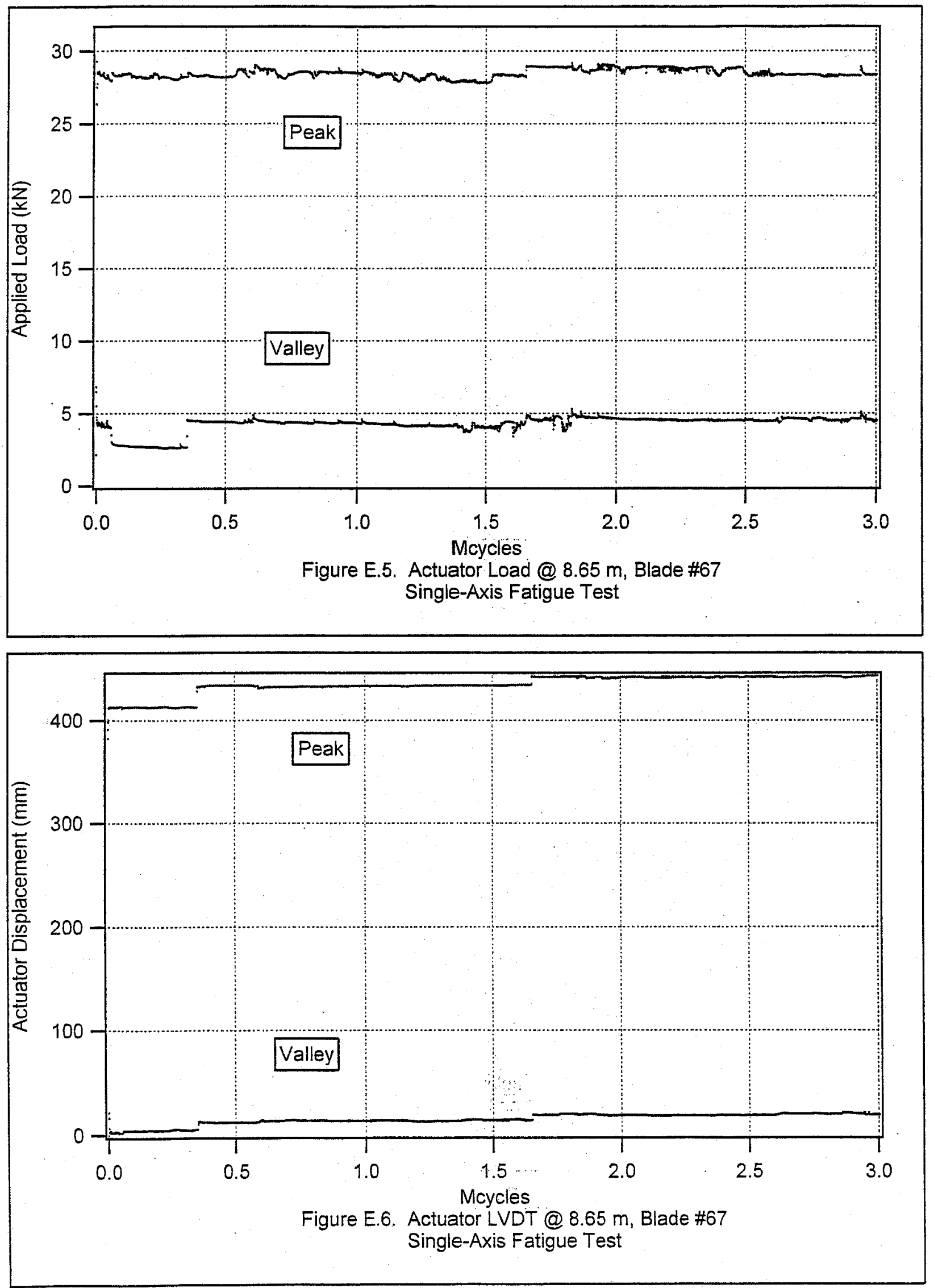

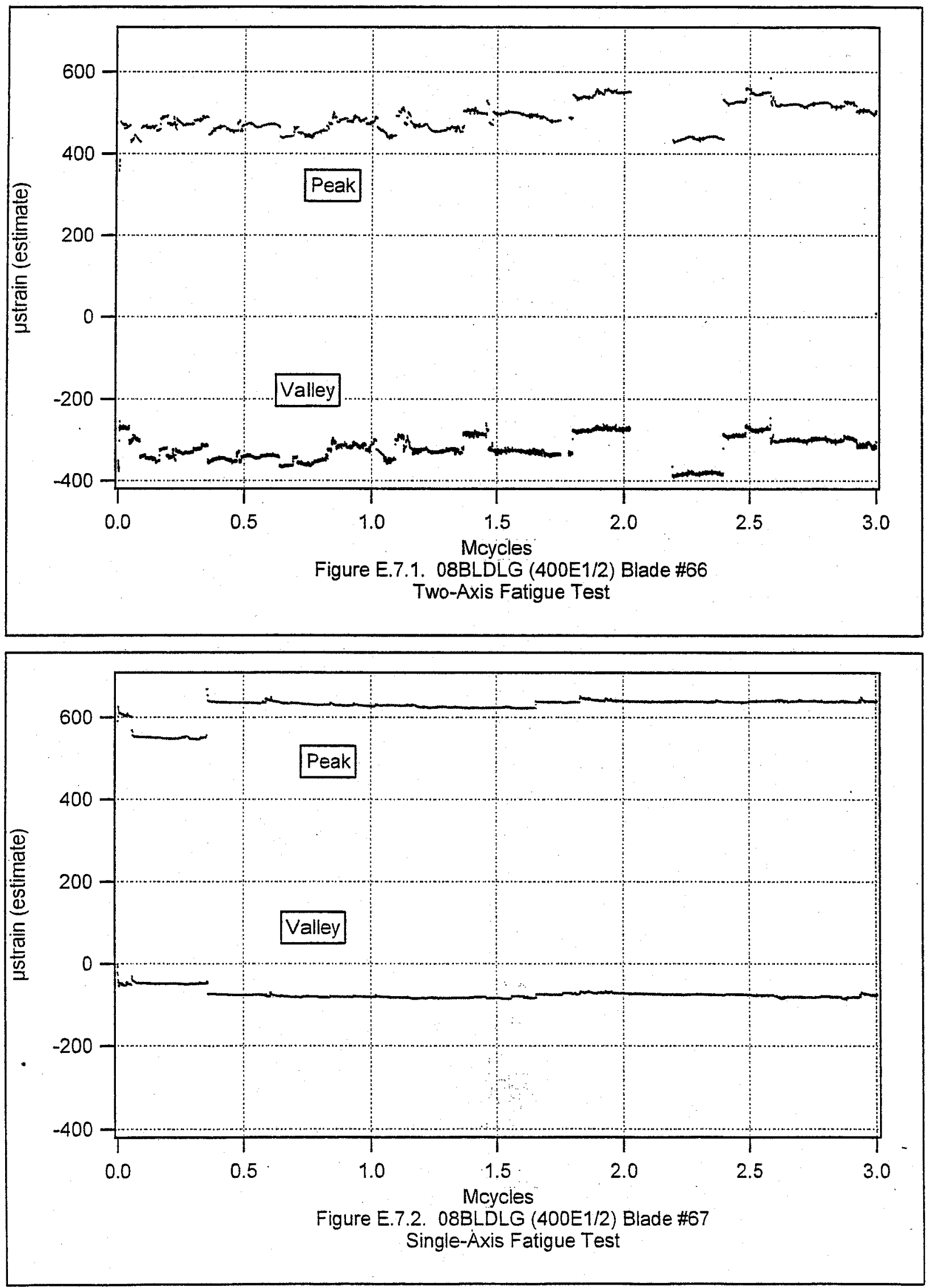

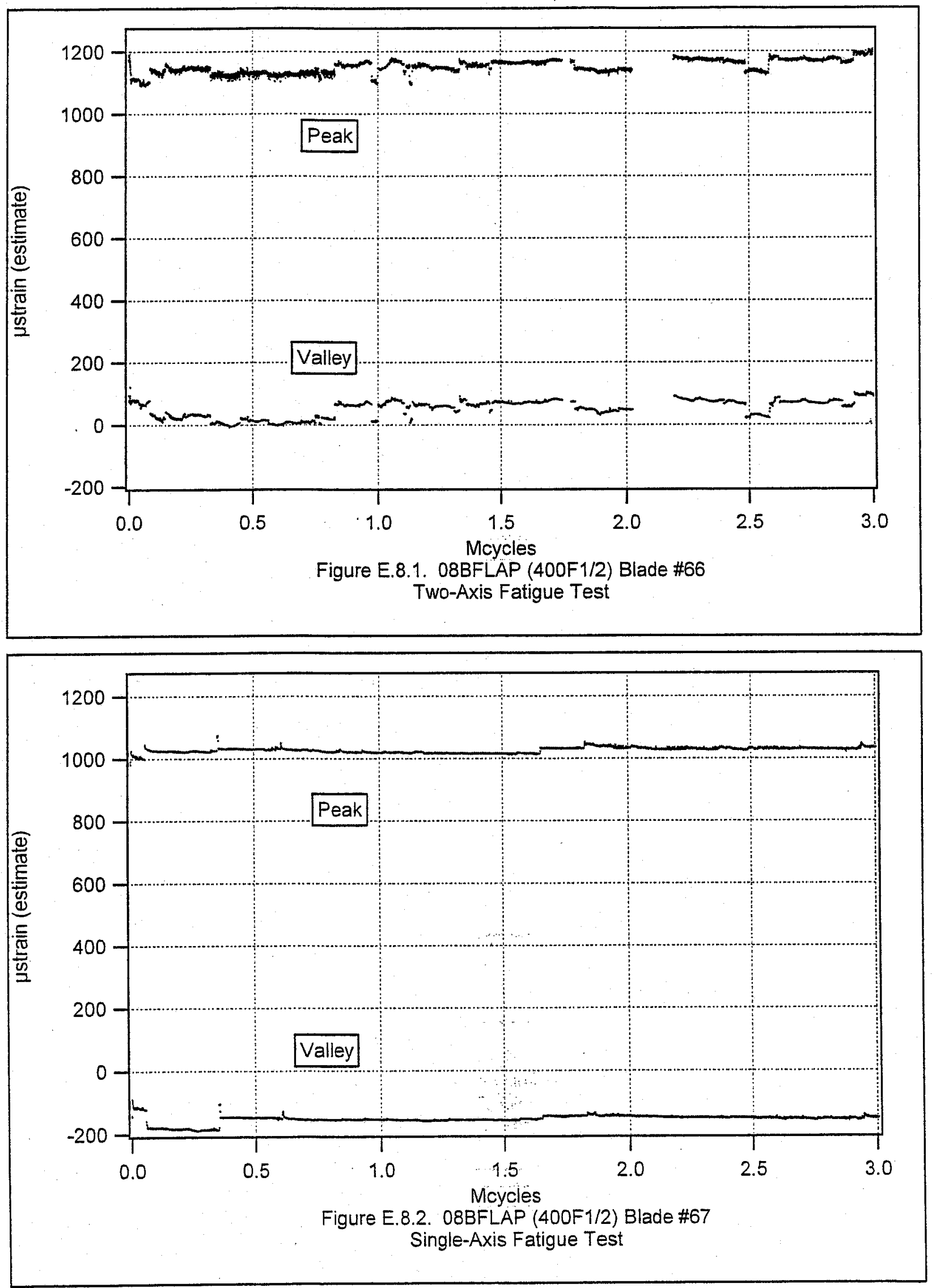

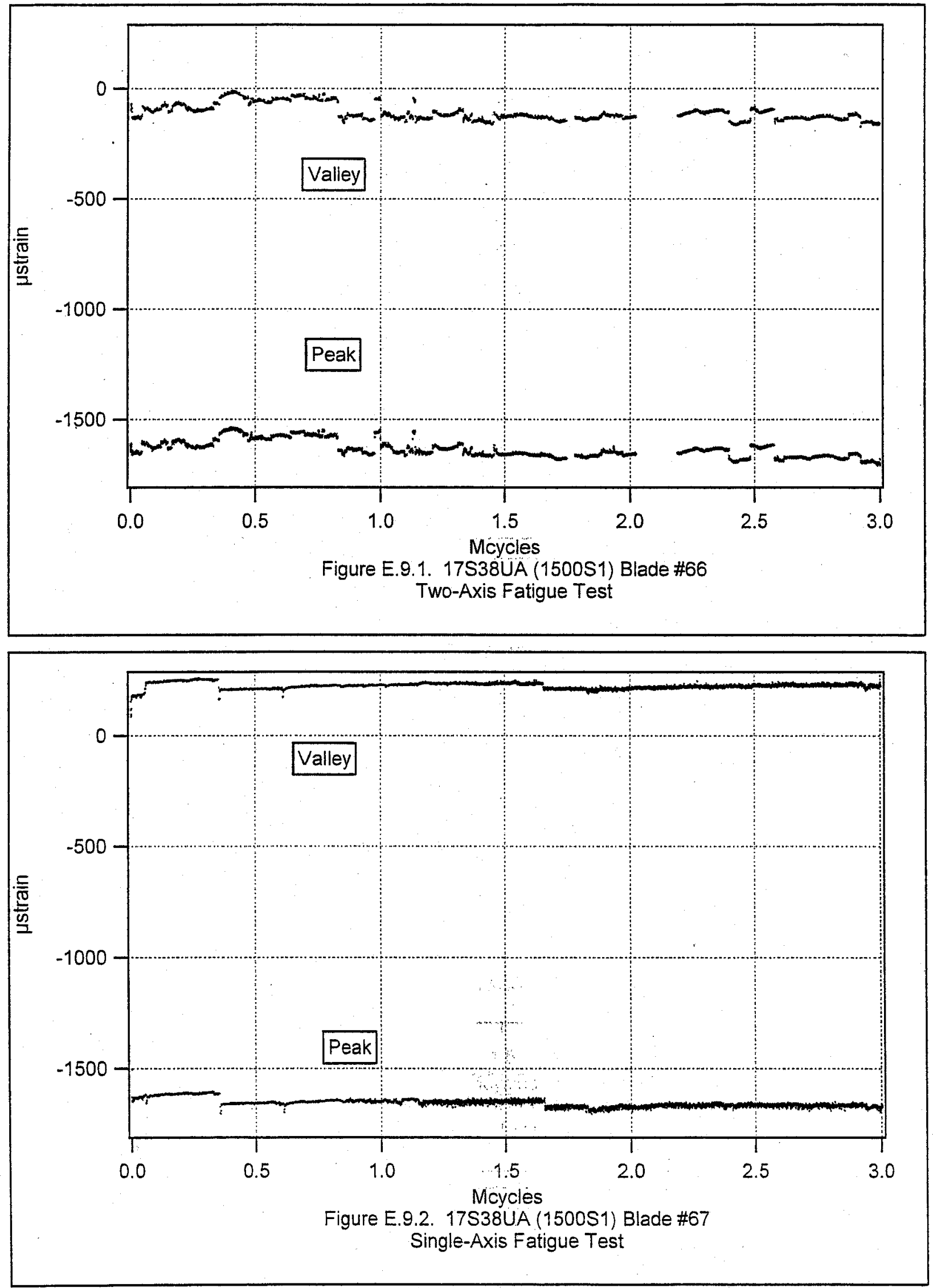

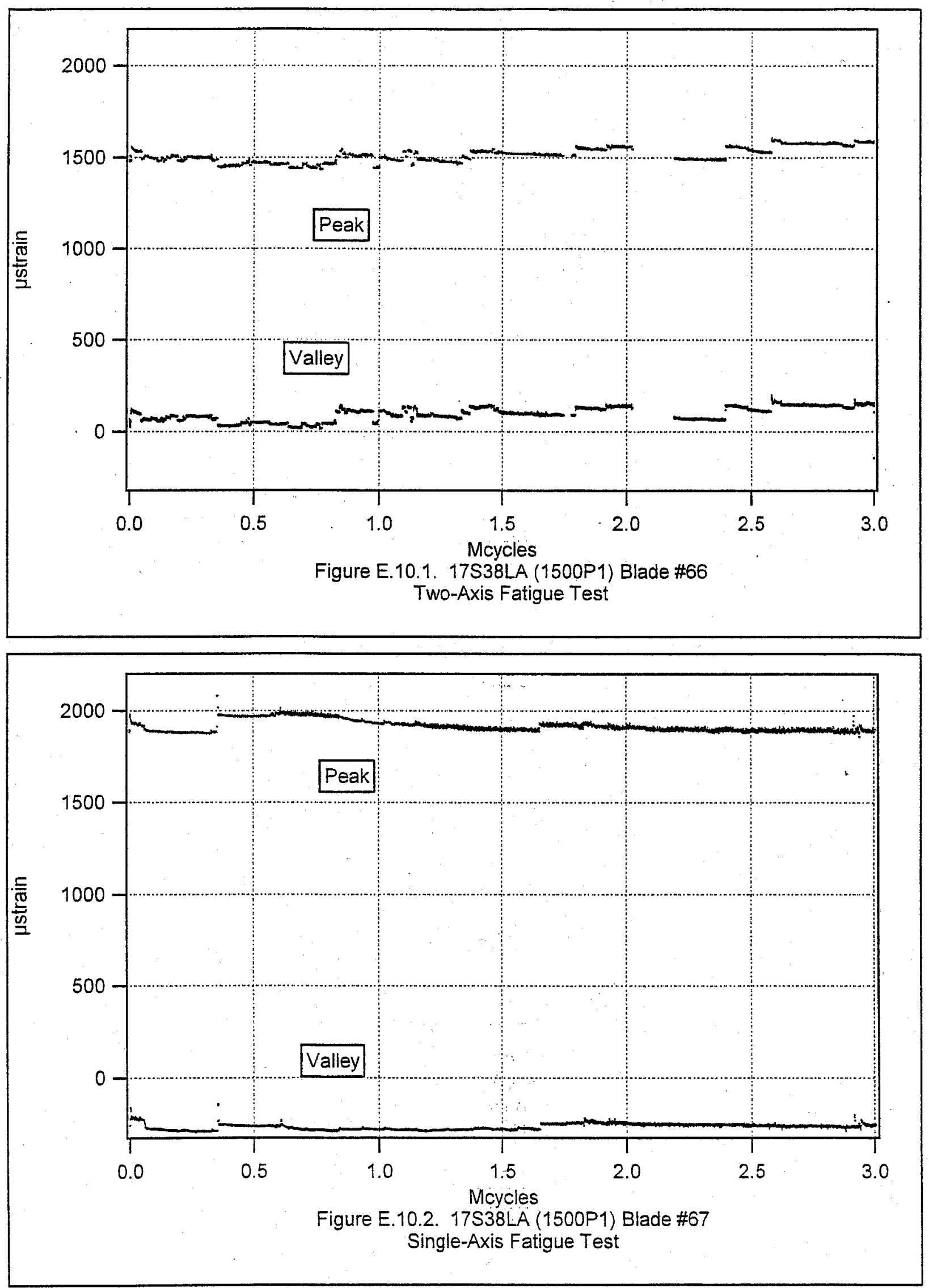

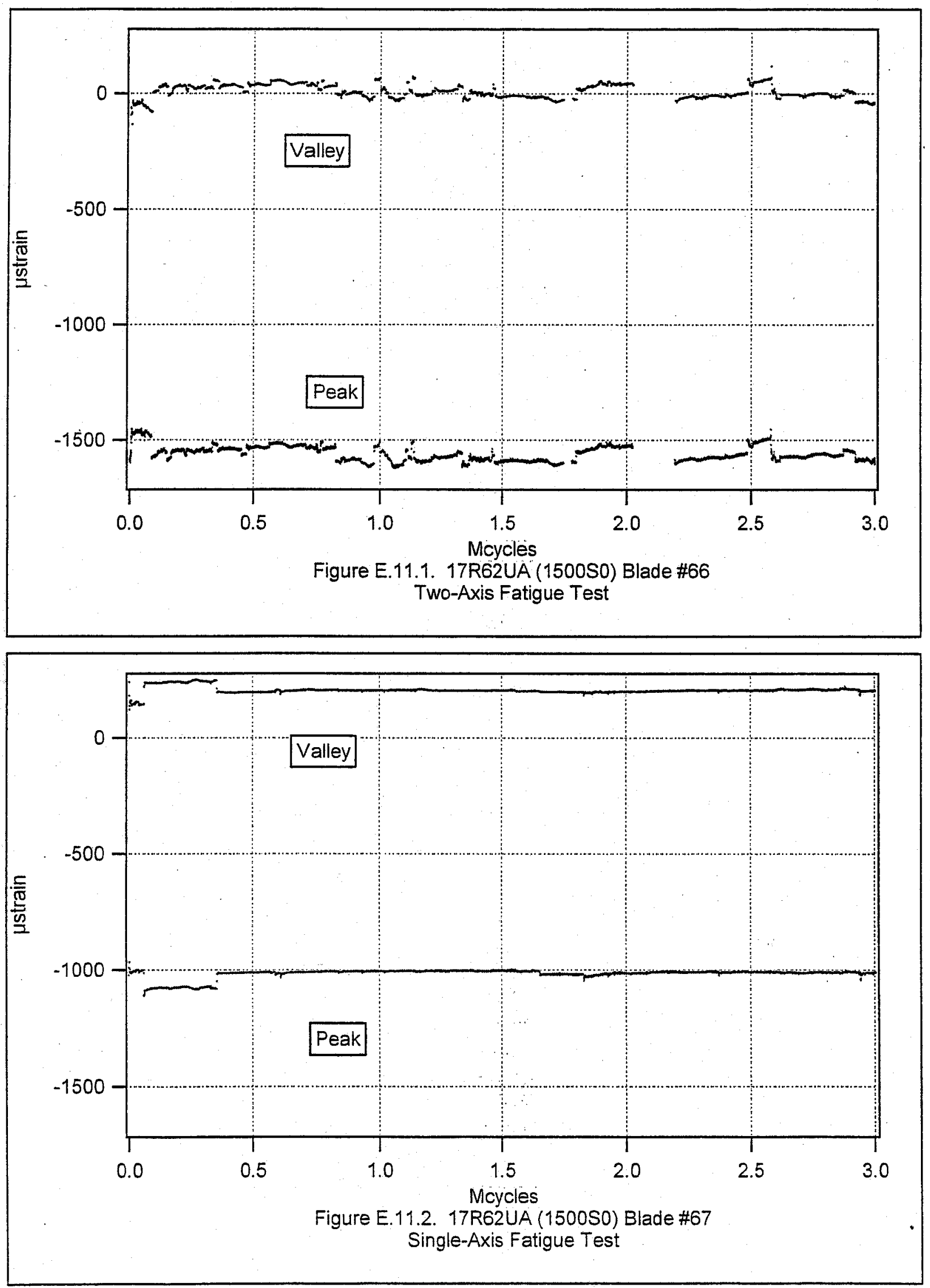

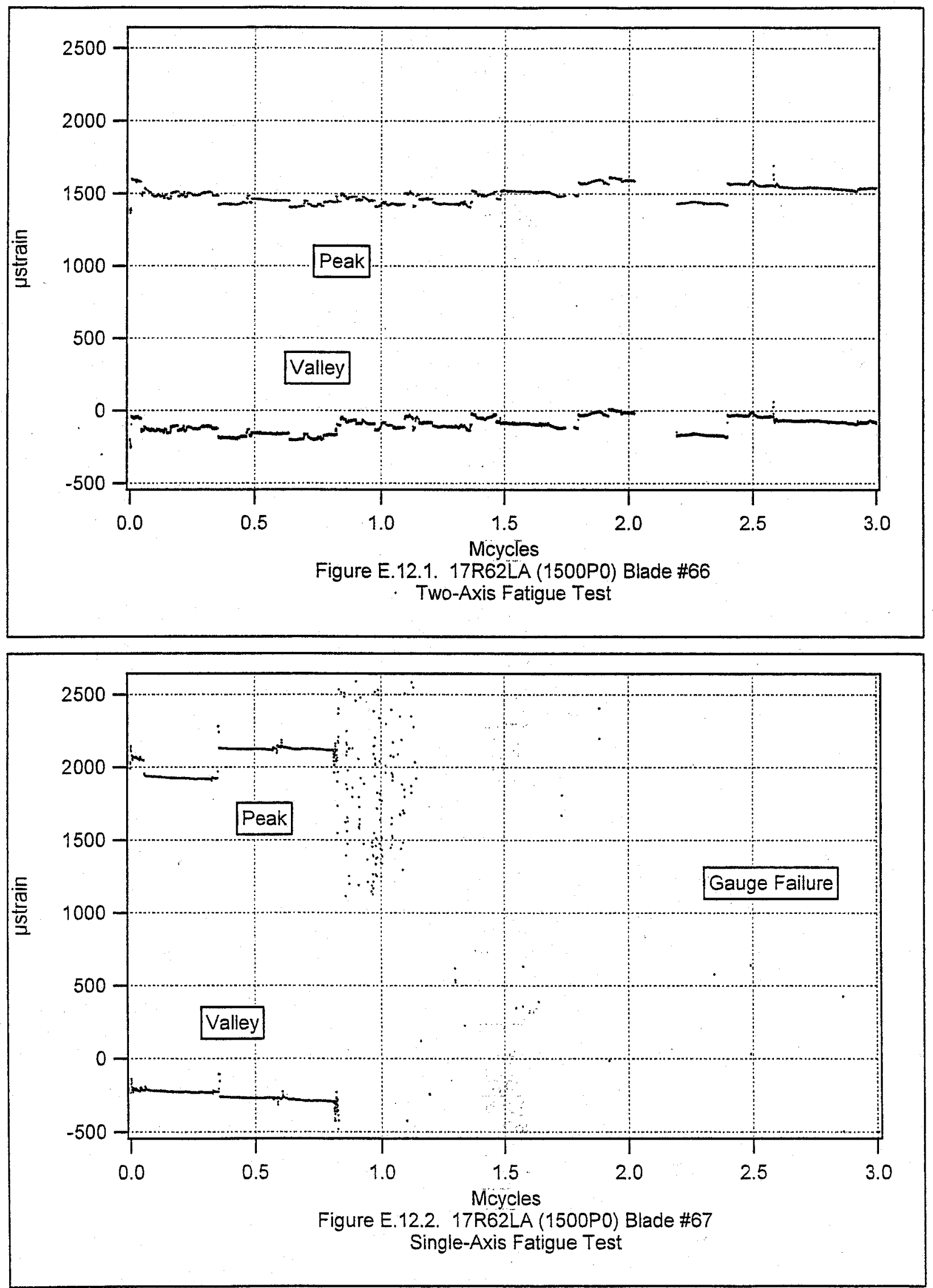

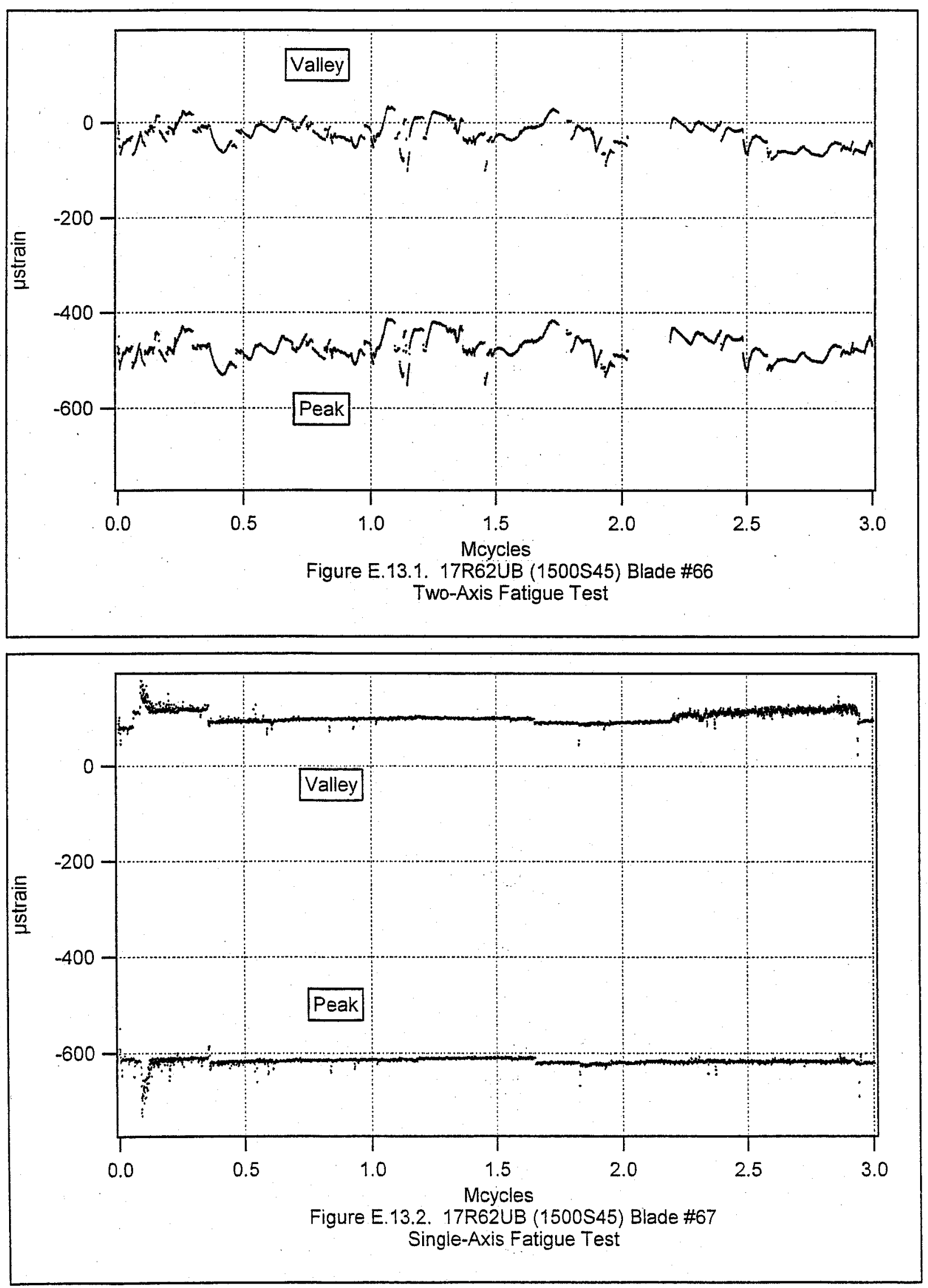

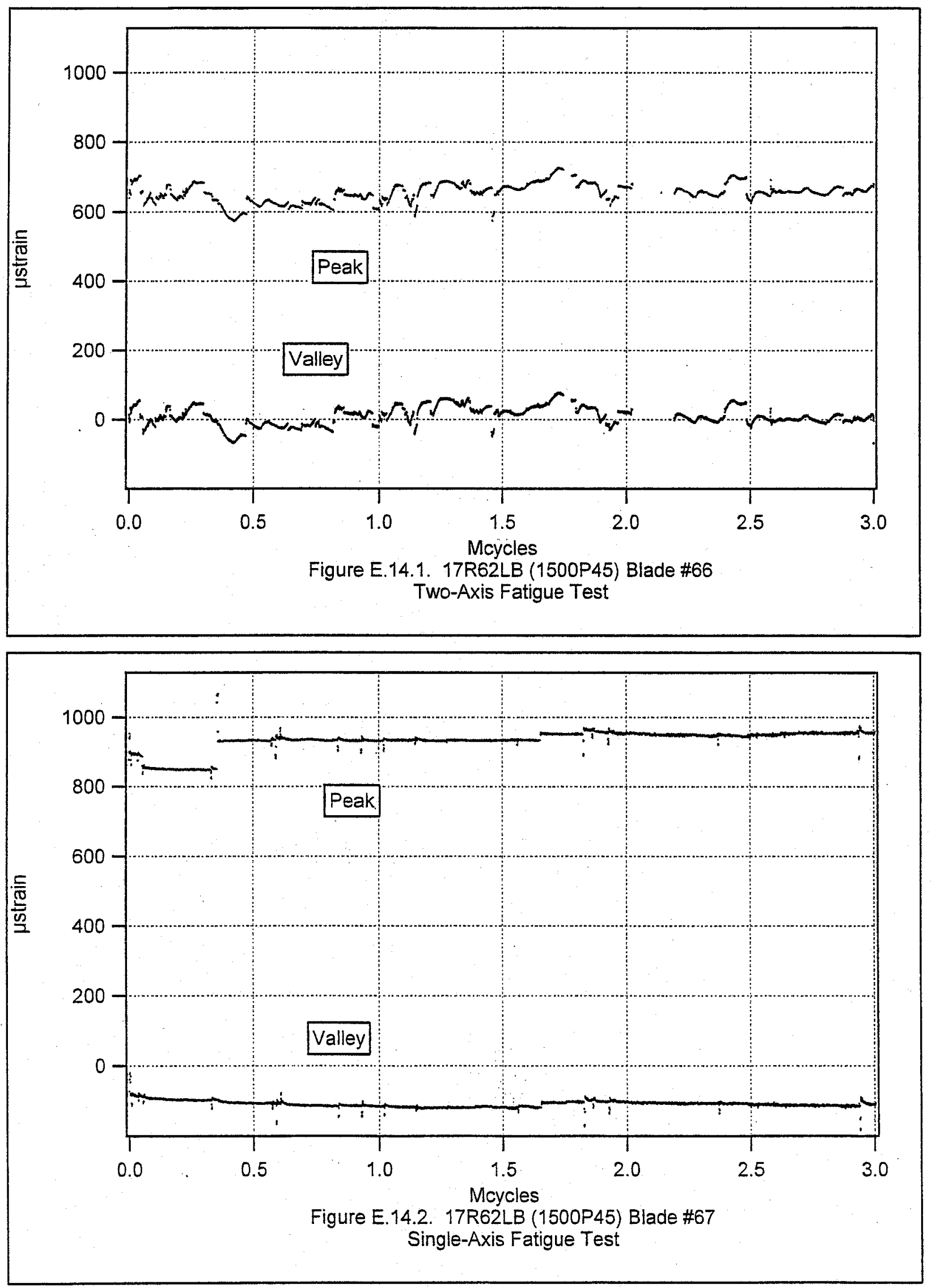

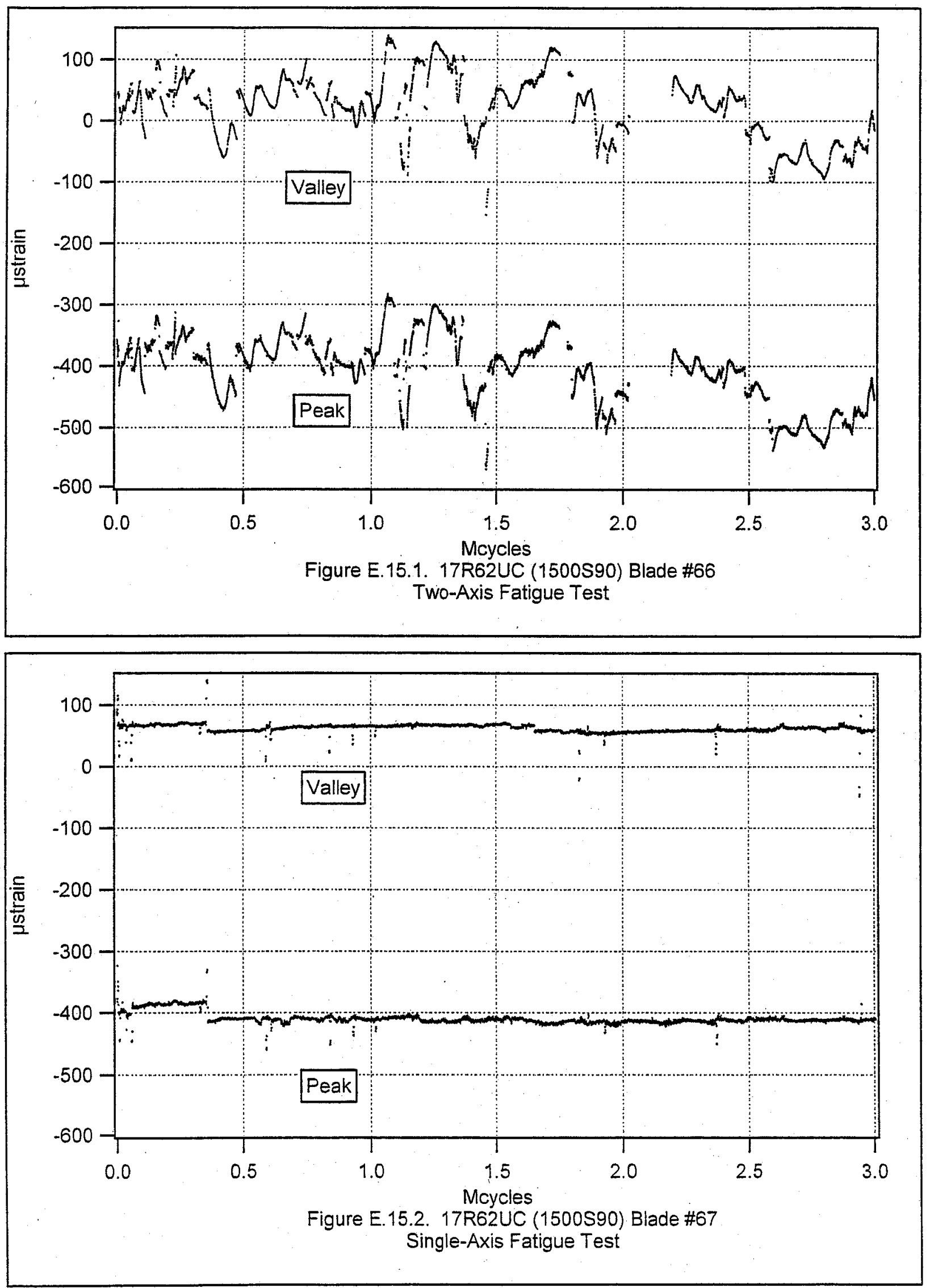

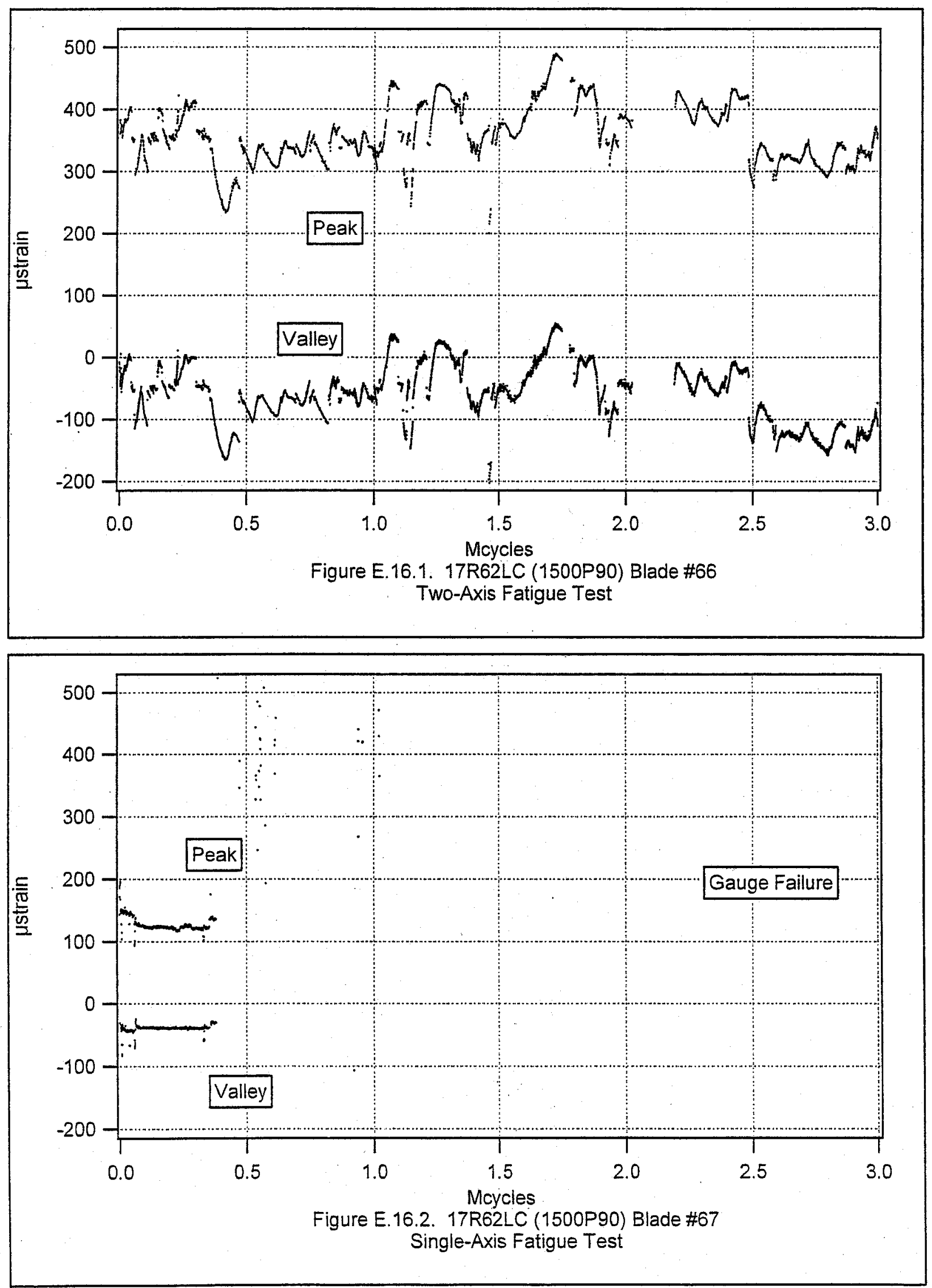

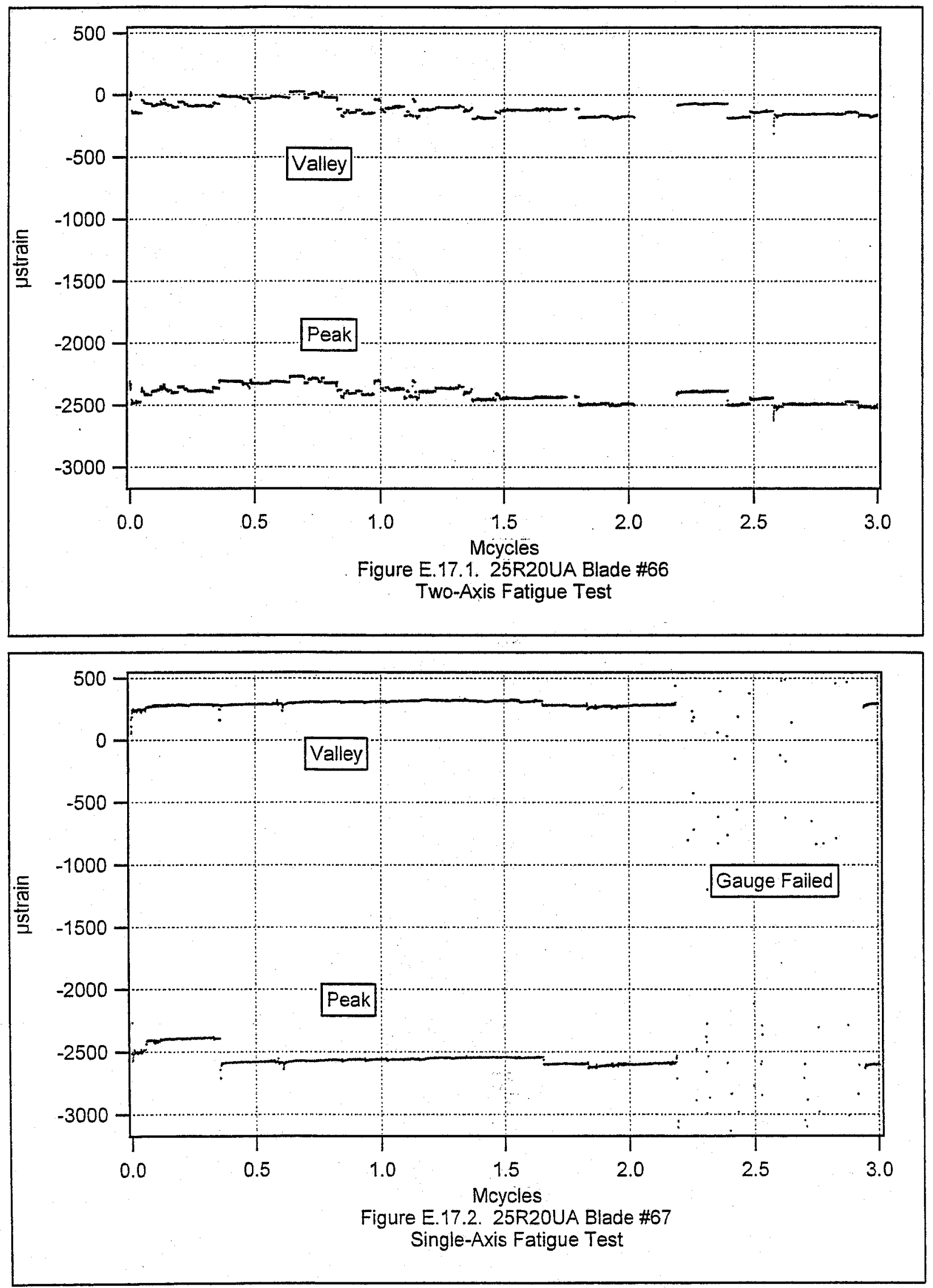

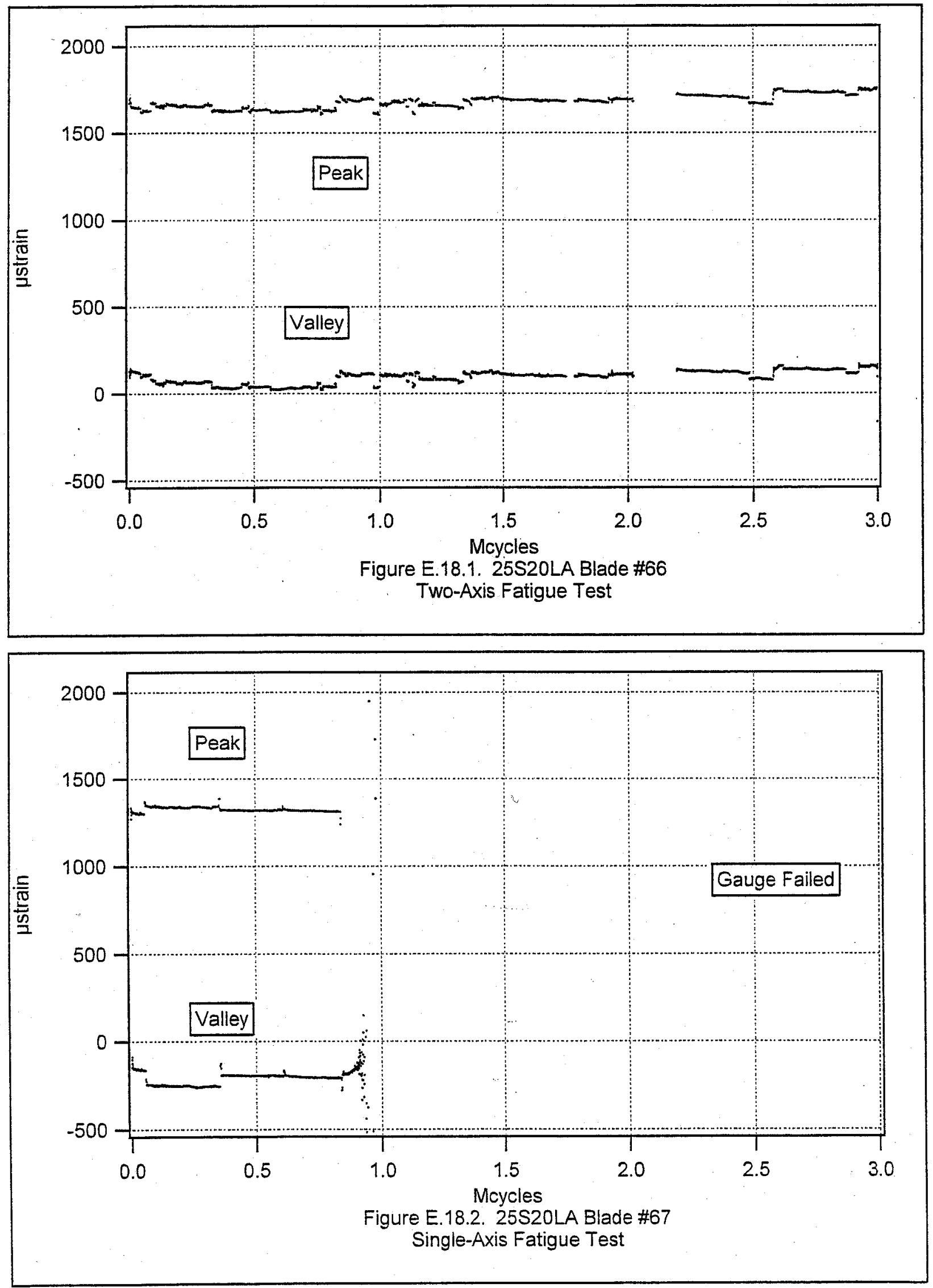


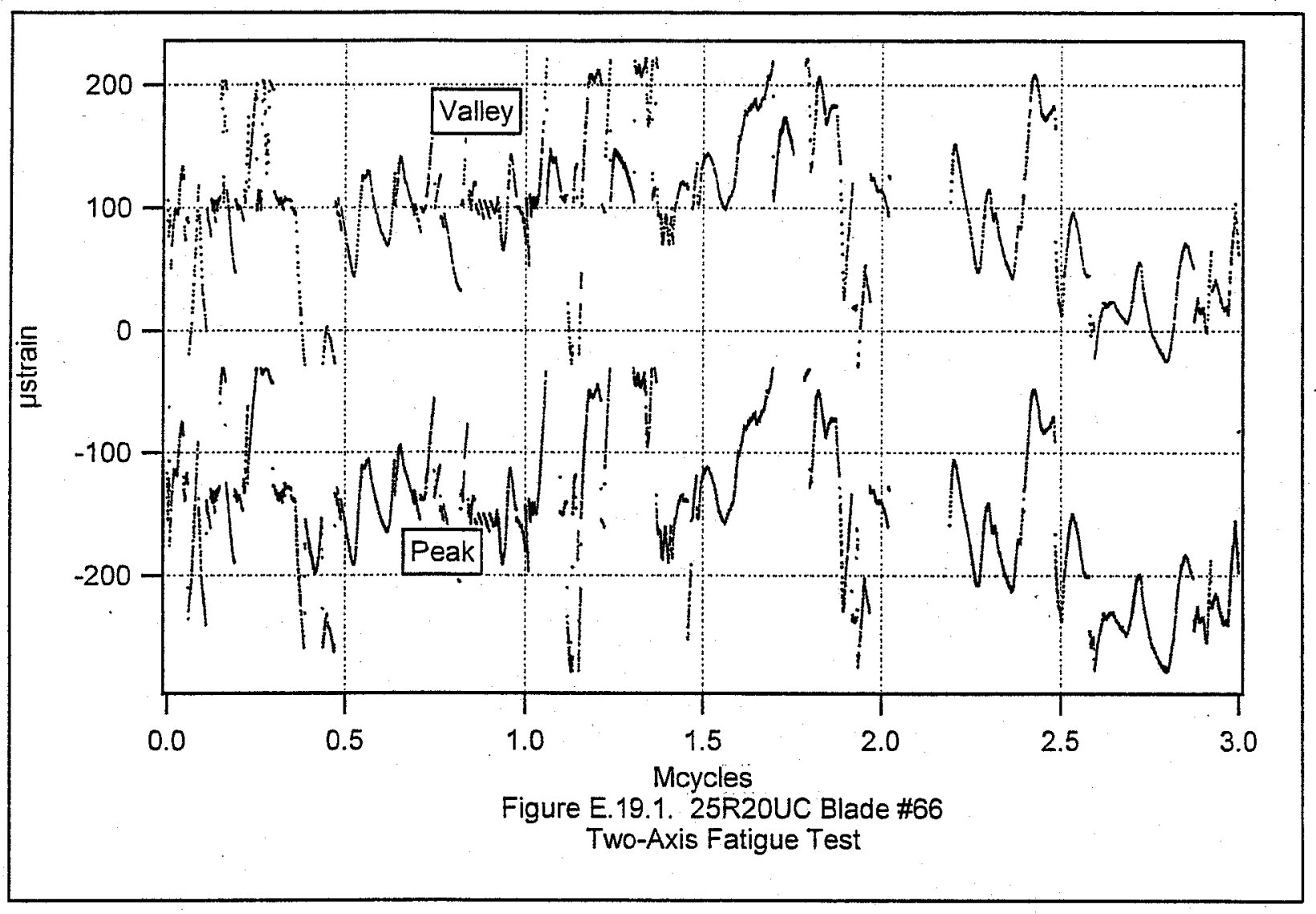

Gauge not measured during Blade $\# 67$ test. 

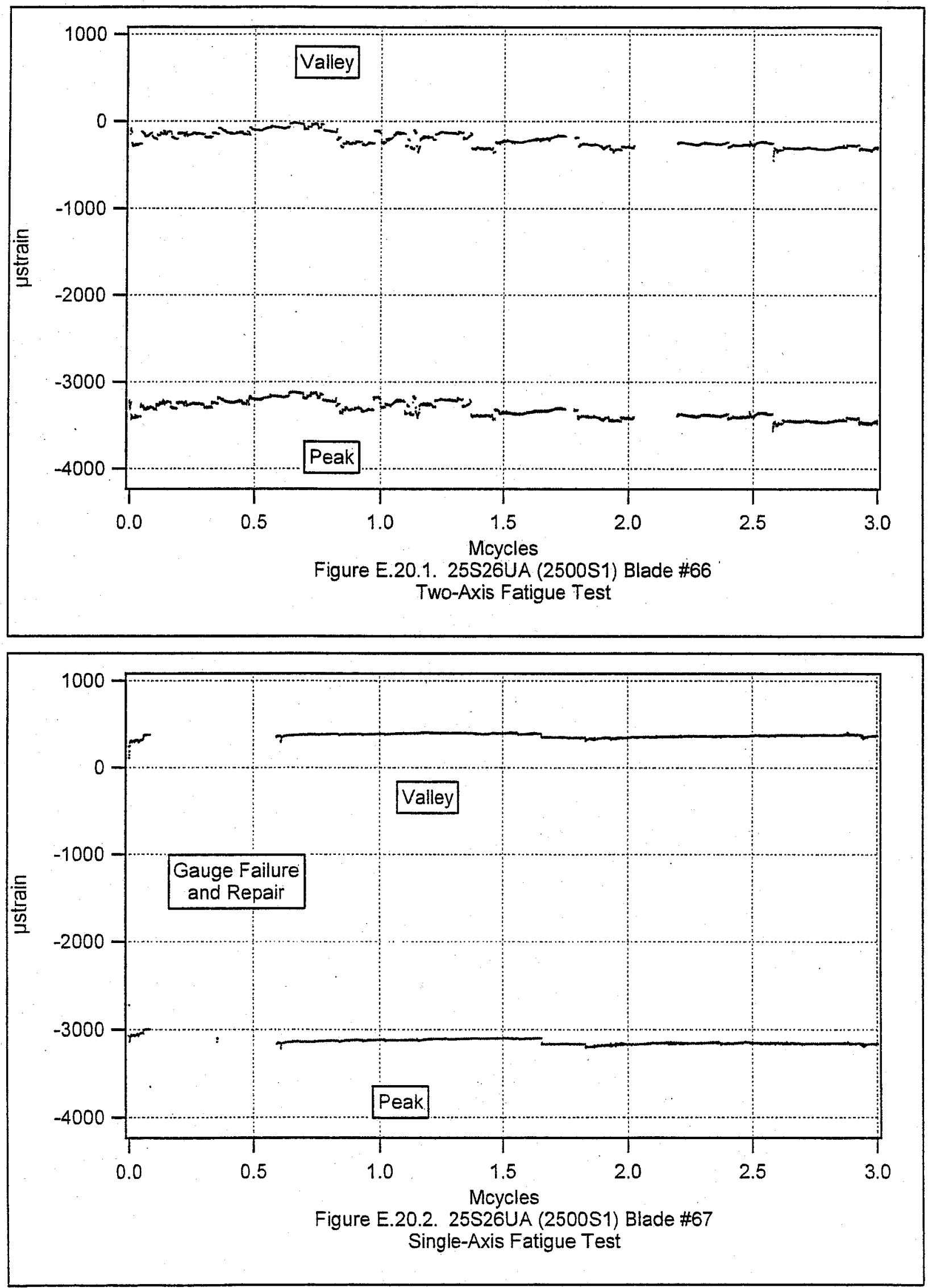

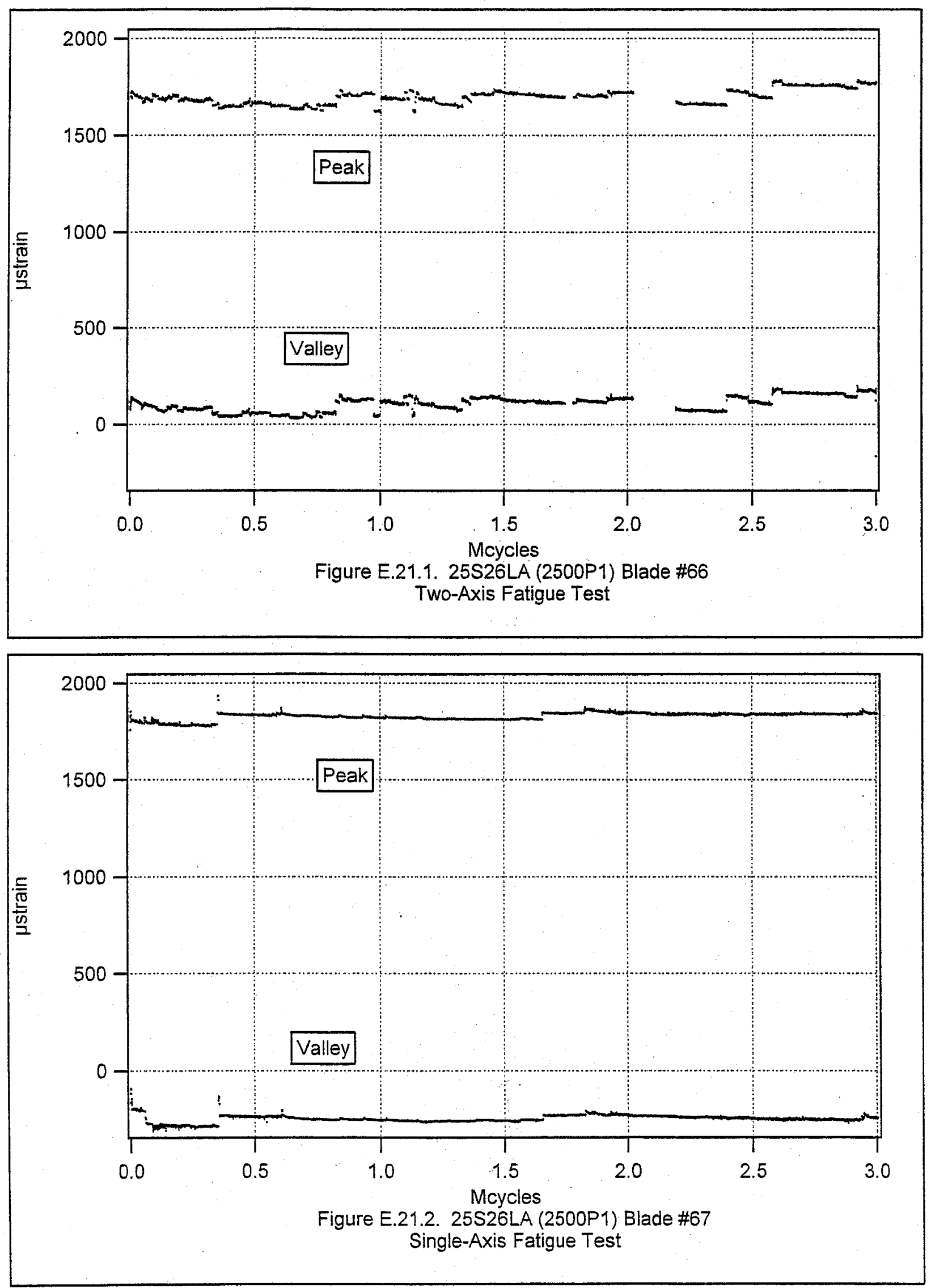

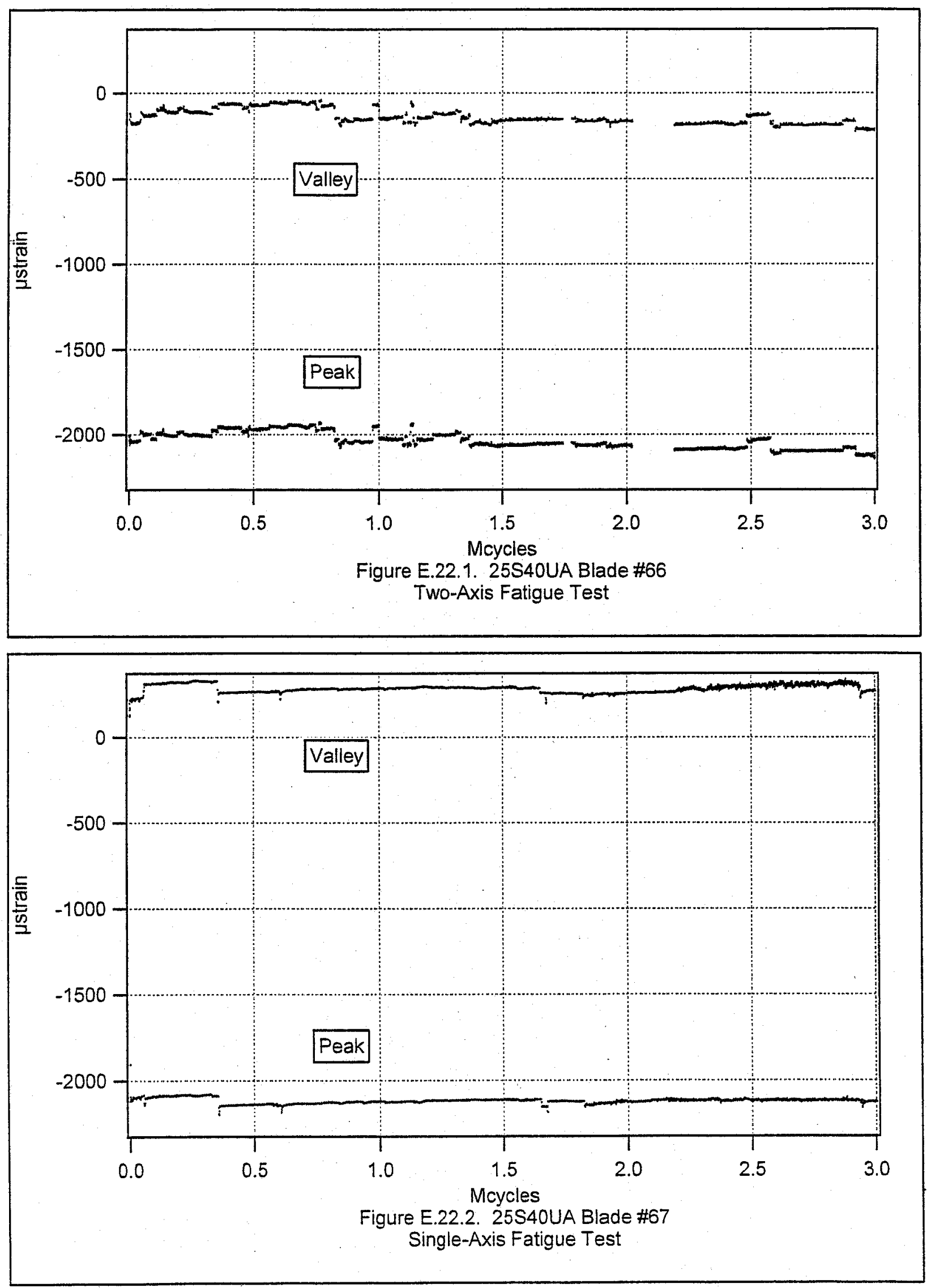

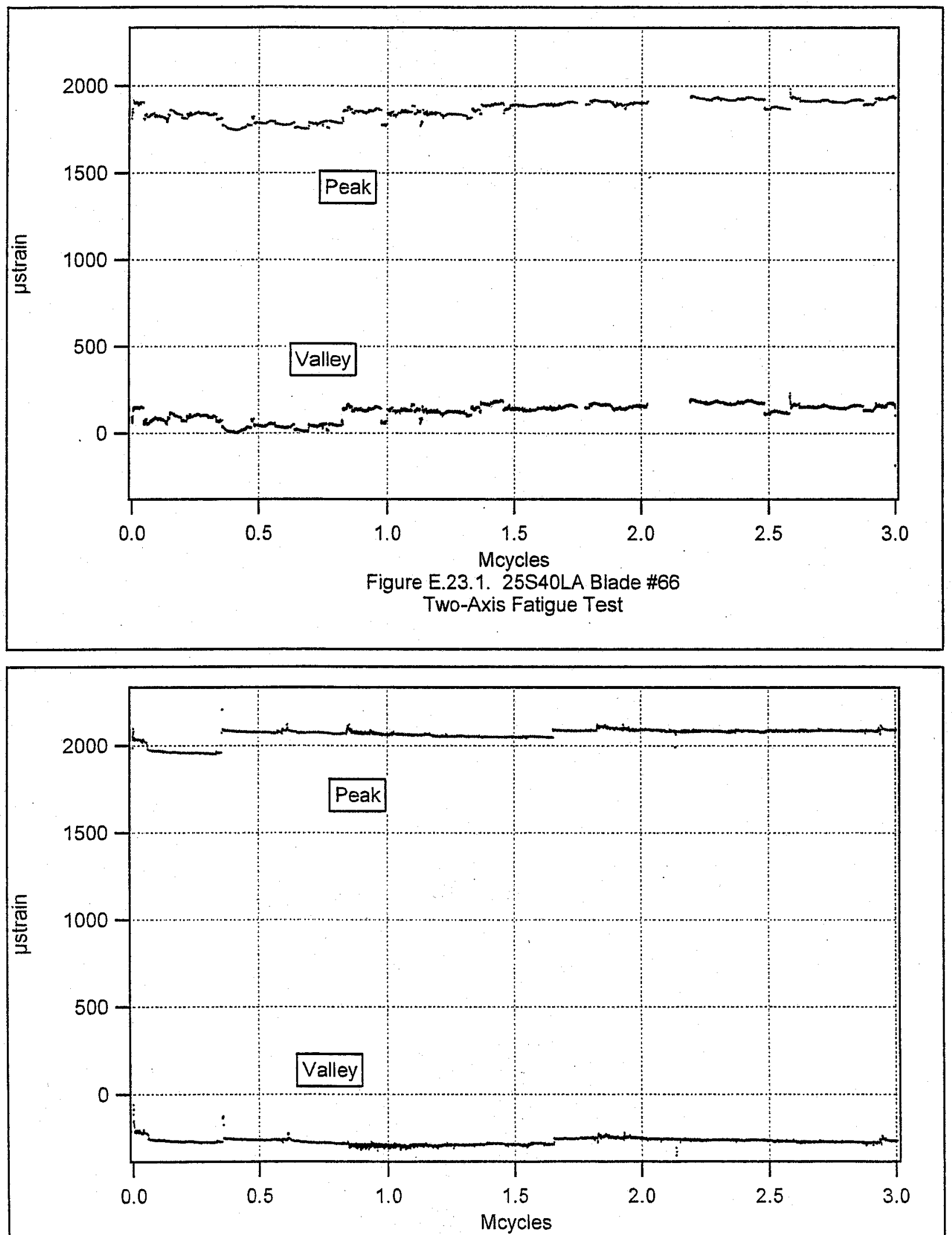

Figure E.23.2. 25S40LA Blade \#67

Single-Axis Fatigue Test 

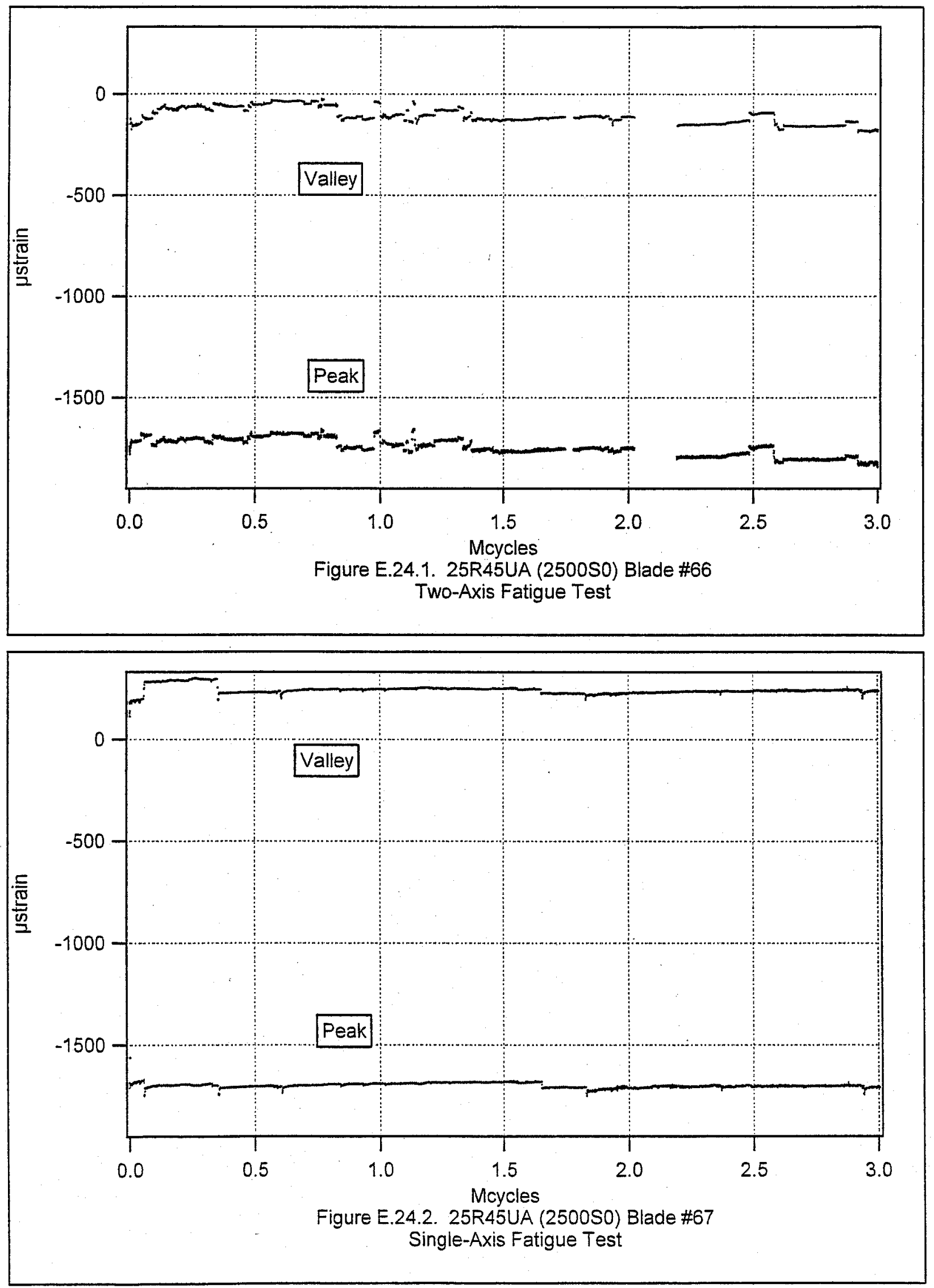

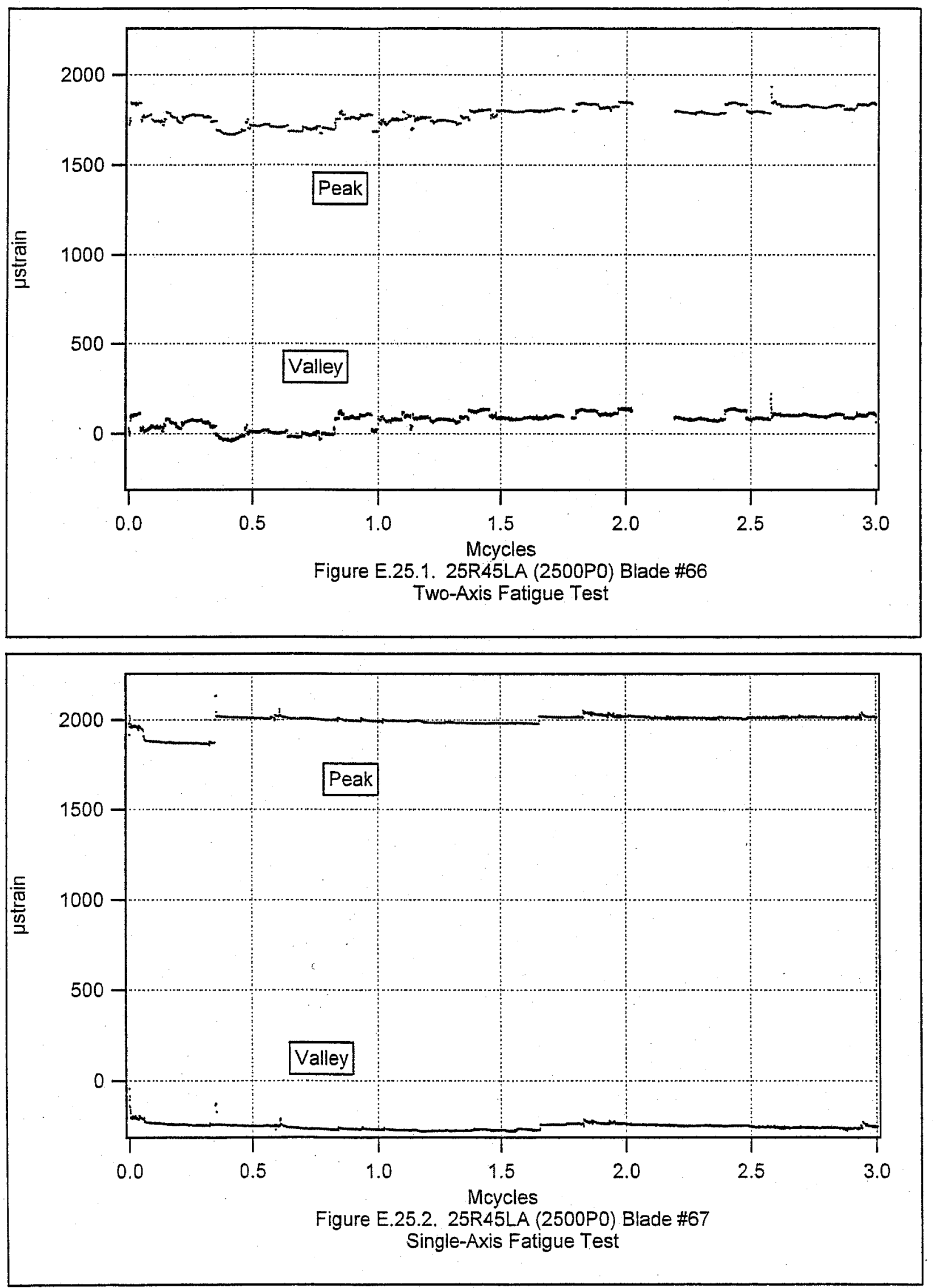

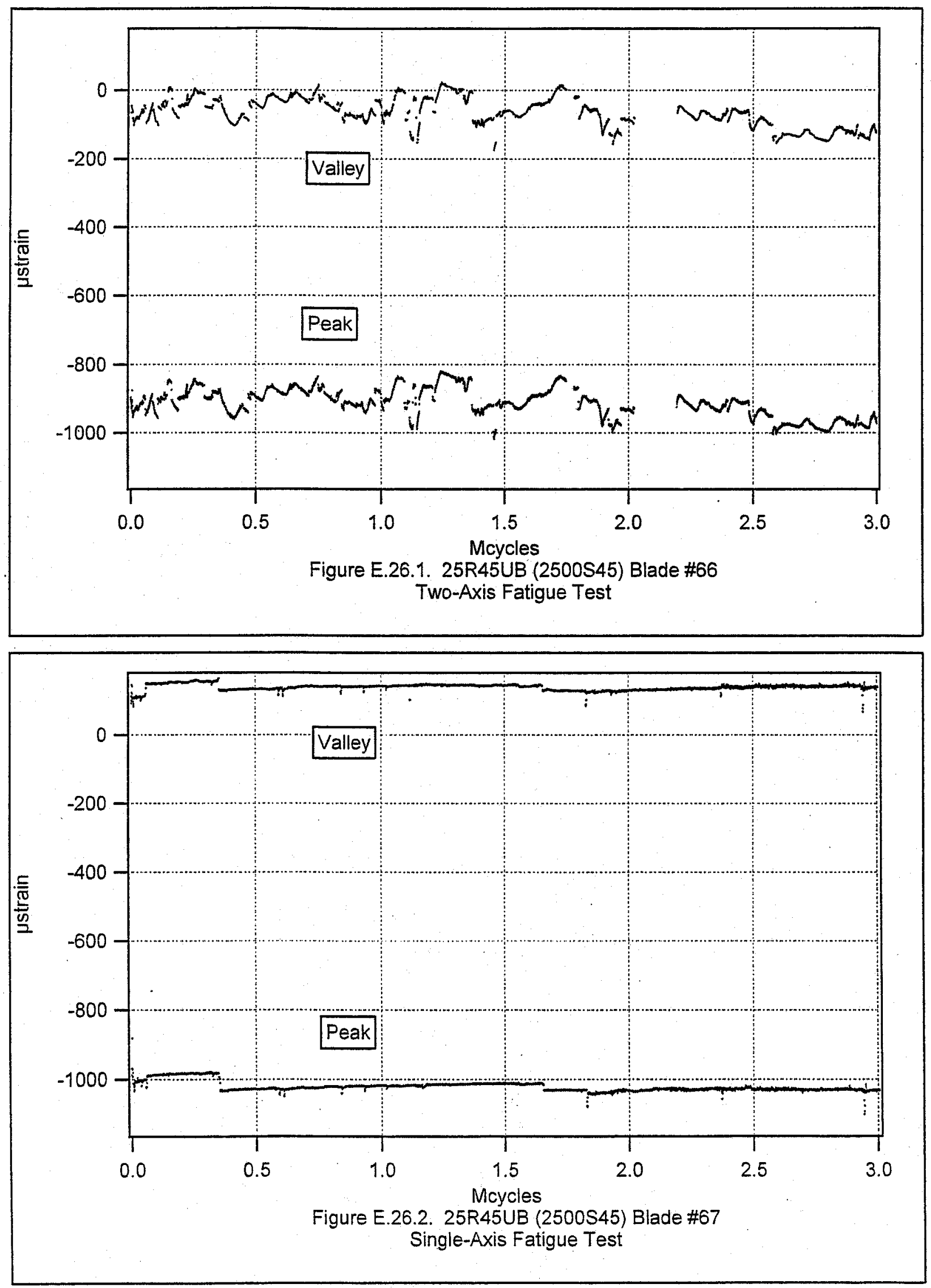

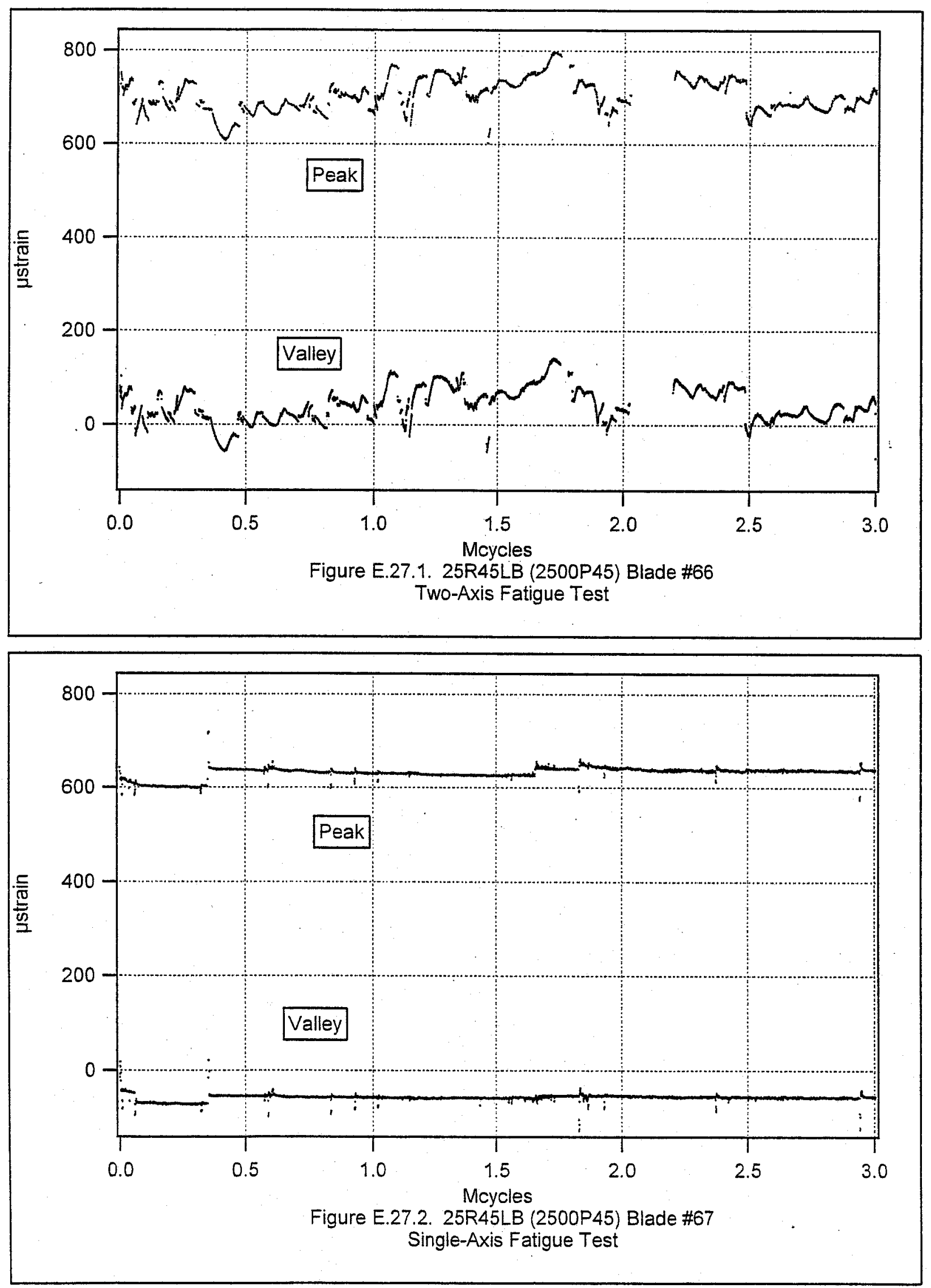

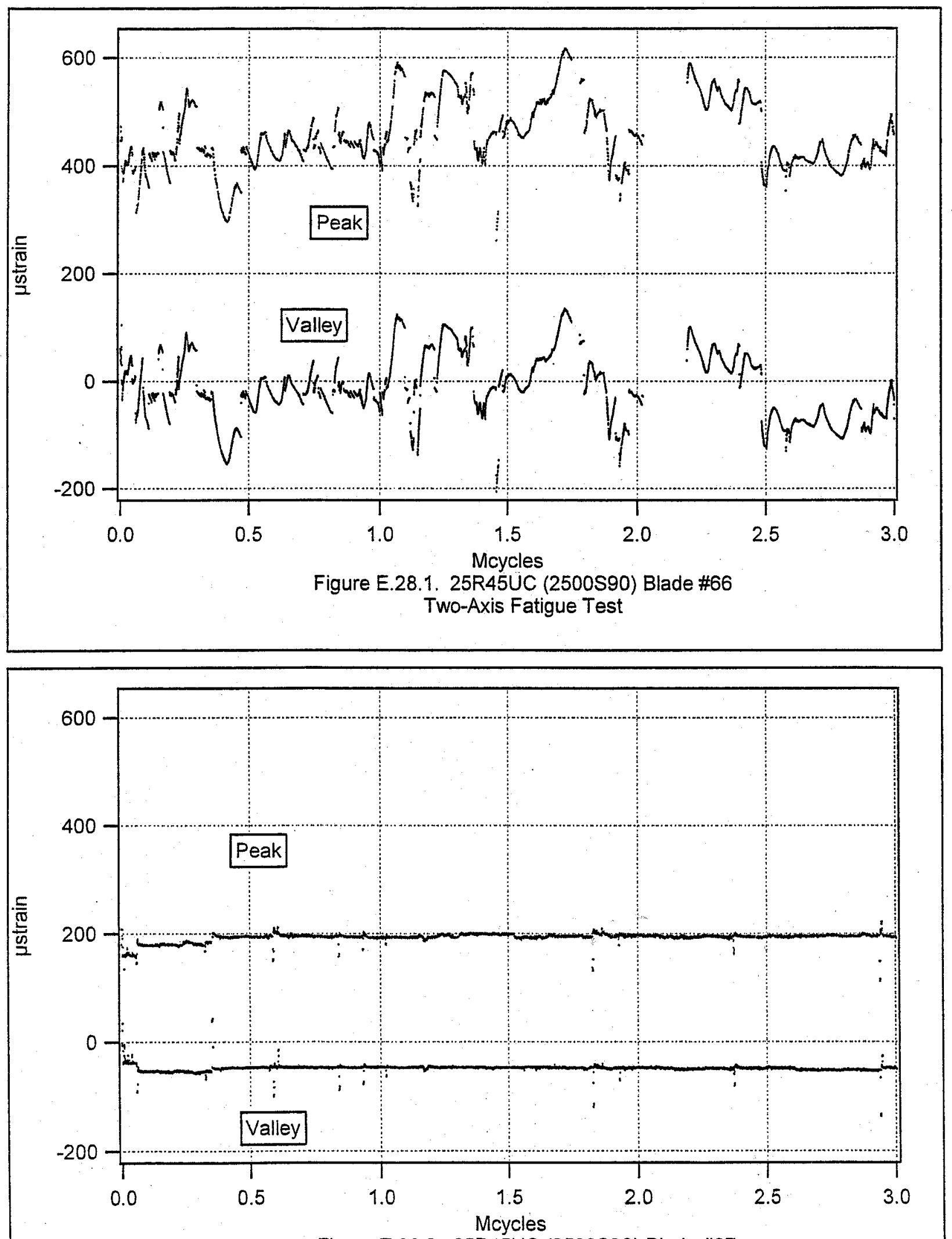

Figure E.28.2. 25R45UC (2500S90) Blade \#67

Single-Axis Fatigue Test 

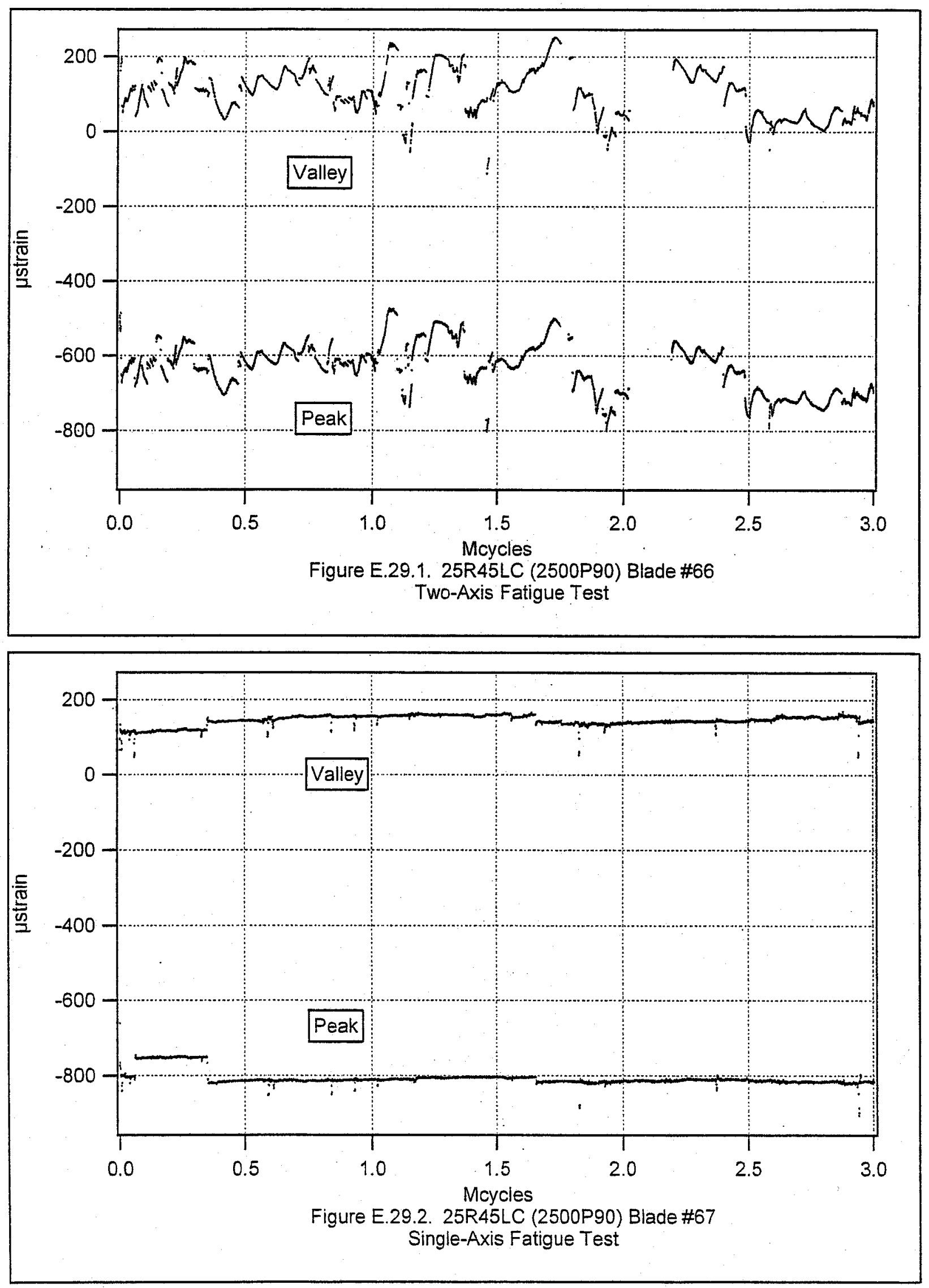

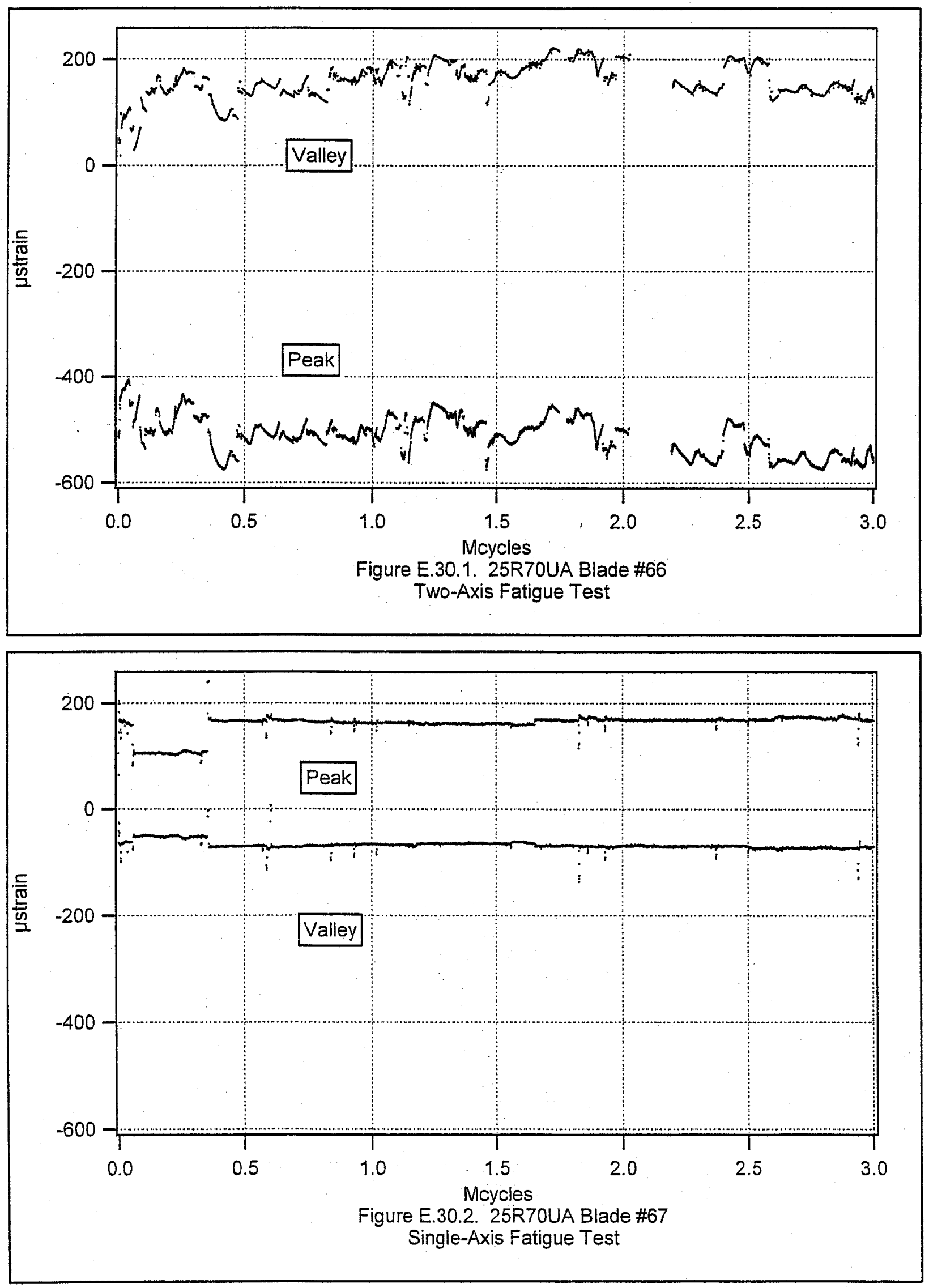

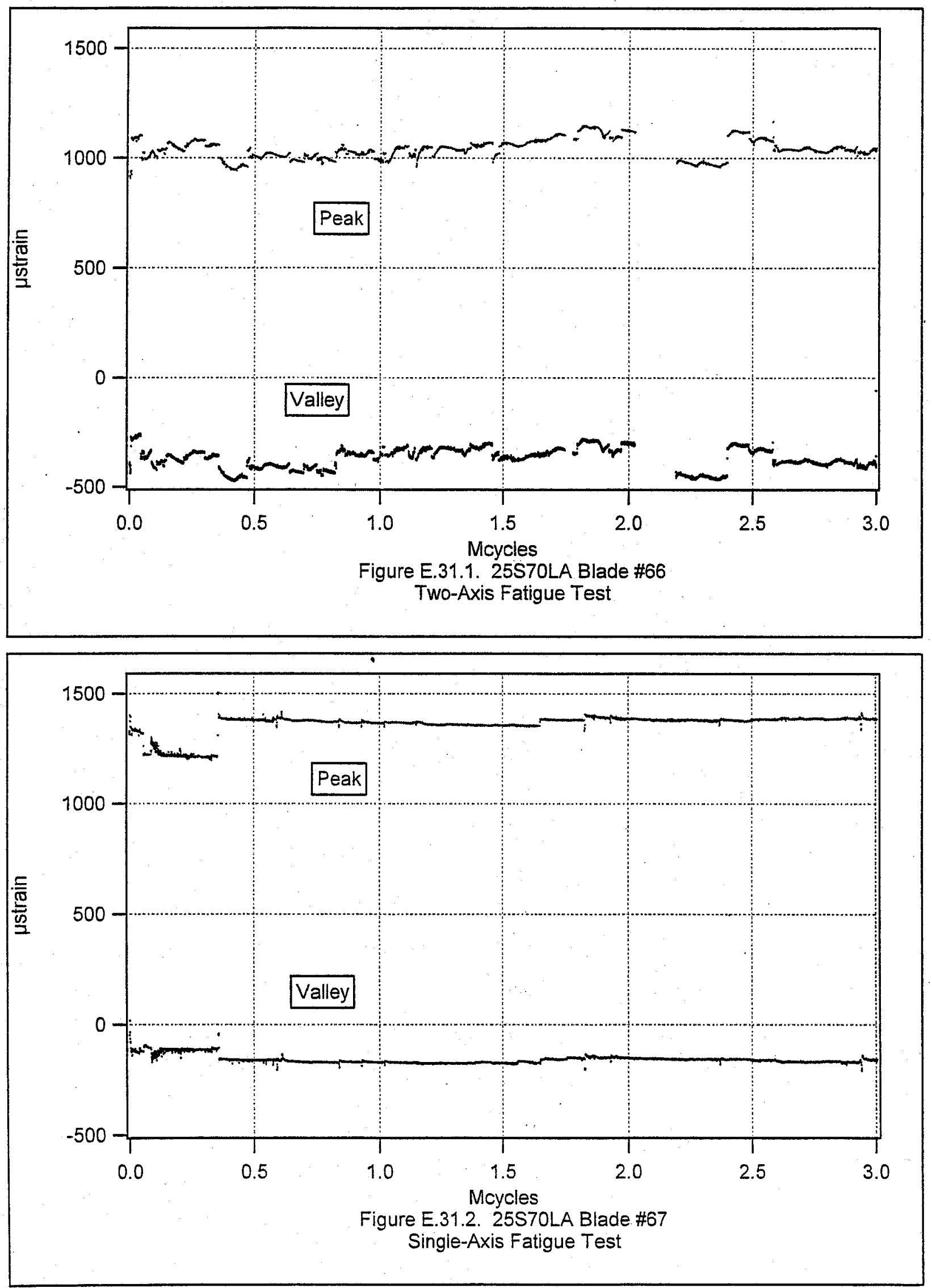


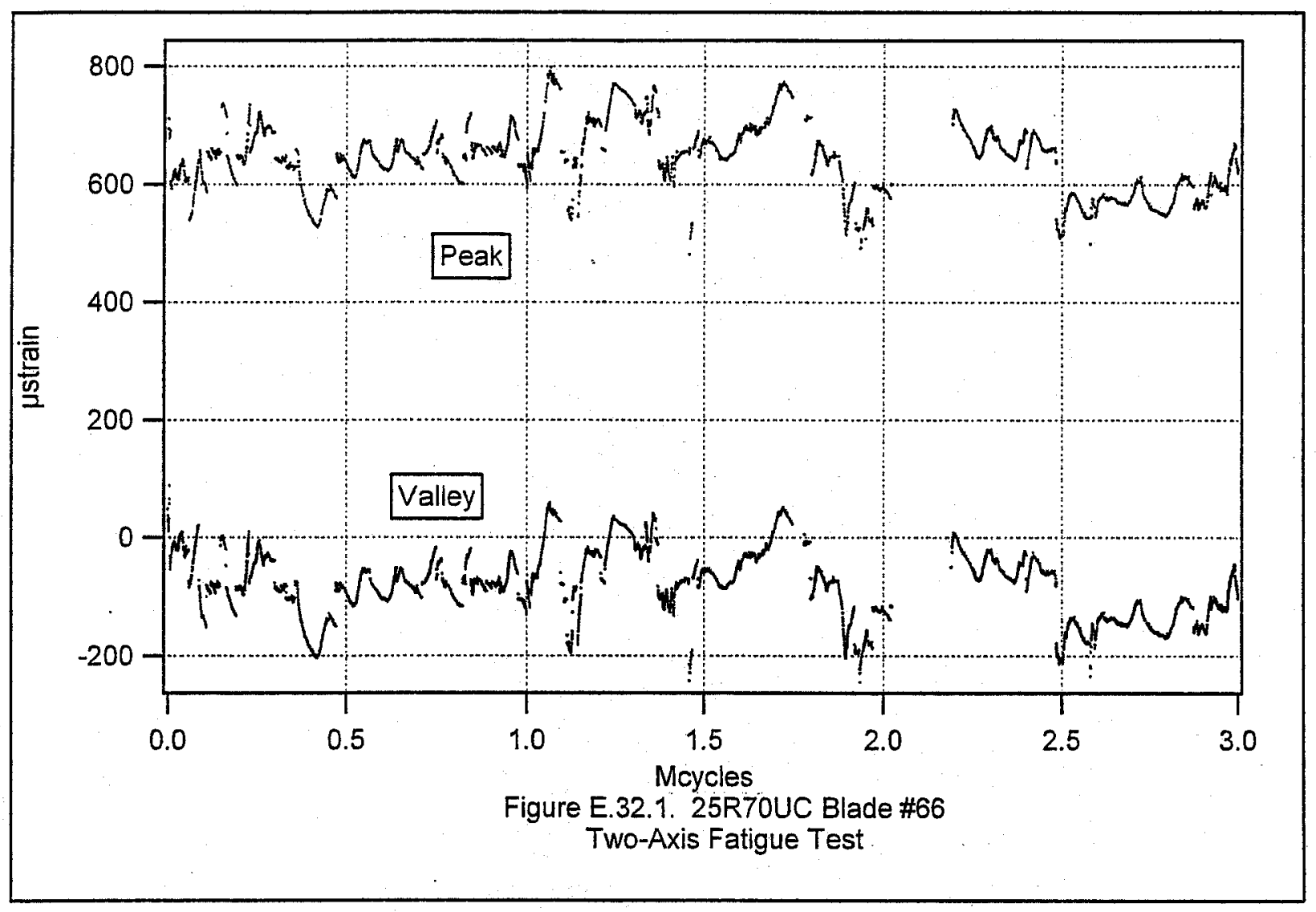



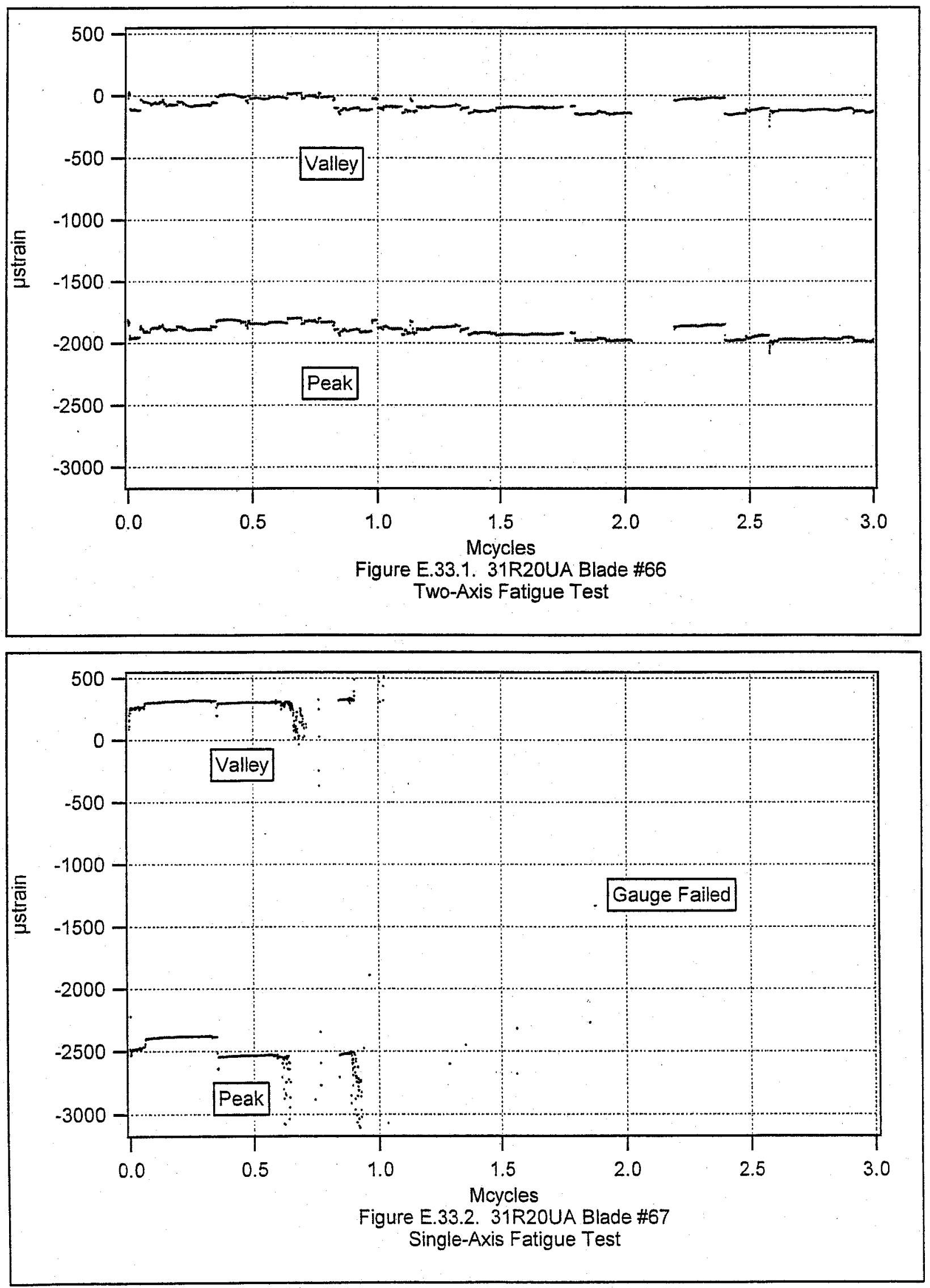

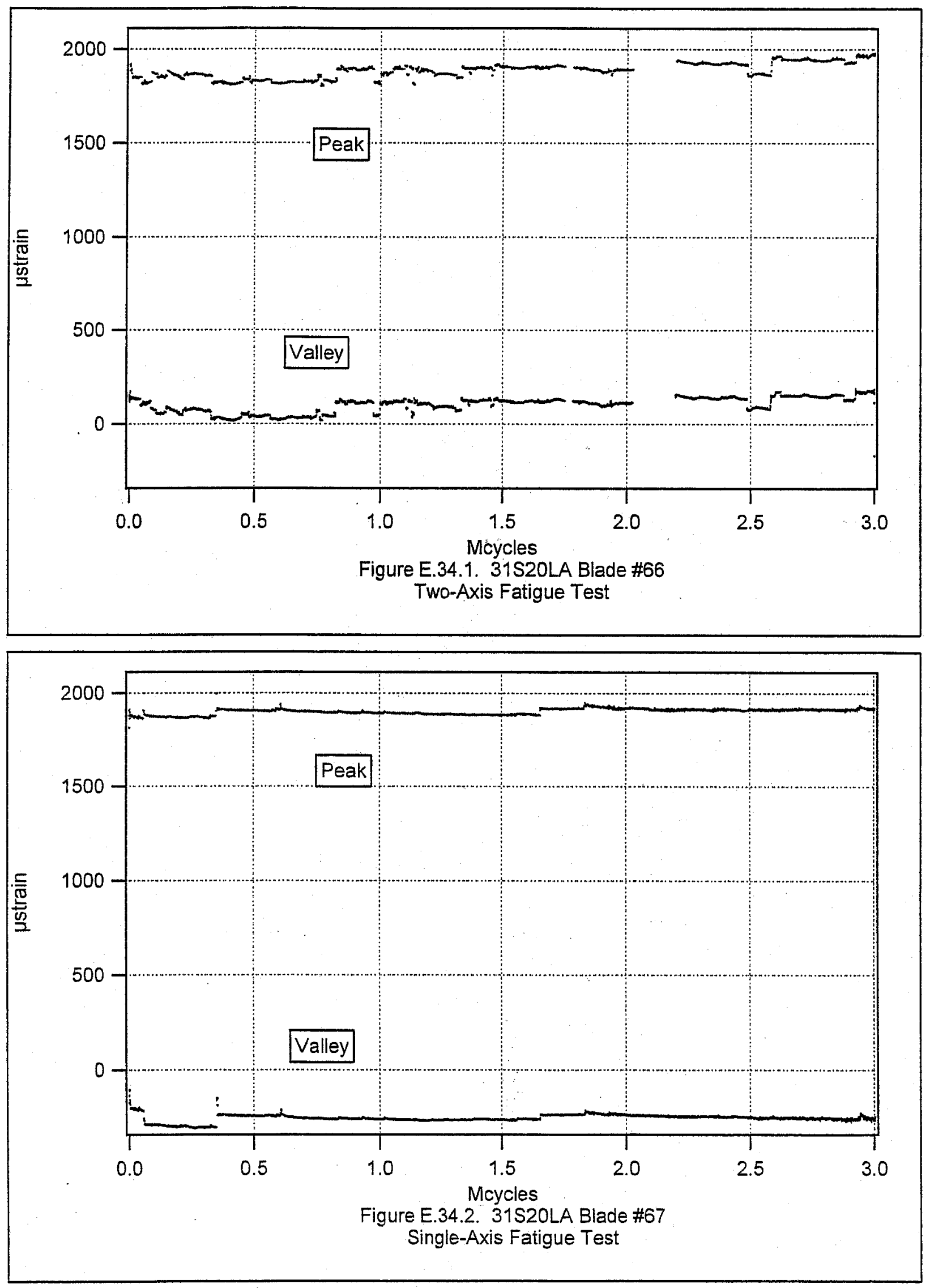


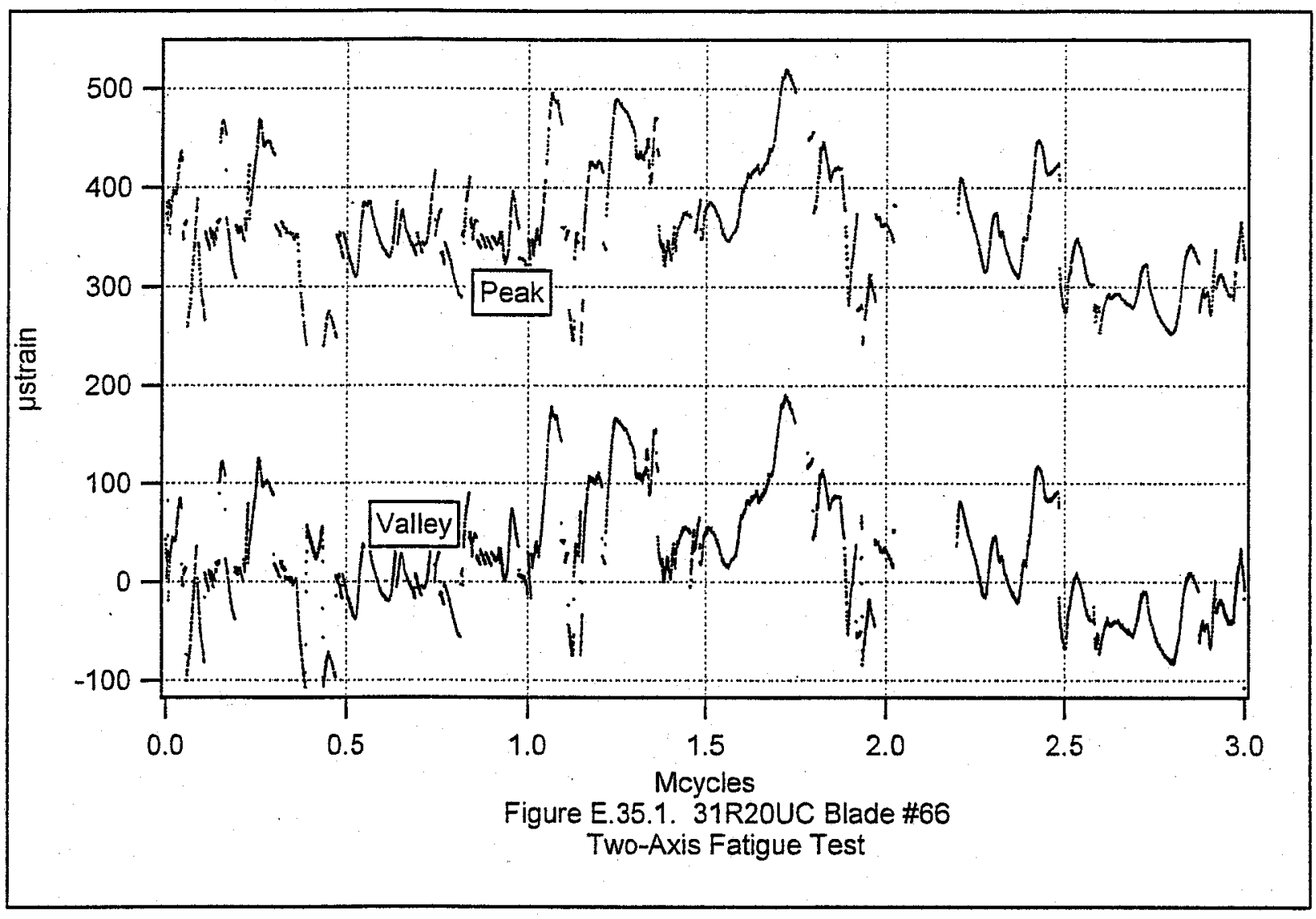

Gauge not measured during Blade \#67 test. 

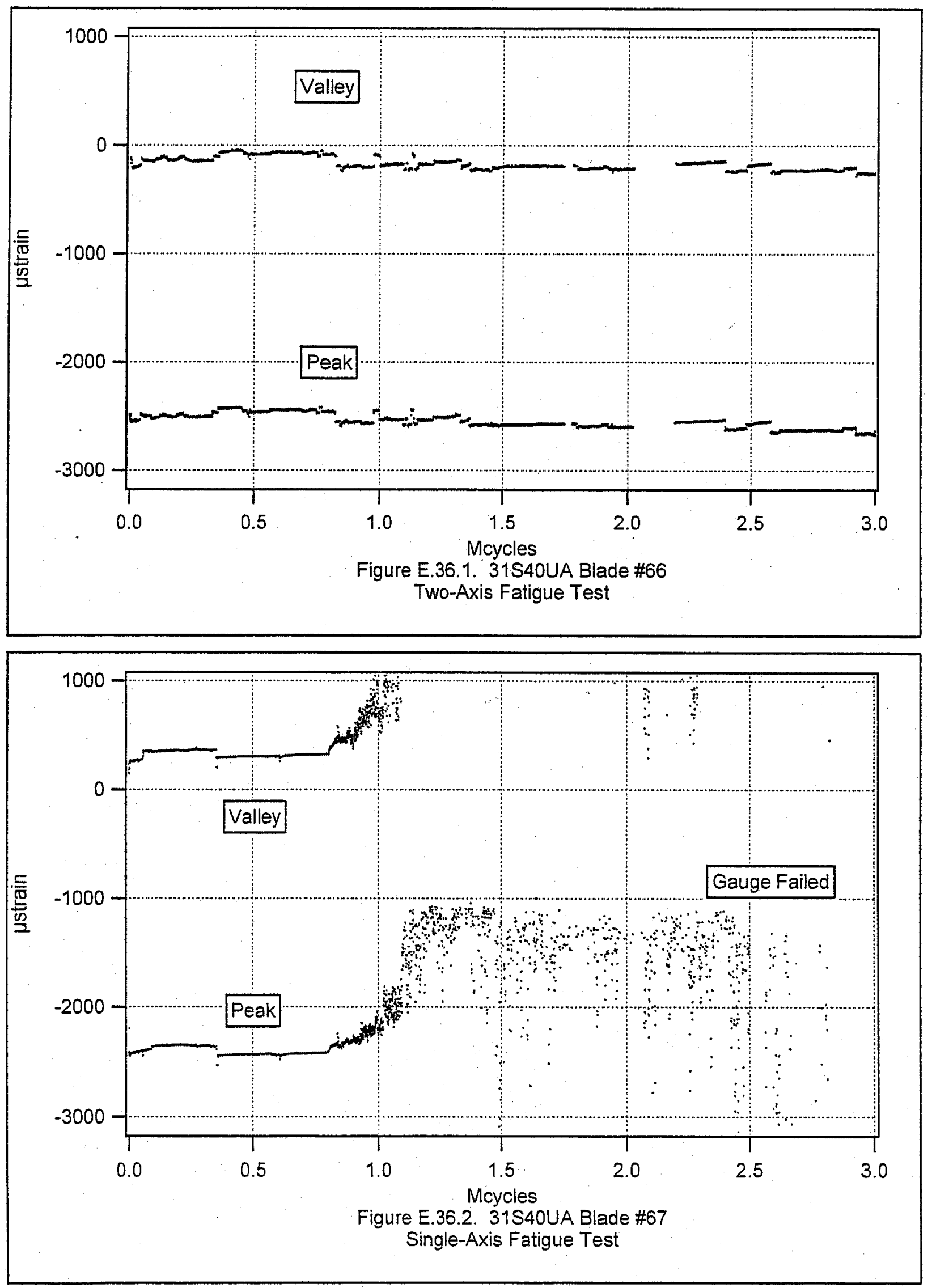

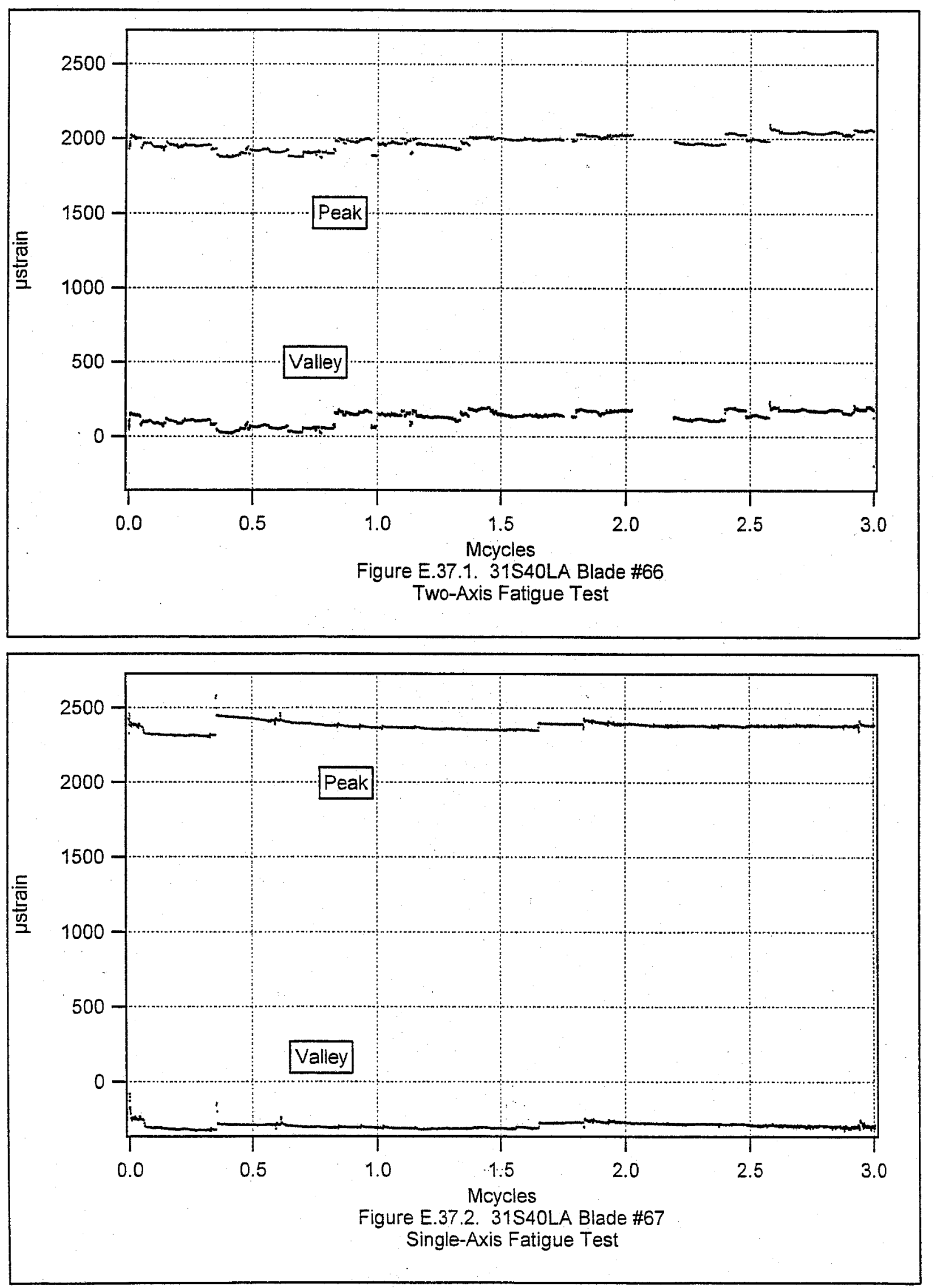

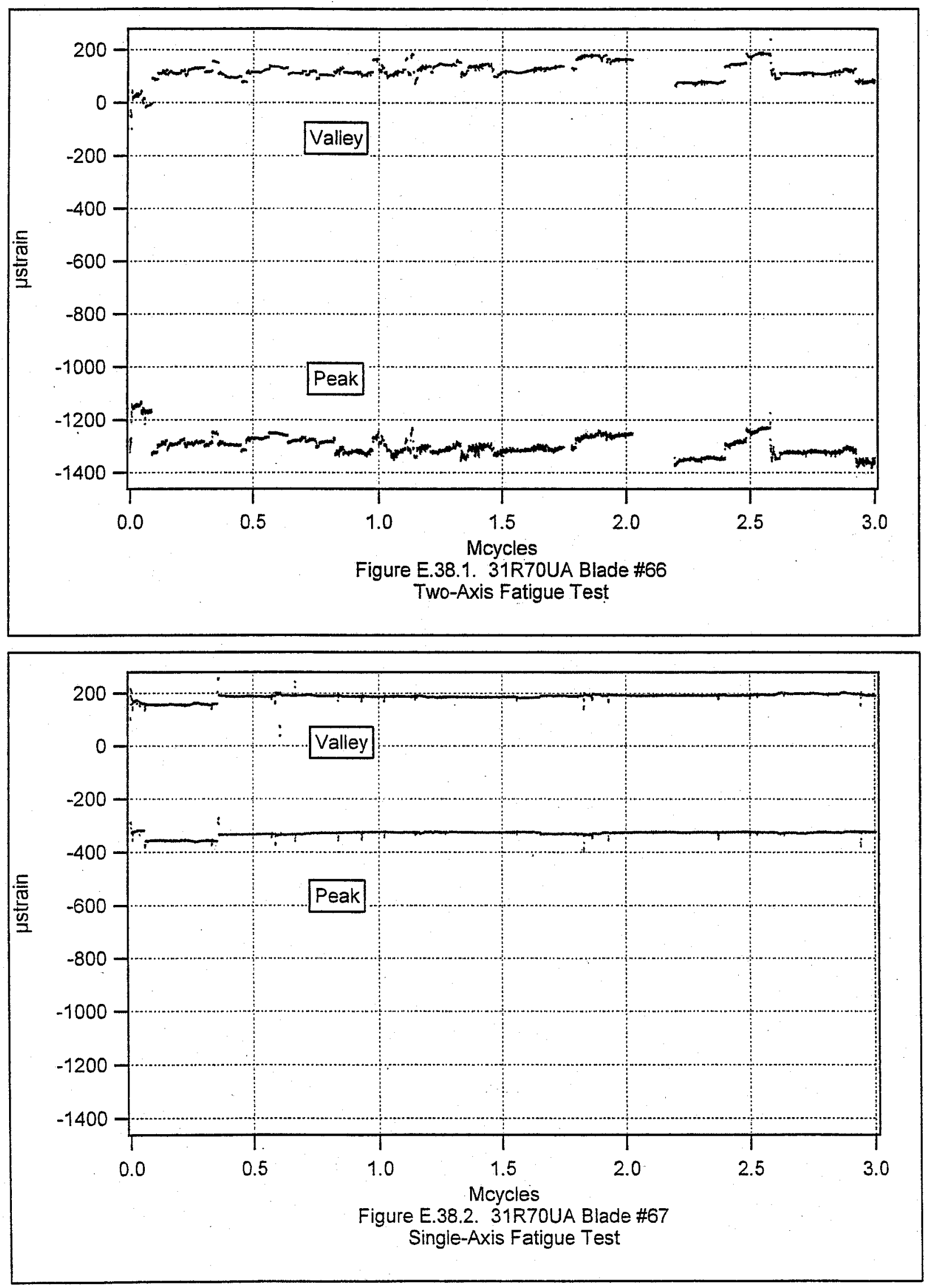

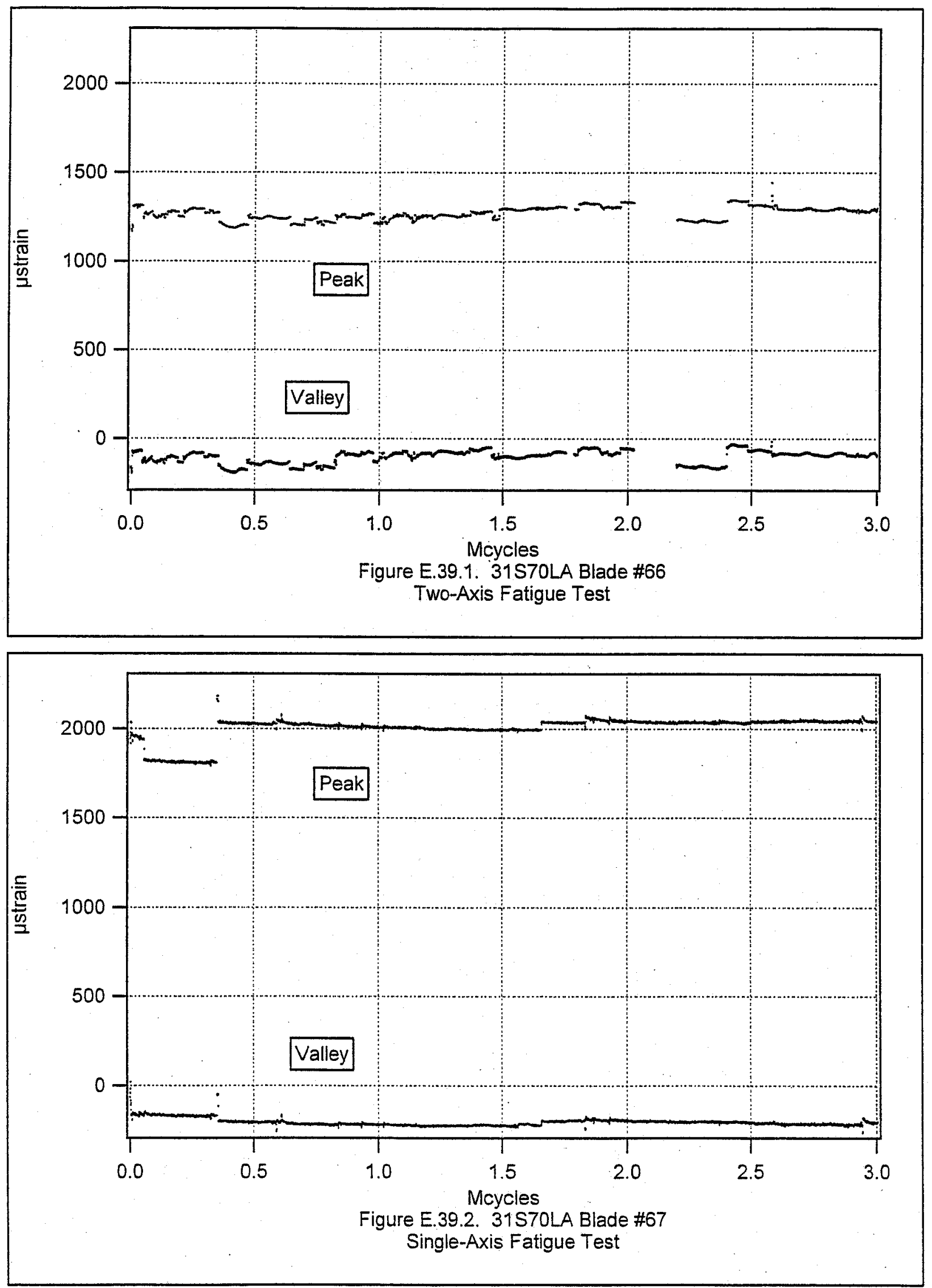


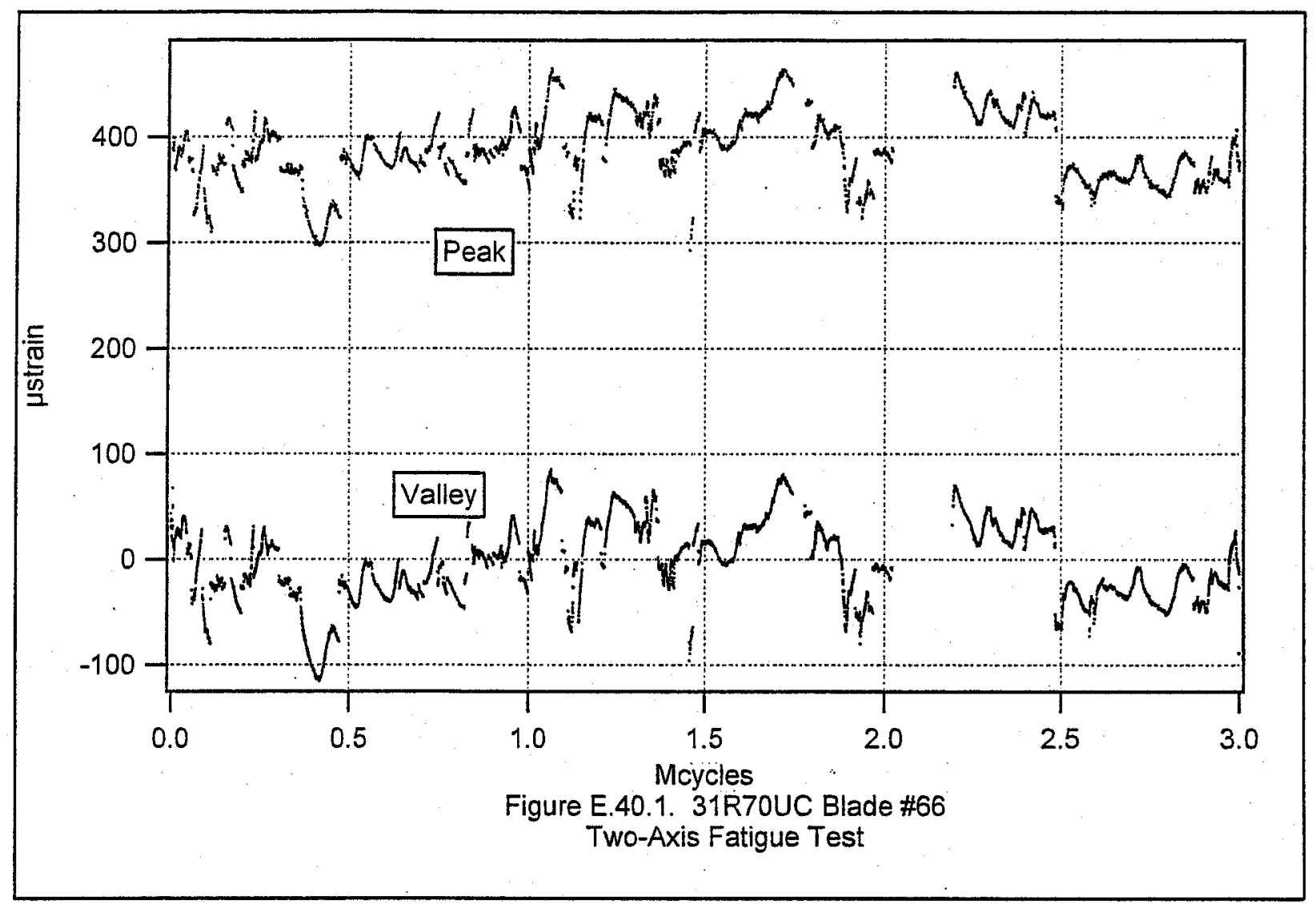

Gauge not measured during Blade $\# 67$ test. 

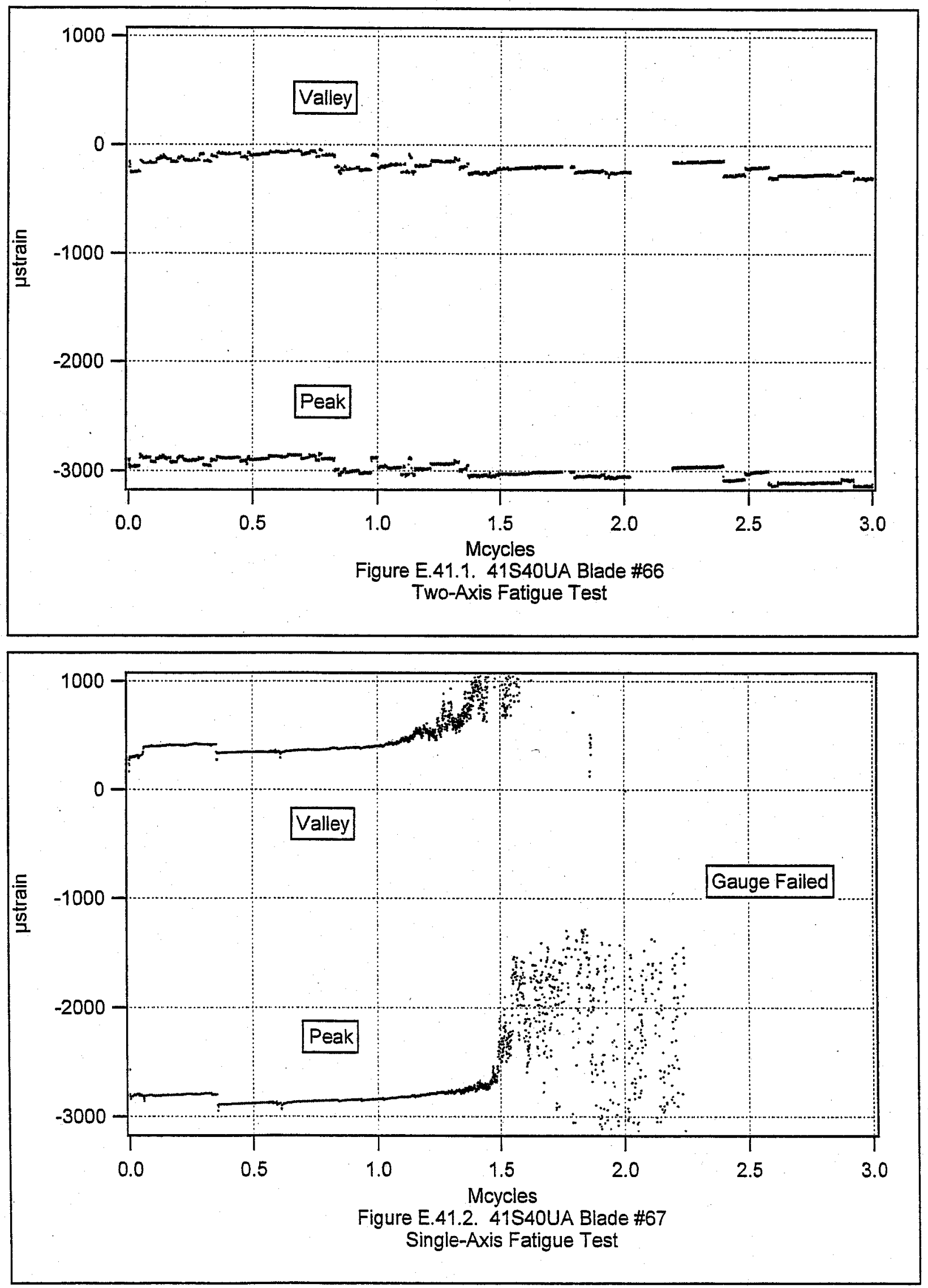

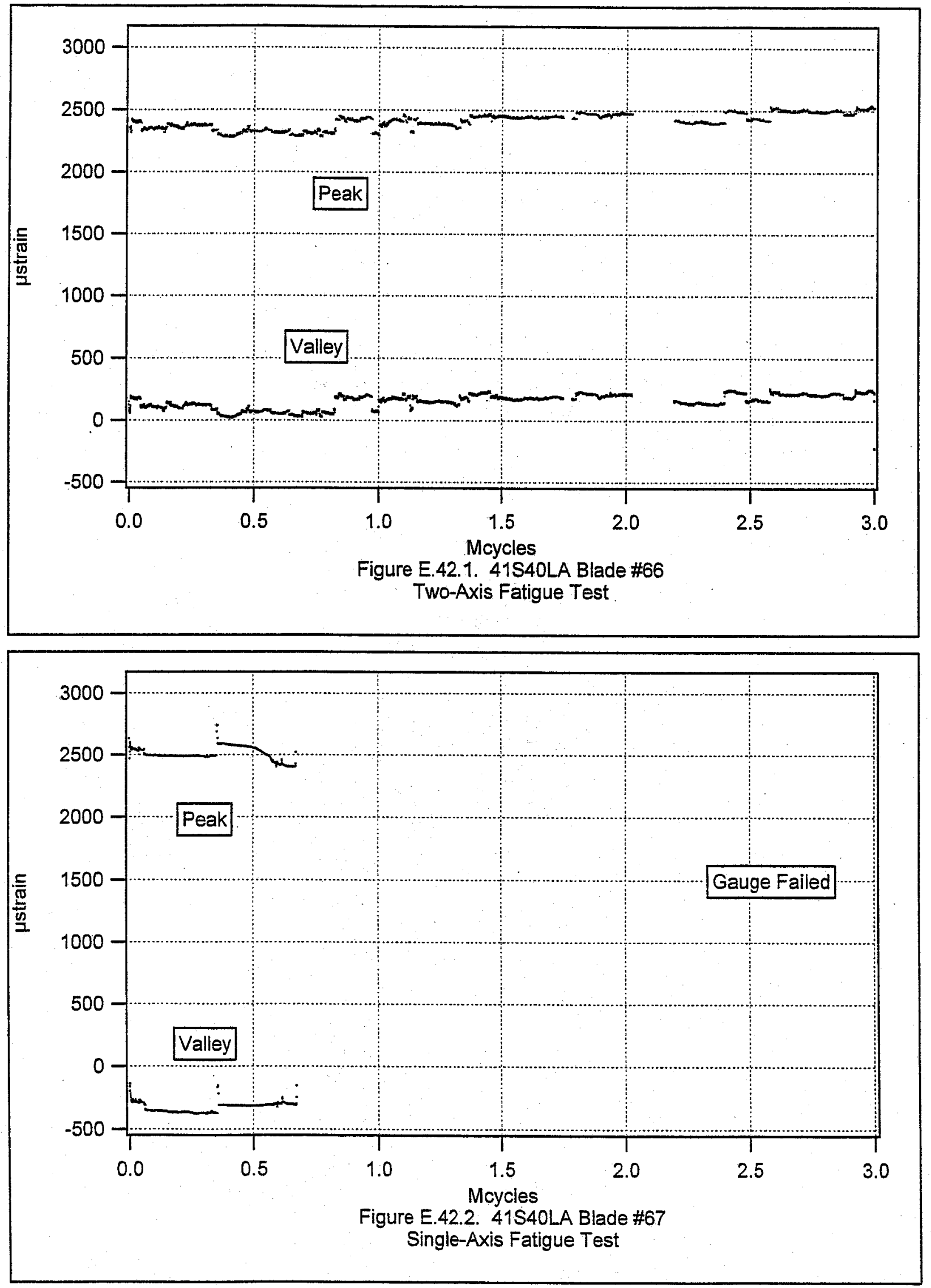


\section{Appendix F}

Correspondence

SMT [21] Pre-load in bolts

Jeroen 8

SMT [98] CRES strain-gauge locations

SMT [100] Nomenclature for common gauges

SMT [25] Radial position, pull direction, etc.

SMT [47] Data sets 


\section{Larwood, Scott}

From: $\quad$ Jeroen van Dam [vandam@ecn.nl]

ent: Tuesday, May 26, 1998 7:19 AM

To:

Subject:

smt-2-」@ecn.nl

[21] pre-load in bolts

NedWind provided the following data:

The torque they use is $800 \mathrm{Nm}$ giving a preload of $220 \mathrm{kN}$ for the M24 10.9 bolts.

Thus a preload of $220 \mathrm{kN}$ has to be used by all laboratories for the bolts connecting the blade flange to the test rig.

Jeroen van. Dam 


\section{Energieonderzoek Centrum Nederland \\ Netherlands Energy Research Foundation ECN}

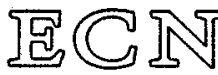

energy innovation

ECN SOLAR AND WIND ENERGY

Bernard Bulder

Pantelis Vionis

ECN Solar \& Wind Energy

Martin Winther-Jensen CRES

Walter Musial

Risø National Laboratory NREL

NREL

Scott Larwood

DUT, Stevin Laboratory

Don van Delft

DUT, Stevin Laboratory

Direct line: +31224564277

Petten, 18 May 1998

Telefax : +31 224563214

Our ref. : JvD/mb 98-471/7.4262.01.02.20

Subject : Jeroen 8 revision 2

Dear colleagues,

I herewith send you a copy of the Jeroen 8 document revision 2 .

Yours sincerely,

bla MBrate (seck.)

Jeroen van Dam

ECN Solar \& Wind Energy

Experiments \& Assessment

Enc1. 


\title{
Working document of the EWTTPD project \\ Subtask 2: Blade Test Methods and Techniques
}

\section{"Jeroen8"}

\author{
Jeroen van Dam \\ ECN, Petten \\ 15 May 1998
}

JEROEN8.SMT

Revision: 2

Replaces: "Handout for the third meeting of the EWTTPD project" dd March 18, 1998 


\section{Contents}

CONTENTS .2

TESTS TO BE PERFORMED WITHIN THE EWTTPD-PROJECT, SUBTASK 2 3

STRAIN GAGE MARKINGS MADE ON THE BLADE . 6

COMMON STRAIN GAGES... .6

SUGGESTION FOR THE TABLE OF CONTENTS FOR THE MEASUREMENT REPORTS. 7

BLADE NUMBERS. .8

EXPLANATION OF TERMS IN DESIGN DOCUMENTATION 9 


\section{Tests to be performed within the EWTTPD-project, Subtask 2}

\section{Used information:}

- European Wind Turbine Testing Procedure Developments, Annex I: project Programme

- Minutes of the second subtask 2 meeting

- "Eigenfrequentie metingen aan een NW-25 Rotorblad bij Nedwind te Heerhugowaard d.d. 23 oktober 1992"

- "Technische notitie bladtest NW25", T. Dobbe, 20-11-92

The last two documents describe eigenfrequency measurements and the derivation of the loads used for a blade bending test. The documents are both written in Dutch. During the blade bending tests deflections were only measured at the load application point and at the tip.

\section{Mass}

The mass of the blade has to be determined, a rough indication of the mass distribution is obtained by measuring the centre of gravity.

\section{Eigenfrequencies}

Five eigenfrequencies have to be measured:

The first two bending frequencies in the directions perpendicular and parallel to the tip chord.

The first torsional eigenfrequency.

From the test report :

- First torsional eigen-frequency: $37.5 \mathrm{~Hz}$

\section{Damping}

Besides the eigenfrequencies also damping has to measured. This has to be done for different tip deflections to distinguish the aerodynamic and structural damping. Since structural damping is dependent of temperature the eigenfrequencies will be determined at two temperature levels.

The damping is defined as:

$\zeta=\frac{1}{2 \pi n} \ln \frac{x_{1}}{x_{n+1}}$

\section{Strain distribution}

Rotorline has performed a static test in 1992. The blade was loaded in flapwise and lead-legwise direction seperately. The maximum flatwise bending moment came from loadcase 93 . To apply the maximum bending moment Rotorline has applied a test load of $23000 \mathrm{~N}$ at $7 \mathrm{~m}$ meter from the blade flange. The edgewise bending test was performed with a load of $7150 \mathrm{~N}$ at seven meters from the blade root. The maximum edgewise bending moment came from loadcase 97 , but this value has not been used.

From the test report:

Calculated deflections when loads are applied at 7 meter from the blade flange:

\begin{tabular}{lccc} 
load [N] & load direction & displacement at $7[\mathrm{~m}]$ & tip displacement \\
\hline 23000 & flap & $150 \mathrm{~mm}$ & $382 \mathrm{~mm}$ \\
7150 & lead lag & $20 \mathrm{~mm}$ & $45 \mathrm{~mm}$
\end{tabular}


As agreed upon during the third meeting the loading of the blade should go up to $75 \%$ of the limit load. The flap wise and lead-leg loads shall be applied seperately.

From the maximum loads in the file NW25.cmb bending moment distribution lines have been constructed. These deviate from the lines used by Rotorline. Keeping the load application point the same as for the Rotorline test (thus 7.65 meter from the rotorcentre), the test load giving the same bending moment at the blade flange can be calculated. Multiplying this with a load factor of 1.5 for the limit load and 0.75 for the $75 \%$ level gives the following loads:

$14809 \mathrm{~N}$ in lead leg direction

$24723 \mathrm{~N}$ in flapwise direction

The bending moment distribution of the most severe load cases are given in Figure 1 and 2 . The test load is also depicted in these graphs.

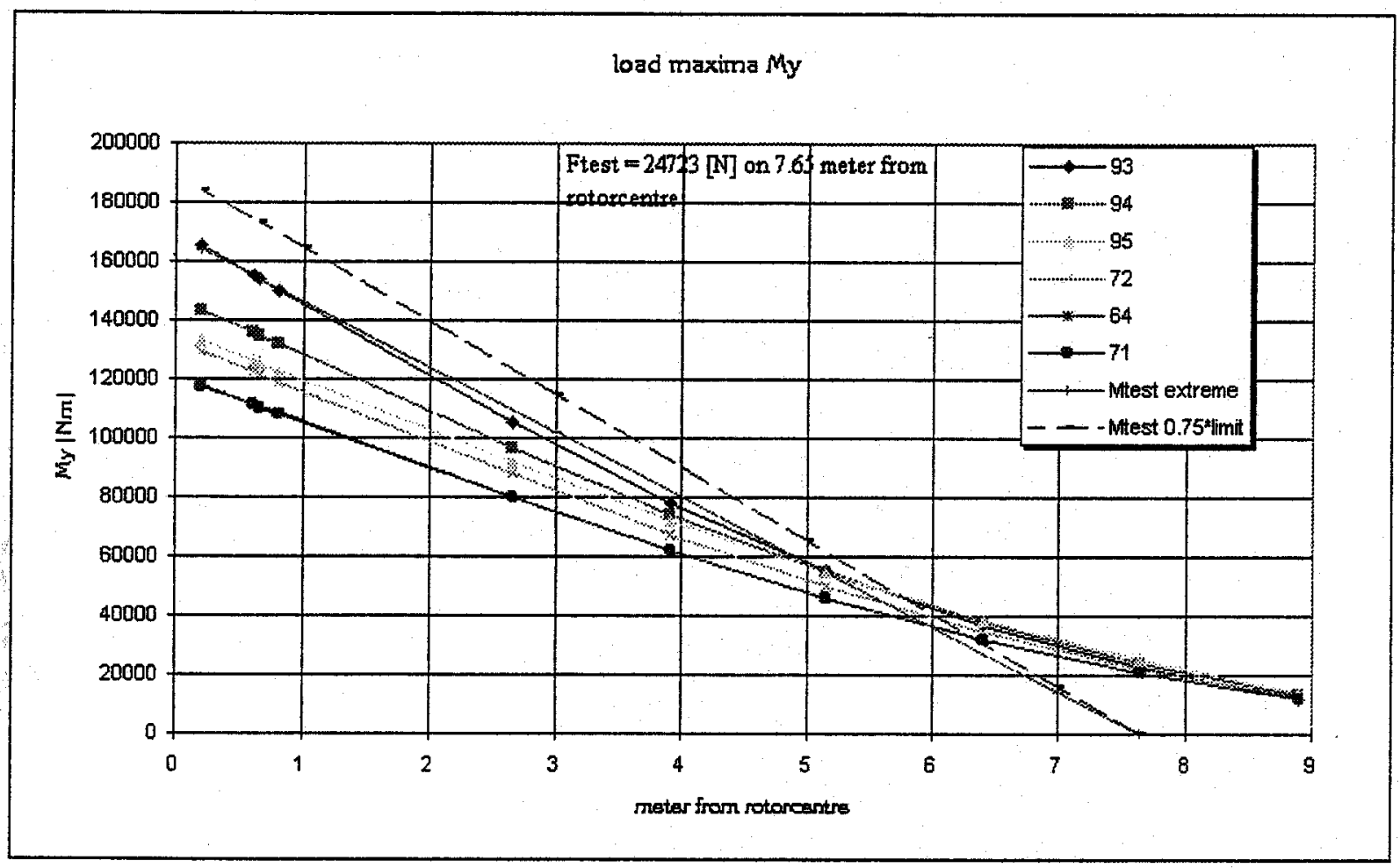

Figure 1: Flapwise bending moment distribution for the most severe load cases and the test load. 


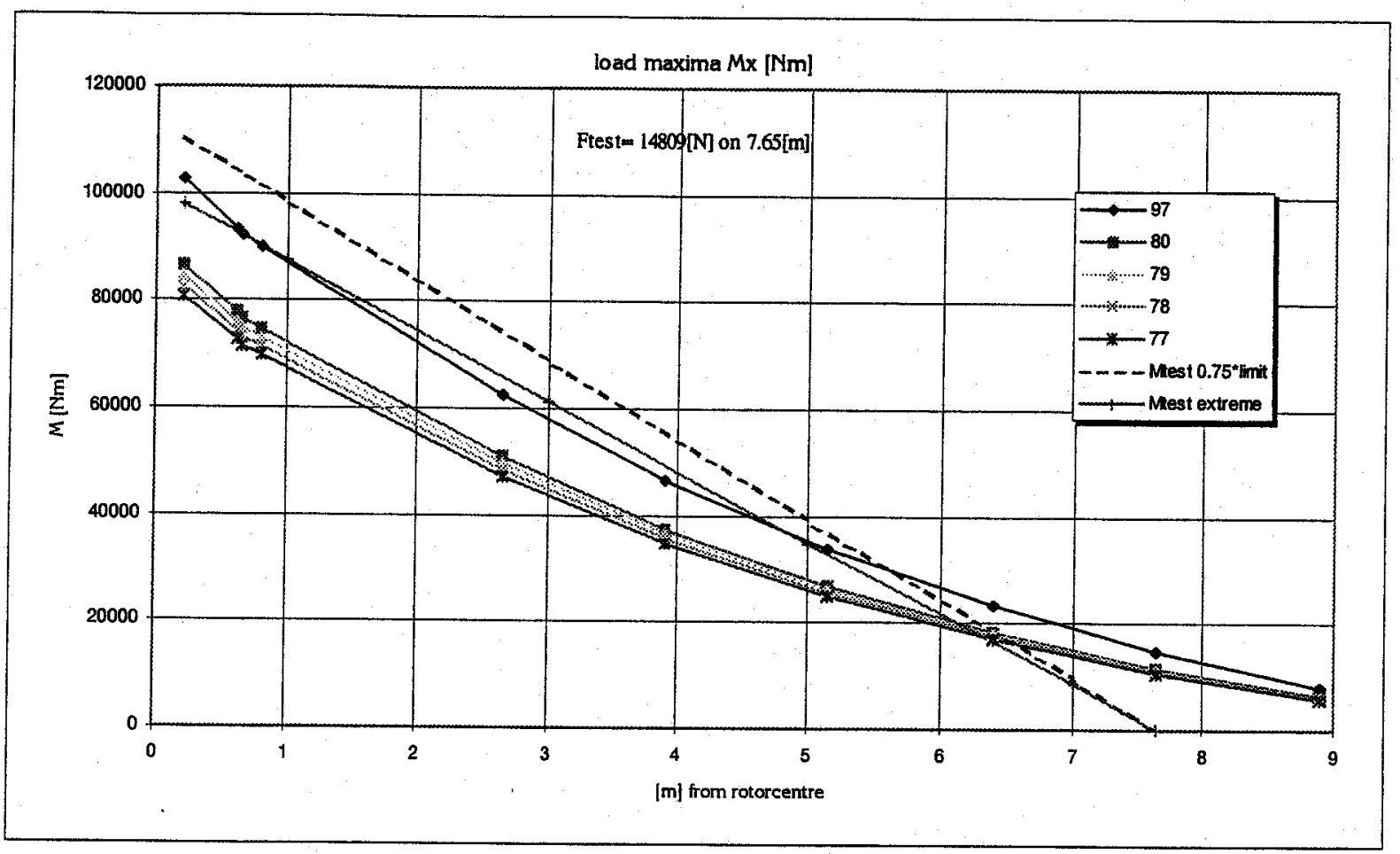

Figure 2: Lead-leg bending moment distribution for the most severe load cases and the test load.

At least the deflection of the tip and the load application point should be recorded.

The most critical section for buckling during the test is the tail between $R=2.65$ and $R=3.15$ meter from the blade root.

\section{Static test}

For the static test no special procedures are prescribed.

\section{Fatigue test}

For the fatigue test no special procedures have to be prescribed. Bussiness as usual is the starting point.

\section{Post mortum}

For the post mortum tests it should be known which areas are of interest for investigation. At least the laminate thickness of the root section should be checked. Other areas of interest are expected to follow from the strain distribution test, static test and fatigue test. 


\section{Strain gage markings made on the blade}

The blades have been marked with the lines as depicted in Figure 3. These lines are drawn on both sides of the blade. The lines at 1000, 1500, 2000 and $2500 \mathrm{~mm}$ from the blade flange are perpendicular to the pitch axis. From the pitch-line intersection lines are applied with a distance of $200 \mathrm{~mm}$.

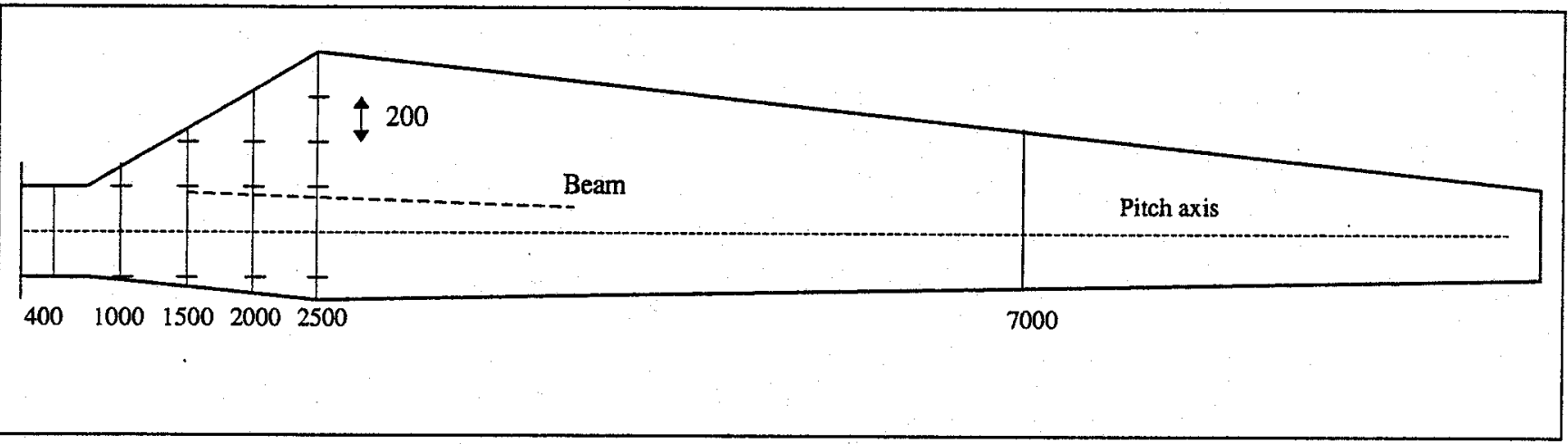

Figure 3: Blade markings

\section{Common strain gages}

Instead of prescribing what type of strain gages should be placed at which position, for a limited number of places on the blade the sort of information to be measured is prescribed. In this way every partner is free to use the type of strain gage and bridge configuration which is preferred by the laboratory.

All locations at both sides of the blade.

1. The bending moment parallel and perpendicular to the blade tip should be measured at $400 \mathrm{~mm}$ from the blade flange. Markers are placed on the blade giving these locations.

2. At the cross-sections $1500 \mathrm{~mm}$ and $2500 \mathrm{~mm}$ from the flange on both sides of the blade:

-A rosette should be placed at $2500 \mathrm{~mm}$ from the blade flange at $80 \mathrm{~mm}$ from the beam towards the tail. At least the strain in direction of the pitch axis should be measured.

-The strain parallel to the pitch axis should be measured $190 \mathrm{~mm}$ from the beam towards the nose

All together this comes to a total of 20 strain gages.

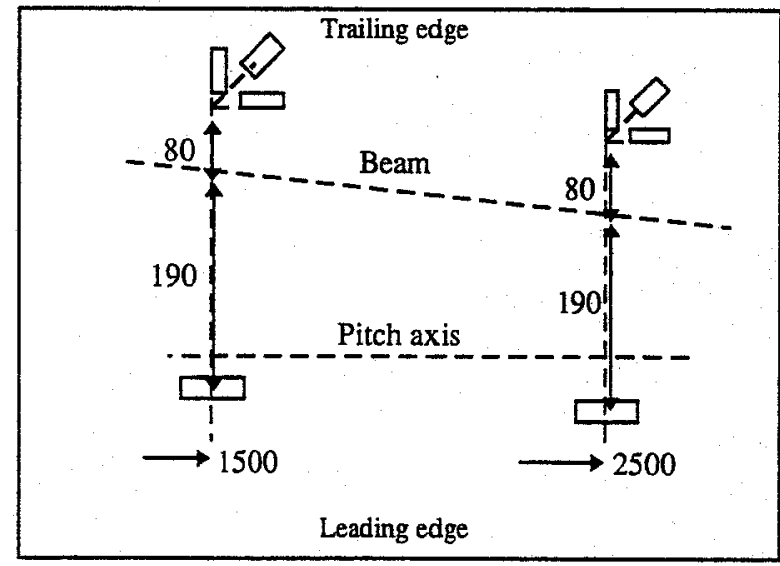

Figure 4: Locations of common strain gages (dimensions in $\mathrm{mm}$ ). 


\section{Suggestion for the table of contents for the measurement reports.}

Each test laboratory

- Objective

- Test plan

Test rig

Test plan

Measurement plan

- Blade property tests:

- Mass distribution

Test method

Test equipment

Results (mass, center of gravity)

- Eigenfrequencies

Test method

Test equipment

Results (frequencies, damping)

- Strain distribution:

Test loads

Test equipment

Results (loads, deflections, strains)

- Fatigue test:

Test loads (how derived, which areas are tested)

Test equipment

Results (loads, deflections, strains, damage)

- Static test

- Post Mortum test

- Conclusions

Final report

- Objectives

- Description of blade

- Description of design loads

- Abstract of main characteristics / results of separate tests

- Comparison of: test loads, test result,....

- Recommendations 


\section{Blade numbers}

\begin{tabular}{ll} 
Setnr. /Bladenr. & Laboratory \\
\hline $22 / 65$ & ECN p/a TU Delft \\
$22 / 66$ & NREL, USA \\
$22 / 67$ & NREL, USA \\
$24 / 71$ & CRES, Greece \\
$24 / 72$ & CRES, Greece \\
$24 / 73$ & TU Delft \\
$27 / 81$ & Risø, Denmark
\end{tabular}

The blade properties of each blade, like mass, centre of gravity and balance mass as determined by Rotorline can be found on the three pages included.

$\begin{array}{ll}\text { setnummer } & \text { set number } \\ \text { Balanceergegevens } & \text { balancing data } \\ \text { Prod nr. } & \text { Production number } \\ \text { blad nr. } & \text { blade number within the set }\end{array}$

The mass of the blade and centre of gravity were determined by weighing with two loadcells, one at the flange and one at $\mathrm{L}=9.5$ meter.
F1 flens $(\mathrm{kg})$
$\mathrm{F} 2 \mathrm{~L}=9.5(\mathrm{~kg})$
mass measured at the flange
F totaal stat mom (kgm) mass measured at $L=9.5$ the total weigth $\mathrm{Zp}(\mathrm{m})$ statical moment centre of gravity in meters from flange

The last four columns are of the balanced blade.

corr. stat. mom. the statical moment after balancing balanceer massa $(\mathrm{kg}) \max 9.5$ balancing mass, this mass may maximally be $9.5 \mathrm{~kg}$ One blade in the set does not get extra mass this is indicated with:"geen balan. massa" corr. Zp (m)

Eind massa the centre of gravity after balancing blade mass plus balancing mass

Geometrische gegevens geometrical data

\section{Columns:}

1. " $\mathrm{L}=$ ": gives a radial position in meters.

2. "gemeten": gives a measured value in mm from which the local angle is calculated.

3. "wrongafw.": the difference between the theoretical angle and the actual angle.

4. "nominaal": gives the theoretical angle.

5. "werkelijk": gives the measured angle.

6. Indicates whether or not the measured difference is within the limits.

Grootste wrongverschil in rotorset:

Per radial position the largest deviation between the measured angles in a rotorblade set is given. This difference may maximally be $0.5^{\circ}$

Geometrie-overzicht: this is a plot with the measured local twist angles for the three blades

Location of balance weigth:

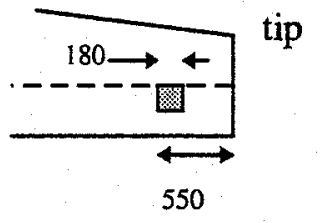




\section{Explanation of terms in design documentation}

\section{Jeroen5: "Laminaatopbouw Nedwind 25m/250"}

80 in cilindrische deel

achterkast

detail

doorsnede

glasbreedte

idem

"inklemming" sterktebaan met afstroomzijde

laag

malrand

nominaal

schaal

staart laminaat

tiplaminaat

tot 15 in de tip

type glas

versch.

verscherving

Verscherving sterktebaan complex (schematisch excl. "inklemming" neus en staartlaminaat), decrease of laminate of the complex strengthlayers (schematic, meaning excluding the overlap of nose and tail laminate)

Verschuivingsrichting staartlaminaat

vullaminaat
80 in the cilindrical part

part between the beam and the trailing edge

detail

cross-section

glasswidth

the same

clamping of the strength layer by the trailing edge

laminate

layer

edge of the mould

nominal

scale

tail laminate

tip laminate

till 15 in the tip

type of glass

decrease

decrease

Jeroen6: "Glasoverzicht", J.M.P. Leeuwenberg, 20-04-93

aan

aanstroomzijde

achterk.

af

afstroomzijde

afdeklaminaat

anti krimpstroken

bladwortel

breed $\mathrm{mm}$

Complex

csm

drukzijde

einde comp.

flens

geknipt dd

gelam. dd / gelamin. dd

Glasoverzicht

glastype

hijspuntversterking

impregnator the layer is located in the leading edge

leading edge

rear section

the layer is located in the trailing edge

trailing edge

cover laminate

anti shrink layers

blade root

width [mm]

layer existing of three layers: $100 \mathrm{gr}$ mat, $2 * 150 \mathrm{gr}+/-45^{\circ}$ and $1134 \mathrm{gr} 0^{\circ} \mathrm{UD}$.

chopped strands mats.

pressure side

?

flange

cut on date

laminated on date

overview of used glass layers

glass type

hoist point reinforcement

This layer is put in the mould by a crane to position the fiber direction carefully. 


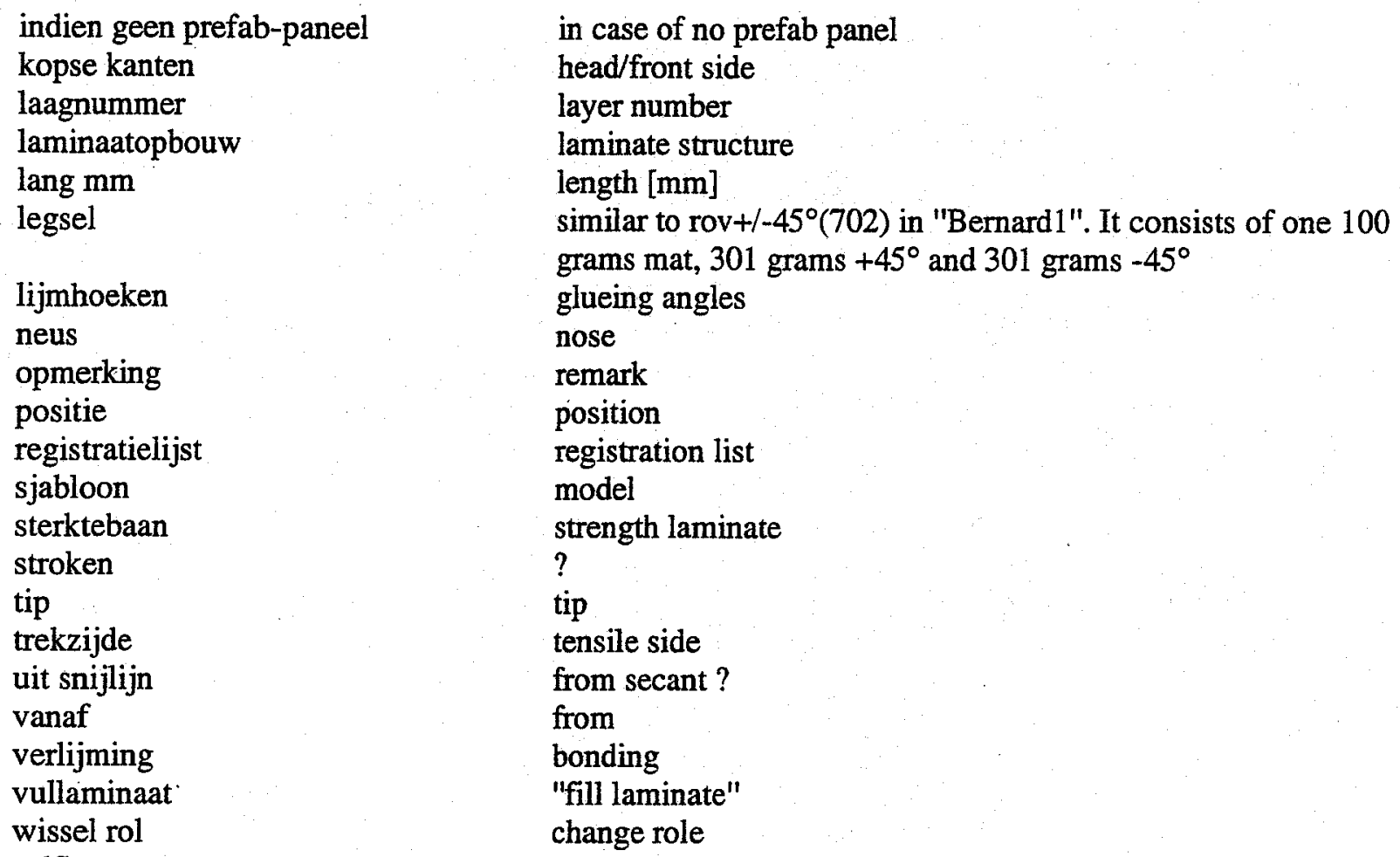

In the column "glastype" the number mentioned before the "/" is the amount of grams per square meter.

page 10:

1) layer 1 mat $225 / 10$ is only applied there where the gelcoat has also been applied. Thus not on the bonding areas

2) layer $12 \& 14$ are in the tip on the trailing edge $500 \mathrm{~mm}$ from the cutting edge to prevent too large a thickness.

4) Put the the fill laminate in the blade root until a smooth surface is formed. It may be adjusted in width

5) If in this column the remark $2 X$ is made the layer has to be applied twice and it is laminated as mat $450 / 45^{\circ}$ on the foam panel. The layers connect per set of 4 with a distance of $100 \mathrm{~mm}$.

\section{Bernard1: "Strength calculations of the NW25 rotorblade design"}

Page A1

\section{Blad lengte}

kegelhoek

tilthoek

geprojecteerd oppervlak

bladmateriaal

gewicht van een compleet rotorblad

ligging van zwaartepunt tov bladwortel

Page A2

koorde verloop (lineair)

smalste koorde (excl. afr)

breedte

radiale positie blade length

cone angle

tilt angle

projected surface (per blade)

blade material

weigth of a complete rotorblade

centre of gravity with respect to the blade root

chord distribution (linear)

smallest chord (excl. curving)

chord length

radial position 


$\begin{array}{ll}\text { profiel dikte } & \text { profile thickness } \\ \text { wrong verloop } & \begin{array}{l}\text { twist distribution } \\ \text { tip twist angle } \\ \text { totale twist hoek }\end{array} \\ \text { bladvoet } & \begin{array}{l}\text { walle root } \\ \text { wanddikte }\end{array} \\ \text { bevestiging } & \text { connection } \\ \text { bouten } & \text { bolts } \\ \text { aantal } & \text { number } \\ \text { steekcirkel } & \text { pitch diameter } \\ \text { aerodynamisch profiel serie(s) } & \text { aerodynamic profile series } \\ & \\ \text { Page A8: huidlaminaat } & \text { skin laminate } \\ \text { Page A9: bevestigingsbouten } & \text { connection bolts } \\ \text { Page A33: Massa verdeling } & \text { mass distribution } \\ \text { Page 35: lijntraagheid } & \text { products of inertia }\end{array}$

\section{Page A37 through A54}

Gives a copy of the first volume of the design report of the bladeroot. Below a very brief summary is given of some parts of the report. The bladeroot calculations have been performed by Polymarin.

Some additional figures and tables are included which is not included in the "Bernard1" report.

1. General:

Contains no information of importance to the project

\section{Structure}

Here it is described how the blade root is constructed: A pin/hole joint clamped between two

3. Geometry steel flanges. The outer flange segmented in three parts.

Here some geometrical factors are calculated:

width/diameter, edge/diameter and side/diameter. The ' means that the 21 bolts of the pin/hole connection have been considered instead of the 24 in the blade hub connection.

4. Materials and material properties

\subsection{Materials}

Flanges are made of nodular cast steel GGG40.3

The laminate in the root is glassfiber reinforced polyester consisting of $40 \%+/-45^{\circ}, 50 \%$ UD fibers and $10 \%$ randomly oriented fibers.

The bolts are quality 8.8 made of $42 \mathrm{CrMo} 4$

4.2 material properties

4.2.1 GGG40.3 according to DIN 1693

For extremes: sigma allowable: $166 \mathrm{MPa}$. Fatigue strength is taken from

Roloff/Matek giving a stress interval of $258 \mathrm{MPa}$ at a mean stress of $63 \mathrm{MPa}$ with a survival probability of $90 \%$. Assuming a normal distribution, the correction factor for $97.5 \%$ is 0.85 .

4.2.2. GVP

Two UTS's are given one based on a research project on fatigue: $240 \mathrm{MPa}$ and one based on data from NedWind giving a value of $346 \mathrm{MPa}$ for statical loads and 189 MPa for dynamical loads.

\subsubsection{Bolts}

The bolt quality 8.8 gives $\sigma_{0.2}=640 \mathrm{MPa}$ and a tensile stress of $800 \mathrm{MPa}$. The calculation value for extremes is $426 \mathrm{MPa}$. For the calculation value for fatigue values have been taken from Roloff/Matek.

\section{Loads}

No extra information 


\section{Calculation method}

First stress in the laminate is calculated Multiplying with (w/d)' gives the average plain stress in the laminate near the bolts.

The force will go partly to the flanges by friction through the bolts. For the load distribution a FEM-calculation is made.

The stresses in the steel flanges have been calculated by multipying the stressses with $(w / d)$ for the undisturbed cross section and $(w /(w-d))^{1 *} f_{c}$ for the material between the bolts. Also a stress concentration for the curvature near the hub/blade connection is calculated. In case this stress concentration factor $\left(f_{s p}\right)$ is larger than the $(w /(w-d))^{\prime} * f_{c}$ this is the most critical location.

7. Load transfer by friction

A friction coefficient of 0.12 is assumed. With a pre-stress of $15 \mathrm{MPa}$ this gives a stress reduction for the GVP of $17.5 \mathrm{MPa}$ and 14.5 MPa for the GGG.

\section{Dimensioning}

\subsection{GVP}

The stress in the laminate has been calculated with a program called MEP. The averaged plain stress just above the hole of the bolts is critical .This stress has been derived by multiplying the stres in the laminate with (w/d)' and decreasing it with the $17.5 \mathrm{MPa}$ for friction.

8.1.1. Fatigue damage

The fatigue damage hasd been calculated in two ways:

1) using UTS $=240 \mathrm{MPa}$ and the fatigue formulation: $S=U T S-B * \log N$ giving a damage of 0.64

2) using UTS and UCS of $189 \mathrm{MPa}$ and using the goodman relation, giving a damage of 0.51

8.1.2 Static calculation

The maximum stress is caused by load case 93 giving a stress of $82.1 \mathrm{MPa}$.

\subsection{GGG}

For the calculations it has been assumed that the outer flange carries maximally $76 \%$ of the loads and the inner flange carries maximally $50 \%$ of the loads.

8.2.1. Fatigue calculations

8.2.1.1 Material between the bolts

For the inner flange: $(w /(w-d))^{1 *} f_{c}=4.36$ and $f_{s p}$ is 4.08

For the outer flange: $(w /(w-d))^{\prime *} f_{c}=4.05$ and $f_{s p}$ is 4.08

The fatigue calcualtions have been performed according to NEN 2063 which is standard for welding. This standard uses the $S-n$ curve given in figure $2 . \Delta \sigma_{k}$ is taken from the Smith diagram in figure 3 , which is for $\mathrm{N}=1 * 10^{6}$ cycles. $\Delta \sigma_{\mathrm{k}}$ is calculated to be $101 \mathrm{MPa}$. This gives a damage of 0.015 for the outer flange and 0.085 for the inner flange.

The maximum stress range in the outer flange is $105 \mathrm{MPa}$ and in the inner flange 116 $\mathrm{MPa}$ both caused by load case 77 .

8.2.1.2 Material above the bolts.

Maximum stress in the outer flange : 79MPa ; maximum stress in the inner flange 66 MPa both caused by load case 72 .

\subsubsection{Static calculations}

8.2.2.1 Material between the bolts (table 8)

Outerflange: $112 \mathrm{MPa}$; inner flange $126 \mathrm{MPa}$ both caused by load case 93 .

8.2.2.2. Material above the bolts (table 7)

outer flange: $90 \mathrm{MPa}$; inner flange $78 \mathrm{MPa}$ due to load case 93.

8.3 bolts

Here the stresses in the bolts have been calculated showing that the bolts are strong enough. 


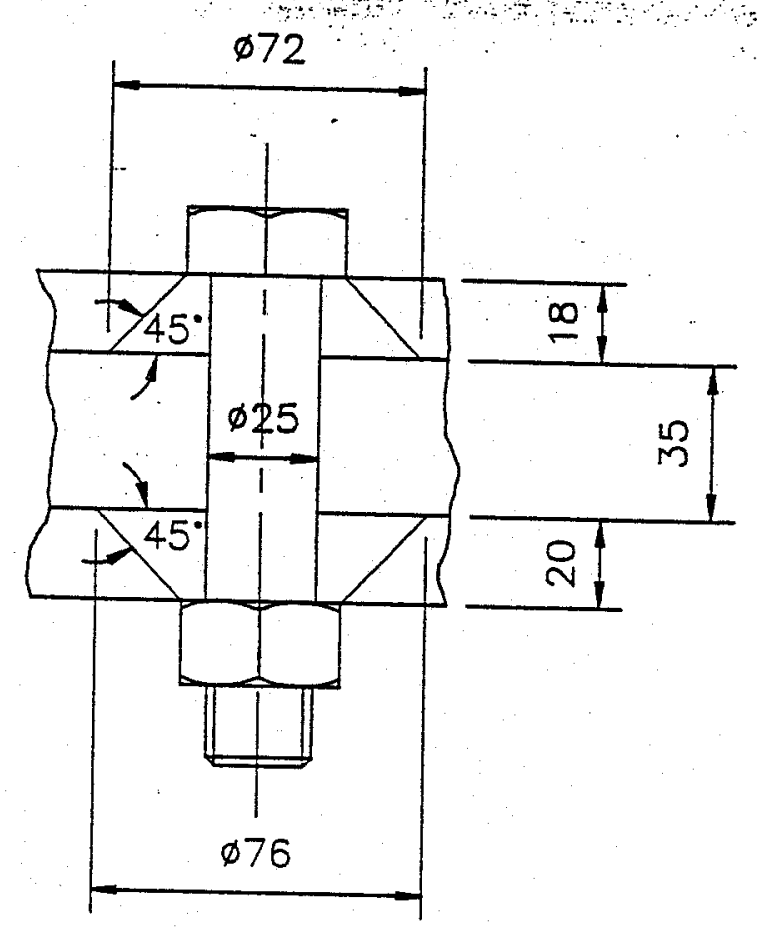

Figuur 1. Wrijvingsoppervlak pasboutverbinding.

Fiction surface qlass/stel bed connedion

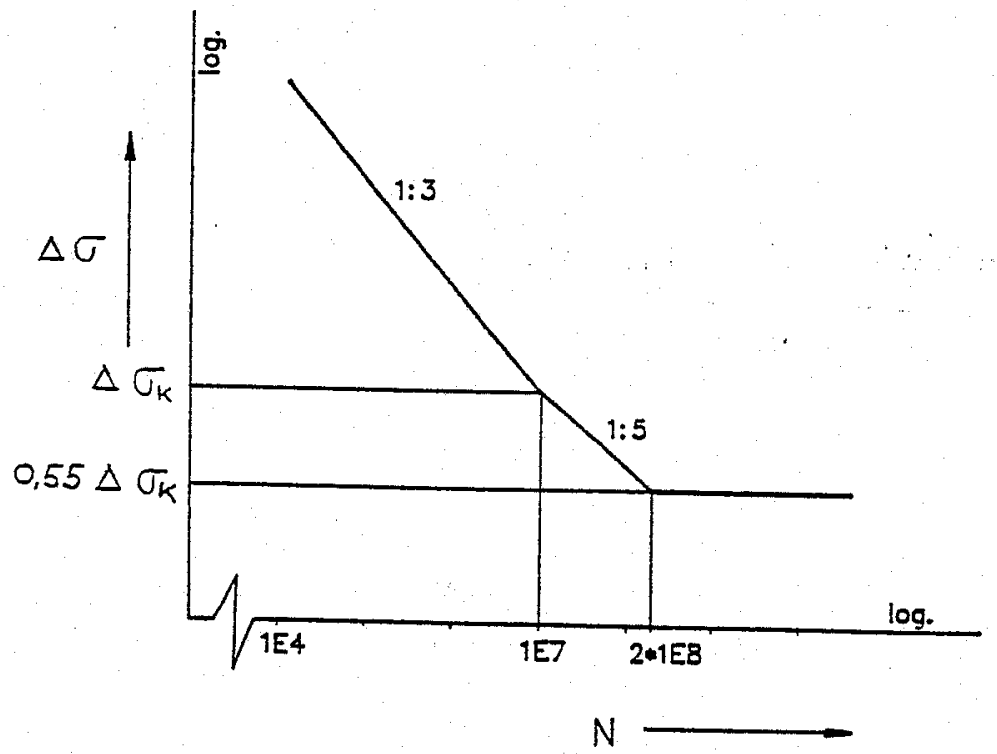

Figuur 2. $\Delta \sigma-N$ lijn 


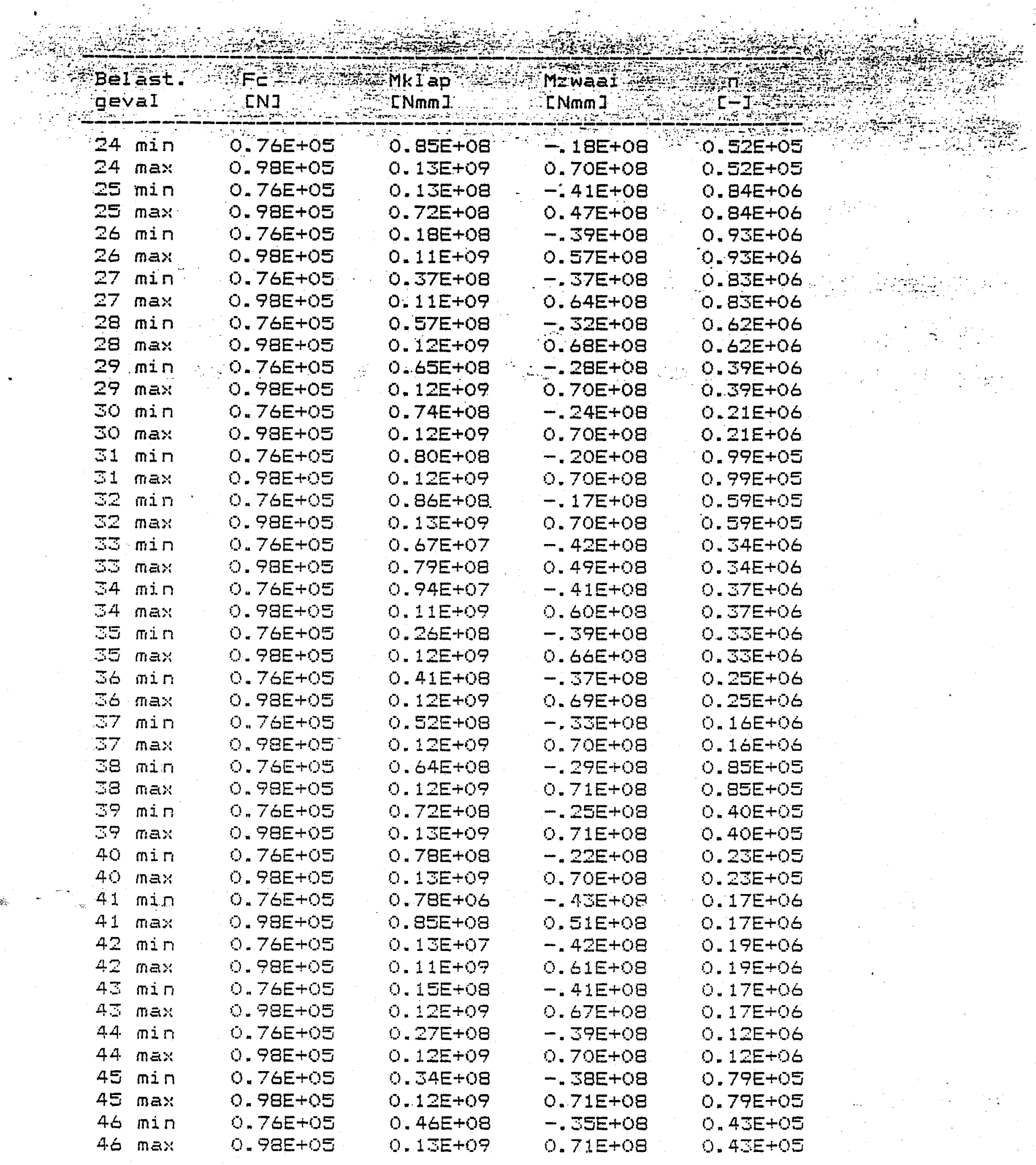

Tabel 2. Belaetinggeval $24 \mathrm{t} / \mathrm{m} 46$. 


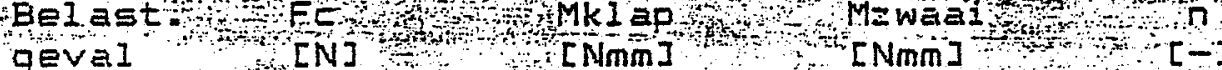
geval [N] [Nmm] $[-]$

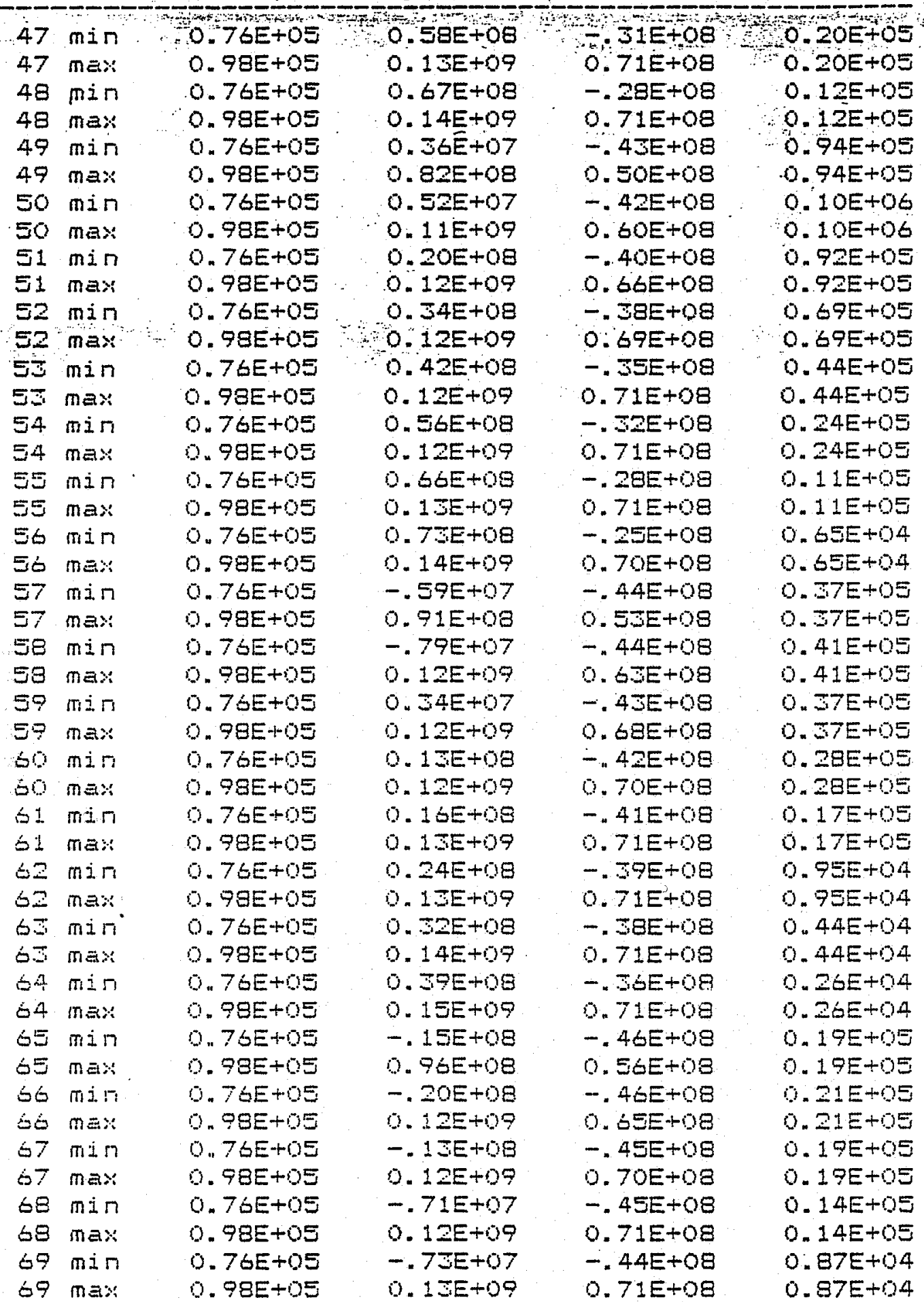

Tabe1 3. Belastinggeval $47 \mathrm{t} / \mathrm{m} 69$. 
and

:Belast a geval [N] $[\mathrm{Nmm}]+[\mathrm{Nmm}]+3]$

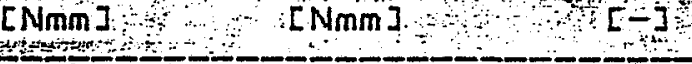

\begin{tabular}{|c|c|c|c|c|c|}
\hline 70 & $\min$ & $0.76 E+05$ & $-32 E+07$ & $-44 E+08$ & $0.47 E+04$ \\
\hline 70 & $\max$ & $0.98 E+05$ & $0.14 E+0 \%$ & $0.72 E+08$ & $0.47 E+04$ \\
\hline 71 & $\min$ & $0.76 E+05$ & $0.11 E+06$ & $-: 43 E+08$ & $0.22 E+04$ \\
\hline 71 & $\max$ & $0.98 E+05$ & $0.15 E+09$ & $0.72 E+08$ & $0.22 E+04$ \\
\hline 72 & $\min$ & $0.76 E+05$ & $0.33 E+07$ & $-.42 E+08$ & $0.13 E+04$ \\
\hline 72 & max & $0.98 E+05$ & $0.16 E+09$ & $0.71 E+08$ & $13 E+04$ \\
\hline $7 \Xi$ & $\min$ & $-.11 E+05$ & $-55 E+07$ & $-.41 E+08$ & $.77 E+04$ \\
\hline 73 & $\max$ & $0.99 E+05$ & $0.73 E+08$ & $0.93 E+08$ & $.77 E+04$ \\
\hline 74 & min & $-.11 E+05$ & $-.13 E+0 \theta$ & $-.42 E+08$ & $.85 E+04$ \\
\hline 74 & $\max$ & $0.99 E+05$ & $0.92 E+08$ & $0.93 E+08$ & $0.85 E+04$ \\
\hline 75 & min & $-11 E+05$ & $-.67 E+07$ & $-.4 \mathrm{SE}+\mathrm{OB}$ & $0.76 E+04$ \\
\hline 75 & max & $0.99 E+05$ & $0.11 E+09$ & $0.93 E+08$ & $0.76 E+04$ \\
\hline 76 & $\min$ & $-.11 E+05$ & $-.11 E+07$ & $-.44 E+08$ & $0.57 E+04$ \\
\hline 76 & $\max$ & $0.99 E+05$ & $0.12 E+09$ & $0.92 E+08$ & $0.57 E+04$ \\
\hline 77 & min & $-.11 E+05$ & $-.85 E+05$ & $-.44 E+08$ & $0.36 E+04$ \\
\hline 77 & $\max$ & $0.99 E+05$ & $0.12 E+09$ & $0.71 E+08$ & $0.30 E+04$ \\
\hline 78 & $\min$ & $-.11 E+0 E$ & $0.62 E+07$ & $-.46 E+0 \theta$ & $0.19 E+04$ \\
\hline 78 & $\max$ & $0.99 E+05$ & $0.12 E+09$ & $0.91 E+08$ & $0.19 E+04$ \\
\hline 79 & $\min$ & $-.11 E+05$ & $0.13 E+08$ & $-.46 E+08$ & $0.90 E+03$ \\
\hline 79 & Inङx & $0.99 E+05$ & $0.12 E+09$ & $0.90 E+08$ & $.90 E+05$ \\
\hline 80 & $\min$ & $-.11 E+05$ & $0.20 E+08$ & $-.47 E+08$ & $0.54 E+03$ \\
\hline 80 & $m a x$ & $0.97 E+05$ & $0.12 \mathrm{E}+09$ & $0.88 E+08$ & $0.54 E+0$. \\
\hline 81. & min & $0.76 E+05$ & $0.2 S E+0 Q$ & $-.39 E+08$ & $.76 E+08$ \\
\hline 81 & $\max$ & $0.98 E+05$ & $0.49 E+08$ & $0.43 E+08$ & $.76 E+08$ \\
\hline 82 & $\min$ & $0.76 E+05$ & $0.39 E+08$ & $-.34 E+08$ & $.84 E+08$ \\
\hline 82 & $\max$ & $0.99 E+05$ & $0.82 E+08$ & $0.47 E+08$ & $.84 E+08$ \\
\hline 85 & $\min$ & $0.76 E+05$ & $0.60 E+08$ & $-.27 E+08$ & $.75 E+08$ \\
\hline 83 & $\max$ & $98 E+05$ & $0.75 E+08$ & $0.57 E+08$ & $.75 E+08$ \\
\hline 84 & min & $76 E+05$ & $0.73 E+08$ & $-n .22 E+08$ & $.56 E+08$ \\
\hline 84 & $m=x$ & $73 E+05$ & $0.10 E+09$ & $0.62 E+08$ & $.56 E+08$ \\
\hline $8 \Xi$ & $\min$ & $7 \in E+O E$ & $0.77 E+08$ & $-.18 E+0 \theta$ & $.5 E E+0 \theta$ \\
\hline 85 & $\max$ & $98 E+65$ & $0.11 E+09$ & $.66 E+08$ & $0.5 E E+08$ \\
\hline 86 & $\min$ & $0.76 E+05$ & $0.84 E+08$ & $-.15 E+0 \theta$ & $0.19 E+08$ \\
\hline 96 & $m \equiv x$ & $0.98 E+05$ & $0.12 E+09$ & $0.68 E+0 \Omega$ & $0.19 E+08$ \\
\hline 87 & min & $0.76 E+05$ & $0.88 E+08$ & $-.13 E+08$ & $0.89 E+07$ \\
\hline 87 & $\max$ & $0.98 E+65$ & $0.12 E+09$ & $0.69 E+08$ & $0.89 E+07$ \\
\hline 88 & $\min$ & $0.76 E+05$ & $0.92 E+08$ & $-.12 E+08$ & $0.55 E+07$ \\
\hline $8 \mathrm{~B}$ & $m \equiv \lll$ & $0.98 E+05$ & $0.12 E+0 \%$ & $0.69 E+08$ & $0.5 .3 E+07$ \\
\hline 69 & min & $0.76 E+05$ & $0.18 E+08$ & $-.41 E+0 \theta$ & $0.32 E+0 \theta$ \\
\hline 39 & $m \equiv x$ & $0.98 E+05$ & $0.26 E+08$ & $0.41 E+08$ & $0.32 E+08$ \\
\hline 90 & $\min$ & $0.76 E+05$ & $0.53 E+08$ & $-.21 E+08$ & $0.23 E+07$ \\
\hline 90 & $\max$ & $0.98 E+05$ & $0.16 E+07$ & $0.67 E+08$ & $0.2 B E+0 ?$ \\
\hline 91 & min & $0.00 E+00$ & $0.00 E+00$ & $0.00 E+00$ & $0.58 E+06$ \\
\hline 91 & $\max$ & $0.11 E+05$ & $0.15 E+09$ & $0.50 E+08$ & $0.38 E+06$ \\
\hline 92 & $\min$ & $-.39 E+04$ & $0.15 E+08$ & $-.46 E+08$ & $0.12 E+06$ \\
\hline 92 & $\max$ & $0.16 E+05$ & $0 . \Xi \pm E+08$ & $0.54 E+08$ & $0.12 E+06$ \\
\hline
\end{tabular}

Tabel 4. Bel astinggeval $70 \mathrm{t} / \mathrm{m}$ 92. 


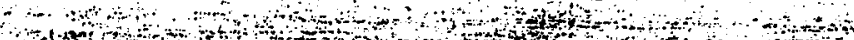

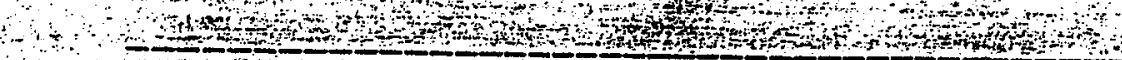

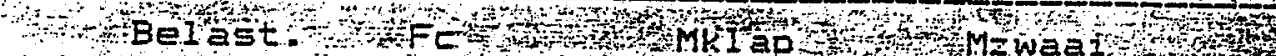

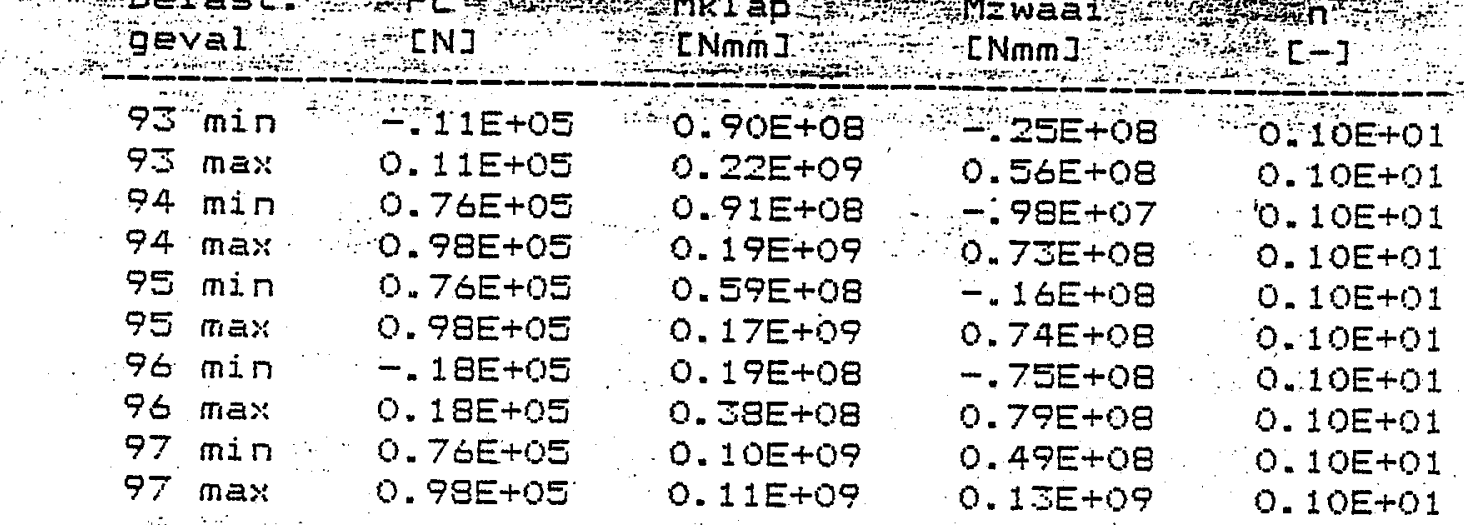

$0.98 E+05$

$0.11 E+0 \%$

$0.13 E+09$

$0.1 O E+01$

Tabel 5. Eelastinggeval $93 \mathrm{t} / \mathrm{m} 97$. 
Goadcase max compression Allowable

Belasting-14Max.druk-

Toelaatbare

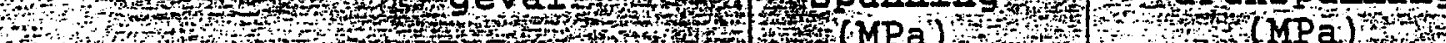

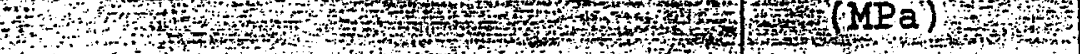

30 का

$93 \max$

82.1

$94 \max$

$95 \max$

$96 \max$

$97 \max$

$34+1$
82.1
71.6
23.5
68.1

326

326

326

326

326

Tabel 6. Max. drukspanningen in GVP onder de pasbouten. max compression stress in glass-fibe under the balts of plactic/sted connedian

\begin{tabular}{|c|c|c|c|}
\hline $\begin{array}{l}\text { Belasting- } \\
\text { geval }\end{array}$ & $\begin{array}{l}\text { Max. } \\
\text { spann } \\
\text { buitenflens } \\
\text { (MPa) } \\
\text { aden fLANGE }\end{array}$ & $\begin{array}{l}\text { aruk- } \\
\text { ing } \\
\text { binnenflens } \\
\text { (MPa) } \\
\text { mineflang }\end{array}$ & $\begin{array}{l}\text { Toelaatbare } \\
\text { drukspanning } \\
\text { (MPa) }\end{array}$ \\
\hline $93 \max$ & 90.8 & 77.8 & 166 \\
\hline $94 \max$ & 89.6 & 75.4 & 166 \\
\hline $95 \max$ & 80.4 & 67.3 & 166 \\
\hline $96 \max$ & 29.1 & 23.4 & 166 \\
\hline $97 \max$ & 77.4 & 64.0 & 166 \\
\hline
\end{tabular}

maximum compression strees in stel under the plestic/ stal-bodt connedion Tabel 7. Max. drukspanningen in GGG40.3 onder de pasbouten.

\begin{tabular}{l|r|r|r}
$\begin{array}{l}\text { Belasting- } \\
\text { geval }\end{array}$ & \multicolumn{2}{|c|}{$\begin{array}{c}\text { Max. trek- } \\
\text { spanning } \\
\text { buitenfens } \\
\text { binnenflens } \\
(\mathrm{MPa})\end{array}$} & $\begin{array}{c}\text { Toelaatbare } \\
\text { drukspanning } \\
(\mathrm{MPa})\end{array}$ \\
\hline $93 \mathrm{max}$ & 111.6 & 125.8 & 166 \\
$94 \mathrm{max}$ & 110.4 & 122.5 & 166 \\
$95 \mathrm{max}$ & 100.6 & 111.5 & 166 \\
$96 \mathrm{max}$ & 46.2 & 51.7 & 166 \\
$97 \max$ & 97.1 & 107.0 & 166
\end{tabular}

Tabel 8. Max. trekspanningen in GGG40.3 tussen de pasbouten. tonsils butives bolis 


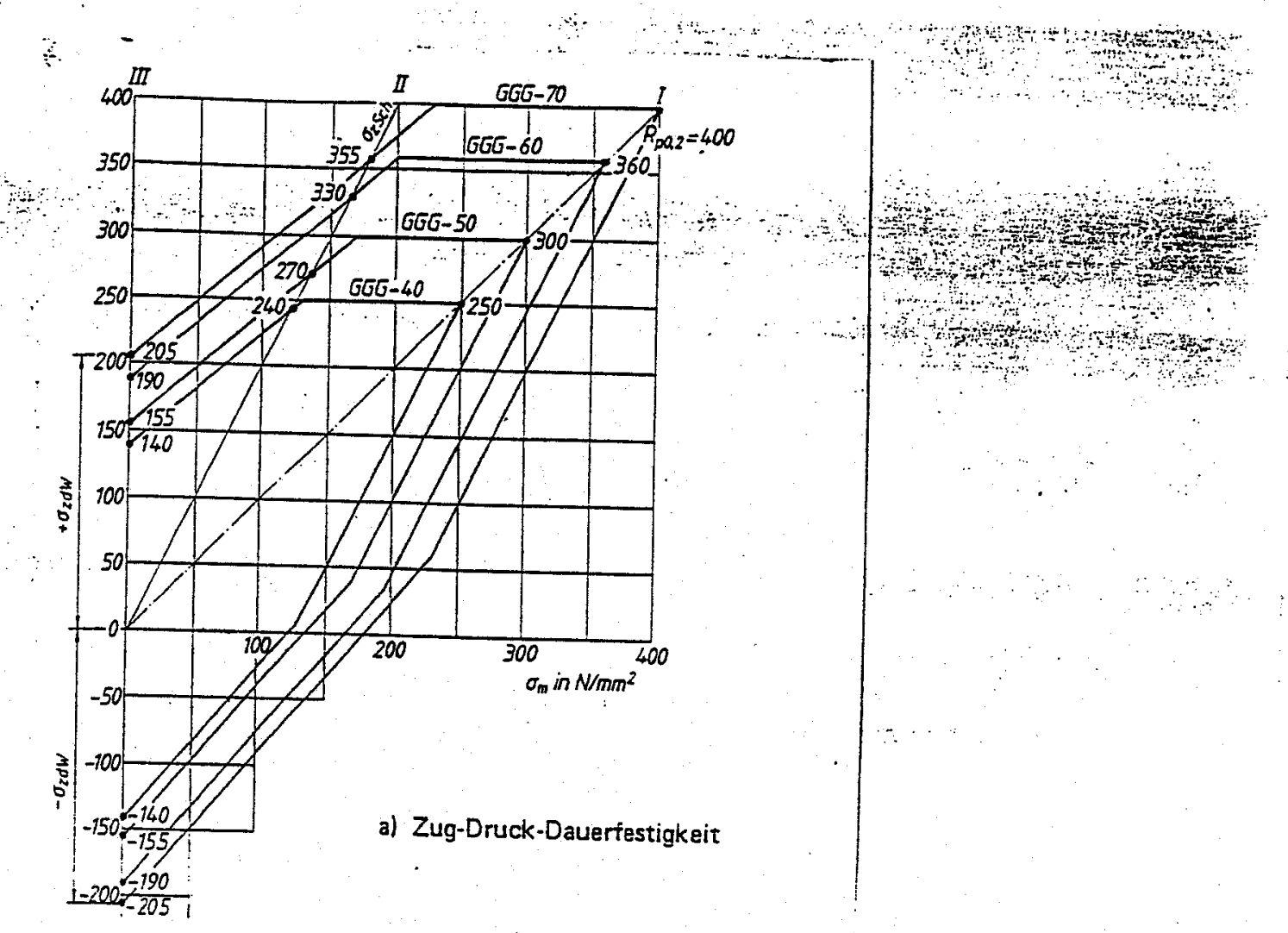

Figuur 3. Smith-diagram GGG40.3 trek/druk. Tnsild plesing

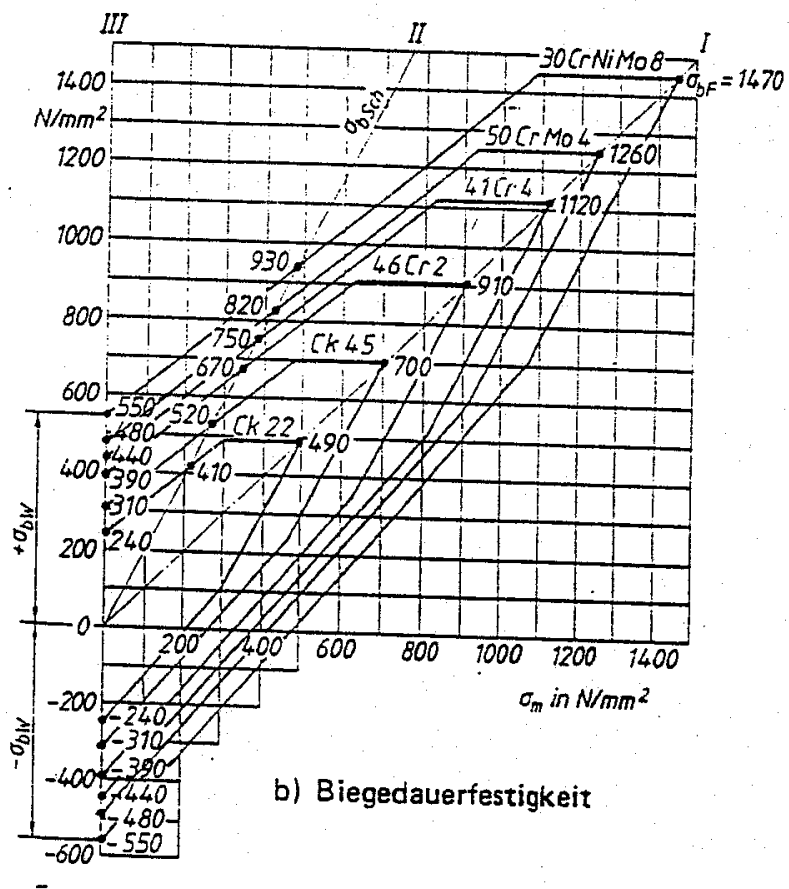

Die nicht dargestellten Vergütungsstähle können wie folgt eingesetzt werden:

34CrNiMo6

$30 \mathrm{CrMOV} 4$ wie $30 \mathrm{CrNiMo} 8$

42CrMo4

36 CrNiMo4 3 wie 50CrMo4

$50 \mathrm{CrV} 4$

34CrMo4 wie $41 \mathrm{Cr} 4$

$28 \mathrm{Cr} 4$ wie $46 \mathrm{Cr}_{2}$

$\mathrm{C} 45$ wie $\mathrm{Ck} 45$

$\mathrm{C} 22$ wie $\mathrm{Ck} 22$

$\mathrm{C} 60$ und $\mathrm{C} 50$ liegen etwa zwischen

$\mathrm{CK} 45$ und $46 \mathrm{Cr} 2$.

$\mathrm{C} 40,32 \mathrm{Cr} 2, \mathrm{C} 35, \mathrm{C} 30, \mathrm{C} 25$ liegen etwa zwischen $C_{k 22}$ und $C k 45$.

Figuur 4. Smith-diagram 42CrMo4 buiging.

$$
\text { Eeromia }
$$




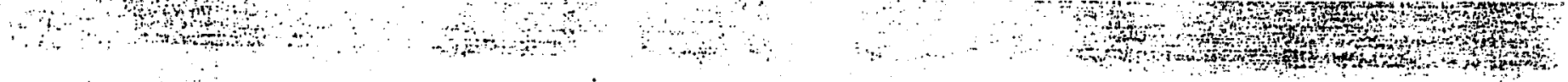

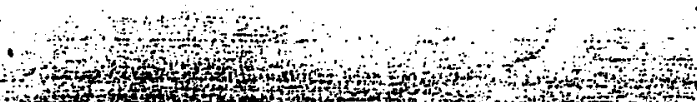

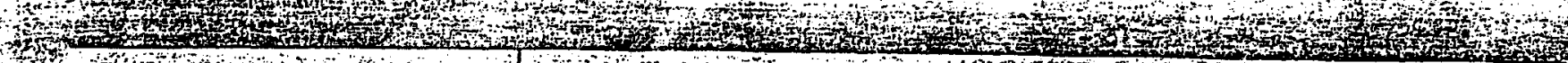

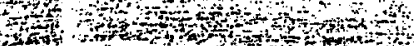
(1)

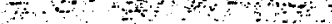
Fo

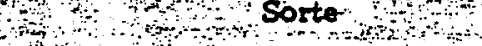
a

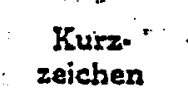

Werkstoff: nummer

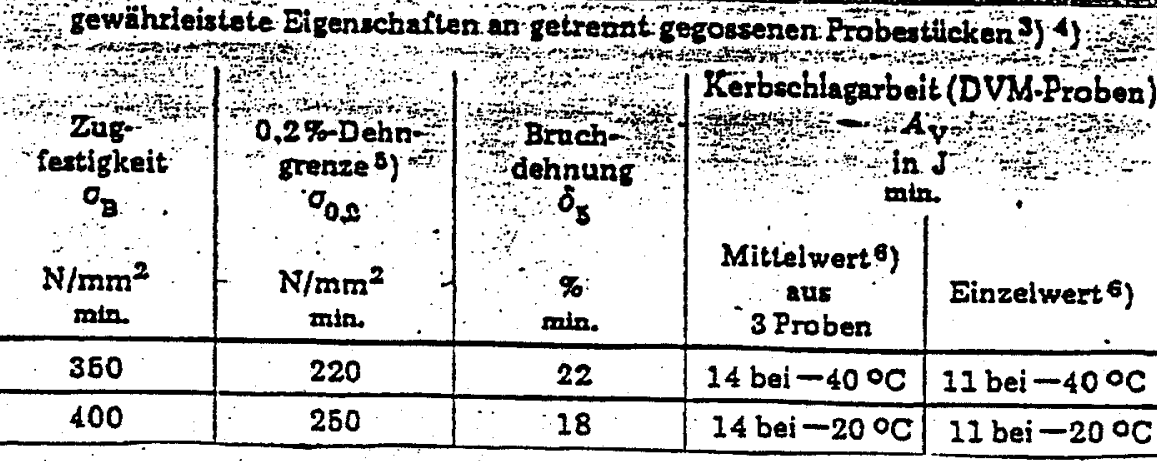

Tabel 9. Mechanische eigenschappen GGG40.3

GGG-35.3

0.7033

0.7043

How

Mutranid procentes

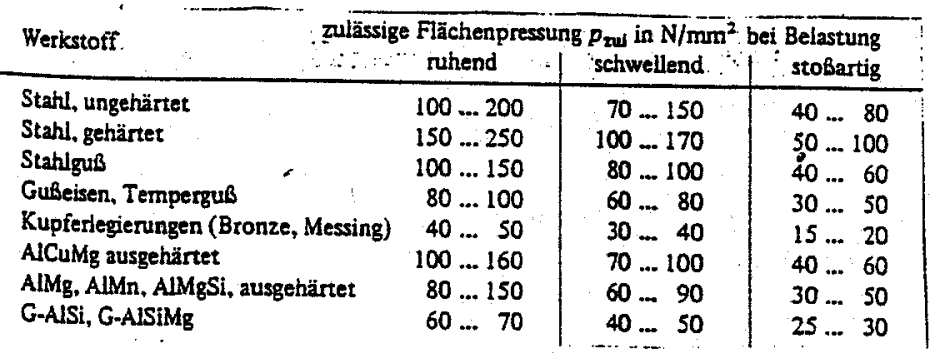

Tabel 10. Toelaatbare vlaktedruk gietijzer.

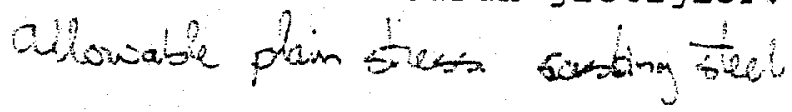




\section{Larwood, Scott}

Trom:

ent:

To:

Subject:
Bernard Bulder [bulder@ecn.nl]

Wednesday, December 09, 1998 8:42 AM

'SMT Distribution'

[98] [Fwd: Strain gauge location \& Project plan]

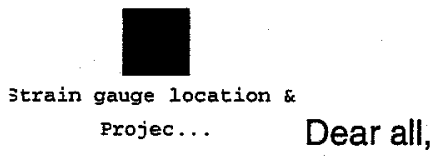

I received a strain gauge position measurement document

from Cres. I noticed today that I have to redistribute

this to all partners. Due to the fact that the email

addresses from Cres members did change the distribution list did not work well.

Sorry for this delay.

Kind regards,

Bernard Bulder

Netherlands Energy Research Foundation ECN

Unit Renewable Energy, section Wind Energy

tel. $+31(0) 224564102$

' $7 x .+31(0) 224563214$

mail: bulder@ecn.nl 
From:

ent:

To:

Subject:
Vassilis Kolovos [vkolov@cress.gr]

Monday, December 07, 1998 8:14 AM

bulder@ecn.nl

Strain gauge location \& Project plan

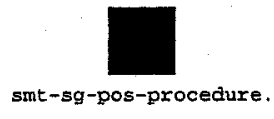

doc

Dear Bernard,

Since I don't know if the e-mails I sent, regarding the strain gauge location measurenment procedure\& Project plan, have been distributed via the mailbox, I am sending to you just to make sure they will be distributed.

1. Attached is the procerure, in Word97 format, for measuring the (common) strain gauge positions. It is in response to action $\mathbf{5 . 0 5}$

2. Regarding the project planning, the best we can do at CRES is to start the second fatigue test on 1st April

with an end date the 31st of May. According to the project planning you have produced, the finish data in this case appears to be the 5th of June. I ' $\mathrm{m}$ affraid this is the only realistic dates, in whics case we have to take advantage of the two months deadline after the end of the for project for submitting the final reports.

Best Regards,

, assilis Kolovos, Wind Energy Department

Center for Renewable Energy Sources

19th $\mathrm{km}$ Marathonos Av.

GR-190 09 PIKERMI, GREECE

Tel:+30-1-6039900

Fax:+30-1-6039905 


\section{STRAIN GAUGE POSITION MEASUREMENT}

The purpose of this procedure is to establish a common reference system for the measurement of the strain gauge positions among the partners of the project.

\section{Reference System Definition}

The radial position of the strain gauges, i.e. along the longitudinal (pitch) axis of the blade, is referenced with respect to the flange (root) separation plane.

The circumferencial position of the strain gauges is referenced with respect of the trailing edge of the blade assigned as the starting point with measuring direction along the pressure side of the blade.

\section{Root hole notation}

Having positioned the blade horizontally with the tip cord perpendicular to the ground and trailing edge upward, there are two hammer markings on the flange of the blade. The first root hole (bolt) toward the pressure side of the blade is denoted as hole \#1P, and the following ones as $2 \mathrm{P}, 3 \mathrm{P}$, etc. Following the same pattern, the first hole toward the suction side of the blade is denoted as \#1S, and the ones thereafter as $2 \mathrm{~S}, 3 \mathrm{~S}$, etc.

$$
\text { obay }
$$

\section{Blade/flange bolt notation}

Having the blade horizontal with the tip chord perpendicular to the ground and trailing edge upward, the middle bolt of the upper steel segment is aligned with the trailing edge of the blade. This bolt is denoted as the "trailing edge bolt". (Alternatively, it is the fourth bolt of the upper steel segment, irrespective of which side of the segment is chosen for starting the numbering).

\section{Trailing edge line marking}

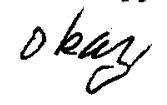

Since there is not a clear trailing edge from the cylindrical part of the blade up to the first aerodynamic section, one has to be defined and marked on the blade.

The following procedure is suggested:

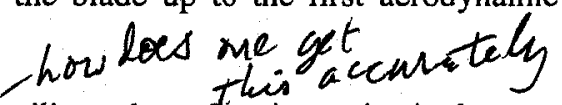

1. Mark the section being $2.10 \mathrm{~m}$ distance from the flange on the trailing edge. Starting point is the root separation plane at the two hammer marks spots on the flange.

2. At this location, the trailing edge is curved, hence the midpoint of this arc has to be defined. Measuring the thickness of the trailing edge with a vernier three (3) $\mathrm{cm}$ below the trailing edge, the midpoint is marked as the half of this distance, denoted as the "2.10m trailing edge spot". okay

3. Position one end of a chord at the center of the trailing edge bolt. Mark the second point at end of the strain gauge at $400 \mathrm{~mm}$ from the root, on its longitudinal axis on the trailing edge of the cylindrical part of the blade. The other end of the chord has to be the "2.10m trailing edge spot". Now the trailing edge line can be marked on the blade as the projection of this chord on the blade surface. (The trailing edge line should pass through/from strain gauge on the trailing edge of the cylindrical part of the blade at $400 \mathrm{~mm}$ from the root.) Practically, by pushing the chord on the blade surface starting from the "2.10m trailing edge spot" every ten (10) $\mathrm{cm}$, up to the trailing edge strain gauge, should yield the trailing edge line with no more that 1 or $2 \mathrm{~mm}$ discrepancy between the four labs. oblay

\section{Radial strain gauge position measurement}

1. Position the beginning of the measuring tape at the root separation plane, passing it through hole $3 \mathbf{P}$ for measuring the distance of (common) strain gauges having been glued above the beam (according to JEROEN8) on the pressure side of the blade. olsay

2. Record the distance of the strain gauge midpoint from the root separation plane. o han

For the rest of the strain gauges the procedure is the same but the reference holes are as follows:

- Gauges below the beam (on the pressure side), hole $6 \mathrm{P}$ has to be the reference bray

- Strain gauges having been glued above the beam (according to JEROEN8) on the suction side of the blade, hole $4 \mathrm{~S}$ has to be the reference ofzay

- Gauges below the beam (on the suction side), hole 7S has to be the reference

NOTE: The measuring tape has to be parallel to the pitch axis. Since the strain gauges are will not be on the line of the measuring tape, use of a right angle instrument will give the reading of the strain gauge midpoint distance from the root.

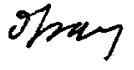




\section{Circumferential strain gauge position measurement}

\section{$>$ For section $1500 \mathrm{~mm}$ from flange:}

Starting from the trailing edge line toward the pressure side of the beam, and measuring along the already marked section, record the distance of the strain gauge midpoint (from the trailing edge line). The measuring

tape has to follow the shape of the airfoil section that the measurement is taken. dhay
$>$ For section $400 \mathrm{~mm}$ from the flange:

Starting point is the trailing edge strain gauge axis. Measuring procedure as above.

$>$ For section $2500 \mathrm{~mm}$ from flange:

Starting point is the (trailing) edge on the pressure side (since the "actual trailing edge" has a few millimetres thickness). Measuring procedure as above. rhey

\section{Comments}

Regarding the positioning of the (common) rosettes, the position of the midpoint of each individual strain gauge of the rosette has to be measured and not of the whole grid. As Scott noticed in mail[92], the make and type of the strain gauges used has to be mentioned.

I believe this is a quite simple way to be followed, and it should not introduce more than 2 or $3 \mathrm{~mm}$ uncertainty in the measured positions. If it looks vague, a set of photographs illustrating the marking procedure can be produced and distributed via the mailbox, in *.jpg format. 


\section{Larwood, Scott}

From:

ent:

To:

Subject:
J.J.D. van Dam [vandam@ecn.nl]

Thursday, February 18, 1999 9:18 AM

smt

[100] Nomeclature for common gages

smt_gages_nomen.do

c (microsoft... In the accompanying document I have made a proposal for the common gages.

E-Mail : vandam@ecn.nl - J.J.D. van Dam

ECN - Energy Research Foundation Department: ECN - Duurzame Energie, Zon \& Wind

Telephone: (+31) 224564903

Fax:

(+31) 224563214

P.O. box 1 1755 ZG Petten Country: The Netherlands

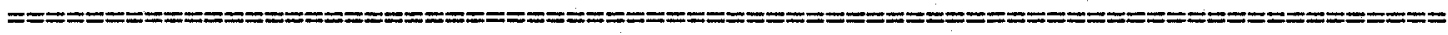




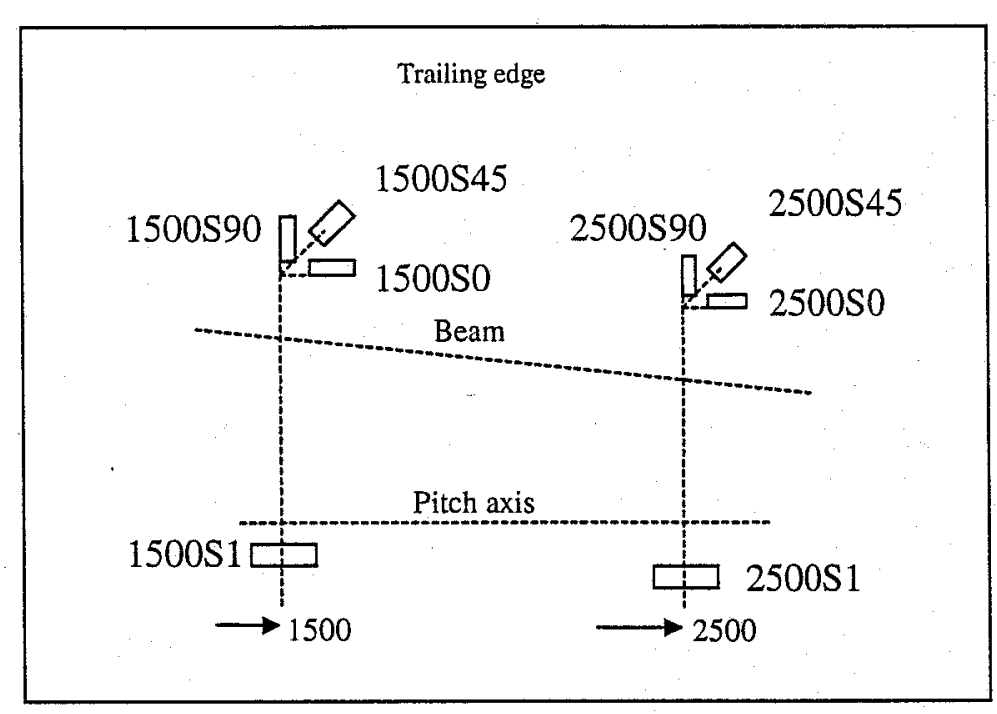

$\sin [100]$

For the pressure side the same names can be used but then with a "P" instead of an "S"

For the section at $\mathrm{R}=400$, four gages:

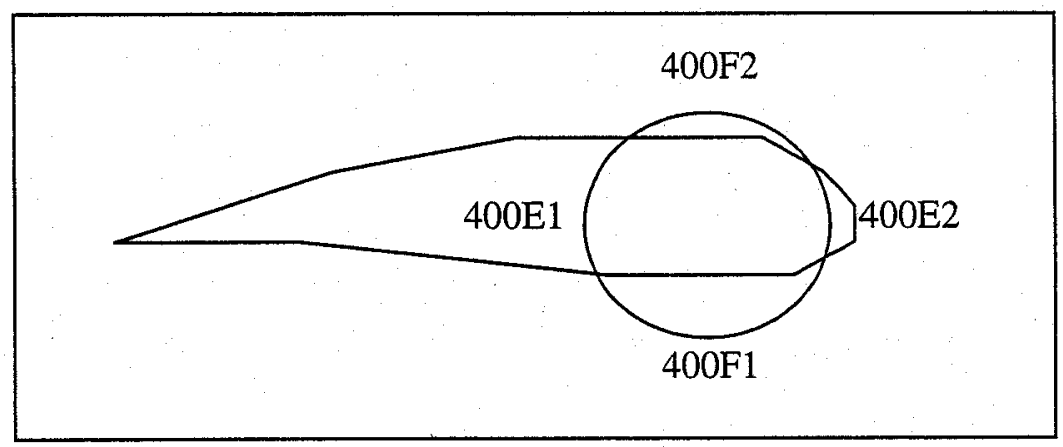


From:

ent:

ro:

Subject:
Jeroen van Dam [vandam@ecn.nl]

Tuesday, June 02, 1998 4:23 AM

smt-2-l@ecn.nl

[25] radial position, pull direction, etc.

Dear colleagues,

There was some uncertianty on the radial postitions for the loads given in the timeseries. The time series files were based on the files NW25.CMB and NW25.CSB. The radial positions for the laods in these fiels were given in the file NW25.LKB. However in Bernard1 a different version of this file is printed as in Jeroen4. We checked with rotorline which version should be used and their answer was that the radial positions in the file on the floppy disk should be used. This version was also put on the FTP-site.

Pulling direction for edgewise. The loads are given as $\mathrm{Mx}$ and $\mathrm{My}$ these are loads in the rotorplane and perpendicular to that plane. We shall assume that the tip angle is zero. Thus the loads are paralel and perpendicular to the tip chord. Edgewise = paralel, flatwise $=$ perpendicular .

Coordinate files/ points plotted in Bernard 1: Plotting these files and comparing these with the graphs in Bernard1 seems to lead to the conclusion that, if there is any difference it will be small. Thus I assumed that the points are comparable.

Deflection static test: The deflections given in email [11] were taken from a rotorline report. In that report the blade is roughly modelled in three rismatic pieces, each with an E-modulus of $25000 \mathrm{~N} / \mathrm{mm} 2$.

$\begin{array}{lll}R \text { (mm from flange) } & \text { Iflat } & \text { I_edge } \\ 0-2500 & 1.15^{\star} 10^{\wedge} 9 & 1.7^{*} 10^{\wedge} 9^{-} \\ 2500-4500 & 4.7^{*} 10^{\wedge} 8 & 1.55^{*} 10^{\wedge} 9 \\ 4500-7000 & 1.6^{*} 10^{\wedge} 8 & 8^{*} 10^{\wedge} 8\end{array}$

Roughly checking the input data does give large deviations between this model and the farob data.

Of course to get better results one could do the calculations with the farob data available and using more elements.

If required I could fax a copy of the simple-beam calculations.

Jeroen van Dam 
Crom:

ant:

ro:

Subject:

Jeroen van Dam [vandam@ecn.nl]

Wednesday, July 15, 1998 6:09 AM

smt-2-l@ecn.nl

[47] data sets

There are some differences between the data of Bernard 1 and Alex 9 . After a discussion with rotorline, Alex and I have decided that we think the following data should be used:

- UTS, UCS, E-modulus, coordinates and table I with cross-sectional properties from ALEX - 9

Meaning for the strength laminate: UTS $=372$, UCS $=260$; for the noseltail laminate UTS $=87$ and UCS $=76$. These values are without the material factors $\mathrm{C} 1, \mathrm{C} 2$ and $\mathrm{C} 3$.

E-modulus for the strength laminate $=24500$ and for noseltail $E=7000$

- SCF's, load factor and material factor from Bernard 1.

- Loads from NW25time.***

The fatigue damage mentioned in the tables on pages A15 - A22 is later corrected by the use of a correction factor which is explained on page 13 of bernard1. This is an explanation of why fatigue damage found in our models could deviate from the one found in these tables.

Vith the data mentioned above I found a fatigue damage of 0.11 on the tail $i$ the cross section at $R=3151$. Alex found a damage of 0.24 on the same point.

Jeroen van Dam 
TP-500-29103

\section{Appendix G}

Acoustic Emissions Report 


\title{
Acoustic Emission Monitoring of Static and Fatigue Tests On a Nedwind 25 Wind Turbine Blade
}

\author{
A.G. Beattie
}

\section{Executive Summary}

A Nedwind 25 wind turbine blade was subjected to both a static load test and a fatigue test at the National Wind Technology Center. Both tests were acoustically monitored with a 24 channel Physical Acoustics Corp. Spartan AT acoustic emission system.

In the static test, the blade was loaded from rest to four successively higher peak loads. These loads were $5800 \mathrm{lbs}$., $6240 \mathrm{lbs}$., $8150 \mathrm{lbs}$. and $8900 \mathrm{lbs}$. applied to a saddle fixture at station $8650 \mathrm{~mm}$ from the axis of rotation of the blade. The acoustic emission indicated at least minor damage to the bottom (tension side) of the root during the two higher loadings. On the blade upper surface (compression side), a small clustering of emission events was seen near the end of a fabric ply. All of this emission occurred at the peak load of $8900 \mathrm{lbs}$. The conclusions were that there was some damage to the root very close to the edge of the steel clamp and the possible start of a crack in the epoxy at the end of a ply on the upper surface.

The fatigue test was conducted primarily at a frequency of $1.5 \mathrm{~Hz}$ and a peak load of approximately $6550 \mathrm{lbs}$. applied to the same fixture used in the static test. In one of the preliminary setup runs, a peak load of $7400 \mathrm{lbs}$. was applied for about 400 cycles at $0.5 \mathrm{~Hz}$. This produced emission on the bottom of the blade. Emission was also located over a wide band on the top of the blade. During this preliminary test, the acoustic emission data rate from the whole blade was about 160 sensors excited per second per second. After this test, the data rate dropped to about half and remained down for approximately $1,500,000$ cycles. It then started increasing and was 250 to 350 hits per second for the last half of the fatigue test. This is expected acoustic emission behavior.

The root area generated large amounts of located emission in a band about 45degrees from the tension maximum toward the trailing edge at around 700,000 to 900,000 cycles. This was the most intense emission seen during the test but did not appear to effect the performance of the blade. Lesser amounts of emission were seen on the bottom of the root for the rest of the test with the region of maximum density rotating towards the bottom of the blade.

The top of the blade started to develop areas of high located emission density around 700,000 cycles. Five different clusters showed up during the rest of the test with some of them showing periods of increased and then decreased emission rates.

In the end, the blade did not experience structural failure so the significance of the acoustic emission data is not known. Several regions of apparently intense damage were seen but they did not result in structural failure. One has to conclude that a well designed FRP structure is extremely damage tolerant. 


\title{
Acoustic Emission Monitoring of Static and Fatigue Tests on a Nedwind 25 Wind Turbine Blade
}

\author{
Dr. Alan G. Beattie \\ Physical Acoustics Corporation* \\ PO Box 464 \\ Corrales, NM 87048
}

\begin{abstract}
:
A Nedwind 25 wind turbine blade was subjected to both a static and a fatigue test at the National Wind Technology Center near Boulder CO. This blade was acoustically monitored during both tests. The blade did not physically fail during these tests even though large amounts of apparent damage were detected by the acoustic monitoring and several physical cracks were seen in the blade. In this report, areas where there was damage detected will be listed along with the approximate test time when they occurred.
\end{abstract}

\section{Experimental Set Up:}

The acoustic instrumentation was a Physical Acoustics Corp. (PAC) Spartan AT acoustic emission system. There were twenty-four acoustic emission channels, twentythree which were used in the test. The sensors used were PAC R6-I sensors having a resonant frequency around $60 \mathrm{KHz}$ and containing integral $40 \mathrm{~dB}$. preamplifiers. The bandwidth of the sensor-preamp package is 30 to $100 \mathrm{KHz}$. A PAC $9100 \mathrm{~A}$ voltage-time gate was used restrict the acquired data to the upper $10 \%$ of the load range during the fatigue test. The Nedwind blade had its root bolted to a large fixed steel fixture. The blade tip was cut off and a saddle fixture placed around the blade at spanwise station $8650 \mathrm{~mm}$. The load was applied to this fixture by a hydraulic actuator.

Two different regions of the blade were monitored, the root region adjacent to the mounting ring and the top of the blade, about from spanwise station $2300 \mathrm{~mm}$ to station $4800 \mathrm{~mm}$. Eight sensors were applied to the root region. Two rows of four sensors were glued onto the blade with G.E. Silicone II glue. The first row (sensors 1-4) were at station $150 \mathrm{~mm}$, mounted on the outer metal clasp between the attachment bolts. The second row (sensors 5-8) were mounted at station $404 \mathrm{~mm}$ on the FRP surface of the blade. The sensors were 90 degrees apart in both rows with the rows rotated by 45 degrees from each other. Sensor 5 was on the top of the blade and sensor 7 on the bottom.

Fifteen sensors (sensors 9 to 23) were applied to the top of the blade. There were three rows of five sensors, each row running parallel to the long axis of the blade. The center row was mounted along the center line of the blade with sensors $610 \mathrm{~mm}$ apart starting a station $2335 \mathrm{~mm}$. The other two rows were parallel to the center row, $305 \mathrm{~mm}$ toward the leading edge and $305 \mathrm{~mm}$ toward the trailing edge. The overall pattern consisted of two series of adjoining rectangles. The sensors were numbered with 9 at station 2335 near the leading edge, 11 at station 2335 toward the trailing edge, 21 at station 4775 
near the leading edge and 23 at station 4775 toward the trailing edge. Sensors 18 and 21 were respectively +280 and $+255 \mathrm{~mm}$ from the center line to accommodate the blade taper.

Slightly different programs were used for analysis of two regions on the blade. The location algorithm calculated the most probable source location from the signal arrival times. An event was defined as all the sensors hit either on the blade or in the root area within a time period of 800 microseconds. For the root region, The data set used in the calculation was the arrival times of the first four sensors hit. There were no restrictions on which four sensors were hit. The use of the extra sensor in the data set means that the calculated location is the most probable location for those four arrival times. An arrival sequence of sensors $5,6,7,8$ is a legal hit sequence for a location some distance toward the tip from that row of sensors. For the root region, the surface was treated as the plane created by unrolling the cylinder. No attempt was made before the calculation to determine whether the data were consistent or not. The program contains a parameter which gives an estimate of the goodness of the fit for the solution. A solution was accepted only if this parameter indicated a relatively consistent set of arrival times and the calculated location fell within the circumferential boundaries of the root and within the blade station range of 0 to $1000 \mathrm{~mm}$.

For the region on the top of the blade, the surface was treated as a plane. The data set used was any four of the first five sensors hit which lay on the corners of one of the small rectangles in the sensor pattern. Again, the fitting criteria had to be met and the calculated location had to lie within a rectangle with dimensions $20 \%$ larger than the sensor pattern.

The experimental intention had been to use the voltage time gate to restrict the collected data to emission occurring in the top $10 \%$ of the load cycle. Unfortunately, the signal out of the load cell showed some noise and some apparent effects of blade resonances. The voltage-time gate was quite difficult to use because of the jitter on the sine wave and it became moot when the Spartan AT stopped responding to the time gate output signal. As a result, for all but two of the preliminary tests, all of the acoustic emission data was collected. This resulted in 750 Mbyte data files. The Spartan AT would stop when the file reached this size and wait until the file was removed. Thus there was quite a bit of missed data. Because of data overload and a computer mishap where an entire file was lost, it is estimated that somewhere between one half and two thirds of the three million cycles were actually acoustically monitored. However, it is thought that few, if any, trends were missed since the monitored intervals were spread through out the test.

The fatigue test showed many located events which occurred in the load range between 5000 and $6000 \mathrm{lbs}$. The peak load seen in most of the fatigue test was $6600 \mathrm{lbs}$. Since the original intention had been to ignore data from the lower $90 \%$ of the load range, the computer was programmed to discard all hits which occurred at loads below $6000 \mathrm{lbs}$. A check showed that the absence of the events occurring at lower loads, had no appreciable effect on the apparent damage patterns. 
Acoustic emission event locations on the root during the third static loading

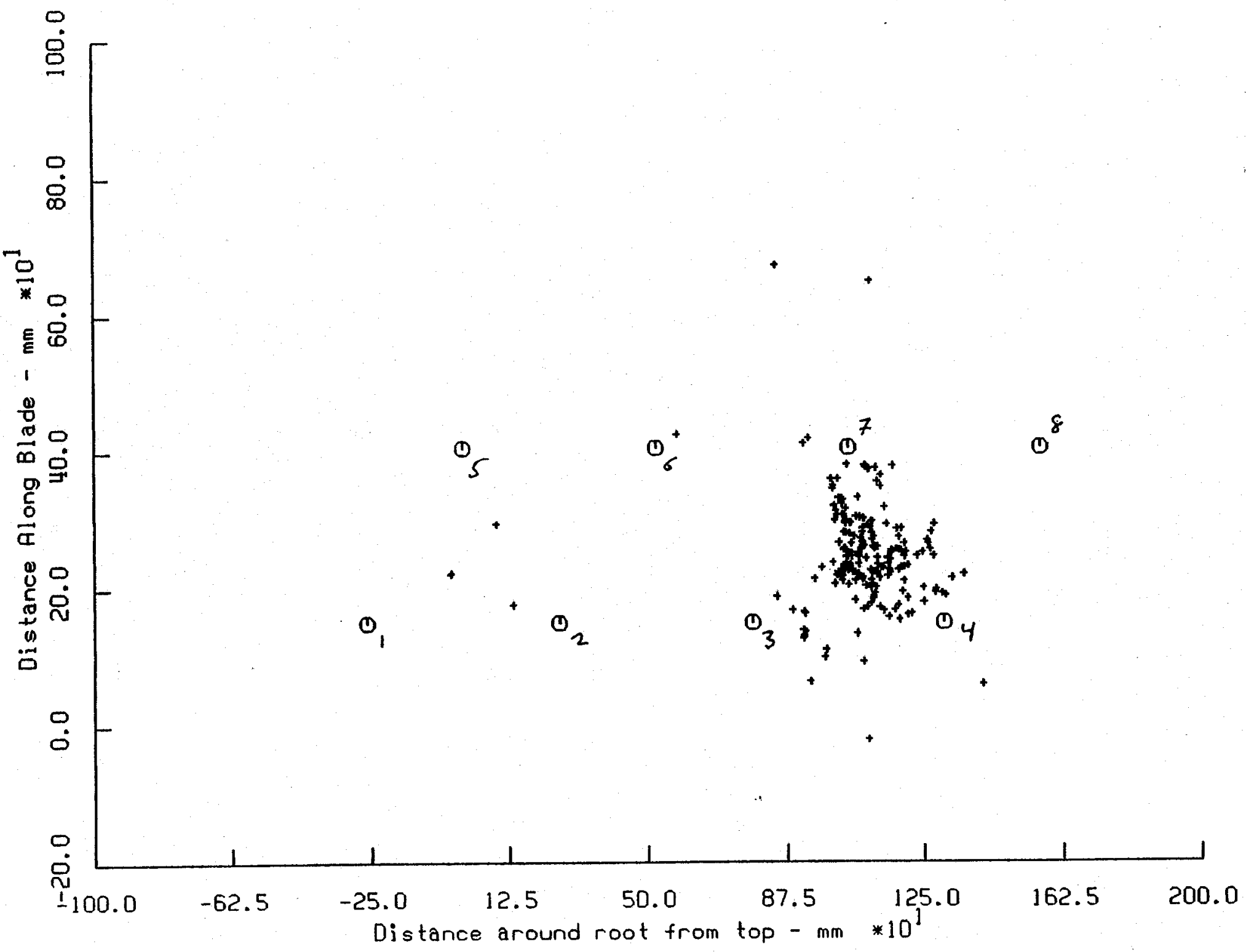

Figure 1. 
Acoustic emission event locations on the blade top during the fourth static loading

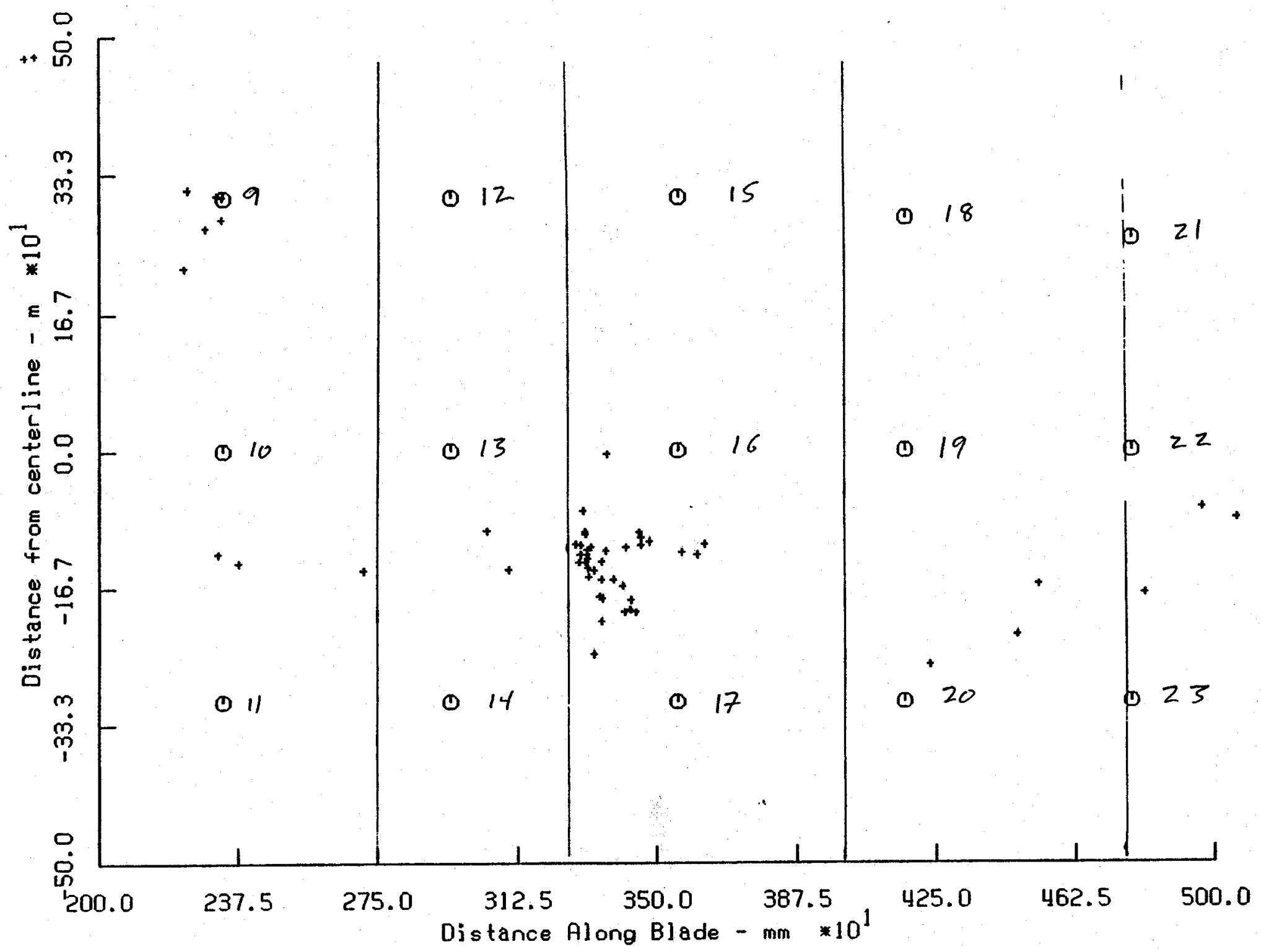

Figure 2 


\section{Static Test:}

The static load was always positive. Four separate loadings were performed. They were from 0. to 5800 . lbs., from 0 . to $6240 \mathrm{lbs}$., from 0 . to $8150 \mathrm{lbs}$. and from 0 . to 8900 . lbs. load. In the root region, some located acoustic events were seen on each loading. Events were seen on the bottom of the root in the triangle formed by sensors 3, 4 and 7 with the number of events increasing on the second and third loadings and decreasing somewhat on the fourth. On the first two loadings, a few events were seen on the top of the blade. Figure 1 shows the event map for the third loading. It is evident that some damage was occurring on the static test on the bottom of the blade. However, because of the large acoustic velocity differences between fiberglass and steel, it was impossible to determine whether the damage was occurring inside the steel mount or in the fiberglass beyond the mount.

In the instrumented region on the top surface of the blade, little emission was seen on the first two loadings. The third loading produced well scattered emission, generally between the center and rear sensor rows. A small cluster appeared in the rectangle formed by sensors 13,14,16 and 17. In the fourth loading, most of the emission was in this cluster. Examining the load values, it was found that almost all of the emission in this cluster occurred at the peak load of $8900 \mathrm{lb}$. Going back to the engineering drawings, a fiberglass ply dropout was found at approximately the location of the cluster. Figure 2 shows the located events during the forth loading. The vertical lines are the locations of the ply ends from the blade drawings.

The static test results indicated that the blade survived with only minor damage. However the cluster of events on the top of the blade at a ply dropout suggests that the onset of substantial damage near the ply dropout was starting at the peak load of 8900 lbs. A conclusion, drawn from the acoustic data from the static test is that the bottom of the root was experiencing some damage throughout the static loadings. On the top of the blade, the cluster at station $3250 \mathrm{~mm}, 150$ to $300 \mathrm{~mm}$ behind the center line indicated that around 8900 lbs. load, the fiberglass or epoxy in this region near the ply end was starting to crack.

\section{Fatigue tests:}

After the static test, the blade was rotated - degrees with the leading edge being raised. The load was applied to the same fixture, again at station $8650 \mathrm{~mm}$. The fatigue test was started on 13 October and ran into 17 November. It was shut down several times for maintenance and repair during this period. The acoustic emission system was also down for part of this period and the down time of the two systems did not always coincide. It might be desirable to tie the occurrence of features in the acoustic data to the cycle count. However, the amount of work necessary to correlate the cycle count to the acoustic time data did not appear worth while at this time. Therefore only the test day(s) over which a feature was seen will be given. The test days when acoustic data was taken were $1-8,12-15,24,25,28-30,32,33,35$. The missing file covered the period day 17-21. During some of the days not covered, the test was down for equipment repair and some of the days toward the end of the test were only partially covered when the system stopped due to a full data file.

The cyclic rate for the test began at $1.5 \mathrm{~Hz}$ and was raised to $1.75 \mathrm{~Hz}$ early in the test. This appeared to be too fast so the load rate was dropped back to $1.5 \mathrm{~Hz}$. The peak 
Acoustic emission event locations on the root during the first 500 cycles

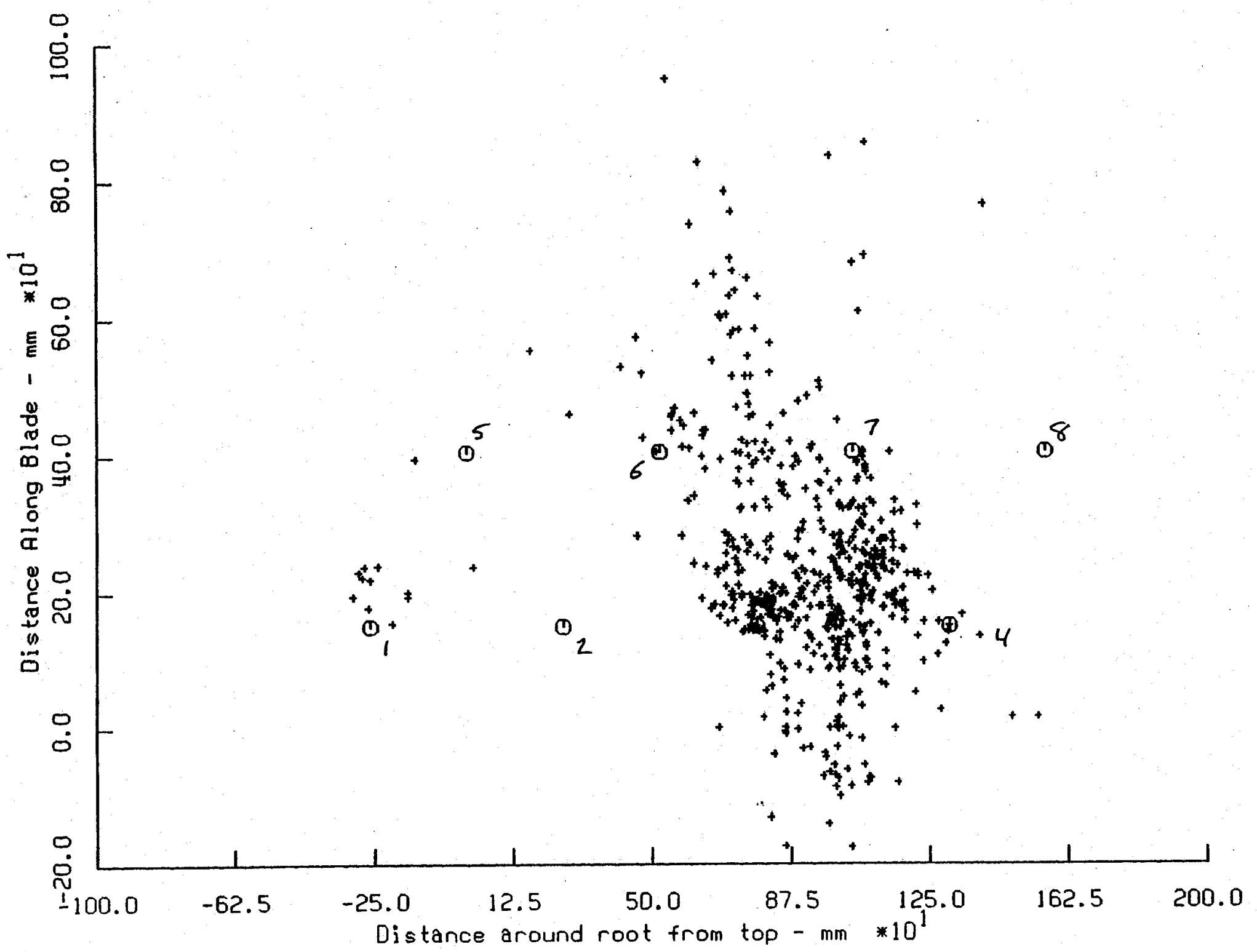

Figure 3. 
Acoustic emission locations on the blade top during the first 500 cycles

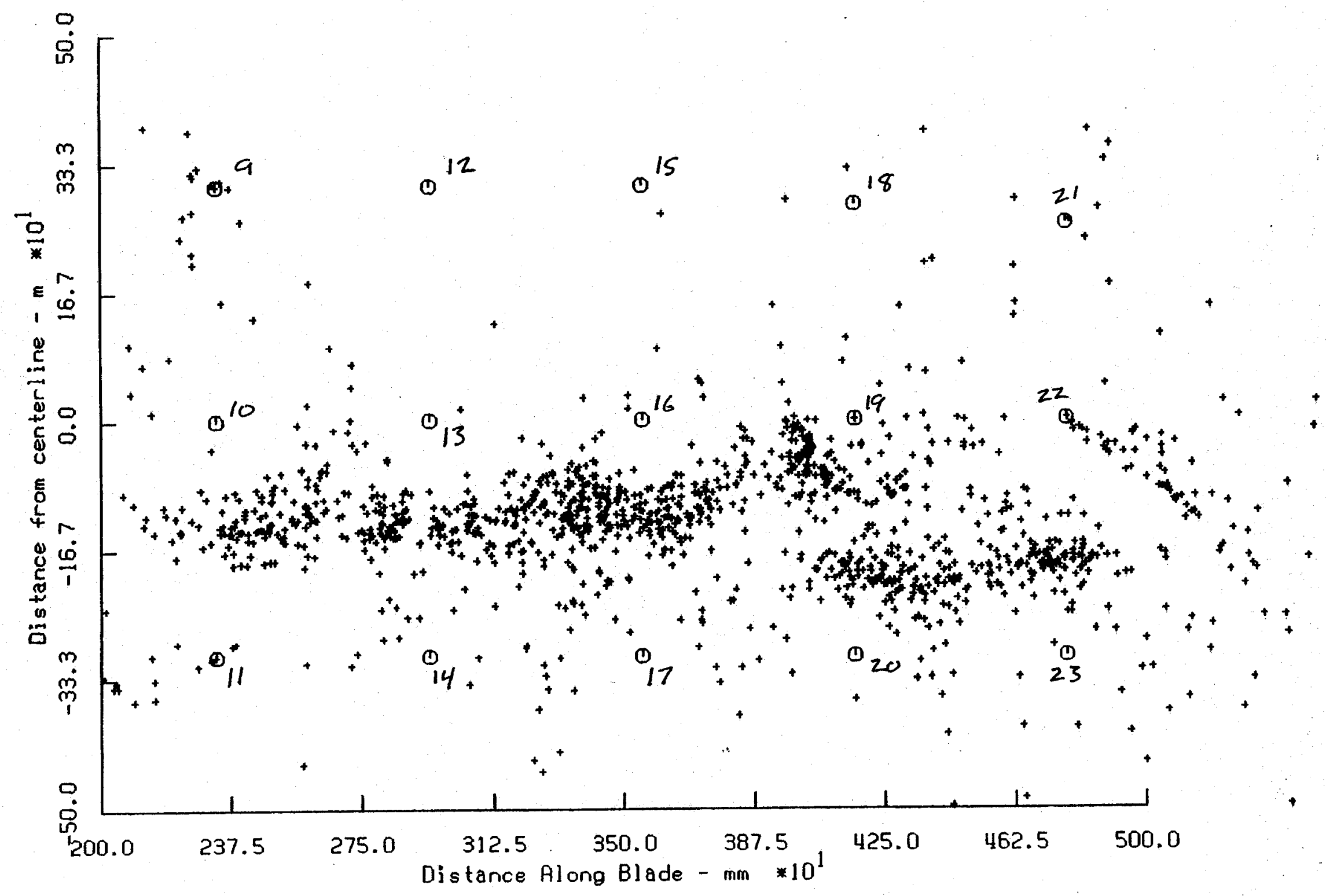

Figure 4 
load was set between 6500 an $6600 \mathrm{lbs}$. load. The exact value was hard to determine because of jitter on the load cell signal, possibly caused by low frequency resonances in the blade. Several short preliminary runs were made in order to check the functioning of the test equipment and to set the test parameters. On the second preliminary run, the cycle rate was set at $0.5 \mathrm{~Hz}$. However the peak load on this run was measured on the load cell at a maximum of $7440 \mathrm{lbs}$. This test was run for 571 cycles above $6000 \mathrm{lbs}$. load. It was not set to full load immediately. The last 400 cycles reached $7400 \mathrm{lbs}$. load during this run. For the rest of the fatigue test, the peak load did not exceed $6500 \mathrm{lbs}$.

During this preliminary run, 567 located events were seen in the root area and 1362 on the blade, an average of 1.0 events per cycle from the root area and 2.4 events per cycle from the blade. The number of hits detected averaged 160 per second. The data from the root region showed most of the emission to be located on the bottom of the blade, as shown in figure 3. Most of the apparent damage was on the bottom of the blade near end of the clamp between the steel mounting ring and the FRP. It is probable that the epoxy bond between the steel and the FRP was degrading during this run. The monitored region on the top of the blade also showed considerable located emission, shown in figure 4. A band of apparent damage is seen running the length of the monitored region between 100 and $200 \mathrm{~mm}$ behind the middle row of sensors.

After the second preliminary run, the cycle rate was raised and the peak load was reduced. Both the located emission and the hit rate ( 77 hits per second) was lower than the preliminary run for the first week of the test. Then on day 7 , a large number of locatable events were seen on the bottom of the root. Figure 5 shows these located events seen during a fifteen hour period during day 7 and 8 . These events are seen on the root about 45 degrees between the rear and the bottom of the blade. They appear to extend from about the edge of the steel clamp out to station 1000. This is the highest density of located events that was seen during the testing. The number of events located on the root decreased and then slowly increased toward the end of the test. Figure 6 shows the located events in the root region from a twenty-four hour file taken over days 32 and 33. There is again much located emission near the bottom of the root. The location of maximum emission density appears to have moved about 20 degrees towards the bottom of the root from the locations seen in figure 5.

Visual observation of the root showed that early in the test, there was a crack in the epoxy on the bottom quadrant of the root along the edge of the steel clamp. Later on this crack had spread along the edge of the clamp completely around the root. It appears that the epoxy-steel adhesive bond failed early in the test and that the FRP blade was held to the steel root mount only by the clamp and bolts for at least the last $80 \%$ of the fatigue test.

There were few located events on the blade top for the seven days following the preliminary run but those which were located spread out in the same general location pattern seen in figure 4. Then small regions of apparently dense damage start showing up. Figure 7 shows the approximate locations of these regions. Region A showed a few locations on day one at peak loads below $6600 \mathrm{psi}$. It appeared strongly during the 15 hour file over days 7-8 and then reappeared on days $25,28-30$ and $32-33$. The location suggests that the damaged area curves around the leading edge onto the lower surface of the blade. Region B first showed up as a small indication on days 12-15 and 24-25. It then appeared much stronger on days 28-30,32-33 and 35. Region $C$ was seen only on 
Acoustic emission event locations on the root during days 7 and 8

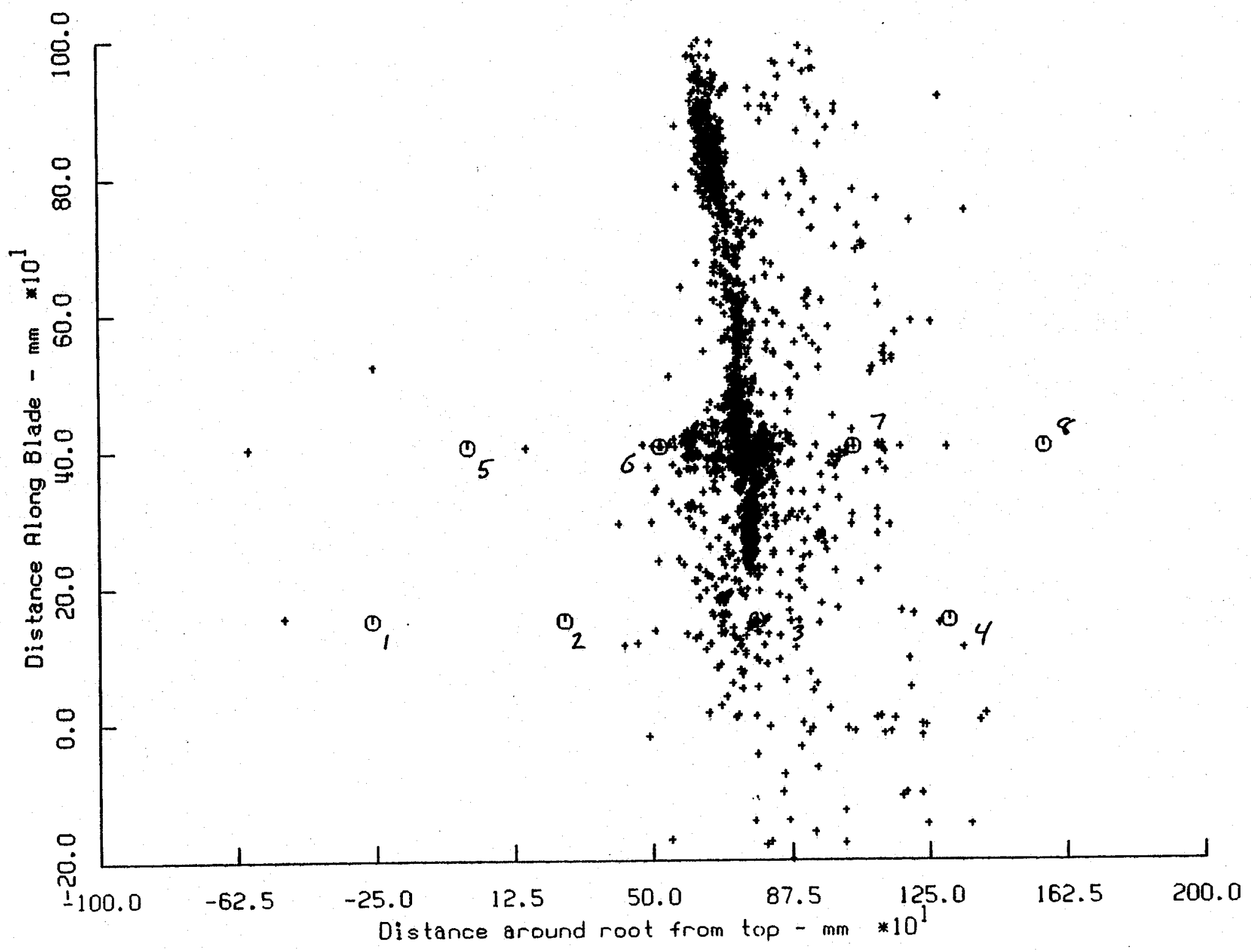

Figure 5 
Acoustic emission event locations on the root during days 32 and 33

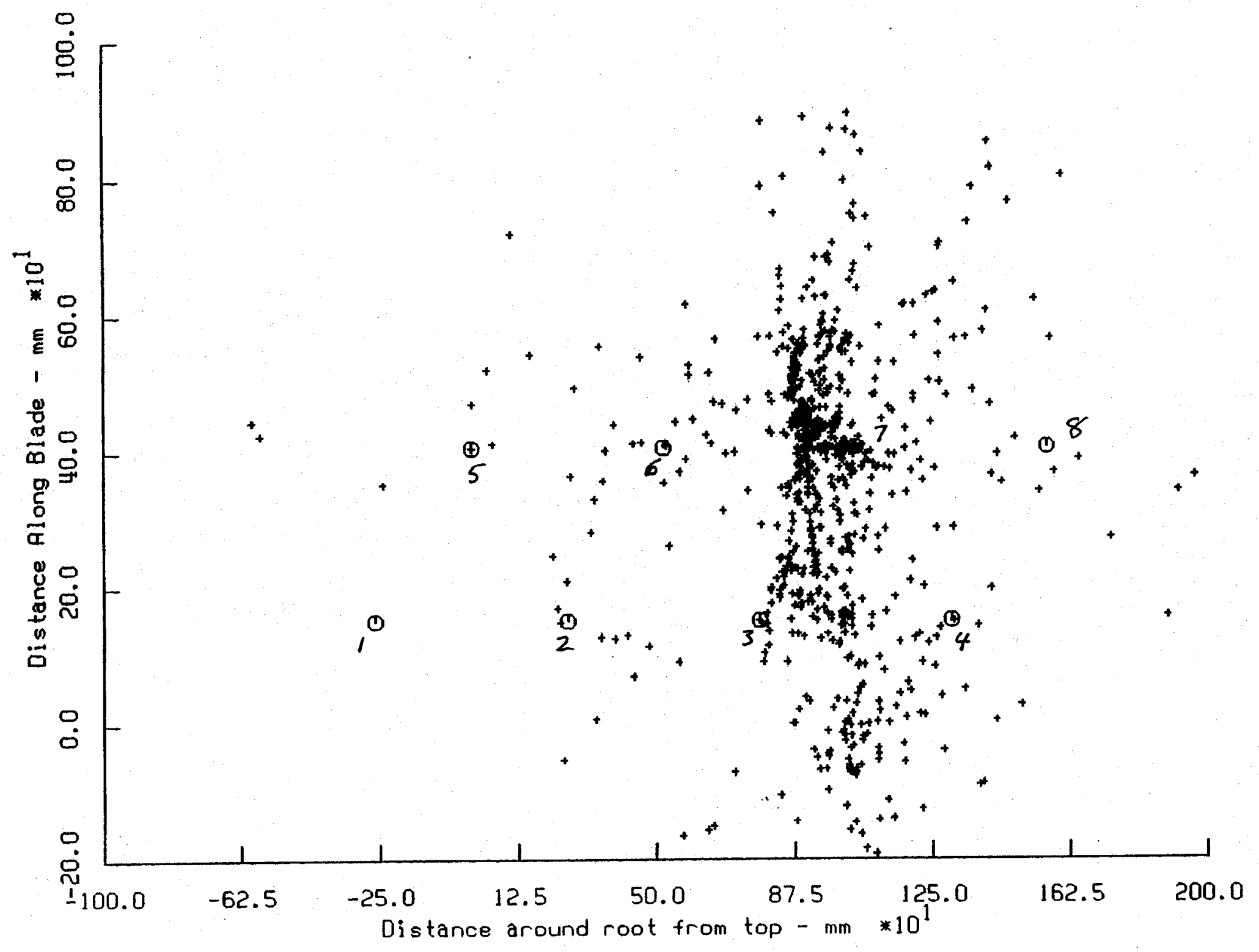

Figure 6 
Locations of damage regions on the blade top during the fatigue test

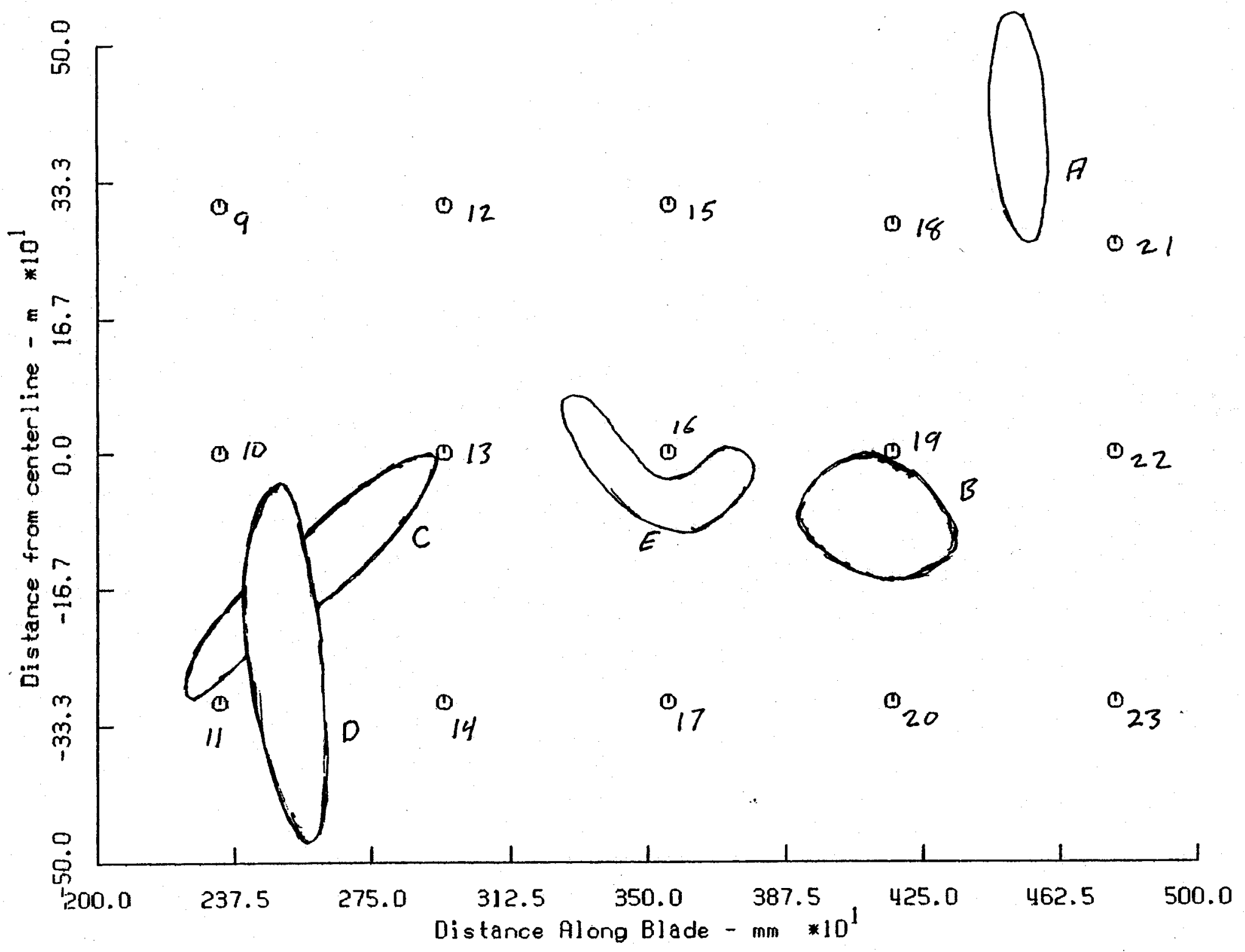

Figure 7. 
Acoustic emission event locations on the blade top during days 29 and 30

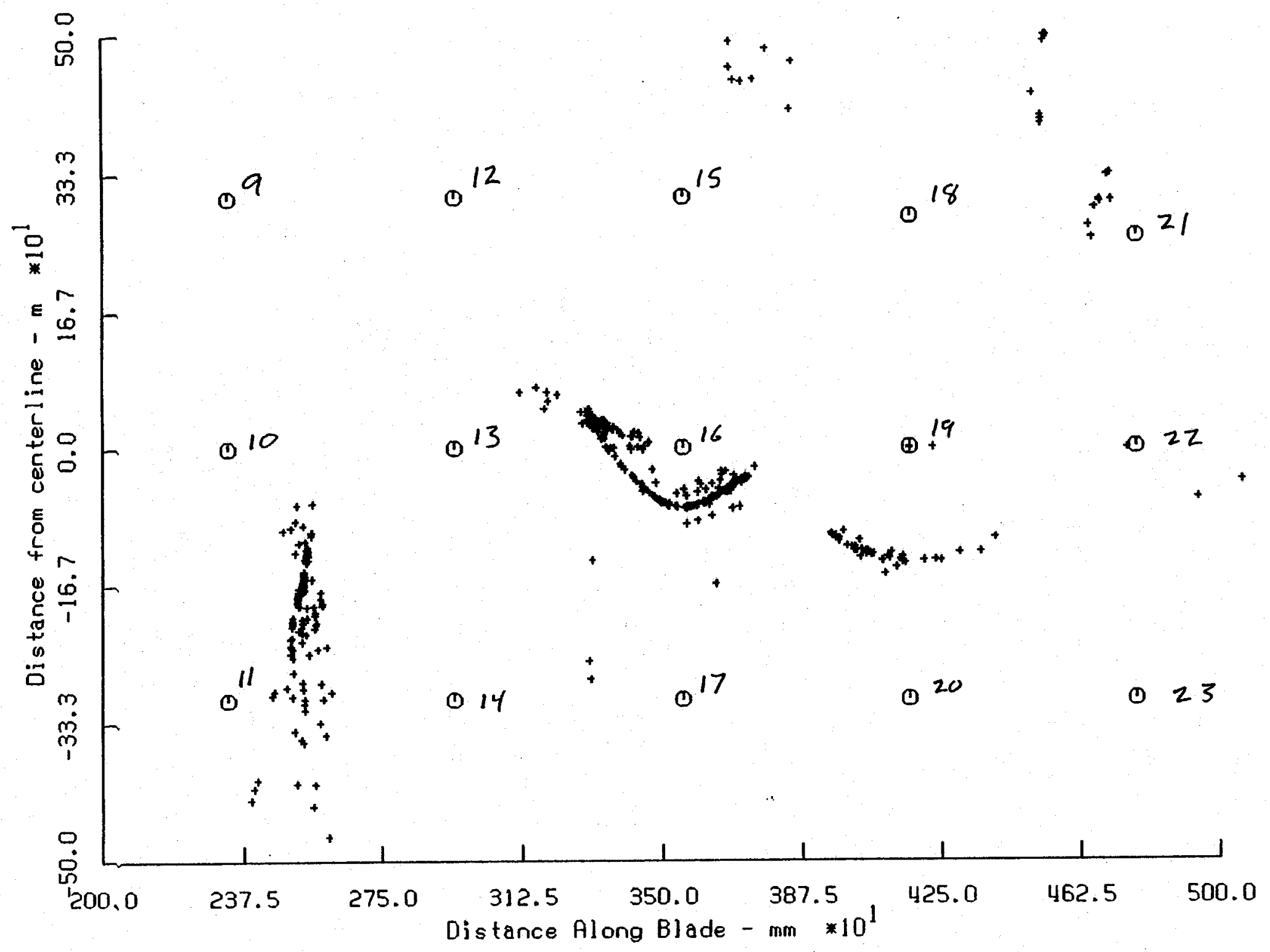

Figure 8. 
day 25 while D was seen on days $25,28-30$, and 35 . Finally, region $\mathrm{E}$ was seen quite strongly on days $29-30$ and again on day 35 . Figure 8 shows the located data from the 29 hour file starting on day 29. Locations in regions A, B D and E are seen. The unusual shapes in region $B$ and $E$ were not changed by varying the values of the fitting parameter values in the location program.

\section{Discussion}

After the initial data from the first 571 cycles, the data rate from the blade decreased by a factor of three to four. The data rate did not reach the level seen in the first 500 cycles until day 25 . It then slowly increased to about a rate of 1.5 to 2.0 times that initial rate by the end of the test. It appears that the 571 cycles at $7400 \mathrm{lbs}$. load preempted much of the damage which would have occurred at the load of $6550 \mathrm{lbs}$. for the next $1,500,000$ cycles.

The data rate in hits per second did not correlate with the rate of located events, either on the root or on the blade top. After day 25 , the hit rate was high and relatively constant through out each run. However the rate of located events for most of the runs was relatively steady for the first 10,000 seconds and then slowly dropped to zero by twenty to thirty thousand seconds, Usually a few events then showed up toward the middle or end of the run. This drop off was not caused by the lack of AE hits but by the lack of hits in the short time period which defined an event. The same number of sensors were hit over a period of several minutes, but the sensors were excited individually at random, not the 4 to 15 sensors hit within the same one millisecond time span which defines a locatable event. At the end of a run, the test was usually stopped for a few minutes to an hour while the data was transferred out of the acoustic emission system computer for storage. It is difficult to understand how a short respite from cyclic loading could restart the generation of emissions from single flaws which hit multiple sensors. This observation is included for completeness. At the moment it is not understood.

\section{Conclusions:}

The most important conclusion about this blade is that after a static test and $3,000,000$ cycles of a fatigue test, the blade was still apparently intact. The epoxy bond between the FRP blade and the root ring clamp had long since broken but the mechanical clamp was still holding the blade. A visible crack appeared on the trailing edge of the blade within the first few days of the fatigue test. At the end of the test it had shown no apparent growth.

The acoustic signature of the static test indicated that some damage occurred on the bottom of the root region and that there was damage at the maximum load near a ply end on the top of the blade. The fatigue test continued the damage at the bottom of the root region. At seven days, the acoustic data suggested that the FRP might be turning to powder on the bottom of the root. Despite this, the root region was apparently intact at the end of the test. The apparent damage during the static test at the ply end on the top of the blade was not seen in the fatigue test. Figure 9 shows a map of the first $6000 \mathrm{~mm}$ of the top of the blade, including sensor locations and areas of damage seen during the fatigue test. No gross visible indications of damage were seen in the five areas located by the acoustic monitor. The amount of acoustic emission generated and located on this 
Top of Blade showing sensor locations and areas of acoustically determined fatigue damage

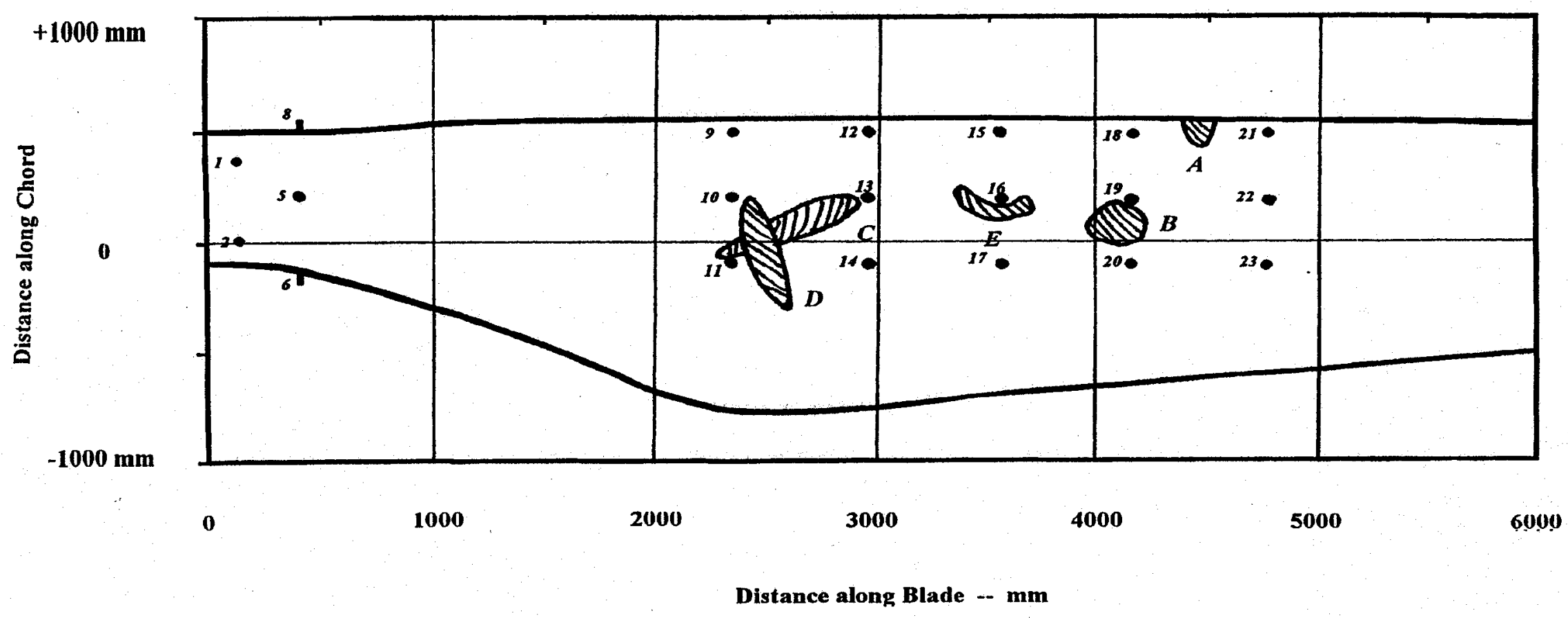

Figure 9. 
blade was extremely high. But while the blade groaned and jiggled during the test, it survived. I can only draw two conclusions from this test. 1) If the loads were a realistic emulation of field conditions, the blade was over designed. 2) FRP is an extremely damage tolerant material when designed correctly.

\section{Acknowledgement:}

This was a joint project carried out by Sandia National Lab and the National Wind Technology Center. The Wind Energy staffs of both laboratories were very helpful. I would especially like to thank Mark Rumsey of Sandia and Scott Larwood, Scott Hughes, Mike Jenks and Cynthia Szydiek of NREL for their help.

*This work was performed under contract BD-7680 between Sandia National Laboratory and Physical Acoustics Corporation. 
TP-500-29103

\section{Appendix H}

Drawings and Calibration Records

Adapter plate

Load saddle

Strain-gauge data sheets 


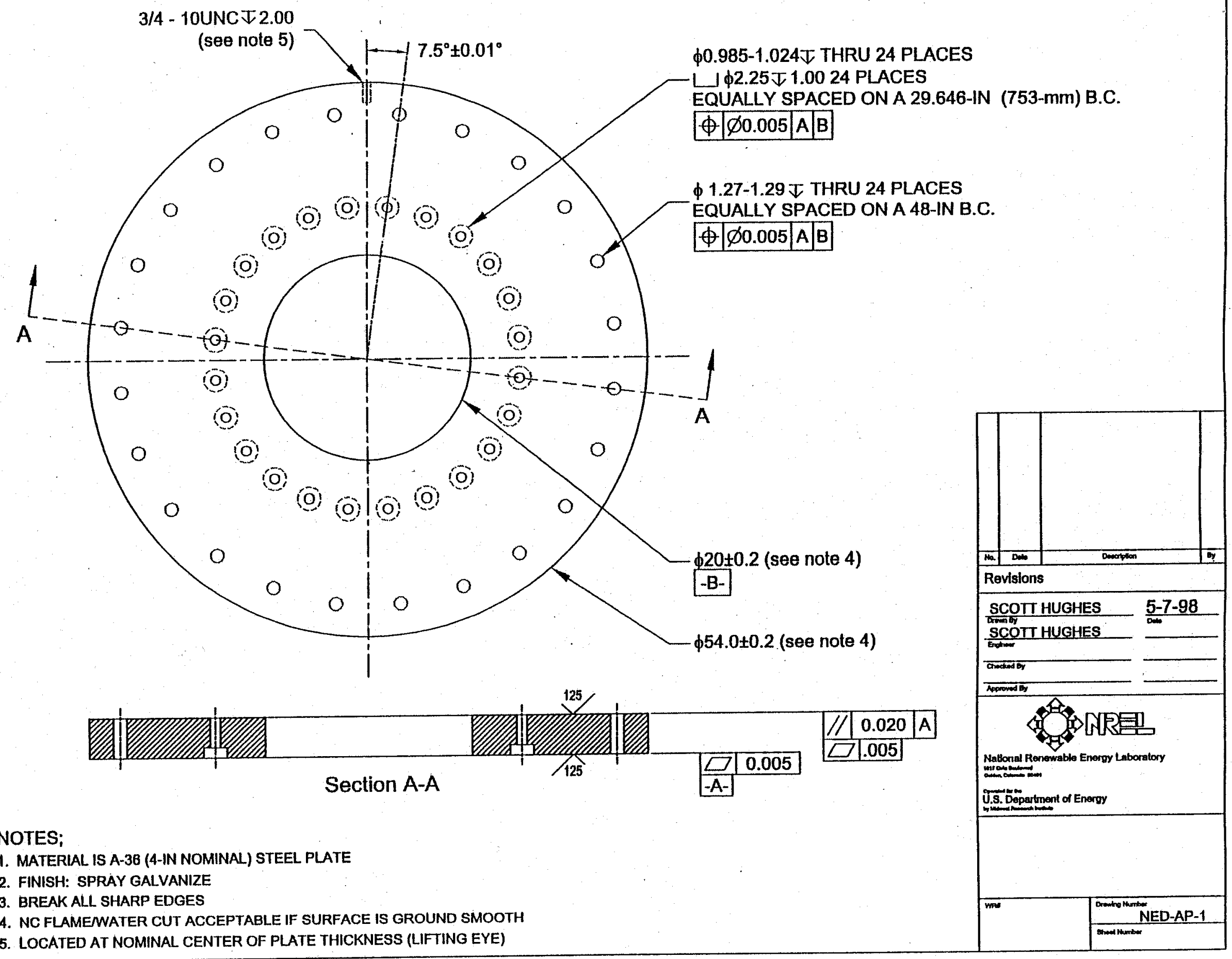

1. MATERIAL IS A-3B (4-IN NOMINAL) STEEL PLATE

2. FINISH: SPRAY GALVANIZE

4. NC FLAMEMATER CUT ACCEPTABLE IF SURFACE IS GROUND SMOOTH

5. LOCATED AT NOMINAL CENTER OF PLATE THICKNESS (LIFTING EYE) 


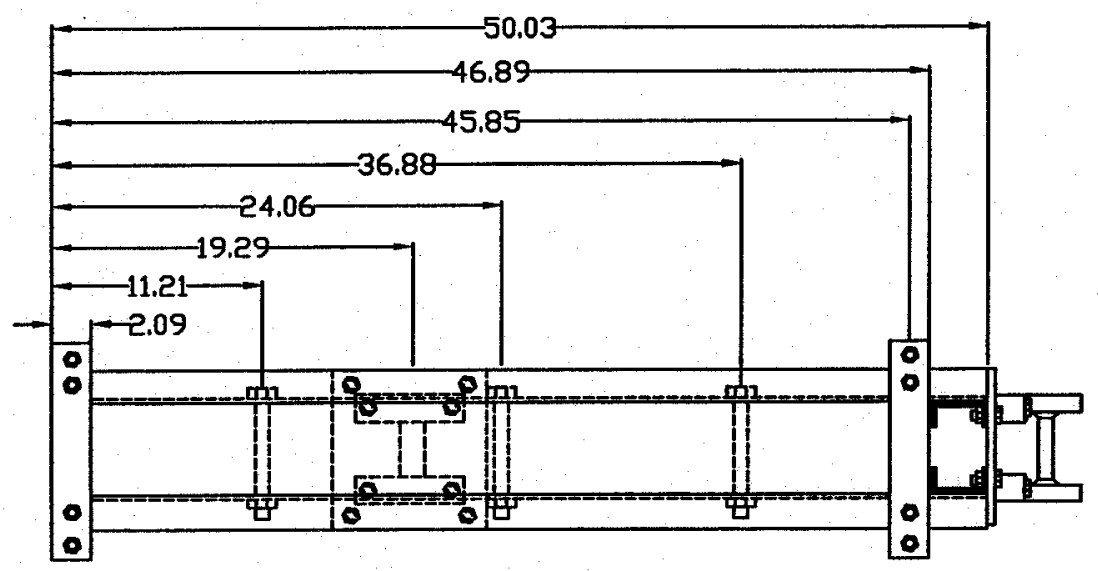

$12 \times 2 \times 3 / 4$ Inch plate drllled for 21.5 inches of $1 / 2$ Inch $b 7$ all thread
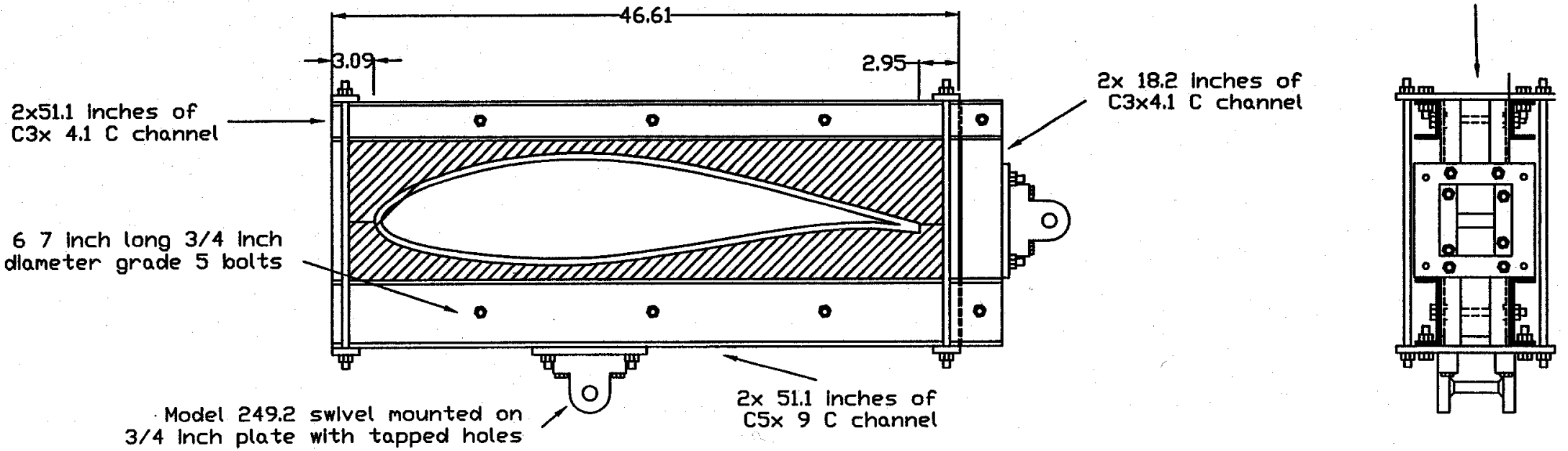


\section{EMEME ENGINEERING DATA SHEET}

THE INFOAMATION APPEARING ON THIS SHEET HAS BEEN COMPILED SPECIFI CALLY FOR THE GAGES CONTAINED IN THIS PACKAGE. THIS FOAM IS PAODUCED WIATY ASCUPATC VERT QUALA A A TYPE, BATCH, AND LOT NUMBER. HOO1

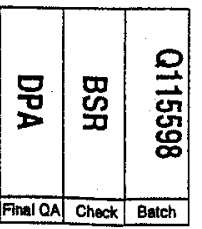

\section{EMEME Micro-Measurements Division \\ Made in USA}

MEASUREMENTS GROUP, INC. RALEIGH, NORTH CAROLNA

\begin{tabular}{|c|}
\hline PRECISION \\
STRAIN GAGES \\
\hline
\end{tabular}

F007

\section{GENERAL INFORMATION: WK-SERIES STRAIN GAGES}

GENERAL DESCRIPTION: WK-Series gages are a family of fully encapsulated K-alloy strain gages used in both experimental stress analysis and transducer applicalions. These gages have integral high-endurance lead ribbons with a backing and encapsulation matrix consisting of a high-temperature epoxy-phenclie resin system reinforced with glass fiber.

TEMPERATUAE RANGE: $-452^{\circ}$ to $+550^{\circ} \mathrm{F}\left(-269^{\circ}\right.$ to $\left.+290^{\circ} \mathrm{C}\right)$ for continuous use in statle messurements. Useful to $+700^{\circ} \mathrm{F}\left(+370^{\circ} \mathrm{C}\right)$ for short term exposure.

SELF TEMPERATUAE COMPENSATION: See data curve below.

STRAIN LUMITS: $\pm 1.5 \%$ at room temperature; $\pm 1.0 \%$ at $-320^{\circ} \mathrm{F}\left(-195^{\circ} \mathrm{C}\right) ; \pm 3 \%$ at $+400^{\circ} \mathrm{F}\left(+205^{\circ} \mathrm{C}\right)$.

FATIQUE LFE: $10^{\circ}$ cycles at $\pm 1500 \mu \mathrm{in} / \mathrm{in}(\mu \mathrm{m} / \mathrm{m}) ; 10^{7}$ cycles at $\pm 1800 \mu \mathrm{in} / \mathrm{n}(\mu \mathrm{m} / \mathrm{m})$. Longer gage lengths and lower resistances show greater ondurances and lass scotter th fatigue tifo.

BONDING AQENTS: High-lemperature epoxy adhesives are recommended for best performance over the entire temperature range Micro-Measurements M-Bond 610,600 and M-Bond GA-60 afe paricularly compatible with WK-Series gages. Fefer to M-M Catalog A-110 for information on bonding agents, and Bullatin B-130 for installation procedures.

LEADWIRE SYSTEM: Two flat, high-enduranes leads attached to each tab permil 3-wire or 4-wire systems to be carried directly to the gage, minimizing leadwire errors over the wide useful temperature range of the WK-Series strain gages. Option SP-30 WK-Sortes gages are supplied with single $0.005 \mathrm{in}$. $(0.73 \mathrm{~mm}$ ) diameter nicket-clad copper wire leads. Option $\$$ P-30 reduces fatigue life of WK-Series gages and should not be selscted where best cyclic endurance is required. Internal tab connections on these gages are made with $+770^{\circ} \mathrm{F}\left(+410^{\circ} \mathrm{C}\right)$ solder. Leadwires may be soft soldered, spot-welded or slver soldered. Feter to M-M Bulletin B-132 for information on solders.

NOTE: The backing of WK-Series gages has been spectally treated for optimum bond formation with all appropriate strain gage adhesives. No further clearing is nacessary If contamination of the prepared aurface is avoided during handling. c038

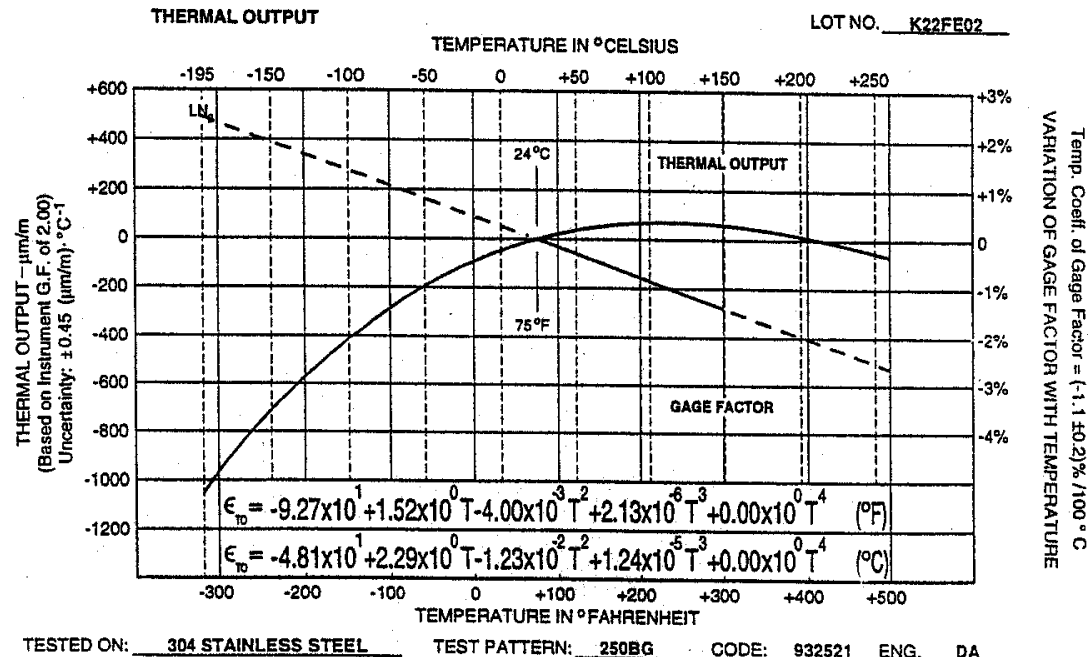

TEST PROCEDURES USED BY MICRO-MEASUREMENTS

OPTICAL DEFECT ANALYSIS $\ldots \ldots \ldots$ M-M Procedures and Standards GAGE RESISTANCE AT $24^{\circ} \mathrm{C}$ AND $50 \%$ RH $\because \ldots \ldots$ Mith procedure, Direct NIST Tracestlity on Resistance Standards

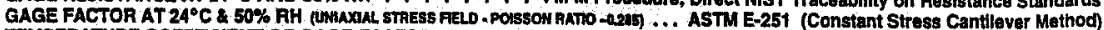
TEMPEPATURE COEFFICIENT OF GAGE FACTOR . Astu E-251 (Slow Hoating Rato Continuoction Method TRANSVERSE SENSITVTTY AT $24^{\circ} \mathrm{C}$ AND $50 \%$ RH $\because \ldots$ ASTM FATIGUE LFE $\ldots \ldots \ldots \ldots \ldots$ A $\ldots \ldots$ ASTM E-25

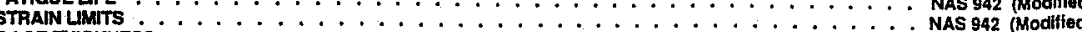
GAGE THICKNESS $\cdots \cdots$ CREEP AND DAIFT .

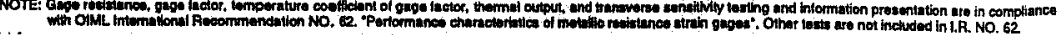

\section{single \\ element gages. for Niv}




\section{EMEMIE LIVINEERING UAIA SHEEI \\ TME INFORMATION AFPEARING ON THIS SHEET HAS BEEN COMPILED SPECIFCALLY FOR THE GAGES CONTAINED IN THIS PACKAGE. THIS FORM IS PRODUCED WTH ADVANCED EDUIPMENT \& PROCEDURES SHOULO ANY QUESTIONS ARISE RELATVE TO THANCE VERTFACATION OF ALL DATA SUPPLIED HEREM AND LOT NUMBER \\ HoO

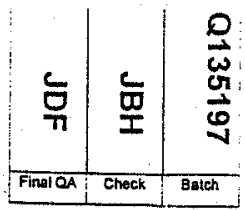

\section{EMEME $\underset{\substack{\text { Micro-Measurements } \\ \text { Division }}}{\text { DMEon }}$}

MEASUREMENTS GROUP, INC. RALEIGH, NORTH CAROLINA
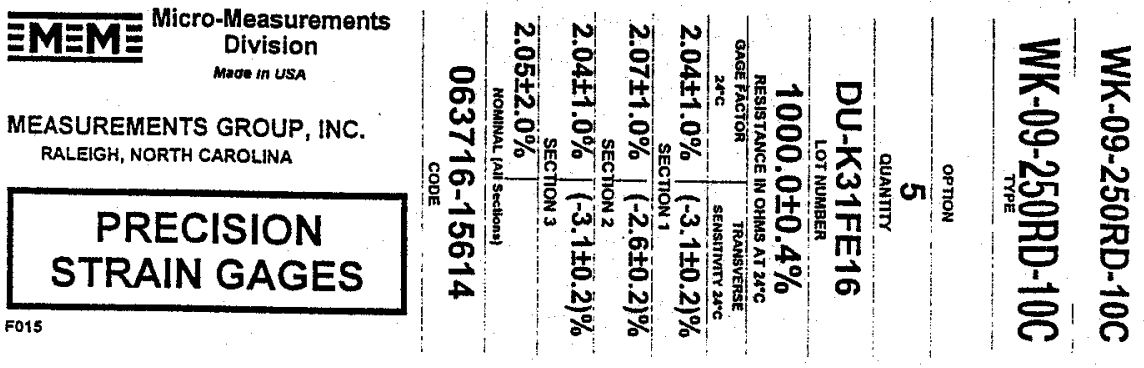

\section{GENERAL INFORMATION: WK-SERIES STRAIN GAGES}

GENERAL DESCRIPNON: WK-Series gages are a family of fully encepsulated K-alloy strain gages used in both experimental stress analysis and transducer applications. These gages have integral high-endurance lead ribbons with a becking and encapsulation matrix consisting TEMPERATURE RANGE: $-452^{*}$ to $+550^{\circ} \mathrm{F}\left(-269^{\circ}\right.$ to $\left.+290^{\circ} \mathrm{C}\right)$ for continuous use in static measurements. Useful to $+700^{\circ} \mathrm{F}\left(+370^{\circ} \mathrm{C}\right)$ for
short torm exposure.

SELF TEMPERATURE COMPENSATION: See data curve betow.

STRAIN LIMITS: $\pm 1,5 \%$ at room temperature; $\pm 1.0 \%$ at $-320^{\circ} \mathrm{F}\left(-195^{\circ} \mathrm{C}\right) ; \pm 3 \%$ at $+400^{\circ} \mathrm{F}\left(+205^{\circ} \mathrm{C}\right)$

FATIGUE LIFE: $10^{8}$ cyeles at \pm 1500 in/in ( $\mu \mathrm{m} / \mathrm{m}$ ); $10^{7} \mathrm{cycles}$ at $\pm 1800 \mu \mathrm{ir} / \mathrm{in}$ ( $\mathrm{\mu m} / \mathrm{m}$ ). Longer gage lengths end lower resistances show BONDING AGENTS:

Micro-Mesents: High-temperature epoxy adhesives are recommended for best performence over the entire temperature range, Micro-Measurements M-Bond 610,600 and M-Bond GA-60 are particularly compatible with WK-Series gages. Refer to M-m Catalog A-110

EADWIRE SYSTEM: Two flat, high-endurance leads attached to aach tab permil 3-wire or 4wire systems to barried directly to the gage, minimizing leadwire errors over the wide useful temperature range of the WA-Seriss strain gages. Option SP-30 WK-Series WK-Series gages and should not be in. (0.13 mm) diameter nickel-clad copper wire leads. Option SF-30 reduces fatigue life of made with $+570^{\circ} \mathrm{F}\left(+300^{\circ} \mathrm{C}\right)$ solder. Leadwires may be soft soldered, spot required. Internal tab conneotions on these gages are for information on solders. G038

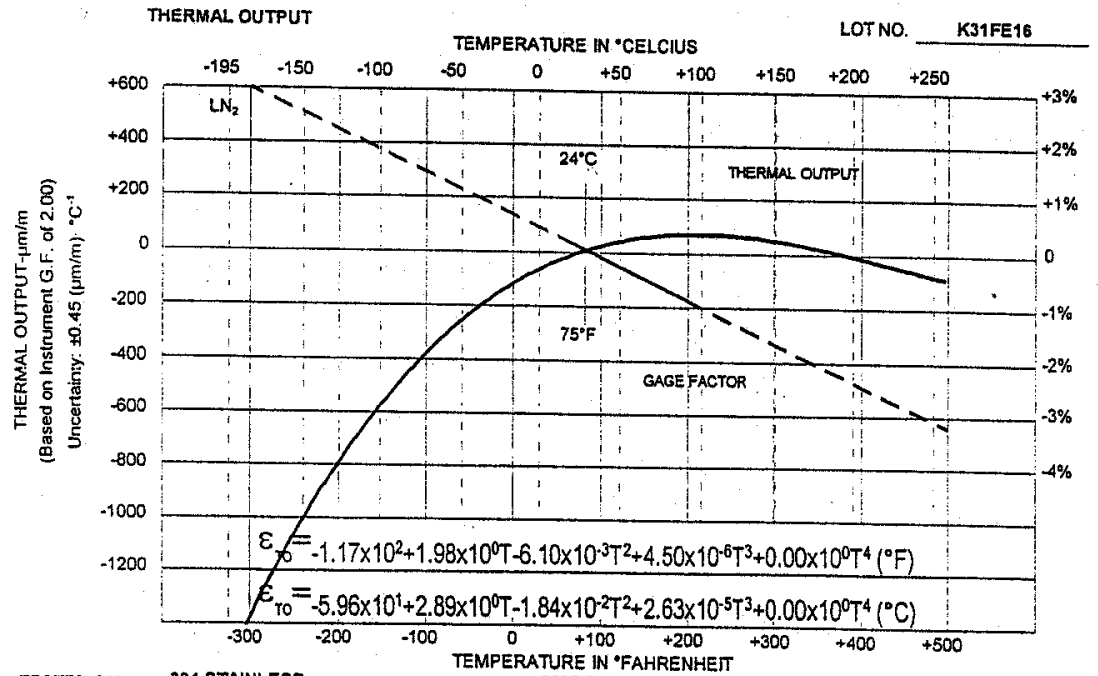

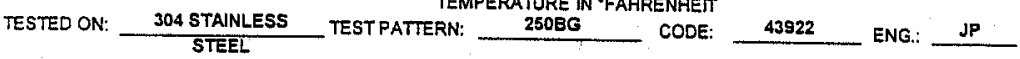

TEST PROCEDURES USED BY MICRO-MEASUREMENTS

OPTICAL DEFECT ANALYSIS GAGE RESISTANCE AT $24^{\circ} \mathrm{C}$ AND $50 \%$ RH . . . . . . . M-M Procedure, Direct NIST Tracability on Resistance Standard

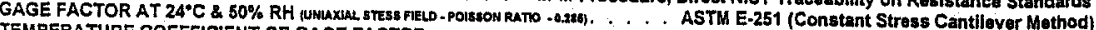
A..... ATSM E-251 (Stap Deflection Methad) THERMAL OUTPUT . . : . . . ASTM E-251 (Slow Heating Rate, Continuously Recordod) TRANSVERSE SENSITIVITY AT $24^{\circ} \mathrm{C}$ AND $50 \% \mathrm{H} \ldots \ldots \ldots \ldots \ldots \ldots \ldots \ldots \ldots \ldots$ ASTM E-251

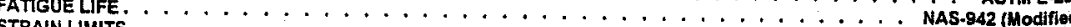

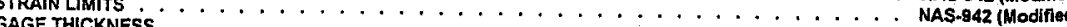

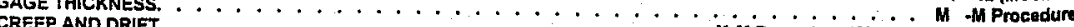

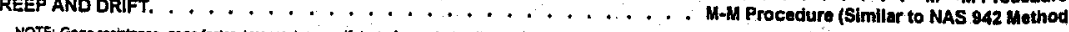
T001 


\section{REPORT DOCUMENTATION PAGE}

Form Approved OMB NO. 0704-0188

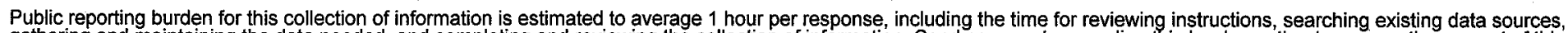

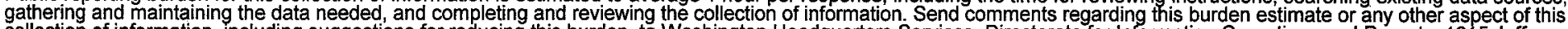

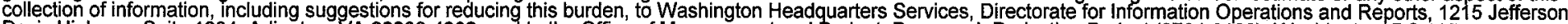

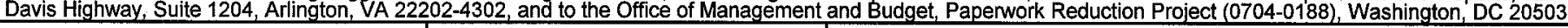
1. AGENCY USE ONLY (Leave blank)
2. REPORT DATE
March 2001
3. REPORT TYPE AND DATES COVERED
Technical Report

4. TITLE AND SUBTITLE

NedWind 25 Blade Testing at NREL for the European Standards Measurement and

Testing Program

5. FUNDING NUMBERS

WER112450

6. AUTHOR(S)

S. Larwood, NREL; G. Freebury, G. Edward Engineering; A. Beattie, Physical Acoustics Corp.

7. PERFORMING ORGANIZATION NAME(S) AND ADDRESS(ES)

National Renewable Energy Laboratory REPORT NUMBER

1617 Cole Blvd.

Golden, CO 80401-3393

TP-500-29103

9. SPONSORING/MONITORING AGENCY NAME(S) AND ADDRESS(ES)

National Renewable Energy Laboratory

1617 Cole Blvd.

Golden, CO 80401-3393

10. SPONSORING/MONITORING AGENCY REPORT NUMBER

TP-500-29103

11. SUPPLEMENTARY NOTES

NREL Technical Monitor:

12a: DISTRIBUTION/AVAILABILITY STATEMENT

National Technical Information Service

12b. DISTRIBUTION CODE

U.S. Department of Commerce

5285 Port Royal Road

Springfield, VA 22161

13. ABSTRACT (Maximum 200 words)

In the mid-90s the European community initiated the Standards, Measurements, and Testing (SMT) program to harmonize testing and measurement procedures in several industries. Within the program, a project was carried out called the European Wind Turbine Testing Procedure Development. The second part of that project, called Blade Test Methods and Techniques, included the United States and was devised to help blade-testing laboratories harmonize their testing methods. This report provides the results of those tests conducted by the National Renewable Energy Laboratory.

14. SUBJECT TERMS

15. NUMBER OF PAGES 252

Wind turbine blade testing, measurement standards, wind energy

16. PRICE CODE

17. SECURITY CLASSIFICATION OF REPORT

Unclassified
18. SECURITY CLASSIFICATION OF THIS PAGE

Unclassified
19. SECURITY CLASSIFICATION OF ABSTRACT Unclassified
20. LIMITATION OF ABSTRACT

UL 